WSRC-TR-2000-00305

SRT-RPP-2000-00011

\title{
Preliminary Ion Exchange Modeling for Removal of Technetium from Hanford Waste Using SuperLig ${ }^{\circledR} 639$ Resin
}

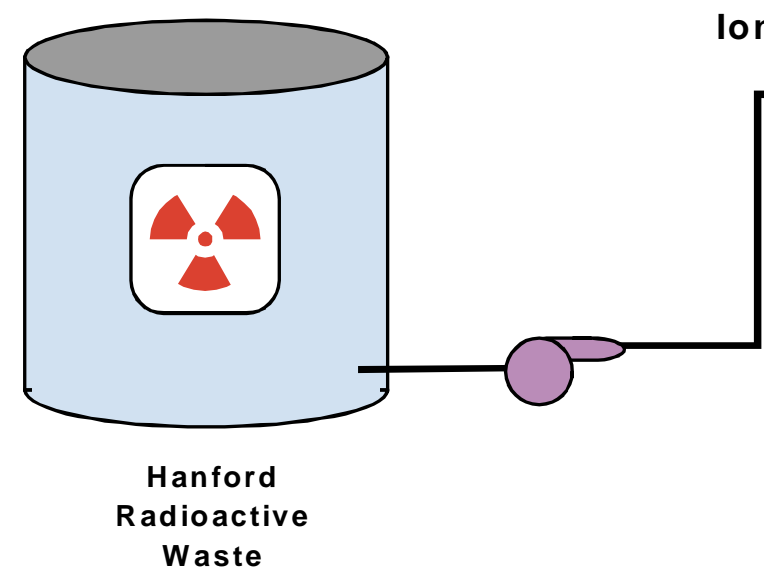

Ion Exchange Columns

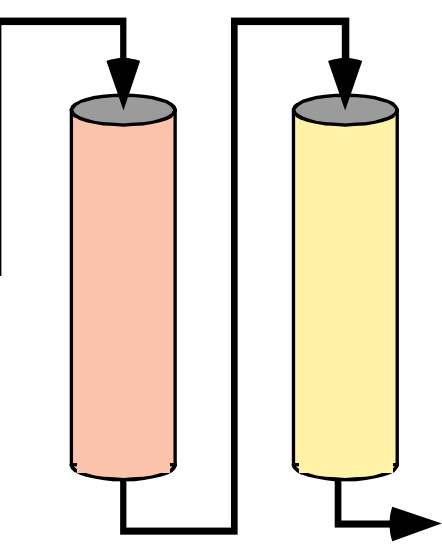

Liquid effluent treated as low level radioactive waste

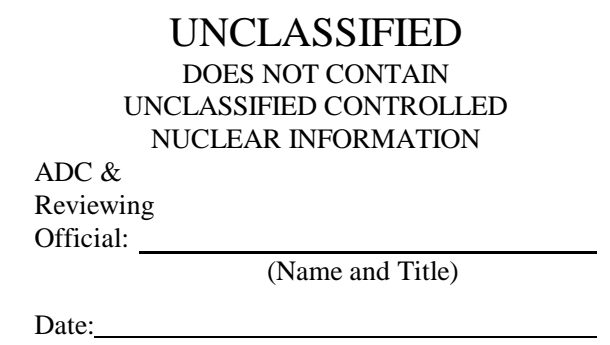

Westinghouse Savannah River Company

Savannah River Site

Aiken, SC 29808

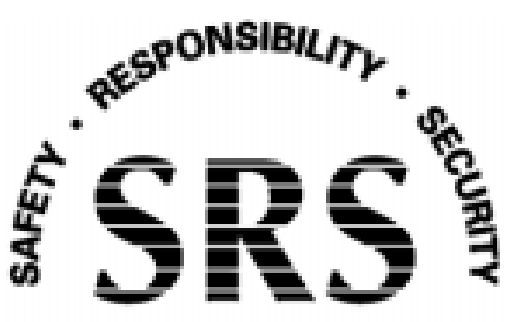


This document was prepared in conjunction with work accomplished under Contract No.

DE-AC09-96SR18500 with the U.S. Department of Energy.

\section{DISCLAIMER}

This report was prepared as an account of work sponsored by an agency of the United States Government. Neither the United States Government nor any agency thereof, nor any of their employees, makes any warranty, express or implied, or assumes any legal liability or responsibility for the accuracy, completeness, or usefulness of any information, apparatus, product or process disclosed, or represents that its use would not infringe privately owned rights. Reference herein to any specific commercial product, process or service by trade name, trademark, manufacturer, or otherwise does not necessarily constitute or imply its endorsement, recommendation, or favoring by the United States Government or any agency

thereof. The views and opinions of authors expressed herein do not necessarily state or reflect those of the United States Government or any agency thereof.

This report has been reproduced directly from the best available copy.

Available for sale to the public, in paper, from: U.S. Department of Commerce, National Technical Information Service, 5285 Port Royal Road, Springfield, VA 22161, phone: (800)

553-6847, fax: (703) 605-6900, email: orders@ntis.fedworld.gov online ordering: http://www.ntis.gov/ordering.htm

Available electronically at http://www.doe.gov/bridge

Available for a processing fee to U.S. Department of Energy and its contractors, in paper, from: U.S. Department of Energy, Office of Scientific and Technical Information, P.O. Box 62, Oak Ridge, TN 37831-0062, phone: (865 ) 576-8401, fax: (865) 576-5728, email: reports@ adonis.osti.gov 
DISCLAIMER

This report was prepared by the Westinghouse Savannah River Corporation (Westinghouse) for the United States Department of Energy under Contract DE-AC09-96SR18500 and is an account of work performed under that Contract. Neither the United States, the United States Department of Energy, nor Westinghouse, nor any of their employees, makes any warranty, expressed or implied, or assumes any legal liability or responsibility for the accuracy, completeness, or usefulness of any information, apparatus, product, or process disclosed herein, or represents that its use will not infringe privately owned rights. Reference herein to any specific commercial product, process or service by trade name, mark, manufacturer, or otherwise does not necessarily constitute or imply endorsement, recommendation, or favoring of same by Westinghouse or by the United States Government or any agency thereof. The views and opinions of authors expressed herein do not necessarily state or reflect those of the United States Government or any agency thereof. 
WSRC-TR-2000-00305

SRT-RPP-2000-00011

KEYWORDS:

Hanford River Protection Project Ion Exchange Technology SuperLig Resins Technetium Cesium VERSE Code Column Modeling

RETENTION - Permanent

\section{Preliminary Ion Exchange Modeling for Removal of Technetium from Hanford Waste Using SuperLig ${ }^{\circledR} 639$ Resin}

SAVANNAH RIVER TECHNOLOGY CENTER

L. Larry Hamm

Frank G. Smith, III

Daniel J. McCabe

Publication Date: August 2000

Westinghouse Savannah River Company

Savannah River Site

Aiken, SC 29808

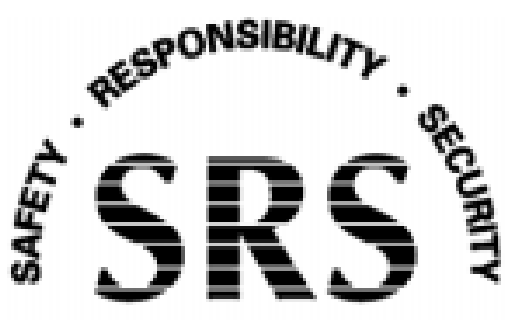


DOCUMENT: WSRC-TR-2000-00305 (SRT-RPP-2000-00011)

TITLE: Preliminary Ion Exchange Modeling for Removal of Technetium from Hanford Waste Using SuperLig ${ }^{\circledR} 639$ Resin

\section{APPROVALS}

Date:

L. Larry Hamm, Co-author (EM\&S Group/SRTC)

Date:

Frank G. Smith, III, Co-author (PC\&C Group/SRTC)

Date:

Daniel J. McCabe, Co-author (WTT Group/SRTC)

Date:

Steve T. Wach, RPP Pretreatment Manager (WTT Group/SRTC)

Date:

Harold F. Sturm, Jr., RPP Program Manager (WPTS/SRTC)

Date:

Willam D. King, Technical Reviewer (WTT Group/SRTC) 


\section{TABLE OF CONTENTS}

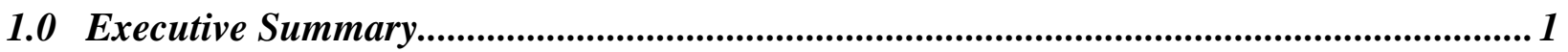

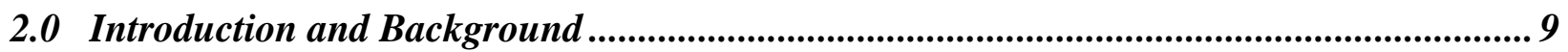

2.1 Ion Exchange Modeling ............................................................................................................................. 9

2.2 Chosen Ion Exchange Material .................................................................................................. 10

2.3 Report Overview.................................................................................................................................. 10

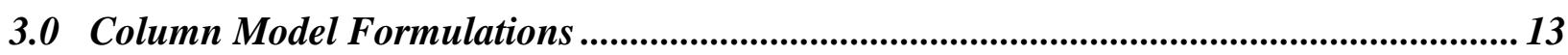

3.1 The Multi-Component Model................................................................................................................ 14

3.2 The Single-Component Model........................................................................................................ 16

3.3 The Technetium-SuperLig ${ }^{\circledR} 639$ System ............................................................................... 16

4.0 Equilibrium Adsorption Isotherm ………………................................................................ 21

4.1 The Isotherm Model ........................................................................................................................ 22

4.2 The Technetium-SuperLig ${ }^{\circledast}$ 639 System ........................................................................................ 25

4.3 Isotherm Parameter Estimations.................................................................................................... 28

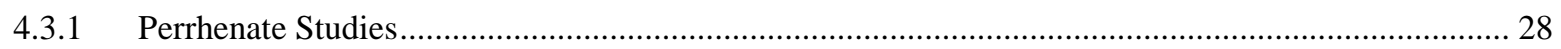

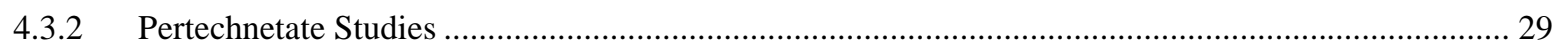

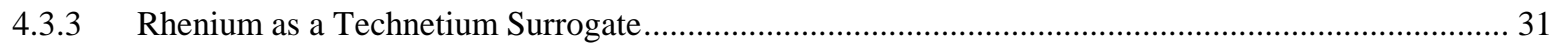

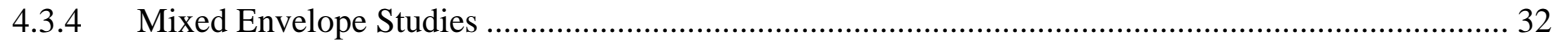

4.4 Impact of Total Ionic Strength......................................................................................... 33

4.5 Impact of Chemical Stability ..................................................................................................... 33

4.6 Application Using VERSE-LC ........................................................................................................ 34

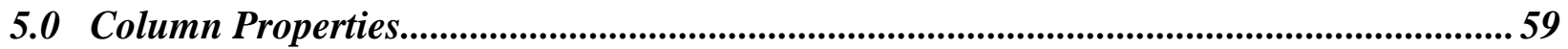

5.1 Basic Constraint Functions ............................................................................................................59

5.2 Densities........................................................................................................................................ 60

5.3 Porosities ........................................................................................................................................60

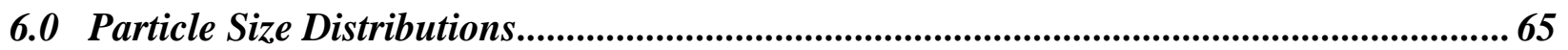

6.1 Sieve Analysis Data .............................................................................................................. 65

6.2 Laser Technology Data ....................................................................................................................... 66

6.3 Visual Analysis Data ........................................................................................................................... 66

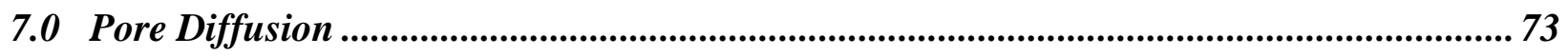

7.1 Waste Density and Viscosity ....................................................................................................... 73

7.2 Molecular Diffusion Coefficients ........................................................................................................ 73

7.3 Pore Diffusion Coefficients.............................................................................................................. 74

8.0 Axial Dispersion and Film Diffusion .................................................................................... 81

8.1 Film Diffusion ........................................................................................................................................ 81 


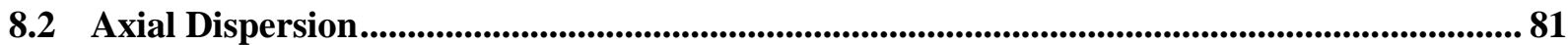

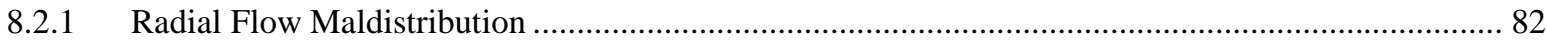

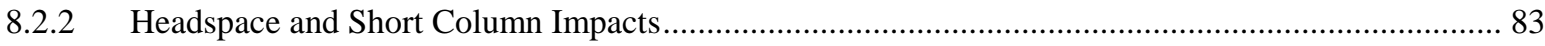

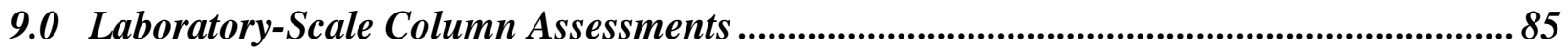

9.1 Intermediate-Scale Perrhenate (WK) Tests................................................................................. 86

9.2 Intermediate-Scale Perrhenate Vendor (IBC) Tests................................................................... 88

9.3 Pilot-Scale Perrhenate (TFL) Tests ........................................................................................................ 88

9.3.1 TFL Run-3 Test ......................................................................................................................................... 90

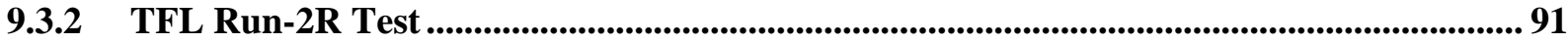

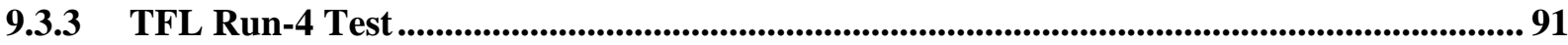

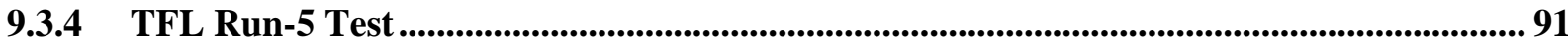

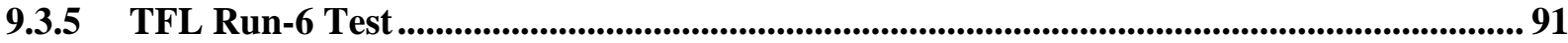

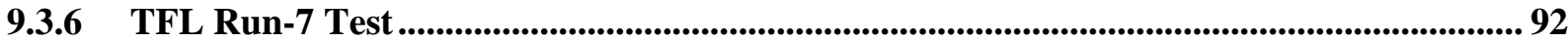

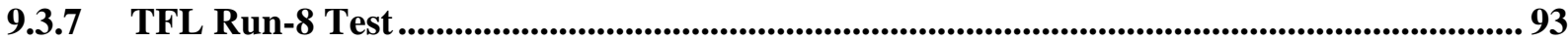

9.3.8 TFL Run-9 Test ...................................................................................................................................... 93

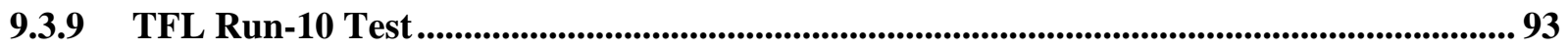

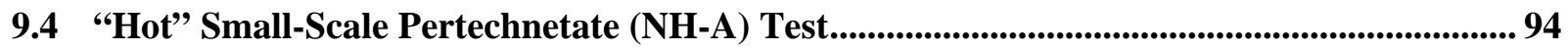

9.5 "Hot" Small-Scale Pertechnetate (NH-B) Test .....................................................................95

9.6 "Hot" Small-Scale Pertechnetate (NH-SC) Test ......................................................................... 96

9.7 "Hot" Intermediate-Scale Pertechnetate (WK-LC) Test .......................................................... 96

9.8 "Hot”' Intermediate-Scale Pertechnetate (SRS Tank 44F) Test ............................................97

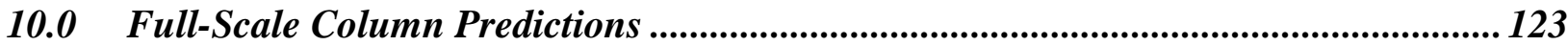

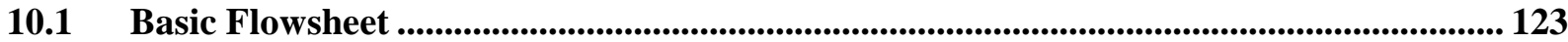

10.2 VERSE-LC Model of Full-Scale Facility ........................................................................................ 124

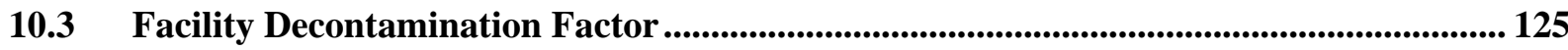

10.4 Parameter Sensitivity Study................................................................................................... 126

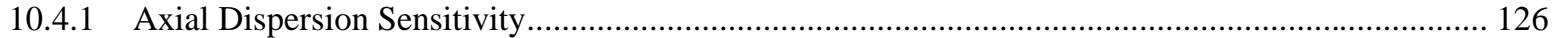

10.4.2 Film Diffusion/Mass Transfer Sensitivity ...................................................................... 127

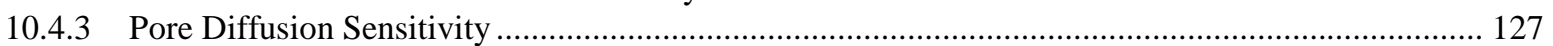

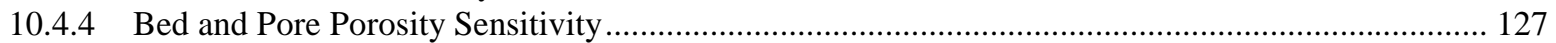

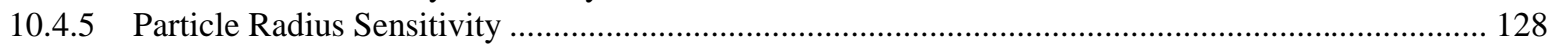

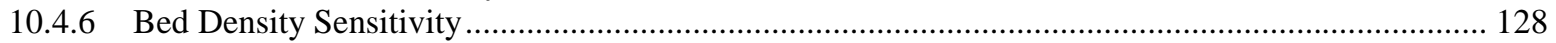

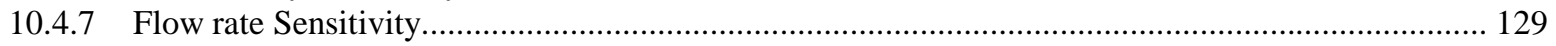

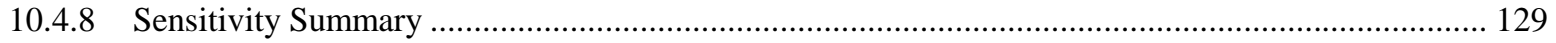

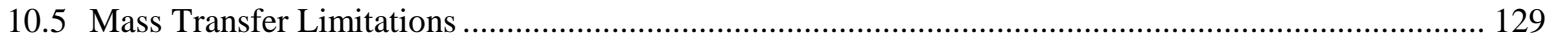

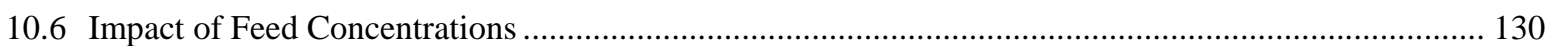

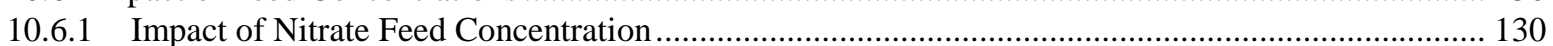

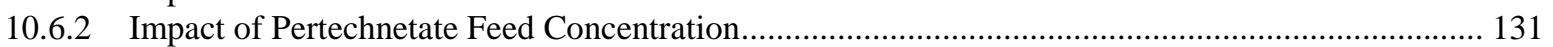

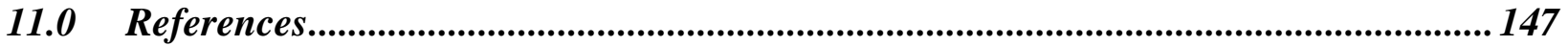


Appendix A (Material Balances for Equilibrium Batch Tests)................................................ 153

A.1 Equilibrium Batch Contact Test Approach .................................................................................. 153

A.2 Material Balance Requirements ................................................................................................... 154

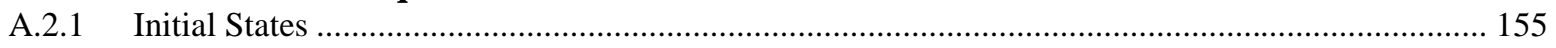

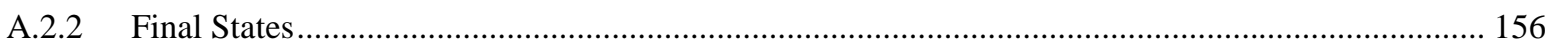

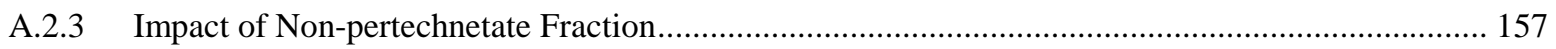

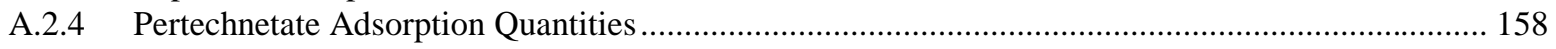

A.3 Adsorption Isotherm Database ......................................................................................................... 159

Appendix B (Lambda Values Based on $K_{d}$ Data)................................................................. 163

B.1 Estimated Perrhenate Lambda Values........................................................................................ 164

B.1.1 WK (Exp-1, 2, 3, and 4) Test Conditions ............................................................................... 164

B.1.2 WK (Exp-5) Test Conditions ………………………………………………………….... 165

B.1.3 IBC (Exp-1) Test Conditions .................................................................................................. 166

B.2 Estimated Pertechnetate Lambda Values ................................................................................. 166

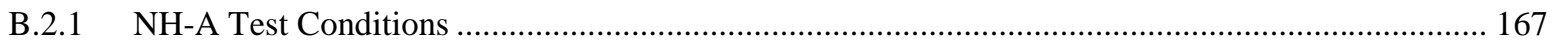

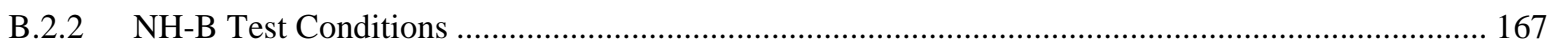

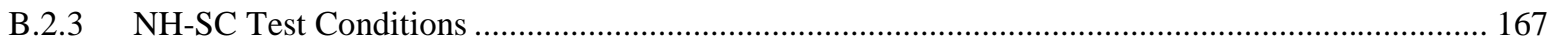

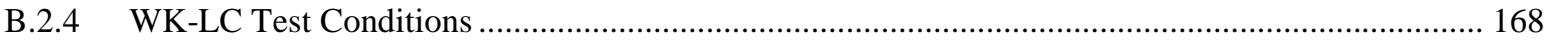

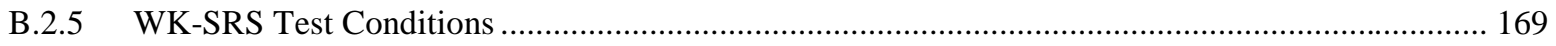

Appendix C (Batch Kinetics Test Input and Output Files) ........................................................ 177

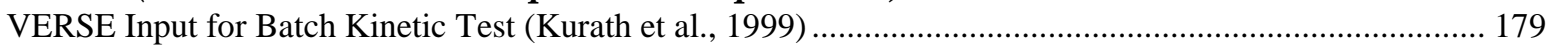

VERSE Output for Batch Kinetic Test (Kurath et al., 1999) ....................................................................... 180

Appendix D (Column Test Input and Output Files).................................................................. 183

VERSE Input for Intermediate-Scale Perrhenate Column (WK Exp-1) Test ............................................... 183

VERSE Output for Intermediate-Scale Perrhenate Column (WK Exp-1) Test .............................................. 183

VERSE Input for Intermediate-Scale Perrhenate Column (WK Exp-2) Test ................................................. 184

VERSE Output for Intermediate-Scale Perrhenate Column (WK Exp-2) Test ............................................... 185

VERSE Input for Intermediate-Scale Perrhenate Column (WK Exp-3) Test ................................................. 186

VERSE Output for Intermediate-Scale Perrhenate Column (WK Exp-3) Test ............................................... 186

VERSE Input for Intermediate-Scale Perrhenate Column (WK Exp-4) Test ................................................. 187

VERSE Output for Intermediate-Scale Perrhenate Column (WK Exp-4) Test .............................................. 188

VERSE Input for Intermediate-Scale Perrhenate Column (WK Exp-5) Test ................................................. 189

VERSE Output for Intermediate-Scale Perrhenate Column (WK Exp-5) Test ............................................. 189

VERSE Input for Intermediate-Scale Perrhenate Column (IBC Exp-1) Test ................................................ 190

VERSE Output for Intermediate-Scale Perrhenate Column (IBC Exp-1) Test .............................................. 191

VERSE Input for Pilot-Scale Perrhenate Column (TFL Run-3) Test............................................................. 192

VERSE Output for Pilot-Scale Perrhenate Column (TFL Run-3) Test ..................................................... 192

VERSE Input for Pilot-Scale Perrhenate Column (TFL Run-2R) Test ......................................................... 194

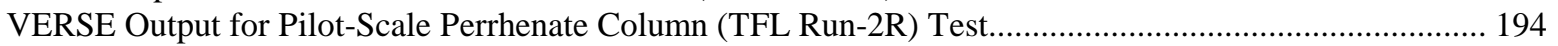

VERSE Input for Pilot-Scale Perrhenate Column (TFL Run-4) Test........................................................... 195

VERSE Output for Pilot-Scale Perrhenate Column (TFL Run-4) Test ......................................................... 196

VERSE Input for Pilot-Scale Perrhenate Column (TFL Run-5) Test............................................................... 197

VERSE Output for Pilot-Scale Perrhenate Column (TFL Run-5) Test ......................................................... 198

VERSE Input for Pilot-Scale Perrhenate Column (TFL Run-6: trans) Test ................................................... 199

VERSE Output for Pilot-Scale Perrhenate Column (TFL Run-6: trans) Test ................................................ 200

VERSE Input for Pilot-Scale Perrhenate Column (TFL Run-7) Test............................................................. 201

VERSE Output for Pilot-Scale Perrhenate Column (TFL Run-7) Test .......................................................... 202

VERSE Input for Pilot-Scale Perrhenate Column (TFL Run-8) Test........................................................... 203

VERSE Output for Pilot-Scale Perrhenate Column (TFL Run-8) Test ........................................................... 204 
VERSE Input for Pilot-Scale Perrhenate Column (TFL Run-9) Test.

VERSE Output for Pilot-Scale Perrhenate Column (TFL Run-9) Test

VERSE Input for Pilot-Scale Perrhenate Column (TFL Run-10) Test.

VERSE Output for Pilot-Scale Perrhenate Column (TFL Run-10) Test

VERSE Input for Small-Scale Pertechnetate Column (NH-A) Test.

VERSE Output for Small-Scale Pertechnetate Column (NH-A) Test ...................................................... 209

VERSE Input for Small-Scale Pertechnetate Column (NH-B) Test ........................................................ 210

VERSE Output for Small-Scale Pertechnetate Column (NH-B) Test ................................................ 211

VERSE Input for Small-Scale Pertechnetate Column (NH-SC) Test ..................................................2 212

VERSE Output for Small-Scale Pertechnetate Column (NH-SC) Test ................................................ 213

VERSE Input for Intermediate-Scale Pertechnetate Column (WK-LC) Test ......................................... 214

VERSE Output for Intermediate-Scale Pertechnetate Column (WK-LC) Test ....................................... 215

VERSE Input for Intermediate-Scale Pertechnetate Column (WK-SRS) Test.......................................... 216

VERSE Output for Intermediate-Scale Pertechnetate Column (WK-SRS) Test ..................................... 216

Appendix E (Full-Scale Facility Input and Output Files) ............................................................ 219

VERSE Input for Full-Scale Facility (Env. A: Single Component Model) .................................................. 223

VERSE Output for Full-Scale Facility (Env. A: Single Component Model) .......................................... 223

VERSE Input for Full-Scale Facility (Env. B: Single Component Model) ............................................ 225

VERSE Output for Full-Scale Facility (Env. B: Single Component Model) ......................................... 225 


\section{LIST OF TABLES}

Table 4-1. Nomenclature used to identify various batch equilibrium tests and column experiments discussed throughout this report.....

Table 4-2. Adsorption isotherm “ $K_{d}$ ” database summary for Perrhenate-SuperLig ${ }^{\circledR} 639$ system (batch contact tests typically assume equilibrium reached in $\sim 24 \mathrm{hrs}$ ).

Table 4-3. Adsorption isotherm “ $K_{d}$ ” database summary for Pertechnetate-SuperLig ${ }^{\circledR} 639$ system (batch contact tests typically assume equilibrium reached in $\sim 24 \mathrm{hrs}$ ) where pure envelope samples were used.

Table 4-4. Adsorption isotherm “ $K_{d}$ ” database summary for Pertechnetate-SuperLig ${ }^{\circledR} 639$ system where volumetrically mixed waste envelope samples were used.............................................................39

Table 4-5. Equilibrium data for Perrhenate on SuperLig ${ }^{\circledR} 639$ based on batch contact tests. .................................40

Table 4-6. Equilibrium data for Pertechnetate on SuperLig ${ }^{\circledR} 639$ based on batch contact tests using pure waste envelope samples................................................................................................................4

Table 4-7. Equilibrium data for Pertechnetate on SuperLig ${ }^{\circledR} 639$ based on batch contact tests using mixed waste envelope samples (Hassan et al., 2000c)

Table 4-8. Estimated binary selectivity coefficient and its confidence level for the Perrhenate-SuperLig ${ }^{\circledR} 639$ system based on the entire set of perrhenate batch contact tests and the binary homovalent isotherm model.

Table 4-9. Batch and Envelope specific predicted (best estimate) binary isotherm model parameters (selectivity coefficient and total ionic capacity) for the Pertechnetate (and perrhenate)-SuperLig ${ }^{\circledR} 639$ system based on available equilibrium batch contact tests and supported by follow-on column studies.

Table 4-10. Species concentrations and rough estimates ${ }^{a}$ for the total ionic strength (in molar units) of various Hanford waste samples and simulants used in batch contact and column tests.

Table 4-11. Parameter identities between the binary VERSE-LC Freundlich/Langmuir Hybrid equilibrium isotherm model and the binary homovalent isotherm system.

Table 4-12. Parameter settings for a binary Freundlich/Langmuir Hybrid equilibrium isotherm model for Pertechnetate (or perrhenate) on SuperLig ${ }^{\circledR} 639$ based on the binary homovalent system.................48

Table 4-13. Parameter settings for an "effective” single component Freundlich/Langmuir Hybrid equilibrium isotherm model for Pertechnetate (or perrhenate) on SuperLig ${ }^{\circledR} 639$ based on the binary homovalent system......

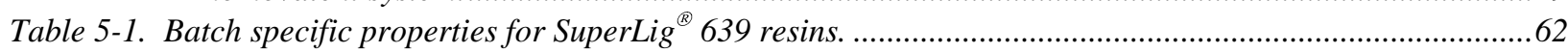

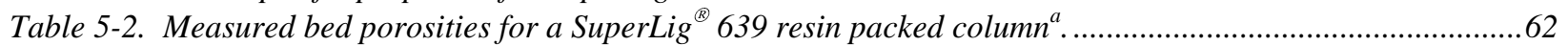

Table 5-3. Computed total porosities for various SuperLig ${ }^{\circledR} 639$ resin arrangements. .............................................63

Table 5-4. Pore porosity as a function of bed porosity at three different total porosity values for the SuperLig ${ }^{\circledR}$ 639 resin.

Table 6-1. Particle size distributions of SuperLig ${ }^{\circledR} 639$ resin with batch ID (\# 981015DHC720011) based on dry sieve analyses. ${ }^{a}$....

Table 6-2. Particle size distributions ${ }^{a}$ of SuperLig ${ }^{\circledR} 639$ (batch \#981104DHC70215) based on Laser Technology.

Table 6-3. Particle size estimates ${ }^{a}$ of SuperLig ${ }^{\circledR} 639$ based on visual measurements.

Table 7-1. Fluid density and dynamic viscosity for water and simulated $5 \mathrm{M}$ sodium waste solution.....................77

Table 7-2. Limiting ionic conductances in water at $25{ }^{\circ} \mathrm{C}$ (Reid et al., 1977; Perry, 1973)...................................78

Table 7-3. Estimated binary molecular and pore diffusion coefficients at $25{ }^{\circ} \mathrm{C}$.....................................................78

Table 9-1. Key features of Pertechnetate (perrhenate)-SuperLig ${ }^{\circledR} 639$ fixed bed full-, pilot-, intermediate-, and small-scale columns.

Table 9-2. Summary of recommended nominal parameter settings for Pertechnetate (perrhenate)-SuperLig ${ }^{\circledR}$ 639 system column modeling.

Table 9-2. Summary of recommended nominal parameter settings for Pertechnetate (perrhenate)-SuperLig ${ }^{\circledR}$ 639 system column modeling (continued).....

Table 9-3. Summary of "best estimate" binary isotherm model parameters for the Pertechnetate (perrhenate)SuperLig ${ }^{\circledR} 639$ system used in column assessment studies. 


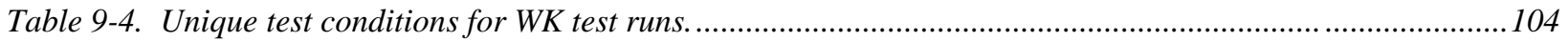

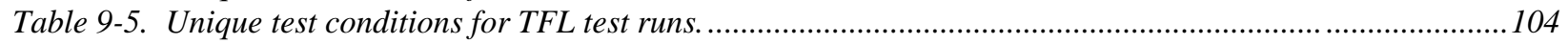

Table 10-1. Key column parameters for the full-scale facility......................................................................... 132

Table 10-2. Estimated overall column technetium loadings at the end of the first and second cycles....................133

Table 10-3. Estimated pertechnetate decontamination factors (D.F.) on a cumulative basis as a function of the number of cycles performed.

Table 10-4. Estimated pertechnetate decontamination factors (D.F.) on a per cycle basis as a function of the number of cycles performed.

Table 10-5. Sensitivity of volumetric flowrate on the exit technetium breakthrough curve of the lead column for the Envelope A test case.

Table 10-6. Sensitivity variables studied and their level of impact on exit technetium breakthrough curves for the Envelope A test case.

Table 10-7. Sensitivity of nitrate feed concentration on the number of column volumes required to reach $50 \%$ breakthrough in the lead column and to reach the lag column exit technetium criteria. ${ }^{a}$.

Table 10-8. Sensitivity of technetium feed concentration on the number of column volumes required to reach $50 \%$ breakthrough in the lead column and to reach the lag column exit technetium criteria. ${ }^{a}$

Table A-1. Adsorption isotherm “ $K_{d}$ ” data ${ }^{a}$ for Pertechnetate-SuperLig ${ }^{\circledR} 639$ system measured by Hassan et al.

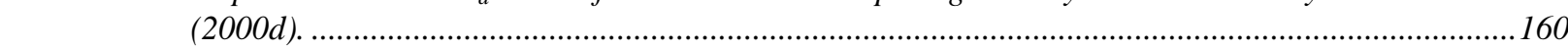

Table A-2. Updated adsorption isotherm data for $N H-B$ tests based on material balance analyses.......................161

Table B-1. Comparison of measured versus computed Lambda values for the various perrhenate batch equilibrium tests and column experiments presented in the main body of this report......

Table B-2. Comparison of measured versus computed Lambda values for the various pertechnetate batch equilibrium tests and column experiments presented in the main body of this report......

Table C-1. Key measurements made during the multiple batch kinetics tests of Kurath et al., 1999......................177

Table C-2. Key parameters measured or specified during the batch kinetics tests of Kurath et al., 1999..............178

Table E-1. Key parameter settings ${ }^{a}$ for VERSE-LC simulation of the "effective" single component and binary homovalent anion exchange processes for the full-scale facility when processing Envelope $A$ feed.

Table E-2. Key parameter settings ${ }^{a}$ for VERSE-LC simulation of the "effective" single component and binary homovalent anion exchange processes for the full-scale facility when processing Envelope $B$ feed. 


\section{LIST OF FIGURES}

Figure 1-1. Computed "best estimate" decontamination factors on a cumulative basis for the TechnetiumSuperLig ${ }^{\circledR} 639$ system ion exchange columns for Envelope $A\left(\left[{ }^{99} \mathrm{TcO}_{4}^{-}\right]_{o}=2.580 x 10^{-5} \mathrm{M}^{-}\left[\mathrm{NO}_{3}^{-}\right]_{o}\right.$ $=0.998 \mathrm{M})$ and Envelope $\left.\mathrm{B}\left({ }^{99} \mathrm{TcO}_{4}^{-}\right]_{o}=1.324 \times 10^{-4} \mathrm{M},\left[\mathrm{NO}_{3}^{-}\right]_{o}=0.232 \mathrm{M}\right)$ feed conditions............6

Figure 1-2. Computed "best estimate" decontamination factors on a per cycle basis for the Technetium-

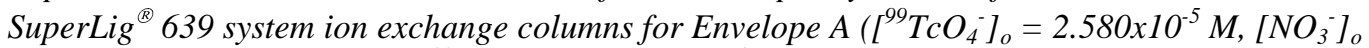
$=0.998 \mathrm{M})$ and Envelope $\mathrm{B}\left(\left[^{99} \mathrm{TcO}_{4}^{-}\right]_{o}=1.324 \times 10^{-4} \mathrm{M},\left[\mathrm{NO}_{3}^{-}\right]_{o}=0.232 \mathrm{M}\right)$ feed conditions...

Figure 3-1. The basic building blocks of a porous particle ion exchange column model. 18

Figure 3-2. Graphical representation of the various mass transport mechanisms considered important for Technetium-SuperLig ${ }^{\circledR} 639$ system ion exchange column modeling.

Figure 3-3. Estimated pertechnetate and nitrate exit breakthrough curves for the full-scale facility based on the porous particle multi-component (i.e., binary) ion exchange column model for Envelope A (241AN-103) waste using SuperLig $639^{\circledR}$ resin.

Figure 3-4. Comparison of estimated pertechnetate exit breakthrough curves for the full-scale facility based on the binary and "effective" single-component ion exchange column models for Envelope A (241AN-103) waste using SuperLig $639^{\circledR}$ resin.

Figure 4-1. Variation in measured pertechnetate and perrhenate $K_{d}$ values on SuperLig ${ }^{\circledR} 639$ resin with respect to their final molar ratios with nitrate. The database shown was taken from three different sites and eight different batches for a total of 88 data points.

Figure 4-2. Variation in measured perrhenate loadings on SuperLig ${ }^{\circledR} 639$ resin with respect to the final molar ratio of nitrate to perrhenate ions. The database shown contains data taken from two different sites and five different batches for a total of 37 data points.

Figure 4-3. Measured versus predicted perrhenate fractional loadings on SuperLig ${ }^{\circledR} 639$ resin. The database shown contains data taken from two different sites and five different batches for a total of 37 data points.

Figure 4-4. Variation in measured perrhenate fractional loadings on SuperLig ${ }^{\circledR} 639$ resin with respect to its final molar ratio with nitrate. The database shown contains data taken from three different batches using the same Envelope A waste simulant (King et al., 2000a).

Figure 4-5. Variation in measured pertechnetate loadings on SuperLig ${ }^{\circledR} 639$ resin with respect to its final molar ratio with nitrate. The database shown contains Envelope A, B, and C data taken from two different sites and five different batches for a total of 47 data points.

Figure 4-6. Variation in measured pertechnetate loadings on SuperLig ${ }^{\circledR} 639$ resin with respect to its final molar ratio with nitrate. The database shown is for the same batch ID (\# 981015DHC720011) contacted with Envelope A, B, and C samples.

Figure 4-7. A comparison of measured to predicted pertechnetate and perrhenate loadings on SuperLig ${ }^{\circledR} 639$ resin with respect to their final molar ratios with nitrate. The database is for batch ID (\# 981015DHC720011) contacted with Env. A simulant (WK-3) and sample (NH-A)....

Figure 4-8. A comparison of measured pertechnetate and perrhenate loadings on SuperLig ${ }^{\circledR} 639$ resin with respect to their final molar ratios with nitrate. The database is for batch ID (\# 981015DHC720011) contacted with Env. A simulant (WK-3) and samples (NH-A, A2).......

Figure 4-9. Variation in measured pertechnetate loadings on SuperLig ${ }^{\circledR} 639$ resin with respect to its final molar ratio with nitrate. The database shown is for batch ID (\# 981015DHC720011) and various mixed envelope samples compared to the pure Envelope A sample.

Figure 4-10. Variation in measured pertechnetate loadings on SuperLig ${ }^{\circledR} 639$ resin with respect to its final molar ratio with nitrate. The database is for batch ID (\# 981015DHC720011) and various mixed envelope samples compared to the pure Envelope B sample.

Figure 4-11. Variation in measured pertechnetate loadings on SuperLig ${ }^{\circledR} 639$ resin with respect to its final molar ratio with nitrate. The database is for batch ID (\# 981015DHC720011) and decontaminated Envelope $C$ samples compared to the pure Envelope C samples.....

Figure 4-12. Variation in binary selectivity coefficient for nitrate and pertechnetate (or perrhenate) on SuperLig ${ }^{\circledR} 639$ resin with respect to a rough estimate of the total ionic strength of the liquidphase solution (a general trend function is also provided). 
Figure 4-13. Impact of chemical exposure to perrhenate $K_{d}$ 's in a simulated Envelope A waste by pre-soaking of SuperLig ${ }^{\circledR} 639$ resin in various ionic solutions (Bruening, 2000c).....

Figure 4-14. A direct comparison of predicted versus measured perrhenate loadings on pre-soaked SuperLig ${ }^{\circledR}$ 639 resin for a sample of Envelope A waste (Bruening, 2000c).

Figure 5-1. Functional behavior between bed porosity and pore porosity for the SuperLig ${ }^{\circledR} 639$ resin highlighting the nominal and sensitivity study values used in column simulations.

Figure 6-1. Weight fraction of particles as a function of sieve sizes for two specific samples of the SuperLig ${ }^{\circledR}$ 639 resin (batch ID \#981015DHC720011) based on dry sieve analysis (data from Hassan et al., 2000b).

Figure 6-2. Volume fraction of particles as a function of particle size for two specific samples of the SuperLig ${ }^{\circledR}$ 639 resin (batch \#981104DHC70215) based on laser technology under a $5 \mathrm{M} \mathrm{Na}^{+}$solution (data from Bruening, 2000a).

Figure 6-3. Number fraction of particles as a function of particle size for two specific samples of the SuperLig ${ }^{\circledR}$ 639 resin (batch \#981104DHC70215) based on laser technology under a $5 \mathrm{M} \mathrm{Na}^{+}$solution (data from Bruening, 2000a).

Figure 7-1. Estimation of the pertechnetate pore diffusion coefficient based on batch kinetics tests performed by Kurath et al. (1999) for pertechnetate and nitrate uptake on SuperLig ${ }^{\circledR} 639$.

Figure 7-2. Estimation of the nitrate pore diffusion coefficient based on batch kinetics tests performed by Kurath et al. (1999) for pertechnetate uptake and nitrate on SuperLig ${ }^{\circledR} 639$.

Figure 7-3. Estimated pertechnetate liquid-phase concentrations during approach to equilibrium based on batch kinetics tests performed by Kurath et al. (1999) for pertechnetate and nitrate uptake on SuperLig ${ }^{\circledR} 639$.

Figure 7-4. The pertechnetate operating curve followed during its approach to its equilibrium curve ("isotherm") based on batch kinetics tests performed by Kurath et al. (1999) for pertechnetate and nitrate uptake on SuperLig ${ }^{(1)} 639$.

Figure 8-1. Estimated impact of column-to-particle diameter ratios on radial velocity profile based on the limited data by Schwartz and Smith (1953).

Figure 8-2. Estimation of the impact from end effects and short columns on axial dispersion based on the limited data by Liles and Geankoplis (1960)

Figure 9-1. A direct comparison of predicted versus measured perrhenate loadings on SuperLig ${ }^{\circledR} 639$ resin for a simulated Envelope A waste (King et al., 2000a). A batch specific binary isotherm model (batch \# 980624001DC) is plotted.

Figure 9-2. A direct comparison of predicted versus measured perrhenate loadings on SuperLig ${ }^{\circledR} 639$ resin for a simulated Envelope A waste (King et al., 2000a). Batch specific binary isotherm models (batch \# 981015DHC720011 \& 990420DHC720067) are plotted..

Figure 9-3. VERSE-LC perrhenate exit breakthrough curve compared to data from WK Exp-1 (King et al., 2000a): $D=2.69 \mathrm{~cm}, L=8.991 \mathrm{~cm}, U=0.51 \mathrm{~cm} / \mathrm{min}, T=20-23{ }^{\circ} \mathrm{C}$.

Figure 9-4. VERSE-LC perrhenate exit breakthrough curve compared to data from WK Exp-2 (King et al., 2000a): $D=2.69 \mathrm{~cm}, L=8.991 \mathrm{~cm}, U=5.20 \mathrm{~cm} / \mathrm{min}, T=20-23{ }^{\circ} \mathrm{C}$.

Figure 9-5. VERSE-LC perrhenate exit breakthrough curve compared to data from WK Exp-3 (King et al., 2000a): $D=2.69 \mathrm{~cm}, L=8.991 \mathrm{~cm}, U=11.0 \mathrm{~cm} / \mathrm{min}, T=20-23{ }^{\circ} \mathrm{C}$.

Figure 9-6. VERSE-LC perrhenate exit breakthrough curve compared to data from WK Exp-4 (King et al., 2000a): $D=4.0 \mathrm{~cm}, L=4.066 \mathrm{~cm}, U=0.48 \mathrm{~cm} / \mathrm{min}, T=20-23{ }^{\circ} \mathrm{C}$.

Figure 9-7. VERSE-LC perrhenate exit breakthrough curves compared to data from WK Exp-5 (King et al., 2000a): $D=2.69 \mathrm{~cm}, L=8.798 \mathrm{~cm}, U=0.43 \mathrm{~cm} / \mathrm{min}, T=20-23{ }^{\circ} \mathrm{C}$.

Figure 9-8. A direct comparison of predicted versus measured perrhenate loadings on SuperLig ${ }^{\circledR} 639$ resin for a simulated Envelope A waste (IBC Advanced Technologies, 1996). A batch specific binary isotherm model (batch \# not specified) is plotted.

Figure 9-9. VERSE-LC perrhenate exit breakthrough curve compared to data from IBC Exp-1 (IBC Advanced Technologies, 1996): $D=3.3 \mathrm{~cm}, L=24.0 \mathrm{~cm}, U=6.4 \mathrm{~cm} / \mathrm{min}, T=25{ }^{\circ} \mathrm{C}$.

Figure 9-10. Loading cycle VERSE-LC lead/lag column breakthrough curve predictions using different model parameter settings and comparison to data from the TFL Run-3 experiment (Steimke et al., 2000), $\left(18-24^{\circ} \mathrm{C}\right)$. 
Figure 9-11. Loading cycle VERSE-LC lead/lag column breakthrough curve predictions compared to data from the TFL Run-3 experiment (Steimke et al., 2000) using fresh columns, $\left(18-24{ }^{\circ} \mathrm{C}\right)$.

Figure 9-12. Loading cycle VERSE-LC lead/lag column breakthrough curve predictions compared to data from the TFL Run-2R experiment (Steimke et al., 2000) using a preloaded lead column, (18-24 $\left.{ }^{\circ} \mathrm{C}\right)$. . .

Figure 9-13. Loading cycle VERSE-LC lead/lag column breakthrough curve predictions compared to data from the TFL Run-4 experiment (Steimke et al., 2000) using a preloaded lead column, (18-24 $\left.{ }^{\circ} \mathrm{C}\right)$

Figure 9-14. Loading cycle VERSE-LC lead/lag column breakthrough curve predictions compared to data from the TFL Run-5 experiment (Steimke et al., 2000) using a preloaded lead column, (18-24 $\left.{ }^{\circ} \mathrm{C}\right)$.

Figure 9-15. Predicted VERSE-LC lead and lag column perrhenate axial loading profiles at the end of test runs Run-3, 2R, 4, and 5 (the lag column profiles were shifted to the lead column position, then the lag column was set to zero, and used in the next test run simulation).

Figure 9-16. Cumulative volume of feed processed during the loading cycle of the TFL Run-6 experiment (Steimke et al., 2000).

Figure 9-17. Volumetric flowrate of feed during the loading cycle of the TFL Run-6 experiment Steimke et al. (2000) (test data along with VERSE-LC transient and steady-state input values are shown)....

Figure 9-18. Loading cycle VERSE-LC lead/lag column breakthrough curve predictions compared to data from TFL Run-6 experiment (Steimke et al., 2000) where predictions based on an average fixed feed flowrate and a transient value are shown, $\left(18-24^{\circ} \mathrm{C}\right)$.

Figure 9-19. Loading cycle VERSE-LC lead/lag column breakthrough curve predictions compared to data from the TFL Run-6 experiment (Steimke et al., 2000) using a fresh lead column, (18-24 ${ }^{\circ} \mathrm{C}$ ).

Figure 9-20. Loading cycle VERSE-LC lead/lag column breakthrough curve predictions compared to data from the TFL Run-7 experiment (Steimke et al., 2000) using a preloaded lead column, (18-24 $\left.{ }^{\circ} \mathrm{C}\right)$.

Figure 9-21. Loading cycle VERSE-LC lead/lag column breakthrough curve predictions compared to data from the TFL Run-8 experiment (Steimke et al., 2000) using a preloaded lead column, (18-24 $\left.{ }^{\circ} \mathrm{C}\right)$.

Figure 9-22. Predicted VERSE-LC lead and lag column perrhenate axial loading profiles at the end of test runs Run-6, 7, and 8 (the lag column profiles were shifted to the lead column position, then the lag column was set to zero, and used in the next test run simulation).....

Figure 9-23. Loading cycle VERSE-LC lead/lag column breakthrough curve predictions compared to data from the TFL Run-9 experiment (Steimke et al., 2000) using a fresh lead column, (18-24 $\left.{ }^{\circ} \mathrm{C}\right) . . . . . . .116$

Figure 9-24. Loading cycle VERSE-LC lead/lag column breakthrough curve predictions compared to data from the TFL Run-10 experiment (Steimke et al., 2000) using a fresh lead column, (18-24 $\left.{ }^{\circ} \mathrm{C}\right)$.......116

Figure 9-25. TFL Run-9 and Run-10 loading cycle lead/lag column breakthrough curve data by Steimke et al. (2000) indirectly illustrating the degree of linearity in the binary perrhenate adsorption isotherm over the operating range of these column experiments, (18-24 $\left.{ }^{\circ} \mathrm{C}\right)$.

Figure 9-26. A comparison of predicted versus measured pertechnetate/perrhenate loadings on SuperLig ${ }^{\circledR} 639$ resin for Hanford Envelope A waste (King et al., 2000a; Hassan et al., 2000a). Batch specific binary isotherm models (batch \#981015DHC720011) are plotted.

Figure 9-27. VERSE-LC total molar technetium exit breakthrough curves compared to data from Hassan et al. (2000a) based on a Hanford Envelope A waste taken from Tank 241-AN-103, D = 1.1 cm, L= $10.73 \mathrm{~cm}, U=0.268 \mathrm{~cm} / \mathrm{min}, T=25-27{ }^{\circ} \mathrm{C}$.

Figure 9-28. A comparison of predicted versus measured pertechnetate/perrhenate loadings on SuperLig ${ }^{\circledR} 639$ resin for Hanford Envelope A \& B wastes (King et al., 2000a; Hassan et al., 2000d). Batch specific isotherm models (batch \#981015DHC720011) are plotted.

Figure 9-29. VERSE-LC total molar technetium exit breakthrough curves compared to data from Hassan et al. (2000d) based on a Hanford Envelope B waste taken from Tank 241-AZ-102, D = 1.1 cm, L= $11.57 \mathrm{~cm}, U=0.289 \mathrm{~cm} / \mathrm{min}, T=25-27{ }^{\circ} \mathrm{C}$.

Figure 9-30. A comparison of predicted versus measured pertechnetate/perrhenate loadings on SuperLig ${ }^{\circledR} 639$ resin for Hanford Envelope A, B, \& C wastes (King et al., 2000a; Hassan et al., 2000b). Batch specific isotherm models (batch \#981015DHC720011) are plotted..... 
Figure 9-31. VERSE-LC total molar technetium exit breakthrough curves compared to data from Hassan et al. (2000b) based on a Hanford Envelope C (SC) waste taken from Tank 241-AN-102, D =1.1 cm, L $=11.79 \mathrm{~cm}, U=0.295 \mathrm{~cm} / \mathrm{min}, T=25-27{ }^{\circ} \mathrm{C}$.

Figure 9-32. A comparison of predicted versus measured pertechnetate/perrhenate loadings on SuperLig ${ }^{\circledR} 639$ resin for Hanford Env. A B, \& C wastes (King et al., 2000a,c; Hassan et al., 2000b). Batch specific isotherm models (batch \#981015DHC720011) are plotted.

Figure 9-33. VERSE-LC total molar technetium exit breakthrough curves compared to data from King et al. (2000c) based on a Hanford Envelope C (LC) waste taken from Tank 241-AN-102, D = 2.69 cm, $L=51.87 \mathrm{~cm}, U=0.927 \mathrm{~cm} / \mathrm{min}, T=25-27{ }^{\circ} \mathrm{C}$.

Figure 9-34. A direct comparison of predicted versus measured pertechnetate loadings on SuperLig ${ }^{\circledR} 639$ resin for SRS Tank 44F waste (King et al., 2000b). Binary isotherm models based NH-A data evaluated at expected and lower nitrate concentrations are plotted.

Figure 9-35. VERSE-LC total molar technetium exit breakthrough curves compared to data from King et al. (2000b) based on a SRS waste taken from Tank $44 F$ (two nitrate estimates shown), D = $2.7 \mathrm{~cm}, L$ $=8.75 \mathrm{~cm}, U=0.452 \mathrm{~cm} / \mathrm{min}, T=25-26{ }^{\circ} \mathrm{C}$.

Figure 10-1. Basic flowsheet for full-scale ion exchange facility for removal of technetium (in its pertechnetate form) using the SuperLig ${ }^{\circledR} 639$ resin.

Figure 10-2. VERSE-LC model representing the full-scale flowsheet for removal of technetium (in its pertechnetate form) using the SuperLig ${ }^{\circledR} 639$ resin.

Figure 10-3. VERSE-LC model best estimate predictions for multiple cycling of the full-scale facility for the removal of technetium (in its pertechnetate form) from Envelope A waste (241-AN-103) using the SuperLig ${ }^{\circledR} 639$ resin.

Figure 10-4. VERSE-LC model best estimate predictions for cycle number 4 of the full-scale facility for the removal of technetium (in its pertechnetate form) from Envelope A waste (241-AN-103) using the SuperLig ${ }^{\circledR} 639$ resin.

Figure 10-5. VERSE-LC model best estimate prediction of the technetium column profiles for all cycles of the full-scale facility for the removal of technetium (in its pertechnetate form) from Envelope A waste (241-AN-103) using the SuperLig ${ }^{\circledR} 639$ resin.....

Figure 10-6. VERSE-LC model predictions for multiple cycling of the full-scale facility for the removal of technetium (in its pertechnetate form) from Envelope B waste (241-AZ-102) using the SuperLig ${ }^{\circledR}$ 639 resin.

Figure 10-7. VERSE-LC model prediction of the technetium column profiles for all cycles of the full-scale facility for the removal of technetium (in its pertechnetate form) from Envelope B waste (241-AZ102) using the SuperLig ${ }^{\circledR} 639$ resin.

Figure 10-8. Variation of the overall pertechnetate decontamination factor on a cumulative basis with respect to the number of operating cycles assumed for each waste envelope......

Figure 10-9. Variation of the overall pertechnetate decontamination factor on a per cycle basis for each waste envelope.

Figure 10-10. Sensitivity of full-scale column breakthrough curve to axial dispersion for the Envelope A test case.

Figure 10-11. Sensitivity of full-scale column breakthrough curve to mass transfer film coefficient for the Envelope A test case.

Figure 10-12. Sensitivity of full-scale column breakthrough curve to pertechnetate pore diffusivity for the Envelope A test case.

Figure 10-13. Sensitivity of full-scale column breakthrough curve to bed and particle porosities for the Envelope A test case.

Figure 10-14. Sensitivity of full-scale column breakthrough curve to particle radius for the Envelope A test case

Figure 10-15. Sensitivity of full-scale column breakthrough curve to bed density for the Envelope A test case. ....144

Figure 10-16. Sensitivity of volumetric flowrate on the exit technetium breakthrough curve of the lead column for the Envelope A test case.

Figure 10-17. The number of column volumes required to reach 50\% technetium breakthrough on the lead column and to reach $2 \%$ of the feed technetium (exit criterion) on the lag column for the Envelope A test case. 
Figure 10-18. Impact of mass transfer resistance on the exit technetium breakthrough curve of the lead column for the Envelope A test case.

Figure 10-19. Impact of nitrate feed concentration on the exit technetium breakthrough curves for the lead and lag columns given an initially technetium free set of columns where all other parameter settings correspond to those used for the Envelope A case study.

Figure 10-20. Impact of technetium feed concentration on the exit technetium breakthrough curves for the lead and lag columns given an initially technetium free set of columns where all other parameter settings correspond to those used for the Envelope A case study.

Figure A-1. Impact that initial non-pertechnetate fraction in liquid-sample has on final molar ratio of nitrate to pertechnetate during batch contact and re-contact tests on SuperLig ${ }^{\circledR} 639$ (data by Hassan et al., 2000d).

Figure A-2. The remaining amount (in terms of percent of initial amount) of non-pertechnetate contained in the liquid samples during the re-contact test series for all available re-contact tests based on pertechnetate and SuperLig ${ }^{\circledR} 639$ resin.

Figure B-1. A favorable isotherm with tangents $\left(d q_{i} / d c_{p i}\right)$ at $c_{p i}=0$ and at a point $c_{p i}>0$, and with a chord of that point.

Figure B-2. Predicted versus measured perrhenate $K_{d}$ values for an Envelope A waste simulant where the isotherm models is shown for the nitrate level used in both batch contact test WK-1 and column tests WK Exp-1 through Exp-4 (King et al., 2000a).

Figure B-3. Predicted versus measured perrhenate $K_{d}$ values for an Envelope A waste simulant where the isotherm models are shown for the nitrate level used in both batch contact tests WK-2 \& WK-3 and column test WK Exp-5 (King et al., 2000a).

Figure B-4. Predicted versus measured perrhenate $K_{d}$ values for an Envelope A waste simulant where the isotherm model is shown for the nitrate level used in the column test IBC Exp-1 (IBC Advanced Technologies, 1996).

Figure B-5. Predicted versus measured pertechnetate $K_{d}$ values for Envelope A (241-AN-103) waste samples where the isotherm models are shown for nitrate levels used in NH-A batch contact and column testing (Hassan et al., 2000a).

Figure B-6. Predicted versus measured pertechnetate $K_{d}$ values for Envelope B (241-AZ-102) waste samples where the isotherm model is shown for the nitrate level used in the NH-B column testing (Hassan et al., 2000d).

Figure B-7. Predicted versus measured pertechnetate $K_{d}$ values for Envelope "Small" C (241-AN-102) waste samples where the isotherm model is shown for the nitrate level used in the NH-SC column testing (Hassan et al., 2000b).

Figure B-8. Predicted versus measured pertechnetate $K_{d}$ values for Envelope "Large" C (241-AN-102) waste samples where the isotherm models are shown for the nitrate levels used in the WK-LC batch contact and column testing (King et al., 2000c).....

Figure B-9. Predicted versus measured pertechnetate $K_{d}$ values for SRS Tank $44 F$ waste sample where the isotherm models are shown for the nitrate level used in the WK-SRS batch contact and column testing (King et al., 2000b)..... 
(This Page Intentionally Left Blank) 


\section{TABLE OF NOTATION}

A, B Binding constants for Langmuir isotherm, $\mathrm{M}^{-1}$.

$\mathrm{CV}, \mathrm{BV} \quad$ Active column (bed) volume, $\mathrm{ml}$.

$\mathrm{c}_{\mathrm{bi}}$

Species i conc. in bed fluid, M.

$\mathrm{c}_{\mathrm{pi}}$

Species i conc. in pore fluid, M.

$\overline{\mathrm{c}}_{\mathrm{pi}}$

$\overline{\mathrm{C}}_{\mathrm{pi}}$

Species i solid surface conc. (or loadings), gmole $/ \mathrm{g}_{\text {resin }}$ or mmole $/ \mathrm{g}_{\text {resin }}$.

$\overline{\mathrm{C}}_{\mathrm{T}}$

Species i solid surface conc. based on column volume, gmole/ $\mathrm{L}_{\mathrm{CV}}$ or $\mathrm{M}$.

Total ion-exchange capacity of resin, $\mathrm{mmole} / \mathrm{g}_{\text {resin }}$.

$\overline{\mathrm{C}}_{\mathrm{Ti}}$

Species i ion-exchange capacity of resin, mmole/ $\mathrm{g}_{\mathrm{resin}}$.

$\mathrm{C}_{\mathrm{T}}$

Total cationic strength of solution, M.

$\operatorname{cdf}(\mathrm{x}) \quad$ Cumulative distribution function for the variable $\mathrm{x}$.

D Column diameter, $\mathrm{cm}$.

D.F. Decontamination factor.

$\mathrm{D}_{\mathrm{pi}} \quad$ Species i pore diffusion coefficient, $\mathrm{cm}^{2} / \mathrm{min}$.

$\tilde{\mathrm{D}}_{\mathrm{pi}} \quad$ Species i "overall” pore diffusion coefficient, $\mathrm{cm} 2 / \mathrm{min}$.

$\mathrm{D}_{ \pm}^{\infty} \quad$ Binary diffusion coefficient at infinite dilution, $\mathrm{cm}^{2} / \mathrm{s}$.

$D_{A B} \quad$ Binary diffusion coefficient for A diffusing through solvent $\mathrm{B}, \mathrm{cm}^{2} / \mathrm{s}$.

$\mathrm{D}_{\infty \mathrm{i}} \quad$ Species i diffusion coefficient, $\mathrm{cm}^{2} / \mathrm{min}$.

$\mathrm{E}_{\mathrm{bi}} \quad$ Species i axial dispersivity, $\mathrm{cm}^{2} / \mathrm{min}$.

F Ratio of dry-to-"as received" resin mass

$F \quad$ Faraday constant, $96,500 \mathrm{C} /$ g-equiv.

J "J factor" analogy dimensionless number.

$\mathrm{k}_{\mathrm{f}} \quad$ Liquid film mass transfer coefficient, $\mathrm{cm} / \mathrm{min}$.

$\mathrm{K}_{\mathrm{di}} \quad$ Species i distribution coefficient, $\mathrm{M}^{-1}$ or $\mathrm{ml} / \mathrm{g}$.

$\mathrm{K}_{\mathrm{ji}} \quad$ Equilibrium constant between species $\mathrm{j}$ and $\mathrm{i}$.

$\tilde{\mathrm{K}}_{\mathrm{ji}} \quad$ Selectivity coefficient between species $\mathrm{j}$ and $\mathrm{i}$.

$\mathrm{L}$

$\mathrm{m}_{\mathrm{i}}$

$\mathrm{m}_{\text {re } \sin }$

$\mathrm{M}_{\mathrm{i}}$

$\mathrm{M}_{\mathrm{ai}}, \mathrm{M}_{\mathrm{bi}}$
Axial length of active bed of column, $\mathrm{cm}$.

Mass of species i, g.

Mass of resin, $\mathrm{g}$.

Species i molecular weight, g/gmole.

Freundlich/Langmuir Hybrid model exponents for species i. 


\begin{tabular}{|c|c|}
\hline $\mathrm{N}_{\mathrm{s}}$ & Total number of cations of interest. \\
\hline $\mathrm{N}_{\mathrm{c}}$ & Total number of chemical reactions. \\
\hline $\operatorname{pdf}(x)$ & Probability distribution function for the variable $\mathrm{x}$. \\
\hline Q & Column volumetric flow rate, $\mathrm{ml} / \mathrm{min}$. \\
\hline $\mathrm{q}_{\mathrm{i}}$ & Species i fractional surface site loading. \\
\hline $\mathrm{r}$ & Radial coordinate within avg. size particle, $\mathrm{cm}$. \\
\hline $\mathrm{R}$ & Ideal gas constant, $8.314 \mathrm{~J} /$ gmole-K. \\
\hline $\mathrm{R}_{\mathrm{i}}$ & Isotherm model residual for $i^{\text {th }}$ data point. \\
\hline $\mathrm{R}_{\mathrm{A}}$ & Radius of diffusing particle, $\mathrm{cm}$. \\
\hline $\operatorname{Re}$ & Reynolds Number. \\
\hline$<\mathrm{R}_{\mathrm{p}}>$ & Average particle radius, $\mu \mathrm{m}$. \\
\hline $\mathrm{Sc}_{\mathrm{i}}$ & Species i Schmidt Number. \\
\hline $\mathrm{t}$ & Time. \\
\hline $\mathrm{T}$ & Absolute temperature, $\mathrm{K}$. \\
\hline $\mathrm{u}$ & Linear interstitial velocity, $\mathrm{cm} / \mathrm{min}$. \\
\hline $\mathrm{u}^{\prime}$ & Retarded linear interstitial velocity, $\mathrm{cm} / \mathrm{min}$. \\
\hline $\mathrm{u}_{\text {peak }}$ & Peak radial velocity, $\mathrm{cm} / \mathrm{min}$. \\
\hline $\mathrm{u}_{\mathrm{CL}}$ & Column centerline velocity, $\mathrm{cm} / \mathrm{min}$. \\
\hline $\mathrm{U}$ & Superficial (Darcy) velocity, $\mathrm{cm} / \mathrm{min}$. \\
\hline $\mathrm{V}_{\text {bed }}$ & Total volume of active column, $\mathrm{ml}$. \\
\hline $\mathrm{V}_{\text {void }}$ & Total volume of voids within active column, ml. \\
\hline $\mathrm{V}_{\text {pore }}$ & Total volume of pores within particles, $\mathrm{ml}$. \\
\hline $\mathrm{V}_{\text {part }}$ & Total volume of particles within active column, ml. \\
\hline $\mathrm{V}_{\text {sld }}$ & Total volume of solid resin within active column, ml. \\
\hline $\mathrm{V}_{\mathrm{CSTR}}$ & Volume of inlet/outlet headspaces, $\mathrm{ml}$. \\
\hline $\mathrm{z}$ & Axial coordinate, $\mathrm{cm}$. \\
\hline $\mathrm{z}_{+}, \mathrm{z}_{-}$ & valences of cation and anion, respectively. \\
\hline
\end{tabular}

\section{Greek}

$\beta \quad$ Isotherm parameter constant.

$\hat{\beta}_{\mathrm{i}} \quad$ Langmuir "effective" single isotherm model constant.

$\beta_{\mathrm{i}}, \mathrm{a}_{\mathrm{i}}, \mathrm{b}_{\mathrm{i}} \quad$ Freundlich/Langmuir Hybrid model coefficients for species i.

$\kappa \quad$ Boltzmann's constant. 


$\begin{array}{ll}\tau_{\mathrm{p}} & \text { Particle tortuosity. } \\ \lambda & \text { Lambda value }\left(\equiv \mathrm{K}_{\mathrm{d}} \rho_{\mathrm{b}}\right), \mathrm{ml}_{\mathrm{resin}} / \mathrm{ml}_{\mathrm{Bv}} . \\ v_{\mathrm{j}} & \text { Species j stoichiometric coefficient. } \\ \varepsilon_{\mathrm{b}} & \text { Bed porosity. } \\ \varepsilon_{\mathrm{p}} & \text { Particle porosity. } \\ \varepsilon_{\mathrm{T}} & \text { Total porosity within column bed. } \\ \sigma_{\mathrm{q}} & \text { Isotherm model standard deviation. } \\ \sigma_{\mathrm{K}} & \text { Selectivity coefficient standard deviation. } \\ \mu_{\mathrm{B}} & \text { Dynamic viscosity of solvent mixture. } \\ \mu_{\mathrm{w}} & \text { Dynamic viscosity of feed solution, centi-poise. } \\ \rho_{\mathrm{w}} & \text { Density of feed solution, g/ml. } \\ \rho_{\mathrm{b}} & \text { Bed density of active column, } \mathrm{g} / \mathrm{ml} . \\ \rho_{\mathrm{s}} & \text { Solid (particle) density of resin, } \mathrm{g} / \mathrm{ml} . \\ \lambda_{+}^{\mathrm{o}}, \lambda_{-}^{\mathrm{o}} & \text { Limiting ionic conductance for cation and anion, mhos/equiv. }\end{array}$

\section{Data Set Labeling}

WK-1,2,3 Batch specific equilibrium contact tests reported by King et al., 2000a.

WK Exp-1 Column experiment number 1 reported by King et al., 2000a.

WK Exp-2 Column experiment number 2 reported by King et al., 2000a.

WK Exp-3 Column experiment number 3 reported by King et al., 2000a.

WK Exp-4 Column experiment number 4 reported by King et al., 2000a.

WK Exp-5 Column experiment number 5 reported by King et al., 2000a.

TFL Column experiments (all runs) reported by Steimke et al., 2000.

IBC-1 Batch equilibrium contact tests reported by IBC Advanced Technologies, 1996.

IBC Exp-1 Column experiment number 1 reported by IBC Advanced Technologies, 1996.

IBC-2 Batch equilibrium contact tests reported by IBC Bruening, R. L., 2000c.

NH-A Batch equilibrium contact tests reported by Hassan et al., 2000a.

NH-A Column experiments reported by Hassan et al., 2000a.

NH-A2 Batch equilibrium contact tests reported by Hassan et al., 2000c.

NH-B Batch equilibrium contact tests reported by Hassan et al., 2000d.

NH-B Column experiments reported by Hassan et al., 2000d.

NH-SC Batch equilibrium contact tests reported by Hassan et al., 2000b.

NH-SC Column experiments reported by Hassan et al., 2000b. 
WK-LC Batch equilibrium contact tests reported by King et al., 2000c.

WK-LC Column experiments reported by King et al., 2000c.

WK-SRS Batch equilibrium contact tests reported by King et al., 2000b.

WK-SRS Column experiments reported by King et al., 2000 b.

PNNL Batch equilibrium contact tests reported by Kurath et al., 1999.

DM-A Batch equilibrium contact tests reported by Hassan and McCabe, 1997c.

DM-A Column experiments reported by Hassan and McCabe, 1997a.

DM-B Batch equilibrium contact tests reported by McCabe, 1997.

DM-B Column experiments reported by Hassan and McCabe, 1997d.

DM-C Batch equilibrium contact tests reported by Hassan and McCabe, 1998.

DM-C Column experiments reported by Hassan and McCabe, 1997b. 


\subsection{Executive Summary}

The performance of a proposed ion exchange column using SuperLig ${ }^{\circledR} 639$ resin for the removal of technetium (in the form of pertechnetate, ${ }^{99} \mathrm{TcO}_{4}{ }^{-}$) from Hanford high level radioactive alkaline waste is discussed. This report represents a status report on our current ability and knowledge with regard to modeling the Technetium-SuperLig ${ }^{\circledR} 639$ resin ion-exchange system. Only the loading phase of the cycle process is addressed within this report. Existing bench-scale column tests (twenty in total) and batch equilibrium experiments ( $\sim 88$ data points) are addressed. Recent pilot-scale column tests performed at the Savannah River Technology Center are also included. The methodology employed and the results from sensitivity analyses are discussed. Ongoing bench-scale testing and additional future pilot-scale testing will be assessed in a future report. Future analysis efforts will also address the elution phase of the process cycle. The sensitivity analyses provide guidance on what experimental areas of support will potentially have the biggest impact on column performance and design predictions. The sensitivity analyses also help to identify key parameters that aid in resin procurement acceptance criteria.

The major accomplishments and conclusions are:

- An approach to correlating the batch equilibrium data has been devised based on a simple algebraic isotherm model derived assuming an average value for the binary selectivity coefficient. "Effective" single component (i.e., pertechnetate) and binary (i.e., nitrate plus pertechnetate) anion exchange isotherm models were created. The adequacy of this approach is tested by comparison to the available equilibrium batch contact database and through their use in column simulations.

- The isotherm models were developed assuming that the major competitors for active sites on the SuperLig ${ }^{\circledR} 639$ resin are the various nitrate (i.e., $\mathrm{NaNO}_{3}$ and $\mathrm{KNO}_{3}$ ) and pertechnetate (i.e., $\mathrm{NaTcO}_{4}$ and $\mathrm{KTcO}_{4}$ ) species. No distinctions are made between the sodium or potassium forms (i.e., their adsorption rates are considered to be identical). It is also assumed that SuperLig ${ }^{\circledR} 639$ resin adsorbs only technetium in its pertechnetate form and that there are no liquid-phase reactions of importance that either create or consume pertechnetate on the time-scales of interest.

- Significant variability exists between the various series of batch equilibrium " $K_{d}$ " test data considered. A variety of isotherm models and statistical techniques were attempted. However, insufficient experimental data addressing the ion-exchange mechanisms at the active resin sites are available to directly pin down the true reasons.

- Due to the added unknown with regard to the fraction of non-pertechnetate contained within each waste sample, the uncertainties associated with the pertechnetate " $K_{d}$ " studies can become large. Especially when a series of re-contact tests are being considered where the finite sample volume continues to concentrate in the non-pertechnetate species. Under these conditions the calculated final concentration of pertechnetate in the liquid sample after each contact period becomes progressively more sensitive to the growing error in the analysis for the fraction of non-pertechnetate present. However, several re-contact tests in series can 
potentially help in determining what the original liquid-sample non-pertechnetate fraction was (or at least set its upper bound).

- Indirect analysis of the available batch re-contact test data suggests that some level of conversion of non-pertechnetate into pertechnetate may be occurring. Unfortunately, analytical uncertainties are large enough that the above hypothesis can not be confirmed and further $\mathrm{K}_{\mathrm{d}}$ tests are recommended to help determine if liquid-phase reactions are important over the time frame of interest. Unaccounted for competitors may also be contributing to the results observed. However if true, after each resin contact test the pertechnetate depleted liquid sample would gradually be enriched in pertechnetate due to the equilibrium shift. In fact, liquid-phase reactions such as these could be beneficially used by retreatment of waste initially high in non-pertechnetate (e.g., Envelope $\mathrm{C}$ wastes) with intermediate wait times to allow equilibrium between pertechnetate and its non-pertechnetate forms to be established. Such an approach would need to include an analysis of the cost and benefits, since additional equipment and/or lost production throughput could be incurred.

- The total ion-exchange capacity of the SuperLig ${ }^{\circledR} 639$ resin was assumed to be batch dependent. Values ranging from 0.3466 to $0.8804 \mathrm{mmole} / \mathrm{g}_{\text {resin }}$ were estimated based on available batch contact test data. By assuming that each adsorption site is independent from its neighbors, the total ionic exchange capacities for $\mathrm{TcO}_{4}{ }^{-}$and $\mathrm{NO}_{3}{ }^{-}$were set equal to the above total ion-exchange capacity values. A high level of sensitivity exists (similar to the sensitivity associated with a bed density variation) between breakthrough curve prediction and variation in ion-exchange capacities.

- Initial efforts to generalize the binary adsorption isotherm model to account for batch variability and waste types were unsuccessful. Averaged values for the binary selectivity coefficient were computed and used for each unique liquid waste-sample and simulant. The binary selectivity coefficient shows a strong dependence on variations in total ionic strength and composition among the various liquid samples. Future efforts to account for this variability through liquid-phase activity coefficients will be addressed.

- Both "effective" single-component (i.e., pertechnetate) and binary (i.e., pertechnetate plus nitrate) column transport simulations were performed. For the technetium loading-phase only, justification is made that the simpler "effective" single-component column model is quite adequate for design purposes. For future elution-phase modeling, the binary model or a higher order multi-component column transport model will be necessary along with a binary or higher anion-exchange isotherm model.

- Recent chemical stability studies for determining the perrhenate adsorption capacity of SuperLig ${ }^{\circledR} 639$ resin have been published indicating some level of history dependence may exist; however, due to analytical analysis uncertainties no conclusive exposure guidelines can be drawn. Since the adsorption isotherm is the dominant factor in determining column performance, degradation in resin capacity resulting from previous chemical exposure should be experimentally investigated further. Furthermore, if modest levels of exposure dependence do exist, more careful and consistent batch contact testing should be considered where the pretreatment history of the resin prior to the contact test is monitored, controlled, 
and recorded. During the numerous loading cycles performed in the pilot facility no obvious capacity lost was observed.

- Due to the uncertainty associated with the fraction of non-pertechnetate forms contained within the various waste envelope samples, difficulties exist in obtaining binary isotherm models for pertechnetate that have high degrees of confidence. Since the isotherms are nearly linear in the column operating range of interest, these uncertainties in non-pertechnetate fractions primarily impact the adsorption isotherm model and are not compounded by the column transport terms as well.

- The use of the Lambda value for estimating $50 \%$ pertechnetate breakthrough for the Technetium-SuperLig ${ }^{\circledR} 639$ system is questionable. Measured Lambda values based on available column tests ranged from $12 \%$ to $90 \%$ of their computed values (these variations correlated more with superficial velocity than with waste type). These discrepancies can be explained due to the occurrence of mass transfer limitations. For the majority of column tests their adsorption isotherm was relatively linear over their operating range, indicating that the Lambda value discrepancies can not be accounted for due to non-linear isotherm affects.

- SuperLig ${ }^{\circledR} 639$ resin batch mixtures can be handled by computing a mixture total ionic capacity (i.e., mass weighted value) based on the total ionic capacities for every batch present within the mixture. The averaging is to be done on a mass fraction basis since total ionic capacity is on a mmole $/ \mathrm{g}_{\mathrm{resin}}$ basis.

- For the majority of column modeling parameters required to perform an ion-exchange transport simulation, a methodology was developed that can be reused and updated as future test data become available. The transport properties were established by means other than fitting to the column data directly. During the assessment phase of the methodology (by comparing predicted to measured column performance) no effort to improve these predictions, by altering the initial estimates of the various transport parameters, was necessary. This provides some level of confidence that the initially chosen transport parameter settings are appropriate.

- To properly test the validity or range of applicability of rhenium as an acceptable surrogate for technetium, a comparison of the pertechnetate versus perrhenate adsorption isotherms was made by looking at the various batch adsorption data available and drawing conclusions from them. Overlooking the slight differences in ionic composition and total ionic strength existing between the simulant and sample adsorption data considered, adsorption levels for pertechnetate $\left(\mathrm{TcO}_{4}^{-}\right)$are estimated to be $\sim 70 \%$ higher than for perrhenate $\left(\mathrm{ReO}_{4}{ }^{-}\right)$. This $\sim 70 \%$ difference in adsorption levels was further substantiated by comparing the above data/models to a special batch contact test that was designed to specifically address this issue.

- Model simulations were run for a total of twenty different (both perrhenate and pertechnetate) experimental column tests to assess the predictability of the methodology. The exit breakthrough curve predictions for the perrhenate tests are very reasonable when compared to the available data sets. Even for the pilot-scale sequential column tests, where the lag column in a previous test is used as the lead column in a follow-on test, perrhenate exit breakthrough curve predictions were reasonably accurate. However, for the pertechnetate simulations significant deviations from the data occurred in some cases and were believed to 
be predominately the result of inaccuracies in their isotherm models. The data sets themselves sometime had significant data scatter within them. The existence of nonpertechnetate forms of ${ }^{99} \mathrm{Tc}$ complicates the analysis efforts both in the creation of an appropriate isotherm model, as well as for modeling the column loading cycle. In a few cases the estimated fraction of non-pertechnetate within the various waste samples differed when based on the equilibrium contact tests versus the column exit breakthrough curves.

- In general, the predictions for removal of technetium during a column simulation were conservative with respect to the available breakthrough data (i.e., predicted breakthrough would occur earlier than measured).

- Based on this methodology full-scale facility "best estimate" simulations were run for two different waste envelopes (Envelopes A and B) where the same lag (guard) column exit technetium criterion was employed (i.e., $2 \%$ of the feed technetium). For the Envelope A (AN-103) feed, 212 column volumes per cycle can be processed where the lead column loads to $\sim 70 \%$ or greater for each cycle and a cycle average decontamination factor $\sim 227$ is achieved. For the Envelope B (AZ-102) feed, 253 column volumes per cycle can be processed where the lead column loads to $\sim 73 \%$ or greater for each cycle and a cycle average decontamination factor $\sim 235$ is achieved. A 100\% loading refers to the maximum technetium loading (in the form of pertechnetate) achievable by the resin at the specified feed conditions.

- The number of column volumes required to reach $50 \%$ breakthrough in the lead column is only slightly sensitive to flowrate. On the other hand, the slower the flow rate the sharper the concentration profile remains leading to progressively higher technetium loadings on the lead column prior to reaching a fixed exit criterion for the lag column. Based on the Envelope A feed, the number of column volumes required to reach a fixed lag column exit criterion (i.e., $2 \%$ of the feed technetium) were estimated to be 273,327 , and 355 for volumetric flow rates of 6.0, 3.0, and 1.5 CV/hr, respectively (156, 252, and $361 \mathrm{CVs}$ for Envelope B feed).

- Quantified uncertainties resulting in operational margins have not yet been computed; however, full-scale facility model sensitivities were computed. Uncertainties in the adsorption isotherms, pore diffusion coefficients, and the total amount of resin by mass contained within the columns have the dominant impact on column performance. A prioritization of model parameters is provided and discussed. Future experimental efforts should focus on the high impact parameter needs.

- Based on sensitivity simulations we see that liquid film resistance is having a negligible impact on the technetium breakthrough curves, while mass transfer resistance due to pore diffusion within the particles has a modest impact on the shape of the breakthrough curve. The number of column volumes required to reach the $50 \%$ technetium breakthrough point under no mass transfer limitations is predominately set by the adsorption isotherm ( 381 $\mathrm{CV}$ ), while accounting for pore diffusion resistance only $\sim 327 \mathrm{CV}$ (i.e., a $14 \%$ reduction) of feed can be processed.

- Based on limited batch kinetics tests performed at PNNL, an estimate of the pore diffusion coefficient for the pertechnetate anion was computed (the nitrate value was estimated by scaling the pertechnetate value). The pore diffusion coefficient for the pertechnetate anion is 
estimated to be $1.002 \times 10^{-4} \mathrm{~cm}^{2} / \mathrm{min}$, which is $~ 35 \%$ of its estimated "free" molecular diffusion coefficient. This factor of $\sim 3$ difference probably accounts for pore restriction and tortuosity. Additional batch kinetics tests for both pertechnetate and nitrate are recommended.

- Over the majority of pertechnetate concentrations that the operating facility will experience, the adsorption isotherm model for pertechnetate is relatively linear. Therefore, most of the time the performance of the ion-exchange columns is independent (in a normalized sense) of the technetium inlet feed concentration. For molar ratios of nitrate to pertechnetate less than $\sim 2 \times 10^{4}$, the isotherm becomes progressively more non-linear and a growing dependence on the inlet concentration is observed. For example, the $\mathrm{NO}_{3} / \mathrm{TcO}_{4}$ mole ratio for $\mathrm{AN}-103$ waste is $\sim 3.9 \times 10^{+4}$, implying that a column with this feed ratio would be operating entirely within the linear range of its isotherm.

- Since nitrate competes with pertechnetate for available adsorption sites, the performance of the ion-exchange columns is dependent upon the nitrate inlet feed concentration. Sensitivity results indicate that this dependence can be significant over the expected operating range of inlet feed conditions.

- To date, the available sieve analysis data for estimating the mean particle size of SuperLig ${ }^{\circledR}$ 639 resin are too coarse and the available laser technology instruments saturate at particle sizes less than observed in the population. Limited visual measurements were made to estimate the mean particle radius and additional particle size distribution studies are recommended.

The current design and operational strategy appear sufficient to achieve the desired decontamination factors. However, significant uncertainty exists in understanding the causes of column performance variability (i.e., it is believed that the majority of uncertainties reside with unknown factors influencing the isotherm model). The numerical model presented in this report can be used to gain insight into these uncertainties and optimize system performance. Excellent agreement with the perrhenate pilot-scale testing was achieved only after adjustments were made to the adsorption isotherm model used. The current transport (column) model appears to be reasonably adequate for predicting column behavior for Envelope A and B wastes, but further work with respect to competitors is necessary for Envelope C wastes. It should be noted, however, that even the variability extremes exceed the minimum design performance criteria.

For preliminary design needs, computed "best estimate" decontamination factors (D.F.) on a cumulative basis are provided in Figure 1-1 for the Technetium-SuperLig ${ }^{\circledR} 639$ system and in Figure 1-2 on a per cycle basis. These data are best applied to either Envelope A or Envelope B wastes, where similar levels of total ionic strength and composition are present. Results for the two different waste types are shown where the lag column exit criterion was set to $2 \%$ of the feed technetium concentration. Each curve identifies (with symbols) where a cycle ends and a new one begins. At the end of a cycle, the lead column is eluted and the lead-lag positions are reversed. Because some pertechnetate passes the lead column and loads onto the lag column, the level of pertechnetate loading on the lag column initially varies per start of cycle, until pseudo- 
equilibrium is reached after a few cycles. The higher technetium feed concentration for Envelope $\mathrm{B}$ is partially compensated for by its lower nitrate feed concentration.

The decontamination factors (D.F.'s) presented in Figure 1-1 represent D.F. values on a cumulative basis computed from initial operation up to the end of each cycle shown. For example, D.F. values for operating three cycles represents the cumulative D.F. value obtained by integration over the entire time period (i.e., includes cycles 1, 2, and 3). D.F. values for individual cycles (such as, operation during cycle 3 alone) are presented in Figure 1-2.

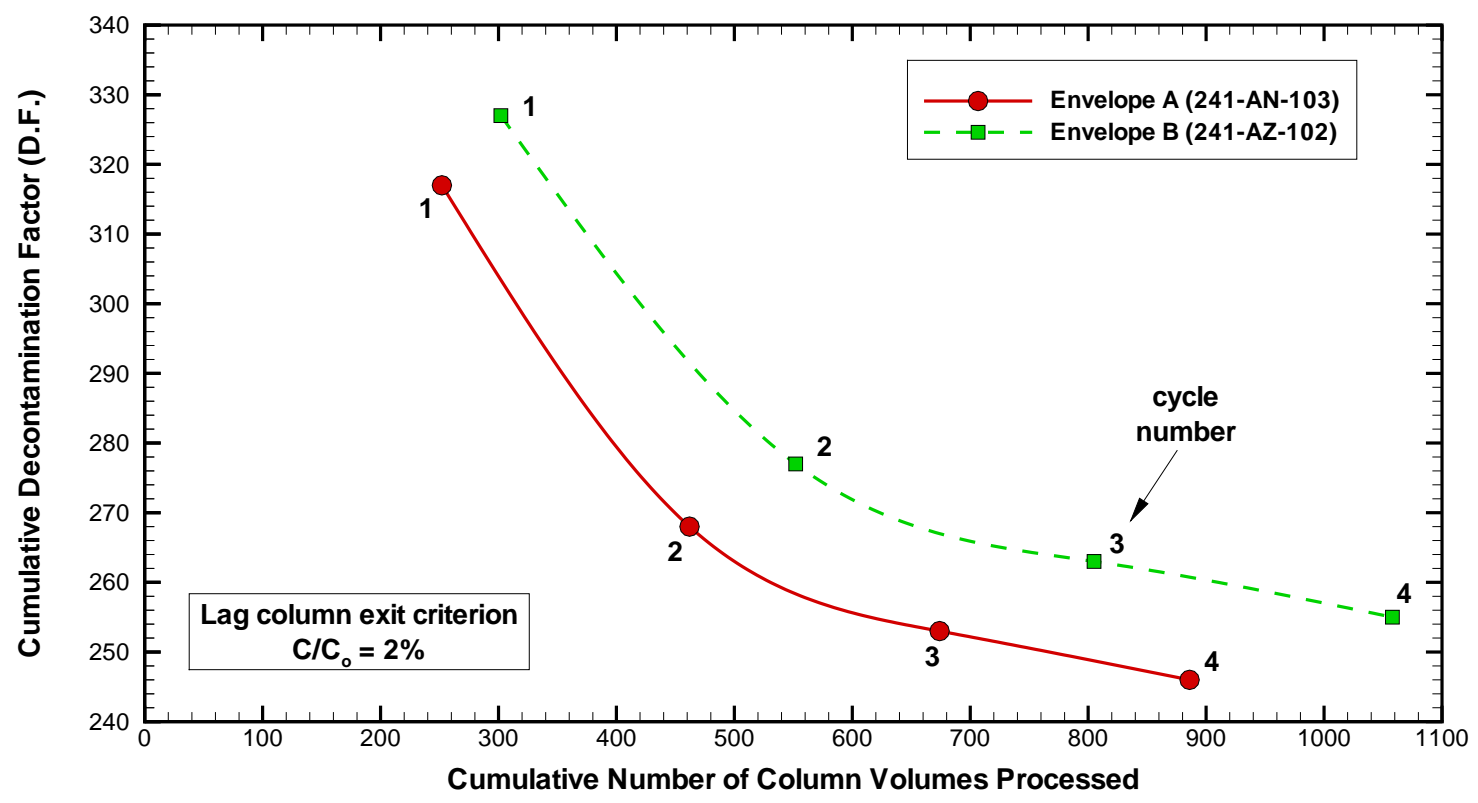

Figure 1-1. Computed "best estimate" decontamination factors on a cumulative basis for the Technetium-SuperLig ${ }^{\circledR} 639$ system ion exchange columns for Envelope $\mathrm{A}\left({ }^{99} \mathrm{TcO}_{4}{ }^{-}\right]_{0}=$ $\left.2.580 \times 10^{-5} \mathrm{M},\left[\mathrm{NO}_{3}\right]_{\mathrm{o}}=0.998 \mathrm{M}\right)$ and Envelope B $\left({ }^{99} \mathrm{TcO}_{4}\right]_{\mathrm{o}}=1.324 \times 10^{-4} \mathrm{M},\left[\mathrm{NO}_{3}\right]_{\mathrm{o}}=$ $0.232 \mathrm{M})$ feed conditions. 


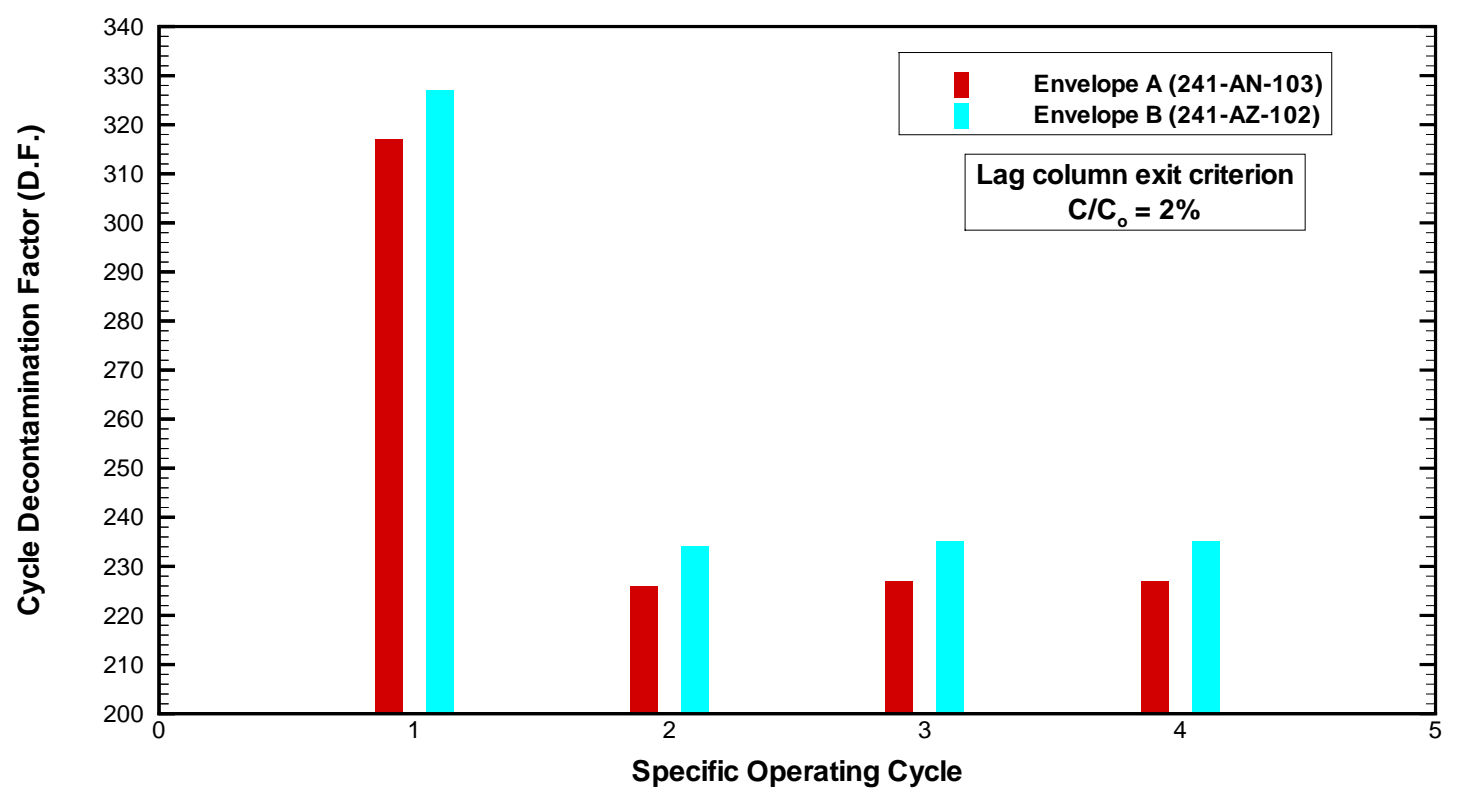

Figure 1-2. Computed "best estimate" decontamination factors on a per cycle basis for the TechnetiumSuperLig ${ }^{\circledR} 639$ system ion exchange columns for Envelope A $\left(\left[{ }^{99} \mathrm{TcO}_{4}\right]_{\mathrm{o}}=2.580 \times 10^{-5} \mathrm{M}\right.$, $\left.\left[\mathrm{NO}_{3}{ }^{-}\right]_{\mathrm{o}}=0.998 \mathrm{M}\right)$ and Envelope B $\left(\left[{ }^{99} \mathrm{TcO}_{4}{ }^{-}\right]_{\mathrm{o}}=1.324 \times 10^{-4} \mathrm{M},\left[\mathrm{NO}_{3}{ }^{-}\right]_{\mathrm{o}}=0.232 \mathrm{M}\right)$ feed conditions. 


\subsection{Introduction and Background}

A proposed facility is being designed for the immobilization of Hanford underground storage tank radioactive waste. The waste is pretreated to split it into Low Activity Waste (LAW) and High Level Waste (HLW) streams for separate vitrification. One unit process in the facility is designed to remove radioactive technetium by ion-exchange from a highly alkaline aqueous phase. A resin specifically designed with moderately high selectivity for technetium (in its pertechnetate form only) under high ionic strength (acidic as well as alkaline) conditions is being investigated. This resin also is elutable under lower ionic strength conditions (e.g., adequate elution occurs under water or dilute nitric acid conditions). The proposed design of the facility consists of two sets of two packed columns placed in series (i.e., a lead column followed by a lag (guard) column configuration). During operation, upon reaching a specified technetium concentration criterion at the exit of the lag column, operation is switched to the second set of lead and lag columns. The technetium-loaded lead column is processed (i.e., washed and eluted) and switched to the lag position. The previous lag column is then placed in the lead position (without eluting) and the system is ready for use in the next cycle. For a well designed process, the loading and elution processes result in significant volume reductions in aqueous high level waste.

\subsection{Ion Exchange Modeling}

This ion-exchange system is one of many unit operations within a larger process flowsheet. Experimental efforts are currently underway to characterize the resin and the ion-exchange process in support of the overall design. Modeling the ion-exchange process in detail provides supporting key information needed in establishing the overall flowsheet. For example, cycle (time) average decontamination factors are required at the overall flowsheet level. Separate (offline) detailed transient column modeling provides these average decontamination factors where the detail of the analysis is not restricted due to constraints imposed by the flowsheet runtime and storage requirements. The decontamination factors presented in this report represent cumulative averages over the specified time interval of interest.

In addition, modeling:

- Reduces the overall number of experiments required;

- Provides guidance on experimental efforts and focuses attention on the critical parameters;

- Evaluates the adequacy and consistency of multiple data sets;

- Consolidates available information on a particular ion exchange system; and

- Establishes then confirms full-scale facility design and operational requirements. 


\subsection{Chosen Ion Exchange Material}

IBC Advanced Technologies, Inc. (American Fork, UT) has developed a new class of sequestering ligand agents (referred to as SuperLig ${ }^{\circledR}$ in Izatt et al., 1993) that selectively removes various radionuclides (cesium, strontium, technetium, etc.) from high ionic-strength alkaline solutions based on molecular recognition technology and macrocyclic chemistry (covalent bonding). Earlier studies have demonstrated that one of these materials (SuperLig ${ }^{\circledR}$ 639) can remove technetium (in its pertechnetate form only) from simulated and actual Hanford alkaline waste even in the presence of excess quantities of nitrate, sodium, and potassium. The SuperLig $^{\circledR} 639$ resin can be eluted when the affinity for pertechnetate adsorption drops significantly with lowering ionic strength. The variation of pertechnetate adsorption with respect to ionic strength can be seen indirectly through available elution studies. The visual appearance of SuperLig $^{\circledR} 639$ can vary slightly between batches and very little swelling occurs upon exposure to liquid solutions of varying alkalinity. In general its shape is roughly spherical with "mean" particle (i.e., diameter) size distributions measured through sieve analyses. Sieve and laser technology analyses have determined its size distribution to vary between approximately 400 to 900 microns with a mean size of $\sim 750$ microns (based on separate visual measurements). The chemical stability of SuperLig ${ }^{\circledR} 639$ material was investigated by Bruening (2000c). Bruening found that the pertechnetate adsorption capacity of SuperLig ${ }^{\circledR} 639$ material might depend upon the material exposure history. Based on the available equilibrium batch contact data, the expected total ionic capacity of the various SuperLig ${ }^{\circledR} 639$ resins ranged from approximately 0.35 to $0.88 \mathrm{mmole}_{\text {sites }} / \mathrm{g}_{\text {resin }}$ (on a dried resin basis). The relative affinity for pertechnetate versus nitrate anions is also seen to be total ionic strength and composition dependent.

Based on limited analytical data of the eluate retrieved from elution cycles during various column tests, the following two anions appear to be the predominate species competing for active surface sites: Pertechnetate $\left[\mathrm{TcO}_{4}{ }^{-}\right]$and Nitrate $\left[\mathrm{NO}_{3}{ }^{-}\right]$. The above list is not comprehensive and further studies to determine all significant anions should be considered. Our current estimate for the relative affinities of SuperLig ${ }^{\circledR} 639$ resin for ion-exchange is $\mathrm{TcO}_{4}{ }^{-}>\mathrm{NO}_{3}{ }^{-}>>\left(\mathrm{SO}_{4}{ }^{2-}, \mathrm{Cl}^{-}, \mathrm{OH}^{-}\right.$, $\mathrm{NO}_{2}^{-}$, and $\mathrm{CO}_{3}{ }^{2-}$ ), while the relative affinity for other potential competitors has not yet been determined. It is believed that pertechnetate in its sodium and potassium forms (i.e., $\mathrm{NaTcO}_{4}$ and $\mathrm{KTcO}_{4}$ ) is actually adsorbed onto the surface sites, not the anions themselves. The surface affinities for $\mathrm{NaTcO}_{4}$ and $\mathrm{KTcO}_{4}$ are assumed to be equal. Similar arguments applied to the nitrate species, as well.

\subsection{Report Overview}

This report focuses on the technetium-loading phase of a complete cycle. An analysis methodology is developed where as much of the available and pertinent data on the TechnetiumSuperLig $^{\circledR} 639$ system is incorporated. Many of the model parameters are currently defined by direct experimentation. However, some of these parameters are based on limited data or significant uncertainties with regard to the data existed. In several cases assumptions had to be made prior to the assessment efforts (e.g., column test exit breakthrough curves). The 
methodology can easily be updated as new information becomes available (e.g., measured bed and pore porosities or mean particle radius).

This document represents a status report on our current knowledge and capability to model the ion-exchange process for the Technetium-SuperLig ${ }^{\circledR} 639$ system under various Hanford feed conditions. The methodology, its justification, assessment, and application to the proposed facility is discussed in the following sections. Supporting information has also been provided in several appendices and wherever possible references to available published data/information pertinent to the discussion has been cited.

Section 3 briefly discusses the transport model chosen for modeling column behavior. The governing equations and an appropriate simplification is presented. For the modeling efforts presented in this report the VERSE-LC code was chosen (Berninger et al., 1991) based on its availability and widespread (and accepted) use in this field. Essentially, the same methodology was used in earlier analyses for the Cesium-SuperLig ${ }^{\circledR} 644$ system as presented by Hamm et al. (2000). Local equilibrium between the pore fluid and its neighboring surface sites is assumed where equilibrium adsorption isotherm(s) must be specified. The algebraic isotherm model(s) used and the database employed in its creation are discussed in Section 4. Improvements to the available batch contact test databases in support of isotherm model development are mentioned in Appendix A. The use of lambda values for estimating column performance for various column experiments presented throughout this report is discussed in Appendix B where it is shown that for the Technetium-SuperLig ${ }^{\circledR} 639$ system its use should be limited. Key column properties are addressed in Section 5 where the constraint between the porosities is highlighted. Particle size distribution and swelling effects for the SuperLig ${ }^{\circledR} 639$ resin under Hanford feed conditions is addressed in Section 6. Pore diffusion and Brownian motion are discussed in Section 7 where an assessment to batch kinetics data is provided. The VERSE-LC code input and output files for the batch kinetics simulations are provided in Appendix C. In Section 8 the constitutive models for axial dispersion and film diffusion are presented. Headspace and short column impacts are also discussed where a correction factor is developed from limited literature data. Section 9 contains the laboratory-scale (including pilot-scale) column assessments (20 in total). Appendix D contains the VERSE-LC code input and output files for each laboratory-scale simulation. Based on the current design specifications for the full-scale facility, Section 10 presents full-scale column predictions for two Hanford waste feeds (i.e., Envelope A waste from tank 241-AN-103 and Envelope B waste from tank 241-AZ-102), along with a series of sensitivity analyses. The VERSE-LC code input and output files for the full-scale facility simulations are contained in Appendix E. 


\subsection{Column Model Formulations}

The modeling of ion exchange columns is typically broken up into two basic categories:

- An equilibrium model generally highly empirical in nature, and

- A column model based on one-dimensional solute transport.

In this section the equations for the multi-component and the simpler "effective" singlecomponent ion exchange column models are addressed. Justification for use of the simpler "effective" single-component column model is provided where its use is limited to the loading cycle of the process only. Section 4 of this report addresses both equilibrium models considered (i.e., the binary isotherm model and the "effective" single-component isotherm model).

To take into account the various mechanisms for ion transport and adsorption as it travels down an ion exchange column, a porous particle solute transport formulation has experienced widespread use and acceptability. For this class of column models five basic aspects of the ion exchange column are addressed as highlighted in Figure 3-1. In order of their importance with respect to predicting exit breakthrough curves for the Technetium-SuperLig ${ }^{\circledR} 639$ system, they are:

- Bed Definition (high impact) - column size, geometry and resin mass have a very direct impact on overall column performance, with particle geometry having a slightly less important impact (Shifts entire breakthrough curve with respect to number of column volumes required to reach a specified concentration level);

- Adsorption Isotherms (high impact) - resin affinities for the various competing ions of interest have a very direct impact on overall column performance (Shifts entire breakthrough curve with respect to number of column volumes required to reach a specified concentration level and for non-linear isotherms alters breakthrough curve shape as well as its sensitivity with respect to inlet feed conditions);

- Pore Diffusion (moderate impact) - intra-particle mass transport by pore diffusion to available surface sites has a moderate impact on overall column performance, with particle geometry having a slightly less important impact (under non-limiting mass transfer conditions it alters the shape of exit breakthrough curves typically by a rotation about the $\sim 50 \%$ relative concentration level with slight shifting; under limiting mass transfer conditions the rotation is generally at a point higher than $50 \%$ );

- Film Diffusion (low impact) - liquid mass transport by film diffusion across the particle-tobed boundary has a low impact on overall column performance (Alters the shape of exit breakthrough curves typically by a rotation about the $\sim 50 \%$ relative concentration level with slight shifting); 
- Axial Dispersion (low impact) - mass transport along the column by axial dispersion has a low impact on overall column performance (Alters the shape of exit breakthrough curves typically by a rotation about the $\sim 50 \%$ relative concentration level with slight shifting);

The above stated levels of impact are based on sensitivity studies and are relative values. Mechanisms such as surface migration or adsorption kinetics are not included in our column model since their impacts were considered to be negligible or already indirectly incorporated into the other features during our parameter estimation process. A simple graphical representation of the various transport mechanisms listed above and considered to be important for the Technetium-SuperLig ${ }^{\circledR} 639$ system is shown in Figure 3-2.

\subsection{The Multi-Component Model}

For the Technetium-SuperLig ${ }^{\circledR} 639$ resin system a porous particle multi-component ion exchange column model was considered. In this model we assume that the kinetics associated with local ion exchange at an active resin site are very fast (faster than the various liquid mass transfer mechanisms that transport ions to that site). Assuming radial effects to be negligible within the active region of the packed bed (i.e., a large column-to-particle diameter ratio), a onedimensional species (ion) transport equation for the mobile phase (within the bed) becomes

$\varepsilon_{\mathrm{b}} \frac{\partial \mathrm{c}_{\mathrm{bi}}}{\partial \mathrm{t}}+\varepsilon_{\mathrm{b}} \mathrm{u} \frac{\partial \mathrm{c}_{\mathrm{bi}}}{\partial \mathrm{z}}=\varepsilon_{\mathrm{b}} \mathrm{E}_{\mathrm{bi}} \frac{\partial^{2} \mathrm{c}_{\mathrm{bi}}}{\partial \mathrm{z}^{2}}-\left(\frac{3}{<\mathrm{R}_{\mathrm{p}}>}\right)\left(1-\varepsilon_{\mathrm{b}}\right) \mathrm{k}_{\mathrm{f}}\left(\mathrm{c}_{\mathrm{bi}}-\left.\mathrm{c}_{\mathrm{pi}}\right|_{\mathrm{r}=\mathrm{R}_{\mathrm{p}}}\right)$,

storage advection

axial

dispersion liquid film diffusion

(mass transfer)

with boundary and initial conditions

$$
\begin{array}{ll}
\mathrm{z}=0, & \varepsilon_{\mathrm{b}} \mathrm{E}_{\mathrm{b}} \frac{\partial \mathrm{c}_{\mathrm{bi}}}{\partial \mathrm{z}}=\mathrm{uL}\left[\mathrm{c}_{\mathrm{bi}}-\mathrm{c}_{\mathrm{bi}}^{\mathrm{feed}}(\mathrm{t})\right], \\
\mathrm{z}=1, & \varepsilon_{\mathrm{b}} \mathrm{E}_{\mathrm{b}} \frac{\partial \mathrm{c}_{\mathrm{bi}}}{\partial \mathrm{z}}=0, \\
\mathrm{t}=0, & \mathrm{c}_{\mathrm{bi}}=\mathrm{c}_{\mathrm{bi}}(0, \mathrm{z}) .
\end{array}
$$

Assuming uniformly sized spherical particles with a homogeneous distribution of pores, a onedimensional species transport equation for the pore phase (within an average sized particle of resin) becomes

$$
\begin{aligned}
& \varepsilon_{\mathrm{p}} \frac{\partial \mathrm{c}_{\mathrm{pi}}}{\partial \mathrm{t}}+\left(1-\varepsilon_{\mathrm{p}}\right) \overline{\mathrm{C}}_{\mathrm{T}} \sum_{\mathrm{j}=1}^{\mathrm{N}_{\mathrm{s}}}\left[\left(\frac{\partial \mathrm{q}_{\mathrm{i}}}{\partial \mathrm{c}_{\mathrm{pj}}}\right) \frac{\partial \mathrm{c}_{\mathrm{pj}}}{\partial \mathrm{t}}\right]=\varepsilon_{\mathrm{p}} \mathrm{D}_{\mathrm{pi}} \frac{1}{\mathrm{r}^{2}} \frac{\partial}{\partial \mathrm{r}}\left[\mathrm{r}^{2} \frac{\partial \mathrm{c}_{\mathrm{pi}}}{\partial \mathrm{r}}\right], \\
& \text { storage } \\
& \text { surface } \\
& \text { adsorption }
\end{aligned}
$$

with boundary and initial conditions 


$$
\begin{array}{ll}
\mathrm{r}=0, & \varepsilon_{\mathrm{p}} \mathrm{D}_{\mathrm{p}} \frac{\partial \mathrm{c}_{\mathrm{bi}}}{\partial \mathrm{r}}=0, \\
\mathrm{r}=\left\langle\mathrm{R}_{\mathrm{p}}\right\rangle, & \varepsilon_{\mathrm{p}} \mathrm{D}_{\mathrm{p}} \frac{\partial \mathrm{c}_{\mathrm{bi}}}{\partial \mathrm{r}}=\mathrm{k}_{\mathrm{f}}\left(\mathrm{c}_{\mathrm{bi}}-\mathrm{c}_{\mathrm{pi}}\right), \\
\mathrm{t}=0, & \mathrm{c}_{\mathrm{pi}}=\mathrm{c}_{\mathrm{pi}}(0, \mathrm{r}) .
\end{array}
$$

In Eq. (3-2) it is assumed that the pore diameters are large relative to the size of migrating ions of interest. Therefore, Fickian diffusion is acceptable and surface migration is considered to be small when compared to pore diffusion.

Assuming local equilibrium between the pore fluid and its neighboring surface sites, an equilibrium isotherm model for the ion exchange between the pore and solid phases can be generically expressed as:

$$
\begin{aligned}
\mathrm{q}_{\mathrm{i}}= & \mathrm{F}_{\mathrm{i}}\left(\overline{\mathrm{C}}_{\mathrm{T}}, \mathrm{c}_{\mathrm{p} 1}, \mathrm{c}_{\mathrm{p} 2}, \cdots, \mathrm{c}_{\mathrm{pN}_{\mathrm{s}}}\right), \quad \mathrm{i}=1, \mathrm{~N}_{\mathrm{s}}, \\
& \text { multi-component isotherm }
\end{aligned}
$$

where it has been assumed that surface loadings for the $\mathrm{i}^{\text {th }}$ species can be explicitly related to the liquid concentrations locally. The number of species required to model the behavior of the $i^{\text {th }}$ species depends upon its dependence on other species through the functional form (i.e., $\mathrm{F}_{\mathrm{i}}$ ) of the isotherm model [Eq. (3-3)]. Specific application of Eq. (3-3) to the technetium-SuperLig ${ }^{\circledR} 639$ resin system is discussed in Section 4. Initial and boundary conditions for Eqs. (3-1) and (3-2) must also be specified. For further details on these equations and their solution in VERSE-LC see Berninger et al. (1991). Helfferich and Carr (1993) provide an excellent review paper describing the behavior of non-linear waves in chromatography and also a brief listing of available algorithms (see their Table I.4). Their paper provides very clear insight into how the above equation set behaves for non-linear isotherms consistent with the system of interest discussed in this report.

For the modeling efforts presented in this report the VERSE-LC code was chosen (Berninger et al., 1991) based on its availability and widespread (and accepted) use in this field. Prior to applying VERSE-LC to the ion exchange modeling presented in this report a verification process was completed and the results of that effort are reported in Hamm et al. (1999). The verification process provided us quality assurance that the installed PC Window95 ${ }^{\mathrm{TM}}$ version of VERSE-LC (i.e., version 7.80) was capable of adequately solving the above mentioned equations and also helped us to better understand how to accurately use the VERSE-LC code (e.g., mesh refinement requirements and input/output options). For all column results presented in this report numerical errors associated with the results of VERSE-LC should be very small when compared to the uncertainties associated with various model input parameters (bed density, particle radius, pore diffusion, etc.). 


\subsection{The Single-Component Model}

Under certain situations the porous particle multi-component transport equations discussed in Section 3.1 can be adequately decoupled to a series of single-component transport equations. The reduction to single-component equations is:

- valid when the total ionic strength, $\mathrm{C}_{\mathrm{T}}$, is the same between the column's native and feed solutions; or

- a reasonable approximation when one ion absorbs significantly more onto the resin than others.

Making the same basic assumptions as in Section 3.1 the single-component equations can be derived. For each species a one-dimensional species (ion) transport equation for the mobile phase (within the bed) becomes

$$
\begin{aligned}
& \varepsilon_{\mathrm{b}} \frac{\partial \mathrm{c}_{\mathrm{b}}}{\partial \mathrm{t}}+\varepsilon_{\mathrm{b}} \mathrm{u} \frac{\partial \mathrm{c}_{\mathrm{b}}}{\partial \mathrm{z}}=\varepsilon_{\mathrm{b}} \mathrm{E}_{\mathrm{b}} \frac{\partial^{2} \mathrm{c}_{\mathrm{b}}}{\partial \mathrm{z}^{2}}-\left(\frac{3}{<\mathrm{R}_{\mathrm{p}}>}\right)\left(1-\varepsilon_{\mathrm{b}}\right) \mathrm{k}_{\mathrm{f}}\left(\mathrm{c}_{\mathrm{b}}-\left.\mathrm{c}_{\mathrm{p}}\right|_{\mathrm{r}=\mathrm{R}_{\mathrm{p}}}\right), \\
& \text { storage advection axial liquid film diffusion } \\
& \text { dispersion (mass transfer) }
\end{aligned}
$$

where initial and boundary conditions are consistent with Eqs. (3-1b,c,d). A one-dimensional species transport equation for the pore phase (within a particle of resin) becomes

$$
\begin{array}{cc}
\varepsilon_{\mathrm{p}} \frac{\partial \mathrm{c}_{\mathrm{p}}}{\partial \mathrm{t}}+\left(1-\varepsilon_{\mathrm{p}}\right) \overline{\mathrm{C}}_{\mathrm{T}}\left(\frac{\partial \mathrm{q}}{\partial \mathrm{c}_{\mathrm{p}}}\right) \frac{\partial \mathrm{c}_{\mathrm{p}}}{\partial \mathrm{t}}= & \varepsilon_{\mathrm{p}} \mathrm{D}_{\mathrm{p}} \frac{1}{\mathrm{r}^{2}} \frac{\partial}{\partial \mathrm{r}}\left[\mathrm{r}^{2} \frac{\partial \mathrm{c}_{\mathrm{p}}}{\partial \mathrm{r}}\right], \\
\text { storage } & \begin{array}{c}
\text { Fickian pore } \\
\text { adsorption } \\
\text { diffusion }
\end{array}
\end{array}
$$

where initial and boundary conditions are consistent with Eqs. (3-2b,c,d).

The equilibrium isotherm model for species $\mathrm{i}$ for the ion exchange between the pore and solid phases becomes:

$$
\mathrm{q}=\frac{\mathrm{c}_{\mathrm{p}}}{\beta+\mathrm{c}_{\mathrm{p}}},
$$

\section{single-component isotherm}

where Eq. (3-6) is of the Langmuir form and $\beta$ is a function of the feed conditions.

\subsection{The Technetium-SuperLig ${ }^{\circledR} 639$ System}

Based on our current understanding, for the Technetium-SuperLig ${ }^{\circledR} 639$ resin system the competition for anion exchange loading at the resin sites is primarily between technetium (in its pertechnetate form only) and nitrate. Prior to the loading phase the initial nitrate, sodium, and 
potassium levels in the resin pretreatment solution are approximately $0 \mathrm{M}, 1.0 \mathrm{M}$, and $0 \mathrm{M}$, respectively. During the loading phase these concentration levels increase to approximately 0.1 to-2.0 M nitrate, 5.0 $\mathrm{M}$ sodium, and 0.0-to- $0.5 \mathrm{M}$ potassium. Therefore, a total ionic concentration wave will initially pass through the column. Based on available batch equilibrium studies estimates for the relative affinities for adsorption have been computed as discussed in Section 4 (i.e., the resin affinities are $\mathrm{TcO}_{4}{ }^{-}>\mathrm{NO}_{3}{ }^{-}$).

Given the above information, early column performance (say the first 5 to 10 column volumes or so) probably will require the use of the multi-component formulations of Section 3.1. Long-term performance should be adequately handled using the simpler single-component formulations of Section 3.2. To check the validity of these statements, pertechnetate exit breakthrough curves from several column simulations were compared where both the multi-component (i.e., the binary model) and single-component formulations were used. Very similar results were obtained. To illustrate the differences in timing for the two ionic species, the lead and lag column exit breakthrough curves for each species is plotted in Figure 3-3 for a multi-component simulation of the full-scale facility. The results shown in Figure 3-3 are based on feed concentrations consistent with Envelope A waste samples taken from tank 241-AN-103. As expected nitrate breakthrough is the fastest and then two orders of magnitude later followed by pertechnetate. Under identical operating conditions the pertechnetate exit breakthrough curves based on the multi-component and single-component column models were computed. As shown in Figure 3-4, when the single-component formulations are used, the pertechnetate breakthrough curves are basically identical (i.e., only slightly altered during the first column volumes or so).

Since significant CPU savings are achieved when the single-component model is used and the differences are well within our current predictive capabilities, the majority of column analyses presented in this report were performed using the single-component model. This simplification only applies to the loading cycle and for future elution studies a multi-component version will be required. 


\section{Axial Dispersion}

residence time tests (end-effects \& short column impacts)

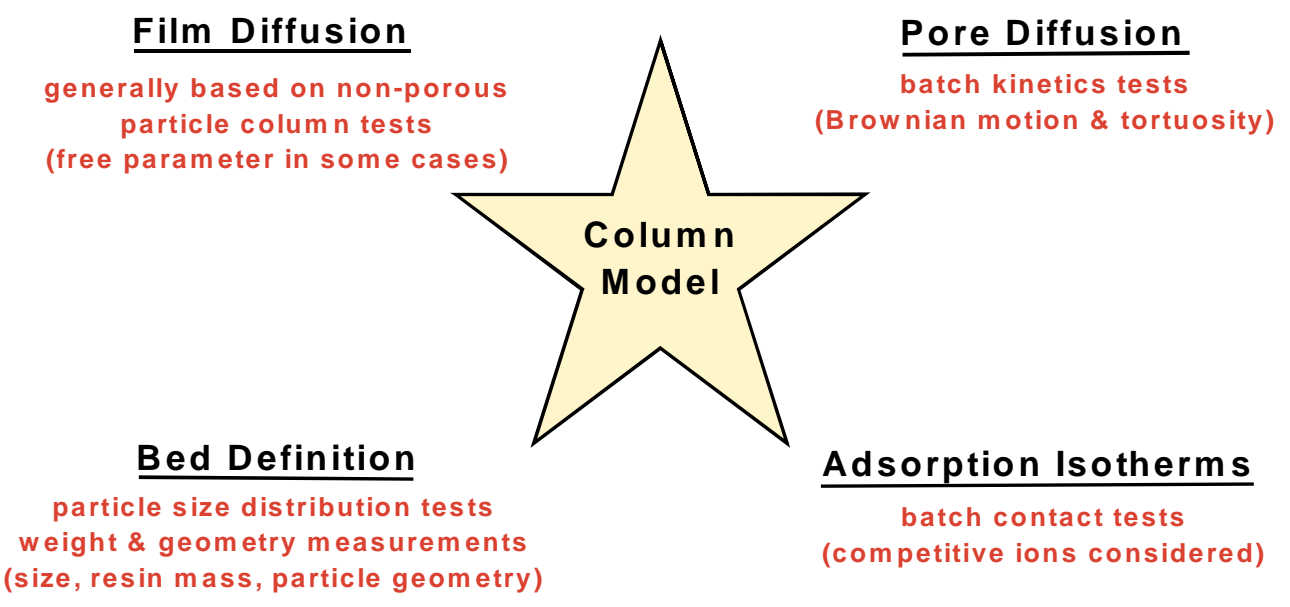

Figure 3-1. The basic building blocks of a porous particle ion exchange column model. 


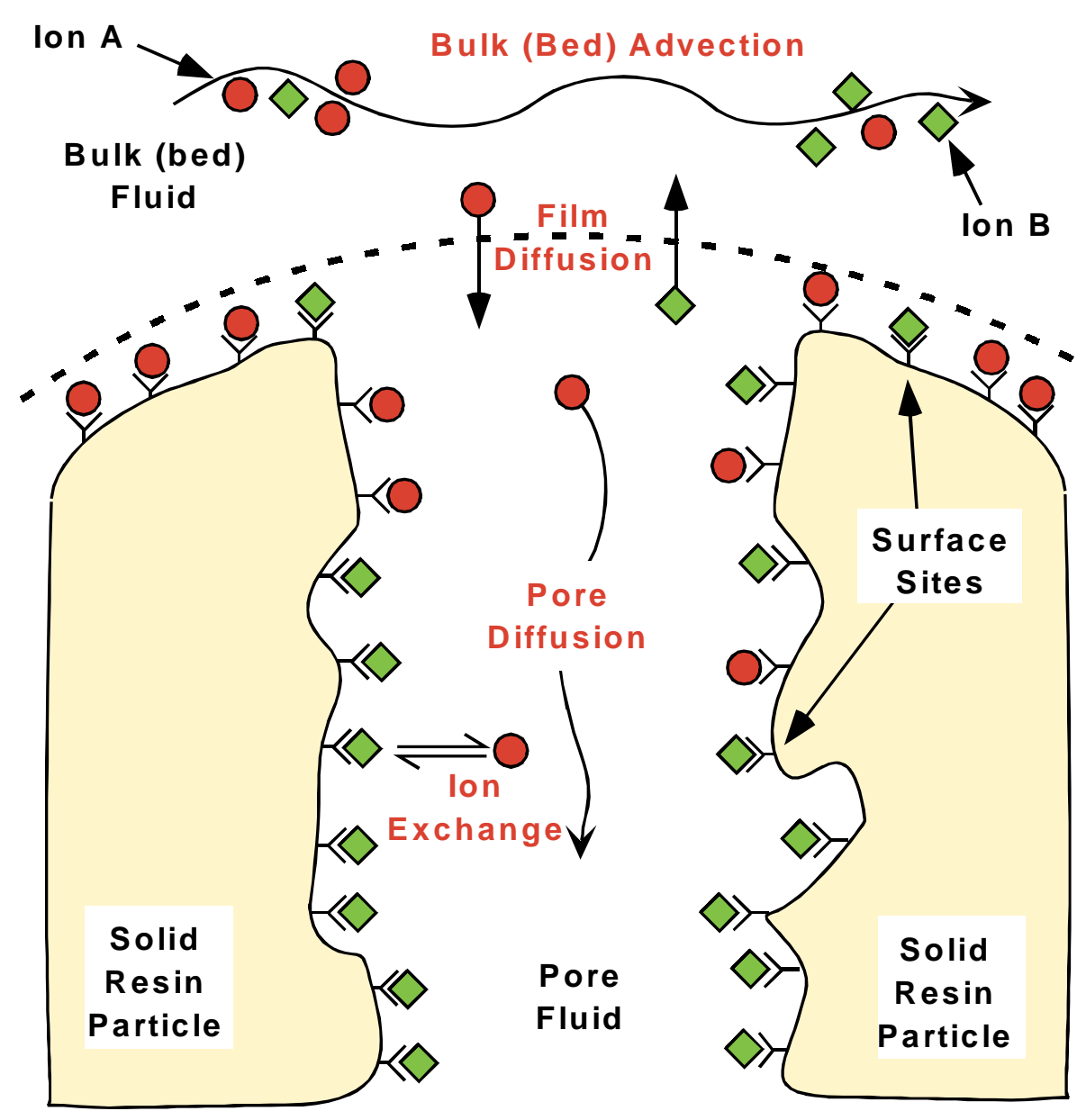

Figure 3-2. Graphical representation of the various mass transport mechanisms considered important for Technetium-SuperLig ${ }^{\circledR} 639$ system ion exchange column modeling. 
Preliminary Ion Exchange Modeling for Removal of Technetium from Revision (Date):

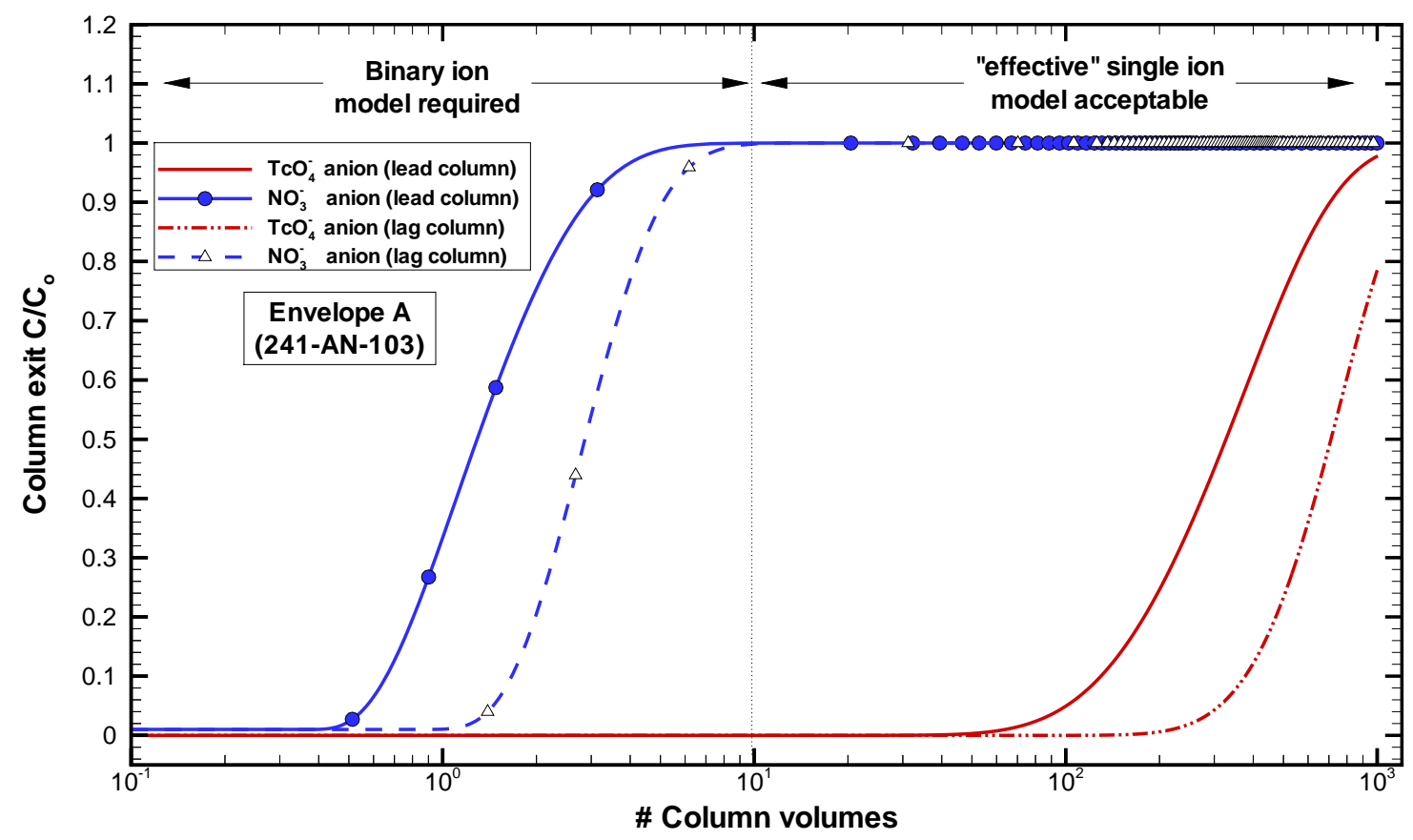

Figure 3-3. Estimated pertechnetate and nitrate exit breakthrough curves for the full-scale facility based on the porous particle multi-component (i.e., binary) ion exchange column model for Envelope A (241-AN-103) waste using SuperLig $639^{\circledR}$ resin.

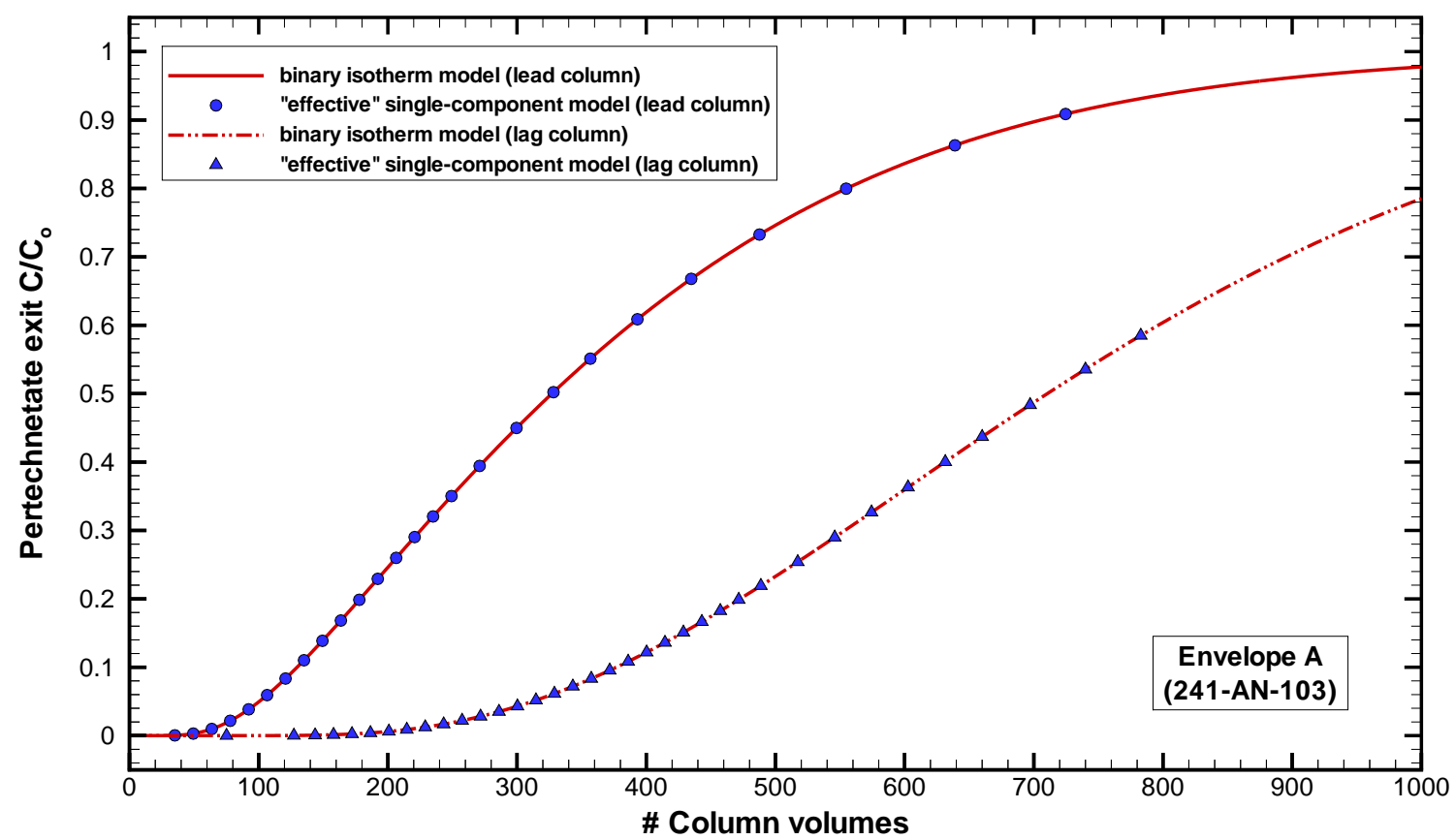

Figure 3-4. Comparison of estimated pertechnetate exit breakthrough curves for the full-scale facility based on the binary and "effective" single-component ion exchange column models for Envelope A (241-AN-103) waste using SuperLig $639^{\circledR}$ resin. 


\subsection{Equilibrium Adsorption Isotherm}

In our column modeling efforts we assume that the rate of chemical adsorption (i.e., exchange of ions at a surface site) is very fast when compared to the rates of diffusion within the pore fluid and mass transfer across the liquid film at the outer boundaries of the particles. In other words, we assume that local equilibrium exists between the pore fluid and its neighboring surface sites. With this assumption an algebraic expression relating ionic (or species) concentrations between the pore fluid and the solid resin (i.e., surface sites) can be established. No explicit attempt is made in this report to verify this assumption. In an indirect manner this assumption is either verified or incorporated into some of the model parameters. In addition, we assume that the resin contains homogeneous adsorption sites whose concentration (sites per gram of resin) is independent of total ionic strength or solution composition. To date only one ion-exchange capacity number has been provided by the vendor and for varying engineered resin batches it is likely that the total ionic capacity will vary. Therefore, as part of the isotherm model development effort, the total ionic capacity is considered to be an additional parameter that is estimated based on the available batch specific equilibrium contact data.

In deriving an appropriate isotherm model the following items were considered:

- To keep reasonable runtimes an algebraic form of an isotherm model was desired that would be compatible/consistent with standard column models;

- The form of the isotherm model is to be thermodynamically consistent with the local massaction equations where appropriate;

- The effects of competing anions within possible feed solutions needed to be easily addressed (i.e., able to handle the expected range of Hanford waste feeds without major alterations required);

- A large amount of the available batch equilibrium " $\mathrm{K}_{\mathrm{d}}$ " data needed to be considered to statistically reduce any unwanted biases that may be present;

- Batch variability must be handled by adjusting the total ionic capacity of each batch; and

- Compensate for differing total ionic strength and ionic composition of the various expected waste envelopes by adjusting the average value of the binary selectivity coefficient.

Based on these considerations a binary homovalent isotherm model was developed and is presented in this section. Overall the model meets all of the above items; however, the confidence intervals for the model are higher than hoped. Adsorption differences between pertechnetate and its surrogate (perrhenate) are observed; however, no definitive explanation to the root causes can be made at this time. In Appendix A, further discussion of the isotherm model is given, where the effects associated with non-pertechnetate forms and nitrate solution shifts impacting pertechnetate (and perrhenate) loading are investigated. To adequately model the elution cycle, the impact of hydroxyl ion $\left(\mathrm{OH}^{-}\right)$(and other competitors) on pertechnetate loading may be required. The available equilibrium contact data indicates that pertechnetate 
adsorption levels drop off significantly with reduced total ionic strength. No attempt to incorporate the variation of liquid-phase activity coefficients is made in this report. Future updates to this model will address these issues.

Based on the equilibrium contact data it is believed that the selectivity coefficient of SuperLig ${ }^{\circledR}$ 639 resin between nitrate and pertechnetate differs from its value between nitrate and perrhenate. The selectivity coefficients are most likely total ionic strength and anion composition dependent; however, if these variables are held fixed it is believed that similar values for the selectivity coefficients for differing batch materials will be achieved. It is assumed that the total ionic capacity of the SuperLig ${ }^{\circledR} 639$ resin is primarily batch dependent with little dependence on total ionic strength of the solution or on the type/composition of competing anions (e.g., nitrate, pertechnetate, or perrhenate).

In the isotherm development below, and later in its application in Section 9, we are assuming that the total ionic exchange capacity of the resin (i.e., number of active adsorption sites in millimoles per gram of resin on a dry basis) is independent of the liquid-phase total ionic strength and the composition of competing anions. We are assuming that batch differences are primarily related to improvements (or process variances) in the engineering/manufacturing of the SuperLig ${ }^{\circledR} 639$ resin (i.e., number of sites per gram), not alterations in the chemistry (e.g., linker arm) associated with a given adsorption site (i.e., receptor/ligand). Also, we employ average values for the selectivity coefficients based on inlet column feed conditions; even though, they are in general a function of the liquid-phase total ionic strength and the solution ionic composition down the columns. No attempt to account for this dependence through liquid-phase activity coefficients is made. Future equilibrium contact tests (to be performed at PNNL) are planned to better address these various assumptions and given the new data sets upgrades to the isotherm model can be considered.

The isotherm model development discussed below follows very closely to the development efforts presented by Hamm et al. (2000) for the Cesium-SuperLig ${ }^{\circledR} 644$ ion-exchange system. For the Cesium-SuperLig ${ }^{\circledR} 644$ ion-exchange system, cation exchange (e.g., $\mathrm{Cs}^{+}$replacing $\mathrm{Na}^{+}$) processes were occurring at the resin adsorption sites. However, for the pertechnetate (or perrhenate)-SuperLig ${ }^{\circledR} 639$ system, it is believed that molecular-exchange (e.g., $\mathrm{NaTcO}_{4}$ replacing $\mathrm{NaNO}_{3}$ ) not anion-exchange processes are occurring.

In the next subsection a binary isotherm model is developed based on an ion-exchange process and in the following subsection its specific application to the pertechnetate (or perrhenate)SuperLig $^{\circledR} 639$ system is discussed. There, the issue involving molecular species versus anion exchange is addressed.

\subsection{The Isotherm Model}

The total concentration of pore fluid anions is defined as

$$
\mathrm{C}_{\mathrm{T}}=\sum_{\mathrm{i}=1}^{\mathrm{N}_{\mathrm{c}}} \mathrm{c}_{\mathrm{pi}},
$$


while the total anion-exchange capacity of the resin is defined as

$$
\overline{\mathrm{C}}_{\mathrm{T}}=\sum_{\mathrm{i}=1}^{\mathrm{N}_{\mathrm{c}}} \overline{\mathrm{c}}_{\mathrm{pi}}
$$

The fraction of surface sites occupied by the $\mathrm{i}^{\text {th }}$ anion is defined as

$$
\mathrm{q}_{\mathrm{i}} \equiv \frac{\overline{\mathrm{c}}_{\mathrm{pi}}}{\overline{\mathrm{C}}_{\mathrm{T}}}=\frac{\overline{\mathrm{c}}_{\mathrm{pi}}}{\overline{\mathrm{C}}_{\mathrm{Ti}}},
$$

where it is assumed that each ionic species exchange capacity is equivalent to the total exchange capacity (at present no explicit measurements are available to ascertain the validity of this assumption).

As mentioned above we are making the important assumption of local chemical equilibrium. Hence, among the $\mathrm{N}_{\mathrm{c}}$ exchanging ions in the system, there are $\mathrm{N}_{\mathrm{c}}-1$ independent equilibrium mass-action expressions of the form

$$
\tilde{\mathrm{K}}_{\mathrm{ji}} \equiv \frac{1}{\widetilde{\mathrm{K}}_{\mathrm{ij}}}=\left(\frac{\mathrm{q}_{\mathrm{j}}}{\mathrm{c}_{\mathrm{pj}}}\right)^{v_{\mathrm{j}}}\left(\frac{\mathrm{c}_{\mathrm{pi}}}{\mathrm{q}_{\mathrm{i}}}\right)^{v_{\mathrm{i}}} \quad \text { and } \quad \tilde{\mathrm{K}}_{\mathrm{ii}} \equiv 1,
$$

where $v_{\mathrm{j}}$ is the stoichiometric coefficient for species $\mathrm{j}$ and $\tilde{\mathrm{K}}_{\mathrm{ji}}$ is the ion selectivity coefficient between species $\mathrm{j}$ and $\mathrm{i}$. Equations (4-4) correspond to the stoichiometric ion-exchange for phase equilibrium:

$$
v_{\mathrm{j}}\left[\mathrm{A}_{\mathrm{j}}\right]_{\text {pore }}+v_{\mathrm{i}}\left[\mathrm{A}_{\mathrm{i}}\right]_{\mathrm{re} \mathrm{sin}} \stackrel{\mathrm{K}_{\mathrm{ji}}}{\longleftrightarrow} v_{\mathrm{j}}\left[\mathrm{A}_{\mathrm{j}}\right]_{\text {re sin }}+v_{\mathrm{i}}\left[\mathrm{A}_{\mathrm{i}}\right]_{\text {pore }},
$$

where $\mathrm{K}_{\mathrm{ji}}$ is the equilibrium constant. Even though the equilibrium constant is a true constant for a given temperature, the selectivity coefficients are compositionally dependent since non-unity activity coefficients will exist. This variation can be addressed in a thermodynamically consistent manner using the approach presented by Polzer et al. (1992). An application of this technique is presented in Zheng et al. (1995) for cesium ion exchange using crystalline silicotitanates (CSTs). However, in the development that follows average values for the selectivity coefficients are assumed. If accuracy requires it, in future work this functional dependence will be addressed. Also, reaction Eq. (4-5) implicitly assumes that a single surface site represents an ionic exchange unit. For some exchange systems multiple surface sites constitute an ionic exchange unit (Zheng et al., 1995) which can have profound effects on certain ionic species.

As originally demonstrated in the classical work by Rubin and James (1973) and later by Valocchi et al. (1981), if we consider only monovalent or divalent anions, the $\mathrm{N}_{\mathrm{c}}$ chemical equations (i.e., Eqs. (4-2, 3, and 4)) can be combined to yield the explicit multi-component exchange isotherms: 


$$
\mathrm{q}_{\mathrm{i}} \equiv \frac{\overline{\mathrm{c}}_{\mathrm{pi}}}{\overline{\mathrm{C}}_{\mathrm{T}}}=\overline{\mathrm{C}}_{\mathrm{T}} \cdot \mathrm{F}_{\mathrm{i}}\left(\mathrm{c}_{\mathrm{p} 1}, \mathrm{c}_{\mathrm{p} 2}, \ldots, \mathrm{c}_{\mathrm{pN}_{\mathrm{c}}}, \tilde{\mathrm{K}}_{\mathrm{ji}}\right) \quad \text { for } \quad \mathrm{i}=1,2, \ldots, \mathrm{N}_{\mathrm{c}} .
$$

Making use of the above equations, the two adsorption isotherms for a binary homovalent exchange process (i.e., $\mathrm{N}_{\mathrm{c}}=2, v_{1}=v_{2}=1$ ) can be expressed in the form:

$$
\mathrm{q}_{\mathrm{i}} \equiv \frac{\overline{\mathrm{c}}_{\mathrm{pi}}}{\overline{\mathrm{C}}_{\mathrm{T}}}=\frac{\widetilde{\mathrm{K}}_{\mathrm{i} 1} \mathrm{c}_{\mathrm{pi}}}{\mathrm{c}_{\mathrm{p} 1}+\widetilde{\mathrm{K}}_{21} \mathrm{c}_{\mathrm{p} 2}} \quad \text { for } \quad \mathrm{i}=1,2
$$

where use is made of the identities given by Eq. (4-4). In the case where the feed solution has the same total normality as the native solution (i.e., $\mathrm{C}_{\mathrm{T}}=$ constant), Eq. (4-7) reduces from the binary exchange problem to the well-known single-species adsorption isotherm that has been studied extensively in the literature. Thereby, the multi-component ionic transport problem also reduces down to uncoupled single-component transport problems for each species as discussed in Section 3. Under the limitation of constant total normality, Eq. (4-7) takes the familiar form known as the Langmuir isotherm:

$$
\mathrm{q}_{1}=\frac{\tilde{\mathrm{K}}_{12} \mathrm{c}_{\mathrm{p} 1}}{1+\left[\frac{\left(\tilde{\mathrm{K}}_{21}-1\right)}{\mathrm{C}_{\mathrm{T}}}\right] \mathrm{c}_{\mathrm{p} 1}} \Rightarrow \frac{\mathrm{Ac}_{\mathrm{p} 1}}{1+\mathrm{Bc}_{\mathrm{p} 1}} .
$$

where the "binding constants" A and B are usually derived from adsorption data.

Equations (4-7) represent our chosen adsorption isotherm model that contains two physically based parameters that must be determined based on available adsorption data. Furthermore, only data for one species on the solid surface is required. For larger numbers of competing anions $(>2)$ in a homovalent exchange process additional terms are added to the denominator of Eq. (47). The isotherm derivations for heterovalent exchange processes become increasingly more complicated beyond two species.

A distribution coefficient (i.e., a "chord" of the isotherm) for each species can be expressed as

$$
\mathrm{K}_{\mathrm{di}} \equiv \frac{\mathrm{q}_{\mathrm{i}}}{\mathrm{c}_{\mathrm{pi}}}=\frac{\tilde{\mathrm{K}}_{\mathrm{i} 1}}{\mathrm{c}_{\mathrm{p} 1}+\widetilde{\mathrm{K}}_{21} \mathrm{c}_{\mathrm{p} 2}} \quad \text { for } \quad \mathrm{i}=1,2 .
$$

The distribution coefficient (typically referred to as a " $K_{d}$ " value) generally varies with composition where for favorable isotherms its value diminishes with increasing concentrations. The $K_{d}$ value represents the chord (not the tangential) slope of the isotherm as shown in Appendix B of Hamm et al. (2000). Under favorable isotherm conditions concentration profiles down a column tend to approach an asymptote resulting from the balancing of axial dispersion versus the self-sharpening tendency of the non-linear (convex) isotherm. Given the fixed and finite number of available adsorption sites the isotherms of interest have the typical favorable (e.g., Langmuir like) shape. Generally, for very low fluid concentrations the isotherms are 
reasonably linear with approximately constant $\mathrm{K}_{\mathrm{d}}$ values. Over the typical range of pertechnetate (or perrhenate) feed the isotherm models developed below are relatively linear.

\subsection{The Technetium-SuperLig ${ }^{\circledR} 639$ System}

For the expected pretreated waste feeds to the SuperLig ${ }^{\circledR} 639$ ion exchange columns (i.e., maximum values being set by design specifications), the following two (plus a surrogate) competing anions must be considered:

$$
\begin{array}{lll}
\mathrm{XO}_{4}{ }^{-} & \left(0 \text { to } 5.7 \times 10^{-4} \mathrm{M}\right) & \text { (component } 1: \mathrm{X}={ }^{99} \mathrm{Tc} \text { or its surrogate Re) } \\
\mathrm{NO}_{3}{ }^{-} & (0.2 \text { to } 4.0 \mathrm{M}) & \text { (component } 2: \text { nitrate) }
\end{array}
$$

Note that early on equilibrium contact tests were performed by IBC Advanced Technologies, Inc. (1996) to determine the impact of various potential competitors on the $\mathrm{K}_{\mathrm{d}}$ value of perrhenate on the SuperLig ${ }^{\circledR} 639$ resin. The potential competitors $\mathrm{SO}_{4}{ }^{2-}, \mathrm{Cl}^{-}, \mathrm{OH}^{-}, \mathrm{NO}_{2}{ }^{-}$, and $\mathrm{CO}_{3}{ }^{2-}$ were found to have minimal impact on the measured $\mathrm{K}_{\mathrm{d}}$ values of perrhenate. On the other hand, $\mathrm{NO}_{3}{ }^{-}$was verified as a prime competitor for adsorption sites.

For the various molecular species competing for surface sites during the loading phase of a cycle, the following generic mass-action expression applies based on Eq. (4-5):

$$
\left[\overline{\mathrm{Y}^{+}\left(\mathrm{NO}_{3}\right)^{-}}\right]+\left[\mathrm{Y}^{+}\left(\mathrm{XO}_{4}\right)^{-}\right] \stackrel{{ }^{\mathrm{YY}} \mathrm{K}_{12}}{\longleftrightarrow}\left[\overline{\mathrm{Y}^{+}\left(\mathrm{XO}_{4}\right)^{-}}\right]+\left[\mathrm{Y}^{+}\left(\mathrm{NO}_{3}\right)^{-}\right]
$$

where the symbols $\mathrm{X}$ and $\mathrm{Y}^{+}$refer to

$$
\mathrm{Y}^{+} \rightarrow \mathrm{Na}^{+} \text {or } \mathrm{K}^{+} \quad \text { and } \quad \mathrm{X} \rightarrow \mathrm{Tc} \text { or } \mathrm{Re} .
$$

Therefore, for either technetium or rhenium based waste solutions Eq. (4-10) represents four possible mass-action processes. The SuperLig ${ }^{\circledR} 639$ resin selectively adsorbs technetium (and rhenium) only in its oxide form of pertechnetate (or perrhenate). For example, for a technetium based waste solution in contact with the SuperLig ${ }^{\circledR} 639$ resin the following four mass-action processes apply:

$$
\begin{gathered}
{\left[\overline{\mathrm{NaNO}_{3}}\right]+\left[\mathrm{NaTcO}_{4}\right] \stackrel{{ }^{\mathrm{NaNa}} \mathrm{K}_{12}}{\longleftrightarrow}\left[\overline{\mathrm{NaTcO}_{4}}\right]+\left[\mathrm{NaNO}_{3}\right],} \\
{\left[\overline{\mathrm{NaNO}_{3}}\right]+\left[\mathrm{KTcO}_{4}\right] \stackrel{{ }^{\mathrm{NaK}} \mathrm{K}_{12}}{\longleftrightarrow}\left[\overline{\mathrm{KTcO}_{4}}\right]+\left[\mathrm{NaNO}_{3}\right]} \\
{\left[\overline{\mathrm{KNO}_{3}}\right]+\left[\mathrm{NaTcO}_{4}\right] \stackrel{\mathrm{KNa}_{12}}{\longleftrightarrow}\left[\overline{\mathrm{NaTcO}_{4}}\right]+\left[\mathrm{KNO}_{3}\right]} \\
{\left[\overline{\mathrm{KNO}_{3}}\right]+\left[\mathrm{KTcO}_{4}\right] \stackrel{\mathrm{KK}_{12}}{\longleftrightarrow}\left[\overline{\mathrm{KTcO}_{4}}\right]+\left[\mathrm{KNO}_{3}\right]}
\end{gathered}
$$

where the bars imply the solid surface phase. Four similar mass-action processes apply for rhenium based waste solutions. 
Current equilibrium contact tests used to compute $\mathrm{K}_{\mathrm{d}}$ 's only measure the total liquid-phase concentrations of technetium (or rhenium) prior to resin contact and after some pre-determined mixing time (i.e., typically 24,48 or 72 hours of contact). Total liquid-phase concentration of nitrate is measured prior to contact only. No experimental information is available to determine independent selectivity coefficients consistent with the four individual mass-action expressions of Eq. (4-11). Instead, a "pseudo" selectivity coefficient can be computed based on Eq. (4-10) where the total concentrations of nitrate and pertechnetate (or perrhenate) anions are employed. The "pseudo" mass-action expression for technetium now becomes:

$$
\left[\overline{\mathrm{NO}_{3}^{-}}\right]+\left[\mathrm{TcO}_{4}^{-}\right] \stackrel{\mathrm{K}_{12}}{\longleftrightarrow}\left[\overline{\mathrm{TcO}_{4}^{-}}\right]+\left[\mathrm{NO}_{3}^{-}\right],
$$

which looks identical to the stoichiometric ion-exchange process discussed in the above subsection. Therefore, the adsorption isotherm model described by Eq. (4-7) for a binary homovalent exchange process is applicable for the pertechnetate (or perrhenate)-SuperLig ${ }^{\circledR} 639$ system. For the above system the "pseudo" binary isotherms (as defined by Eq. (4-7)) become:

$$
\mathrm{q}_{\mathrm{XO}_{4}^{-}} \equiv \frac{\overline{\mathrm{c}}_{\mathrm{pXO}_{4}^{-}}}{\overline{\mathrm{C}}_{\mathrm{T}}}=\frac{\mathrm{c}_{\mathrm{pXO}_{4}^{-}}}{\mathrm{c}_{\mathrm{pXO}_{4}^{-}}+\widetilde{\mathrm{K}}_{21} \mathrm{c}_{\mathrm{pNO}_{3}^{-}}},
$$

and

$$
\mathrm{q}_{\mathrm{NO}_{3}^{-}} \equiv \frac{\overline{\mathrm{p}}_{\mathrm{pNO}_{3}^{-}}}{\overline{\mathrm{C}}_{\mathrm{T}}}=\frac{\widetilde{\mathrm{K}}_{21} \mathrm{c}_{\mathrm{pNO}_{3}^{-}}}{\mathrm{c}_{\mathrm{pXO}_{4}^{-}}+\widetilde{\mathrm{K}}_{21} \mathrm{c}_{\mathrm{pNO}_{3}^{-}}} .
$$

Equations (4-13) relate liquid-phase species concentrations to their counterpart surface concentrations where two unique parameters (i.e., an avg. selectivity coefficient and a total ionic capacity) must be obtained through a fitting procedure. The total ion exchange capacity of the resin converts surface concentrations into fractional loadings as indicated in Eqs. (4-13). Note that measured surface concentrations for only one of the species are required. Ideally, to uniquely estimate these two parameters with high confidence, adsorption data spanning the full range of liquid-phase concentrations would be necessary. At low concentrations the selectivity coefficient dominates, while at high concentrations the total ion exchange capacity dominates.

The vendor (IBC Advanced Technologies) provided a total perrhenate exchange capacity of $\sim 0.5$ mmole $e_{\mathrm{Re}} / \mathrm{g}_{\text {resin }}$ for "as received" resin whose batch ID was unknown. For two batches measured (i.e., 980624001DC and 981015DHC720011), F factors defined as the ratio of dry-to-"as received" mass of resin were 0.986 and 0.987 , respectively (see, Hassan et al., 1999a). For both the adsorption isotherm development and the column assessments, the total exchange capacity of SuperLig ${ }^{\circledR} 639$ was assumed to be only batch dependent and estimated using the batch contact database. We further assume for each batch ID that the ionic exchange capacities for perrhenate, pertechnetate, and nitrate are equivalent and are the same as the estimated value for the total exchange capacity. The impact associated with the assumptions made with regard to ionic exchange capacities is discussed in Section 10 where sensitivity studies are presented. An impact 
resulting in a variation in total ionic exchange capacity is similar to an impact resulting from a variation in bed density, since they both appear in the transport analysis as a product together.

Equilibrium contact test data (and the column data when performed) was gathered from the majority of available data sources for the pertechnetate (or perrhenate)-SuperLig ${ }^{\circledR} 639$ system of interest. Table 4-1 defines the nomenclature used throughout this report to reference the data and their sources. Table 4-2 for perrhenate studies, Table 4-3 for pertechnetate studies using pure envelope samples, and Table 4-4 for pertechnetate studies using mixed envelope samples provide a brief overview of the various data sources and their unique features. As indicated in Tables 42, 4-3, and 4-4:

- Eight different batches of SuperLig ${ }^{\circledR} 639$ resin were tested;

- Both actual "hot" waste tank samples based on pertechnetate and "cold" simulated waste based on the surrogate perrhenate were considered;

- All three waste envelopes (A, B, and C) and various mixtures were tested;

- A modest range of solutions with varying $\mathrm{NO}_{3}{ }^{-}$concentration and molar ratios (i.e., nitrate over pertechnetate or perrhenate ratio) were tested;

- Test data taken by three different facilities (i.e., IBC, PNNL, and SRTC) were gathered;

- A modest range of solutions with varying total ionic strength were tested; and

- Pertechnetate loadings as high as $48 \%$ of the estimated maximum value were achieved.

The database (i.e., 39 perrhenate and 49 pertechnetate data points) considered for developing the binary isotherm model is listed in Tables 4-5, 4-6, and 4-7. The measured pertechnetate and perrhenate $K_{d}$ values as a function of liquid-phase molar ratios (i.e., nitrate/pertechnetate and nitrate/perrhenate ratios) are plotted in Figure 4-1. Liquid-phase molar ratios varied over four orders of magnitude. The majority of $\mathrm{K}_{\mathrm{d}}$ measurements assumed an adequate approach to equilibrium had occurred within 24 hours, while some tests were carried out for up to 72 hours. Batch kinetics timing is discussed with respect to pore diffusion in Section 7 where an estimate of the approach times to equilibrium is provided.

As illustrated in Figure 4-1, the systematic differences observed between data sets taken at different facilities (e.g., IBC, PNNL, and SRTC) can not be explained due to variations in nitrate concentration levels alone. The variations observed perhaps also result from variability in batch material, other competing anions, total ionic strength, or solution composition. $\mathrm{K}_{\mathrm{d}}$ data using Envelopes A, B, and C for eight different batch ID's are shown in Figure 4-1 where the data for each batch has the same symbol and color. Uncertainties associated with the stated (in some cases assumed) waste sample concentrations probably greatly exceed the errors in experimental and analytical measurement techniques used at the various facilities. Generally, hysteresis of the resin material's adsorption properties is assumed to be negligible. However, as discussed below, chemical stability tests indicate that some level of history dependence may be present and could account for some of the scatter observed between different data sets and facilities. 


\subsection{Isotherm Parameter Estimations}

To establish the "pseudo" binary adsorption isotherms for the two (assumed) dominant anions, one independent selectivity coefficient must be determined based on the equilibrium contact test data. Unfortunately, the total ion exchange capacity is also unknown for many of the batch ID's considered in the column performance assessment efforts of Section 9. To isolate and better estimate these two parameters uniquely, special efforts and further assumptions were made and are discussed below.

Based on the functional form chosen these two parameters can be obtained from equilibrium contact tests where only one of the solid-phase species concentrations is known. For the Pertechnetate (or perrhenate)-SuperLig ${ }^{\circledR} 639$ system the isotherm model to be considered takes the form

$$
\mathrm{q}_{\mathrm{XO}_{4}^{-}} \equiv \frac{\overline{\mathrm{p}}_{\mathrm{XO}_{4}^{-}}}{\overline{\mathrm{C}}_{\mathrm{T}}}=\frac{\mathrm{c}_{\mathrm{pXO}_{4}^{-}}}{\mathrm{c}_{\mathrm{pXO}_{4}^{-}}+\widetilde{\mathrm{K}}_{21} \mathrm{c}_{\mathrm{pNO}_{3}^{-}}}
$$

which can also be represented in terms of surface concentration (or loading) as:

$$
\overline{\mathrm{c}}_{\mathrm{pXO}_{4}^{-}}=\frac{\overline{\mathrm{C}}_{\mathrm{T}}}{1+\tilde{\mathrm{K}}_{21}\left[\frac{\mathrm{c}_{\mathrm{pNO}_{3}^{-}}}{\mathrm{c}_{\mathrm{pXO}_{4}^{-}}}\right]} .
$$

As mentioned earlier, we assume that batch material differences only impact the number of available adsorption sites per gram of resin (i.e., the total ion exchange capacity), while surfaceto-liquid species equilibria can be dependent upon the total ionic strength of the solution, as well as its ionic composition.

With this in mind:

- Total ion exchange capacities were estimated for each batch ID used in the available contact tests and column studies; and

- Unique "pseudo" selectivity coefficients were computed for each contact test or column study where the liquid-phase sample (or simulant) waste was different.

The parameter estimations are discussed in the following subsections.

\subsubsection{Perrhenate Studies}

In general the uncertainties associated with the perrhenate studies are less than those associated with the pertechnetate studies and we shall focus first on the perrhenate batch contact tests. Table 4-2 summarizes and Table 4-5 lists the available batch contact test data for adsorption of perrhenate onto the SuperLig ${ }^{\circledR} 639$ resin (see Appendix A for additional information regarding 
the estimation of the $\mathrm{K}_{\mathrm{d}}$ and loading values). The perrhenate loadings provided in Table 4-5 are plotted in Figure 4-2 as a function of the molar ratio of nitrate to perrhenate ions as suggested by the functional form of Eq. (4-15). The 37 data points plotted in Figure 4-2 span five different material batch ID's and three different waste simulants.

Focusing on the King et al. (2000a) data set reduces us to three different batch ID's tested using the same waste simulant. Since the solution was made from scratch, the ionic concentrations and composition contained within this simulant are relatively well known. Under these conditions it is assumed that the total ion exchange capacity, $\overline{\mathrm{C}}_{\mathrm{T}}$, may be different between each batch. However, while using the same waste simulant it is assumed that the selectivity coefficient, $\widetilde{\mathrm{K}}_{21}$, is one unique value for all tests.

A non-linear regression analysis based on the maximum likelihood principle (see Anderson et al., 1978) was performed on Eq. (4-15) along with the perrhenate loading database provided by King et al. (2000a). Using the same weighting scheme as discussed in Section 4 of Hamm et al. (2000), an average selectivity coefficient and three batch dependent capacities were computed. The results from the maximum likelihood algorithm are tabulated in Table 4-8 along with upper/lower confidence levels and relative errors for the fitted selectivity coefficient.

Based on these computed parameters, estimated fractional loadings for the King et al. (2000a) database were computed and are also listed in Table 4-5. A comparison of predicted versus measured fractional perrhenate loadings is shown in Figure 4-3. In Figure 4-4 the isotherm predictions of perrhenate fractional loadings are compared to the King et al. (2000a) database. Overall the fractional loading data follow a single unique curve as expected. A couple of the data points are high and based on $\mathrm{K}_{\mathrm{d}}$ plots are suspect. The isotherm model prediction represents the data very well except at high perrhenate concentrations (i.e., low molar ratio). Model deviations at higher perrhenate concentrations can be expected since the assumption of a constant selectivity coefficient becomes progressively less accurate.

The estimated parameter values are listed in Table 4-9 for the test batch ID's tested by King et al. (2000a). The estimated parameter values for the remaining batch ID's and liquid-samples in Table 4-9 are discussed below.

\subsubsection{Pertechnetate Studies}

Due to the added unknown with regard to the fraction of non-pertechnetate contained within each waste sample, the uncertainties associated with the pertechnetate studies can become large. Especially when a series of re-contact tests are being considered where the finite sample volume continues to concentrate the non-pertechnetate species. Under these conditions the calculated final concentration of pertechnetate in the liquid sample after each contact period becomes progressively more sensitive to the error in the analysis for the growing fraction of nonpertechnetate within the liquid-sample. However, several re-contact tests in series can potentially help in determining what the original liquid-sample non-pertechnetate fraction was (or at least set its upper bound). For further discussion on the mass balance analysis used to address the nonpertechnetate fraction and the finite volume of the liquid-samples, see Appendix A. Depending 
upon the reaction rates occurring between the various technetium forms, it is possible that the non-pertechnetate fraction may change over the time periods of interest (i.e., during contact experiment test, storage of feed, or prior to later column experiments).

Table 4-3 lists eleven available batch contact test data sets for adsorption of pertechnetate onto the SuperLig ${ }^{\circledR} 639$ resin when using pure samples of Envelope A, B, and C (see Appendix A for additional information regarding the estimation of the $\mathrm{K}_{\mathrm{d}}$ and loading values). The pertechnetate loadings provided in Table 4-6 are plotted in Figure 4-5 as a function of the molar ratio of nitrate to pertechnetate ions as suggested by the functional form of Eq. (4-15). The 47 data points plotted in Figure 4-5 span five different material batch ID's and ten different waste samples (i.e., ranging over various Hanford Envelope A, B, C samples and one SRS Tank 44F sample). Due to variability in the batch material, total ionic exchange strength, and solution ionic composition, significant scatter is observed in Figure 4-5.

However, for a given data set (i.e., batch material and liquid-sample) generally the pertechnetate loadings follow a single curve whose slope/shape is quite consistent with other data sets. For example, as shown in Figure 4-6 the data sets of NH-A, NH-B, NH-SC, and WL-LC all belong to a specific batch ID (\# 981015DHC720011) where their resultant loading curves are selfconsistent and similar to each other (i.e., offset from each other by a vertical shift).

Since it is assumed that SuperLig ${ }^{\circledR} 639$ resin can only adsorb technetium in its pertechnetate form, the measured total technetium concentration change (before and after) of a liquid-sample during a contact experiment represents the amount of pertechnetate loaded onto the resin. Therefore, uncertainties associated with the liquid-sample's initial non-pertechnetate fraction only impacts the "equilibrium" molar ratio of nitrate to pertechnetate (through the final measured pertechnetate concentration). As such, the data-pairs (i.e., original sample plus its duplicate) generally show more scatter in the molar ratio than in their loadings. This can clearly be seen in Figure 4-6 for the NH-B data set where the differences grow at higher molar ratios.

Also shown in Figure 4-6 are three binary isotherm model predictions. Here the selectivity coefficient has been adjusted to account for the liquid-phase envelope differences. The three isotherm models shown correspond to the:

- original perrhenate model $\left(\mathrm{K}_{21}=1.3630 \times 10^{-3}\right)$ fitted to the perrhenate data in the above subsection and provides a reasonable fit to the pertechnetate Envelope Large-C (WK-LC) samples;

- reduced adsorption model $\left(\mathrm{K}_{21}=2.6735 \times 10^{-3}\right)$ fitted to the pertechnetate Envelope B (NH-B) samples which is also applicable for Envelope Small-C (NH-SC) samples; and

- original pertechnetate model $\left(\mathrm{K}_{21}=7.7418 \times 10^{-4}\right)$ fitted to the pertechnetate Envelope A (NHA) samples.

A closer look at some of the observed differences and similarities in Figure 4-6 are discussed below. 


\subsubsection{Rhenium as a Technetium Surrogate}

All isotopes of technetium are radioactive. For example, technetium-99 (i.e., ${ }^{99} \mathrm{Tc}$ ) has in its ground state and its meta-stable state radioactive half-life's of $2.13 \times 10^{5}$ years and 6.01 hours, respectively (data taken from GE Nuclear Energy, 1996). Rhenium was initially chosen as a chemical surrogate for technetium allowing column tests to be performed more cheaply and without having to deal with a radioactive substance and its radioactive waste. In the periodic table rhenium is just beneath technetium in the same chemical group and the use of the perrhenate anion to mimic the pertechnetate anion has been previously studied by Schroeder et al. (1995). They found that the tetrahedral geometries of these two anion species result in nearly identical ion sizes and were considered to be sufficiently similar to provide a reasonable basis for column performance comparisons (as performed by King et al., 2000a).

To properly test the validity or range of applicability of rhenium as an acceptable surrogate for technetium, a comparison of the pertechnetate versus perrhenate adsorption isotherms must be considered where all other variables are identical (same batch material, liquid-sample composition, phase ratio, initial concentrations, etc.). Unfortunately, no such ideal databases exist to date. However, comparisons can be made by looking at the available batch adsorption data and drawing conclusions from them.

For example, both perrhenate and pertechnetate batch contact data have been taken for the same batch ID (\# 981015DHC720011) using an Envelope A simulant and sample, respectively. The adsorption data for perrhenate is listed in Table 4-5 under test ID WK-3, while for pertechnetate the data is listed in Table 4-6 under test ID NH-A. Slight differences in ionic composition and total ionic strength exist between the simulant and sample as seen in Table 4-10 (e.g., $5.22 \mathrm{M}$ versus $5.52 \mathrm{M}$ in total ionic strength and $1.13 \mathrm{M}$ versus $1.037 \mathrm{M}$ in nitrite $\left[\mathrm{NO}_{2}^{-}\right]$concentration). A comparison of the predicted and measured loadings is shown in Figure 4-7 as a function of the molar ratio with nitrate as suggested by the functional form of Eq. (4-15). The binary isotherm model predictions are in very good agreement with their appropriate data sets. The two binary isotherm models shown differ only in their parameter value for the selectivity coefficient (i.e., $1.363 \times 10^{-3}$ for the simulant versus $7.7418 \times 10^{-4}$ for the sample; a $43 \%$ difference).

At a given fixed molar ratio this corresponds to an approximately $76 \%$ increase in loading for pertechnetate when compared to perrhenate. As discussed below with regard to the impact total ionic strength has on selectivity coefficient, the total ionic strength difference probably accounts for only $\sim 6 \%$ of the measured difference. The remaining difference (i.e., $\sim 70 \%$ ) is believed to represent adsorption differences between pertechnetate versus perrhenate on SuperLig ${ }^{\circledR} 639$ resins.

This $70 \%$ difference in adsorption levels is further substantiated by comparing the above data/models to special batch contact data taken by Hassan (unpublished results). The special contact tests were designed specifically to address this issue. Decontaminated Envelope A (tank 241-AN-103) samples with a nitrate concentration of $0.998 \mathrm{M}$ were spiked in pertechnetate and perrhenate species, then used in equilibrium contact tests (i.e., 24 hour of contact) with the same resin batch ID (\# 981015DHC720011). The loading results for these tests (test ID of NH-A2) are 
listed in Table 4-5 for the perrhenate measurements and in Table 4-6 for the pertechnetate measurements. Both original, plus duplicate, samples were tested. The original sample results are suspect due to the significant departure from other $\mathrm{K}_{\mathrm{d}}$ test data available and are listed only for completeness. The duplicate samples represent reasonable $\mathrm{K}_{\mathrm{d}}$ test data and are shown for comparison to the earlier Envelope A data in Figure 4-8. Each decontaminated Envelope A data point falls very close to its associated isotherm model curve. Only slight adjustments are required to these isotherm models for them to pass through the data points. With those adjustments the average loading difference would be again $\sim 70 \%$.

\subsubsection{Mixed Envelope Studies}

Follow-on batch contact studies by Hassan et al. (2000c) were performed to measure the pertechnetate adsorption impact resulting when various mixed envelope samples are used as summarized in Table 4-4. The pertechnetate loadings provided in Table 4-7 are plotted in Figures 4-9 to 4-11 as a function of the molar ratio of nitrate to pertechnetate ions as suggested by the functional form of Eq. (4-15). In all cases the mixed (or decontaminated) samples behave similar to the Envelope that they predominately contain. The shifts present are generally in the direction towards the minor sample waste component, as expected.

In order to compute the pertechnetate loadings the mixed sample's fraction of non-pertechnetate had to be estimated. The non-pertechnetate fraction within the mixed liquid-sample was computed as a volume average value based on the fractions estimated for the pure envelope contact tests. The pertechnetate fractional loadings were computed where the total ion exchange capacity of the resin in $\left[\mathrm{mmole}_{\mathrm{Td}} / \mathrm{g}_{\mathrm{resin}}\right]$ was the volume average value based on the fractions estimated for the pure envelope contact tests.

Four of the mixed envelope samples were predominately made from Envelope A (i.e., 10 parts Env. A with 1 part Env. B or Env. C) and a comparison of the loadings associated with these mixed samples versus the pure Envelope A data can be seen in Figure 4-9. The measured loadings from the mixed samples are very consistent with the pure Envelope A sample. The data differences in contact periods appears to be minor (i.e., 4 hours versus 2 weeks contact times).

Two of the mixed envelope samples were predominately made from Envelope B (i.e., 10 parts Env. B with 1 part Env. C) and a comparison of the loadings associated with these mixed samples versus the pure Envelope B data can be seen in Figure 4-10. The measured loadings from the mixed samples are very consistent with the pure Envelope B sample. Also shown are the measured loadings from a Cs-only decontaminated B sample.

Cesium-only decontaminated Large-C samples were measured and a comparison of the loadings associated with this decontaminated sample versus the pure Envelope Small-C and Large-C data can be seen in Figure 4-11. The measured loadings from the Cs-only decontaminated sample are very consistent with the pure Envelope $\mathrm{C}$ samples. 


\subsection{Impact of Total Ionic Strength}

As mentioned earlier, since liquid-phase activity coefficients are dependent upon the total ionic strength of a solution, then the "averaged" estimated values for the binary selectivity coefficient will also depend upon the total ionic strength. Rough estimates (i.e., actually lower bounds) of the total ionic strength for several of the waste samples and simulants used during equilibrium contact tests were computed. In Table 4-10 the published molar concentrations for many of the important ions in these test solutions have been tabulated. Using the following definition for the total ionic strength based on molar concentrations, estimates were computed and are listed in the bottom row of Table 4-10:

$$
\mu=\frac{1}{2} \sum_{\mathrm{i}}^{\text {ions }}\left[\left|v_{\mathrm{i}}\right|^{2} \mathrm{c}_{\mathrm{pi}}\right] .
$$

The functional dependence of the binary selectivity coefficient between nitrate and pertechnetate (or perrhenate) with respect to total ionic strength is shown in Figure 4-12. To highlight the general dependence, the general trend can be seen by the dashed curve given by

$$
\tilde{\mathrm{K}}_{21} \approx \frac{0.0065}{\mu} .
$$

The general trend, as expressed by the data and Eq. (4-17), indicates that an increase in total ionic strength reduces the binary selectivity coefficient resulting in an increase in the affinity of the SuperLig $639^{\circledR}$ resin to adsorb the pertechnetate (or perrhenate) anion. This is consistent with the current elution cycle data where a decrease in total ionic strength (e.g., low strengths $<1 \mathrm{M}$ ) results in a significant reduction in the resin's ability to retain the pertechnetate (or perrhenate) anions. As shown in Figure 4-12, the Small-C liquid sample demonstrates behavior inconsistent with the rest of the samples considered. The reasons for this discrepancy are unknown at this time.

Note that Eq. (4-17) only represents the general trend and should not be used except for scoping studies where no pertinent adsorption data is available at the desired total ionic strength. In future analysis efforts a consideration of the available breakthrough curve data for the elution cycle may assist in improving/extending this functional dependence.

\subsection{Impact of Chemical Stability}

Bruening (2000c) has performed a series of equilibrium contact tests on SuperLig ${ }^{\circledR} 639$ to ascertain its chemical stability with regard to adsorption capacity for perrhenate. These tests were attempted to determine the level of degradation (if any) in binding or ion-exchange capacity as a function of the resin's chemical exposure to expected process liquids (i.e., both expected and extreme concentrations of the chemicals expected to be in contact with this resin during its lifecycle). $\mathrm{K}_{\mathrm{d}}$ contact tests were performed using a Hanford Envelope A LAW simulant where the resin was treated prior to the tests by pre-soaking the resin from 1 day up to 1 month in a specified chemical solution. 
Little definitive information can be extracted from this series of tests due to the analytical uncertainties in measuring liquid-phase perrhenate concentrations as discussed by Bruening (2000c). Clear (and in some cases complete) degradation occurred for resin samples subjected (by pre-soaking) to high nitric acid solutions $(>0.5 \mathrm{M})$, while for the remaining cases a rise in measured $K_{d}$ 's occurred initially followed by a drop-off in value as shown in Figure 4-13. If this initial rise then fall in $K_{d}$ value is real, the following possible processes may be occurring: (1) the initial rise is the result of the fact that the fresh resin $K_{d}$ values are low due to poor contact associated with initial floating of the resin during the contact period; (2) the initial rise is the result of increased active adsorption sites resulting from fragmentation of the particle surfaces; and (3) the eventual drop is the result of reduced active adsorption sites due to the chemical attack of the linker arm from the bead to the ligand. If the effects shown in Figure 4-13 are reasonable trends to expect (subject to the stated analytical uncertainties), then within 1 to 4 weeks of operation marked drop-off in adsorption performance should be anticipated and accounted for in the column designs. It is recommended that further testing be performed in this arena to narrow the uncertainty in the results. No indication of degradation was observed in the Thermal Fluids Laboratory Pilot-Scale testing (Steimke et al., 2000), which subjected this resin to a caustic simulant for more than ten cycles.

In Figure 4-14 a comparison is made between the "best estimate" binary isotherm model for perrhenate and those resins pre-exposed to Hanford Envelope A, B, and C simulants. Predicted versus measured perrhenate loadings are plotted where the predicted curve passes through the data points corresponding to "fresh" (no pre-soaking) resins. As expected based on the data presented in Figure 4-13, measured perrhenate loadings above and below the predicted isotherm are observed.

Since the adsorption isotherm is the dominant factor in determining column performance, degradation in resin capacity resulting from previous chemical exposure should be experimentally investigated further. With such data guidelines, as to the acceptable level of chemical exposure subject to design specifications, can be established. Furthermore, if modest levels of exposure dependence do exist, more careful and consistent batch contact testing should be considered where the pretreatment history of the resin prior to the contact test is monitored, controlled, and recorded.

\subsection{Application Using VERSE-LC}

VERSE-LC has several equilibrium adsorption isotherm models to choose from (see user manual by Whitley and Wang, 1996). For our set of equilibrium isotherms as defined by Eq. (4-7) the VERSE-LC option of a Freundlich/Langmuir Hybrid (option F) can conform to its functional form. As pointed out by Hamm et al. (1999), in VERSE-LC input the surface concentration (e.g., in units of gmole/g $\mathrm{g}_{\text {resin }}$ ) is expected to be pre-multiplied by the bed density of the active column (e.g., resulting in gmole/ $\mathrm{L}_{\mathrm{cv}}$ ). For input to VERSE-LC we use the conversion:

$$
\overline{\mathrm{C}}_{\mathrm{pi}}=\rho_{\mathrm{b}} \overline{\mathrm{c}}_{\mathrm{pi}} \quad \text { for } \quad \mathrm{i}=1,2,
$$


resulting in the following two isotherms when applied to Eq. (4-7) for the pertechnetate (or perrhenate)-SuperLig ${ }^{\circledR} 639$ system:

$$
\overline{\mathrm{C}}_{\mathrm{pXO}_{4}^{-}}=\frac{\rho_{\mathrm{b}} \overline{\mathrm{C}}_{\mathrm{T}} \mathrm{c}_{\mathrm{pXO}_{4}^{-}}}{\mathrm{c}_{\mathrm{pXO}_{4}^{-}}+\tilde{\mathrm{K}}_{21} \mathrm{c}_{\mathrm{pNO}_{3}^{-}}}
$$

and

$$
\overline{\mathrm{C}}_{\mathrm{pNO}_{3}^{-}}=\frac{\rho_{\mathrm{b}} \overline{\mathrm{C}}_{\mathrm{T}} \tilde{\mathrm{K}}_{21} \mathrm{c}_{\mathrm{pNO}_{3}^{-}}}{\mathrm{c}_{\mathrm{pXO}_{4}^{-}}+\tilde{\mathrm{K}}_{21} \mathrm{c}_{\mathrm{pNO}_{3}^{-}}}
$$

for the species containing pertechnetate (or perrhenate) and nitrate anions, respectively.

The VERSE-LC Freundlich/Langmuir Hybrid model is expressed as:

$$
\overline{\mathrm{C}}_{\mathrm{pi}}=\frac{\mathrm{a}_{\mathrm{i}} \mathrm{c}_{\mathrm{pi}}^{\mathrm{M}_{\mathrm{ai}}}}{\beta_{\mathrm{i}}+\mathrm{b}_{1} \mathrm{c}_{\mathrm{p} 1}^{\mathrm{M}_{\mathrm{b} 1}}+\mathrm{b}_{2} \mathrm{c}_{\mathrm{p} 2}^{\mathrm{M}_{\mathrm{b} 2}}} \quad \text { for } \quad \mathrm{i}=1,2
$$

where the model parameters $\left(a_{i}, b_{i}, M_{a i}, M_{b i}\right.$, and $\beta_{i}$ for $\left.i=1,2\right)$ can be determined from the parameter values associated with the binary homovalent model and the relationship between the two models is provided in Table 4-11. For the various batch ID's and waste envelopes to be considered in this report, the computed parameter values for Eq. (4-20) are listed in Table 4-12.

The Freundlich/Langmuir Hybrid model can also be used for an effective single component case as well. Here the nitrate concentration throughout the column is assumed to be at its feed concentration level. For an effective single-component pertechnetate (or perrhenate) isotherm, Eq. (4-20) under these conditions reduces to:

$$
\overline{\mathrm{C}}_{\mathrm{p} 1}=\frac{\mathrm{a}_{1} \mathrm{c}_{\mathrm{pl}}^{\mathrm{M}_{\mathrm{a}}}}{\left[\beta_{\mathrm{i}}+\mathrm{b}_{2} \mathrm{c}_{\mathrm{p} 2}^{\mathrm{M}_{\mathrm{b} 2}}\right]+\mathrm{b}_{1} \mathrm{c}_{\mathrm{pl}}^{\mathrm{M}_{\mathrm{b} 1}}} \Rightarrow \frac{\mathrm{a}_{1} \mathrm{c}_{\mathrm{pl}}^{\mathrm{M}_{\mathrm{ai}}}}{\hat{\beta}_{\mathrm{i}}+\mathrm{b}_{1} \mathrm{c}_{\mathrm{p} 1}^{\mathrm{M}_{\mathrm{b} 1}}}
$$

where the beta parameter for pertechnetate (or perrhenate) becomes dependent upon the nitrate feed concentration. For the various batch ID's and waste envelopes to be considered in this report, the computed parameter values for Eq. (4-21) are listed in Table 4-13. 
Table 4-1. Nomenclature used to identify various batch equilibrium tests and column experiments discussed throughout this report.

\begin{tabular}{|c|c|c|c|c|c|}
\hline Test ID & Type of data & $\begin{array}{l}\text { Specific } \\
\text { test case }\end{array}$ & anion & $\begin{array}{l}\text { Test Temp } \\
\left({ }^{\circ} \mathrm{C}\right)\end{array}$ & Reference report \\
\hline WK-1,2,3 & Batch equilibrium tests & All tests & $\operatorname{Re}$ & $19-22^{\circ} \mathrm{C}$ & King et al., 2000a \\
\hline WK Exp-1 & Column experiments & Exp. 1 & $\operatorname{Re}$ & $20-23{ }^{\circ} \mathrm{C}$ & King et al., 2000a \\
\hline WK Exp-2 & Column experiments & Exp. 2 & $\operatorname{Re}$ & $20-23^{\circ} \mathrm{C}$ & King et al., 2000a \\
\hline WK Exp-3 & Column experiments & Exp. 3 & $\operatorname{Re}$ & $20-23{ }^{\circ} \mathrm{C}$ & King et al., 2000a \\
\hline WK Exp-4 & Column experiments & Exp. 4 & $\operatorname{Re}$ & $20-23^{\circ} \mathrm{C}$ & King et al., 2000a \\
\hline WK Exp-5 & Column experiments & Exp. 5 & $\operatorname{Re}$ & $20-23{ }^{\circ} \mathrm{C}$ & King et al., 2000a \\
\hline TFL & Column experiments & All runs & $\operatorname{Re}$ & $\begin{array}{l}18-20^{\circ} \mathrm{C} \\
22-24^{\circ} \mathrm{C}\end{array}$ & $\begin{array}{c}\text { Steimke et al., } 2000 \\
\left(\sim 4{ }^{\circ} \mathrm{C} \text { gradient down columns }\right)\end{array}$ \\
\hline IBC-1 & Batch equilibrium tests & All tests & $\operatorname{Re}$ & $25^{\circ} \mathrm{C}$ & IBC Advanced Technologies, 1996 \\
\hline IBC Exp-1 & Column experiments & Cycle 1 & $\operatorname{Re}$ & $25^{\circ} \mathrm{C}$ & IBC Advanced Technologies, 1996 \\
\hline IBC-2 & Batch equilibrium tests & All tests & $\operatorname{Re}$ & $25^{\circ} \mathrm{C}$ & Bruening, R. L., 2000c \\
\hline NH-A & Batch equilibrium tests & All tests & $\mathrm{Tc}$ & $25-27^{\circ} \mathrm{C}$ & Hassan et al., 2000a \\
\hline NH-A & Column experiments & All tests & Tc & $25-27^{\circ} \mathrm{C}$ & Hassan et al., 2000a \\
\hline $\mathrm{NH}-\mathrm{A} 2$ & Batch equilibrium tests & All tests & $\mathrm{Re} / \mathrm{Tc}$ & $26^{\circ} \mathrm{C}$ & Hassan (unpublished results) \\
\hline NH-B & Batch equilibrium tests & All tests & $\mathrm{Tc}$ & $25-27^{\circ} \mathrm{C}$ & Hassan et al., 2000d \\
\hline NH-B & Column experiments & All tests & $\mathrm{Tc}$ & $25-27^{\circ} \mathrm{C}$ & Hassan et al., 2000d \\
\hline NH-SC & Batch equilibrium tests & All tests & $\mathrm{Tc}$ & $25-27^{\circ} \mathrm{C}$ & Hassan et al., 2000b \\
\hline NH-SC & Column experiments & All tests & $\mathrm{Tc}$ & $25-27^{\circ} \mathrm{C}$ & Hassan et al., 2000b \\
\hline WK-LC & Batch equilibrium tests & All tests & Tc & $25-27^{\circ} \mathrm{C}$ & King et al., 2000c \\
\hline WK-LC & Column experiments & All tests & Tc & $25-27^{\circ} \mathrm{C}$ & King et al., 2000c \\
\hline WK-SRS & Batch equilibrium tests & All tests & $\mathrm{Tc}$ & $25-26^{\circ} \mathrm{C}$ & King et al., 2000b \\
\hline WK-SRS & Column experiments & All tests & $\mathrm{Tc}$ & $25-26^{\circ} \mathrm{C}$ & King et al., 2000b \\
\hline PNNL & Batch equilibrium tests & All tests & Tc & $\sim 21^{\circ} \mathrm{C}$ & Kurath et al., 1999 \\
\hline DM-A & Batch equilibrium tests & All tests & $\mathrm{Tc}$ & $\sim 26^{\circ} \mathrm{C}$ & Hassan and McCabe, 1997c \\
\hline DM-A & Column experiments & All tests & $\mathrm{Tc}$ & $\sim 26^{\circ} \mathrm{C}$ & Hassan and McCabe, 1997a \\
\hline DM-B & Batch equilibrium tests & All tests & $\mathrm{Tc}$ & $\sim 26^{\circ} \mathrm{C}$ & McCabe, 1997 \\
\hline DM-B & Column experiments & All tests & $\mathrm{Tc}$ & $\sim 26^{\circ} \mathrm{C}$ & Hassan and McCabe, 1997d \\
\hline DM-C & Batch equilibrium tests & All tests & $\mathrm{Tc}$ & $\sim 26^{\circ} \mathrm{C}$ & Hassan and McCabe, 1998 \\
\hline DM-C & Column experiments & All tests & Tc & $\sim 26^{\circ} \mathrm{C}$ & Hassan and McCabe, 1997b \\
\hline
\end{tabular}


Table 4-2. Adsorption isotherm " $K_{d}$ " database summary for Perrhenate-SuperLig ${ }^{\circledR} 639$ system (batch contact tests typically assume equilibrium reached in $\sim 24 \mathrm{hrs}$ ).

\begin{tabular}{|c|c|c|c|c|c|c|c|}
\hline $\begin{array}{l}\text { Test } \\
\text { ID }\end{array}$ & $\begin{array}{c}\text { SuperLig }^{\circledR} 639 \\
\text { batch } \\
\text { ID }\end{array}$ & $\begin{array}{l}\text { Simulated } \\
\text { waste } \\
\text { envelope \& } \\
\text { tank \# }\end{array}$ & $\begin{array}{c}\text { Mole \% } \\
\text { non- } \mathrm{ReO}_{4}^{-}\end{array}$ & $\begin{array}{c}\text { Range of } \\
\mathrm{ReO}_{4}^{-} \\
{[\mathrm{M}]}\end{array}$ & $\begin{array}{c}\text { Range of } \\
\mathrm{NO}_{3}^{-} \\
{[\mathrm{M}]}\end{array}$ & $\begin{array}{c}\text { Maximum \% } \\
\mathrm{ReO}_{4}^{-} \\
\text {loading on } \\
\text { resin }\end{array}$ & Comments \\
\hline WK-1 & 980624001DC & $\begin{array}{c}\text { Simulant A } \\
\text { 241-AN-105 }\end{array}$ & $\sim 0 \%$ & $\begin{array}{l}1.27 \times 10^{-5} \text { to } \\
5.54 \times 10^{-4} \mathrm{M}\end{array}$ & $\begin{array}{l}1.24 \text { to } \\
1.25\end{array}$ & $18.9 \%$ & Good repeatability \\
\hline WK-2 & 990420DHC720067 & $\begin{array}{c}\text { Simulant A } \\
\text { 241-AN-105 }\end{array}$ & $\sim 0 \%$ & $\begin{array}{l}6.01 \times 10^{-6} \text { to } \\
6.39 \times 10^{-6} \mathrm{M}\end{array}$ & 1.25 & $0.4 \%$ & Batch variability study \\
\hline WK-3 & 981015DHC720011 & $\begin{array}{c}\text { Simulant A } \\
\text { 241-AN-105 }\end{array}$ & $\sim 0 \%$ & $\begin{array}{l}3.01 \times 10^{-7} \text { to } \\
8.89 \times 10^{-5} \mathrm{M}\end{array}$ & $\begin{array}{l}1.23 \text { to } \\
1.25\end{array}$ & $4.6 \%$ & Good repeatability \\
\hline NH-A2 & 981015DHC720011 & $\begin{array}{c}\text { Sample A } \\
\text { 241-AN-103 }\end{array}$ & $\sim 1 \%$ & $\begin{array}{l}1.27 \times 10^{-7} \text { to } \\
4.90 \times 10^{-6} \mathrm{M}\end{array}$ & 0.991 & $0.4 \%$ & $\begin{array}{l}\text { Specially designed test to } \\
\text { check validity of rhenium as } \\
\text { a surrogate for technetium. }\end{array}$ \\
\hline IBC-1 & ID not recorded & $\begin{array}{l}\text { Simulant A } \\
\text { range }\end{array}$ & $\sim 0 \%$ & $\begin{array}{l}2.35 \times 10^{-5} \text { to } \\
3.99 \times 10^{-5} \mathrm{M}\end{array}$ & $\begin{array}{c}1.10 \text { to } \\
4.10\end{array}$ & $2.5 \%$ & $\begin{array}{c}\text { Early on tests varying nitrate } \\
\text { concentration }\end{array}$ \\
\hline IBC-2 & 981104DHC70215 & $\begin{array}{c}\text { Simulant A } \\
\text { 241-AN-105 }\end{array}$ & $\sim 0 \%$ & $\begin{array}{l}3.33 \times 10^{-5} \text { to } \\
5.37 \times 10^{-5} \mathrm{M}\end{array}$ & 1.36 & $1.5 \%$ & $\begin{array}{l}\text { Investigated chemical } \\
\text { stability by pre-soaking }\end{array}$ \\
\hline
\end{tabular}


Table 4-3. Adsorption isotherm " $K_{d}$ " database summary for Pertechnetate-SuperLig ${ }^{\circledR} 639$ system (batch contact tests typically assume equilibrium reached in $\sim 24 \mathrm{hrs}$ ) where pure envelope samples were used.

\begin{tabular}{|c|c|c|c|c|c|c|c|}
\hline $\begin{array}{c}\text { Test } \\
\text { ID }\end{array}$ & $\begin{array}{c}\text { SuperLig }^{\circledR} 639 \\
\text { batch } \\
\text { ID }\end{array}$ & $\begin{array}{l}\text { Waste envelope } \\
\text { \& tank \# }\end{array}$ & $\begin{array}{c}\text { Mole \% } \\
\text { non-TcO }^{b}\end{array}$ & $\begin{array}{c}\text { Range of } \\
\mathrm{TcO}_{4}^{-} \\
{[\mathrm{M}]}\end{array}$ & $\begin{array}{c}\text { Range of } \\
\mathrm{NO}_{3}^{-} \\
{[\mathrm{M}]}\end{array}$ & $\begin{array}{c}\mathrm{Max}_{\%} \\
\mathrm{TcO}_{4}^{-} \\
\text {loading }\end{array}$ & Comments \\
\hline NH-A & $981015 \mathrm{DHC} 720011$ & $\begin{array}{c}\text { Sample A } \\
241-A N-103\end{array}$ & $\begin{array}{l}\sim 2 \% \text { to } \\
\sim 50 \%\end{array}$ & $\begin{array}{l}8.05 \times 10^{-8} \text { to } \\
4.27 \times 10^{-5} \mathrm{M}\end{array}$ & $\begin{array}{l}1.56 \text { to } \\
1.57\end{array}$ & $3.0 \%$ & $\begin{array}{l}\text { Increase in relative ratio of non- } \\
\mathrm{TcO}_{4}^{-} \text {during re-contact tests. }\end{array}$ \\
\hline NH-A2 & $981015 \mathrm{DHC} 720011$ & $\begin{array}{c}\text { Sample A } \\
241-\mathrm{AN}-103\end{array}$ & $\sim 1 \%$ & $\begin{array}{l}3.01 \times 10^{-8} \text { to } \\
2.25 \times 10^{-7} \mathrm{M}\end{array}$ & 0.991 & $0.03 \%$ & $\begin{array}{c}\text { Specially designed test to check } \\
\text { validity of rhenium as a } \\
\text { surrogate for technetium. }\end{array}$ \\
\hline NH-B & 981015DHC720011 & $\begin{array}{l}\text { Sample B } \\
\text { 241-AZ-102 }\end{array}$ & $\begin{array}{l}\sim 0 \% \text { to } \\
\sim 24 \%\end{array}$ & $\begin{array}{l}5.27 \times 10^{-9} \text { to } \\
1.47 \times 10^{-5} \mathrm{M}\end{array}$ & $\begin{array}{l}0.249 \text { to } \\
0.268\end{array}$ & $2.0 \%$ & $\begin{array}{l}\text { Increase in relative ratio of non- } \\
\mathrm{TcO}_{4}^{-} \text {during re-contact tests. }\end{array}$ \\
\hline NH-SC & 981015DHC720011 & $\begin{array}{l}\text { Sample Small-C } \\
\text { 241-AN-102 }\end{array}$ & $\begin{array}{l}\sim 73 \% \text { to } \\
\sim 95 \%\end{array}$ & $\begin{array}{l}1.08 \times 10^{-6} \text { to } \\
7.92 \times 10^{-6} \mathrm{M}\end{array}$ & $\begin{array}{c}1.87 \text { to } \\
1.89\end{array}$ & $0.1 \%$ & $\begin{array}{l}\text { Large initial non- } \mathrm{TcO}_{4}^{-} \text {fraction } \\
\text { during contact tests. }\end{array}$ \\
\hline WK-LC & $981015 \mathrm{DHC} 720011$ & $\begin{array}{l}\text { Sample Large-C } \\
241-\mathrm{AN}-102\end{array}$ & $\begin{array}{l}\sim 2 \% \text { to } \\
\sim 99 \%\end{array}$ & $\begin{array}{l}3.93 \times 10^{-7} \text { to } \\
6.82 \times 10^{-5} \mathrm{M}\end{array}$ & $\begin{array}{c}1.87 \text { to } \\
1.89\end{array}$ & $2.9 \%$ & $\begin{array}{l}\text { Increase in relative ratio of non- } \\
\mathrm{TcO}_{4}^{-} \text {during re-contact tests. }\end{array}$ \\
\hline WK-SRS & $981015 \mathrm{DHC} 720011$ & $\begin{array}{l}\text { Sample Small-C } \\
\text { 241-AN-102 }\end{array}$ & $\sim 2 \%$ & $\begin{array}{l}2.67 \times 10^{-6} \text { to } \\
2.69 \times 10^{-6} \mathrm{M}\end{array}$ & $\begin{array}{c}0.490 \text { to } \\
0.491\end{array}$ & $0.5 \%$ & $\begin{array}{l}\text { Non- } \mathrm{TcO}_{4}^{-} \text {fraction assumed } \\
\text { based on column results. }\end{array}$ \\
\hline PNNL-A & $980624001 \mathrm{DC}$ & $\begin{array}{c}\text { Sample A } \\
241-\mathrm{AW}-101\end{array}$ & $\sim 2 \%$ & $\begin{array}{l}1.35 \times 10^{-6} \text { to } \\
3.63 \times 10^{-5} \mathrm{M}\end{array}$ & $\begin{array}{l}1.98 \text { to } \\
1.99\end{array}$ & $47.5 \%$ & $\begin{array}{l}\text { Batch kinetics tests performed } \\
\text { for } \mathrm{TcO}_{4}^{-} \text {. Revised Tc concs. }\end{array}$ \\
\hline PNNL-C & $980624001 \mathrm{DC}$ & $\begin{array}{c}\text { Sample C } \\
241-\mathrm{AN}-107\end{array}$ & $\sim 75 \%$ & $\begin{array}{l}8.90 \times 10^{-7} \text { to } \\
9.10 \times 10^{-7} \mathrm{M}\end{array}$ & 2.06 & $0.9 \%$ & $\begin{array}{c}\text { Revised rev.-0 Tc concentrations } \\
\text { used. }\end{array}$ \\
\hline DM-A & ID not recorded & $\begin{array}{c}\text { Sample A } \\
\text { 241-AW-101 }\end{array}$ & $\sim 2 \%$ & $\begin{array}{l}1.08 \times 10^{-6} \text { to } \\
1.91 \times 10^{-6} \mathrm{M}\end{array}$ & 1.38 & $0.8 \%$ & $\begin{array}{c}\text { Total ion exchange capacity set } \\
\text { to IBC value. }\end{array}$ \\
\hline DM-B & ID not recorded & $\begin{array}{l}\text { Sample B } \\
\text { 241-AN-105 }\end{array}$ & $\sim 2 \%$ & $\begin{array}{l}6.33 \times 10^{-6} \text { to } \\
6.48 \times 10^{-6} \mathrm{M}\end{array}$ & 1.40 & $1.6 \%$ & $\begin{array}{c}\text { Total ion exchange capacity set } \\
\text { to IBC value. }\end{array}$ \\
\hline DM-C & ID not recorded & $\begin{array}{c}\text { Sample C } \\
241-\mathrm{AN}-107\end{array}$ & $\sim 70 \%$ & $\begin{array}{l}4.79 \times 10^{-6} \text { to } \\
8.00 \times 10^{-6} \mathrm{M}\end{array}$ & 2.43 & $0.02 \%$ & $\begin{array}{c}\text { Total ion exchange capacity set } \\
\text { to IBC value. }\end{array}$ \\
\hline
\end{tabular}

${ }^{a}$ Originally an Envelope A sample that was modified to fall into the Envelope B category.

b Multiple recontact tests using the same liquid sample shifts the fraction of non-pertechnetate upwards. 
Table 4-4. Adsorption isotherm " $\mathrm{K}_{\mathrm{d}}$ " database summary for Pertechnetate-SuperLig ${ }^{\circledR} 639$ system where volumetrically mixed waste envelope samples were used.

\begin{tabular}{|c|c|c|c|c|c|c|}
\hline $\begin{array}{c}\text { Test }^{\text {a }} \\
\text { ID }\end{array}$ & $\begin{array}{l}\text { Waste envelope } \\
\text { mixture }\end{array}$ & $\begin{array}{c}\text { Mole \% } \\
\text { non-TcO }_{4}^{-}\end{array}$ & $\begin{array}{c}\text { Range of } \\
\mathrm{TcO}_{4}^{-} \\
{[\mathrm{M}]}\end{array}$ & $\begin{array}{c}\text { Range of } \\
\mathrm{NO}_{3}^{-} \\
{[\mathrm{M}]}\end{array}$ & $\begin{array}{c}\mathrm{Max}^{\%} \\
\mathrm{TcO}_{4}^{-} \\
\text {loading }\end{array}$ & Comments \\
\hline $\mathrm{B} / \mathrm{A}(1: 10) 4 \mathrm{hrs}$ & $\begin{array}{l}\text { Env A (10 parts }) \\
\text { Env B ( } 1 \text { part })\end{array}$ & $\begin{array}{l}\sim 2 \% \\
\quad \text { to } \\
\sim 50 \%\end{array}$ & $\begin{array}{l}8.05 \times 10^{-8} \text { to } \\
4.27 \times 10^{-5} \mathrm{M}\end{array}$ & $\begin{array}{l}1.56 \text { to } \\
1.57\end{array}$ & $3.0 \%$ & $\begin{array}{l}\text { Increase in relative ratio of non- } \\
\mathrm{TcO}_{4}^{-} \text {during re-contact tests. }\end{array}$ \\
\hline $\mathrm{B} / \mathrm{A}(1: 10) 2 \mathrm{wks}$ & $\begin{array}{l}\text { Env A (10 parts }) \\
\text { Env B ( } 1 \text { part })\end{array}$ & $\begin{array}{l}\sim 0 \% \\
\quad \text { to } \\
\sim 24 \%\end{array}$ & $\begin{array}{l}5.27 \times 10^{-9} \text { to } \\
1.47 \times 10^{-5} \mathrm{M}\end{array}$ & $\begin{array}{c}0.249 \text { to } \\
0.268\end{array}$ & $2.0 \%$ & $\begin{array}{l}\text { Increase in relative ratio of non- } \\
\mathrm{TcO}_{4}{ }^{-} \text {during re-contact tests. }\end{array}$ \\
\hline C/A $(1: 10) 4$ hrs & $\begin{array}{l}\text { Env A (10 parts }) \\
\text { Env C ( } 1 \text { part })\end{array}$ & $\begin{array}{l}\sim 73 \% \text { to } \\
\sim 95 \%\end{array}$ & $\begin{array}{l}1.08 \times 10^{-6} \text { to } \\
7.92 \times 10^{-6} \mathrm{M}\end{array}$ & $\begin{array}{c}1.87 \text { to } \\
1.89\end{array}$ & $0.1 \%$ & $\begin{array}{c}\text { Large initial non- } \mathrm{TcO}_{4}^{-} \text {fraction } \\
\text { during } \\
\text { contact tests. }\end{array}$ \\
\hline C/A (1:10) 2 wks & $\begin{array}{l}\text { Env A (10 parts }) \\
\text { Env C ( } 1 \text { part })\end{array}$ & $\begin{array}{l}\sim 2 \% \\
\quad \text { to } \\
\sim 82 \%\end{array}$ & $\begin{array}{l}5.21 \times 10^{-6} \text { to } \\
6.82 \times 10^{-5} \mathrm{M}\end{array}$ & $\begin{array}{c}1.87 \text { to } \\
1.89\end{array}$ & $2.9 \%$ & $\begin{array}{l}\text { Increase in relative ratio of non- } \\
\mathrm{TcO}_{4}{ }^{-} \text {during re-contact tests. }\end{array}$ \\
\hline C/B (1:10) $4 \mathrm{hrs}$ & $\begin{array}{l}\text { Env B (10 parts) } \\
\text { Env C (1 part) }\end{array}$ & $\sim 2 \%$ & $\begin{array}{l}2.67 \times 10^{-6} \text { to } \\
2.69 \times 10^{-6} \mathrm{M}\end{array}$ & $\begin{array}{c}0.490 \text { to } \\
0.491\end{array}$ & $0.5 \%$ & $\begin{array}{l}\text { Non- } \mathrm{TcO}_{4}^{-} \text {fraction assumed based } \\
\text { on column results. }\end{array}$ \\
\hline $\mathrm{C} / \mathrm{B}(1: 10) 2 \mathrm{wks}$ & $\begin{array}{l}\text { Env B (10 parts }) \\
\text { Env C (1 part) }\end{array}$ & $\sim 2 \%$ & $\begin{array}{l}1.35 \times 10^{-6} \text { to } \\
3.63 \times 10^{-5} \mathrm{M}\end{array}$ & $\begin{array}{l}1.98 \text { to } \\
1.99\end{array}$ & $47.5 \%$ & $\begin{array}{l}\text { Non- } \mathrm{TcO}_{4}{ }^{-} \text {fraction assumed based } \\
\text { on column results. }\end{array}$ \\
\hline $\begin{array}{l}\text { Decon. Large-C } 24 \\
\text { hrs }\end{array}$ & $\begin{array}{l}\text { Decontaminated } \\
\text { Env Large-C }\end{array}$ & $\sim 15 \%$ & $\begin{array}{l}8.90 \times 10^{-7} \text { to } \\
9.10 \times 10^{-7} \mathrm{M}\end{array}$ & 2.06 & $0.9 \%$ & Cesium removal prior to testing. \\
\hline Decon. Large-C 2 wks & $\begin{array}{l}\text { Decontaminated } \\
\text { Env Large-C }\end{array}$ & $\sim 2 \%$ & $\begin{array}{l}1.08 \times 10^{-6} \text { to } \\
1.91 \times 10^{-6} \mathrm{M}\end{array}$ & 1.38 & $0.8 \%$ & Cesium removal prior to testing. \\
\hline Decon. B 2 wks & $\begin{array}{c}\text { Decontaminated } \\
\text { Env B }\end{array}$ & $\sim 2 \%$ & $\begin{array}{l}6.33 \times 10^{-6} \text { to } \\
6.48 \times 10^{-6} \mathrm{M}\end{array}$ & 1.40 & $1.6 \%$ & Cesium removal prior to testing. \\
\hline
\end{tabular}

${ }^{a}$ All mixed envelope batch contact tests were performed using the same SuperLig ${ }^{\circledR} 639$ batch ID (\# 981015DHC720011) and contact times tested were 4 hours, 1 day, and 2 weeks. 
Table 4-5. Equilibrium data for Perrhenate on SuperLig ${ }^{\circledR} 639$ based on batch contact tests.

\begin{tabular}{|c|c|c|c|c|c|c|}
\hline $\begin{array}{c}\text { Sample } \\
\text { Description }\end{array}$ & $\begin{array}{c}\text { Liquid } \\
\mathrm{NO}_{3}^{-} \\
{[\mathrm{M}]}\end{array}$ & $\begin{array}{c}\text { Liquid } \\
\mathrm{ReO}_{4}^{-} \\
{[\mathrm{M}]}\end{array}$ & $\begin{array}{c}{\text { Non- } \mathrm{ReO}_{4}^{-}}^{-} \\
\text {Fraction }^{\mathrm{b}} \\
{[\%]}\end{array}$ & $\begin{array}{c}\mathrm{ReO}_{4}^{-} \\
\mathrm{K}_{\mathrm{d}} \\
{[\mathrm{ml} / \mathrm{g}]}\end{array}$ & $\begin{array}{c}\mathrm{ReO}_{4}^{-} \\
\text {loading } \\
{\left[\text { mmole }_{\mathrm{Re}} / \mathrm{g}_{\text {resin }}\right]}\end{array}$ & $\begin{array}{c}\mathrm{ReO}_{4}^{-} \\
\text {fractional } \\
\text { loading }^{\mathrm{c}},[-]\end{array}$ \\
\hline WK-1 (I) & 1.245 & 1.273E-05 & 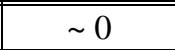 & 204 & $2.602 \mathrm{E}-03$ & $7.506 \mathrm{E}-03$ \\
\hline WK-1 (I)D & 1.245 & $1.300 \mathrm{E}-05$ & $\sim 0$ & 198 & $2.575 \mathrm{E}-03$ & $7.429 \mathrm{E}-03$ \\
\hline WK-1 (R1) & 1.240 & $4.232 \mathrm{E}-06$ & $\sim 0$ & 201 & $8.497 \mathrm{E}-04$ & $2.452 \mathrm{E}-03$ \\
\hline WK-1 (R1)D & 1.240 & 4.039E-06 & $\sim 0$ & 220 & 8.879E-04 & $2.562 \mathrm{E}-03$ \\
\hline WK-1 (I) & 1.245 & $1.944 \mathrm{E}-05$ & $\sim 0$ & 289 & $5.616 \mathrm{E}-03$ & $1.620 \mathrm{E}-02$ \\
\hline WK-1 (I)D & 1.245 & $1.681 \mathrm{E}-05$ & $\sim 0$ & 348 & $5.845 \mathrm{E}-03$ & $1.686 \mathrm{E}-02$ \\
\hline WK-1 (I) & 1.245 & 1.319E-04 & $\sim 0$ & 184 & $2.425 \mathrm{E}-02$ & $6.996 \mathrm{E}-02$ \\
\hline WK-1 (I)D & 1.245 & $1.325 \mathrm{E}-04$ & $\sim 0$ & 182 & $2.412 \mathrm{E}-02$ & $6.960 \mathrm{E}-02$ \\
\hline WK-1 (I) & 1.245 & $3.330 \mathrm{E}-04$ & $\sim 0$ & 147 & $4.897 \mathrm{E}-02$ & $1.413 \mathrm{E}-01$ \\
\hline WK-1 (I)D & 1.245 & $3.411 \mathrm{E}-04$ & $\sim 0$ & 141 & $4.810 \mathrm{E}-02$ & $1.388 \mathrm{E}-01$ \\
\hline WK-1 (I) & 1.246 & $5.480 \mathrm{E}-04$ & $\sim 0$ & 120 & $6.558 \mathrm{E}-02$ & $1.892 \mathrm{E}-01$ \\
\hline WK-1 (I)D & 1.246 & 5.543E-04 & $\begin{array}{l}\sim 0 \\
\end{array}$ & 117 & $6.464 \mathrm{E}-02$ & $1.865 \mathrm{E}-01$ \\
\hline WK-2 (I) & 1.245 & $6.015 \mathrm{E}-06$ & $\sim 0$ & 536 & $3.226 \mathrm{E}-03$ & $3.664 \mathrm{E}-03$ \\
\hline WK-2 (I)D & 1.245 & $6.391 \mathrm{E}-06$ & $\sim 0$ & 498 & $3.185 \mathrm{E}-03$ & $3.618 \mathrm{E}-03$ \\
\hline WK-3 (I) & 1.245 & $7.496 \mathrm{E}-06$ & $\overline{\sim 0}$ & 400 & $2.996 \mathrm{E}-03$ & $4.628 \mathrm{E}-03$ \\
\hline WK-3 (I)D & 1.245 & $7.625 \mathrm{E}-06$ & $\sim 0$ & 390 & $2.972 \mathrm{E}-03$ & 4.592E-03 \\
\hline WK-3 (R1) & 1.240 & $1.414 \mathrm{E}-06$ & $\sim 0$ & 426 & $6.020 \mathrm{E}-04$ & $9.301 \mathrm{E}-04$ \\
\hline WK-3 (R1)D & 1.240 & $1.413 \mathrm{E}-06$ & $\sim 0$ & 424 & 5.995E-04 & $9.263 \mathrm{E}-04$ \\
\hline WK-3 (R2) & 1.235 & $3.008 \mathrm{E}-07$ & $\sim 0$ & 382 & $1.148 \mathrm{E}-04$ & $1.773 \mathrm{E}-04$ \\
\hline WK-3 (R2)D & 1.234 & $3.061 \mathrm{E}-07$ & $\sim 0$ & 328 & $1.005 \mathrm{E}-04$ & $1.553 \mathrm{E}-04$ \\
\hline WK-3 (I) & 1.245 & $8.657 \mathrm{E}-05$ & $\sim 0$ & 347 & $3.000 \mathrm{E}-02$ & $4.636 \mathrm{E}-02$ \\
\hline WK-3 (I)D & 1.245 & 8.894E-05 & $\sim 0$ & 336 & $2.989 \mathrm{E}-02$ & $4.619 \mathrm{E}-02$ \\
\hline NH-A2 (I) ${ }^{\text {d }}$ & 0.991 & 1.268E-07 & $\sim 1.0$ & 20389 & $2.585 \mathrm{E}-03$ & 3.994E-03 \\
\hline NH-A2 (I)D & 0.991 & 4.903E-06 & $\begin{array}{l}1.0 \\
\end{array}$ & 458 & $2.245 \mathrm{E}-03$ & $3.469 \mathrm{E}-03$ \\
\hline IBC-1 (I) & 1.097 & $3.985 \mathrm{E}-05$ & $\sim 0$ & 704 & $1.251 \mathrm{E}-02$ & $2.469 \mathrm{E}-02$ \\
\hline IBC-1 (I) & 2.097 & $3.019 \mathrm{E}-05$ & $\sim 0$ & 440 & $1.130 \mathrm{E}-02$ & $2.231 \mathrm{E}-02$ \\
\hline IBC-1 (I) & 2.347 & $3.445 \mathrm{E}-05$ & $\sim 0$ & 311 & $1.022 \mathrm{E}-02$ & $2.017 \mathrm{E}-02$ \\
\hline IBC-1 (I) & 3.097 & $2.954 \mathrm{E}-05$ & $\sim 0$ & 258 & $9.565 \mathrm{E}-03$ & $1.888 \mathrm{E}-02$ \\
\hline IBC-1 (I) & 4.097 & $2.349 \mathrm{E}-05$ & $\sim 0$ & 237 & $9.273 \mathrm{E}-03$ & $1.830 \mathrm{E}-02$ \\
\hline IBC-2 (I) & 1.364 & 4.296E-05 & $\bar{~} \sim 0$ & 215 & $9.250 \mathrm{E}-03$ & 1.429E-02 \\
\hline IBC-2 (I)D & 1.364 & $4.296 \mathrm{E}-05$ & $\sim 0$ & 215 & $9.250 \mathrm{E}-03$ & $1.429 \mathrm{E}-02$ \\
\hline IBC-2 (E) & 1.364 & $3.437 \mathrm{E}-05$ & $\sim 0$ & 282 & $9.686 \mathrm{E}-03$ & $1.496 \mathrm{E}-02$ \\
\hline IBC-2 (E)D & 1.364 & $3.813 \mathrm{E}-05$ & $\sim 0$ & 244 & $9.305 \mathrm{E}-03$ & $1.438 \mathrm{E}-02$ \\
\hline IBC-2 (E) & 1.364 & $3.437 \mathrm{E}-05$ & $\sim 0$ & 274 & $9.413 \mathrm{E}-03$ & $1.454 \mathrm{E}-02$ \\
\hline IBC-2 (E)D & 1.364 & $3.330 \mathrm{E}-05$ & $\sim 0$ & 286 & $9.522 \mathrm{E}-03$ & $1.471 \mathrm{E}-02$ \\
\hline IBC-2 (E) & 1.364 & $4.726 \mathrm{E}-05$ & $\sim 0$ & 182 & $8.597 \mathrm{E}-03$ & $1.328 \mathrm{E}-02$ \\
\hline IBC-2 (E)D & 1.364 & $4.834 \mathrm{E}-05$ & $\sim 0$ & 176 & $8.488 \mathrm{E}-03$ & $1.312 \mathrm{E}-02$ \\
\hline IBC-2 (E) & 1.364 & $5.156 \mathrm{E}-05$ & $\sim 0$ & 175 & $9.033 \mathrm{E}-03$ & $1.396 \mathrm{E}-02$ \\
\hline IBC-2 (E)D & 1.364 & $5.371 \mathrm{E}-05$ & $\sim 0$ & 164 & $8.815 \mathrm{E}-03$ & $1.362 \mathrm{E}-02$ \\
\hline
\end{tabular}

${ }^{a}$ Type of contact test identifier: (I) for initial contact test with fresh resin, (R) for re-contact test where number refers to the number of previous contacts, or (E) for initial contact test with pre-soaked resin. (D) implies duplicate test.

${ }^{\mathrm{b}}$ The non-perrhenate fraction within the liquid sample is an inferred value based on re-contact data when available.

${ }^{\mathrm{c}}$ The perrhenate fractional loadings represent the fraction of resin sites occupied by perrhenate where the total ion exchange capacity of the resin in $\left[\mathrm{mmole}_{\mathrm{Re}} / \mathrm{g}_{\mathrm{resin}}\right]$ was assumed to be only batch material dependent.

${ }^{\mathrm{d}}$ Data point is suspect since it is a significant outlier. 
WESTINGHOUSE SAVANNAH RIVER COMPANY

Preliminary Ion Exchange Modeling for Removal of Technetium from Hanford Waste Using SuperLig ${ }^{\circledR} 639$ Resin
Report:

WSRC-TR-2000-00305

Revision (Date):

$0(11 / 29 / 00)$

Page:

Table 4-6. Equilibrium data for Pertechnetate on SuperLig ${ }^{\circledR} 639$ based on batch contact tests using pure waste envelope samples.

\begin{tabular}{|c|c|c|c|c|c|c|}
\hline $\begin{array}{c}\text { Sample } \\
\text { Description }^{\mathrm{a}}\end{array}$ & $\begin{array}{c}\text { Liquid } \\
\mathrm{NO}_{3}^{-} \\
{[\mathrm{M}]}\end{array}$ & $\begin{array}{c}\text { Liquid } \\
\mathrm{TcO}_{4}^{-} \\
{[\mathrm{M}]}\end{array}$ & $\begin{array}{c}\text { Non- } \mathrm{TcO}_{4}^{-} \\
\text {Fraction b } \\
{[\%]}\end{array}$ & $\begin{array}{c}\mathrm{TcO}_{4}^{-} \\
\mathrm{K}_{\mathbf{d}} \\
{[\mathrm{ml} / \mathrm{g}]}\end{array}$ & $\begin{array}{c}\mathrm{TcO}_{4}^{-} \\
\text {loading } \\
\left.\text { [mmole }_{\mathrm{Tc}} / \mathbf{g}_{\text {resin }}\right]\end{array}$ & $\begin{array}{c}\mathrm{TcO}_{4}^{-} \\
\text {fractional } \\
\text { loading }^{\mathrm{c}},[-]^{\mathrm{e}}\end{array}$ \\
\hline NH-A (I) & 1.566 & 4.377E-06 & $\sim 2.0$ & 484 & $2.120 \mathrm{E}-03$ & $3.276 \mathrm{E}-03$ \\
\hline NH-A (I)D & 1.566 & $3.477 \mathrm{E}-06$ & $\begin{array}{l}2.0 \\
\sim\end{array}$ & 576 & $2.004 \mathrm{E}-03$ & $3.096 \mathrm{E}-03$ \\
\hline NH-A (R1) & 1.561 & 4.759E-07 & $\sim 10.0$ & 799 & $3.801 \mathrm{E}-04$ & 5.874E-04 \\
\hline NH-A (R1)D & 1.561 & 4.964E-07 & $\sim 12.3$ & 628 & $3.116 \mathrm{E}-04$ & $4.814 \mathrm{E}-04$ \\
\hline NH-A (R2) & 1.556 & $8.055 \mathrm{E}-08$ & $\sim 50.6$ & 489 & $3.935 \mathrm{E}-05$ & $6.080 \mathrm{E}-05$ \\
\hline NH-A (R2)D & 1.556 & 9.837E-08 & $\sim 49.5$ & 429 & $4.219 \mathrm{E}-05$ & $6.519 \mathrm{E}-05$ \\
\hline NH-A (S) & 1.566 & $4.223 \mathrm{E}-05$ & $\sim 2.0$ & 454 & $1.916 \mathrm{E}-02$ & $2.961 \mathrm{E}-02$ \\
\hline NH-A (S)D & 1.566 & $4.265 \mathrm{E}-05$ & $\begin{array}{l}\sim 2.0 \\
\end{array}$ & 450 & $1.917 \mathrm{E}-02$ & $2.963 \mathrm{E}-02$ \\
\hline NH-A2 (I) $^{d}$ & 0.991 & $3.013 \mathrm{E}-08$ & $\sim \sim 1.0$ & 6159 & $1.856 \mathrm{E}-04$ & $2.867 \mathrm{E}-04$ \\
\hline NH-A2 (I)D & 0.991 & $2.247 \mathrm{E}-07$ & $\sim 1.0$ & 779 & $1.750 \mathrm{E}-04$ & 2.704E-04 \\
\hline NH-B (I) & 0.268 & $1.390 \mathrm{E}-05$ & $\sim 0.03$ & 917 & $1.266 \mathrm{E}-02$ & $1.956 \mathrm{E}-02$ \\
\hline NH-B (I)D & 0.268 & $1.473 \mathrm{E}-05$ & $\sim 0.03$ & 854 & $1.266 \mathrm{E}-02$ & $1.957 \mathrm{E}-02$ \\
\hline NH-B (R1) & 0.262 & $1.338 \mathrm{E}-06$ & $\sim 0.27$ & 833 & $1.117 \mathrm{E}-03$ & $1.726 \mathrm{E}-03$ \\
\hline NH-B (R1)D & 0.262 & $1.089 \mathrm{E}-06$ & $\sim 0.25$ & 1147 & $1.229 \mathrm{E}-03$ & $1.898 \mathrm{E}-03$ \\
\hline NH-B (R2) & 0.256 & $1.191 \mathrm{E}-07$ & $\sim 2.77$ & 738 & $9.004 \mathrm{E}-05$ & $1.391 \mathrm{E}-04$ \\
\hline NH-B (R2)D & 0.256 & $2.054 \mathrm{E}-07$ & $\sim 3.34$ & 372 & $6.975 \mathrm{E}-05$ & $1.078 \mathrm{E}-04$ \\
\hline NH-B (R3) & 0.249 & 5.272E-09 & $\sim 24.2$ & 1158 & $9.374 \mathrm{E}-06$ & $1.448 \mathrm{E}-05$ \\
\hline NH-B (R3)D & 0.249 & $2.905 \mathrm{E}-08$ & $\sim 15.5$ & 1169 & $1.278 \mathrm{E}-05$ & $1.975 \mathrm{E}-05$ \\
\hline NH-SC (I) & 1.885 & 5.153E-06 & $\begin{array}{c}\sim 73.0 \\
\end{array}$ & 155 & $6.630 \mathrm{E}-04$ & $1.024 \mathrm{E}-03$ \\
\hline NH-SC (I)D & 1.885 & $7.916 \mathrm{E}-06$ & $\sim 73.0$ & 57 & 5.892E-04 & 9.104E-04 \\
\hline NH-SC (R1) & 1.879 & $2.027 \mathrm{E}-06$ & $\sim 87.1$ & 138 & $2.790 \mathrm{E}-04$ & 4.312E-04 \\
\hline NH-SC (R1)D & 1.880 & $2.517 \mathrm{E}-06$ & $\sim 80.6$ & 195 & $4.906 \mathrm{E}-04$ & $7.581 \mathrm{E}-04$ \\
\hline NH-SC (R2) & 1.874 & $1.080 \mathrm{E}-06$ & $\sim 94.5$ & 87 & $9.422 \mathrm{E}-05$ & $1.456 \mathrm{E}-04$ \\
\hline NH-SC (R2)D & 1.875 & $3.075 \mathrm{E}-06$ & $\sim 92.9$ & na & na & na \\
\hline WK-LC (I) & 1.885 & $5.51 \mathrm{E}-06$ & $\begin{array}{c}\sim 60.0 \\
\end{array}$ & 250 & $1.380 \mathrm{E}-03$ & $2.132 \mathrm{E}-03$ \\
\hline WK-LC (I)D & 1.885 & $4.76 \mathrm{E}-06$ & $\sim 60.0$ & 312 & $1.485 \mathrm{E}-03$ & $2.294 \mathrm{E}-03$ \\
\hline WK-LC (R1) & 1.880 & $1.21 \mathrm{E}-06$ & $\sim 84.0$ & 332 & $4.028 \mathrm{E}-04$ & $6.224 \mathrm{E}-04$ \\
\hline WK-LC (R1)D & 1.880 & 3.93E-07 & $\sim 85.9$ & 1114 & 4.379E-04 & $6.766 \mathrm{E}-04$ \\
\hline WK-LC (R2) & 1.874 & $2.21 \mathrm{E}-06$ & $\sim 96.0$ & na & na & na \\
\hline WK-LC (R2)D & 1.875 & $1.79 \mathrm{E}-06$ & $\sim 98.7$ & na & na & na \\
\hline WK-LC (S) & 1.885 & $6.82 \mathrm{E}-05$ & $\sim 2.0$ & 277 & $1.892 \mathrm{E}-02$ & $2.923 \mathrm{E}-02$ \\
\hline WK-LC (S)D & 1.885 & $5.96 \mathrm{E}-05$ & $\begin{array}{l}\sim 2.0 \\
\end{array}$ & 298 & $1.776 \mathrm{E}-02$ & $2.744 \mathrm{E}-02$ \\
\hline WK-SRS (I) & 0.490 & $2.686 \mathrm{E}-06$ & $\begin{array}{l}\sim 2.0 \\
\end{array}$ & 1150 & 3.09E-03 & 4.771E-03 \\
\hline WK-SRS (I)D & 0.491 & $2.668 \mathrm{E}-06$ & $\sim 2.0$ & 1194 & $3.19 \mathrm{E}-03$ & $4.922 \mathrm{E}-03$ \\
\hline PNNL-A (I) & 1.985 & $1.349 \mathrm{E}-06$ & $\begin{array}{l}\sim 2.0 \\
\end{array}$ & 4240 & 5.718E-03 & $1.650 \mathrm{E}-02$ \\
\hline PNNL-A (I)D & 1.985 & $1.019 \mathrm{E}-05$ & $\sim 2.0$ & 459 & $4.671 \mathrm{E}-03$ & $1.348 \mathrm{E}-02$ \\
\hline PNNL-A (I) & 1.985 & $6.107 \mathrm{E}-06$ & $\sim 2.0$ & 6959 & $4.250 \mathrm{E}-02$ & $1.226 \mathrm{E}-01$ \\
\hline PNNL-A (I)D & 1.985 & 5.864E-06 & $\sim 2.0$ & 7450 & $4.369 \mathrm{E}-02$ & $1.260 \mathrm{E}-01$ \\
\hline PNNL-A (I) & 1.986 & $3.632 \mathrm{E}-05$ & $\sim 2.0$ & 4422 & $1.606 \mathrm{E}-01$ & $4.634 \mathrm{E}-01$ \\
\hline PNNL-A (I)D & 1.987 & $2.418 \mathrm{E}-05$ & $\sim 2.0$ & 6813 & $1.648 \mathrm{E}-01$ & $4.754 \mathrm{E}-01$ \\
\hline PNNL-A (I) & 1.985 & 5.783E-06 & $\sim 2.0$ & 723 & $4.183 \mathrm{E}-03$ & $1.207 \mathrm{E}-02$ \\
\hline PNNL-C (I) & 2.055 & 9.100E-07 & $2 \sim 75.0$ & 3421 & 3.113E-03 & 8.980E-03 \\
\hline
\end{tabular}




\begin{tabular}{|c|c|c|c|c|c|c|}
\hline $\begin{array}{c}\text { Sample } \\
\text { Description }\end{array}$ & $\begin{array}{l}\text { Liquid } \\
\mathrm{NO}_{3}^{-} \\
{[\mathrm{M}]}\end{array}$ & $\begin{array}{c}\text { Liquid } \\
\text { TcO }_{4}^{-} \\
{[\mathrm{M}]}\end{array}$ & $\begin{array}{c}\mathrm{Non}_{-\mathrm{TcO}_{4}}^{-} \\
\text {Fraction }^{b} \\
{[\%]}\end{array}$ & $\begin{array}{c}\mathrm{TcO}_{4}^{-} \\
\mathbf{K}_{\mathbf{d}} \\
{[\mathrm{ml} / \mathrm{g}]}\end{array}$ & $\begin{array}{c}\mathrm{TcO}_{4}^{-} \\
\text {loading } \\
\left.\text { [mmole }_{\mathrm{Tc}} / \mathrm{g}_{\text {resin }}\right]\end{array}$ & $\begin{array}{c}\mathrm{TcO}_{4}^{-} \\
\text {fractional } \\
\text { loading }^{c},[-]^{\mathrm{e}}\end{array}$ \\
\hline PNNL-C (I)D & 2.055 & $8.897 \mathrm{E}-07$ & $\sim 75.0$ & 3602 & $3.205 \mathrm{E}-03$ & $9.246 \mathrm{E}-03$ \\
\hline DM-A (I) & 1.383 & $1.082 \mathrm{E}-06$ & $\begin{array}{c}\sim 2.0 \\
\end{array}$ & 3612 & $3.906 \mathrm{E}-03$ & $7.711 \mathrm{E}-03$ \\
\hline DM-A (I)D & 1.383 & $1.913 \mathrm{E}-06$ & $\sim 2.0$ & 2247 & $4.298 \mathrm{E}-03$ & $8.483 \mathrm{E}-03$ \\
\hline DM-B (I) & 1.404 & $6.328 \mathrm{E}-06$ & $\begin{array}{l}\sim 2.0 \\
\end{array}$ & 1214 & $7.681 \mathrm{E}-03$ & $1.516 \mathrm{E}-02$ \\
\hline DM-B (I)D & 1.405 & $6.480 \mathrm{E}-06$ & $\sim 2.0$ & 1283 & $8.313 \mathrm{E}-03$ & $1.641 \mathrm{E}-02$ \\
\hline DM-C (I) & 2.431 & 4.788E-06 & $2 \sim 70.0$ & 22 & $\begin{array}{l}1.049 \mathrm{E}-04 \\
\end{array}$ & $2.071 \mathrm{E}-04$ \\
\hline DM-C (I)D & 2.432 & 7.999E-06 & $\begin{array}{l}\sim 70.0 \\
\end{array}$ & 8 & $6.559 \mathrm{E}-05$ & $1.295 \mathrm{E}-04$ \\
\hline
\end{tabular}

${ }^{a}$ Type of contact test identifier: (I) for initial contact test with fresh resin, (R) for re-contact test where number refers to the number of previous contacts, or (S) for initial contact test with spiked ${ }^{99} \mathrm{Tc}$. (D) implies duplicate test.

${ }^{\mathrm{b}}$ The non-pertechnetate fraction within the sample is an inferred value based on re-contact data when available.

${ }^{c}$ The pertechnetate fractional loadings represent the fraction of resin sites occupied by pertechnetate where the total ion exchange capacity of the resin in $\left[\mathrm{mmole}_{\mathrm{Tc}} / \mathrm{g}_{\mathrm{resin}}\right]$ was assumed to be only batch material dependent.

${ }^{d}$ Data point is suspect since it is a significant outlier.

e The computed pertechnetate $K_{d}$ values listed are based on material balance analyses discussed in Appendix A and the original experimental measurements. 
Table 4-7. Equilibrium data for Pertechnetate on SuperLig ${ }^{\circledR} 639$ based on batch contact tests using mixed waste envelope samples (Hassan et al., 2000c).

\begin{tabular}{|c|c|c|c|c|c|c|}
\hline Sample Description ${ }^{a}$ & $\begin{array}{c}\text { Liquid } \\
\mathrm{NO}_{3}^{-} \\
{[\mathrm{M}]}\end{array}$ & $\begin{array}{c}\text { Liquid } \\
\mathrm{TcO}_{4}^{-} \\
{[\mathrm{M}]}\end{array}$ & $\begin{array}{c}\text { Non-TcO }_{4}^{-} \\
\text {Fraction b } \\
{[\%]}\end{array}$ & $\begin{array}{c}\mathrm{TcO}_{4}^{-} \\
\mathrm{K}_{\mathbf{d}} \\
{[\mathrm{ml} / \mathrm{g}]}\end{array}$ & $\begin{array}{c}\mathrm{TcO}_{4}^{-} \\
\text {loading } \\
{\left[\text { mmole }_{\mathrm{Tc}} / \mathrm{g}_{\text {resin }}\right]}\end{array}$ & $\begin{array}{c}\mathrm{TcO}_{4}^{-} \\
\text {fractional } \\
\text { loading }^{\mathrm{c}},[-]\end{array}$ \\
\hline $\mathrm{B} / \mathrm{A}(1: 10) 4 \mathrm{hrs}$ & 1.446 & $5.210 \mathrm{E}-06$ & $\begin{array}{c}\sim 1.8 \\
\sim\end{array}$ & 623 & $3.246 \mathrm{E}-03$ & $5.015 \mathrm{E}-03$ \\
\hline $\mathrm{B} / \mathrm{A}(1: 10) 4 \mathrm{hrs}(\mathrm{D})$ & 1.447 & $5.408 \mathrm{E}-06$ & $\sim 1.8$ & 606 & $3.275 \mathrm{E}-03$ & $5.060 \mathrm{E}-03$ \\
\hline $\mathrm{B} / \mathrm{A}(1: 10) 2 \mathrm{wks}$ & 1.447 & $6.516 \mathrm{E}-06$ & $\begin{array}{c}1.8 \\
\sim\end{array}$ & 546 & $3.557 \mathrm{E}-03$ & $5.496 \mathrm{E}-03$ \\
\hline $\mathrm{B} / \mathrm{A}(1: 10) 2$ wks (D) & 1.446 & $5.480 \mathrm{E}-06$ & $\sim 1.8$ & 653 & $3.579 \mathrm{E}-03$ & $5.530 \mathrm{E}-03$ \\
\hline C/A (1:10) 4 hrs & 1.593 & 4.877E-06 & $2 \sim 6.3$ & 462 & $2.252 \mathrm{E}-03$ & $3.480 \mathrm{E}-03$ \\
\hline C/A (1:10) 4 hrs (D) & 1.594 & $5.084 \mathrm{E}-06$ & $\sim 6.3$ & 449 & $2.284 \mathrm{E}-03$ & $3.530 \mathrm{E}-03$ \\
\hline C/A (1:10) 2 wks & 1.593 & $6.235 \mathrm{E}-06$ & $\sim 6.3$ & 330 & $2.058 \mathrm{E}-03$ & $3.180 \mathrm{E}-03$ \\
\hline C/A (1:10) 2 wks (D) & 1.594 & $4.924 \mathrm{E}-06$ & $\sim 6.3$ & 453 & $2.232 \mathrm{E}-03$ & $3.449 \mathrm{E}-03$ \\
\hline C/B (1:10) $4 \mathrm{hrs}$ & 0.413 & $1.878 \mathrm{E}-05$ & $\bar{c} \sim 4.6$ & 601 & $1.128 \mathrm{E}-02$ & $1.743 \mathrm{E}-02$ \\
\hline $\mathrm{C} / \mathrm{B}(1: 10) 4 \mathrm{hrs}(\mathrm{D})$ & 0.414 & $1.985 \mathrm{E}-05$ & $\sim 4.6$ & 583 & $1.158 \mathrm{E}-02$ & $1.789 \mathrm{E}-02$ \\
\hline $\mathrm{C} / \mathrm{B}(1: 10) 2 \mathrm{wks}$ & 0.414 & $1.503 \mathrm{E}-05$ & $\sim 4.6$ & 784 & 1.179E-02 & $1.821 \mathrm{E}-02$ \\
\hline C/B (1:10) 2 wks (D) & 0.414 & $1.256 \mathrm{E}-05$ & $\sim 4.6$ & 945 & $1.186 \mathrm{E}-02$ & $1.833 \mathrm{E}-02$ \\
\hline Decon. Large-C 24 hrs & 1.884 & (9.259E-06 & $\sim 50.0$ & 125 & (1.228E-03 & (1.898E-03 \\
\hline Decon. Large-C 24 hrs (D) & 1.884 & $8.640 \mathrm{E}-06$ & $\sim 50.0$ & 151 & $1.230 \mathrm{E}-03$ & $1.901 \mathrm{E}-03$ \\
\hline Decon. Large-C 2 wks & 1.883 & $8.721 \mathrm{E}-06$ & $\sim 50.0$ & 142 & $1.235 \mathrm{E}-03$ & $1.908 \mathrm{E}-03$ \\
\hline Decon. Large-C 2 wks (D) & 1.883 & $9.168 \mathrm{E}-06$ & $\sim 50.0$ & 128 & $1.171 \mathrm{E}-03$ & $1.809 \mathrm{E}-03$ \\
\hline Decon. B 2 wks & 0.266 & 1.094E-05 & $\sim 0.03$ & 743 & 8.131E-03 & $1.256 \mathrm{E}-02$ \\
\hline Decon. B 2 wks (D) & 0.266 & $1.080 \mathrm{E}-05$ & $\sim 0.03$ & 792 & $8.552 \mathrm{E}-03$ & $1.321 \mathrm{E}-02$ \\
\hline
\end{tabular}

a Type of contact test identifier: (D) implies duplicate test and all tests were initial contact tests with fresh resin. All mixed envelope batch contact tests were performed using the same SuperLig ${ }^{\circledR} 639$ batch ID (\# 981015DHC720011) and contact times tested were 4 hours, 1 day, and 2 weeks.

${ }^{\mathrm{b}}$ The non-pertechnetate fraction within the liquid sample is a volume average value based on the fractions estimated for the unmixed envelope contact tests.

${ }^{c}$ The pertechnetate fractional loadings represent the fraction of resin sites occupied by pertechnetate where the total ion exchange capacity of the resin in $\left[\mathrm{mmole}_{\mathrm{Tc}} / \mathrm{g}_{\mathrm{resin}}\right]$ was the volume average value based on the fractions estimated for the unmixed envelope contact tests. 
WESTINGHOUSE SAVANNAH RIVER COMPANY

Preliminary Ion Exchange Modeling for Removal of Technetium from Hanford Waste Using SuperLig ${ }^{\circledR} 639$ Resin
Report:

WSRC-TR-2000-00305

Revision (Date):

$0(11 / 29 / 00)$

Page: 44 of 228

Table 4-8. Estimated binary selectivity coefficient and its confidence level for the Perrhenate-SuperLig ${ }^{\circledR}$ 639 system based on the entire set of perrhenate batch contact tests and the binary homovalent isotherm model.

\begin{tabular}{|c|c|c|c|c|c|c|}
\hline $\begin{array}{c}\text { Binary } \\
\text { Selectivity } \\
\text { Coefficient }\end{array}$ & Definition & $\begin{array}{c}\text { Parameter } \\
\text { Estimate }\end{array}$ & $\begin{array}{c}\text { Approx. } \\
\text { Standard } \\
\text { Error }\end{array}$ & $\begin{array}{c}\text { Relative } \\
\text { Error } \\
(\%)\end{array}$ & $\begin{array}{c}\text { Lower } \\
\text { Confidence } \\
\text { Level }\end{array}$ & $\begin{array}{c}\text { Upper } \\
\text { Confidence } \\
\text { Level }\end{array}$ \\
\hline \hline$\tilde{\mathrm{K}}_{21}$ & $\begin{array}{c}\mathrm{NO}_{3}^{-} \\
\text {to } \mathrm{ReO}_{4}^{-} \\
\text {selectivity }\end{array}$ & $1.363 \times 10^{-3}$ & $9.588 \times 10^{-5}$ & $7.0 \%$ & $1.267 \times 10^{-3}$ & $1.459 \times 10^{-3}$ \\
\hline$\tilde{\mathrm{K}}_{12}$ & $\begin{array}{c}\mathrm{ReO}_{4}^{-} \\
\text {to } \mathrm{NO}_{3}^{-} \\
\text {selectivity }\end{array}$ & 733.62 & 51.60 & $7.0 \%$ & 682.02 & 785.22 \\
\hline
\end{tabular}

Table 4-9. Batch and Envelope specific predicted (best estimate) binary isotherm model parameters (selectivity coefficient and total ionic capacity) for the Pertechnetate (and perrhenate)-SuperLig ${ }^{\circledR} 639$ system based on available equilibrium batch contact tests and supported by follow-on column studies.

\begin{tabular}{|c|c|c|c|c|c|}
\hline $\begin{array}{c}\text { Test } \\
\text { ID }\end{array}$ & Batch ID & Waste type & \begin{tabular}{|}
$\begin{array}{c}\text { Selectivity } \\
\text { coefficient }^{\text {a }}\end{array}$ \\
$\tilde{\mathrm{K}}_{21}$ \\
{$[-]$}
\end{tabular} & $\begin{array}{c}\begin{array}{c}\text { Total ionic } \\
\text { capacity }\end{array}{ }^{\mathrm{b}}, \\
\overline{\mathrm{C}}_{\mathrm{T}} \\
{\left[\mathrm{mmole} / \mathrm{g}_{\text {resin }}\right]}\end{array}$ & Comments \\
\hline WK-1 & 980624001DC & $\begin{array}{l}\text { Env. A simulant } \\
\quad\left(\mathrm{ReO}_{4}^{-}\right)\end{array}$ & $1.3630 \times 10^{-3}$ & 0.3466 & $\begin{array}{l}\text { High confidence of } \sim 0 \% \text { non- } \\
\text { perrhenate. Total ionic } \\
\text { capacity fit to contact data. }\end{array}$ \\
\hline WK-2 & 990420DHC720067 & $\begin{array}{l}\text { Env. A simulant } \\
\quad\left(\mathrm{ReO}_{4}^{-}\right)\end{array}$ & $1.3630 \times 10^{-3}$ & 0.8804 & $\begin{array}{l}\text { High confidence of } \sim 0 \% \text { non- } \\
\text { perrhenate. Total ionic } \\
\text { capacity fit to contact data. }\end{array}$ \\
\hline WK-3 & 981015DHC720011 & $\begin{array}{l}\text { Env. A simulant } \\
\quad\left(\mathrm{ReO}_{4}^{-}\right)\end{array}$ & $1.3630 \times 10^{-3}$ & 0.6472 & $\begin{array}{l}\text { High confidence of } \sim 0 \% \text { non- } \\
\text { perrhenate. Total ionic } \\
\text { capacity fit to contact data. }\end{array}$ \\
\hline $\begin{array}{l}\text { IBC-1 and } \\
\text { IBC Exp-1 }\end{array}$ & Not reported & Simulant range & $1.1269 \times 10^{-3}$ & $\begin{array}{c}0.5066 \\
\text { (vendor value) }\end{array}$ & $\begin{array}{c}\text { Varied nitrate levels in } \\
\text { contact tests. Inconsistency in } \\
\text { contact test data. }\end{array}$ \\
\hline $\begin{array}{l}\text { WK Exp-5 } \\
\quad \text { and } \\
\text { TFL Runs } \\
\text { (all tests) }\end{array}$ & $\begin{array}{c}\text { 50:50 mix of } \\
\text { 990420DHC720067 } \\
\text { 981015DHC720011 }\end{array}$ & $\begin{array}{l}\text { Env. A simulant } \\
\quad\left(\mathrm{ReO}_{4}^{-}\right)\end{array}$ & \begin{tabular}{|c|}
$1.3630 \times 10^{-3}$ \\
(WK Exp-5) \\
$1.7500 \times 10^{-3}$ \\
(TFL Runs)
\end{tabular} & $\begin{array}{l}0.6472 \text { used } \\
(0.7638 \text { is the } \\
\text { mass avg. } \\
\text { value; not } \\
\text { used })\end{array}$ & $\begin{array}{c}\text { The TFL } 28 \% \text { increased } \mathrm{K}_{21} \\
\text { wrt WK's is not explainable. } \\
\text { WK-3 capacity used based on } \\
\text { limited WK-2 data and WK } \\
\text { Exp-5 column comparison. }\end{array}$ \\
\hline NH-A & 981015DHC720011 & $\begin{array}{l}\text { Env. A sample } \\
\text { 241-AN-103 } \\
\left(\mathrm{TcO}_{4}^{-}\right)\end{array}$ & $7.7418 \times 10^{-4}$ & 0.6472 & $\begin{array}{c}\text { Non-pertechnetate }<2 \% \\
\text { based on contact data. } \\
\text { The } 43 \% \text { decreased } \mathrm{K}_{21} \text { wrt } \\
\text { WK-3 due to Tc versus Re. }\end{array}$ \\
\hline
\end{tabular}




\begin{tabular}{|c|c|c|c|c|c|}
\hline $\begin{array}{l}\text { Test } \\
\text { ID }\end{array}$ & Batch ID & Waste type & $\begin{array}{c}\begin{array}{c}\text { Selectivity } \\
\text { coefficient } \\
\text { a }\end{array} \\
\widetilde{\mathrm{K}}_{21} \\
{[-]}\end{array}$ & $\begin{array}{c}\text { Total ionic } \\
\text { capacity }^{b} \\
\overline{\mathrm{C}}_{\mathrm{T}} \\
{\left[\mathrm{mmole} / \mathrm{g}_{\text {resin }}\right]}\end{array}$ & Comments \\
\hline NH-B & 981015DHC720011 & $\begin{array}{l}\text { Env. B sample } \\
\text { 241-AZ-102 } \\
\left(\mathrm{TcO}_{4}^{-}\right)\end{array}$ & $2.6735 \times 10^{-3}$ & 0.6472 & $\begin{array}{c}\text { Non-pertechnetate }<0.03 \% \\
\text { based on contact data. } \\
\text { The } 245 \% \text { increased } \mathrm{K}_{21} \text { wrt } \\
\text { NH-A may be due to total } \\
\text { ionic strength differences. }\end{array}$ \\
\hline NH-SC & 981015DHC720011 & $\begin{array}{l}\text { Env. "Small"-C } \\
\text { 241-AN-102 } \\
\left(\mathrm{TcO}_{4}^{-}\right)\end{array}$ & $2.6735 \times 10^{-3}$ & 0.6472 & $\begin{array}{l}\text { Non-pertechnetate }<73 \% \\
\text { based on contact data. A } \\
\text { similar } \mathrm{K}_{21} \text { wrt NH-B, but } \\
\text { differing total ionic strengths. }\end{array}$ \\
\hline WK-LC & $\begin{array}{l}\text { 981015DHC720011 } \\
\text { (batch tests) and } \\
50: 50 \text { mix of } \\
990420 \text { DHC720067 } \\
981015 \text { DHC720011 } \\
\text { (column test) }\end{array}$ & $\begin{array}{l}\text { Env. "Large"-C } \\
\text { 241-AN-102 } \\
\left(\mathrm{TcO}_{4}^{-}\right)\end{array}$ & $1.3630 \times 10^{-3}$ & 0.6472 & $\begin{array}{l}\text { Non-pertechnetate }<50 \% \\
\text { based on contact data. } \\
\text { The } 50 \% \text { decreased } \mathrm{K}_{21} \text { wrt } \\
\text { NH-SC is not explainable. }\end{array}$ \\
\hline WK-SRS & $\begin{array}{c}\text { 981015DHC720011 } \\
\text { (batch tests) and } \\
50: 50 \text { mix of } \\
990420 \text { DHC720067 } \\
981015 \text { DHC720011 } \\
\text { (column test) }\end{array}$ & $\begin{array}{l}\text { SRS sample } \\
\text { Tank 44F } \\
\left(\mathrm{TcO}_{4}^{-}\right)\end{array}$ & $7.7418 \times 10^{-4}$ & 0.6472 & $\begin{array}{c}\text { Non-pertechnetate }<2 \% \\
\text { based on contact data. }\end{array}$ \\
\hline
\end{tabular}

${ }^{a}$ Based on the equilibrium contact data it is believed that the selectivity coefficient of SuperLig ${ }^{\circledR} 639$ resin between nitrate and pertechnetate differs from its value between nitrate and perrhenate. The selectivity coefficients are most likely total ionic strength and anion composition dependent; however, if these variables are held fixed it is believed that similar values for the selectivity coefficients for differing batch materials will be achieved.

${ }^{b}$ It is assumed that the total ionic capacity of the SuperLig ${ }^{\circledR} 639$ resin is primarily batch dependent with little dependence on total ionic strength of the solution or on the type/composition of competing anions (e.g., nitrate, 
WESTINGHOUSE SAVANNAH RIVER COMPANY

Preliminary Ion Exchange Modeling for Removal of Technetium from Hanford Waste Using SuperLig ${ }^{\circledR} 639$ Resin
Report:

WSRC-TR-2000-00305

Revision (Date):

$0(11 / 29 / 00)$

Page:

46 of 228

Table 4-10. Species concentrations and rough estimates ${ }^{a}$ for the total ionic strength (in molar units) of various Hanford waste samples and simulants used in batch contact and column tests.

\begin{tabular}{|c|c|c|c|c|c|c|c|c|c|}
\hline $\begin{array}{l}\text { Species } \\
\text { ID }\end{array}$ & $\begin{array}{c}\text { WK } \\
\text { (all) } \\
\left(\mathrm{ReO}_{4}^{-}\right) \\
{[\mathbf{M}]}\end{array}$ & $\begin{array}{c}\text { TFL } \\
\text { (all) } \\
\left(\mathrm{ReO}_{4}{ }^{-}\right) \\
{[\mathrm{M}]}\end{array}$ & $\begin{array}{c}\mathrm{IBC}-1 \\
\left(\mathrm{ReO}_{4}{ }^{-}\right) \\
{[\mathrm{M}]}\end{array}$ & $\begin{array}{c}\text { IBC-2 } \\
\left(\mathrm{ReO}_{4}^{-}\right) \\
{[\mathrm{M}]}\end{array}$ & $\begin{array}{c}\mathrm{NH}-\mathrm{A} \\
\left(\mathrm{TcO}_{4}^{-}\right) \\
{[\mathrm{M}]}\end{array}$ & $\begin{array}{c}\mathrm{NH}-\mathrm{B} \\
\left(\mathrm{TcO}_{4}{ }^{-}\right) \\
{[\mathrm{M}]}\end{array}$ & $\begin{array}{c}\mathrm{NH}-\mathrm{SC} \\
\left(\mathrm{TcO}_{4}^{-}\right) \\
{[\mathrm{M}]}\end{array}$ & $\begin{array}{c}\text { WK- } \\
\text { LC } \\
\left(\mathrm{TcO}_{4}^{-}\right) \\
{[\mathrm{M}]}\end{array}$ & $\begin{array}{c}\text { WK- } \\
\text { SRS } \\
\left(\mathrm{TcO}_{4}^{-}\right) \\
{[\mathrm{M}]}\end{array}$ \\
\hline \multicolumn{10}{|l|}{ Cations } \\
\hline $\mathrm{Na}^{+}$ & 5.000674 & 4.930709 & 5.185 & 5.457 & 5.25 & 2.65 & 5.98 & 4.84 & 5.4 \\
\hline $\mathrm{K}^{+}$ & 0.090804 & 0.0892 & 0.1 & 0.0977 & 0.121 & 0.081 & 0.0292 & 0.03 & 0.566 \\
\hline $\mathrm{Pb}^{+}$ & - & - & - & - & - & - & 0.000403 & - & - \\
\hline $\mathrm{Zn}^{2+}$ & - & 0.0000736 & - & 0.0000784 & - & - & - & - & - \\
\hline $\mathrm{Mg}^{2+}$ & - & 0.000105 & - & 0.000114 & - & - & - & - & - \\
\hline $\mathrm{Ca}^{2+}$ & - & 0.00068 & 0.01 & 0.000513 & - & 0.0027 & 0.00514 & - & - \\
\hline $\mathrm{Al}^{3+}$ & - & - & 0.5 & 0.758 & - & - & - & - & - \\
\hline \multicolumn{10}{|l|}{ Anions } \\
\hline $\mathrm{NO}_{3}^{-}$ & 1.25 & 1.24712 & 2.47 & 1.36911 & 1.571 & 0.273 & 1.89 & 1.33 & 0.495 \\
\hline $\mathrm{NO}_{2}^{-}$ & 1.13 & 1.132 & 0.455 & 1.24 & 1.037 & 0.832 & 0.832 & 0.66 & 0.476 \\
\hline $\mathrm{Cl}^{-}$ & 0.12 & 0.12 & 0.185 & 0.132 & 0.061 & 0.0070 & 0.0435 & 0.07 & 0.00927 \\
\hline $\mathrm{F}^{-}$ & - & 0.0047 & 0.1 & 0.00514 & - & 0.0534 & 0.0411 & 0.03 & 0.000338 \\
\hline $\mathrm{OH}^{-}$ & 1.62 & 1.6273 & 3.5 & 4.804 & 2.166 & 0.109 & 1.69 & 1.25 & 4.40 \\
\hline $\mathrm{AlO}_{2}^{-}$ & 0.69 & - & - & - & 0.70 & 0.0279 & 0.272 & 0.21 & 0.2393 \\
\hline $\mathrm{AlO}^{-}$ & - & 0.69 & - & - & - & - & - & - & - \\
\hline $\mathrm{HCOO}^{-}$ & 0.03 & 0.03 & - & 0.00356 & - & - & - & - & 0.00222 \\
\hline $\mathrm{CH}_{3} \mathrm{COO}^{-}$ & 0.02 & 0.0133 & - & 0.00342 & - & - & - & 0.09 & - \\
\hline $\mathrm{CH}_{2} \mathrm{COO}^{-}$ & - & 0.0103 & - & - & - & - & - & - & - \\
\hline $\mathrm{C}_{2} \mathrm{O}_{4}{ }^{2-}$ & 0.003 & 0.0033 & - & - & 0.0059 & 0.0321 & - & - & 0.000746 \\
\hline $\mathrm{CO}_{3}{ }^{2-}$ & 0.10 & 0.0685 & - & 0.107 & - & - & - & - & - \\
\hline $\mathrm{SiO}_{3}{ }^{2-}$ & 0.004 & 0.00352 & - & 0.00386 & 0.0045 & - & - & - & - \\
\hline $\mathrm{CrO}_{4}^{2-}$ & - & - & - & & - & 0.0148 & 0.00169 & - & - \\
\hline $\mathrm{MoO}_{4}{ }^{2-}$ & 0.000402 & 0.0004 & - & 0.0000439 & - & - & - & - & - \\
\hline $\mathrm{SO}_{4}^{2-}$ & 0.0038 & 0.0038 & 0.0485 & & 0.008 & 0.172 & 0.062 & 0.05 & 0.00133 \\
\hline $\mathrm{BO}_{3}{ }^{3-}$ & - & 0.00222 & - & 0.000608 & - & - & - & - & - \\
\hline $\mathrm{PO}_{4}^{3-}$ & 0.003 & 0.0028 & - & 0.00309 & 0.0069 & 0.003 & 0.0126 & - & 0.00312 \\
\hline $\begin{array}{c}\text { Total ionic } \\
\text { strength[M] }\end{array}$ & $>5.22$ & $>5.13$ & $>8.36$ & $>10.21$ & $>5.52$ & $>2.47$ & $>5.57$ & $>4.36$ & $>5.56$ \\
\hline
\end{tabular}

a Only rough estimates (i.e., lower bounds) for the total ionic strength can be computed since a complete listing of the anions and cations in solution is not available. The total ionic strength is computed based on molar units. 
Table 4-11. Parameter identities between the binary VERSE-LC Freundlich/Langmuir Hybrid equilibrium isotherm model and the binary homovalent isotherm system.

\begin{tabular}{|c|c|c||c|}
\hline Parameter $^{\mathrm{a}}$ & $\begin{array}{c}\text { Pertechnetate } \\
\text { or perrhenate } \\
\text { (component 1) }\end{array}$ & $\begin{array}{c}\text { Nitrate } \\
\text { (component 2) }\end{array}$ & $\begin{array}{c}\text { Pertechnetate } \\
\text { or perrhenate } \\
\text { (effective single } \\
\text { component) }\end{array}$ \\
\hline \hline $\mathbf{a}_{\mathbf{i}}($ gmoles/L $\mathbf{C v})$ & $\rho_{\mathrm{b}} \overline{\mathrm{C}}_{\mathrm{T}}$ & $\rho_{\mathrm{b}} \overline{\mathrm{C}}_{\mathrm{T}} \tilde{\mathrm{K}}_{21}$ & $\rho_{\mathrm{b}} \overline{\mathrm{C}}_{\mathrm{T}}$ \\
\hline $\mathbf{b}_{\mathbf{i}}\left(\mathbf{M}^{-\mathbf{1}}\right)$ & 1.0 & $\tilde{\mathrm{K}}_{21}$ & 1.0 \\
\hline $\mathbf{M}_{\mathbf{a} \mathbf{i}}(-)$ & 1.0 & 1.0 & 1.0 \\
\hline $\mathbf{M}_{\mathbf{b i}}(-)$ & 1.0 & 1.0 & 1.0 \\
\hline$\beta_{\mathbf{i}}(-)$ & 0.0 & 0.0 & $\tilde{\mathrm{K}}_{21} \mathrm{c}_{\mathrm{p} 2}^{\mathrm{M}_{\mathrm{b} 2}}$ \\
\hline
\end{tabular}

${ }^{a}$ The parameters for components 1 and 2 refer to pertechnetate (or perrhenate) and nitrate, respectively, when the binary system of interest is the pertechnetate (or perrhenate)-SuperLig ${ }^{\circledR} 639$ system. 
Table 4-12. Parameter settings for a binary Freundlich/Langmuir Hybrid equilibrium isotherm model for Pertechnetate (or perrhenate) on SuperLig ${ }^{\circledR} 639$ based on the binary homovalent system.

\begin{tabular}{|c|c|c|c|c|c|c|}
\hline $\begin{array}{c}\text { Column Test } \\
\text { ID }\end{array}$ & $\begin{array}{c}\text { Component } \\
\text { ID }^{\mathrm{a}}\end{array}$ & $\begin{array}{c}\mathbf{a}_{\mathbf{i}} \\
(\text { gmoles//L } \\
\text { CV })\end{array}$ & $\begin{array}{c}\mathbf{b}_{\mathbf{i}} \\
\left(\mathbf{M}^{-1}\right)\end{array}$ & $\begin{array}{c}\mathbf{M}_{\mathrm{ai}} \\
(-)\end{array}$ & $\begin{array}{c}\mathbf{M}_{\mathbf{b i}} \\
(-)\end{array}$ & $\begin{array}{l}\beta_{\mathrm{i}} \\
(-)\end{array}$ \\
\hline \multirow[t]{2}{*}{ WK Exp-1,2,3,4 } & perrhenate (1) & $1.6953 \mathrm{E}-01$ & 1.0 & 1.0 & 1.0 & 0.0 \\
\hline & nitrate (2) & $2.3106 \mathrm{E}-04$ & $1.3630 \mathrm{E}-03$ & 1.0 & 1.0 & 0.0 \\
\hline \multirow[t]{2}{*}{ WK Exp-5 } & perrhenate (1) & 3.0646E-01 & 1.0 & 1.0 & 1.0 & 0.0 \\
\hline & nitrate (2) & $4.1771 \mathrm{E}-04$ & $1.3630 \mathrm{E}-03$ & 1.0 & 1.0 & 0.0 \\
\hline \multirow[t]{2}{*}{ IBC Exp-1 } & perrhenate (1) & 2.0264E-01 & 1.0 & 1.0 & 1.0 & 0.0 \\
\hline & nitrate (2) & $2.2836 \mathrm{E}-03$ & $1.1269 \mathrm{E}-03$ & 1.0 & 1.0 & 0.0 \\
\hline \multirow{2}{*}{$\begin{array}{l}\text { TFL Runs } \\
\text { (all tests) }\end{array}$} & perrhenate (1) & 3.4109E-01 & 1.0 & 1.0 & 1.0 & 0.0 \\
\hline & nitrate (2) & $5.9691 \mathrm{E}-04$ & $1.7500 \mathrm{E}-03$ & 1.0 & 1.0 & 0.0 \\
\hline \multirow[t]{2}{*}{ NH-A } & pertechnetate (1) & $3.0290 \mathrm{E}-01$ & 1.0 & 1.0 & 1.0 & 0.0 \\
\hline & nitrate (2) & $2.3450 \mathrm{E}-04$ & 7.7418E-04 & 1.0 & 1.0 & 0.0 \\
\hline \multirow[t]{2}{*}{ NH-B } & Pertechnetate (1) & $3.0290 \mathrm{E}-01$ & 1.0 & 1.0 & 1.0 & 0.0 \\
\hline & nitrate (2) & 8.0982E-04 & $2.6735 \mathrm{E}-03$ & 1.0 & 1.0 & 0.0 \\
\hline \multirow[t]{2}{*}{ NH-SC } & Pertechnetate (1) & $3.0290 \mathrm{E}-01$ & 1.0 & 1.0 & 1.0 & 0.0 \\
\hline & nitrate (2) & $8.0982 \mathrm{E}-04$ & $2.6735 \mathrm{E}-03$ & 1.0 & 1.0 & 0.0 \\
\hline \multirow[t]{2}{*}{ WK-LC } & Pertechnetate (1) & 3.0646E-01 & 1.0 & 1.0 & 1.0 & 0.0 \\
\hline & nitrate (2) & 4.1771E-04 & $1.3630 \mathrm{E}-03$ & 1.0 & 1.0 & 0.0 \\
\hline \multirow[t]{2}{*}{ WK-SRS } & pertechnetate (1) & $3.0990 \mathrm{E}-01$ & 1.0 & 1.0 & 1.0 & 0.0 \\
\hline & nitrate (2) & 2.3991E-04 & 7.7418E-04 & 1.0 & 1.0 & 0.0 \\
\hline \multirow[t]{2}{*}{ Full-scale (Env. A) } & pertechnetate (1) & $3.0290 \mathrm{E}-01$ & 1.0 & 1.0 & 1.0 & 0.0 \\
\hline & nitrate (2) & $2.3450 \mathrm{E}-04$ & 7.7418E-04 & 1.0 & 1.0 & 0.0 \\
\hline \multirow[t]{2}{*}{ Full-scale (Env. B) } & pertechnetate (1) & $3.0290 \mathrm{E}-01$ & 1.0 & 1.0 & 1.0 & 0.0 \\
\hline & nitrate (2) & 8.0982E-04 & $2.6735 \mathrm{E}-03$ & 1.0 & 1.0 & 0.0 \\
\hline
\end{tabular}

${ }^{\mathrm{a}}$ Components 1 and 2 refer to species numbers used in the binary homovalent isotherm model. 
Table 4-13. Parameter settings for an "effective" single component Freundlich/Langmuir Hybrid equilibrium isotherm model for Pertechnetate (or perrhenate) on SuperLig ${ }^{\circledR} 639$ based on the binary homovalent system.

\begin{tabular}{|c|c|c|c|c|c|c|c|}
\hline $\begin{array}{c}\text { Column Test } \\
\text { ID }\end{array}$ & $\begin{array}{c}\text { Anion of } \\
\text { interest }\end{array}$ & $\begin{array}{c}\text { Nitrate } \\
\text { Conc. } \\
{[\mathbf{M}]}\end{array}$ & $\begin{array}{c}\mathbf{A}_{\mathbf{i}} \\
\left(\mathbf{g m o l e s} / \mathbf{L}_{\mathbf{C v}}\right)\end{array}$ & $\begin{array}{c}\mathbf{b}_{\mathbf{i}} \\
\left(\mathbf{M}^{-\mathbf{1}}\right)\end{array}$ & $\begin{array}{c}\mathbf{M}_{\mathbf{a i}} \\
(-)\end{array}$ & $\begin{array}{c}\mathbf{M}_{\mathbf{b i}} \\
(-)\end{array}$ & $\begin{array}{c}\beta_{\mathbf{i}} \\
(-)\end{array}$ \\
\hline WK Exp-1,2,3,4 & perrhenate & 1.25 & $1.6953 \mathrm{E}-01$ & 1.0 & 1.0 & 1.0 & $1.70375 \mathrm{E}-03$ \\
\hline WK Exp-5 & perrhenate & 1.25 & $3.0646 \mathrm{E}-01$ & 1.0 & 1.0 & 1.0 & $1.70375 \mathrm{E}-03$ \\
\hline IBC Exp-1 & perrhenate & 2.47 & $2.0264 \mathrm{E}-01$ & 1.0 & 1.0 & 1.0 & $2.78352 \mathrm{E}-03$ \\
\hline TFL Runs & perrhenate & 1.247 & $3.4109 \mathrm{E}-01$ & 1.0 & 1.0 & 1.0 & $2.18243 \mathrm{E}-03$ \\
\hline NH-A & pertechnetate & 0.998 & $3.0290 \mathrm{E}-01$ & 1.0 & 1.0 & 1.0 & $7.72628 \mathrm{E}-04$ \\
\hline NH-B & pertechnetate & 0.232 & $3.0290 \mathrm{E}-01$ & 1.0 & 1.0 & 1.0 & $6.19724 \mathrm{E}-04$ \\
\hline NH-SC & pertechnetate & 1.890 & $3.0290 \mathrm{E}-01$ & 1.0 & 1.0 & 1.0 & $5.05297 \mathrm{E}-03$ \\
\hline WK-LC & pertechnetate & 1.385 & $3.0646 \mathrm{E}-01$ & 1.0 & 1.0 & 1.0 & $1.88776 \mathrm{E}-03$ \\
\hline WK-SRS & pertechnetate & 0.495 & $3.0990 \mathrm{E}-01$ & 1.0 & 1.0 & 1.0 & $3.83217 \mathrm{E}-04$ \\
\hline Full-scale (Env. A) & pertechnetate & 0.998 & $3.0290 \mathrm{E}-01$ & 1.0 & 1.0 & 1.0 & $7.72628 \mathrm{E}-04$ \\
\hline Full-scale (Env. B) & pertechnetate & 0.232 & $3.0290 \mathrm{E}-01$ & 1.0 & 1.0 & 1.0 & $6.19724 \mathrm{E}-04$ \\
\hline
\end{tabular}




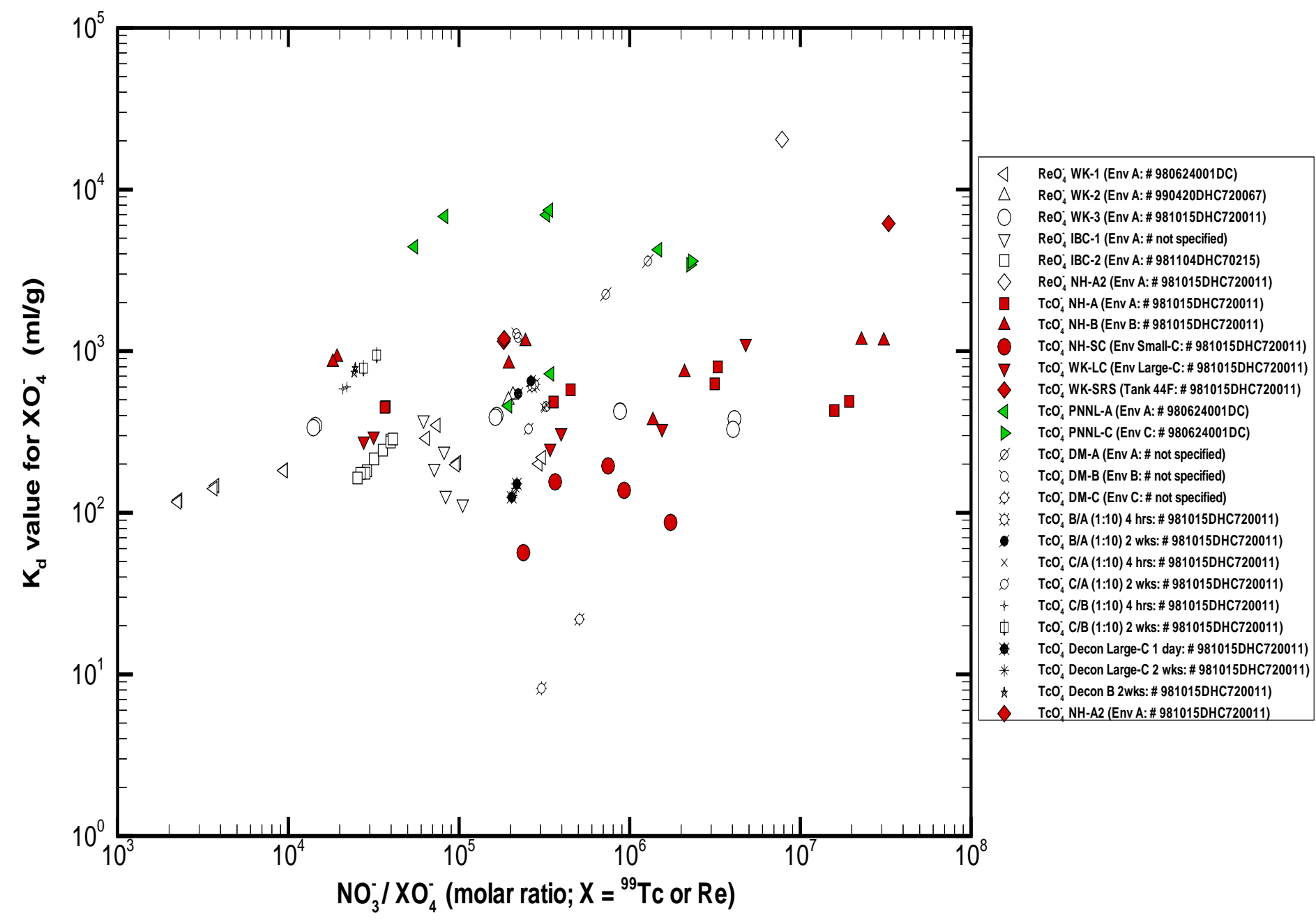

Figure 4-1. Variation in measured pertechnetate and perrhenate $K_{d}$ values on SuperLig ${ }^{\circledR} 639$ resin with respect to their final molar ratios with nitrate. The database shown was taken from three different sites and eight different batches for a total of 88 data points. 


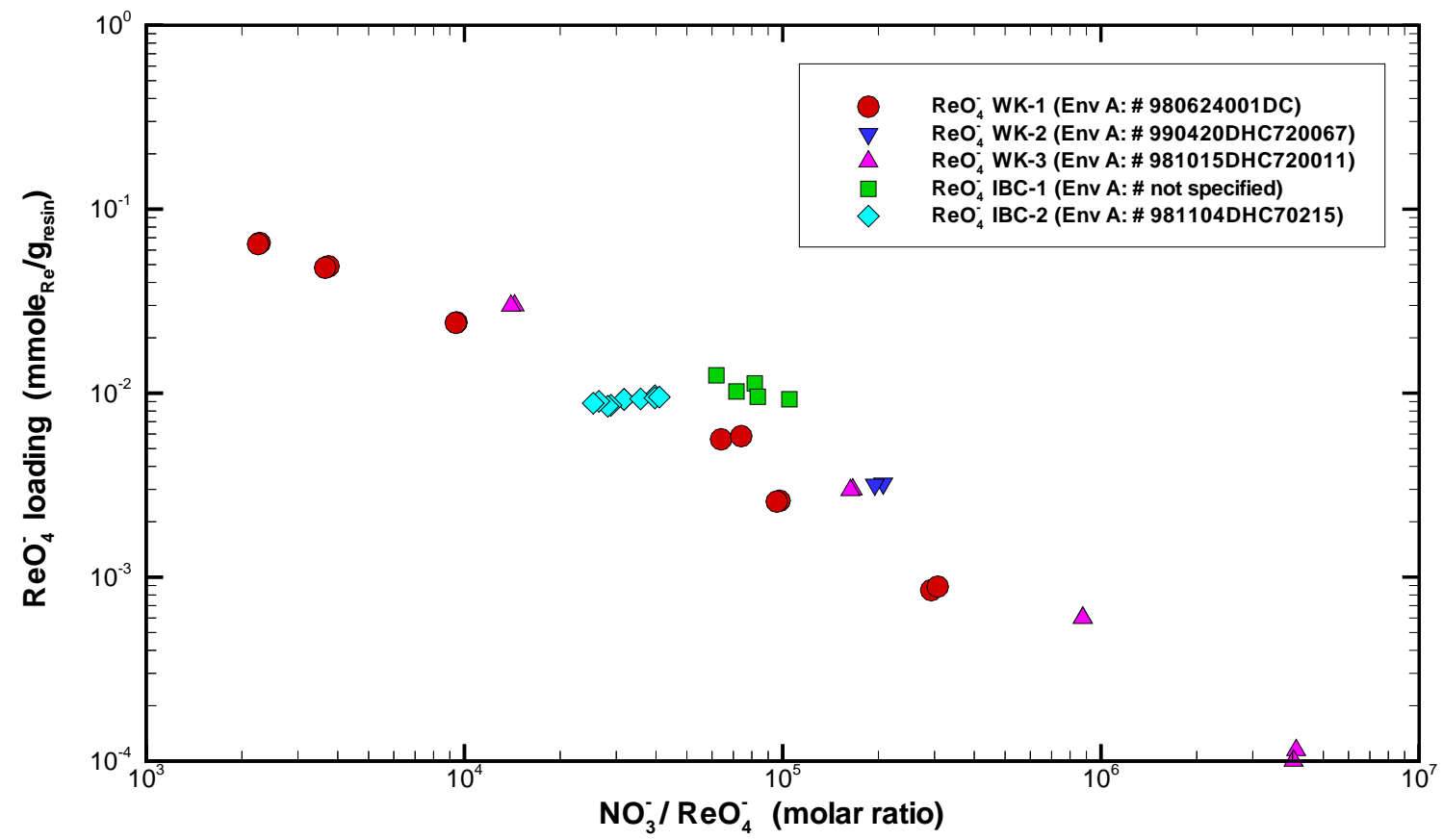

Figure 4-2. Variation in measured perrhenate loadings on SuperLig ${ }^{\circledR} 639$ resin with respect to the final molar ratio of nitrate to perrhenate ions. The database shown contains data taken from two different sites and five different batches for a total of 37 data points.

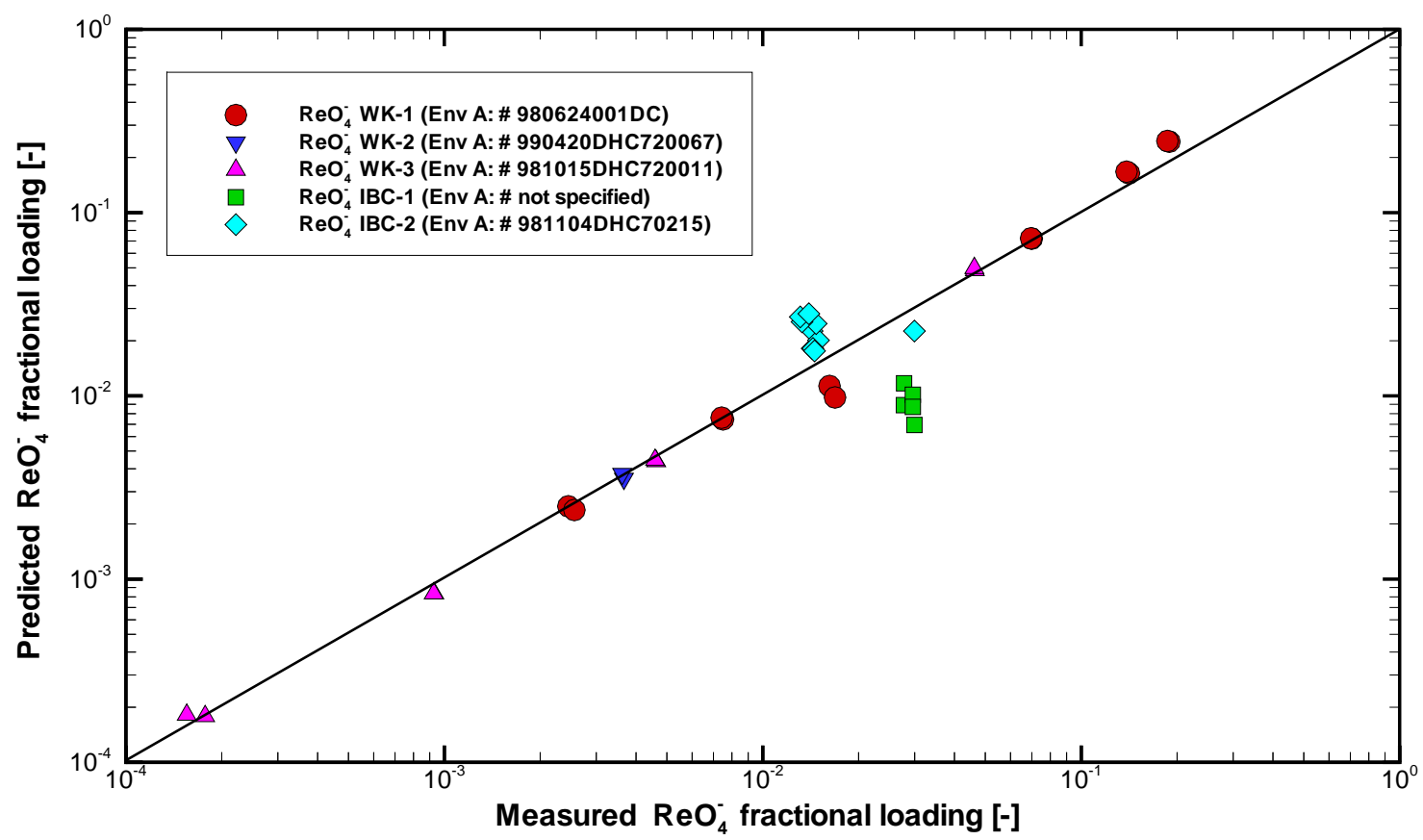

Figure 4-3. Measured versus predicted perrhenate fractional loadings on SuperLig ${ }^{\circledR} 639$ resin. The database shown contains data taken from two different sites and five different batches for a total of 37 data points. 


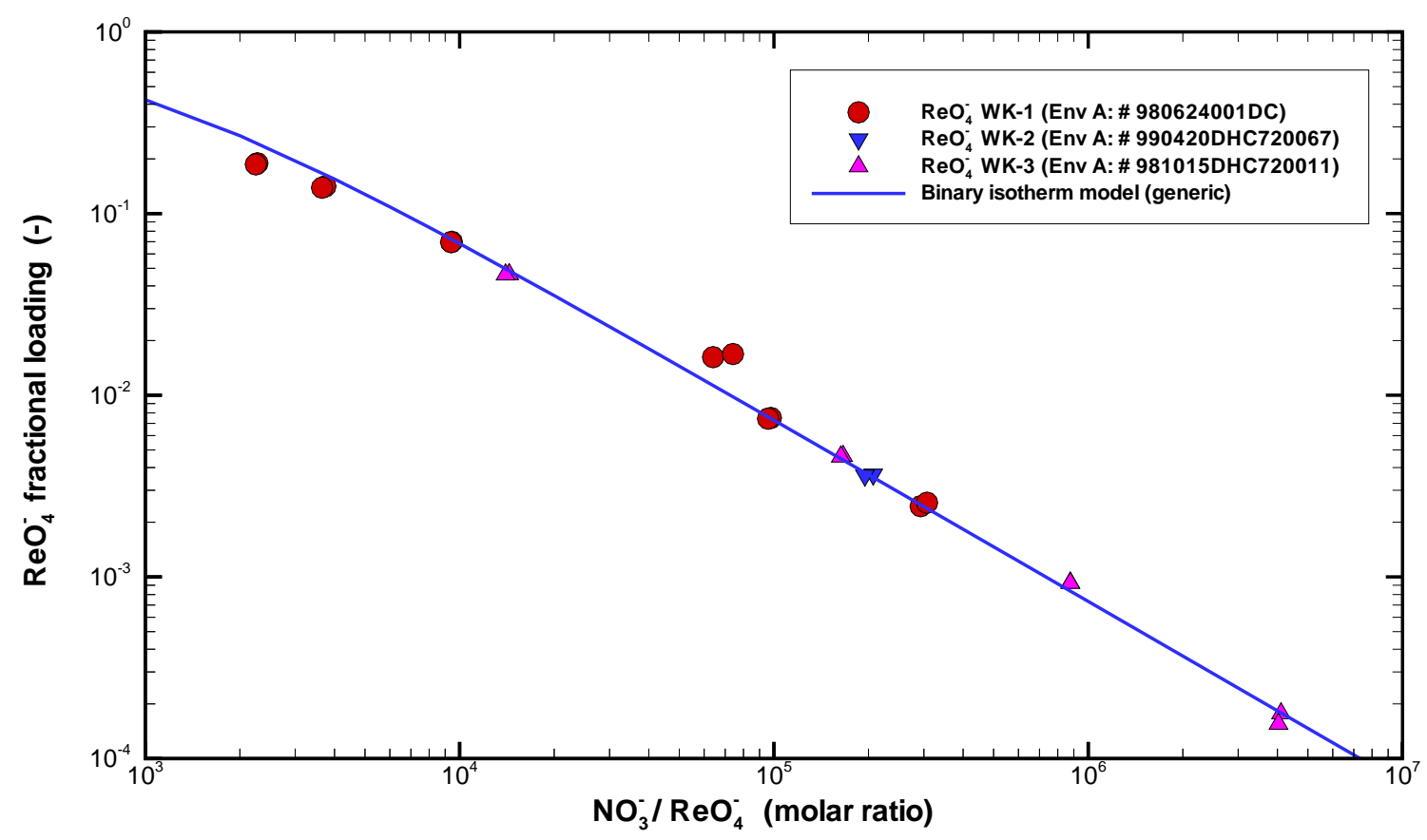

Figure 4-4. Variation in measured perrhenate fractional loadings on SuperLig ${ }^{\circledR} 639$ resin with respect to its final molar ratio with nitrate. The database shown contains data taken from three different batches using the same Envelope A waste simulant (King et al., 2000a).

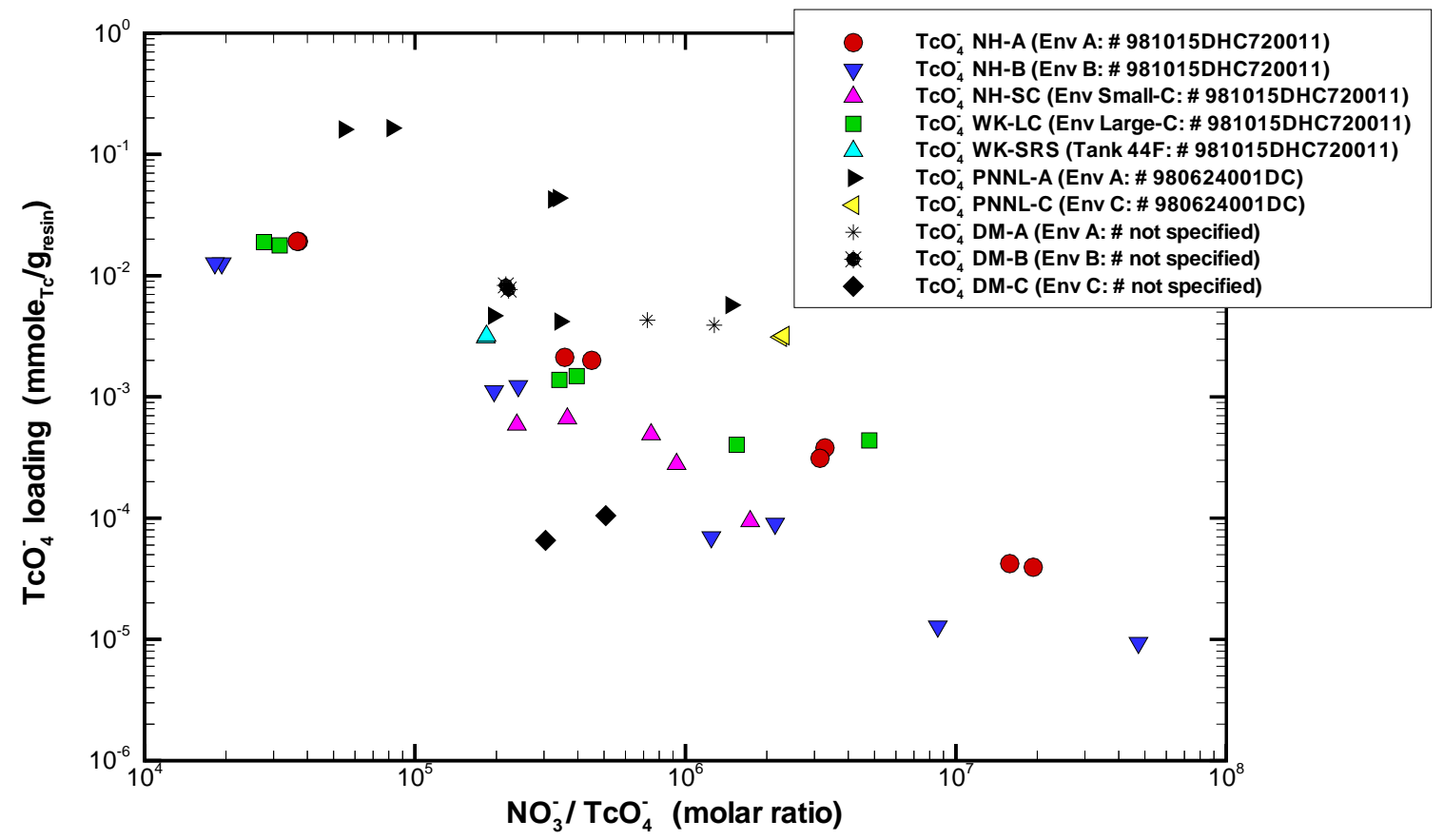

Figure 4-5. Variation in measured pertechnetate loadings on SuperLig ${ }^{\circledR} 639$ resin with respect to its final molar ratio with nitrate. The database shown contains Envelope A, B, and C data taken from two different sites and five different batches for a total of 47 data points. 


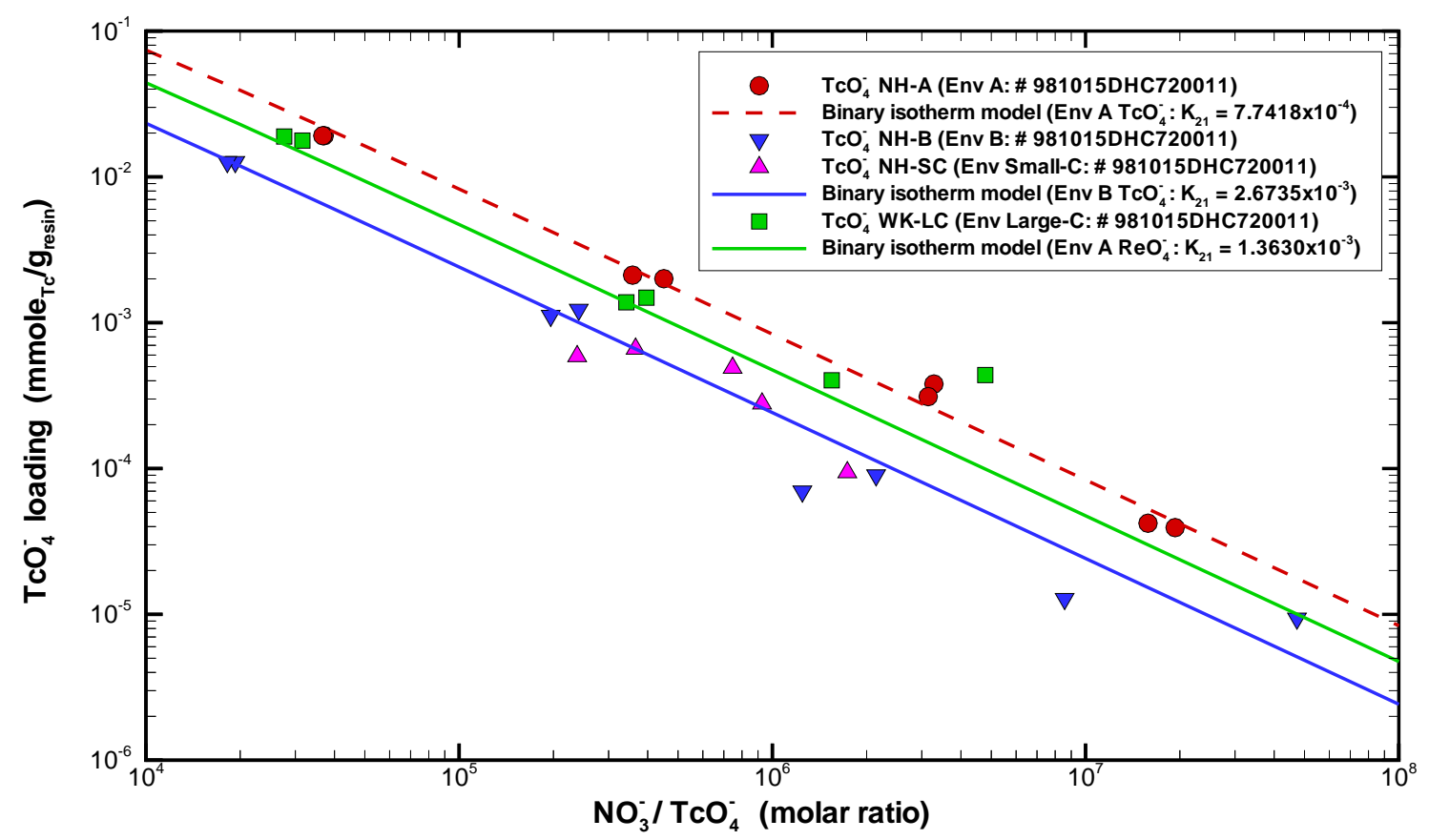

Figure 4-6. Variation in measured pertechnetate loadings on SuperLig ${ }^{\circledR} 639$ resin with respect to its final molar ratio with nitrate. The database shown is for the same batch ID (\# 981015DHC720011) contacted with Envelope A, B, and C samples.

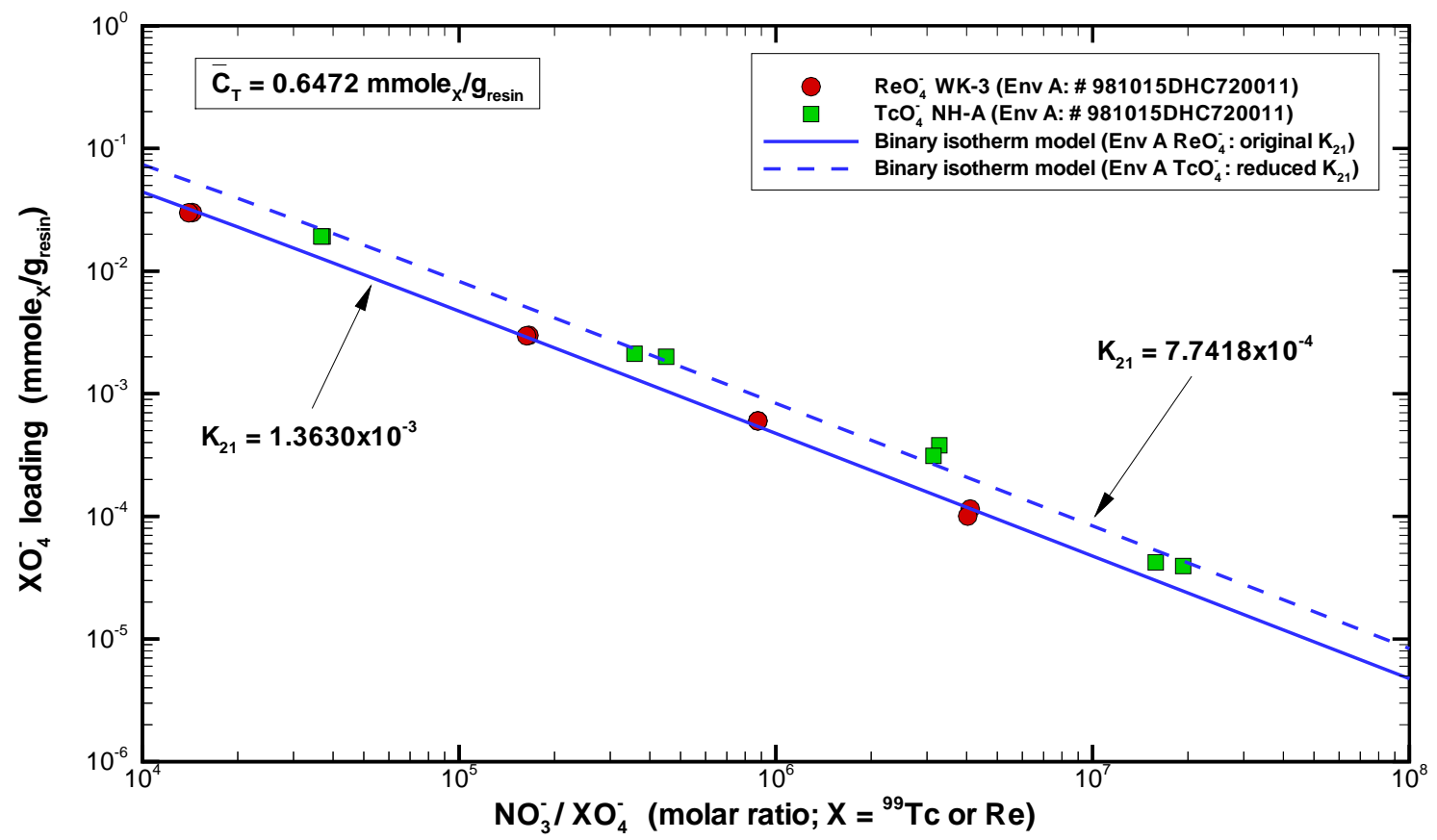

Figure 4-7. A comparison of measured to predicted pertechnetate and perrhenate loadings on SuperLig ${ }^{\circledR}$ 639 resin with respect to their final molar ratios with nitrate. The database is for batch ID (\# 981015DHC720011) contacted with Env. A simulant (WK-3) and sample (NH-A). 


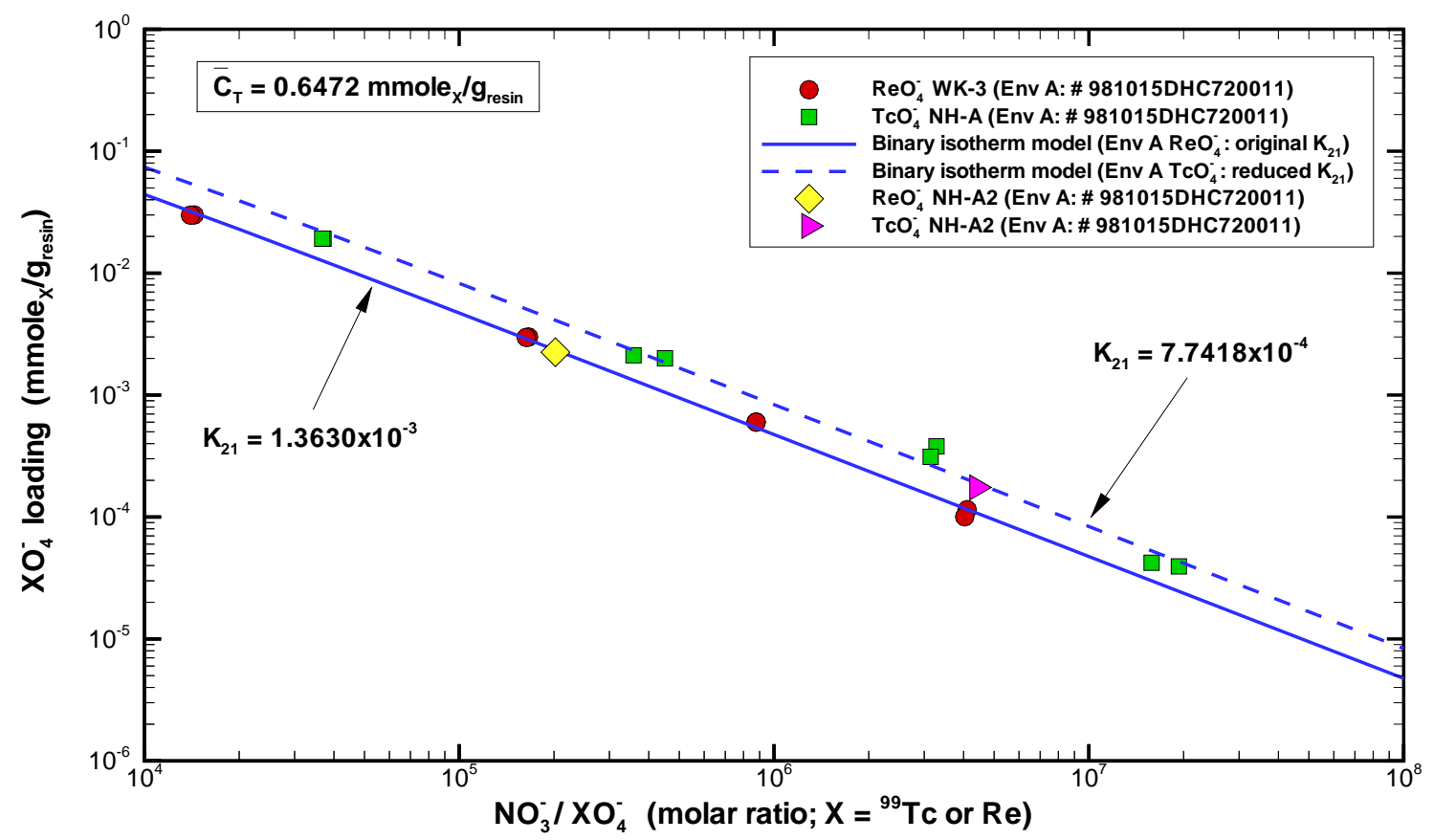

Figure 4-8. A comparison of measured pertechnetate and perrhenate loadings on SuperLig ${ }^{\circledR} 639$ resin with respect to their final molar ratios with nitrate. The database is for batch ID (\# 981015DHC720011) contacted with Env. A simulant (WK-3) and samples (NH-A, A2).

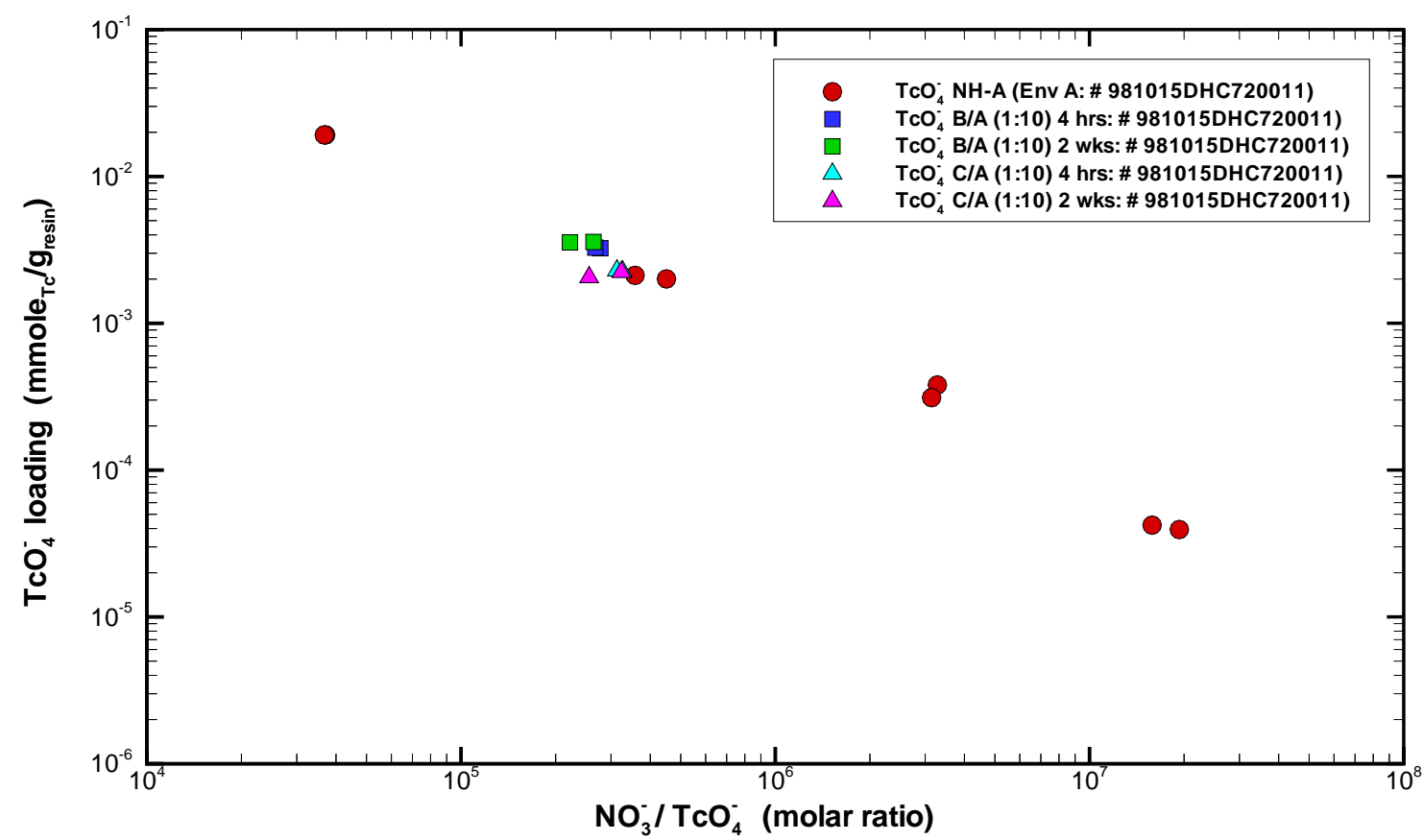

Figure 4-9. Variation in measured pertechnetate loadings on SuperLig ${ }^{\circledR} 639$ resin with respect to its final molar ratio with nitrate. The database shown is for batch ID (\# 981015DHC720011) and various mixed envelope samples compared to the pure Envelope A sample. 


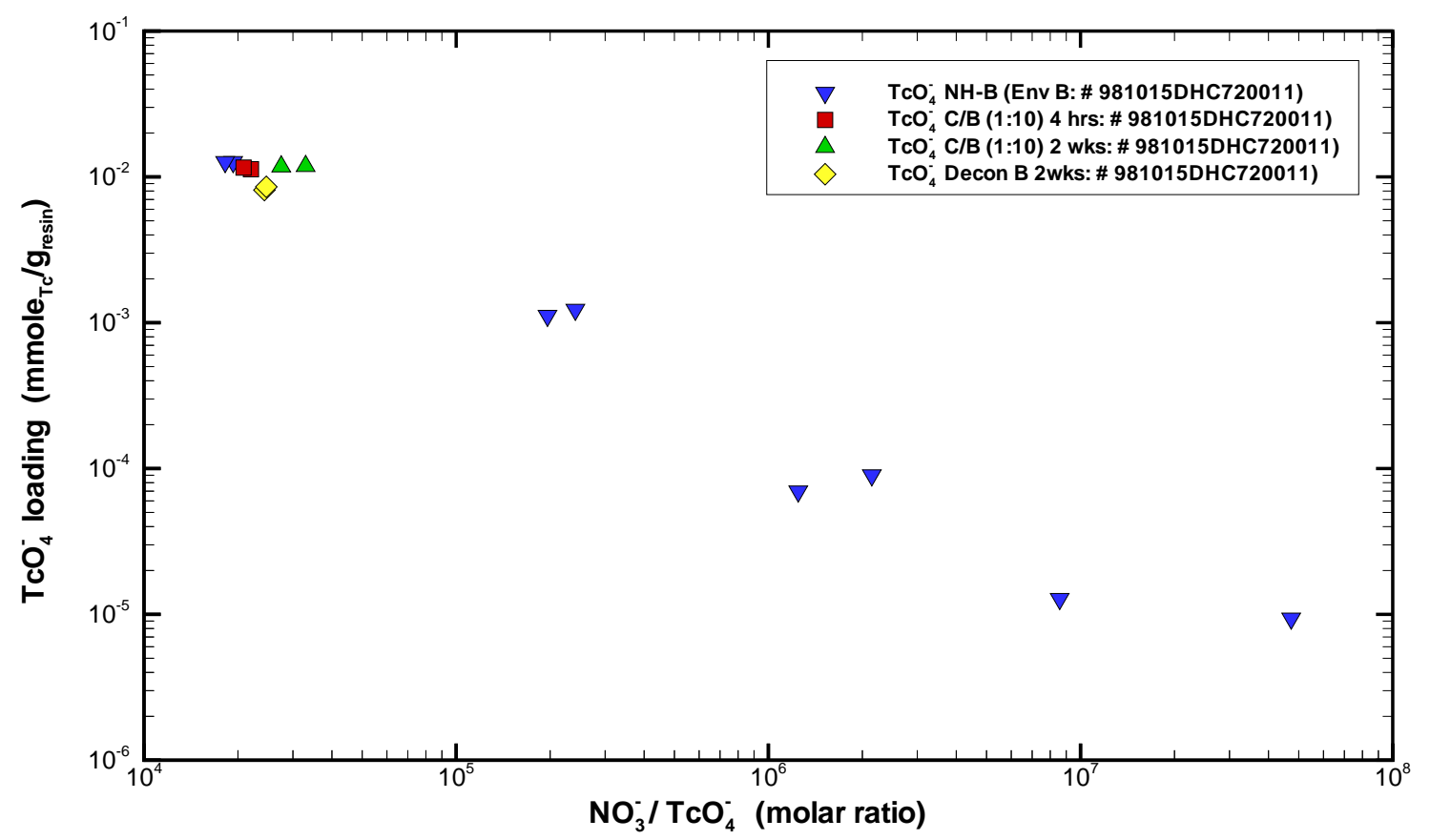

Figure 4-10. Variation in measured pertechnetate loadings on SuperLig ${ }^{\circledR} 639$ resin with respect to its final molar ratio with nitrate. The database is for batch ID (\# 981015DHC720011) and various mixed envelope samples compared to the pure Envelope B sample.

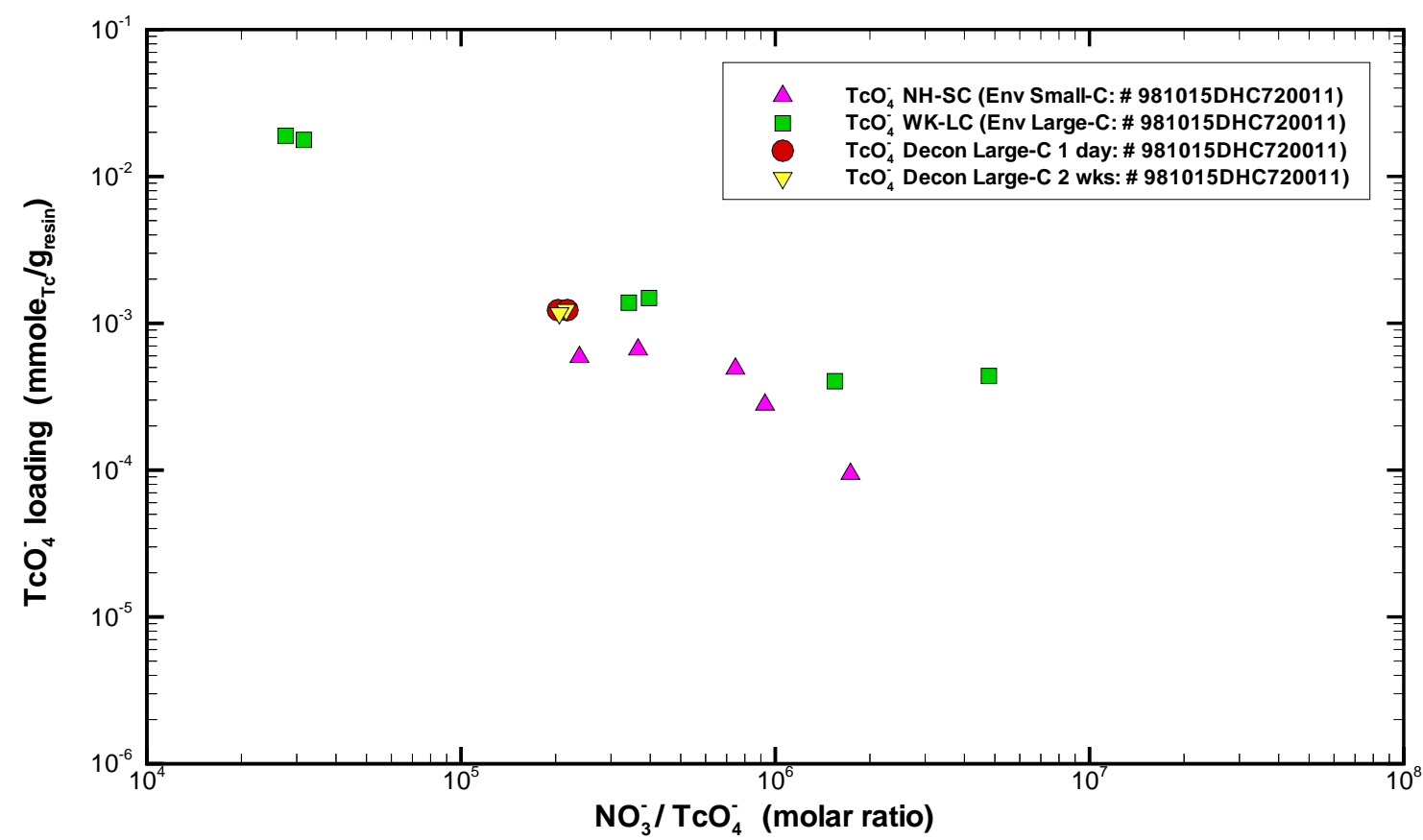

Figure 4-11. Variation in measured pertechnetate loadings on SuperLig ${ }^{\circledR} 639$ resin with respect to its final molar ratio with nitrate. The database is for batch ID (\# 981015DHC720011) and decontaminated Envelope C samples compared to the pure Envelope C samples. 


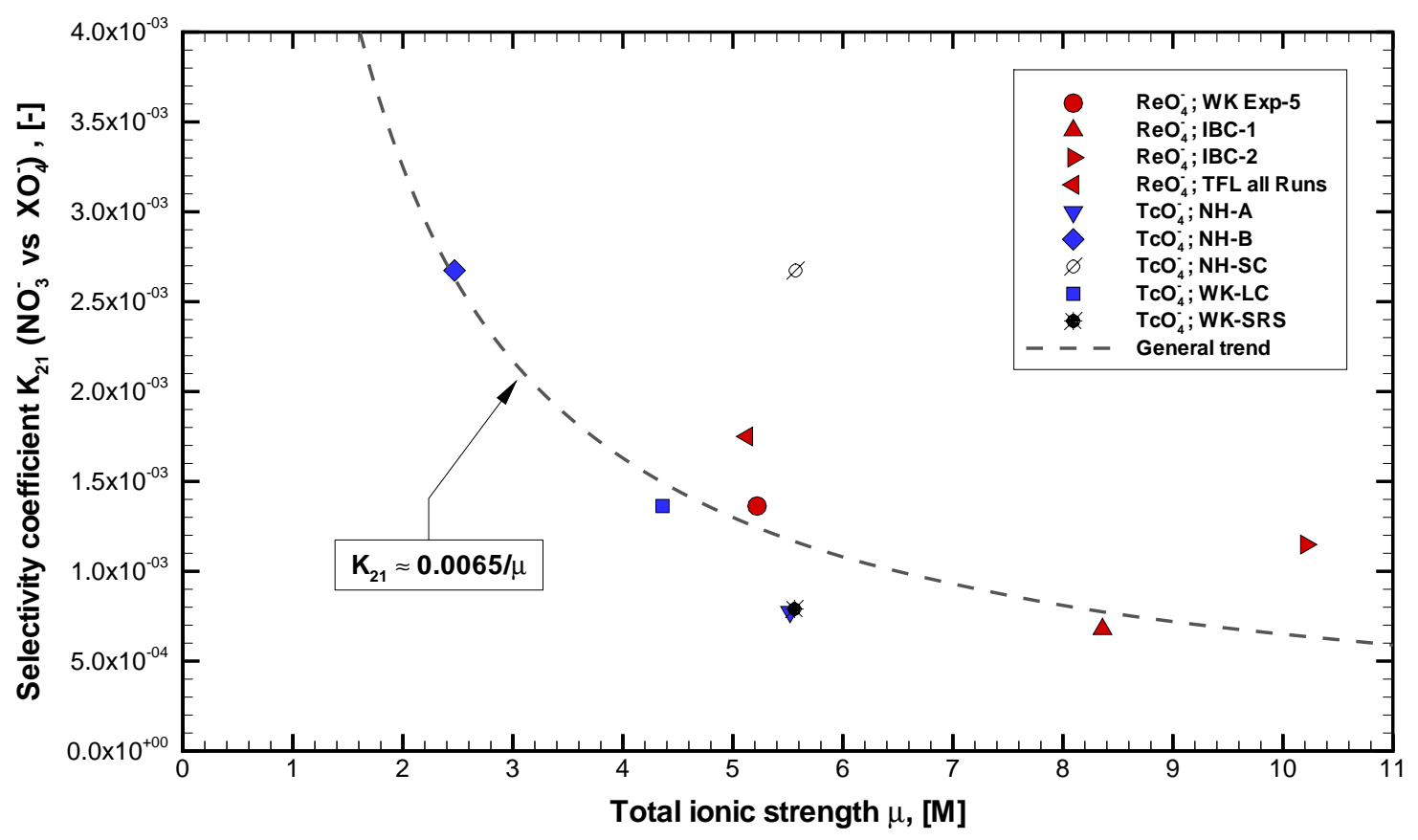

Figure 4-12. Variation in binary selectivity coefficient for nitrate and pertechnetate (or perrhenate) on SuperLig ${ }^{\circledR} 639$ resin with respect to a rough estimate of the total ionic strength of the liquid-phase solution (a general trend function is also provided).

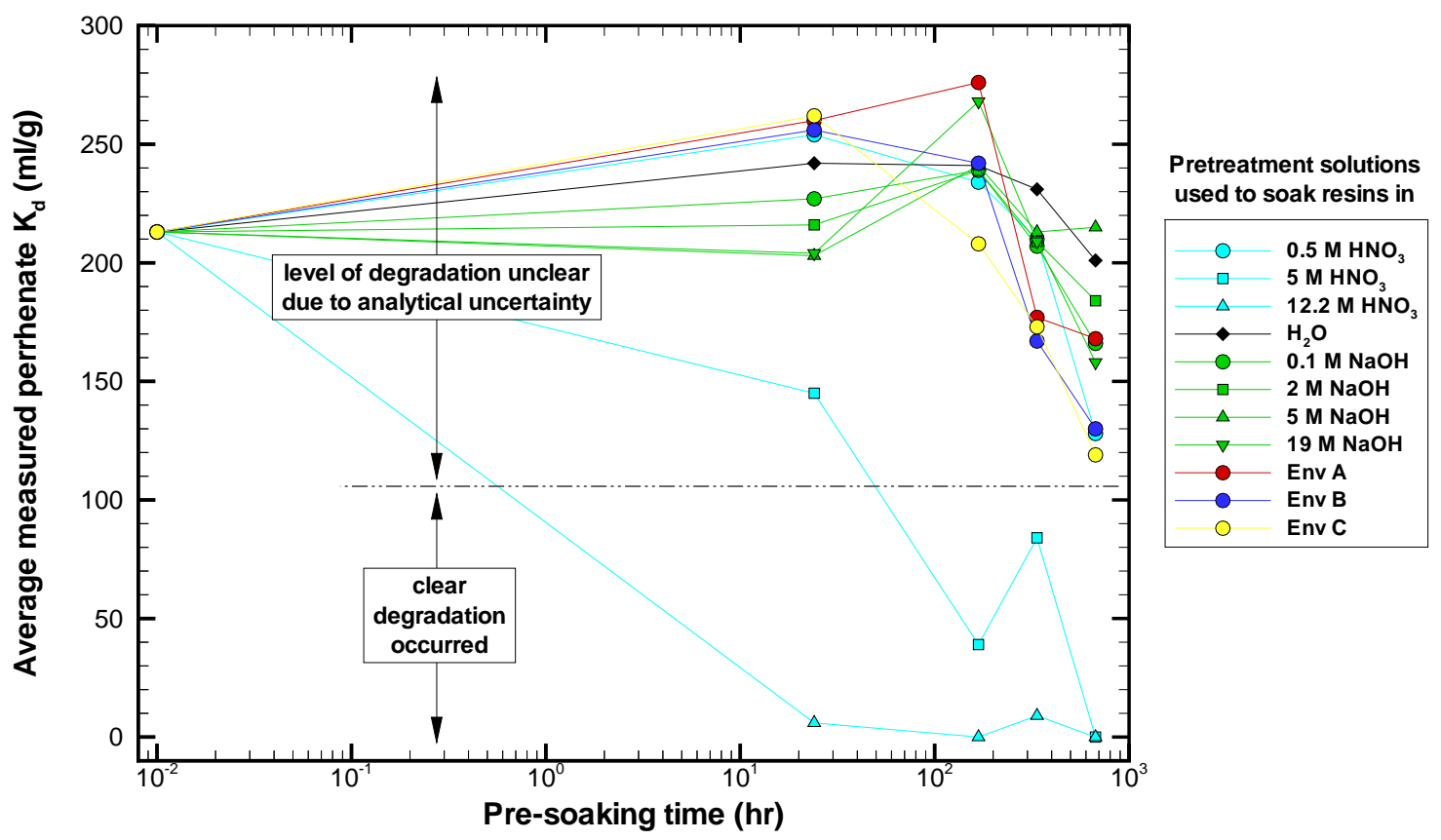

Figure 4-13. Impact of chemical exposure to perrhenate $\mathrm{K}_{d}$ ' $\mathrm{S}$ in a simulated Envelope $\mathrm{A}$ waste by presoaking of SuperLig ${ }^{\circledR} 639$ resin in various ionic solutions (Bruening, 2000c). 
Preliminary Ion Exchange Modeling for Removal of Technetium from Revision (Date):

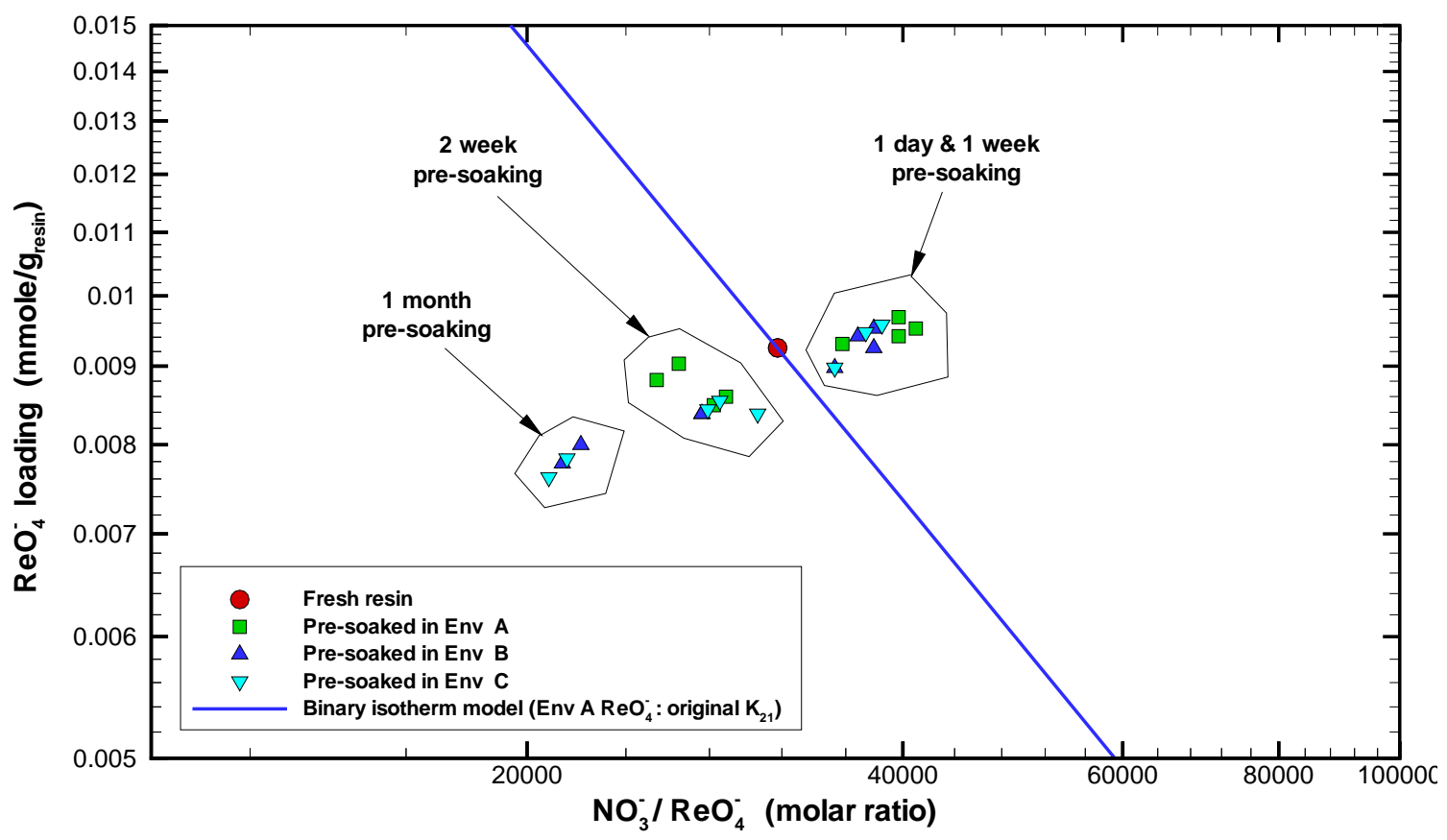

Figure 4-14. A direct comparison of predicted versus measured perrhenate loadings on pre-soaked SuperLig ${ }^{\circledR} 639$ resin for a sample of Envelope A waste (Bruening, 2000c). 


\subsection{Column Properties}

Certain material properties (such as, resin particle density and total ionic capacity) are unique to the ion-exchange material and vary only between batches. On the other hand, composite properties associated with an ion-exchange column (such as, bed density or porosities) are inherently column specific resulting from how it was packed for example. Even when different columns are made from the same batch of resin, column properties can and will vary. During operation upflow and then downflow can result in changes in particle packing arrangements (see, Steimke, 2000). During operational cycles where a significant variation in total ionic strength of the feed occurs, the active bed size of a column can change. The discussion that follows focuses on the column properties required to perform column transport simulations during the loading phase of a column cycle.

\subsection{Basic Constraint Functions}

Based on geometrical considerations not all densities and porosities are independent. The following two expressions place constraints on the densities and porosities:

$$
\varepsilon_{\mathrm{T}}=\varepsilon_{\mathrm{b}}+\left(1-\varepsilon_{\mathrm{b}}\right) \varepsilon_{\mathrm{p}},
$$

and

$$
\rho_{\mathrm{b}}=\rho_{\mathrm{s}}\left(1-\varepsilon_{\mathrm{T}}\right)
$$

where

$$
\begin{array}{ll}
\varepsilon_{\mathrm{T}} & - \text { total porosity of active column, [-] } \\
\varepsilon_{\mathrm{b}} & - \text { bed porosity of active column, [-] } \\
\varepsilon_{\mathrm{p}} & - \text { pore porosity of resin particles, [-] } \\
\rho_{\mathrm{b}} & - \text { bed density of active column, } \mathrm{g} / \mathrm{ml} \\
\rho_{\mathrm{s}} & - \text { solid (particle) density of resin, } \mathrm{g} / \mathrm{ml}
\end{array}
$$

and

$$
\rho_{\mathrm{b}} \equiv \frac{\mathrm{m}_{\mathrm{resin}}}{\mathrm{V}_{\mathrm{bed}}}
$$

For the five variables listed above only three are independent. The various porosities used in Eq. (5-1) are defined as:

$$
\varepsilon_{\mathrm{b}}=\frac{\mathrm{V}_{\text {void }}-\mathrm{V}_{\text {pore }}}{\mathrm{V}_{\text {bed }}} ; \quad \varepsilon_{\mathrm{p}}=\frac{\mathrm{V}_{\text {pore }}}{\mathrm{V}_{\text {part }}} ; \quad \varepsilon_{\mathrm{T}}=\frac{\mathrm{V}_{\text {void }}}{\mathrm{V}_{\text {bed }}}=\frac{\mathrm{V}_{\text {bed }}-\mathrm{V}_{\text {sld }}}{\mathrm{V}_{\text {bed }}},
$$

where 


$$
\begin{array}{ll}
\mathrm{V}_{\text {bed }} & \text { - total volume of active (bed) column, } \mathrm{ml} \\
\mathrm{V}_{\text {void }} & \text { - total volume of voids within active column, } \mathrm{ml} \\
\mathrm{V}_{\text {pore }} & \text { - total volume of pores within particles, } \mathrm{ml} \\
\mathrm{V}_{\text {part }} & \text { - total volume of particles within active column, } \mathrm{ml} \\
\mathrm{V}_{\text {sld }} & \text { - total volume of solid resin within active column, } \mathrm{ml}
\end{array}
$$

\subsection{Densities}

The particle ("material") densities of only two of the resins used in the various batch specific contact and column tests have been reported (i.e., measurements based on buoyancy studies by Hassan et al., 1999a). A summary of their results is given in Table 5-1. As Eq. (5-2) indicates, particle density can be used to assist in determining the total porosity of a packed bed.

The actual amount of resin present within a column is a parameter of prime importance with respect to column performance (i.e., exit breakthrough curves). For the column studies assessed within this report no direct measure of the total amount of resin residing within the active beds was available for most columns (except for test cases TFL by Steimke et al., 2000 and WK-SRS by King et al., 2000b). For those columns whose original resin mass was not measured, the bed density was assumed to be the value reported during either batch contact testing or swelling/buoyancy testing consistent with its batch ID number (see bed densities listed in Table 5-1). The specific values for bed density used in the column simulations presented in this report are listed in Table 9-3 for the assessment cases and in Table 10-1 for the full-scale case.

The bed density used in column modeling applies to the its value under the feed conditions. During pretreatment and feed conditions the resin can swell and shrink. Swelling tests performed by Hassan et al. (1999a) indicate the SuperLig ${ }^{\circledR} 639$ resin experiences little volumetric changes when saturated with varying ionic strength solutions.

\subsection{Porosities}

No direct measured bed, pore (i.e., sometimes referred to as particle), or total porosities have been reported for the various column studies considered. Recent measurement of liquid void fractions for a SuperLig ${ }^{\circledR} 639$ resin packed column, batch ID (\# 981104DHC70215), has been reported by Bruening, R. L., 2000a. Three separate void measurements were made in an $\sim 5 \mathrm{M}$ $\mathrm{Na}^{+}$swollen state. As stated by Bruening, R. L. (2000a), these void fractions represent the volume fraction residing between the beads (particles) and do not include liquid volume within the beads themselves. These volume fractions correspond to bed porosity and the results of the tests are listed in Table 5-2. It is assumed that the average (i.e., nominal) bed porosity value of 0.357 applies to all column simulations considered in this report (except for the pilot-scale TFL columns where increased packing was achieved).

Based on Eq. (5-2) the total porosity of a column is known once the particle and bed densities are specified. Using the values presented in the above subsection and listed in Table 5-1, the total porosity becomes: 


$$
\varepsilon_{\mathrm{T}} \equiv 1-\frac{\rho_{\mathrm{b}}}{\rho_{\mathrm{s}}}
$$

where several values are given in Table 5-3. The nominal value for total porosity is set to the average value for batch ID's (\# 980624001DC) and (\# 981015DHC720011), 0.596. Based on Eq. (5-1) and the nominal bed porosity value of 0.357 , the nominal value for pore porosity becomes 0.371 .

For the pilot-scale TFL columns the increased bed density (i.e., $0.527 \mathrm{~g} / \mathrm{ml}$ ) results in a lower total porosity of 0.541. To compute individual bed and pore porosities (using Eq. (5-1)) we assume that the better resin packing only effects particle arrangement resulting in a lower bed porosity, while pore porosity is unaltered. This results in a value for bed porosity of 0.269 for the TFL columns (while pore porosity remains at 0.371 ).

The value for particle density used in Eq. (5-5) corresponds to the measured value in water where it is assumed that this value does not vary appreciably with respect to ionic strength. A range of possible void distributions exists between the pore and bed porosities constrained by Eq. (5-1) and any specified total porosity computed by Eq. (5-5). In Table 5-4 Eq. (5-1) is used to compute pore porosity for the three different total porosity values tabulated in Table 5-4. The results provided in Table 5-4 are also plotted in Figure 5-1. In Figure 5-1 the estimated region where the majority of columns operate is highlighted with an ellipse. This region is based on the range of values observed for the various materials tested.

Also shown in Figure 5-1 is the average measured porosity for dense packing of mono-sized hard spheres (i.e., widely accepted value of 0.363) as reported by German (1989, page 106). Two thirds of the reported values lie between 0.356 and 0.364 . Greater packing fractions (or smaller bed porosities) can be achieved when multi-sized spheres are employed. Given the non-uniform sizes of the resin particles, no specific lower limit can be uniquely specified. However, the nominal bed porosity value of 0.357 versus the mono-sized value of 0.363 appears reasonable. The greater packing of the TFL columns resulting in a bed porosity value of 0.269 also appears reasonable when particle size distribution data is considered (see, German, 1989, page 147). 
Table 5-1. Batch specific properties for SuperLig ${ }^{\circledR} 639$ resins.

\begin{tabular}{|c|c|c|c|c|}
\hline $\begin{array}{l}\text { Batch } \\
\text { ID }\end{array}$ & $\begin{array}{r}\text { Particle } \\
\text { density } \\
(\mathrm{g} / \mathrm{ml})\end{array}$ & $\begin{array}{c}\text { Dry bed } \\
\text { density, } \\
(\mathrm{g} / \mathrm{ml})\end{array}$ & $\begin{array}{c}\text { "F" factor } \\
\text { at } \sim \mathbf{8 5}{ }^{\circ} \mathrm{C} \\
(-)\end{array}$ & Reference report \\
\hline 980624001DC & 1.219 & 0.489 & 0.986 & King et al., 2000a \\
\hline 980624001DC & - & 0.467 & $0.9334^{b}$ & Kurath et al., 1999 \\
\hline 981015DHC720011 & 1.147 & 0.468 & 0.987 & King et al., 2000a \\
\hline 990420DHC720067 & - & 0.479 & - & King et al., 2000a \\
\hline not reported & - & 0.40 & - & $\begin{array}{c}\text { IBC Advanced } \\
\text { Technologies, } 1996\end{array}$ \\
\hline $\begin{array}{c}\text { 50:50 mix of } \\
\text { 990420DHC720067 } \\
\text { 981015DHC720011 }\end{array}$ & - & 0.527 & - & Steimke et al., 2000 \\
\hline $\begin{array}{c}\text { 50:50 mix of } \\
\text { 990420DHC720067 } \\
\text { 981015DHC720011 }\end{array}$ & - & 0.4788 & - & King et al., 2000b \\
\hline received $12 / 12 / 96$ & - & 0.40 & 0.804 & $\begin{array}{c}\text { Hassan and } \\
\text { McCabe, 1997c }\end{array}$ \\
\hline received 6/2/97 & - & - & 1.00 & McCabe, 1997 \\
\hline not reported & - & 0.40 & 0.804 & $\begin{array}{c}\text { Hassan and } \\
\text { McCabe, } 1998\end{array}$ \\
\hline Average resin & & & & \\
\hline
\end{tabular}

a Based on buoyancy tests of "as received" resins (Hassan et al., 1999a).

$\mathrm{b}$ The $\mathrm{F}$ factor listed is for $\sim 105^{\circ} \mathrm{C}$ conditions. Earlier measurements of the $\mathrm{F}$ factor at $\sim 85^{\circ} \mathrm{C}$ had a value of 0.9855 .

Table 5-2. Measured bed porosities for a SuperLig ${ }^{\circledR} 639$ resin packed column ${ }^{\mathrm{a}}$.

\begin{tabular}{|c|c|c|c|}
\hline $\begin{array}{c}\text { Measurement } \\
\mathbf{1}\end{array}$ & $\begin{array}{c}\text { Measurement } \\
\mathbf{2}\end{array}$ & $\begin{array}{c}\text { Measurement } \\
\mathbf{3}\end{array}$ & $\begin{array}{c}\text { Average } \\
\text { value }\end{array}$ \\
\hline 0.366 & 0.357 & 0.349 & 0.357 \\
\hline
\end{tabular}

${ }^{a}$ Based on batch ID (\# 981104DHC70215) resin and reported by Bruening, R. L. (2000a). 
Table 5-3. Computed total porosities for various SuperLig ${ }^{\circledR} 639$ resin arrangements.

\begin{tabular}{|c|c|c|c|}
\hline $\begin{array}{c}\text { Batch } \\
\text { ID }\end{array}$ & $\begin{array}{c}\text { Particle density, } \\
(\mathbf{g} / \mathbf{m l})\end{array}$ & $\begin{array}{c}\text { Dry bed density, } \\
(\mathbf{g} / \mathbf{m l})\end{array}$ & $\begin{array}{c}\text { Total porosity } \\
(-)\end{array}$ \\
\hline \hline 980624001DC & 1.219 & 0.489 & 0.599 \\
\hline 981015DHC720011 & 1.147 & 0.468 & 0.592 \\
\hline $\begin{array}{c}\text { (TFL columns) } \\
\text { 50:50 mix of } \\
\text { 990420DHC720067 } \\
\text { 981015DHC720011 }\end{array}$ & $\begin{array}{c}1.147 \\
\text { (assumed) }\end{array}$ & 0.527 & 0.541 \\
\hline Nominal setting & - & - & 0.596 \\
\hline
\end{tabular}

Table 5-4. Pore porosity as a function of bed porosity at three different total porosity values for the SuperLig $^{\circledR} 639$ resin.

\begin{tabular}{|c|c|c|c|}
\hline $\begin{array}{c}\text { Bed } \\
\text { porosity } \\
(-)\end{array}$ & $\begin{array}{c}\text { Pore porosity } \\
\text { given } \boldsymbol{\varepsilon}_{\mathbf{T}}=\mathbf{0 . 5 9 9} \\
(-)\end{array}$ & $\begin{array}{c}\text { Pore porosity } \\
\text { given } \boldsymbol{\varepsilon}_{\mathbf{T}}=\mathbf{0 . 5 9 2} \\
(-)\end{array}$ & $\begin{array}{c}\text { Pore porosity } \\
\text { given } \boldsymbol{\varepsilon}_{\mathbf{T}}=\mathbf{0 . 5 4 1} \\
(-)\end{array}$ \\
\hline 0.00 & 0.598852 & 0.591979 & 0.540541 \\
\hline 0.05 & 0.577738 & 0.570504 & 0.516358 \\
\hline 0.15 & 0.528061 & 0.519975 & 0.459459 \\
\hline 0.20 & 0.498564 & 0.489974 & 0.425676 \\
\hline 0.25 & 0.465135 & 0.455972 & 0.387387 \\
\hline 0.30 & 0.426931 & 0.417113 & 0.343629 \\
\hline 0.35 & 0.382848 & 0.372276 & 0.293139 \\
\hline 0.40 & 0.331419 & 0.319965 & 0.234234 \\
\hline 0.45 & 0.270639 & 0.258144 & 0.164619 \\
\hline 0.50 & 0.197703 & 0.183958 & 0.081081 \\
\hline 0.55 & 0.108559 & 0.093287 & na \\
\hline
\end{tabular}

a This total porosity value corresponds to the value estimated for the TFL columns where better resin packing was achieved as discussed in Section 9. 


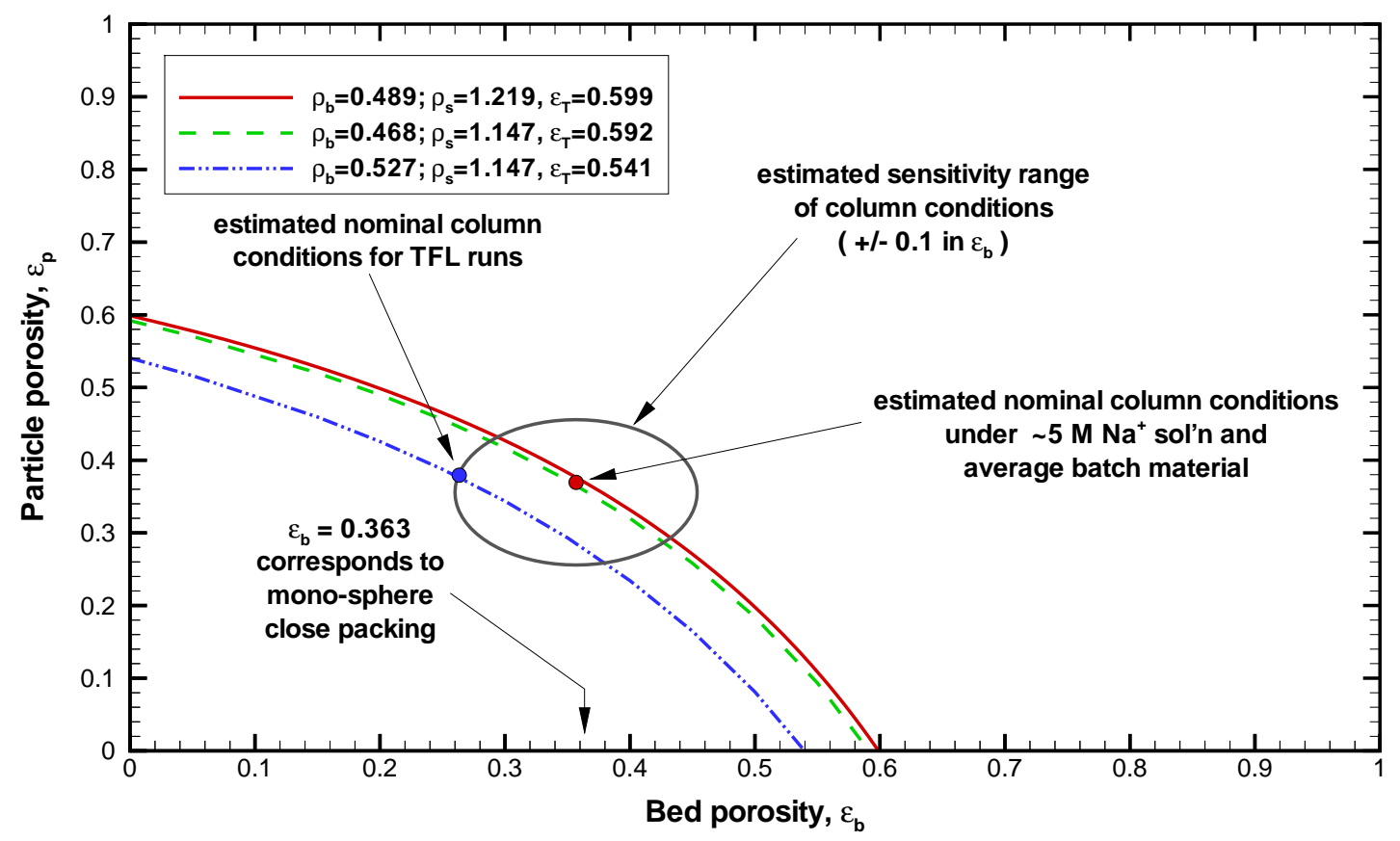

Figure 5-1. Functional behavior between bed porosity and pore porosity for the SuperLig ${ }^{\circledR} 639$ resin highlighting the nominal and sensitivity study values used in column simulations. 


\subsection{Particle Size Distributions}

The majority of particle size distribution measurements made for SuperLig ${ }^{\circledR} 639$ has been performed using traditional sieve analyses with dry "as received" resin or more recent laser technologies. Unfortunately, reported data using both methods when applied to SuperLig ${ }^{\circledR} 639$ resins have resulted in overestimation and underestimation of the average particle radius, respectively. To obtain a more confident value of the average particle radius, visual methods were employed where three of the available batch ID's were tested. Based on these visual tests a mean particle radius for SuperLig ${ }^{\circledR} 639$ resins was estimated to be $377 \mu \mathrm{m}$ and is employed in the column modeling as its nominal value.

The swelling characteristics of SuperLig $^{\circledR} 639$ resins (batch ID \#980624001DC) during pretreatment (i.e., when immersed in acid and caustic pretreatment solutions) is reported by Hassan et al. (1999a). Swollen resin volume per gram of resin was measured for "as received" resin when placed in a $0.25 \mathrm{Na}^{+}$simulated waste solution and when placed in a $5.0 \mathrm{Na}^{+}$solution. The SuperLig $^{\circledR} 639$ resin showed very little variation in volume measurements and will be considered to have bed densities that are not dependent on total ionic strength.

The SuperLig ${ }^{\circledR} 639$ resin is approximately spherical as assumed in the governing equations used to model the ion-exchange process. The column models also assume that the mass transfer and pore diffusion processes can be modeled using a single average size particle to represent the entire population of resin particles. Given the level of knowledge with regard to particle size and shape distributions, the above assumptions should be acceptable.

\subsection{Sieve Analysis Data}

As mentioned above dry sieve analysis data for one of the batches have been reported. Table 6-1 contains sieve analysis data for this batch of resin (i.e., \# 981015DHC720011) reported by Hassan et al. (2000b). The distribution data listed in Table 6-1 was used to generate distribution functions for each of the two samples. The computed distribution functions for each sample are plotted in Figure 6-1.

As illustrated in each of the plots in Figure 6-1, a wide range of particles sizes exist within a given sample. Typically, the actual distribution of sizes between batches also varies significantly. For use in column modeling an estimated mean particle radius is required. Mean particle radii were computed from these distribution functions using:

$$
\left\langle R_{p}\right\rangle=\frac{\int_{0}^{\infty}\left[R_{p}\right] f\left(R_{p}\right) d R_{p}}{\int_{0}^{\infty} f\left(R_{p}\right) d R_{p}} .
$$


Computed values based on Eq. (6-1) are labeled in Figure 6-1 and listed in Table 6-1. The data from this sieve analysis and from other batches that are available (e.g., see Kurath et al., 1999), in general are very coarse. As Figure 6-1 points out, too much weight is given to the upper sieve range resulting in overestimation of the mean particle radius.

\subsection{Laser Technology Data}

The most recent particle size distribution data for the SuperLig ${ }^{\circledR} 639$ resin were published by its manufacturer (IBC, Inc.) for batch (\# 981104DHC70215) in Bruening (2000a). Bruening (2000a) list particle size measurements for this resin in its swollen state in a $5 \mathrm{M} \mathrm{Na}^{+}$solution (i.e., specifically $3 \mathrm{M} \mathrm{NaOH} / 2 \mathrm{M} \mathrm{NaNO}_{3}$ ). Three separate replicate measurements were made for two different resin samples of the same batch.

Percent by volume for a series of particle size ranges were provided by Bruening (2000a). These volume fractions were first normalized and then converted into particle number fractions for each size bracket using the relationship:

$$
\mathrm{N}_{\mathrm{i}}=\frac{3 \mathrm{~V}_{\mathrm{i}}}{4 \pi<\mathrm{R}_{\mathrm{p}}>_{\mathrm{i}}^{3}},
$$

where the average particle radius for each size bracket was set to the bracket's mid-point value. Equation (6-2) assumes that all the particles within a given $\mathrm{i}^{\text {th }}$ size bracket are all equal and spherical. The resulting number fractions are then used as weights for estimating the mean particle radius for each replicate of each sample. The results of these conversions are tabulated in Table 6-2.

The volume fraction measurements for replicate 1 for both samples are plotted in Figure 6-2. Bruening (2000a) indicates that the measurements were made using a laser instrument. All measured distributions appear to be either continuing to rise, or just passing their mode, at their upper particle size range suggesting that the laser instrument saturated at some upper limit. Average particle radiuses of 305 and $312 \mu \mathrm{m}$ were computed for samples 1 and 2, respectively. However, these estimates are probably low since the laser instrument most likely saturated at high particle diameters.

\subsection{Visual Analysis Data}

As discussed above, the available sieve analysis data is in general too coarse resulting in overestimation of the mean particle radius. The laser instrumentation used to date appears to saturate prior to reaching the largest particle sizes in the population resulting in underestimation of the mean particle radius. Therefore, to obtain a better estimate of the mean particle radius three different batch ID's were measured visually (i.e., the old fashion way!). The results of these measurements are tabulated in Table 6-3.

For each batch ID five different samples were drawn from its stockpile and then arranged in a straight line along a metric-ruler. The number of particles contained within a specified length 
was counted and the results of this visual method are given in Table 6-3. An adequate number of particles (i.e., 70 to 182) were lined up such that reasonable repeatability was achieved as seen in Table 6-3. To the eye, batch ID (\# 981015DHC720011) had a wider range of particle sizes than the other two batch ID's. The results in Table 6-3 confirm this visual observation, as well. Even though these measurements are perhaps crude, they are believed to be more representative of the mean particle radius than either technique discussed above.

Table 6-1. Particle size distributions of SuperLig ${ }^{\circledR} 639$ resin with batch ID (\# 981015DHC720011) based on dry sieve analyses. ${ }^{\mathrm{a}}$

\begin{tabular}{|c|c|c|c|c|}
\hline $\begin{array}{c}\text { Mesh opening } \\
\quad(\mu \mathrm{m})\end{array}$ & $\begin{array}{l}\text { Size range } \\
\quad(\mu \mathrm{m})\end{array}$ & $\begin{array}{c}\text { Range mid-point } \\
\qquad(\mu \mathrm{m})\end{array}$ & $\begin{array}{c}\text { Sample-1 } \\
\text { wt } \%\end{array}$ & $\begin{array}{c}\text { Sample-2 } \\
\text { wt \% }\end{array}$ \\
\hline 0 & $0-177$ & - & - & - \\
\hline 177 & $177-210$ & 193.5 & 0.14 & 0.00 \\
\hline 210 & $210-297$ & 253.5 & 0.20 & 0.00 \\
\hline 297 & $297-420$ & 358.5 & 0.70 & 1.09 \\
\hline 420 & $420-595$ & 507.5 & 11.49 & 14.60 \\
\hline 595 & $595-2000$ & 1297.5 & 87.47 & 84.31 \\
\hline 2000 & - & - & - & - \\
\hline \multicolumn{3}{|c|}{ Mean particle radius $(\mu \mathrm{m})$} & 598 & 586 \\
\hline
\end{tabular}

"Sieve analysis performed on "as received" resins (Hassan et al., 2000b). 


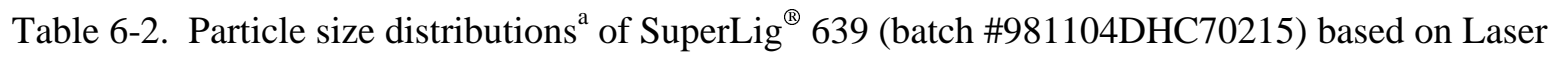
Technology.

\begin{tabular}{|c|c|c|c|c|c|}
\hline $\begin{array}{c}\text { Particle } \\
\text { diameter } \\
\text { range } \\
(\mu \mathrm{m})\end{array}$ & $\begin{array}{c}\text { Particle } \\
\text { diameter } \\
\text { midpoint } \\
(\mu \mathrm{m})\end{array}$ & $\begin{array}{c}\text { Sample 1 } \\
\text { average } \\
\text { volume \% }\end{array}$ & $\begin{array}{c}\text { Sample 1 } \\
\text { average } \\
\text { number \% }\end{array}$ & $\begin{array}{c}\text { Sample 2 } \\
\text { average } \\
\text { volume \% }\end{array}$ & $\begin{array}{c}\text { Sample 2 } \\
\text { average } \\
\text { number \% }\end{array}$ \\
\hline \hline$<410^{\mathrm{b}}$ & - & 0.00 & 0.00 & 0.00 & 0.00 \\
\hline $410-450$ & 430.0 & 0.57 & 1.76 & 0.59 & 1.97 \\
\hline $450-494$ & 472.0 & 3.83 & 9.00 & 3.09 & 7.82 \\
\hline $494-542$ & 518.0 & 10.17 & 18.08 & 7.86 & 15.04 \\
\hline $542-595$ & 568.5 & 16.27 & 21.88 & 13.52 & 19.58 \\
\hline $595-653$ & 624.0 & 19.51 & 19.83 & 18.26 & 19.99 \\
\hline $653-717$ & 685.0 & 18.84 & 14.48 & 19.89 & 16.46 \\
\hline $717-787$ & 752.0 & 14.84 & 8.62 & 17.19 & 10.75 \\
\hline $787-864$ & 825.5 & 9.67 & 4.25 & 11.83 & 5.59 \\
\hline $864-948$ & 906.0 & 6.31 & 2.10 & 7.78 & 2.78 \\
\hline \multicolumn{2}{|c|}{ Mean Radius $(\mu \mathrm{m})=$} & 305 & & 312 \\
\hline
\end{tabular}

${ }^{\text {a }}$ Laser analysis performed on resins in $3 \mathrm{M} \mathrm{NaOH} / 2 \mathrm{M} \mathrm{NaNO}_{3}$ solutions where the results are the average of three replicates and normalized, then converted from volume percent to number percent using Eq. (6-2).

${ }^{\mathrm{b}}$ Not detectable. 
Table 6-3. Particle size estimates ${ }^{\mathrm{a}}$ of SuperLig ${ }^{\circledR} 639$ based on visual measurements.

\begin{tabular}{|c|c|c|c|c|}
\hline $\begin{array}{l}\text { Batch } \\
\text { ID }\end{array}$ & $\begin{array}{c}\text { Number of } \\
\text { particles in } \\
\text { sample } \\
(-)\end{array}$ & $\begin{array}{l}\text { Measured } \\
\text { line length of } \\
\text { sample } \\
(\mathrm{mm})\end{array}$ & $\begin{array}{l}\text { Averaged } \\
\text { particle } \\
\text { diameter } \\
(\mu \mathrm{m})\end{array}$ & $\begin{array}{c}\text { Sample } \\
\text { averaged } \\
\text { particle radius } \\
(\mu \mathrm{m})\end{array}$ \\
\hline \multirow[t]{5}{*}{ 981015DHC720011 } & 70 & 54 & 771.4 & \\
\hline & 170 & 115 & 676.5 & \\
\hline & 130 & 90 & 692.3 & \\
\hline & 150 & 87 & 580.0 & \\
\hline & 155 & 109 & 703.2 & 342 \\
\hline \multirow[t]{5}{*}{ 980624001DC } & 124 & 90 & 725.8 & \\
\hline & 150 & 115 & 766.7 & \\
\hline & 172 & 125 & 726.7 & \\
\hline & 180 & 140 & 777.8 & \\
\hline & 182 & 140 & 769.2 & 377 \\
\hline \multirow[t]{5}{*}{ 990420DHC720067 } & 140 & 115 & 821.4 & \\
\hline & 172 & 135 & 784.9 & \\
\hline & 157 & 130 & 828.0 & \\
\hline & 153 & 135 & 882.4 & \\
\hline & 174 & 140 & 804.6 & 412 \\
\hline \multicolumn{4}{|c|}{ Mean Radius [used as the nominal value] $(\mu \mathrm{m})=$} & 377 \\
\hline
\end{tabular}

${ }^{a}$ Each population sample was placed along a straight line, butted up against each other, where the number of particles within the sample were counted and the total length of the line was measured. 


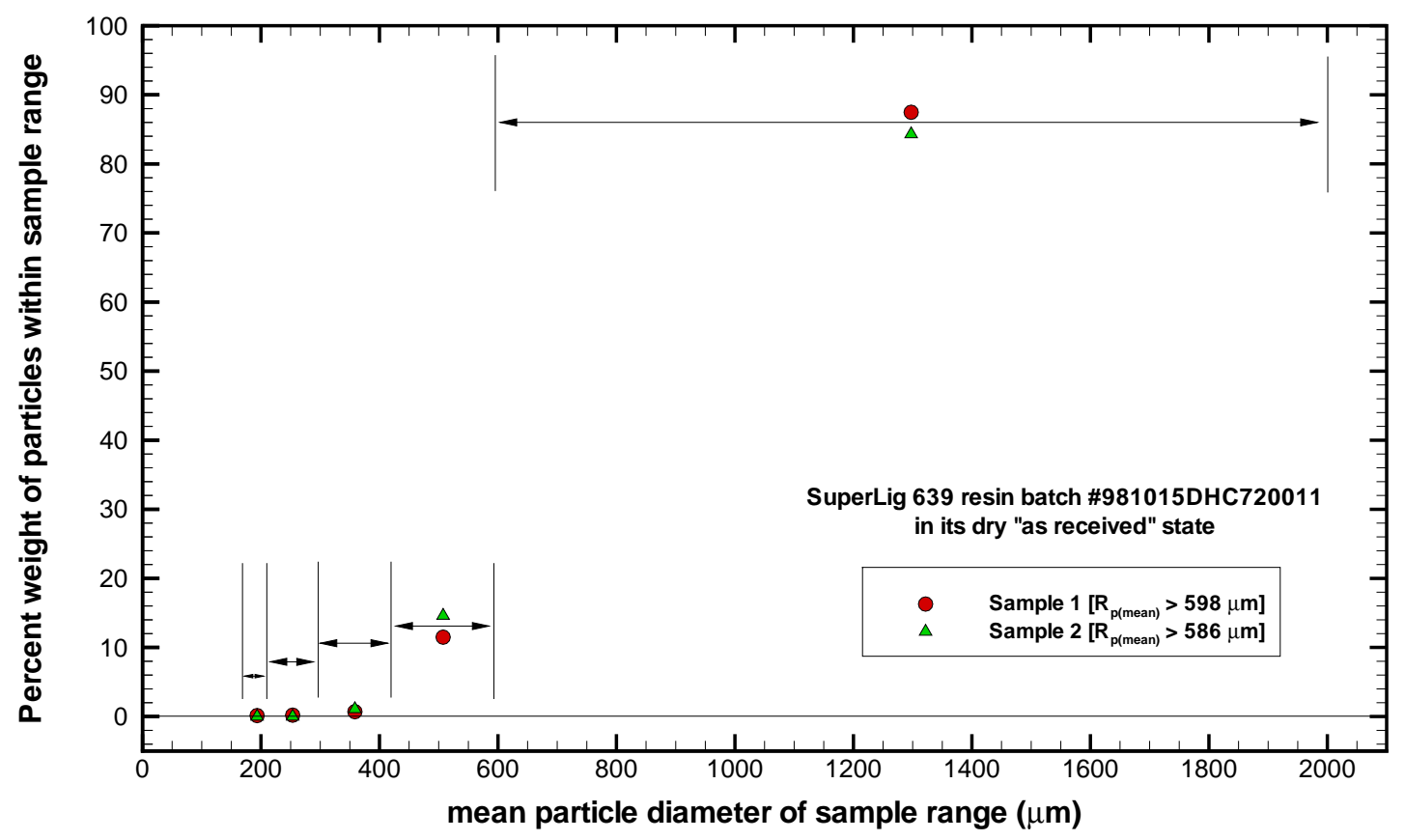

Figure 6-1. Weight fraction of particles as a function of sieve sizes for two specific samples of the SuperLig ${ }^{\circledR} 639$ resin (batch ID \#981015DHC720011) based on dry sieve analysis (data from Hassan et al., 2000b).

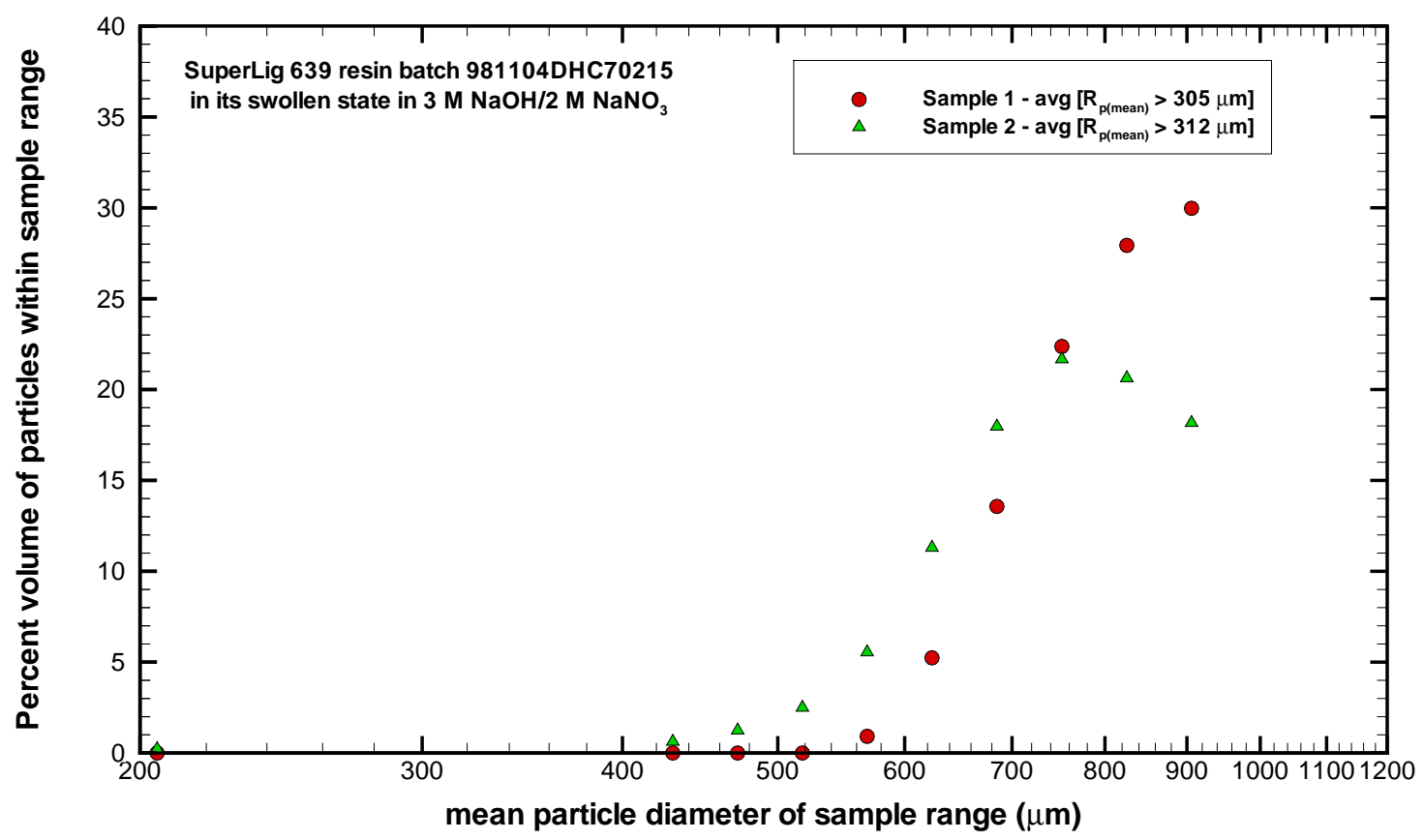

Figure 6-2. Volume fraction of particles as a function of particle size for two specific samples of the SuperLig ${ }^{\circledR} 639$ resin (batch \#981104DHC70215) based on laser technology under a $5 \mathrm{M}$ $\mathrm{Na}^{+}$solution (data from Bruening, 2000a). 


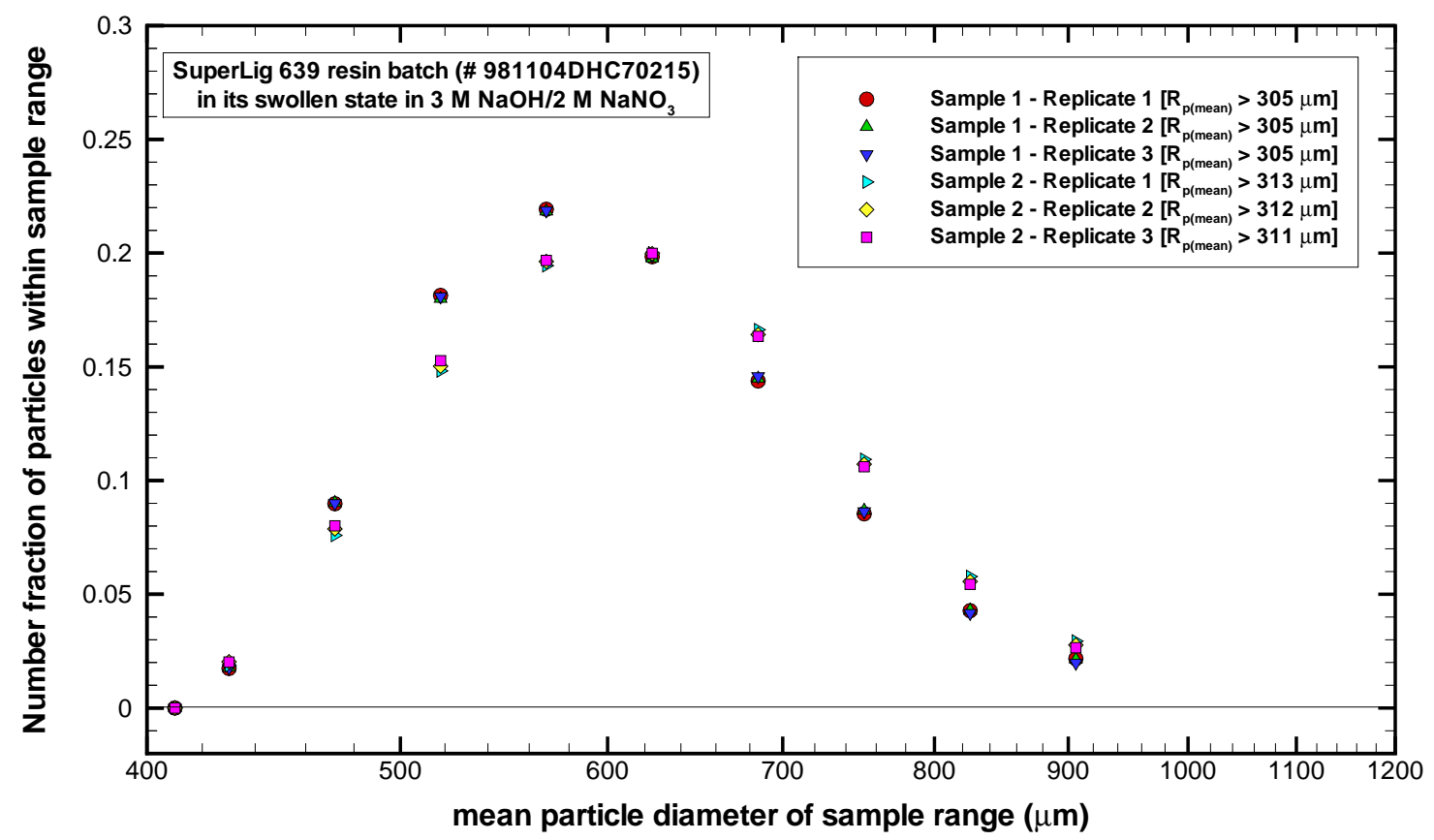

Figure 6-3. Number fraction of particles as a function of particle size for two specific samples of the SuperLig ${ }^{\circledR} 639$ resin (batch \#981104DHC70215) based on laser technology under a 5 M $\mathrm{Na}^{+}$solution (data from Bruening, 2000a). 


\subsection{Pore Diffusion}

As mentioned earlier we assume that the rate of chemical adsorption (i.e., exchange of ions at a surface site) is very fast when compared to the rates of diffusion within the pore fluid and mass transfer across the liquid film at the outer boundary of the resin particles. In this section we discuss the "effective" binary molecular (Brownian motion) diffusion and pore diffusion coefficients for pertechnetate (or perrhenate) and nitrate anions used in the column models. In general molecular and pore diffusion coefficients depend upon the ionic composition of the surrounding fluid. However, for column modeling we shall assume these coefficients to be constant and base their values on the measured composition of a $5 \mathrm{M}$ sodium simulated waste consistent with Envelope A (Steimke et al., 2000). This particular simulant was seeded with perrhenate. It is also assumed that these coefficients apply equally well to both perrhenate and pertechnetate anions.

\subsection{Waste Density and Viscosity}

The fluid properties for this simulated waste of Envelope A were measured and reported by Steimke et al. (2000). The measured values of density and dynamic viscosity for the simulated waste and for pure water are listed in Table 7-1 at $20^{\circ} \mathrm{C}$. Property values for the waste at $25{ }^{\circ} \mathrm{C}$ were estimated based on the measured pure water values also provided in Table 7-1.

\subsection{Molecular Diffusion Coefficients}

Binary diffusion (sometimes referred to as free stream or Brownian motion) coefficients of electrolytes originating from a single salt under dilute conditions can be reasonably estimated by the Nernst-Haskell equation (Reid et al., 1977):

$$
\mathrm{D}_{ \pm}^{\infty}=\left(\frac{\mathrm{RT}}{F^{2}}\right)\left[\frac{\frac{1}{\mathrm{z}_{+}}+\frac{1}{\mathrm{z}_{-}}}{\frac{1}{\lambda_{+}^{\mathrm{o}}}+\frac{1}{\lambda_{-}^{\mathrm{o}}}}\right],
$$

where

$$
\begin{aligned}
& \mathrm{D}_{ \pm}^{\infty} \quad \text { - binary diffusion coefficient at infinite dilution, } \mathrm{cm}^{2} / \mathrm{s} \\
& \lambda_{+}^{\mathrm{o}}, \lambda_{-}^{\mathrm{o}} \text { - limiting ionic conductance for cation and anion, mhos/equivalent } \\
& \mathrm{z}_{+}, \mathrm{z}_{-} \text {- valences of cation and anion, respectively } \\
& F \\
& \mathrm{R}
\end{aligned}
$$

Ionic conductance for the various ions of interest are tabulated in Table 7-2 (Reid et al., 1977; Perry, 1973). Binary pairs for the dominant cation-anion pairs based on this simulated waste for 
Envelope A (Steimke et al., 2000) were considered and their computed diffusion coefficients are listed in Table 7-3.

To account for fluid property differences between the simulated waste and pure water a correction factor was applied. Based on a hydrodynamical theory the following expression typically referred to as the Stokes-Einstein equation is obtained (Bird et al., 1960, page 514):

$$
\frac{\mathrm{D}_{\mathrm{AB}} \mu_{\mathrm{B}}}{\kappa \mathrm{T}}=\frac{1}{6 \pi \mathrm{R}_{\mathrm{A}}},
$$

where

$$
\begin{array}{ll}
D_{A B} & - \text { binary diffusion coefficient for A diffusing through solvent } B \\
\mu_{B} & - \text { dynamic viscosity of solvent mixture } \\
R_{A} & - \text { radius of diffusing particle } \\
\kappa & - \text { Boltzmann's constant }
\end{array}
$$

Based on Eq. (7-2), as a correction factor the ratio of dynamic viscosities (i.e., pure water versus waste) was applied to the computed diffusion coefficients from Eq. (7-1). The viscosity corrected values are also provided in Table 7-3. In Cussler (1984) the "effective" binary ionic diffusion coefficient of cesium in essentially pure water is $1.236 \times 10^{-3} \mathrm{~cm}^{2} / \mathrm{min}$ at $25^{\circ} \mathrm{C}$, which is within $16 \%$ of the estimated value computed from Eq. (7-1).

The ionic radii of sodium and potassium are 0.95 and 1.33 angstroms with average hydration numbers of 4 and 3, respectively. All metal cations are hydrated in aqueous media, where, for example, sodium migrates perhaps in the form $\mathrm{Na}\left(\mathrm{H}_{2} \mathrm{O}\right)_{4}{ }^{+}$. Reasonable values for the radii of the hydrated alkali metal ions sodium and potassium are $~ 2.76$ and $~ 2.32$ angstroms (Peters et al., 1974), respectively. Therefore, sodium is bigger and slower moving than potassium in aqueous solutions consistent with the predictions listed in Table 7-3.

Anions are characteristically less heavily hydrated. Schroeder et al. (1995) found that the tetrahedral geometries for perrhenate and pertechnetate result in nearly identical ion sizes and it is speculated that their diffusion coefficients will be similar.

Molecular diffusion coefficients are important in determining key dimensionless numbers (e.g., Schmidt Number, Sc) used in various constitutive law correlations pertinent to column transport modeling. They also provide an upper bound for pore diffusion coefficients.

\subsection{Pore Diffusion Coefficients}

Within the complicated pore structure of the resin particles we assume that net fluid motion is approximately zero resulting in equal-molar counter-diffusion. "Effective" binary diffusion coefficients based on Fick's law are assumed where surface migration is considered negligible. Surface migration generally becomes increasingly more important as the migrating ions increase in size relative to the pore aperture (Froment and Bishoff, 1979). Knudsen diffusion occurs when the molecular dimensions of the ions approach their mean free path lengths. 
Specific information on the actual pore sizes were not available at the time of this report; however, IBC vendor information suggests that the pore sizes are large relative to the size of migrating ions of interest and that pore diffusion coefficients should not be significantly lower than their molecular values. However, some level of reduction is expected resulting from bends along the pore paths that are generally accounted for by a particle tortuosity factor (Smith, 1981; Froment and Bishoff, 1979) defined as:

$$
\mathrm{D}_{\mathrm{pi}} \cong \frac{1}{\tau_{\mathrm{p}}} \mathrm{D}_{\infty \mathrm{i}},
$$

Typical values for catalyst particle tortuosity are between 2 and 8 . Based on the expected large pore diameters the tortuosity values for SuperLig ${ }^{\circledR} 639$ may actually range as low as from near 1 to 3 .

For small ions Mackie and Meares (1955) suggest that the intra-particle pore diffusion coefficient can be estimated from

$$
\mathrm{D}_{\mathrm{pi}} \cong\left[\frac{\varepsilon_{\mathrm{p}}}{\left(2-\varepsilon_{\mathrm{p}}\right)^{2}}\right] \mathrm{D}_{\infty \mathrm{i}},
$$

However, for larger molecules pore diffusion coefficient experiments are required. Ideally, pore diffusion coefficients can be derived from batch kinetics distribution studies where the mass transfer resistance associated with film diffusion is minimized through significant mechanical mixing (note that, mixing techniques must be limited such that physical grinding of the particles does not become excessive). A time-dependent technetium distribution study was performed in simulated DSSF waste by Kurath et al., 1999.

Batch kinetics tests, where inadequate mixing is achieved between the solid and solution, result in overall diffusion coefficients that are in effect smaller than the actual pore diffusion coefficient. Therefore, the use of the batch kinetics data taken by Kurath et al. (1999) can provide us with a lower bound estimate of pore diffusion, while molecular diffusion becomes our upper bound. Sufficient mechanical mixing during these tests is assumed, such that the kinetics data measured represent only the mass transfer resistance associated with pore diffusion (i.e., mass transfer resistance due to film diffusion is assumed to be small).

To estimate pertechnetate and nitrate pore diffusion coefficients using the kinetics test data presented in Kurath et al. (1999), a VERSE-LC model was set up consistent with the experimental conditions specified in their report:

- Initially $0.0484 \mathrm{~g}$ of resin was placed into contact with $5.0 \mathrm{ml}$ of Envelope A simulant solution at concentrations of $\sim 5 \mathrm{M} \mathrm{Na}^{+}, 1.990 \mathrm{M} \mathrm{NO}_{3}^{-}$, and $4.631 \times 10^{-5} \mathrm{M}^{99} \mathrm{Tc}$;

- Initially the resin is assumed to be fresh containing no pertechnetate or nitrate anion species at its adsorption sites; 
- VERSE-LC geometry parameters were set consistent with the experimental setup, while other parameters were set consistent with the parameters discussed in the column modeling section of this report;

- The film mass transfer and axial dispersion coefficients were set to high values in order to appropriately model the experimental behavior using VERSE-LC (i.e., experimentally the liquid-sample remains well-mixed throughout the contact period resulting from the mechanical mixing);

- A binary transport simulation, along with a binary isotherm model, was chosen to model both the pertechnetate and nitrate anions;

- Transient liquid pertechnetate and nitrate concentrations were computed using VERSE-LC, while experimental values were computed from the various batch contact test data (i.e., contact tests with varying contact times were performed as listed in Table C-1) and associated information contained within their report (and summarized in Table C-2); and

- Binary equilibrium isotherms were used consistent with the late time (i.e., 72 hour contact time for test W39-72) measured $K_{d}$ value where complete equilibrium was assumed to have been reached in 72 hours of contact.

Sample VERSE-LC input and output decks are provided in Appendix C. The measured liquid pertechnetate concentration for various contact tests (which approximate the transient values at various times during a single contact test) are also provided in Table C-1 of Appendix C. Table $\mathrm{C}-2$ contains various key parameters used in this analysis.

To model the transient behavior occurring during a single batch contact test, special VERSE-LC parameter settings are required. To simulate a well-mixed beaker of liquid-sample one finite element representing the bed is chosen where the axial dispersion coefficient is set to a very large value to ensure negligible concentration gradients exist throughout the bed volume (i.e., liquid region outside the particles). The flowrate through this "artificial" column is set to zero (i.e., actually a very small value is necessary since the superficial velocity is used to compute various dimensionless numbers). Initially, in VERSE-LC the pore spaces are assumed to be filled with liquid free of the various anions of interest (i.e., pertechnetate and nitrate). The ionic concentrations of the liquid in the bed space are increased to account for the dilution effect (i.e., ratio of total liquid volume to liquid bed volume) where the total liquid volume (i.e., pore plus liquid bed volumes) is set to the test's initial liquid-sample volume. While the pore porosity is set to the resin's value of $37.1 \%$, the bed porosity is based on the quantities of materials used resulting in $98.75 \%$ (i.e., the majority of volume is occupied by bed liquid).

Since only technetium concentrations were measured, no transient nitrate concentrations are available for comparison. Therefore, it is assumed that the percent reduction in pore versus molecular diffusion coefficients for all anions is similar. To estimate this reduction factor, several VERSE-LC simulations were run by varying the inputted pore diffusion coefficient values from $25 \%$ to $100 \%$ of their molecular values. 
The VERSE-LC results for four key cases (i.e., reduction factors of 20\%, 35\%, 50\%, and 70\%) are compared to the experimental data in Figure 7-1. As expected, a faster than measured pertechnetate uptake response is seen when its pore diffusion coefficient is set to its molecular diffusion value (i.e., its upper bound). For the pertechnetate response data, a value $\sim 35 \%$ of its molecular diffusion value is near optimum. For the column modeling predictions and assessment presented in later sections of this report the pore diffusion coefficient for each ion of interest is set to $35 \%$ of the ion's molecular diffusion value. The values used are listed in Table 7-3. These values correspond to a particle tortuosity of approximately 3 .

The computed transient response for liquid-phase nitrate concentration is shown in Figure 7-2. Its transient response is somewhat insensitive to the range of nitrate pore diffusion coefficients tried. Due to the high initial concentration of nitrate, the resin rapidly fills with nitrate species as indicated by the sudden drop in its liquid-phase concentration as shown in Figure 7-2. Once the resin is filled with nitrate species a gradual swapping of adsorption sites with pertechnetate species occurs. As shown in Figure 7-3, this swapping process requires approximately 48 to 72 hours to approach complete equilibrium due to the mass transfer limitation of pore diffusion. Based on the approach to equilibrium data presented in Figure 7-3, the overall mass transfer process has an approximately 6 to 8 hour half-life for a contact test between pertechnetate and SuperLig ${ }^{\circledR} 639$ resin.

The approach to equilibrium can also be plotted in terms of an operating curve, as shown in Figure 7-4, versus the ultimate equilibrium curve. The difference between these two curves at any point in time represents the current time concentration driving force for mass transfer.

Table 7-1. Fluid density and dynamic viscosity for water and simulated 5 M sodium waste solution.

\begin{tabular}{|c|c|c|}
\hline Fluid property & Pure water & $\begin{array}{c}\text { Simulated } 5 \mathrm{M} \mathrm{Na}^{+} \\
\text {waste solution }\end{array}$ \\
\hline \multicolumn{3}{|l|}{ For $20^{\circ} \mathrm{C}$} \\
\hline Density, $\mathrm{g} / \mathrm{ml}$ & 0.99823 & $1.225^{\mathrm{a}}$ \\
\hline Dynamic viscosity, $\mathrm{cp}$ & 1.002 & $2.94^{\mathrm{a}}$ \\
\hline \multicolumn{3}{|l|}{ For $25^{\circ} \mathrm{C}$} \\
\hline Density, $\mathrm{g} / \mathrm{ml}$ & 0.9970479 & $1.22355^{\mathrm{b}}$ \\
\hline Dynamic viscosity, $\mathrm{cp}$ & 0.8904 & $2.61255^{\mathrm{b}}$ \\
\hline
\end{tabular}

${ }^{\text {a }}$ A $5 \mathrm{M}$ sodium simulated waste consistent with Envelope A where properties were measured at $20{ }^{\circ} \mathrm{C}$ (Steimke et al., 2000).

${ }^{\mathrm{b}}$ Measured properties were adjusted to new temperature based on pure water value ratios. 
Table 7-2. Limiting ionic conductances in water at $25^{\circ} \mathrm{C}$ (Reid et al., 1977; Perry, 1973).

\begin{tabular}{|c|c|}
\hline Ion & $\begin{array}{c}\text { Limiting ionic } \\
\text { conductance } \\
\text { MHOS/equivalent }\end{array}$ \\
\hline \hline Cations \\
\hline $\mathrm{Cs}^{+}$ & 77.30 \\
\hline $\mathrm{K}^{+}$ & 73.50 \\
\hline $\mathrm{Na}^{+}$ & 50.10 \\
\hline $\mathrm{H}^{+}$ & 349.80 \\
\hline \hline $\mathrm{Anions}^{+}$ & \\
\hline $\mathrm{OH}^{-}$ & 198.60 \\
\hline $\mathrm{NO}_{3}^{-}$ & 71.46 \\
\hline $\mathrm{Cl}^{-}$ & 76.35 \\
\hline $\mathrm{NO}_{2}^{-}$ & 72.00 \\
\hline $\mathrm{ReO}_{4}^{-}$ & 55.00 \\
\hline
\end{tabular}

Table 7-3. Estimated binary molecular and pore diffusion coefficients at $25^{\circ} \mathrm{C}$.

\begin{tabular}{|c|c|c|c|}
\hline Ion Pair & $\begin{array}{c}\text { Diffusion coef. in } \\
\text { water } \\
\mathrm{cm}^{2} / \mathrm{min}\end{array}$ & $\begin{array}{c}\text { Diffusion coef. in } \\
\text { simulated 5M Na waste } \\
\mathrm{cm}^{\mathbf{b}} / \mathrm{min}\end{array}$ & $\begin{array}{c}\text { Pore diffusion coef. in } \\
\text { simulated } 5 \mathrm{M} \mathrm{Na} \text { waste } \\
\mathrm{cm}^{2} / \mathrm{min}\end{array}$ \\
\hline \multicolumn{3}{|l|}{ For perrhenate } & \\
\hline $\mathrm{ReO}_{4}^{-}-\mathrm{Na}^{+}$ & 8.377E-04 & $2.849 \mathrm{E}-04$ & \\
\hline $\mathrm{ReO}_{4}^{-}-\mathrm{K}^{+}$ & $1.005 \mathrm{E}-03$ & $3.419 \mathrm{E}-04$ & \\
\hline Mole avg. value ${ }^{a}$ & $8.415 \mathrm{E}-04$ & $2.862 \mathrm{E}-04$ & $1.002 \mathrm{E}-04$ \\
\hline \multicolumn{3}{|l|}{ For nitrate } & \\
\hline $\mathrm{NO}_{3}^{-}-\mathrm{Na}^{+}$ & $9.411 \mathrm{E}-04$ & $3.201 \mathrm{E}-04$ & \\
\hline $\mathrm{NO}_{3}^{-}-\mathrm{K}^{+}$ & $1.158 \mathrm{E}-03$ & $3.938 \mathrm{E}-04$ & \\
\hline Mole avg. value $\mathrm{a}^{\mathrm{a}}$ & $9.460 \mathrm{E}-04$ & $3.218 \mathrm{E}-04$ & $1.126 \mathrm{E}-04$ \\
\hline
\end{tabular}

${ }^{\text {a }}$ Relative mole fractions of $97.75 \% \mathrm{Na}^{+}$and $2.25 \% \mathrm{~K}^{+}$based on simulated waste composition (Steimke et al., 2000).

${ }^{\mathrm{b}}$ Fluid viscosity correction ratio applied based on a measured simulated waste viscosity of $2.94 \mathrm{cp}$ at $20^{\circ} \mathrm{C}$ (Steimke et al., 2000).

${ }^{\mathrm{c}}$ Pore diffusion coefficient set to $35 \%$ of the estimated molecular diffusion value based on analysis of batch kinetics test data of Kurath et al. (1999). 


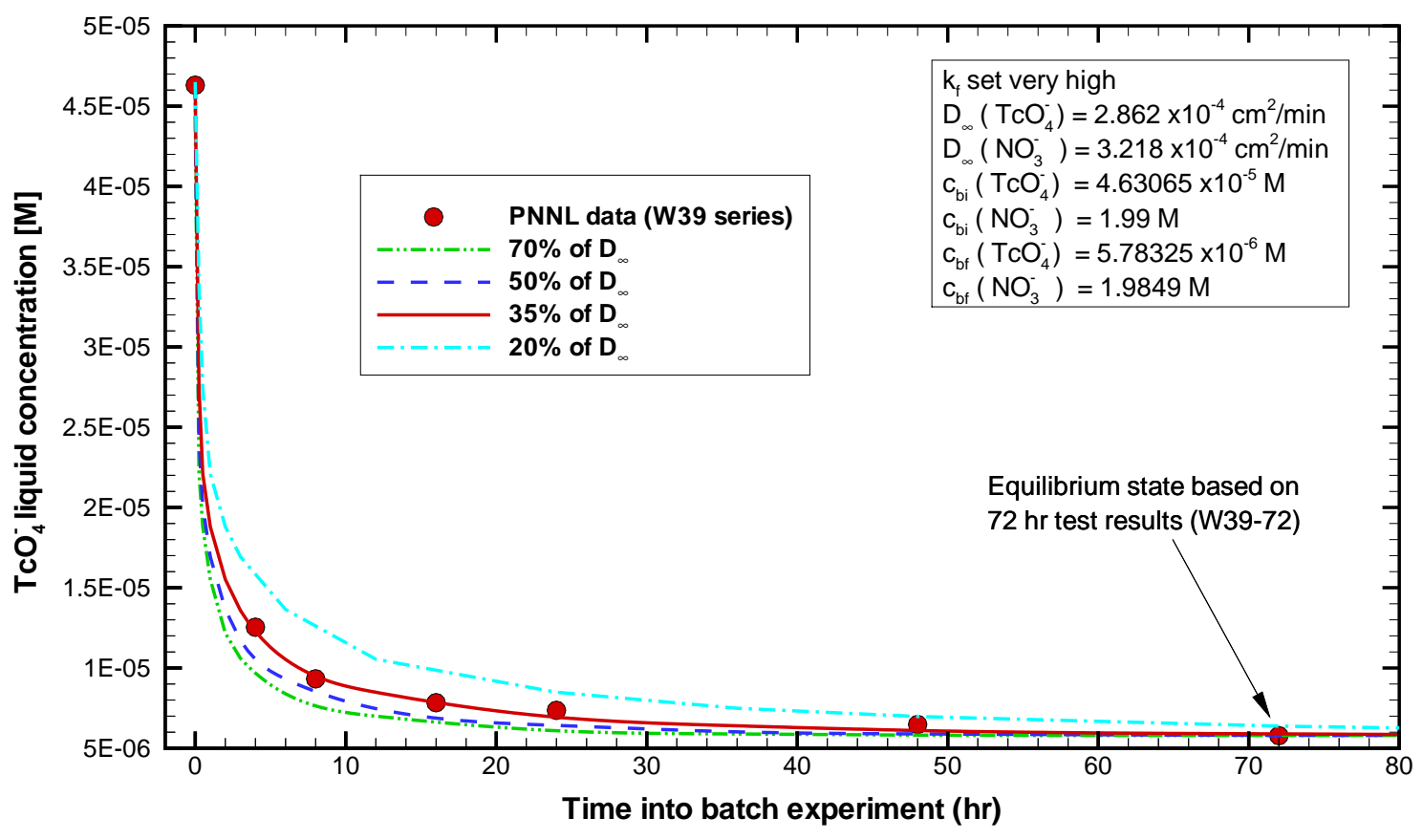

Figure 7-1. Estimation of the pertechnetate pore diffusion coefficient based on batch kinetics tests performed by Kurath et al. (1999) for pertechnetate and nitrate uptake on SuperLig ${ }^{\circledR} 639$.

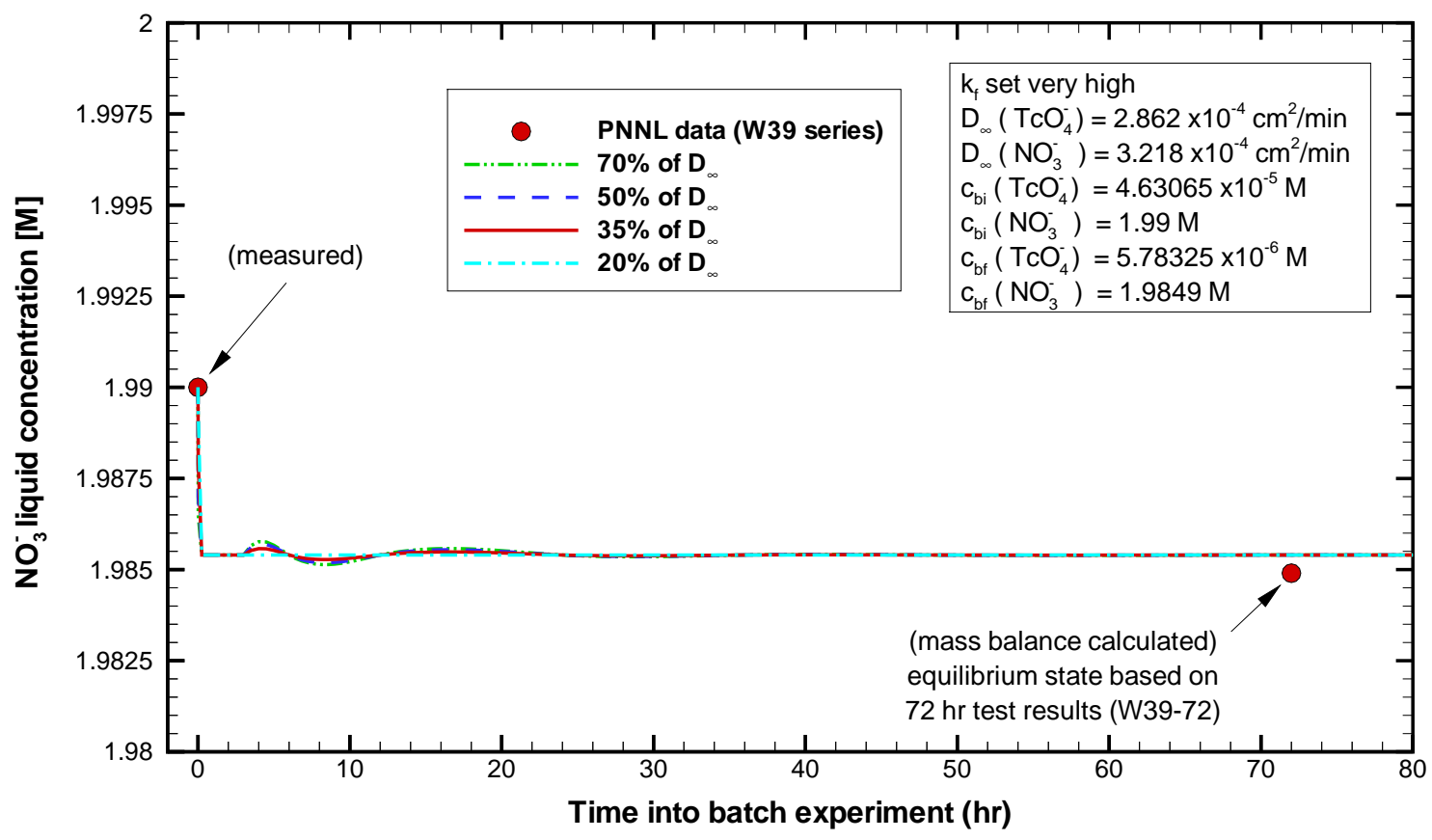

Figure 7-2. Estimation of the nitrate pore diffusion coefficient based on batch kinetics tests performed by Kurath et al. (1999) for pertechnetate uptake and nitrate on SuperLig ${ }^{\circledR} 639$. 


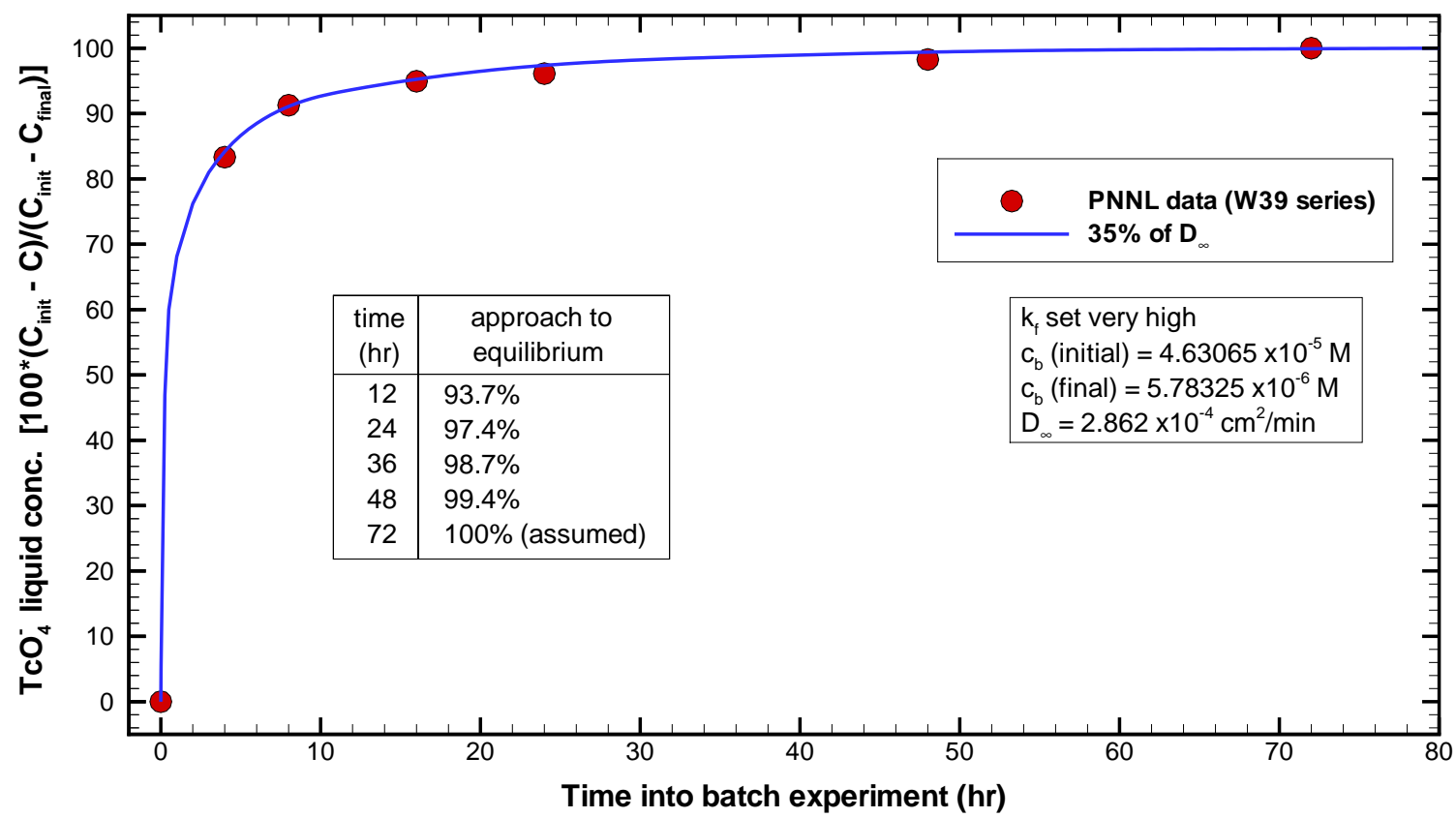

Figure 7-3. Estimated pertechnetate liquid-phase concentrations during approach to equilibrium based on batch kinetics tests performed by Kurath et al. (1999) for pertechnetate and nitrate uptake on SuperLig ${ }^{\circledR} 639$.

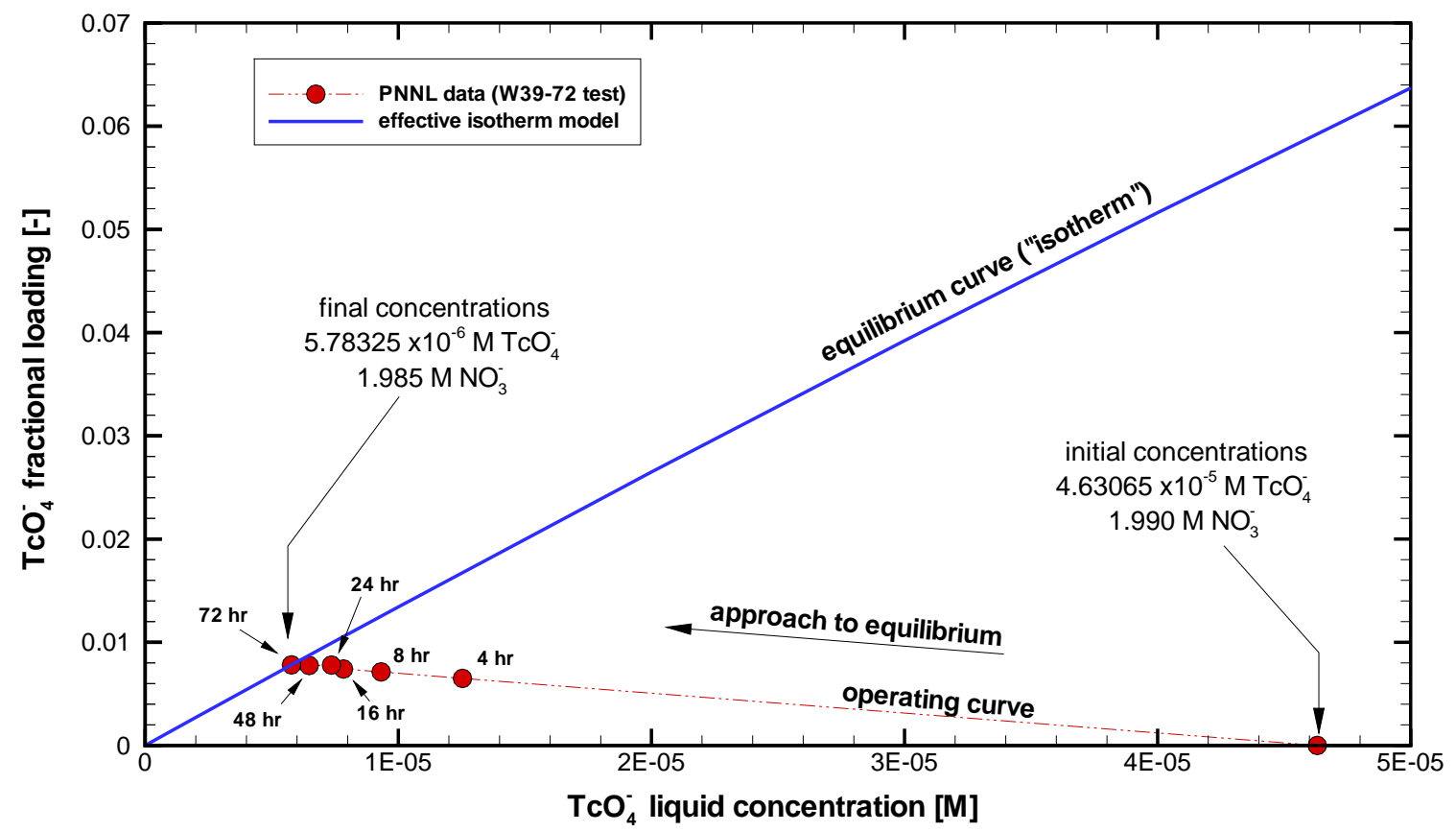

Figure 7-4. The pertechnetate operating curve followed during its approach to its equilibrium curve

("isotherm") based on batch kinetics tests performed by Kurath et al. (1999) for pertechnetate and nitrate uptake on SuperLig ${ }^{\circledR} 639$. 


\subsection{Axial Dispersion and Film Diffusion}

In this section we present the correlations used to define: (1) axial dispersion along the bed length and (2) mass transfer across the liquid film separating the bed fluid from its neighboring particle pore fluid.

\subsection{Film Diffusion}

For the laboratory-scale column tests and proposed full-scale facility, with the SuperLig ${ }^{\circledR} 639$ resin particle size distributions, the Reynolds number range is approximately 0.1 to 1.0 . With respect to published literature this is a very low Reynolds number range. Numerous mass transfer correlations exist as discussed by Foo and Rice (1975, see their Figure 2). One of the correlations compared in Foo and Rice (1975) is one developed by Wilson and Geankoplis (1966) based on low Reynolds number data. Large variations between correlations can be seen; however, our sensitivity to the film coefficient is low as shown in the section discussing sensitivities. Since VERSE-LC has the Wilson and Geankoplis (1966) correlation as an option and this correlation falls somewhat within the spread of available low Reynolds number data we have chosen it for all the column simulations in this report. For each ion species considered, the Wilson and Geankoplis (1966) correlation is expressed as:

$$
\mathrm{J} \equiv\left[\frac{\mathrm{k}_{\mathrm{fi}}}{\mathrm{u} \varepsilon_{\mathrm{b}}}\right] \mathrm{Sc}_{\mathrm{i}}^{2 / 3}=\frac{1.09}{\varepsilon_{\mathrm{b}}} \mathrm{Re}^{-2 / 3}
$$

where the Reynolds number is defined as

$$
\operatorname{Re} \equiv \frac{2 \mathrm{R}_{\mathrm{p}} \rho_{\mathrm{w}} \mathrm{u} \varepsilon_{\mathrm{b}}}{\mu_{\mathrm{w}}},
$$

and the Schmidt number for each species is defined as

$$
\mathrm{Sc}_{\mathrm{i}} \equiv \frac{\mu_{\mathrm{w}}}{\rho_{\mathrm{w}} \mathrm{D}_{\mathrm{i}}^{\infty}}
$$

A standard deviation of approximately $25 \%$ is reported for Eq. (8-1) by Wilson and Geankoplis (1966), while from comparison to the various correlations presented by Foo and Rice (1975) a standard deviation of $100 \%$ to $200 \%$ is observed.

\subsection{Axial Dispersion}

Axial dispersion in packed columns is the result of mechanical dispersion added onto molecular diffusion. For practical flowrates mechanical dispersion dominates. For well-packed columns of sufficient diameter such that wall effects (i.e., channeling) are minimal a variety of correlations exist for long column performance. A brief discussion of minimum column sizing is presented in Brooks (1994). 
In the low Reynolds number range of interest the Chung and Wen (1968) correlation is applicable for sufficiently large columns (i.e., large diameter and length) and is expressed as:

$$
\mathrm{E}_{\mathrm{b}}=\frac{2 \mathrm{R}_{\mathrm{p}} \mathrm{u} \varepsilon_{\mathrm{b}}}{0.2+0.011 \mathrm{Re}^{0.48}}
$$

where the standard deviation of this correlation based on all available data points was reported to be $46 \%$. Equation (8-2) applies for only sufficiently large columns and correction factors must be considered for columns with small diameters and/or short active bed lengths.

\subsubsection{Radial Flow Maldistribution}

Flow maldistribution is caused by packing irregularities. As such the bed porosity varies over the cross-section of a column and increases as the outer wall is approached (even for well-packed columns). "Channeling" near the wall becomes more serious for smaller column diameters and larger particle sizes. As a "rule of thumb" Helfferich (1962) states that this effect becomes significant when the bed diameter is less than thirty times the particle diameter.

The experimental and mathematical basis for this rule of thumb stems from the work of Schwartz and Smith (1953) and Morales et al. (1951). Their experimental efforts were for uniform packing of either spheres or cylinders using air-flow rates in the range of 145 to $547 \mathrm{~cm} / \mathrm{min}$. Over the range of their database they concluded that:

- The radial velocity profile (normalized) is independent of total flowrate and

- The divergence of the radial velocity profile from uniform behavior is less than $20 \%$ for column diameter to particle diameter ratios greater than 30 .

A measure of the degree of non-uniformity in the radial velocity profiles can be made by looking at the ratio of peak-to-average velocity. Based on the limited database of Schwartz and Smith (1953) this peak-to-average velocity ratio is plotted versus column-to-particle diameter ratio in Figure 8-1. As illustrated in Figure 8-1 velocity ratios greater than $100 \%$ can occur for columnto-particle diameter ratios less than 10 and beyond $\sim 50$ the impact is negligible. Also shown in Figure 8-1 is a least squares fit of the data in the power law form:

$$
\frac{\mathrm{u}_{\text {peak }}}{\mathrm{u}_{\mathrm{CL}}}=\left\{\begin{array}{cc}
4.3786\left(\frac{\mathrm{D}}{2<\mathrm{R}_{\mathrm{p}}>}\right)^{-0.372935} & \text { for } \frac{\mathrm{D}}{2<\mathrm{R}_{\mathrm{p}}>}<52.44 \\
1.0 & \text { for } \frac{\mathrm{D}}{2<\mathrm{R}_{\mathrm{p}}>} \geq 52.44
\end{array} .\right.
$$

Note that Eq. (8-3) is based on packed beds with uniformly shaped cylinders and air-flow rates in the range of 145 to $547 \mathrm{~cm} / \mathrm{min}$. This correlation may be suspect for conditions of non-uniformly shaped particles with liquid flows in the range of 0.5 to $12 \mathrm{~cm} / \mathrm{min}$ as applies to the various column tests considered in this report. 
Dorweiler and Fahien (1959) performed similar experiments that agreed with Schwartz and Smith (1953) and went to flowrates as low as $30 \mathrm{~cm} / \mathrm{min}$. In a later study by Fahien and Smith (1955) significant radial effects were observed for column-to-particle diameters less than 20.

The impact associated with non-uniform radial velocity profiles manifests itself in spreading out the exit breakthrough curves in a manner similar to increased axial dispersion. As listed in Table 9.1 of Section 9, several of the column experiments considered have column-to-particle diameter ratios less than 30. In the simulations performed in this report no explicit account was made for this apparent increase in axial dispersion.

When shrinkage of the resin results due to the feed conditions further channeling (sometimes referred to here as fingering) can occur. Byrne and Lapidus (1955) discuss this briefly in their technical note. For the SuperLig ${ }^{\circledR} 639$ resin very little shrinkage occurs upon increased ionic strength of the feed and the total ionic strength variations only occur during the first 5 to 10 column volumes.

\subsubsection{Headspace and Short Column Impacts}

Liles and Geankoplis (1960) conducted experiments to ascertain the impact short column lengths and void headspaces have on axial dispersion in packed bed columns. When end effects were eliminated they concluded that no effects of length on axial dispersion were observed. However, in the presence of end effects such as void headspaces significant effects of length can result. A summary of their data is presented in Figure 8-2 illustrating that the impact can become significant for columns under $\sim 20 \mathrm{~cm}$. Also shown in Figure 8-2 is a least squares fit of the data in the power law form:

$$
\frac{\mathrm{E}_{\mathrm{b}}(\mathrm{L})}{\mathrm{E}_{\mathrm{b}}(\mathrm{L} \rightarrow \infty)}=1.0+61.4988 \mathrm{~L}^{-1.20799},
$$

where column length is in units of cm. As listed in Table 9-1 of Section 9, several of the column experiments considered have column lengths less than 20. In the simulations performed in this report explicit account was made for this apparent increase in axial dispersion based on the power law fit shown in Figure 8-2 and given by Eq. (8-4). 


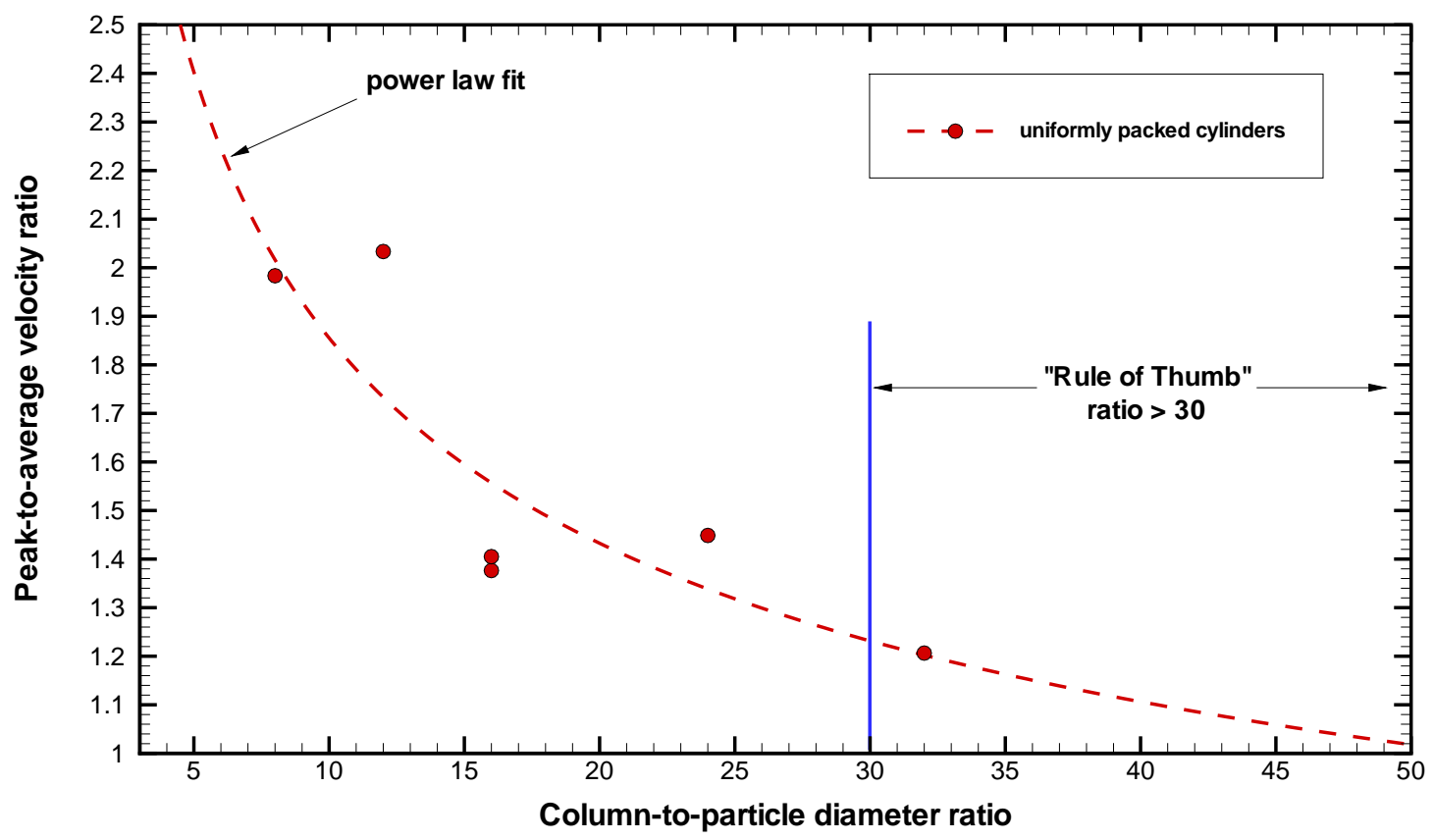

Figure 8-1. Estimated impact of column-to-particle diameter ratios on radial velocity profile based on the limited data by Schwartz and Smith (1953).

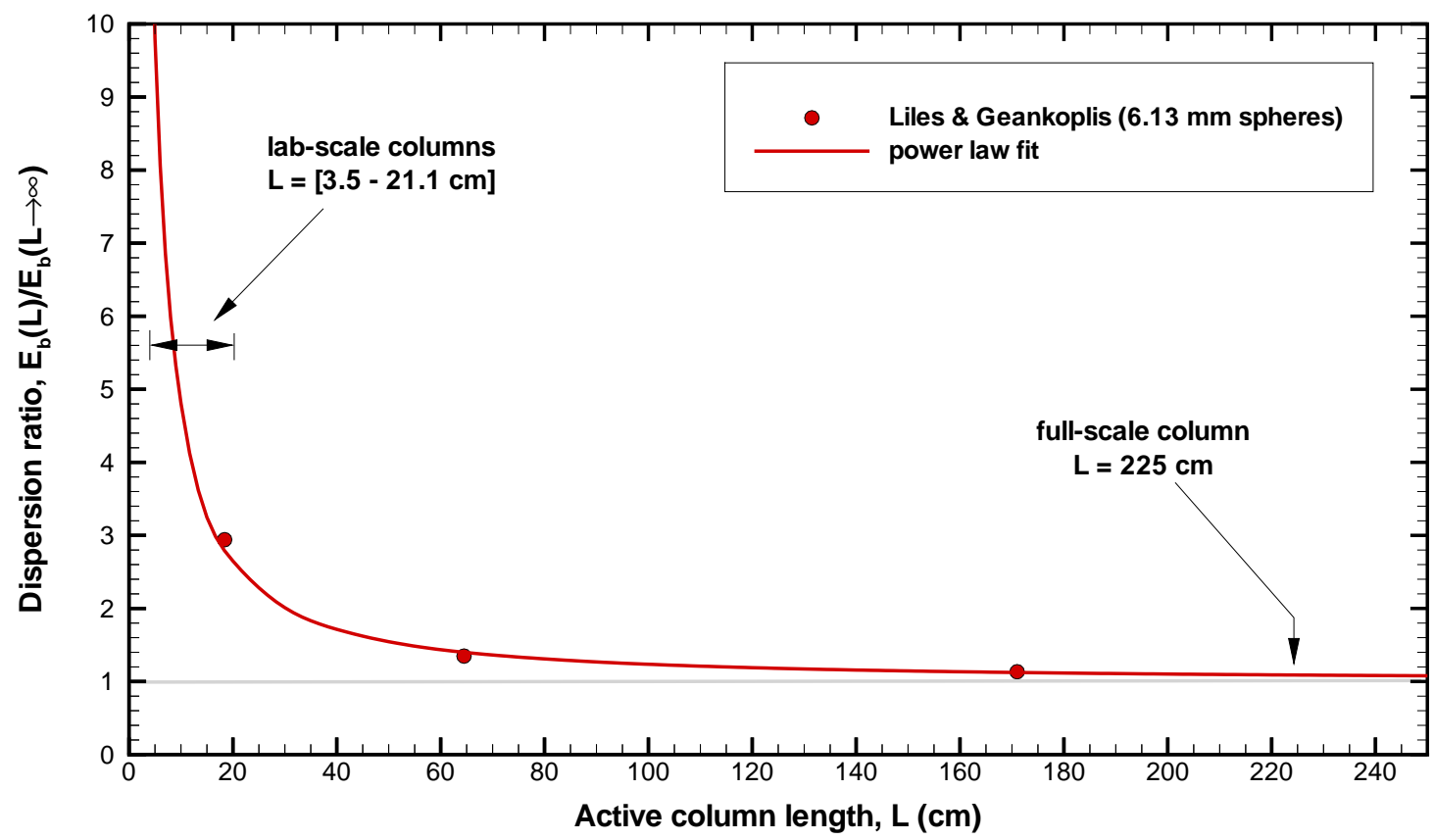

Figure 8-2. Estimation of the impact from end effects and short columns on axial dispersion based on the limited data by Liles and Geankoplis (1960). 


\subsection{Laboratory-Scale Column Assessments}

Numerous laboratory-scale column experiments have been performed to measure the technetium removal capability (in the form of pertechnetate) of the SuperLig ${ }^{\circledR} 639$ resin for feed conditions typical for a range of Hanford waste types (i.e., Envelopes A, B, and C). A listing of the pilotscale, intermediate-scale, and small-scale column studies considered in this section is provided in Table 9-1. For comparison purposes the full-scale columns are also listed in Table 9-1. Key features associated with each column are also given in Table 9-1.

VERSE-LC was used to model 20 of these column experiments where pertechnetate (or its surrogate perrhenate) breakthrough curves were experimentally measured for the SuperLig ${ }^{\circledR} 639$ resin (several differing batch IDs were tested along with corresponding equilibrium contact tests). Comparisons of these model calculations to the corresponding experimental data are provided in the following subsections. The VERSE-LC input and output files for each of the 20 simulations are listed in Appendix D. None of the transport parameter settings were altered during the assessment phase discussed below. The transport properties were established by means other than fitting to the column data directly (e.g., the binary dispersion coefficient for perrhenate was assumed to be equal to the value for pertechnetate which is based on batch kinetics data as discussed in Section 7). However, initial efforts to generalize the binary adsorption isotherm model to account for batch variability and waste types were unsuccessful. Therefore, binary isotherm models for pertechnetate (and perrhenate) were created for each unique batch ID and waste type (i.e., differing total ionic strengths and compositions). For each column test discussed below, a comparison of the isotherm model specifically used versus the appropriate subset of batch equilibrium data is discussed with further general discussions available in Section 4. Chemical equilibrium between the various potential chemical forms of technetium (or rhenium) is not accounted for in the following simulations. Even though VERSELC has the capability to address liquid-phase reactions between various feed constituents, no quantitative information regarding the various types of forms (or their reaction equilibria) is available. Therefore, non-pertechnetate (or non-perrhenate) feed just passes through the columns as an inert species.

To briefly summarize our assessments, the exit breakthrough curve model predictions for perrhenate are very reasonable when compared to the available data sets. Even for sequential column tests, where the lag column in a previous test is used as the lead column in a follow-on test, perrhenate exit breakthrough curve predictions were reasonably accurate. No effort to improve these predictions, by altering the initial estimates of the various transport parameters, was necessary. This provided some level of confidence that the initially chosen transport parameter settings were appropriate. However, for the pertechnetate simulations significant deviations from the data occurred in various cases and were believed to be predominately the result of inaccuracies in their isotherm models. The data sets themselves sometime had significant data scatter within them. The existence of non-pertechnetate forms of ${ }^{99} \mathrm{Tc}$ complicate the analysis efforts both in the creation of an appropriate isotherm model, as well as for modeling the column loading cycle. The possibility of liquid-phase reactions (e.g., 
equilibrium exchange rates) between pertechnetate and various non-pertechnetate forms still remains as a question/concern. In a few cases, the estimated fraction of non-pertechnetate within the various waste samples differed when based on the equilibrium contact tests versus the column exit breakthrough curves. In general, the predictions for removal of pertechnetate during a column simulation were conservative with respect to the available breakthrough data (i.e., predicted breakthrough would occur earlier than measured).

A summary of recommended nominal transport parameter settings for the pertechnetate (perrhenate)-SuperLig ${ }^{\circledR} 639$ system column modeling is provided in Table 9-2. The parameters in Table 9-2 are ordered into groups based on their level of importance with respect to the determination of pertechnetate (perrhenate) exit breakthrough curves. The ordering of these parameters is based on the numerous simulation runs made during this assessment effort and our sensitivity study for the full-scale facility as discussed in Section 10. The parameter settings for the column specific isotherm models used during the assessment effort are listed in Table 9-3.

\subsection{Intermediate-Scale Perrhenate (WK) Tests}

Predictions from five column model simulations are compared to data from a series of experiments by King et al. (2000a) measuring perrhenate removal from a simulant of Hanford Envelope A waste. A brief summary of these column experiments is provided in Table 9-4. The experiments are numbered in the order in which they were run. The first four experiments (i.e., WK Exp-1, WK Exp-2, WK Exp-3, and WK Exp-4) were all run on the same resin (i.e., fixed amount of resin with batch \# 980624001DC) in two different columns. Tests 1, 2, and 3 were run using the same packed column (approximately $2.69 \mathrm{~cm}$ in diameter and $9 \mathrm{~cm}$ long), while for test 4 the resin was repacked into a shorter and wider column (approximately $4.0 \mathrm{~cm}$ in diameter and $4 \mathrm{~cm}$ long resulting in the same volume). In essence, test 4 should be an estimate of the breakthrough curve approximately halfway down the test 1 column (in Table 9-4 note the slight flowrate and feed concentration differences). Tests 1,2,3, and 4 provide data on the functional dependence of the exit breakthrough curves with respect to superficial velocity. In test 5, a 50:50 mixture by mass of batches \# 981015DHC720011 and \# 990420DHC720067 were used in order to mimic the pilot-scale column tests conducted in the Thermal Fluids Laboratory (TFL), discussed in a subsection below. Each test started its loading cycle with a fresh (perrhenate-free) column.

As discussed in Section 4, batch specific isotherm models are required to adequately predict each column exit breakthrough curve. For the first four experiments the same isotherm model is used specifically for batch \# 980624001DC. A direct comparison of the isotherm model prediction for perrhenate loading (mmole/g $\mathrm{g}_{\text {resin }}$ ) versus the appropriate equilibrium contact test data (King et al., 2000a) is made in Figure 9-1. The Hanford Envelope A simulant, both in the contact tests, as

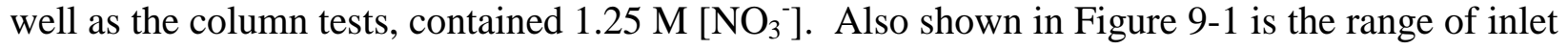
perrhenate feed concentration to the test columns, not the $K_{d}$ tests. The batch-specific isotherm model represents the data well over its entire range.

For the fifth experiment, batch-specific contact tests were performed for batch \# 981015DHC720011 and \# 990420DHC720067, separately. A comparison of these two separate 
batch contact data sets is shown in Figure 9-2. Also shown in Figure 9-2, are two different binary isotherm model predictions based on 100\% by mass of resin batch \# 981015DHC720011 and batch \# 990420DHC720067. The isotherm corresponding to a 50:50 mixture by mass of both batches is simply obtained by interpolation of these two pure batch isotherms. The isotherm models in Figure 9-2 are based on a nitrate feed concentration of $\sim 1.25$ M. For each batch (i.e., solid lines) its corresponding isotherm model has a different total ionic capacity than used in the isotherm model shown in Figure 9-1 (a comparison of parameter settings is provided in Table 93). Based on the TFL column performance behavior discussed later, the selectivity coefficient had to be increased for the TFL isotherm model also shown (i.e., as a red dash-dot line) in Figure 9-2. The total ionic capacity value for the TFL isotherm model is based on the WK-3 data.

Batch mixtures can be handled by computing a mixture total ionic capacity (i.e., mass weighted value) based on the total ionic capacities for every batch present in the mix. The averaging is to be done on a mass fraction basis since total ionic capacity is on a mmole $/ \mathrm{g}_{\text {resin }}$ basis.

The characteristic behavior of the exit breakthrough curve with increasing flowrate is to shift from an S-shaped curve towards an exponential-shaped curve. This type of behavior can be seen in the data, as well as the predictions, shown in Figures 9-3, 9-4, and 9-5. Overall, the VERSELC predictions are reasonable when compared to their appropriate data sets as shown in Figures 9-3 through 9-6. Difficulties in improving the match to the breakthrough data at early times may be the result of the short active column lengths with inlet void headspaces.

For column test WK Exp-5 an isotherm based on a 50:50 mixture of batches \# 981015DHC720011 and \# 990420DHC720067 (i.e., an isotherm with a average value for its total ionic capacity) resulted in a poor prediction of the measured breakthrough data as shown in Figure 9-7. Also shown in Figure 9-7 are the predicted breakthrough curves based on the isotherms for each pure batch. The breakthrough predictions based on the batch \# 981015DHC720011 isotherm fit the data reasonably well (i.e., solid blue line pertaining to WK-3 contact data). Since the contact data associated with batch \# 990420DHC720067 (i.e., 2 data points) is statistically limited, as compared to the contact data for batch \# 981015DHC720011 (i.e., 8 data points), it is believed that the contact data for batch \# 981015DHC720011 are more reliabe and covers a wider range of concentrations. Therefore, for column experiments using some or all of batch \# 990420DHC720067 resin we assume that its isotherm characteristics are identical to those for batch \# 981015DHC720011.

This set of experimental data was judged to be the most consistent and complete set available for model evaluation and no transport parameter adjustments were deemed necessary. Note that, although the same resin material was reused in many of these experiments, the calculations assume that fresh resin is in the column at the start of each experiment since the resin was thoroughly eluted between each test. A listing of the best estimate (nominal) values for all the necessary VERSE-LC column modeling parameters is tabulated in Table 9-2. These nominal values are used throughout all column modeling simulations discussed in this report (excluding certain specified parameter variations resulting from known column conditions; such as bed density). It should be pointed out that some of the parameter settings chosen may not be unique 
and other subsets of parameter values may provide results comparable to the results presented in this assessment section.

\subsection{Intermediate-Scale Perrhenate Vendor (IBC) Tests}

Early on the manufacturer of the SuperLig ${ }^{\circledR} 639$ resin performed a series of equilibrium contact tests followed by a column study (IBC Advanced Technologies, 1996). The loading cycle of the column study used a Hanford Envelope A simulant with a nitrate concentration of $2.47 \mathrm{M}$ seeded with a perrhenate concentration of $1.0 \times 10^{-4} \mathrm{M}$. No information as to the batch ID of the resin was provided. The stated bed density for the IBC column was $\sim 0.4 \mathrm{~g}_{\text {resin }} / \mathrm{ml}_{\mathrm{CV}}$. The vendor also provided us by personal communications a total ionic capacity for this resin of $\sim 0.5 \mathrm{mmole} / \mathrm{g}_{\text {resin }}$ (on an as-received moisture basis) which corresponds on a dry basis to approximately 0.5066 $\mathrm{mmole} / \mathrm{g}_{\mathrm{resin}}$.

A comparison of the batch (unspecified ID) specific binary isotherm model to the equilibrium contact data is shown in Figure 9-8. The five contact data points correspond to a fixed initial perrhenate concentration of $1.0 \times 10^{-4} \mathrm{M}$ with varying initial liquid-phase nitrate concentrations (i.e., $1 \mathrm{M}, 2 \mathrm{M}, 2.35 \mathrm{M}, 3 \mathrm{M}$, and $4 \mathrm{M}$, respectively). The total ionic capacity of this resin batch was set to their specified value of $0.5066 \mathrm{mmole} / \mathrm{g}_{\text {resin. }}$ The nitrate-perrhenate selectivity coefficient was estimated by fitting the isotherm model to the above data where increased weight was given to data points whose nitrate concentration were closer to the column feed concentration of $2.47 \mathrm{M}$ (resulting in a best estimate value of $\mathrm{K}_{21}=1.1269 \times 10^{-3}$ ). The computed binary selectivity coefficient is $\sim 83 \%$ of its value when based on the entire perrhenate $\mathrm{K}_{\mathrm{d}}$ database (i.e., $\mathrm{K}_{21}=1.363 \times 10^{-3}$ ). The results of the isotherm model fit are provided in Table 9-3 for comparison to the various other isotherm model fits.

Figure 9-9 illustrates the comparison of the VERSE-LC prediction of the perrhenate exit breakthrough curve versus the IBC Exp-1 cycle 1 column data. Reasonable agreement between the results and the data were achieved. An adsorption isotherm model resulting in slightly lower loadings would produce a more optimal breakthrough prediction.

\subsection{Pilot-Scale Perrhenate (TFL) Tests}

A pilot-scale test facility was designed, built, and operated in the Thermal Fluids Laboratory (TFL) located at the Savannah River Technology Center (SRTC) where the details of these activities is provided by Steimke et al. (2000). This pilot-scale facility attempts to mimic the full-length columns and the expected operational scenarios of the planned ion-exchange system. Nine of the loading cycle experiments, as documented by Steimke et al. (2000), are considered below and are briefly summarized in Table 9-5. Due to solenoid valve leakage, test Run-1 and Run-2 experienced significant bypass flows and no modeling of the test runs was performed. The test runs considered below are discussed in their chronological testing order, as listed in Table 9-5. For all experimental and simulated results it is assumed that rhenium exists only in its perrhenate form. 
Two test series were performed where initially fresh (i.e., no remaining perrhenate loading) lead and lag columns were employed. Each subsequent test run in a series used the previous test run's lag column in its lead column position. As shown in Table 9-5 test runs $(3,2 \mathrm{R}, 4,5)$ and $(6,7,8)$ constitute the two test run series. The feed composition during both test run series remained essentially constant, while the flowrate varied between each test run and sometimes varied during a test run. For each test run series VERSE-LC simulations were performed up to the point in CV's where the loading cycle had been terminated in the experiment. At this point the predicted perrhenate concentration profile for the lag column was stored and used in the subsequent test run, as its lead column pre-loaded profile (along with a fresh lag column). However, to show the overall performance of the columns the predicted breakthrough curves shown below were extended out to $\sim 360 \mathrm{CVs}$.

In order to measure the impact associated with a variation in perrhenate feed concentration, two test runs (i.e., Run-9 and Run-10) were performed where their perrhenate feed concentrations differed by approximately a factor of 2 . Both test runs were performed starting with fresh lead/lag columns and approximately the same volumetric flowrate.

The measured bed density for the TFL columns was $0.527 \mathrm{~g}_{\text {resin }} / \mathrm{ml}_{\mathrm{CV}}$ (i.e., approximately $632.3 \mathrm{~g}$ of resin per column generating an average column volume of $1200 \mathrm{ml}$ ). This represents an $\sim 11 \%$ increase in bed density compared to the smaller-scale test columns. Perhaps the resin exhibits an increased compressibility when wet and for the $\sim 224 \mathrm{~cm}$ high resin columns the resin experiences larger compressive forces resulting in higher bed densities. Most likely, improved packing of the resin beads was achieved due to operating the TFL columns in upflow and downflow, during the initial column pressure drop testing period. The higher bed density also results in a lower bed porosity value of $\sim 0.269$, while the pore porosity, 0.371 , is assumed to be unaffected due to increased bed packing (i.e., particle rearrangement).

For all TFL test runs a Hanford Envelope A waste simulant was used spiked with a known amount of perrhenate (i.e., $6.874 \times 10^{-5} \mathrm{M}[12.8 \mathrm{mg} / \mathrm{L}$ as Re] except for the last run Run- 10 with a concentration of $3.222 \times 10^{-5} \mathrm{M}[6.0 \mathrm{mg} / \mathrm{L}$ as Re]). For all test runs the inlet feed concentration of $\mathrm{NO}_{3}{ }^{-}$was fixed at $1.247 \mathrm{M}$. The measured feed density and viscosity for this simulant at $20^{\circ} \mathrm{C}$ and $5.0 \mathrm{M}[\mathrm{Na}+]$ are $1.225 \mathrm{~g} / \mathrm{ml}$ and $2.95 \mathrm{cp}$, respectively. As shown in Table 9-5, the above perrhenate feed concentrations are the values obtained based on the feed preparation formula. However, for each test run two feed samples were sent for analytical analyses along with the breakthrough samples. In Table 9-5 the average values of the analytical analyses are provided. Since the column exit rhenium concentrations are based on analytical analyses, the average analytical feed values (not the values based on the formula) were used in normalizing the breakthrough curve data, as well as for input to the VERSE-LC simulations.

Due to atmospheric temperature gradients within the TFL building, measured lead column exit temperatures were 18 to $20^{\circ} \mathrm{C}$ while the exit temperatures from the lag column were 22 to $24{ }^{\circ} \mathrm{C}$. Key parameter settings for the column and isotherm modeling are provided in Table 9-2 and Table 9-3, respectively. 


\subsubsection{TFL Run-3 Test}

The $K_{d}$ database adsorption isotherm consistent with the SuperLig ${ }^{\circledR} 639$ resin batch \# 981015DHC720011 was originally used to simulate the Run-3 column test. As demonstrated above, the intermediate-scale perrhenate WK Exp-5 column results were in excellent agreement with the VERSE-LC predictions. However, when using the same set of isotherm model parameter settings the predicted exit perrhenate breakthrough curves were delayed when compared to the Run-3 data set. This comparison is shown in Figure 9-10 where the predicted curves are labeled "original isotherm". Similar behavior (and more progressive departures for pre-loaded test run series) was observed for several of the later TFL test runs, as well.

Adjustments to the column model parameter settings were required to achieve better predictions (particularly for the pre-loaded tests in each series, see Table 9-5). The TFL columns are very long $(\sim 224 \mathrm{~cm})$ and narrow in diameter $(\sim 2.61 \mathrm{~cm})$, the earlier breakthrough behavior may be the result of local channeling within each column. The VERSE-LC model is 1-dimensional and can not directly account for potential radial channeling impacts. However, the net effect of channeling can be approximated as either an effective increase in axial dispersion or an effective reduction in column loading capacity. The predicted exit perrhenate breakthrough curves for a $28 \%$ increased selectivity coefficient $\left(\tilde{\mathrm{K}}_{21}\right)$ and a factor of 100 increase in axial dispersion are shown in Figure 9-10. Based on these results (and results for the subsequent test runs in this series) the $28 \%$ reduced adsorption capacity (obtained by increasing the binary selectivity coefficient) appeared to better predict the various exit breakthrough curves and was chosen as the model parameter setting to be used throughout the remaining TFL test simulations that follow. As shown in Table 4-10 the feed compositions and estimated total ionic strengths of the TFL runs and WK Exp-5 column test are similar, indicating that the discrepancy is not due to differences in simulant formulation. The reason for the discrepancy has not been determined.

Using the modified isotherm model the exit perrhenate breakthrough curve predictions for $\sim 360$ $\mathrm{CV}$ of operation is shown in Figure 9-11. As shown in Figure 9-11, an increased selectivity coefficient of $\sim 28 \%$ was chosen to evenly distribute the prediction errors between the lead and lag columns (i.e., an optimum value for the selectivity coefficient was determined based on comparisons made to all test runs not just Run-3). In some cases the lead column results slightly predict earlier (or later) breakthrough, while the lag column results slightly predict later (or earlier) breakthrough behavior. Overall, the exit breakthrough predictions are very reasonable.

Note that test Run-3 was briefly stopped on the second day of the loading cycle for $\sim 30$ minutes (see Steimke et al., 2000). This short duration of time was not explicitly modeled since its impact (as confirmed by separate analysis) only marginally shifts the predicted breakthrough curves. The flowrate was modeled as a fixed value corresponding to the average flowrate observed over the entire elapsed time (excluding the 30 minute down time) of the loading cycle. Test Run-3 represents the start of a test run series. 


\subsubsection{TFL Run-2R Test}

In test Run-2R the loaded lag column from test Run-3 was placed in the lead column position with a fresh lag column. As indicated in Table 9-5, the flowrate was also reduced by $\sim 33.5 \%$ and held reasonably constant throughout the loading cycle for test Run-2R. The VERSE-LC predicted exit breakthrough curves are shown in Figure 9-12. Inadvertent mixing of two lead column sample vials occurred due to an automatic sampler malfunction, as highlighted (i.e., purple delta symbols) in Figure 9-12. Overall the predictions are excellent when compared to the data.

\subsubsection{TFL Run-4 Test}

In test Run-4 the loaded lag column from test Run-2R was placed in the lead column position with a fresh lag column. As indicated in Table 9-5, the flowrate was held reasonably constant throughout the loading cycle for test Run-4 at the test Run-2R value. The VERSE-LC predicted exit breakthrough curves are shown in Figure 9-13. As shown in Figure 9-13, VERSE-LC predictions are slightly under-predicting the lead breakthrough curve at early process times. Lag column predictions are consistently low compared to the data.

\subsubsection{TFL Run-5 Test}

In test Run-5 (the last run in this series) the loaded lag column from test Run-4 was placed in the lead column position with a fresh lag column. As indicated in Table 9-5, the flowrate was increased by $\sim 44 \%$ and held reasonably constant throughout the loading cycle for test Run-5. The VERSE-LC predicted exit breakthrough curves are shown in Figure 9-14. The growing trend, as seen in the earlier predicted test runs, can now be seen clearly where the VERSE-LC predictions uniformly under-predict the breakthrough data. A slight adjustment could be made to the binary isotherm model that would minimize the errors over the entire test run series (Run-3, 2R, 4, and 5). However, overall the predictions are reasonable when compared to the various test run data.

The predicted perrhenate concentration profiles, at the time when each of the experimental test runs were terminated, are plotted in Figure 9-15. These are curves representing normalized (with respect to feed) perrhenate concentrations versus normalized (with respect to column length) axial distance through both columns. Generally, the column loading increases with each subsequent cycle. However, for Run-5 its profile shape changes due to the significant increase in flowrate. Pre-loaded lead columns with perrhenate loadings at their inlets as high as $\sim 70 \%$ of the feed value are seen.

\subsubsection{TFL Run-6 Test}

As indicated in Table 9-5, test Run-6 represents an initially fresh lead and lag column arrangement. During test Run-6 the flowrate of feed through the columns varied. Early on, the feed flowrate was stopped for approximately 10 hours. The cumulative volume of feed processed versus elapse time is shown in Figure 9-16. The time dependent volumetric feed 
flowrate was computed by taking the derivative of the data provided in Figure 9-16 and is presented in Figure 9-17. Also shown in Figure 9-17 are two VERSE-LC code input feed flowrates. A step function was employed to represent the actual variation in flowrate experienced by the columns (and is referred to as the transient flow input). For comparison purposes to assist in determining the impact that potential flow variations would have on the prediction of the perrhenate breakthrough curves, an overall average feed flowrate (i.e., fixed in time and shown by the dashed line in Figure 9-17) was also considered.

The predicted perrhenate breakthrough curves using both the transient and average flowrate conditions are compared to the experimental data in Figure 9-18. The experimental data for the lead column suggests that either some residual perrhenate existed on the lead column initially (note that this was intended to be a fresh column) or a small quantity ( $2 \%)$ of channeling occurred. No attempt was made in the VERSE-LC model to account for the early on $\sim 2 \%$ offset in lead column exit concentration.

As shown in Figure 9-18, the lead column exit breakthrough curve exhibits a significant kink at approximately 70 hours of elapse time. This corresponds directly with the $35 \%$ reduction in feed flowrate during that time period as shown in Figure 9-17. The earlier time flowrate changes do not show up in the exit breakthrough curve since they occur prior to any significant breakthrough.

The VERSE-LC predictions for the lead column are sensitive to the assumed behavior of the feed flowrate. As shown in Figure 9-18, the predicted lead column breakthrough curve (when an assumed steady-state value for flowrate is used) does not represent the basic shape of the data. On the other hand, the predictions based on the transient flowrate input are in reasonable agreement with the shape of the data. The slope of the breakthrough curve is very consistent with the data just before and after the kink near 70 hours of elapse time. The predictions for the lag column are consistent with the available data points and are not very sensitive to the assumed variation in feed flowrate input.

Using the transient flowrate boundary condition, the complete predicted exit breakthrough curves are shown in Figure 9-19. Overall, the predictions compare well to the available breakthrough data. Test Run- 6 represents the start of the second test run series.

\subsubsection{TFL Run-7 Test}

In test Run-7 the loaded lag column from test Run- 6 was placed in the lead column position with a fresh lag column. As indicated in Table 9-5, the flowrate was also increased by $\sim 63.6 \%$ and held approximately constant throughout the loading cycle for test Run-7. The VERSE-LC predicted exit breakthrough curves are shown in Figure 9-20. Overall the predictions are excellent when compared to the data. Near $60 \mathrm{CV}$ 's the lead column data exhibit a kink indicating that some test condition probably changed. However, no information referring to such changes were recorded. 


\subsubsection{TFL Run-8 Test}

In test Run-8 (the last run in the second series) the loaded lag column from test Run-7 was placed in the lead column position with a fresh lag column. As indicated in Table 9-5, the flowrate was reduced by $\sim 35.5 \%$ and held reasonably constant throughout the loading cycle for test Run-8. The VERSE-LC predicted exit breakthrough curves are shown in Figure 9-21. Overall the predictions are excellent when compared to the data.

The predicted perrhenate concentration profiles, at the time when each of the experimental test runs were terminated, are plotted in Figure 9-22. Generally, the column loading increases with each subsequent cycle. Pre-loaded lead columns with perrhenate loadings at their inlets as high as $\sim 70 \%$ of the feed value are seen.

\subsubsection{TFL Run-9 Test}

As indicated in Table 9-5, test Run-9 represents an initially fresh lead and lag column arrangement. Test Run-9 along with Run-10 provide data on the impact of varying inlet feed perrhenate concentration on exit breakthrough curves. During test Run-9 the flowrate of feed through the columns was held fixed with an inlet perrhenate concentration of $5.9613 \times 10^{-5} \mathrm{M}$ $(11.1 \mathrm{mg} / \mathrm{L}$ as Re). The VERSE-LC predicted exit breakthrough curves are shown in Figure 923. As shown in Figure 9-23, the VERSE-LC predictions are slightly under-predicting the lead breakthrough curve at early process times, while the lag column predictions are reasonable.

\subsubsection{TFL Run-10 Test}

Test Run-10 is a repeat of Run-9 where the inlet perrhenate feed concentration was reduced by approximately a half (i.e., $11.1 \mathrm{mg} / \mathrm{L}$ down to $5.1 \mathrm{mg} / \mathrm{L}$ as $\mathrm{Re}$ ). If the adsorption isotherm were linear with respect to perrhenate concentration, then the transport equation for the perrhenate species becomes linear, the feed concentration of perrhenate can be factored out of the species transport equation effectively normalizing the equation. As such, the normalized perrhenate exit breakthrough curves (i.e., the perrhenate $\mathrm{C} / \mathrm{C}_{\mathrm{o}}$ versus $\mathrm{CV}$ curves) would become independent of the perrhenate feed concentration, $\mathrm{C}_{\mathrm{o}}$. A comparison of breakthrough curves between Run- 9 and Run-10 provides some measure of the linearity of the binary adsorption isotherm for the perrhenate - SuperLig ${ }^{\circledR} 639$ system.

The VERSE-LC predicted exit breakthrough curves for Run-10 are shown in Figure 9-24. As shown in Figure 9-24, the VERSE-LC predictions are under-predicting the lead breakthrough curve at early process times, while the lag column predictions are under-predicted.

In Figure 9-2 the isotherm model used is plotted. Also shown in Figure 9-2 is the range of perrhenate inlet feed conditions. Over the range of perrhenate concentrations experienced by the TFL columns, the adsorption isotherm is relatively linear indicating that the inlet perrhenate feed concentration should have little impact on the normalized breakthrough curves. A comparison of the Run-9 and Run-10 breakthrough data is shown in Figure 9-25 where it is seen that both the lead and lag column data overlap (within experimental error) for each experiment. 


\section{4 'Hot”' Small-Scale Pertechnetate (NH-A) Test}

Batch equilibrium contact tests and column tests were performed using an actual sample of Hanford Envelope A Waste taken from Hanford Tank 241-AN-103. The removal of pertechnetate from the sample was tested using SuperLig ${ }^{\circledR} 639$ batch \# 981015DHC720011 and the test results are documented by Hassan et al. (2000a). The batch contact tests were performed using the first filtrate salt solution with a recorded nitrate concentration of $1.571 \mathrm{M}$, while the column test used a combined filtrate salt solution whose nitrate concentration was $0.998 \mathrm{M}$.

Four separate batch contact tests (plus replicate samples) were performed. One initial contact test followed by two sequential re-contact tests. The fourth test was an initial contact test spiked with additional pertechnetate. The second re-contact test indicated that the non-pertechnetate fraction of the sample is less than 2.3\%. The NH-A contact test data are shown in Figure 9-26 for comparison to the perrhenate data using an Envelope A simulant. The original selectivity coefficient isotherm model is based on perrhenate only $\mathrm{K}_{\mathrm{d}}$ data (i.e., solid blue line). Based on the estimated pertechnetate loadings in the contact experiments an $\sim 76 \%$ increase in loading results in the upper (i.e., green dashed line) isotherm model for pertechnetate. This corresponds to a $\sim 43 \%$ reduction in selectivity coefficient.

Early on, the column beds floated and twice (i.e., once at $\sim 10 \mathrm{CV}$ and then again at $\sim 20 \mathrm{CV}$ ) the flowrate was stopped and the beds were repacked. After the second event, quartz wool and glass beads were placed over the top of each bed to maintain the bed geometry and the test was restarted. In Figure 9-27 a comparison is made between the VERSE-LC predictions versus measured total technetium (i.e., ${ }^{99} \mathrm{Tc}$ ) exit breakthrough curves for the lead and lag columns. The batch and technetium specific isotherm model presented in Figure 9-26, corresponding to the reduced selectivity coefficient (i.e., green dashed line) model, was used in the column simulation. Overall, the general behavior of the predicted and measured breakthrough curves agree; however, the measured lead column breakthrough data exhibit (what appears to be systematic and periodic) variations not accounted for within the model.

A consistent $\sim 7 \%$ shift in the normalized total molar ${ }^{99} \mathrm{Tc}$ breakthrough data was seen beyond 20 CVs. This breakthrough behavior is consistent with the existence of a $\sim 7 \%$ fraction of nonpertechnetate within the feed stream, although other explanations cannot be ruled out. The isotherm models only account for pertechnetate adsorption. Therefore, the VERSE-LC column simulation was performed where the inlet feed concentration of ${ }^{99} \mathrm{Tc}$ was reduced by $7 \%$ to represent only pertechnetate within the feed. Post-processing of the VERSE-LC results were performed to compute the normalized total molar ${ }^{99} \mathrm{Tc}$ breakthrough curves shown in Figure 927. The $7 \%$ breakthrough could initially be due to floating of the resin, causing partial loading of the lag column. If this entirely explained the data, the curve should have exhibited a downward turn after 30-40 CV. Further testing is needed to determine the cause of the passage of technetium in this test.

Overall, the breakthrough curve predictions are in reasonable agreement with the data. However, the data for both columns demonstrate a stair stepping (jagged but systematic) shape that is somewhat unexplainable, but appears to be consistent between each column. 


\section{5 'Hot”' Small-Scale Pertechnetate (NH-B) Test}

Batch equilibrium contact tests and column tests were performed using an actual sample of Hanford Envelope B Waste taken from Hanford Tank 241-AZ-102. The removal of pertechnetate from the sample was tested using SuperLig ${ }^{\circledR} 639$ batch \# 981015DHC720011 and the test results are documented by Hassan et al. (2000d). The batch contact tests were performed using a filtrate salt solution with a recorded nitrate concentration of $0.273 \mathrm{M}$, while the column test used a diluted filtrate salt solution whose nitrate concentration was reduced to $0.2318 \mathrm{M}$. Dilution with $0.25 \mathrm{M} \mathrm{NaOH}$ solution occurred during the preceding $\mathrm{Cs}$ ion exchange test.

Four separate batch contact tests (plus replicate samples) were performed. One initial contact test followed by three sequential re-contact tests. The third re-contact test indicated that the nonpertechnetate fraction of the sample should be less than $0.03 \%$. The subsequent column test supported this near-zero fraction based on the observed exit breakthrough curves for total molar technetium (i.e., pertechnetate plus non-pertechnetate forms). Non-pertechnetate forms are believed to be un-absorbable onto this resin and therefore the fraction of non-pertechnetate within the feed should shift the lead/lag exit breakthrough curves up to this incoming fraction, with a slight delay due to dilution by the resin pretreatment solution.

The pertechnetate adsorption data for the Envelope B waste sample are shown in Figure 9-28 for comparison to the earlier adsorption data sets and to the various isotherm models. For the Envelope B sample the selectivity coefficient must be increased by $\sim 245 \%$ above its value for the Envelope A sample. This shift in loading is most likely a result of differences in total ionic strength. As illustrated in Figure 4-12, the total ionic strength of the Envelope B sample is $~ 50 \%$ of its value for the Envelope A sample. For NH-B column modeling the isotherm represented by the dash-dot-dot (purple) line in Figure 9-28 is employed.

To account for density changes, the flowrate was adjusted during the early stages of the loading cycle and periodically thereafter checked. In Figure 9-29 a comparison is made between the VERSE-LC predictions versus measured total technetium (i.e., ${ }^{99} \mathrm{Tc}$ ) exit breakthrough curves for the lead and lag columns. The batch and technetium specific isotherm model based on the Envelope B waste sample presented in Figure 9-28, corresponding to the increased selectivity coefficient (i.e., purple dot-dot-dashed line) model, was used in the column simulation. Initially (i.e., first $\sim 70 \mathrm{CVs}$ processed), the general behavior of the predicted and measured breakthrough curves agree; however, beyond $70 \mathrm{CVs}$ the measured lead column breakthrough data make an abrupt shift in the shape of its breakthrough curve. A shift of this nature can result from significant changes in either the flowrate, lead column channeling, or the inlet feed concentrations. The lag column results suggest that no significant channeling occurred. No mention of such changes was made in Hassan et al. (2000d). For example, a modest drop in nitrate feed concentration would result in breakthrough curve changes as shown in Figure 9-29.

Both the equilibrium re-contact tests and the lag column breakthrough curves indicate that the fraction of non-pertechnetate in the Envelope B waste sample was very small (i.e., less than $0.03 \%)$. 


\section{6 “Hot" Small-Scale Pertechnetate (NH-SC) Test}

Batch equilibrium contact tests and column tests were performed using an actual sample of Hanford Envelope C Waste taken from Hanford Tank 241-AN-102. This particular sample of Envelope C waste is typically referred to as the "Small-C" (SC) sample. The removal of pertechnetate from this sample was tested using SuperLig ${ }^{\circledR} 639$ batch \# 981015DHC720011 and the test results are documented by Hassan et al. (2000b). The batch contact tests and the column test were performed using the filtrate salt solution with a recorded nitrate concentration of 1.89 M.

Three separate batch contact tests (plus replicate samples) were performed. One initial contact test followed by two sequential re-contact tests. The second re-contact test indicated that the non-pertechnetate fraction of the sample should be less than $75 \%$. Based on mass balance analyses, along with a comparison to similar $\mathrm{K}_{\mathrm{d}}$ data, an estimated fraction of $\sim 73 \%$ appeared to be optimal. Based on the subsequent column test a non-pertechnetate fraction on the order of $60 \%$ was observed from the exit breakthrough curve for total molar technetium.

A comparison of several sets of batch contact test data is shown in Figure 9-30. The data, as well as the isotherm models, presented in Figure 9-30 all pertain to SuperLig ${ }^{\circledR} 639$ batch \# 981015DHC720011 for varying waste envelopes. Increased data scatter is observed in the Small-C adsorption data. A small shift in the assumed initial contact sample's non-pertechnetate fraction results in increasingly larger shifts in the estimated nitrate -to- pertechnetate ratios for the subsequent re-contact tests. The isotherm model corresponding to the Envelope B waste was considered adequate for use to represent the Envelope Small-C waste.

In Figure 9-31 a comparison is made between the VERSE-LC predictions versus measured total technetium (i.e., ${ }^{99} \mathrm{Tc}$ ) exit breakthrough curves for the lead and lag columns. The batch and technetium specific isotherm model based on the Envelope B waste sample presented in Figure 9-28 was used in the column simulation. Significant scatter appears to exist within the exit breakthrough data for both the lead and lag columns. The modest level of predicted pertechnetate breakthrough on each column is consistent with the slight (to none) slope seen in the breakthrough data.

\section{7 “Hot”' Intermediate-Scale Pertechnetate (WK-LC) Test}

Batch equilibrium contact tests and column tests were performed using an actual sample of Hanford Envelope C Waste taken from Hanford Tank 241-AN-102. This particular sample of Envelope C waste is typically referred to as the "Large-C" (LC) sample. In general the composition of ions within the Large-C and Small-C samples should be similar. The equilibrium contact tests for pertechnetate were performed using SuperLig ${ }^{\circledR} 639$ batch \# 981015DHC720011. The removal of pertechnetate from this sample was column tested using a 50:50 mixture by mass of batches \# 981015DHC720011 and \# 990420DHC720067. The contact and column tests are documented by King et al. (2000c). The batch contact tests and the column test were performed using the filtrate salt solution with a recorded nitrate concentration of $1.385 \mathrm{M}$. 
Four separate batch contact tests (plus replicate samples) were performed. One initial contact test followed by two sequential re-contact tests. The fourth test was an initial contact test with spiked pertechnetate concentration. The first re-contact test indicated that the non-pertechnetate fraction of the sample should be less than $87 \%$. An increased total molar ${ }^{99} \mathrm{Tc}$ concentration in the final liquid sample during the second re-contact test disqualified this re-contact test. Based on the subsequent column test a non-pertechnetate fraction on the order of $70 \%$ was observed from the exit breakthrough curve for total molar technetium.

A comparison of several sets of batch contact test data is shown in Figure 9-32. The data, as well as the isotherm models, presented in Figure 9-32 all pertain to SuperLig ${ }^{\circledR} 639$ batch \# 981015DHC720011 for varying waste envelopes (i.e., Env. A, B, Small-C, and Large-C). The Large- $\mathrm{C}$ adsorption data appear to be following the adsorption isotherm data for the perrhenate study. The isotherm model corresponding to the Envelope A perrhenate simulant was considered adequate for use to represent the Envelope Large-C waste. Note that the adsorption isotherm for Large-C is higher than for Small-C as shown in Figure 9-32. The Large-C sample has a lower ionic strength than the Small-C sample (i.e., $\sim 4.36$ versus $\sim 5.57$ as listed in Table 4-10). The adsorption data for Small-C appears to be inconsistent with Large-C, as well as the other samples considered, as shown in Figure 4-12 where loading level generally increases with ionic strength.

In Figure 9-33 a comparison is made between the VERSE-LC predictions versus measured total technetium (i.e., ${ }^{99} \mathrm{Tc}$ ) exit breakthrough curves for the lead and lag columns. The batch and technetium specific isotherm model based on the Envelope A perrhenate simulant presented in Figure 9-32 was used in the column simulation. Modest scatter appears to exist within the exit breakthrough data for both the lead and lag columns. During the first $20 \mathrm{CVs}$, mixing in the head space results in a gradual rise in the breakthrough data that levels off at approximately $70 \%$ for both the lead and lag columns. This data indicates that $\sim 70 \%$ of the feed technetium was in the non-pertechnetate form and beyond $20 \mathrm{CVs}$ no apparent breakthrough of pertechnetate can be seen based on the breakthrough data itself. On the other hand, the VERSE-LC predictions indicate that an $\sim 10 \%$ increase in exit breakthrough for the lead column should have occurred (i.e., $33 \%$ increase on a pertechnetate only basis). However, given the variability in the measured technetium exit concentrations, no such confirmation can be drawn.

\section{8 “Hot”' Intermediate-Scale Pertechnetate (SRS Tank 44F) Test}

Initial interest in treating the SRS sample for pertechnetate removal resulted from the similarity between the Tank 44F supernate composition and the Hanford Envelope A supernate solutions, as discussed by King et al. (2000b). However, nitrate ion, $\left[\mathrm{NO}_{3}{ }^{-}\right]$, concentrations in the sample are lower than those use in the Envelope A studies (i.e., $\sim 0.50 \mathrm{M}$ as compared to $\sim 1.57 \mathrm{M}$ for NH-A sample). See Table 4-10 for a comparison of the ionic concentration of various other species present between the Tank 44F sample and Hanford Envelope samples.

A 50:50 mixture by mass of batches \# 981015DHC720011 and \# 990420DHC720067 were used to develop the resin column. The measured mixture bed density for the SRS Tank 44F column was $0.479 \mathrm{~g}_{\mathrm{resin}} / \mathrm{ml}_{\mathrm{CV}}$ (i.e., $23.99 \mathrm{~g}$ of resin generating a column volume of $50.1 \mathrm{ml}$ ). This is in 
reasonable agreement with the 50:50 mixture average value of 0.4735 , as computed using the pure batch densities as measured individually by Hassan et al. (1999a).

A comparison of predicted versus measured (i.e., based on batch equilibrium contact tests, see King et al. (2000b)) equilibrium pertechnetate loadings on the SuperLig ${ }^{\circledR} 639$ resin are shown in Figure 9-34. Two separate adsorption isotherm model predictions are shown: (1) the original model based on pertechnetate adsorption from Envelope A samples (i.e., NH-A) evaluated at a nitrate concentration of $0.495 \mathrm{M}$ (i.e., recorded SRS value given by King et al., 2000b) and (2) the same isotherm model evaluated at a lower nitrate concentration of $0.37 \mathrm{M}$ (i.e., an earlier recorded SRS value given by Walker, 1999). The first isotherm model was considered since it represents our analysis methodology. The second isotherm model represents a lower nitrate feed concentration consistent with earlier sample analytical analyses of the Tank 44F solution. The batch contact test data (i.e., a single value with one replicate) shown in Figure 9-34 applies only to batch \# 981015DHC720011 resin.

Potential differences between the SRS Tank 44F sample and the Hanford Envelope A waste (as shown in Table 4-10) may have had an important impact (e.g., a shift in the level of components other than nitrate ions). For example, the hydroxyl ion concentration of the Tank 44F sample is $\sim 4.40 \mathrm{M}$ while for the Envelope A sample it is $2.17 \mathrm{M}$. As seen in Figure 9-34 the pertechnetate loadings for the Tank 44F sample fall beneath the predicted loadings for Envelope A waste (i.e., an $\sim 45 \%$ reduced loading).

Using the two isotherm models described above, VERSE-LC simulations of the loading cycle were performed. The two VERSE-LC pertechnetate exit breakthrough curves are compared to the column data (King et al., 2000b) in Figure 9-35. The "original" isotherm model coincides with the projected data at $50 \%$ breakthrough; however, the shape of the predicted breakthrough is much flatter. Delayed breakthrough occurs when the "lower nitrate feed concentration" isotherm model is employed. However, the lower nitrate feed concentration along with a lower loading isotherm model may provide reasonable breakthrough predictions, as well. The actual breakthrough data appears to fall in between these two estimates with neither curve exhibiting the shape of the data. 
Table 9-1. Key features of Pertechnetate (perrhenate)-SuperLig ${ }^{\circledR} 639$ fixed bed full-, pilot-, intermediate-, and small-scale columns.

\begin{tabular}{|c|c|c|c|c|c|c|c|c|}
\hline $\begin{array}{l}\text { Column } \\
\text { ID }^{a}\end{array}$ & $\begin{array}{l}\text { Active bed } \\
\text { volume } \\
\text { (ml) }\end{array}$ & $\begin{array}{c}\text { Diameter } \\
(\mathbf{c m})\end{array}$ & $\begin{array}{l}\text { Length } \\
\text { (cm) }\end{array}$ & $\begin{array}{l}\text { Column-to- } \\
\text { particle } \\
\text { diameter } \\
\text { ratio }\end{array}$ & $\begin{array}{l}\text { Superficial } \\
\text { velocity } \\
(\mathrm{cm} / \mathrm{min})\end{array}$ & $\mathrm{CV} / \mathrm{hr}$ & $\begin{array}{c}\text { Feed conc.: } \\
\text { total } \mathrm{X}[\mathrm{M}] \\
\mathrm{XO}_{4}^{-}[\mathrm{M}] \\
\mathrm{NO}_{3}^{-}[\mathrm{M}]\end{array}$ & Comments $^{b}$ \\
\hline $\begin{array}{l}\text { Full scale plant } \\
\text { (FSP: } X=T c)\end{array}$ & $1.047 \times 10^{6}$ & 77.0 & 225.0 & 1,021 & 11.3 & 3.0 & $\begin{array}{c}\text { Ranges over } \\
\text { waste tanks }\end{array}$ & $\begin{array}{c}\text { End-effects \& flow } \\
\text { maldistribution unlikely }\end{array}$ \\
\hline $\begin{array}{c}\text { Pilot scale } \\
\text { (TFL: X=Re) }\end{array}$ & 1,200 & 2.614 & 223.7 & 35 & $\begin{array}{c}6.2 \\
\text { to } \\
10.4\end{array}$ & $\begin{array}{l}1.65 \\
\text { to } \\
2.78\end{array}$ & $\begin{array}{c}2 \text { to } 7 \times 10^{-5} \mathrm{M} \\
2 \text { to } 7 \times 10^{-5} \mathrm{M} \\
1.247 \mathrm{M}\end{array}$ & $\begin{array}{c}\text { Envelope A; End-effects } \\
\text { unlikely; partially loaded test } \\
\text { series performed }\end{array}$ \\
\hline $\begin{array}{l}\text { Intermediate scale } \\
\text { Vendor tests } \\
\text { (IBC: } X=\mathrm{Re})\end{array}$ & 205.3 & 3.3 & 24.0 & 44 & 6.4 & 16.0 & $\begin{array}{c}1.0 \times 10^{-4} \mathrm{M} \\
1.0 \times 10^{-4} \mathrm{M} \\
2.47 \mathrm{M} \\
\end{array}$ & $\begin{array}{c}\text { Early on tests; Envelope A; batch } \\
\text { ID not specified }\end{array}$ \\
\hline $\begin{array}{l}\text { Intermediate scale } \\
\quad(\mathrm{WK}: \mathrm{X}=\mathrm{Re})\end{array}$ & $\begin{array}{l}50.0 \\
\text { to } \\
51.1\end{array}$ & $\begin{array}{c}2.69 \\
\text { to } \\
4.0\end{array}$ & $\begin{array}{l}4.07 \\
\text { to } \\
8.99\end{array}$ & $\begin{array}{l}36 \\
\text { to } \\
53\end{array}$ & $\begin{array}{l}0.51 \\
\text { to } \\
11.0\end{array}$ & $\begin{array}{c}3.4 \\
\text { to } \\
73.4\end{array}$ & $\begin{array}{c}7 \text { to } 9 \times 10^{-5} \mathrm{M} \\
7 \text { to } 9 \times 10^{-5} \mathrm{M} \\
1.25 \mathrm{M}\end{array}$ & $\begin{array}{l}\text { Envelope A; used to assess } \\
\text { dispersion and mass transfer } \\
\text { coef. correlations }\end{array}$ \\
\hline $\begin{array}{l}\text { Intermediate scale } \\
(\mathrm{WK}-\mathrm{LC}: \mathrm{X}=\mathrm{Tc})\end{array}$ & 147.4 & 2.69 & 51.87 & 36 & 0.93 & 2.15 & $\begin{array}{c}4.353 \times 10^{-5} \mathrm{M} \\
1.306 \times 10^{-5} \mathrm{M} \\
1.385 \mathrm{M}\end{array}$ & $\begin{array}{l}\text { Envelope Large-C; oversized } \\
\text { columns resulting low } \\
\text { breakthrough values }\end{array}$ \\
\hline $\begin{array}{l}\text { Intermediate scale } \\
\quad(\mathrm{SRS}: \mathrm{X}=\mathrm{Tc})\end{array}$ & 50.1 & 2.7 & 8.75 & 36 & 0.45 & 3.1 & $\begin{array}{c}3.12 \times 10^{-5} \mathrm{M} \\
3.12 \times 10^{-5} \mathrm{M} \\
0.495 \mathrm{M} \\
\end{array}$ & $\begin{array}{c}\text { Savannah River Tank 44F waste } \\
\text { sample considered }\end{array}$ \\
\hline $\begin{array}{c}\text { Small scale } \\
(\mathrm{NH}-\mathrm{A}: \mathrm{X}=\mathrm{Tc})\end{array}$ & $\bar{~} 5.1$ & $\bar{~} 1.1$ & 10.73 & 15 & "0.27 & 3.0 & $\begin{array}{c}2.582 \times 10^{-5} \mathrm{M} \\
2.401 \times 10^{-5} \mathrm{M} \\
0.998 \mathrm{M}\end{array}$ & $\begin{array}{l}\text { Envelope } \mathrm{A} ; \sim 93 \% \mathrm{TcO}_{4}^{-} \text {in } \\
\text { feed; end-effects and flow } \\
\text { maldistribution possible }\end{array}$ \\
\hline $\begin{array}{c}\text { Small scale } \\
(\mathrm{NH}-\mathrm{B}: \mathrm{X}=\mathrm{Tc})\end{array}$ & 5.5 & 1.1 & 11.57 & 15 & 0.29 & 3.0 & $\begin{array}{c}1.324 \times 10^{-4} \mathrm{M} \\
1.324 \times 10^{-4} \mathrm{M} \\
0.232 \mathrm{M}\end{array}$ & $\begin{array}{l}\text { Envelope } \mathrm{B} ; \sim 100 \% \mathrm{TcO}_{4}^{-} \text {in } \\
\text { feed; end-effects and flow } \\
\text { maldistribution possible }\end{array}$ \\
\hline $\begin{array}{c}\text { Small scale } \\
(\mathrm{NH}-\mathrm{SC}: \mathrm{X}=\mathrm{Tc})\end{array}$ & 5.6 & 1.1 & 11.79 & 15 & 0.29 & 3.0 & $\begin{array}{c}4.732 \times 10^{-5} \mathrm{M} \\
1.893 \times 10^{-5} \mathrm{M} \\
1.89 \mathrm{M}\end{array}$ & $\begin{array}{c}\text { Envelope Small-C; } \sim 40 \% \mathrm{TcO}_{4}^{-} \\
\text {in feed; end-effects and flow } \\
\text { maldistribution possible }\end{array}$ \\
\hline
\end{tabular}

b The fraction of non-pertechnetate (or non-perrhenate) in the feed was not directly measured, but inferred from the total molar exit breakthrough curves 
Table 9-2. Summary of recommended nominal parameter settings for Pertechnetate (perrhenate)-SuperLig ${ }^{\circledR} 639$ system column modeling.

\begin{tabular}{|c|c|c|c|c|}
\hline $\begin{array}{c}\text { Key } \\
\text { parameter }\end{array}$ & Definition & $\begin{array}{c}\text { Priority for } \\
\text { predicting } \\
\text { break-through } \\
\text { curve }\end{array}$ & Recommended B. E. settings & Comments \\
\hline$m_{\text {re sin }}$ & mass of resin in column & 1 & column specific & $\begin{array}{l}\text { Key quantity generally assumed to be a } \\
\text { constant during a series of column runs. }\end{array}$ \\
\hline$\overline{\mathrm{C}}_{\mathrm{T}}$ & $\begin{array}{l}\text { total ionic capacity of } \\
\text { resin }\end{array}$ & 1 & $\begin{array}{l}\text { Batch material specific } \\
\quad\left(\text { mmole } / \mathrm{g}_{\text {resin }}\right) \\
\text { [see Table } 9-3 \text { for values] }\end{array}$ & $\begin{array}{l}\text { Batch and feed specific, and based on available } \\
\text { equilibrium contact } \mathrm{K}_{\mathrm{d}} \text { data when available. }\end{array}$ \\
\hline$\rho_{b}$ & bed density & 1 & $\begin{array}{l}\text { Column and batch specific } \\
\qquad\left(\mathrm{g}_{\text {resin }} / \mathrm{ml}_{\mathrm{CV}}\right) \\
\text { [see Table } 9-3 \text { for values] }\end{array}$ & $\begin{array}{l}\text { Ideally computed for each column. Batch } \\
\text { specific generic values used otherwise. }\end{array}$ \\
\hline$\tilde{\mathrm{K}}_{12}$ & $\begin{array}{l}\mathrm{XO}_{4}^{-} \text {to } \mathrm{NO}_{3}^{-} \\
\text {selectivity coefficient }\end{array}$ & 1 & $\begin{array}{l}\text { Total ionic strength and } \\
\text { composition dependent } \\
\text { [see Table 9-3 for values] }\end{array}$ & $\begin{array}{l}\text { Based on conc's not activities and valid for } \\
\qquad \mathrm{X}=\mathrm{Tc} \text { (or Re); not batch specific. }\end{array}$ \\
\hline $\mathrm{L}, \mathrm{D}, \mathrm{V}_{\mathrm{b}}$ & $\begin{array}{l}\text { Length, diameter, \& } \\
\text { volume of column }\end{array}$ & 1 & column specific & $\begin{array}{l}\text { Does not vary significantly with total ionic } \\
\text { strength. }\end{array}$ \\
\hline$<\mathrm{R}_{\mathrm{p}}>$ & $\begin{array}{l}\text { avg. effective radius of } \\
\text { resin }\end{array}$ & 2 & $\begin{array}{c}337 \mu \mathrm{m} \\
\text { (mean value) }\end{array}$ & $\begin{array}{l}\text { Impacts both film and pore diffusion. } \\
\text { Averaging process remains in question. }\end{array}$ \\
\hline $\mathrm{U}, \mathrm{Q}$ & $\begin{array}{l}\text { superficial velocity } \& \\
\text { volumetric flow rate }\end{array}$ & 2 & column specific & $\begin{array}{l}\text { For mass transfer limited columns flow } \\
\text { perturbation dependent. }\end{array}$ \\
\hline $\mathrm{C}_{\mathrm{o}}$ & $\begin{array}{c}\mathrm{XO}_{4}^{-} \& \mathrm{NO}_{3}^{-} \text {inlet } \\
\text { conc's }\end{array}$ & 2 & column specific & $\begin{array}{l}\text { For favorable isotherms higher inlet conc's } \\
\text { sharpen breakthru curves. Only a slightly } \\
\text { favorable adsorption isotherm. }\end{array}$ \\
\hline
\end{tabular}


Table 9-2. Summary of recommended nominal parameter settings for Pertechnetate (perrhenate)-SuperLig ${ }^{\circledR} 639$ system column modeling (continued).

\begin{tabular}{|c|c|c|c|c|}
\hline $\begin{array}{c}\text { Key } \\
\text { parameter }\end{array}$ & Definition & $\begin{array}{l}\text { Priority for } \\
\text { predicting } \\
\text { break-through } \\
\text { curve }\end{array}$ & Recommended B. E. settings & Comments \\
\hline$\varepsilon_{\mathrm{b}}, \varepsilon_{\mathrm{p}}$ & $\begin{array}{l}\text { bed \& particle } \\
\text { porosities }\end{array}$ & 3 & $\begin{array}{c}0.357 \& 0.371 \\
\text { (for nominal conditions) } \\
0.269 \& 0.371 \\
\text { (for TFL column conditions) }\end{array}$ & $\begin{array}{l}\text { Bed porosity based on IBC measurements. } \\
\text { Particle porosity based on batch avg. bed } \\
\text { density of } 0.4875 \mathrm{~g} / \mathrm{ml} \text {. }\end{array}$ \\
\hline $\mathrm{D}_{\mathrm{p}}$ & $\begin{array}{l}\text { pore diffusion } \\
\text { coefficient }\end{array}$ & 3 & $35 \%$ of Brownian diffusion value & $\begin{array}{l}\text { Pores assumed to be relatively large with low } \\
\text { tortuosity. }\end{array}$ \\
\hline $\mathrm{k}_{\mathrm{f}}$ & $\begin{array}{l}\text { liquid film mass transfer } \\
\text { coefficient }\end{array}$ & 3 & $\begin{array}{l}\text { Wilson and Geankoplis (1966) } \\
\text { correlation }\end{array}$ & $\begin{array}{c}\text { This correlation spans the velocity \& particle } \\
\text { sizes of resin. }\end{array}$ \\
\hline $\mathrm{D}_{\infty}$ & $\begin{array}{l}\text { Brownian motion } \\
\text { diffusion coefficient }\end{array}$ & 3 & $\begin{array}{c}\mathrm{TcO}_{4}^{-} \quad 2.004 \times 10^{-4} \mathrm{~cm}^{2} / \mathrm{min} \\
\mathrm{ReO}_{4}^{-} 2.004 \times 10^{-4} \mathrm{~cm}^{2} / \mathrm{min} \\
\mathrm{NO}_{3}^{-} 2.252 \times 10^{-4} \mathrm{~cm}^{2} / \mathrm{min}\end{array}$ & $\begin{array}{l}\text { Based on Nernst-Haskell eqn. \& published } \\
\text { ionic conductances at } 25^{\circ} \mathrm{C} . \mathrm{TcO}_{4}^{-} \text {anion } \\
\text { conductance assumed equal to } \mathrm{ReO}_{4}^{-} \text {anion } \\
\text { value. }\end{array}$ \\
\hline $\mathrm{E}_{\mathrm{b}}$ & $\begin{array}{l}\text { axial longitudinal } \\
\text { dispersion coefficient }\end{array}$ & 4 & Chung \& Wen (1968) correlation & $\begin{array}{l}\text { This correlation based on long column data for } \\
\text { wide range of column conditions. }\end{array}$ \\
\hline $\mathrm{E}_{\mathrm{b}}(\mathrm{L}) / \mathrm{E}_{\mathrm{b}}(\infty)$ & $\begin{array}{l}\text { short column impact } \\
\text { ratio }\end{array}$ & 4 & Liles \& Geankoplis (1960) data & $\begin{array}{l}\text { Power law fit to limited short column tests with } \\
\text { end effects. }\end{array}$ \\
\hline $\mathrm{V}_{\mathrm{CSTR}}$ & $\begin{array}{l}\text { CSTR volumes at } \\
\text { entrance/exit of } \\
\text { columns }\end{array}$ & 4 & column specific & $\begin{array}{c}\text { Estimated based on specified volumes for each } \\
\text { test series. }\end{array}$ \\
\hline
\end{tabular}




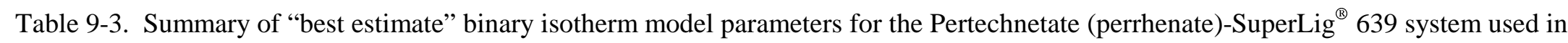
column assessment studies.

\begin{tabular}{|c|c|c|c|c|c|c|}
\hline $\begin{array}{l}\text { Test } \\
\text { ID }\end{array}$ & Batch ID & Waste type & $\begin{array}{l}\text { Bed density } \\
, \rho_{\mathrm{b}} \\
{\left[\mathrm{g}_{\mathrm{resin}} / \mathrm{ml}_{\mathrm{CV}}\right]}\end{array}$ & $\begin{array}{c}\begin{array}{c}\text { Selectivity } \\
\text { coefficient } \\
{ }^{\text {a }}\end{array} \\
\tilde{\mathrm{K}}_{21} \\
{[-]}\end{array}$ & $\begin{array}{c}\text { Total ionic } \\
\text { capacity of resin } \\
\overline{\mathrm{C}}_{\mathrm{T}} \\
{\left[\mathrm{mmole} / \mathrm{g}_{\text {resin }}\right]}\end{array}$ & Comments \\
\hline $\begin{array}{c}\text { WK Exp- } \\
\mathbf{1 , 2 , 3 , 4}\end{array}$ & 980624001DC & $\begin{array}{l}\text { Env. A simulant } \\
\quad\left(\mathrm{ReO}_{4}^{-}\right)\end{array}$ & 0.489 & $1.3630 \times 10^{-3}$ & 0.3466 & $\begin{array}{l}\text { Non-perrhenate of } 0 \% \text { assumed. } \\
\text { Measured bed density by Hassan et al. } \\
\text { (1999a). }\end{array}$ \\
\hline WK Exp-5 & $\begin{array}{c}\text { 50:50 mix of } \\
\text { 990420DHC720067 } \\
\text { 981015DHC720011 }\end{array}$ & $\begin{array}{l}\text { Env. A simulant } \\
\quad\left(\mathrm{ReO}_{4}^{-}\right)\end{array}$ & 0.4735 & $1.3630 \times 10^{-3}$ & 0.6472 & $\begin{array}{l}\text { Non-perrhenate of } 0 \% \text { assumed. } \\
\text { Capacity based on } 100 \% \text { of batch ID } \\
\text { 981015DHC720011 (not explainable). } \\
\text { Avg. bed density of batches used. }\end{array}$ \\
\hline IBC Exp-1 & Not reported & Simulant range & 0.400 & $1.1269 \times 10^{-3}$ & 0.5066 & $\begin{array}{l}\text { Non-perrhenate of } 0 \% \text { assumed. Bed } \\
\text { density and total capacity reported by } \\
\text { vendor used. }\end{array}$ \\
\hline $\begin{array}{l}\text { TFL Runs } \\
\text { (all tests) }\end{array}$ & $\begin{array}{c}\text { 50:50 mix of } \\
\text { 990420DHC720067 } \\
\text { 981015DHC720011 }\end{array}$ & $\begin{array}{l}\text { Env. A simulant } \\
\quad\left(\mathrm{ReO}_{4}^{-}\right)\end{array}$ & 0.527 & $1.7500 \times 10^{-3}$ & 0.6472 & $\begin{array}{l}\text { Non-perrhenate of } 0 \% \text { assumed. TFL } \\
\text { measured bed density higher than } \\
\text { smaller column measurements (better } \\
\text { packing perhaps). }\end{array}$ \\
\hline NH-A & 981015DHC720011 & $\begin{array}{l}\text { Env. A sample } \\
\text { 241-AN-103 } \\
\left(\mathrm{TcO}_{4}^{-}\right)\end{array}$ & 0.468 & $7.7418 \times 10^{-4}$ & 0.6472 & $\begin{array}{c}\text { Non-pertechnetate } \sim 7 \% \text { based on } \\
\text { column test. Measured bed density by } \\
\text { Hassan et al. (1999a). }\end{array}$ \\
\hline NH-B & 981015DHC720011 & $\begin{array}{l}\text { Env. B sample } \\
\text { 241-AZ-102 } \\
\left(\mathrm{TcO}_{4}^{-}\right)\end{array}$ & 0.468 & $2.6735 \times 10^{-3}$ & 0.6472 & $\begin{array}{c}\text { Non-pertechnetate }<0.03 \% \text { based on } \\
\text { column test. Measured bed density by } \\
\text { Hassan et al. (1999a). }\end{array}$ \\
\hline NH-SC & 981015DHC720011 & $\begin{array}{l}\text { Env. “Small”-C } \\
\text { 241-AN-102 } \\
\left(\mathrm{TcO}_{4}^{-}\right)\end{array}$ & 0.468 & $2.6735 \times 10^{-3}$ & 0.6472 & $\begin{array}{c}\text { Non-pertechnetate } \sim 60 \% \text { based on } \\
\text { column test. Measured bed density by } \\
\text { Hassan et al. (1999a). }\end{array}$ \\
\hline
\end{tabular}




\begin{tabular}{|c|c|c|c|c|c|c|}
\hline $\begin{array}{c}\text { Test } \\
\text { ID }\end{array}$ & Batch ID & Waste type & $\begin{array}{l}\text { Bed density } \\
\qquad, \rho_{b} \\
{\left[g_{\text {resin }} / \mathbf{m l}_{\mathrm{CV}}\right]}\end{array}$ & $\begin{array}{l}\begin{array}{c}\text { Selectivity } \\
\text { coefficient }\end{array}{ }^{\text {, }} \text {, } \\
\tilde{\mathrm{K}}_{21} \\
{[-]}\end{array}$ & $\begin{array}{c}\text { Total ionic } \\
\text { capacity of resin }^{\mathrm{b}}, \\
\overline{\mathrm{C}}_{\mathrm{T}} \\
{\left[\mathrm{mmole} / \mathrm{g}_{\mathrm{resin}}\right]}\end{array}$ & Comments \\
\hline WK-LC & $\begin{array}{c}\text { 50:50 mix of } \\
\text { 990420DHC720067 } \\
\text { 981015DHC720011 }\end{array}$ & $\begin{array}{l}\text { Env. "Large"-C } \\
\text { 241-AN-102 } \\
\left(\mathrm{TcO}_{4}^{-}\right)\end{array}$ & 0.4735 & $1.3630 \times 10^{-3}$ & 0.6472 & $\begin{array}{l}\text { Non-pertechnetate } \sim 70 \% \text { based on } \\
\text { column test. Avg. bed density of } \\
\text { batches used. }\end{array}$ \\
\hline WK-SRS & $\begin{array}{c}\text { 50:50 mix of } \\
\text { 990420DHC720067 } \\
\text { 981015DHC720011 }\end{array}$ & $\begin{array}{l}\text { SRS sample } \\
\text { Tank 44F } \\
\left(\mathrm{TcO}_{4}^{-}\right)\end{array}$ & 0.4788 & $\begin{array}{c}7.7418 \times 10^{-4} \\
\text { (based on } \\
\text { Env. A } \\
\text { contact data) }\end{array}$ & 0.6472 & $\begin{array}{c}\text { Non-pertechnetate }>2 \% \text { based on } \\
\text { column test. Measured bed density } \\
\text { used. }\end{array}$ \\
\hline
\end{tabular}

${ }^{\mathrm{a}}$ Based on the equilibrium contact data it is believed that the selectivity coefficient of SuperLig ${ }^{\circledR} 639$ resin between nitrate and pertechnetate differs from its value between nitrate and perrhenate. The selectivity coefficients are most likely total ionic strength and anion composition dependent; however, if these variables are held fixed it is believed that similar values for the selectivity coefficients for differing batch materials will be achieved.

b It is assumed that the total ionic capacity of the SuperLig ${ }^{\circledR} 639$ resin is primarily batch dependent with little dependence on total ionic strength of the solution or on the type/composition of competing anions (e.g., nitrate, pertechnetate, or perrhenate). 
Table 9-4. Unique test conditions for WK test runs.

\begin{tabular}{|c|c|c|c|c|c|}
\hline $\begin{array}{l}\text { Experiment ID } \\
\text { (listed in } \\
\text { chronological } \\
\text { order of } \\
\text { testing) }\end{array}$ & $\begin{array}{c}\text { SuperLig }^{\circledR} 639 \text { resin } \\
\text { batch }^{\text {ID }^{\mathrm{a}}}\end{array}$ & $\begin{array}{l}\text { Column } \\
\text { size } \\
\text { length/ } \\
\text { diameter } \\
(\mathrm{cm} / \mathrm{cm})\end{array}$ & $\begin{array}{c}\text { Average } \\
\text { Volumetric } \\
\text { Flowrate } \\
\text { (CV/hr) }\end{array}$ & $\begin{array}{l}\text { Superficial } \\
\text { velocity } \\
(\mathrm{cm} / \mathrm{min})\end{array}$ & $\begin{array}{c}\mathrm{ReO}_{4}^{-} \\
\text {feed } \\
\text { concentration } \\
{[\mathrm{M}]} \\
(\mathrm{mg} / \mathrm{L})\end{array}$ \\
\hline WK Exp-1 & $100 \% 980624001 \mathrm{DC}$ & $\begin{array}{l}8.991 / \\
2.69\end{array}$ & 3.403 & 0.51 & $\begin{array}{l}8.593 \times 10^{-5} \\
(16.0)\end{array}$ \\
\hline WK Exp-2 & $\begin{array}{l}\text { Column WK Exp-1 } \\
\text { reused }\end{array}$ & $\begin{array}{l}8.991 / \\
2.69\end{array}$ & 34.700 & 5.20 & $\begin{array}{l}8.539 \times 10^{-5} \\
(15.9)\end{array}$ \\
\hline WK Exp-3 & $\begin{array}{c}\text { Column WK Exp-2 } \\
\text { reused }\end{array}$ & $\begin{array}{l}8.991 / \\
2.69\end{array}$ & 73.404 & 11.00 & $\begin{array}{l}8.593 \times 10^{-5} \\
(16.0)\end{array}$ \\
\hline WK Exp-4 & $\begin{array}{l}\text { Resin used in Exp-1,2,3 } \\
\text { reused }\end{array}$ & $\begin{array}{c}4.066 / \\
4.0\end{array}$ & 7.082 & 0.48 & $\begin{array}{l}7.519 \times 10^{-5} \\
(14.0)\end{array}$ \\
\hline WK Exp-5 & $\begin{array}{l}50 \% 981015 \mathrm{DHC} 720011 \\
50 \% 990420 \mathrm{DHC} 720067\end{array}$ & $\begin{array}{c}8.798 / \\
2.69\end{array}$ & 2.933 & 0.43 & $\begin{array}{c}7.519 \times 10^{-5} \\
(14.0)\end{array}$ \\
\hline
\end{tabular}

${ }^{a}$ Columns were all assumed to be initially fresh at start of loading cycle (i.e., perrhenate free).

Table 9-5. Unique test conditions for TFL test runs.

\begin{tabular}{|c|c|c|c|c|}
\hline $\begin{array}{c}\text { Experiment ID } \\
\text { (listed in } \\
\text { chronological } \\
\text { order of testing) }\end{array}$ & $\begin{array}{c}\text { Initial } \\
\text { Condition of } \\
\text { Lead Column }\end{array}$ & $\begin{array}{c}\text { Flowrate } \\
\text { Variation }\end{array}$ & $\begin{array}{c}\text { Average } \\
\text { Volumetric } \\
\text { Flowrate } \\
\text { (CV/hr) }\end{array}$ & $\begin{array}{c}\mathbf{R e O}_{4}^{-} \\
\text {feed concentration } \\
{[\mathbf{M}] /(\mathbf{m g} / \mathbf{L})}\end{array}$ \\
\hline \hline TFL Run-1 & \multicolumn{3}{|c|}{ Not analyzed in this report (solenoid leakage concerns) } \\
\hline TFL Run-2 & \multicolumn{2}{|c|}{ Not analyzed in this report (solenoid leakage concerns) } \\
\hline \hline TFL Run-3 & fresh & fixed & 2.783 & $6.3015 \times 10^{-5}(11.0)$ \\
\hline TFL Run-2R & Run-3 loaded & fixed & 1.850 & $5.3437 \times 10^{-5}(9.95)$ \\
\hline TFL Run-4 & Run-2R loaded & fixed & 1.842 & $6.2030 \times 10^{-5}(11.55)$ \\
\hline TFL Run-5 & Run-4 loaded & fixed & 2.625 & $6.4447 \times 10^{-5}(12.0)$ \\
\hline \hline TFL Run-6 & fresh & transient & 1.650 & $6.1493 \times 10^{-5}(11.45)$ \\
\hline TFL Run-7 & Run-6 loaded & $\sim$ fixed & 2.700 & $6.2030 \times 10^{-5}(11.55)$ \\
\hline TFL Run-8 & Run-7 loaded & fixed & 1.741 & $6.8475 \times 10^{-5}(12.75)$ \\
\hline \hline TFL Run-9 & fresh & fixed & 3.358 & $5.9613 \times 10^{-5}(11.1)$ \\
\hline \hline TFL Run-10 & fresh & fixed & 3.300 & $2.7390 \times 10^{-5}(5.1)$ \\
\hline
\end{tabular}

${ }^{a}$ Lag columns were all assumed to be initially fresh (i.e., perrhenate free).

b A column volume of $1.2 \mathrm{~L}$ was assumed for both the lead and lag columns.

${ }^{c}$ The feed formula for Runs 1 through 9 resulted in $12.8 \mathrm{mg} / \mathrm{L}$ and for Run $106.0 \mathrm{mg} / \mathrm{L}$. However, the average values from analytical analyses are presented and used as $C_{0}$ for normalizing breakthrough curve data. 


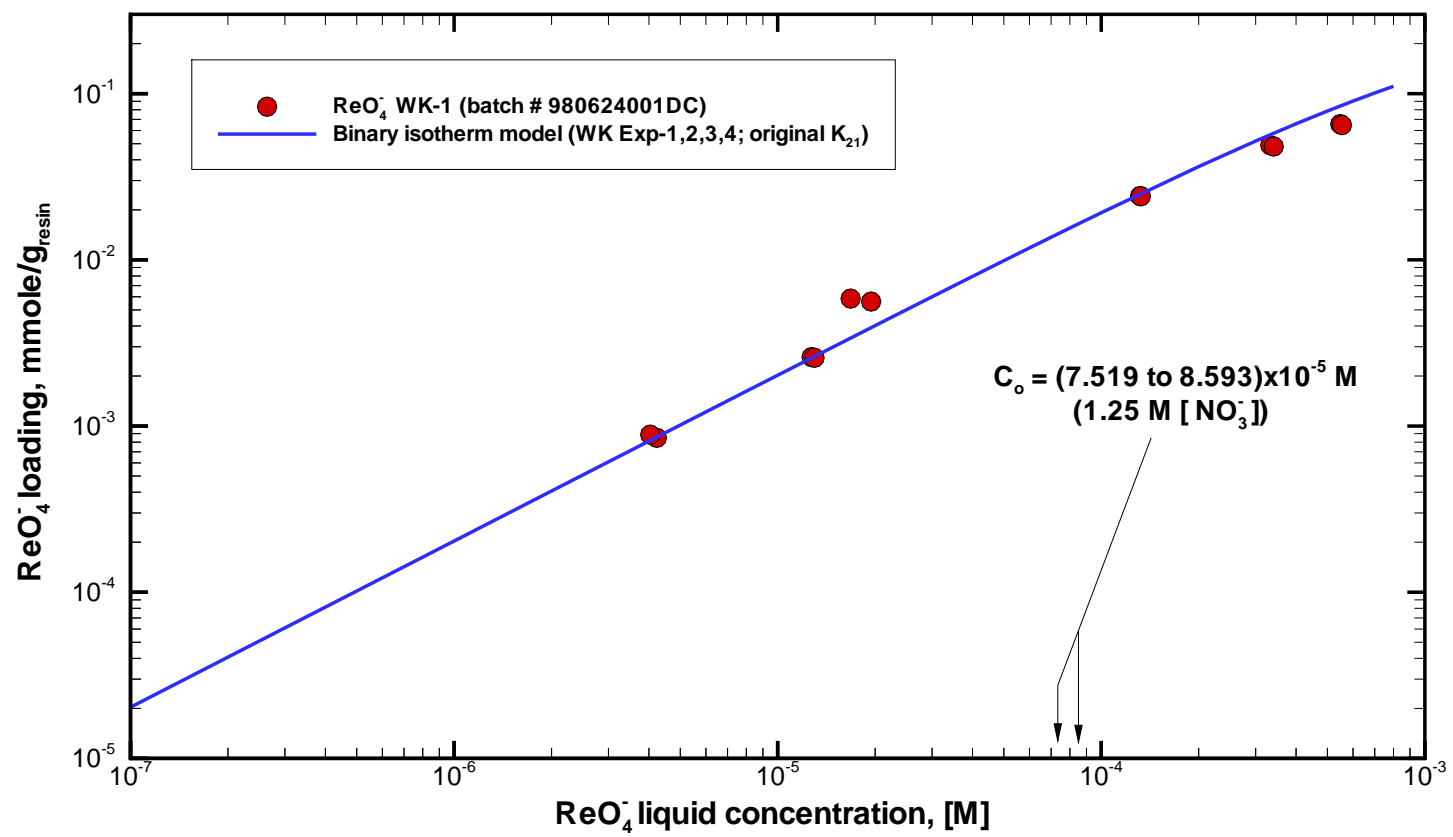

Figure 9-1. A direct comparison of predicted versus measured perrhenate loadings on SuperLig ${ }^{\circledR} 639$ resin for a simulated Envelope A waste (King et al., 2000a). A batch specific binary isotherm model (batch \# 980624001DC) is plotted.

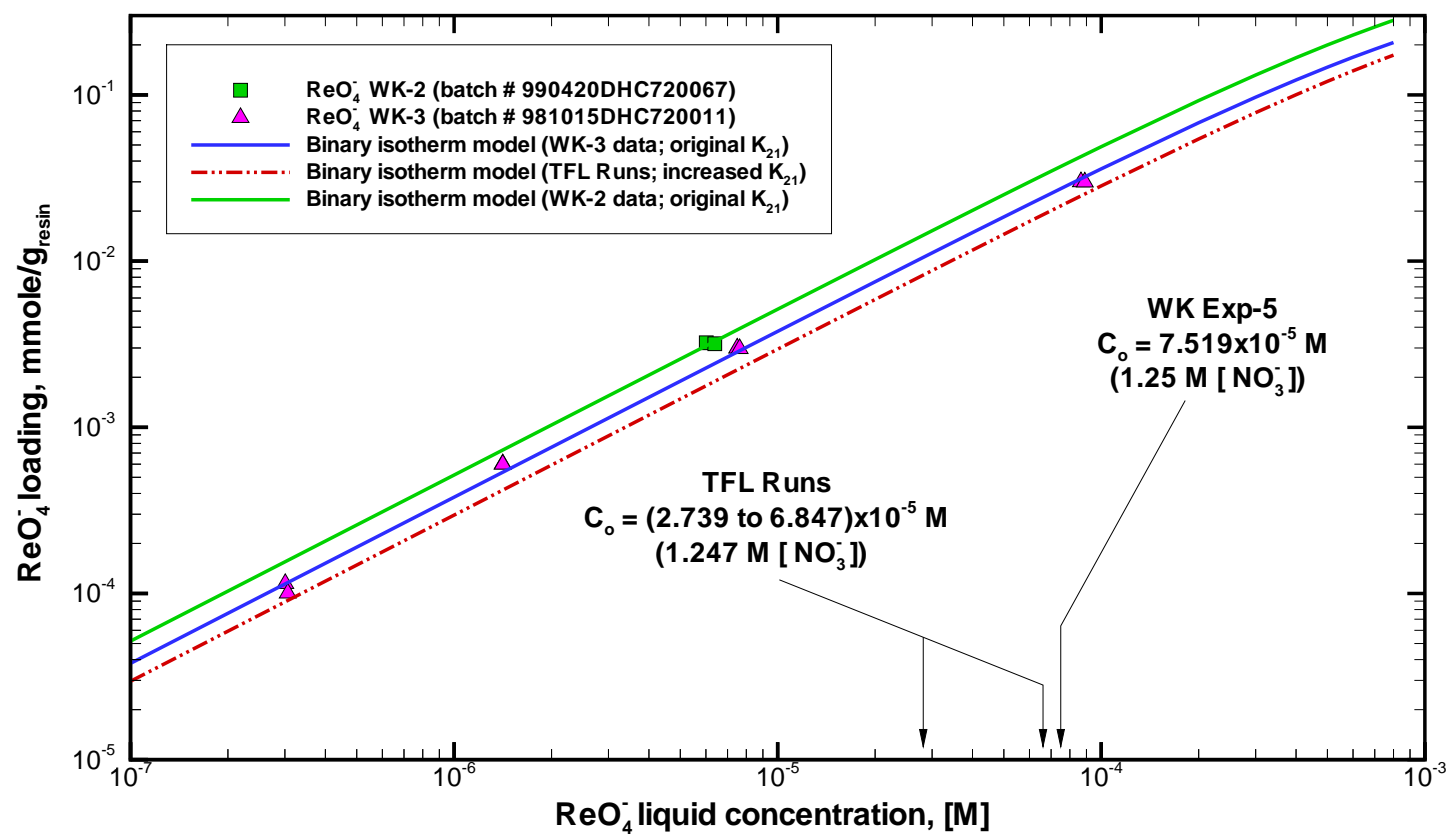

Figure 9-2. A direct comparison of predicted versus measured perrhenate loadings on SuperLig ${ }^{\circledR} 639$ resin for a simulated Envelope A waste (King et al., 2000a). Batch specific binary isotherm models (batch \# 981015DHC720011 \& 990420DHC720067) are plotted. 


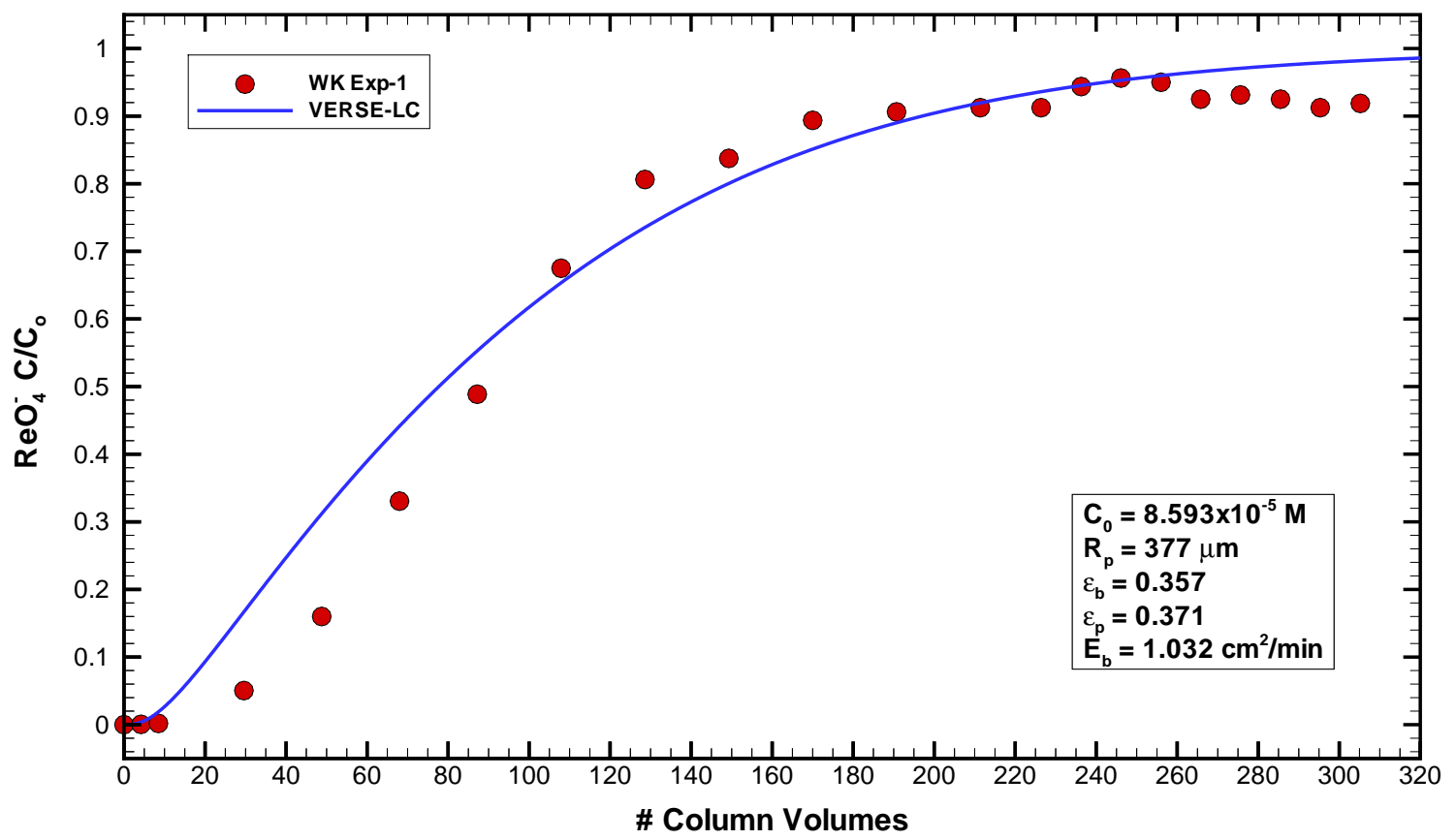

Figure 9-3. VERSE-LC perrhenate exit breakthrough curve compared to data from WK Exp-1 (King et al., 2000a): $\mathrm{D}=2.69 \mathrm{~cm}, \mathrm{~L}=8.991 \mathrm{~cm}, \mathrm{U}=0.51 \mathrm{~cm} / \mathrm{min}, \mathrm{T}=20-23{ }^{\circ} \mathrm{C}$.

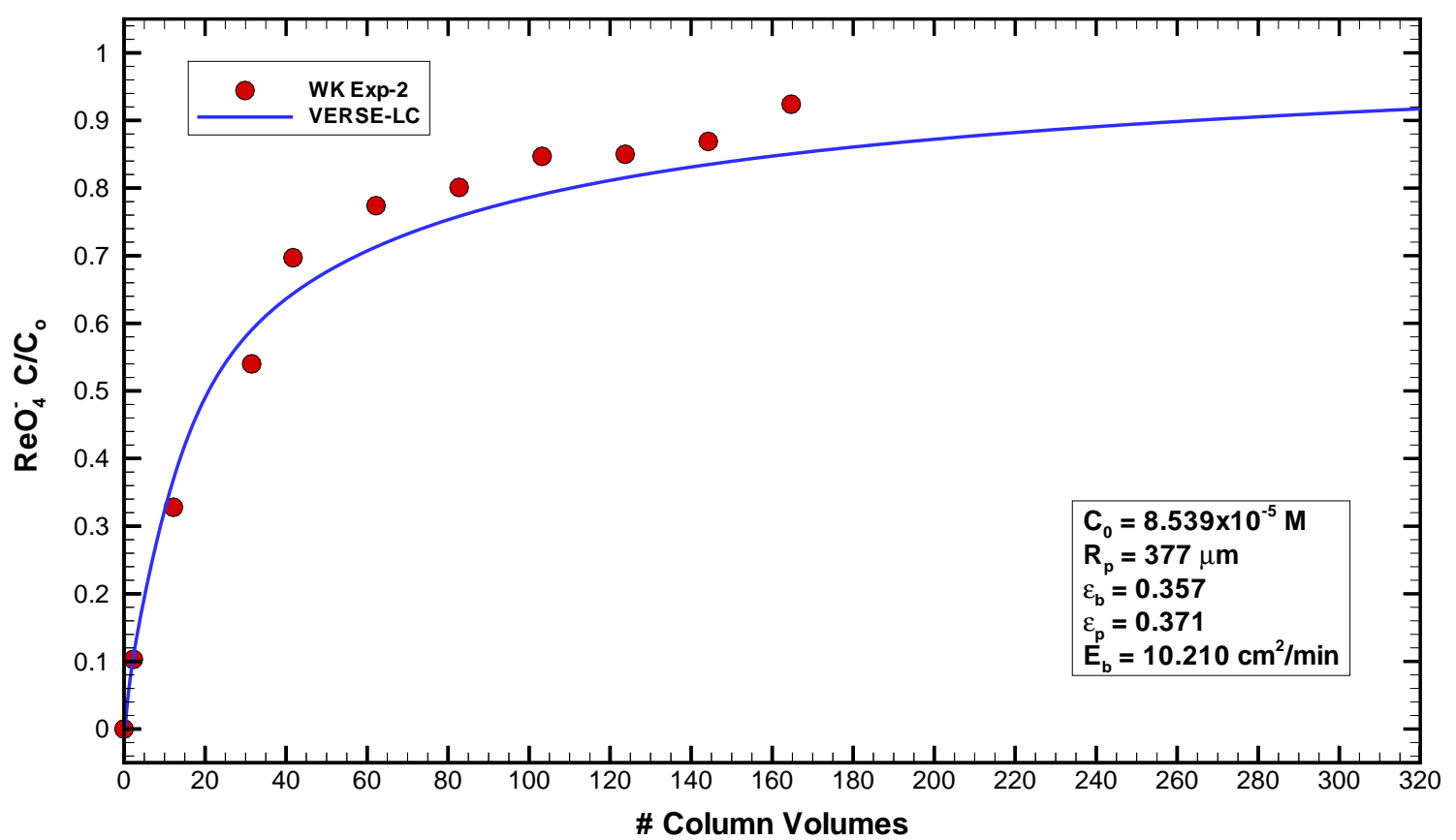

Figure 9-4. VERSE-LC perrhenate exit breakthrough curve compared to data from WK Exp-2 (King et al., 2000a): $\mathrm{D}=2.69 \mathrm{~cm}, \mathrm{~L}=8.991 \mathrm{~cm}, \mathrm{U}=5.20 \mathrm{~cm} / \mathrm{min}, \mathrm{T}=20-23{ }^{\circ} \mathrm{C}$. 


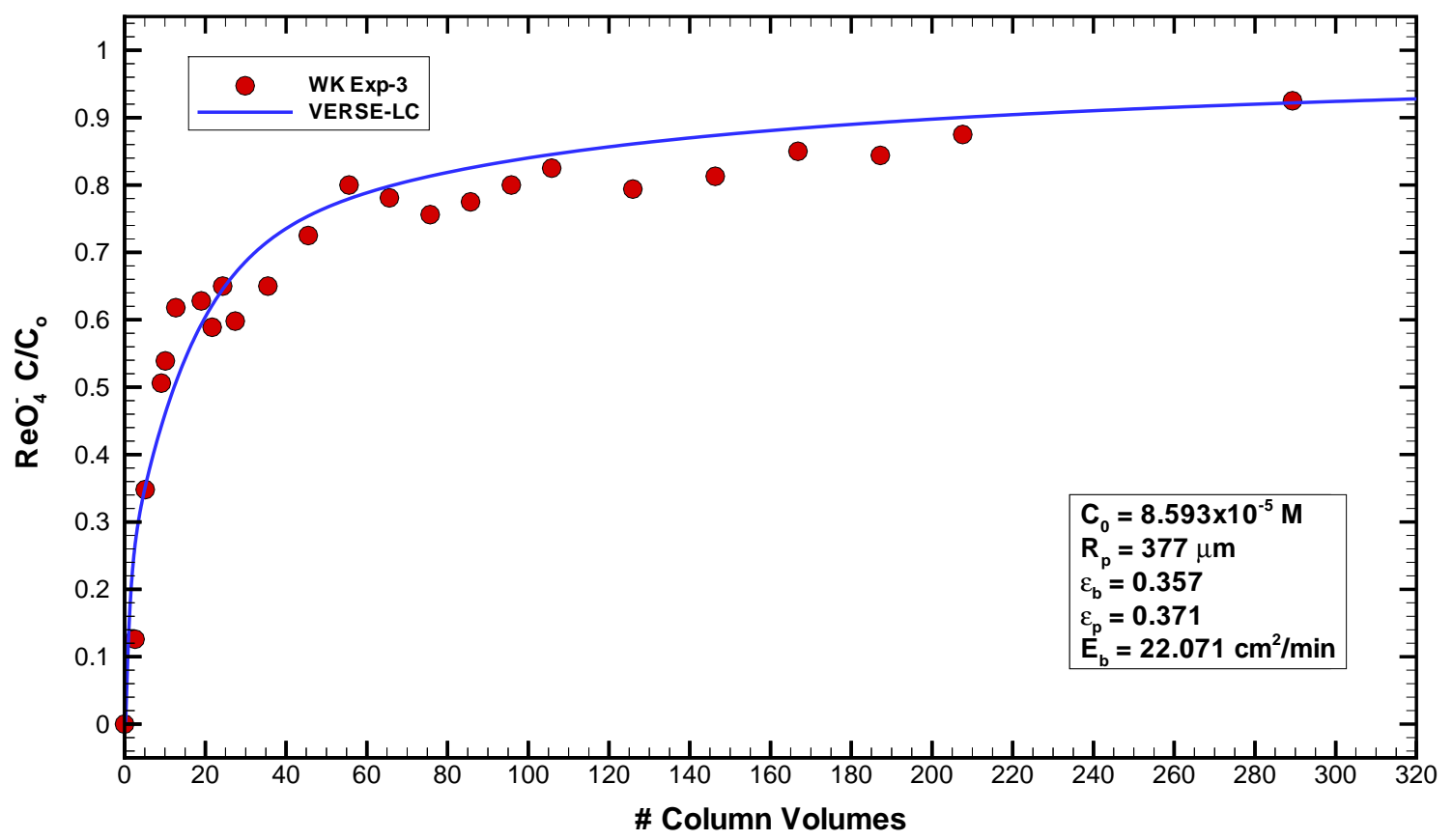

Figure 9-5. VERSE-LC perrhenate exit breakthrough curve compared to data from WK Exp-3 (King et al., 2000a): $\mathrm{D}=2.69 \mathrm{~cm}, \mathrm{~L}=8.991 \mathrm{~cm}, \mathrm{U}=11.0 \mathrm{~cm} / \mathrm{min}, \mathrm{T}=20-23{ }^{\circ} \mathrm{C}$.

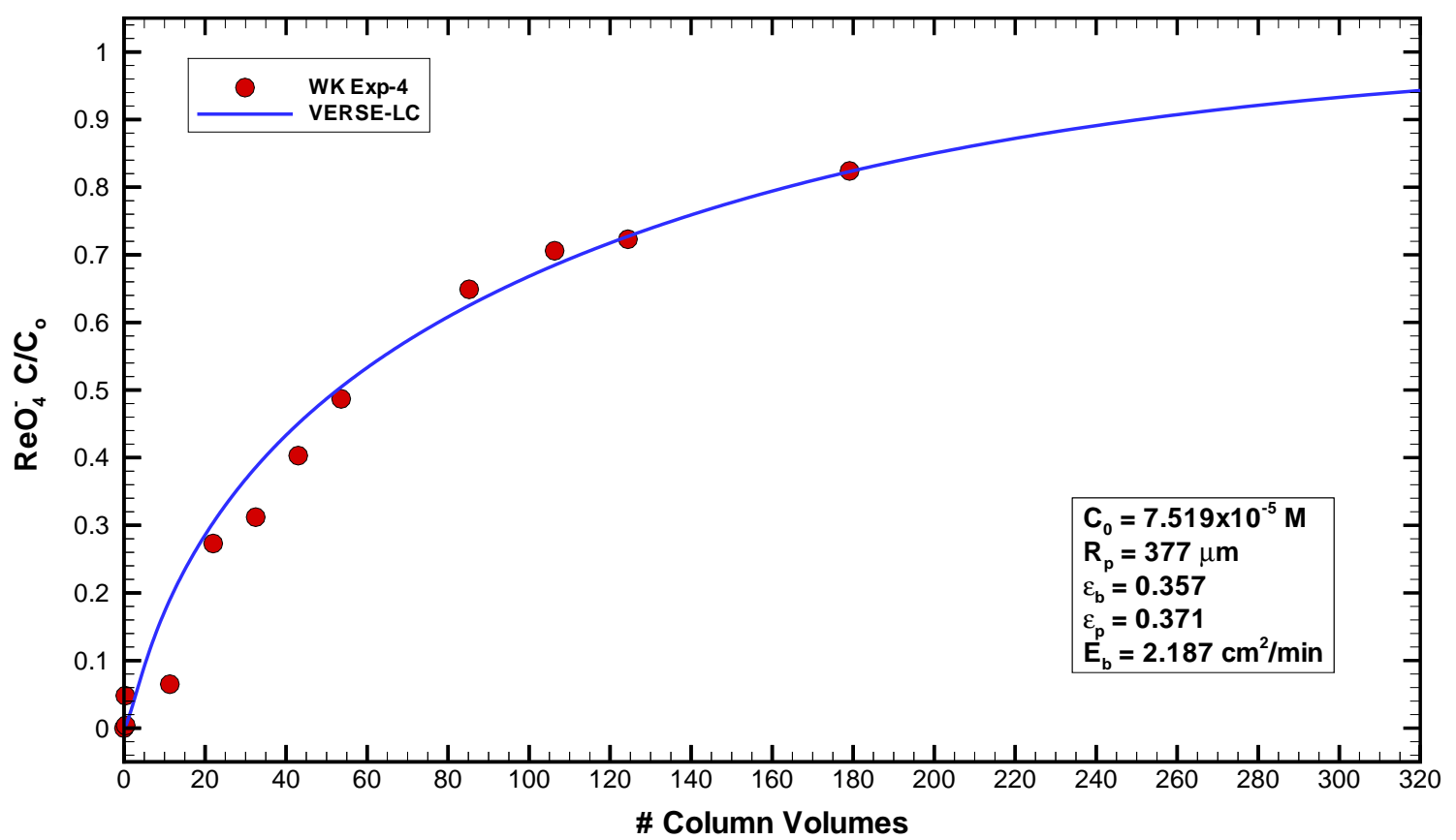

Figure 9-6. VERSE-LC perrhenate exit breakthrough curve compared to data from WK Exp-4 (King et al., 2000a): $\mathrm{D}=4.0 \mathrm{~cm}, \mathrm{~L}=4.066 \mathrm{~cm}, \mathrm{U}=0.48 \mathrm{~cm} / \mathrm{min}, \mathrm{T}=20-23{ }^{\circ} \mathrm{C}$. 


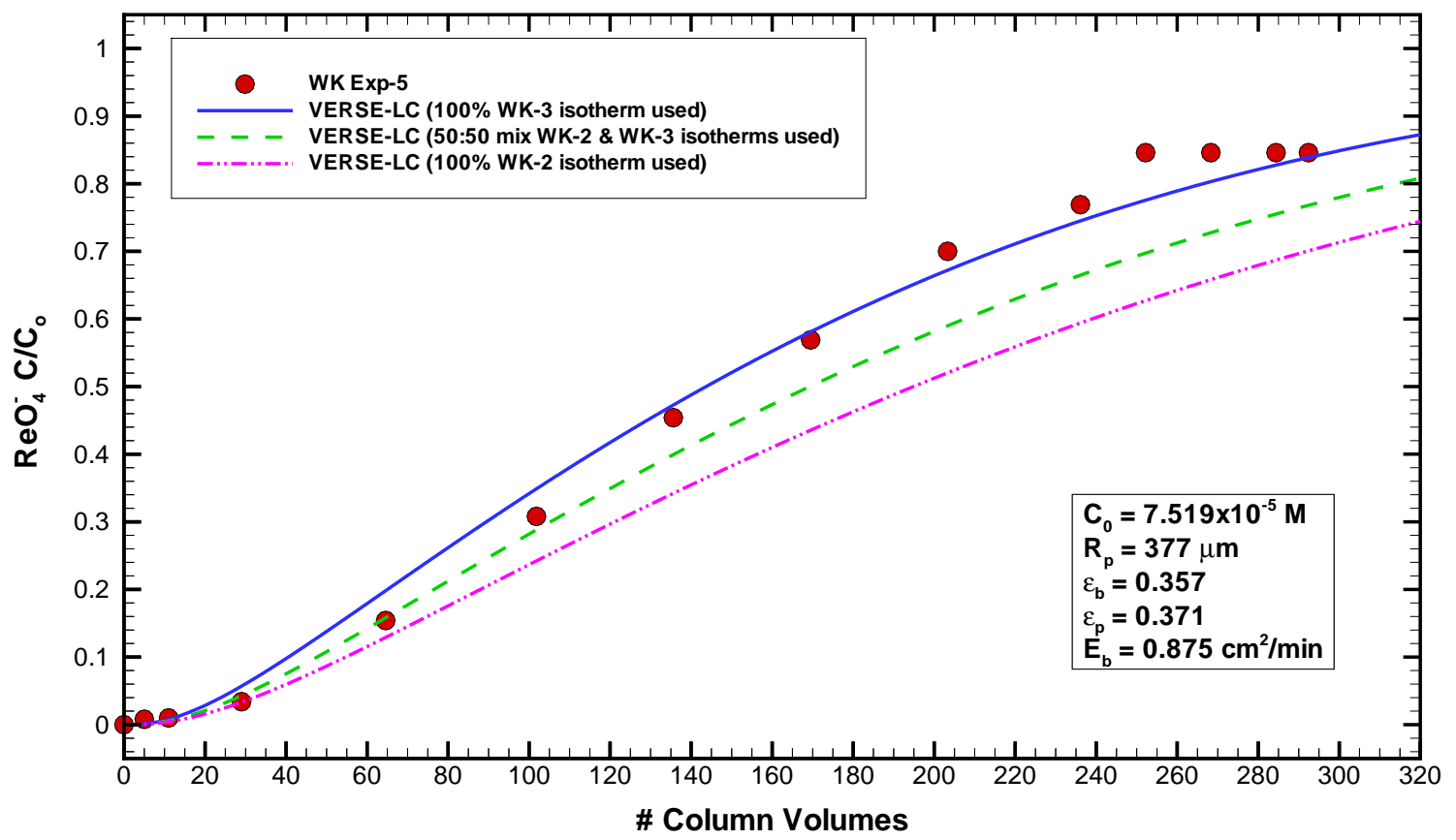

Figure 9-7. VERSE-LC perrhenate exit breakthrough curves compared to data from WK Exp-5 (King et al., 2000a): $\mathrm{D}=2.69 \mathrm{~cm}, \mathrm{~L}=8.798 \mathrm{~cm}, \mathrm{U}=0.43 \mathrm{~cm} / \mathrm{min}, \mathrm{T}=20-23{ }^{\circ} \mathrm{C}$.

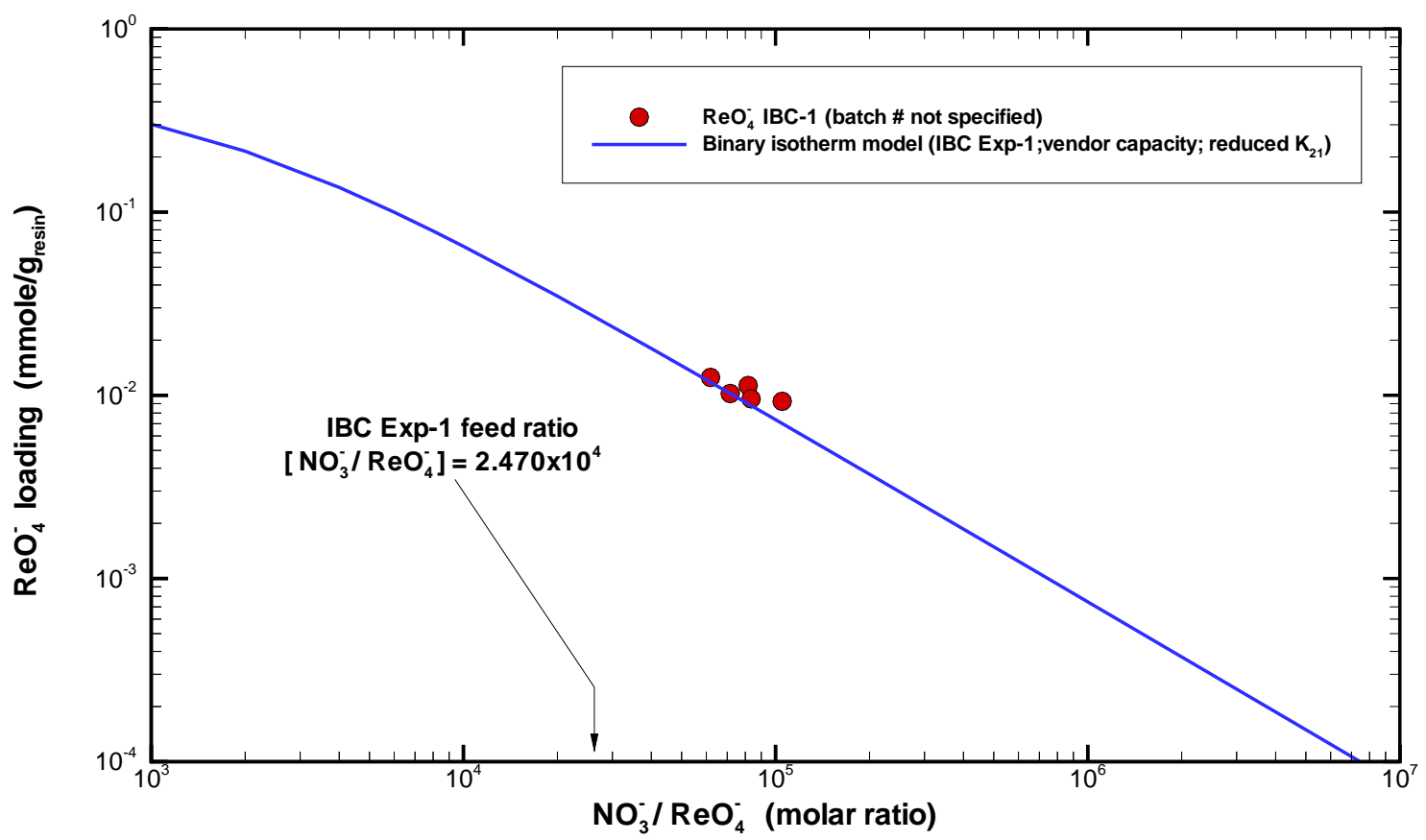

Figure 9-8. A direct comparison of predicted versus measured perrhenate loadings on SuperLig ${ }^{\circledR} 639$ resin for a simulated Envelope A waste (IBC Advanced Technologies, 1996). A batch specific binary isotherm model (batch \# not specified) is plotted. 


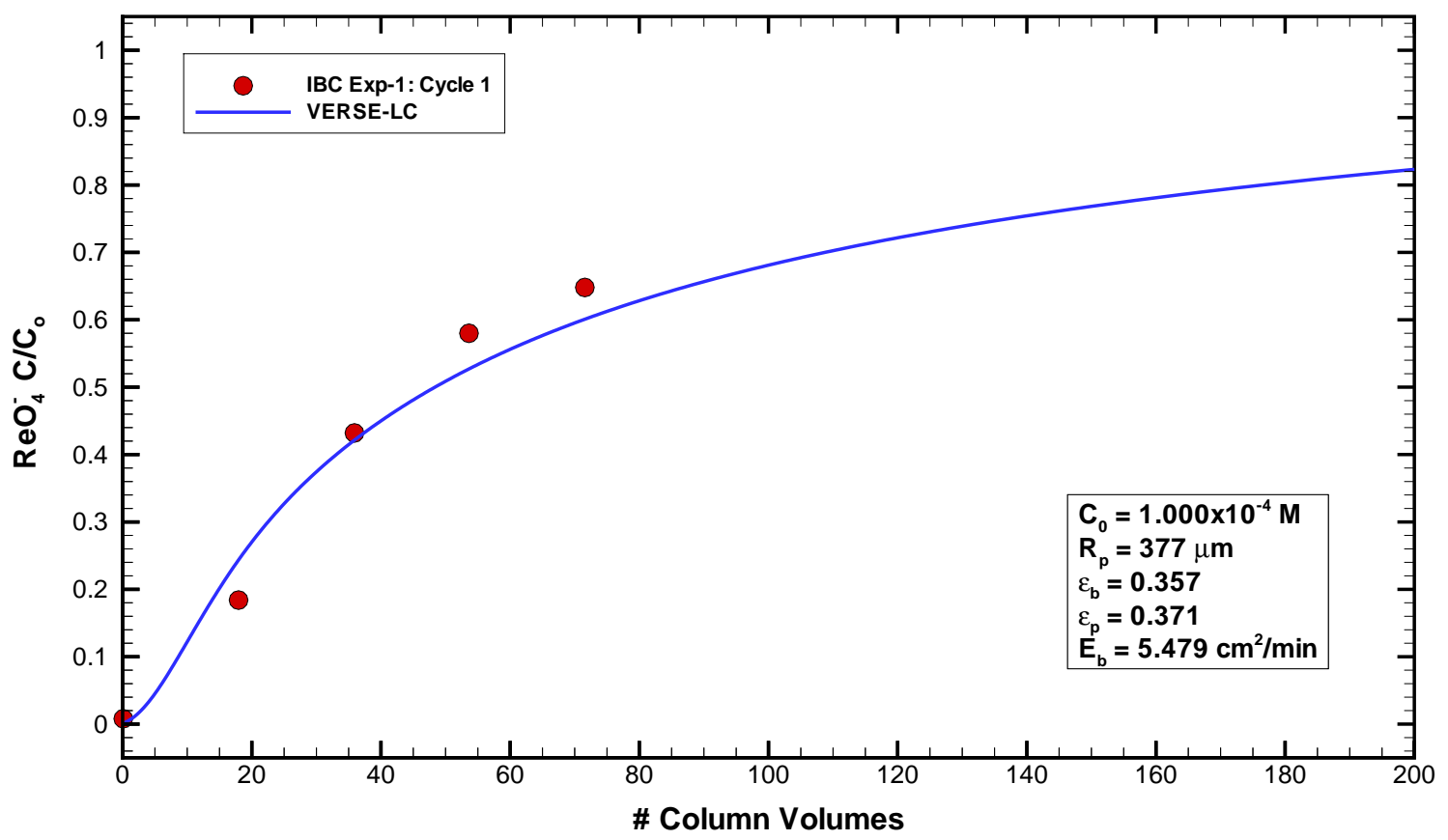

Figure 9-9. VERSE-LC perrhenate exit breakthrough curve compared to data from IBC Exp-1 (IBC Advanced Technologies, 1996): $\mathrm{D}=3.3 \mathrm{~cm}, \mathrm{~L}=24.0 \mathrm{~cm}, \mathrm{U}=6.4 \mathrm{~cm} / \mathrm{min}, \mathrm{T}=25^{\circ} \mathrm{C}$.

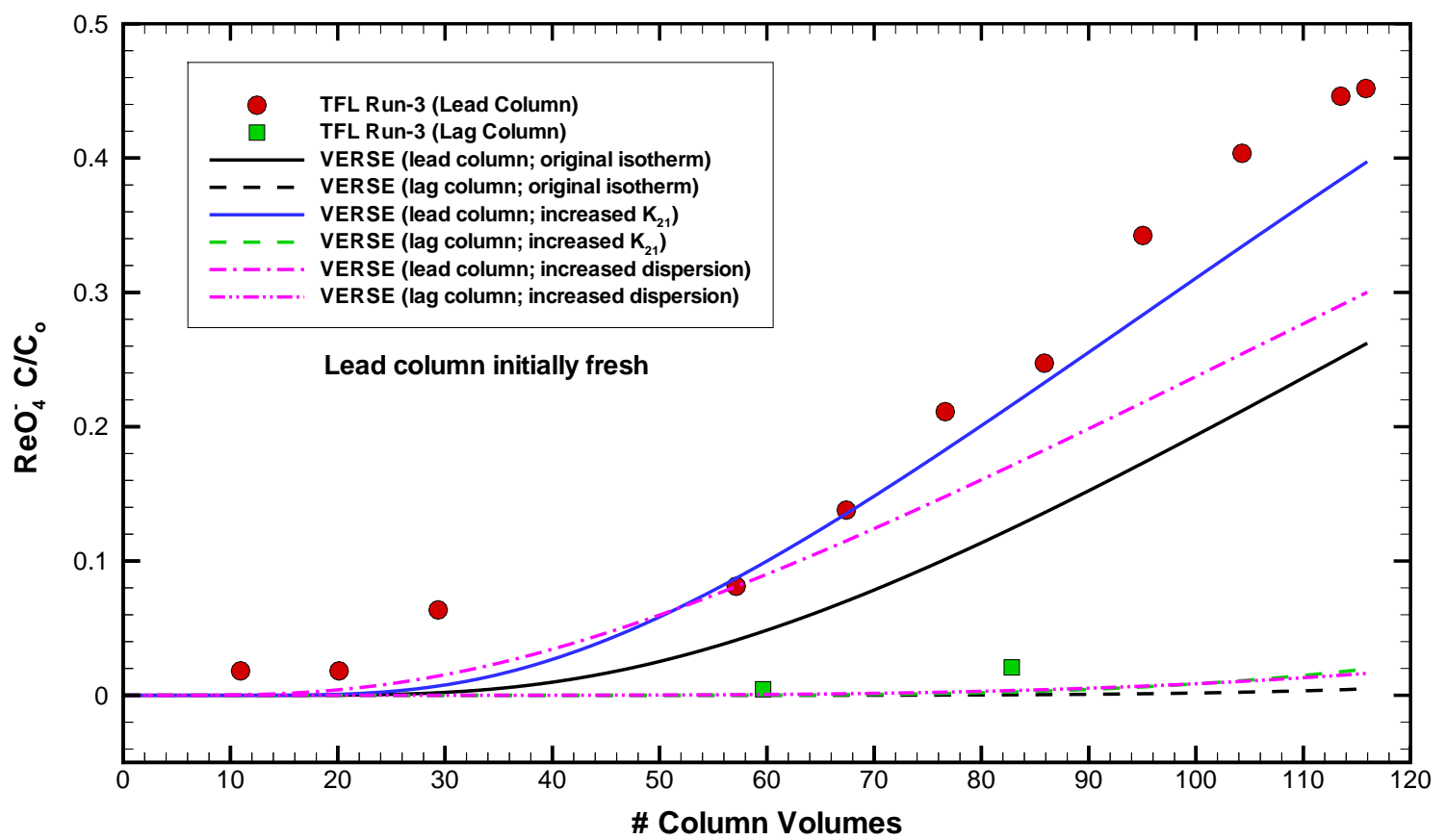

Figure 9-10. Loading cycle VERSE-LC lead/lag column breakthrough curve predictions using different model parameter settings and comparison to data from the TFL Run-3 experiment (Steimke et al., 2000), $\left(18-24^{\circ} \mathrm{C}\right)$. 


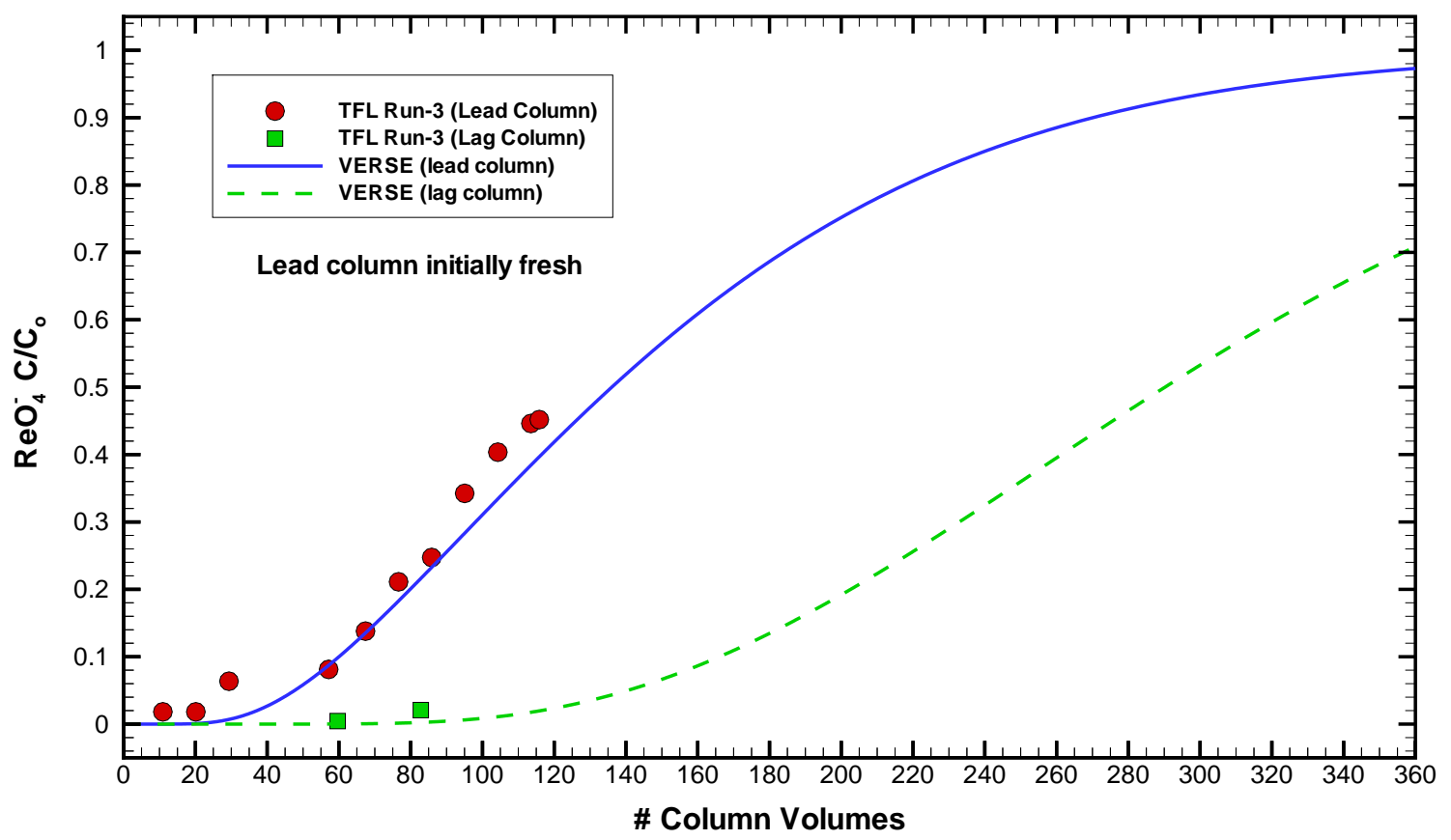

Figure 9-11. Loading cycle VERSE-LC lead/lag column breakthrough curve predictions compared to data from the TFL Run-3 experiment (Steimke et al., 2000) using fresh columns, (18-24

$\left.{ }^{\circ} \mathrm{C}\right)$.

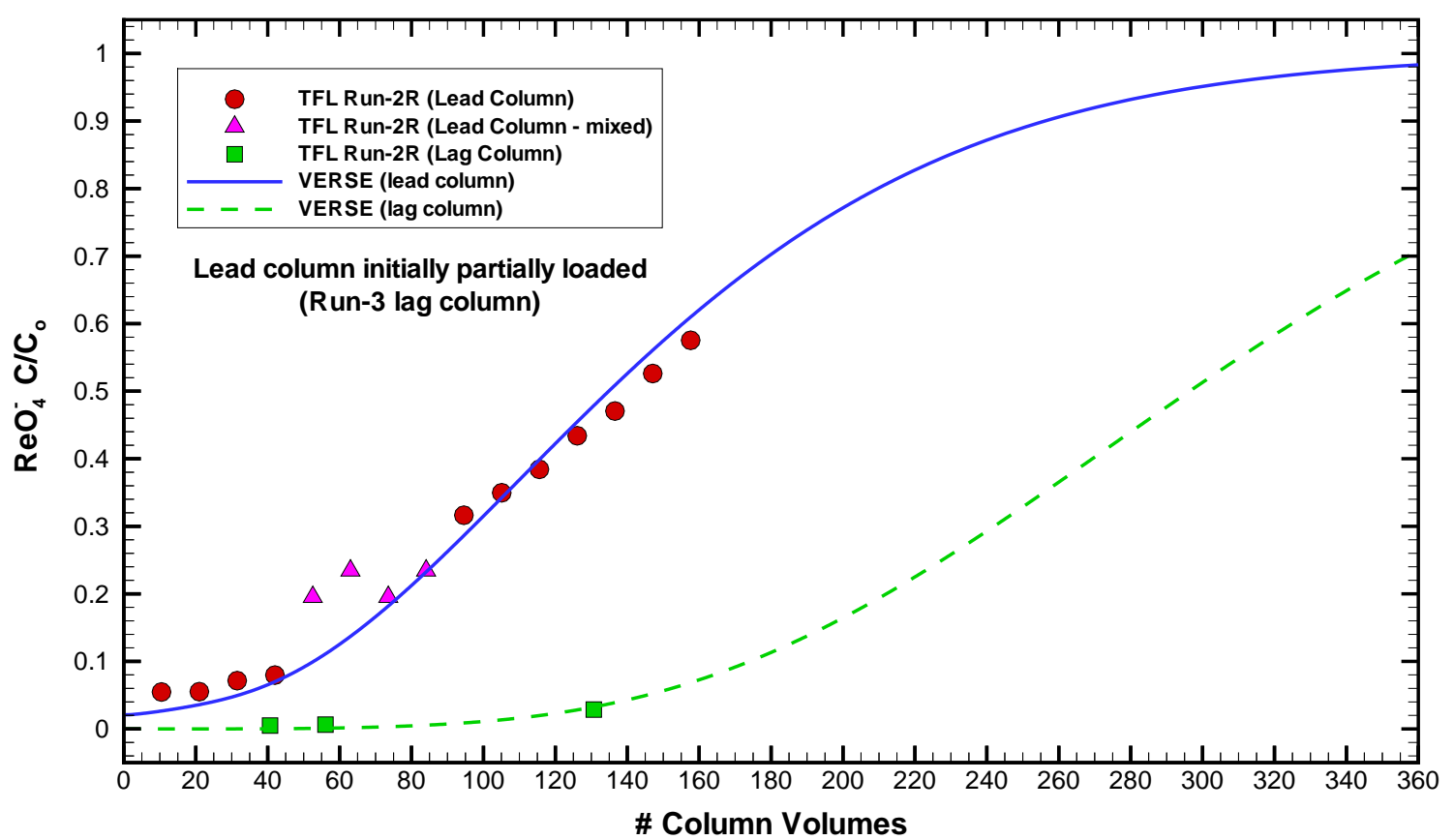

Figure 9-12. Loading cycle VERSE-LC lead/lag column breakthrough curve predictions compared to data from the TFL Run-2R experiment (Steimke et al., 2000) using a preloaded lead column, $\left(18-24^{\circ} \mathrm{C}\right)$. 


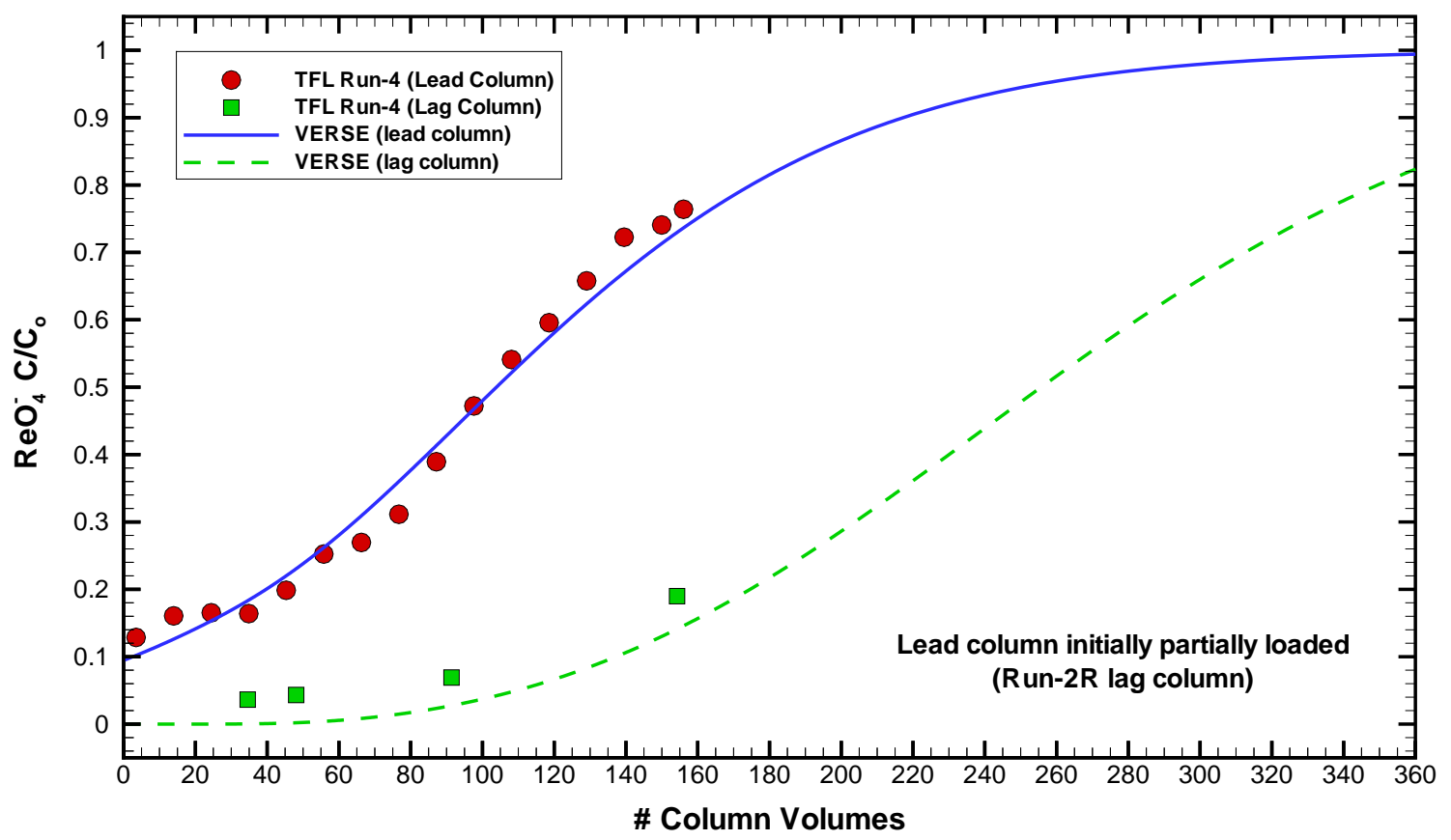

Figure 9-13. Loading cycle VERSE-LC lead/lag column breakthrough curve predictions compared to data from the TFL Run-4 experiment (Steimke et al., 2000) using a preloaded lead column, $\left(18-24{ }^{\circ} \mathrm{C}\right)$.

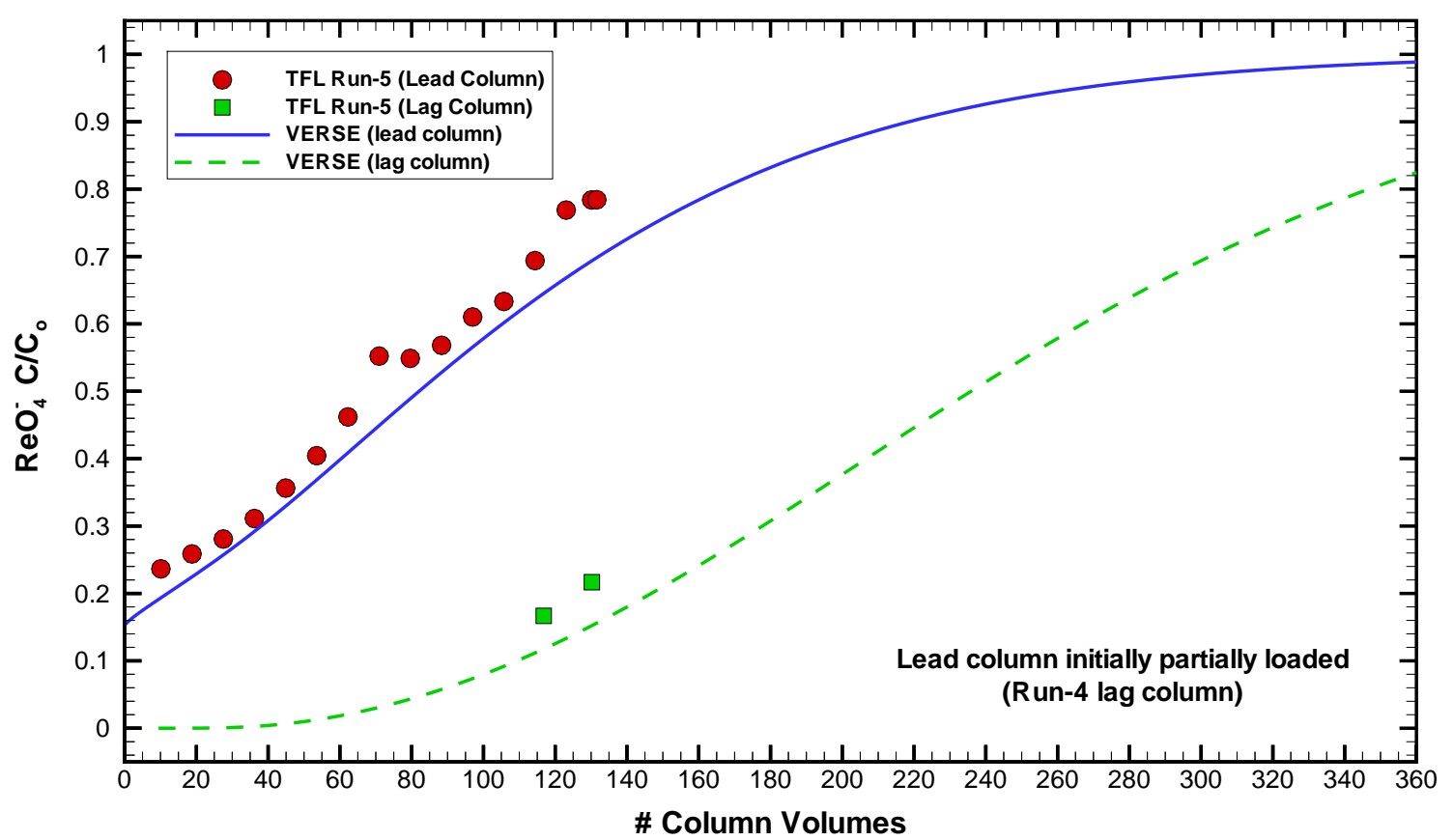

Figure 9-14. Loading cycle VERSE-LC lead/lag column breakthrough curve predictions compared to data from the TFL Run-5 experiment (Steimke et al., 2000) using a preloaded lead column, $\left(18-24^{\circ} \mathrm{C}\right)$. 


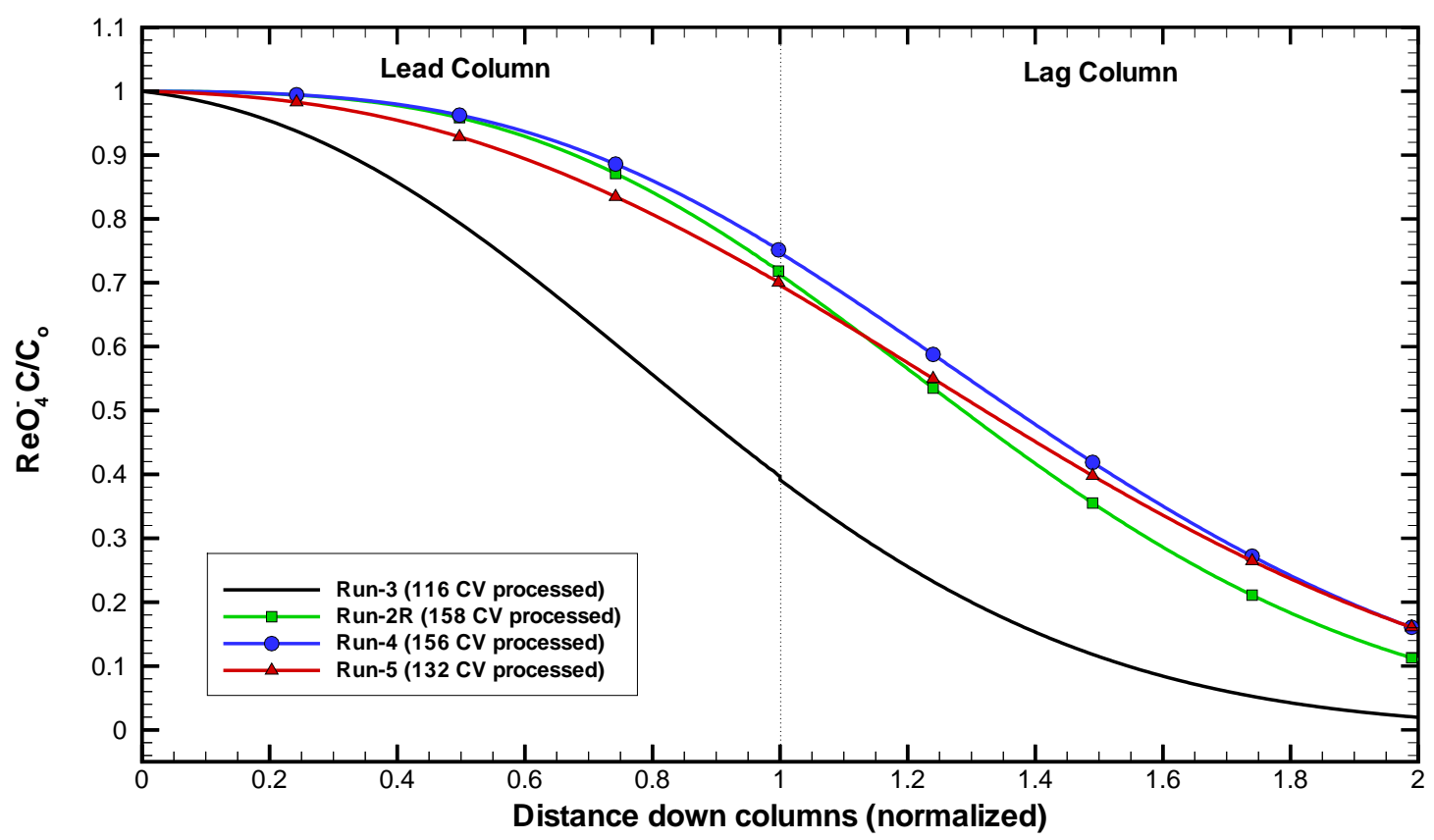

Figure 9-15. Predicted VERSE-LC lead and lag column perrhenate axial loading profiles at the end of test runs Run-3, 2R, 4, and 5 (the lag column profiles were shifted to the lead column position, then the lag column was set to zero, and used in the next test run simulation).

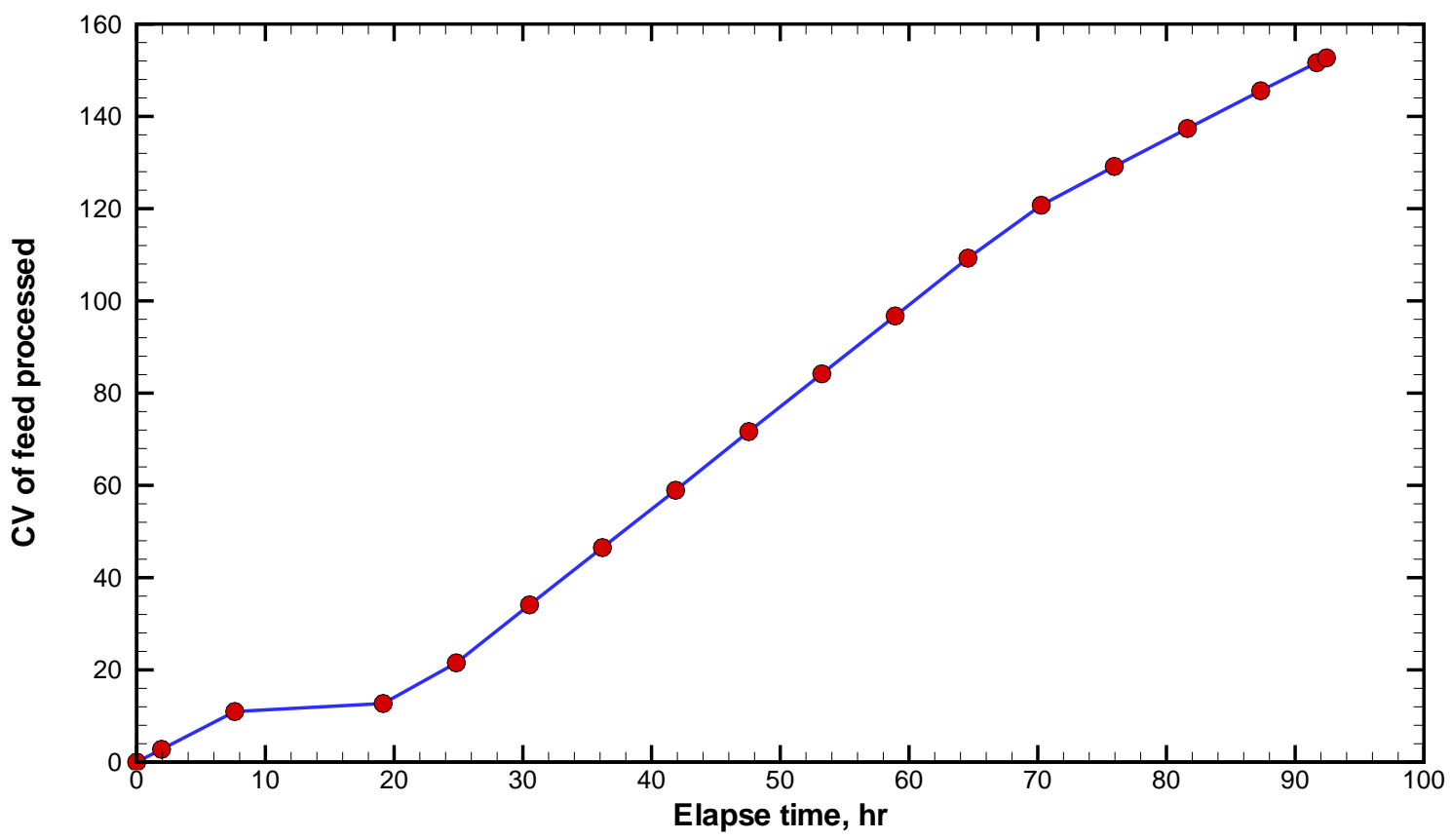

Figure 9-16. Cumulative volume of feed processed during the loading cycle of the TFL Run-6 experiment (Steimke et al., 2000). 


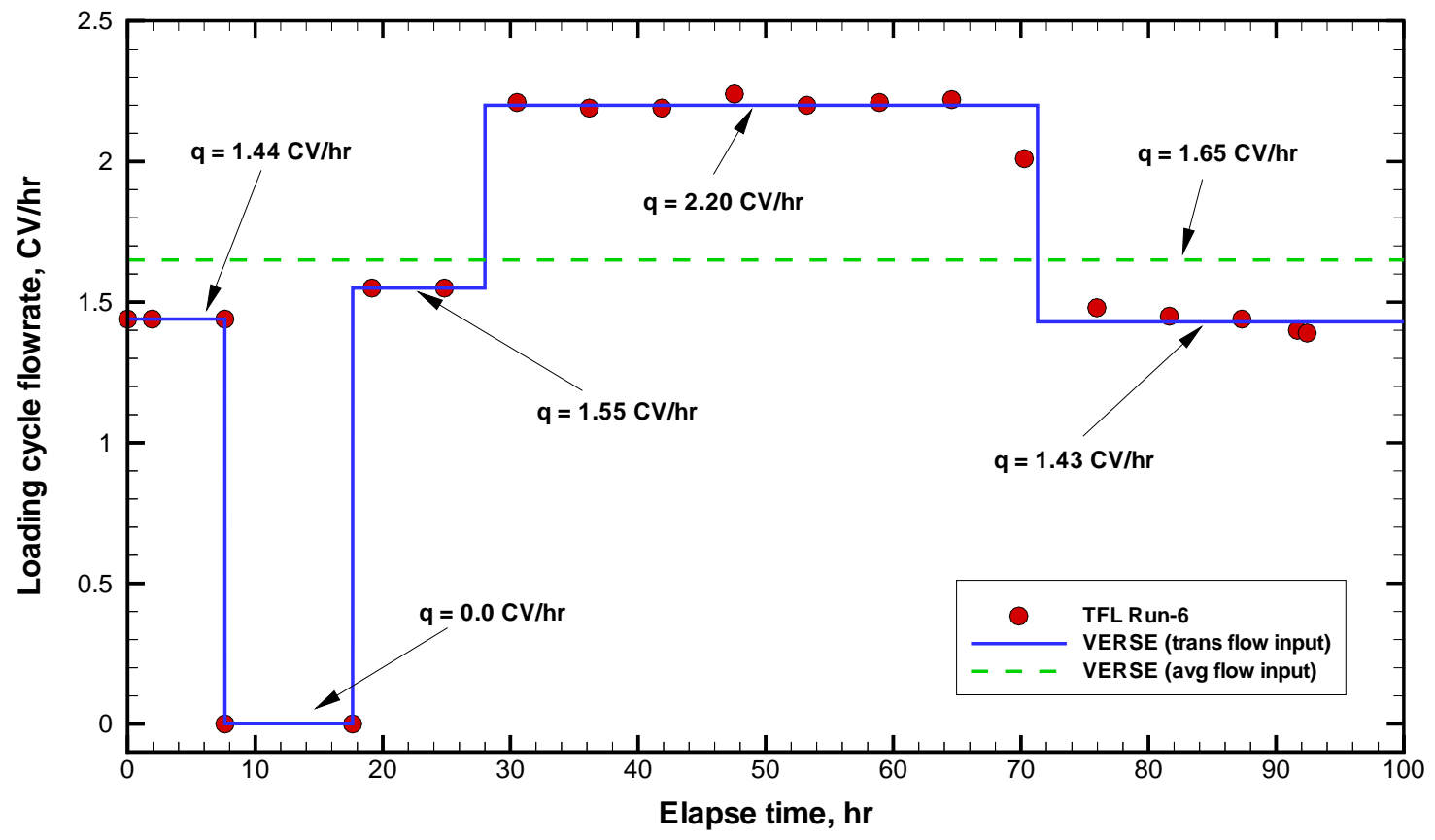

Figure 9-17. Volumetric flowrate of feed during the loading cycle of the TFL Run-6 experiment Steimke et al. (2000) (test data along with VERSE-LC transient and steady-state input values are shown).

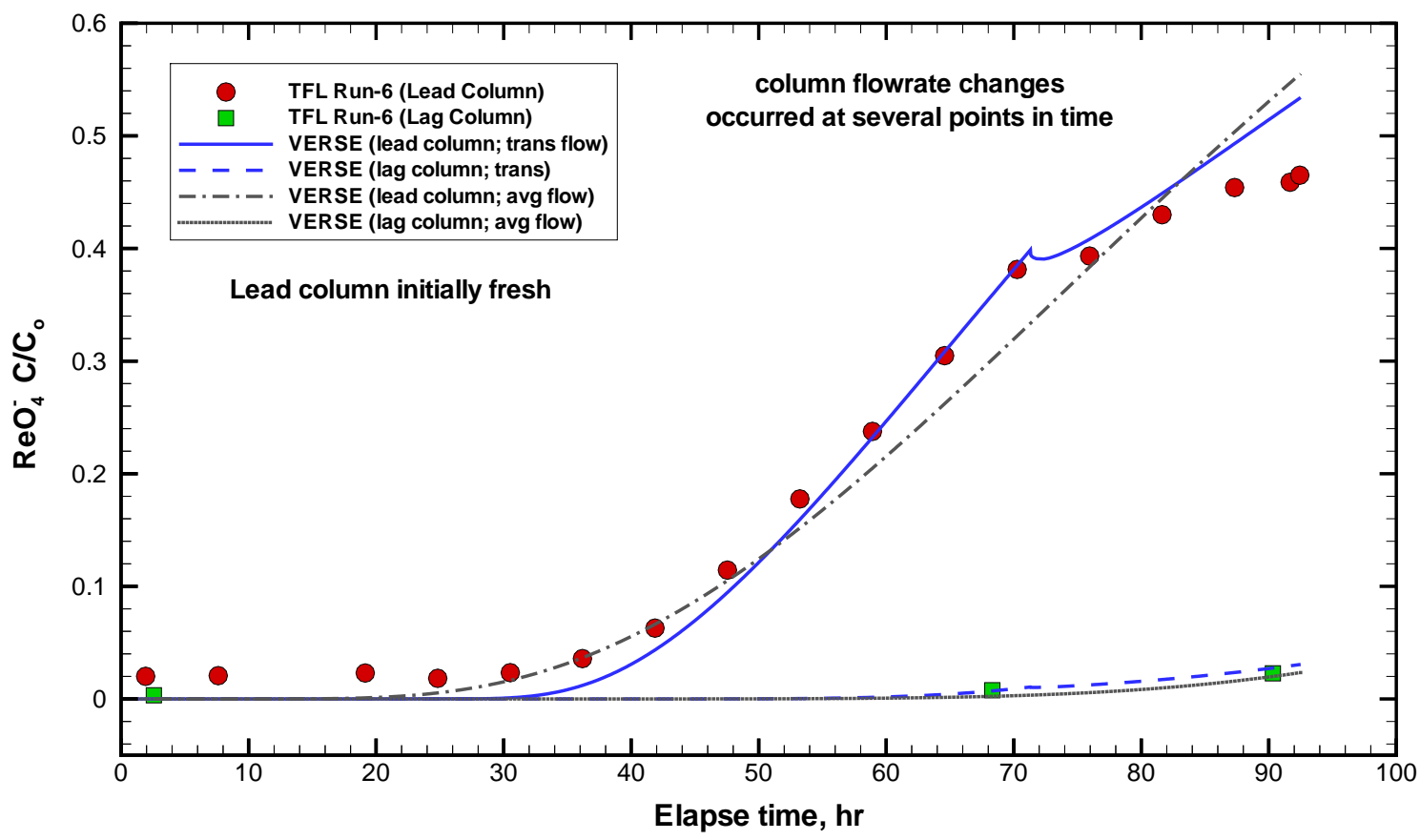

Figure 9-18. Loading cycle VERSE-LC lead/lag column breakthrough curve predictions compared to data from TFL Run-6 experiment (Steimke et al., 2000) where predictions based on an average fixed feed flowrate and a transient value are shown, $\left(18-24{ }^{\circ} \mathrm{C}\right)$. 


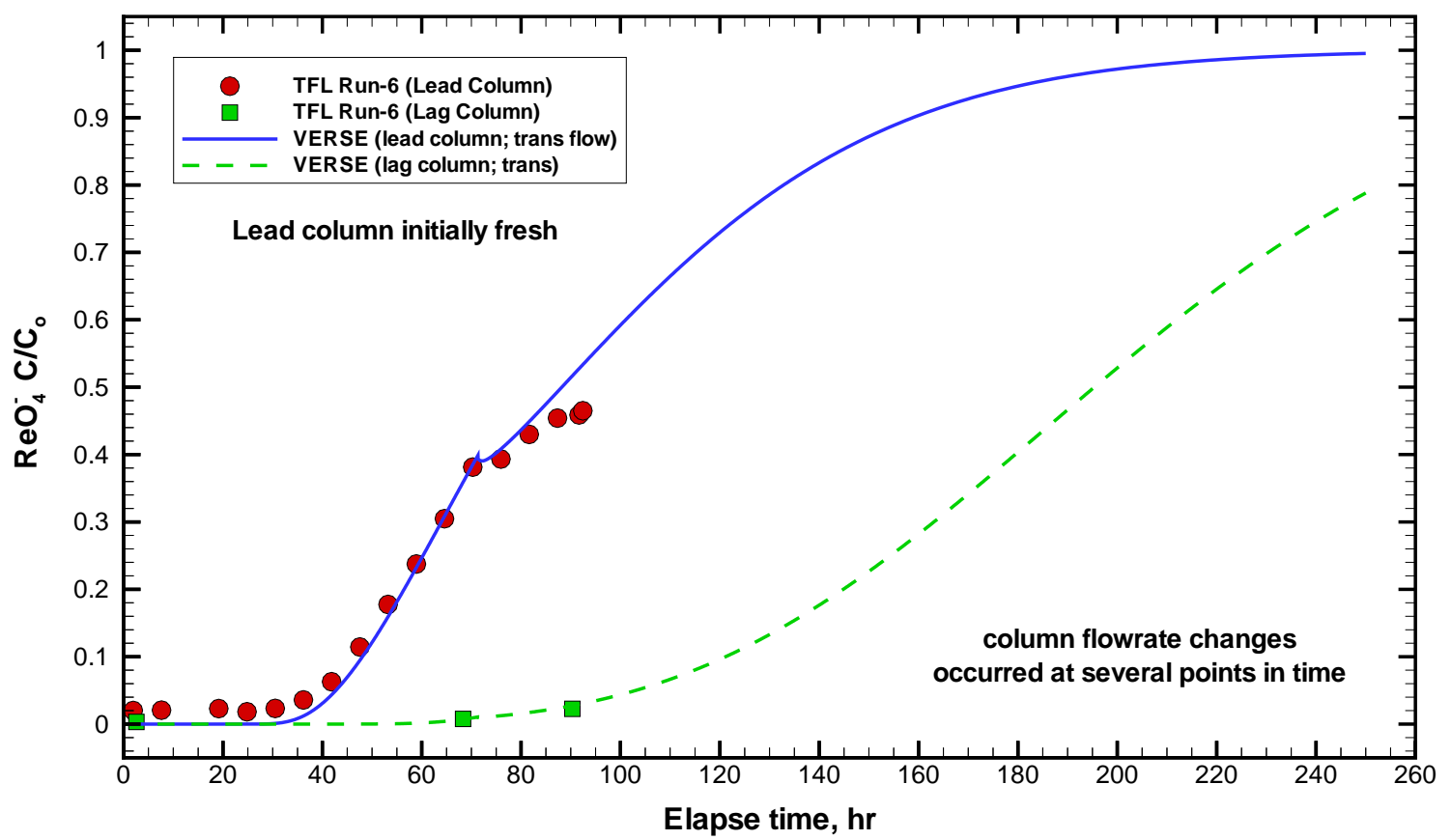

Figure 9-19. Loading cycle VERSE-LC lead/lag column breakthrough curve predictions compared to data from the TFL Run-6 experiment (Steimke et al., 2000) using a fresh lead column, $\left(18-24^{\circ} \mathrm{C}\right)$.

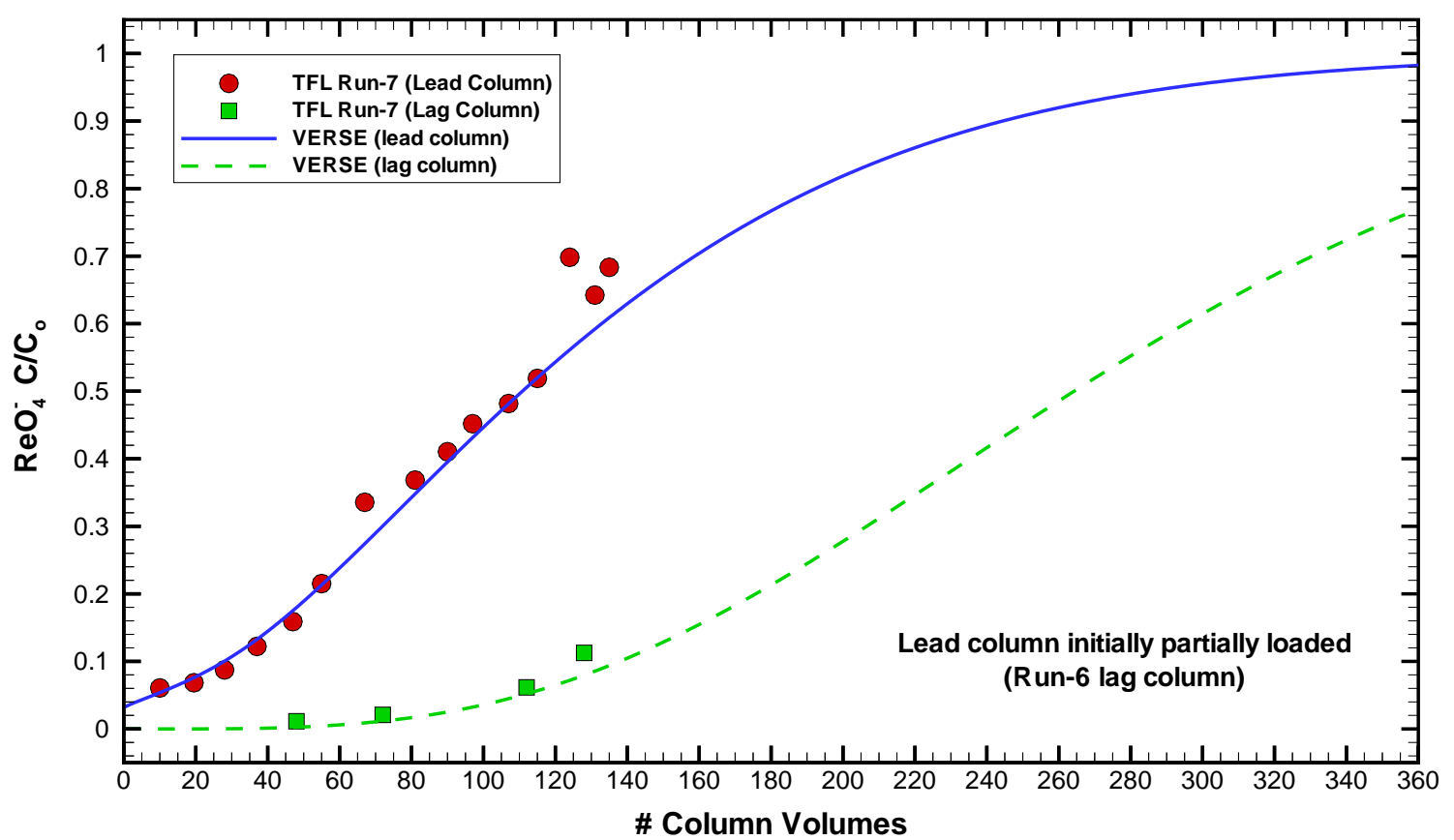

Figure 9-20. Loading cycle VERSE-LC lead/lag column breakthrough curve predictions compared to data from the TFL Run-7 experiment (Steimke et al., 2000) using a preloaded lead column, $\left(18-24^{\circ} \mathrm{C}\right)$. 


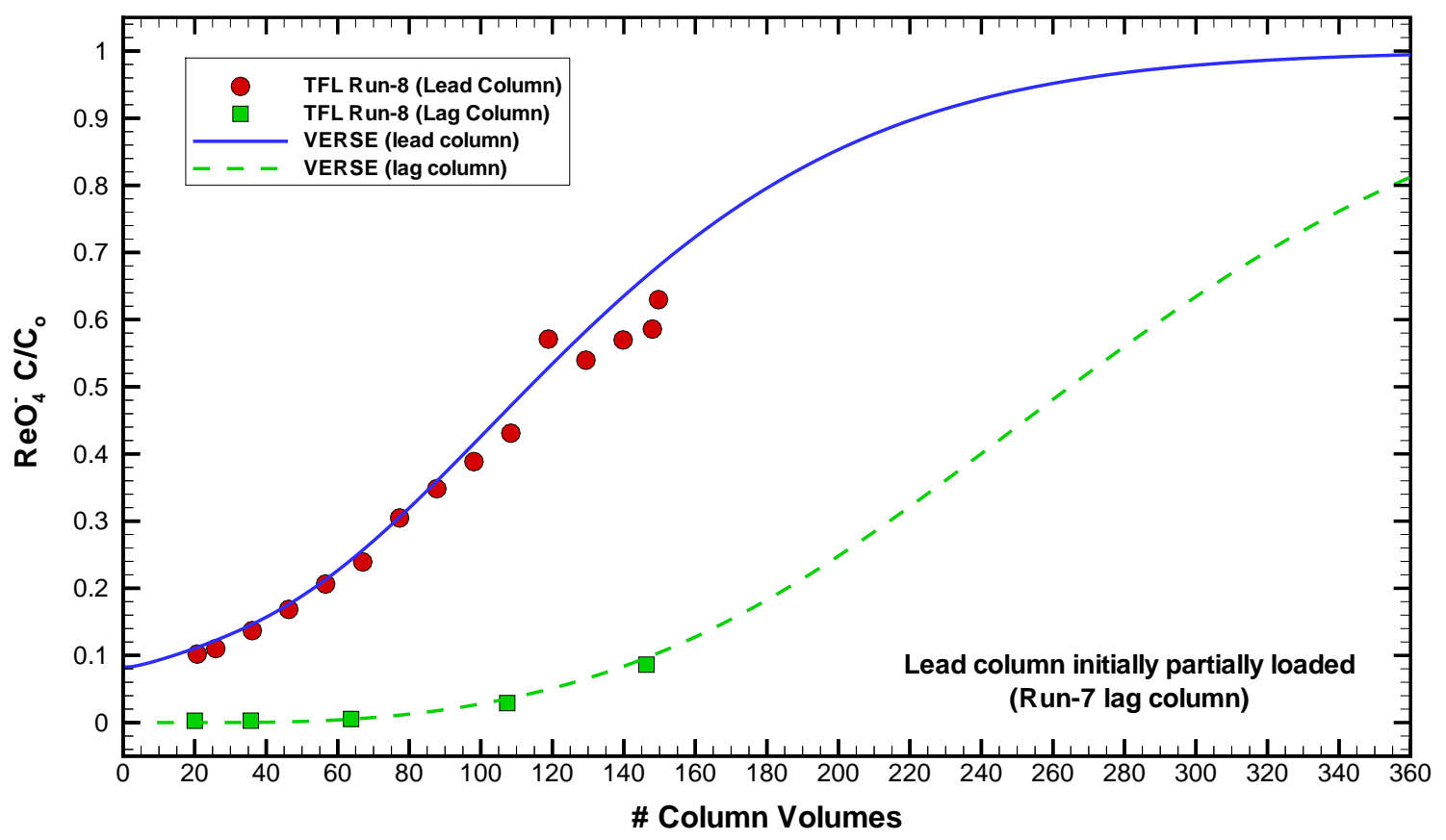

Figure 9-21. Loading cycle VERSE-LC lead/lag column breakthrough curve predictions compared to data from the TFL Run-8 experiment (Steimke et al., 2000) using a preloaded lead column, $\left(18-24^{\circ} \mathrm{C}\right)$.

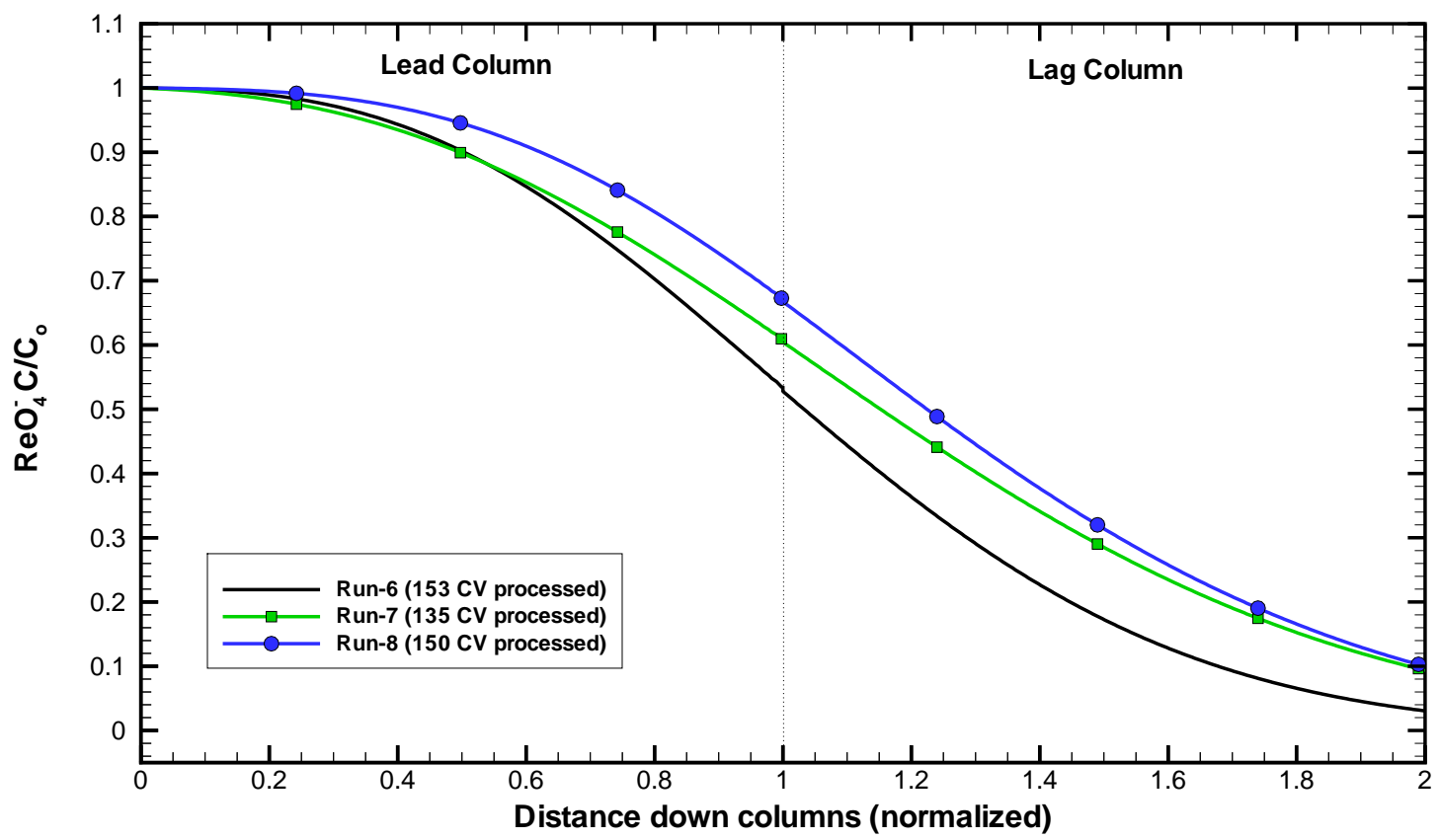

Figure 9-22. Predicted VERSE-LC lead and lag column perrhenate axial loading profiles at the end of test runs Run-6, 7, and 8 (the lag column profiles were shifted to the lead column position, then the lag column was set to zero, and used in the next test run simulation). 


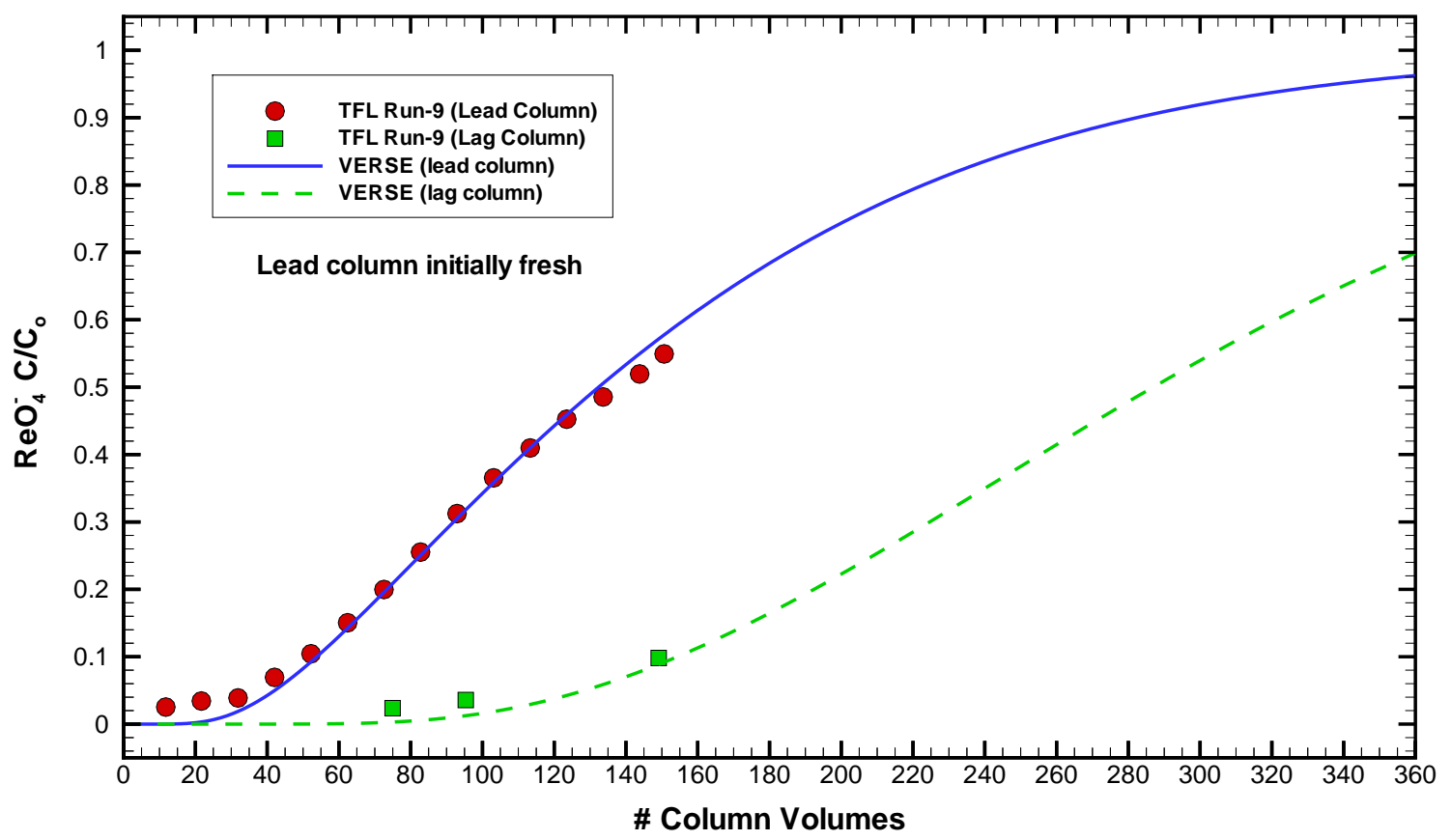

Figure 9-23. Loading cycle VERSE-LC lead/lag column breakthrough curve predictions compared to data from the TFL Run-9 experiment (Steimke et al., 2000) using a fresh lead column, $\left(18-24^{\circ} \mathrm{C}\right)$.

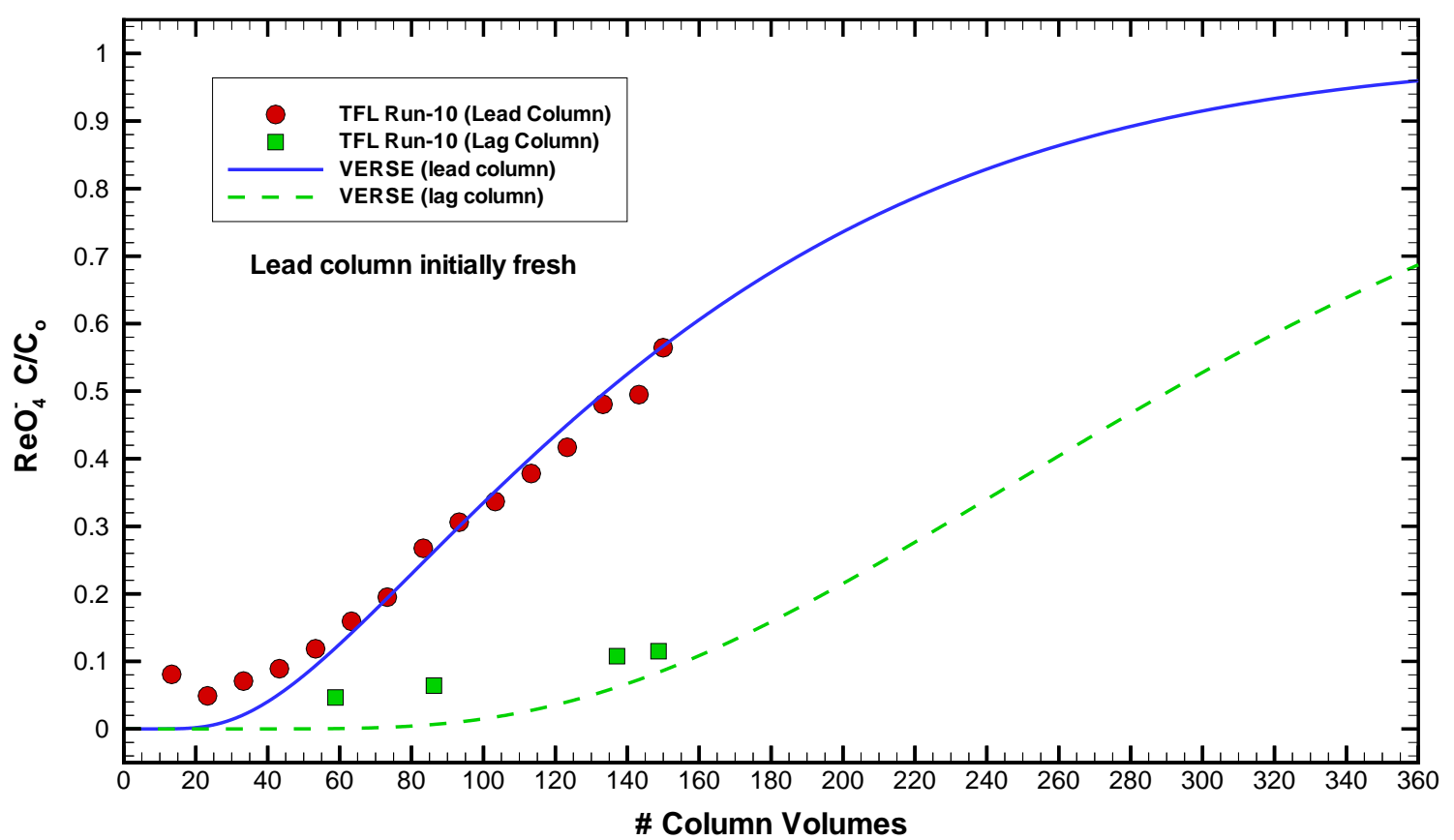

Figure 9-24. Loading cycle VERSE-LC lead/lag column breakthrough curve predictions compared to data from the TFL Run-10 experiment (Steimke et al., 2000) using a fresh lead column, $\left(18-24^{\circ} \mathrm{C}\right)$. 


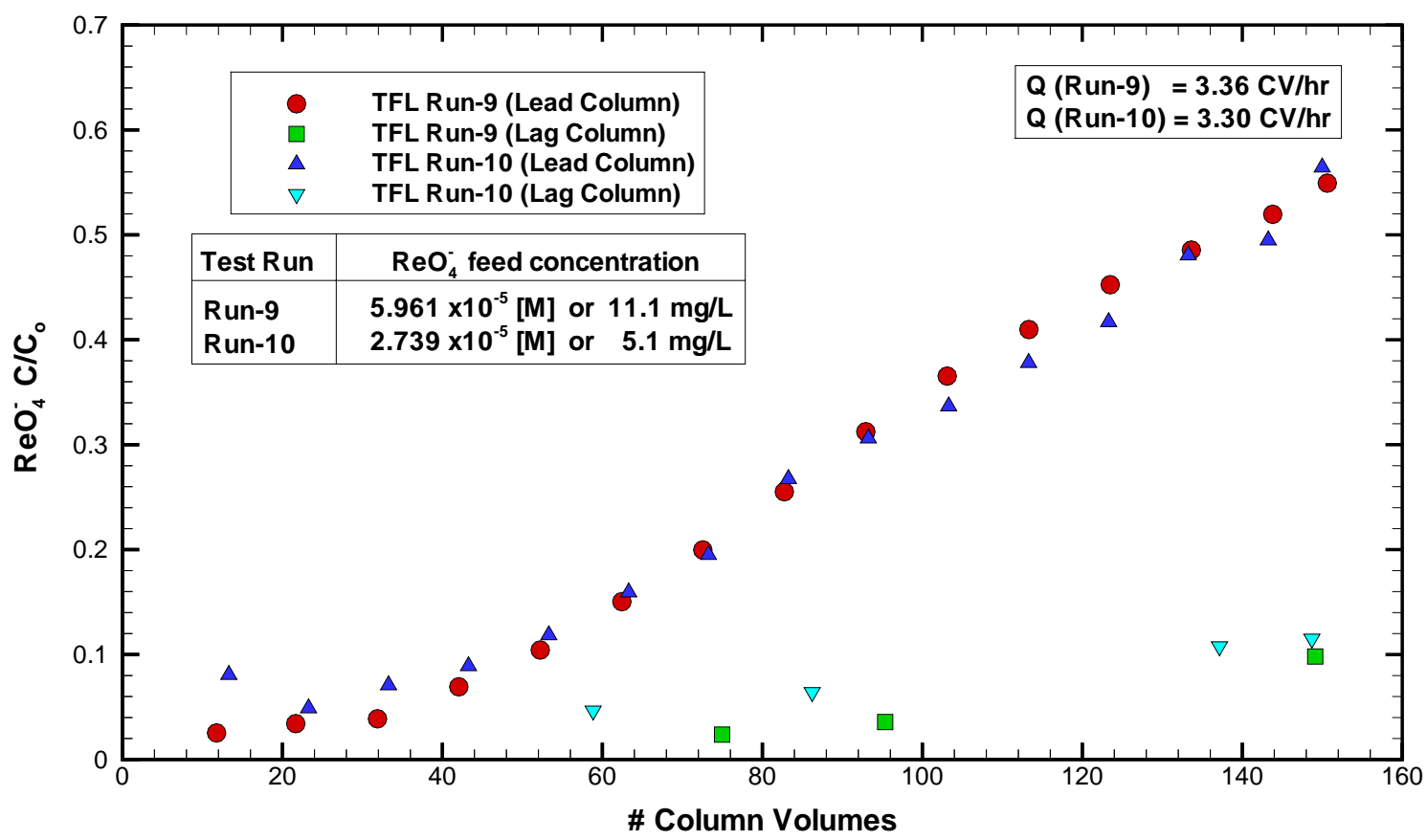

Figure 9-25. TFL Run-9 and Run-10 loading cycle lead/lag column breakthrough curve data by Steimke et al. (2000) indirectly illustrating the degree of linearity in the binary perrhenate adsorption isotherm over the operating range of these column experiments, $\left(18-24^{\circ} \mathrm{C}\right)$.

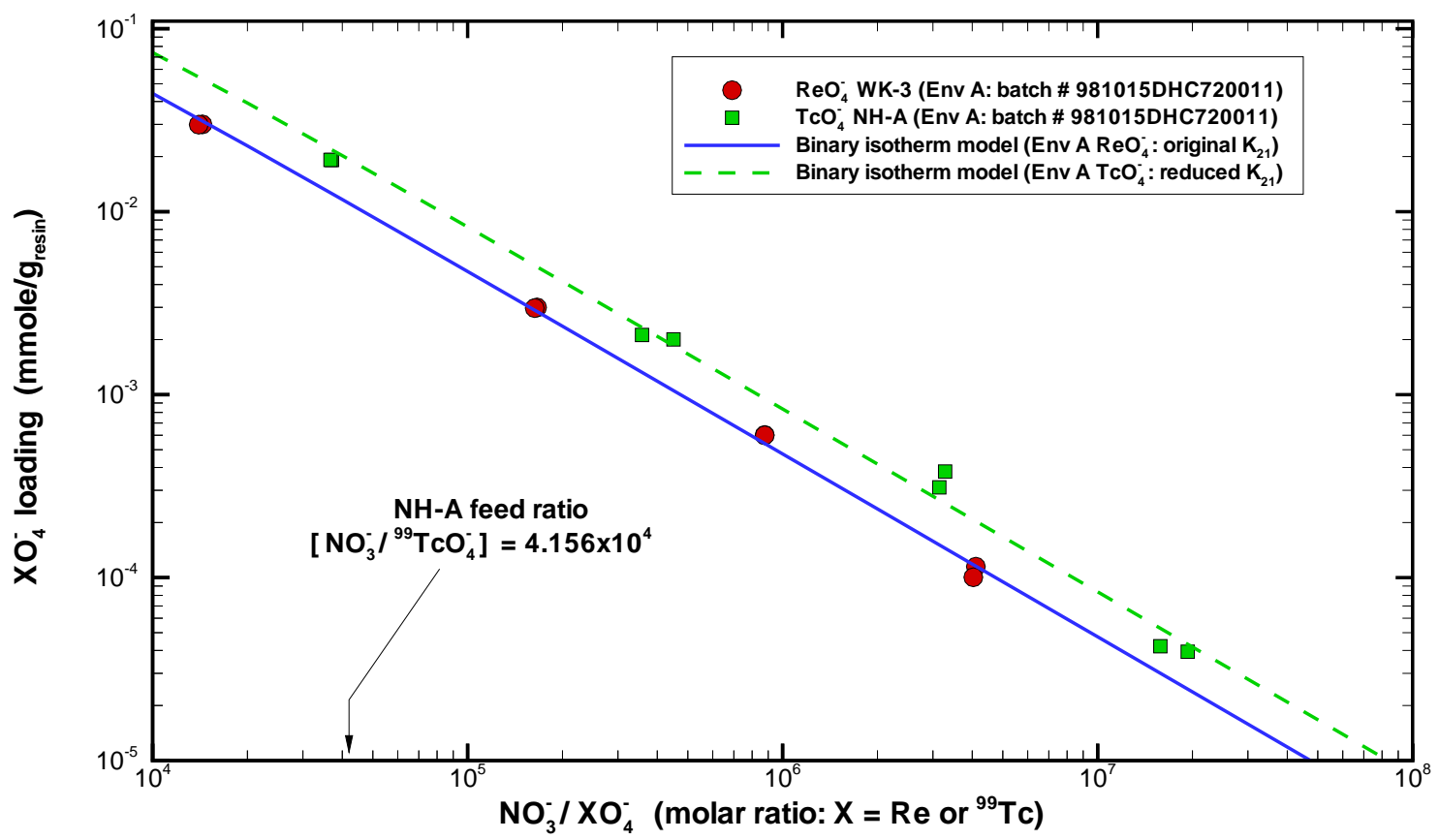

Figure 9-26. A comparison of predicted versus measured pertechnetate/perrhenate loadings on SuperLig ${ }^{\circledR} 639$ resin for Hanford Envelope A waste (King et al., 2000a; Hassan et al., 2000a). Batch specific binary isotherm models (batch \#981015DHC720011) are plotted. 


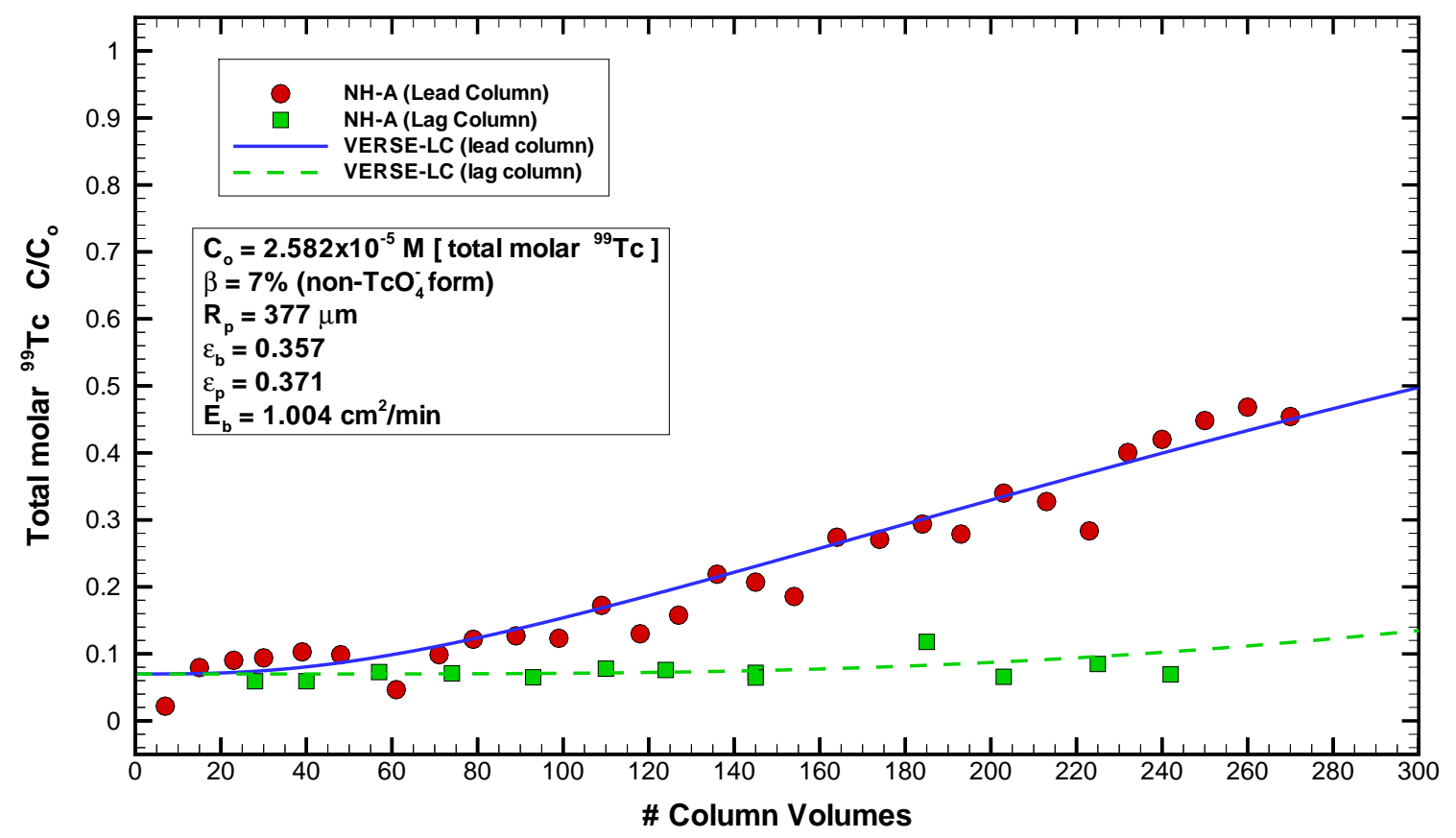

Figure 9-27. VERSE-LC total molar technetium exit breakthrough curves compared to data from Hassan et al. (2000a) based on a Hanford Envelope A waste taken from Tank 241-AN-103, $\mathrm{D}=1.1 \mathrm{~cm}, \mathrm{~L}=10.73 \mathrm{~cm}, \mathrm{U}=0.268 \mathrm{~cm} / \mathrm{min}, \mathrm{T}=25-27^{\circ} \mathrm{C}$.

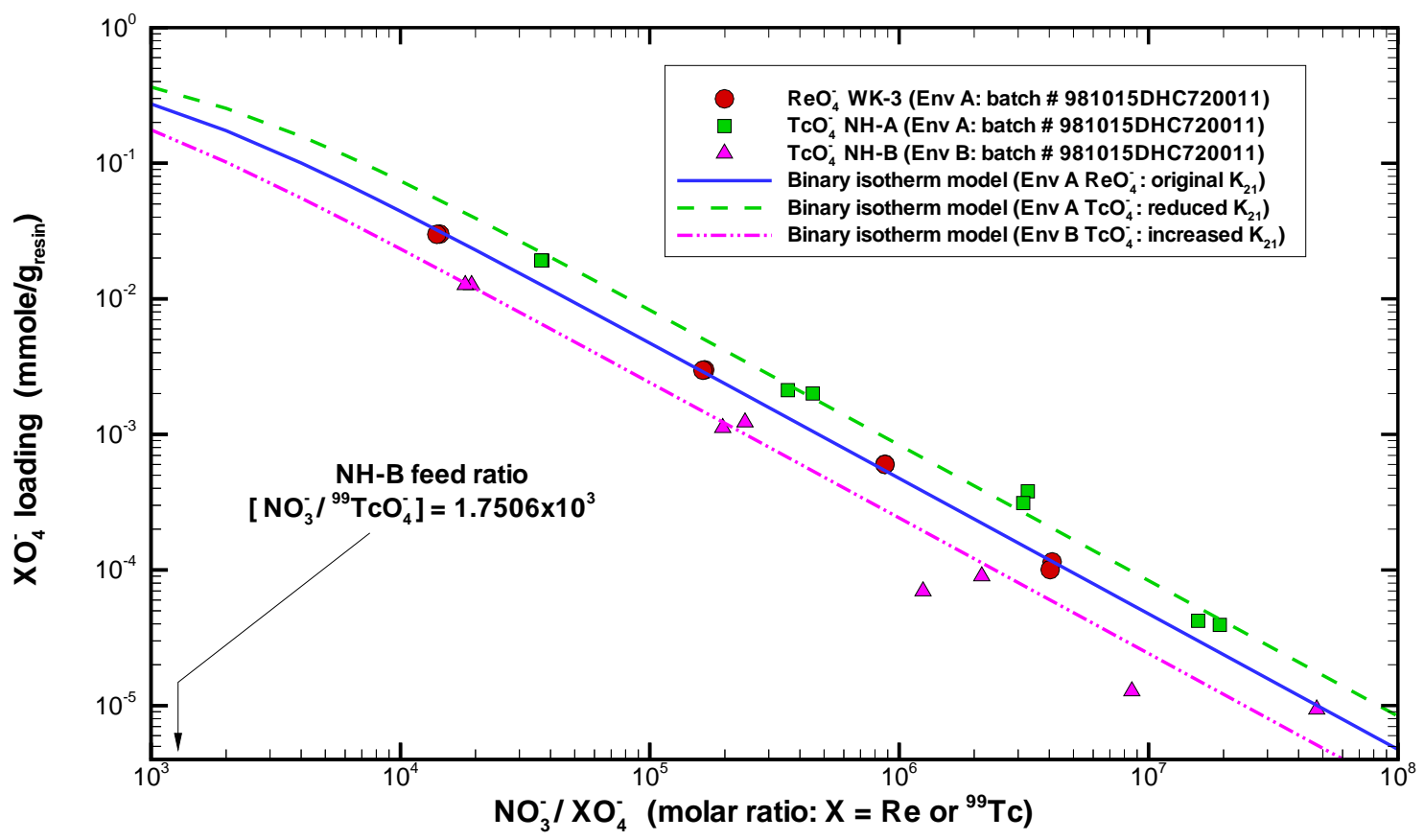

Figure 9-28. A comparison of predicted versus measured pertechnetate/perrhenate loadings on SuperLig ${ }^{\circledR} 639$ resin for Hanford Envelope A \& B wastes (King et al., 2000a; Hassan et al., 2000d). Batch specific isotherm models (batch \#981015DHC720011) are plotted. 


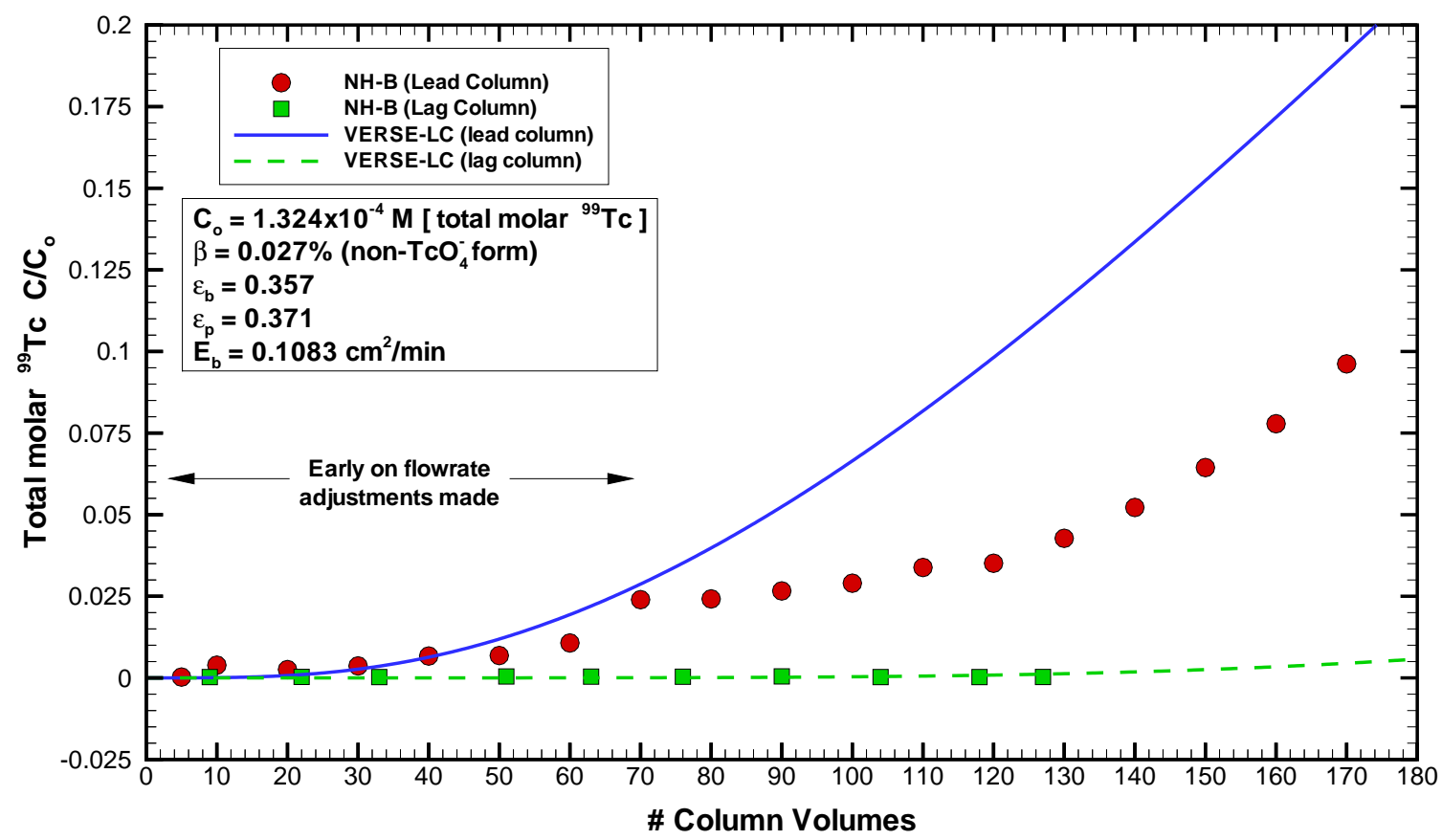

Figure 9-29. VERSE-LC total molar technetium exit breakthrough curves compared to data from Hassan et al. (2000d) based on a Hanford Envelope B waste taken from Tank 241-AZ-102, $\mathrm{D}=1.1 \mathrm{~cm}, \mathrm{~L}=11.57 \mathrm{~cm}, \mathrm{U}=0.289 \mathrm{~cm} / \mathrm{min}, \mathrm{T}=25-27^{\circ} \mathrm{C}$.

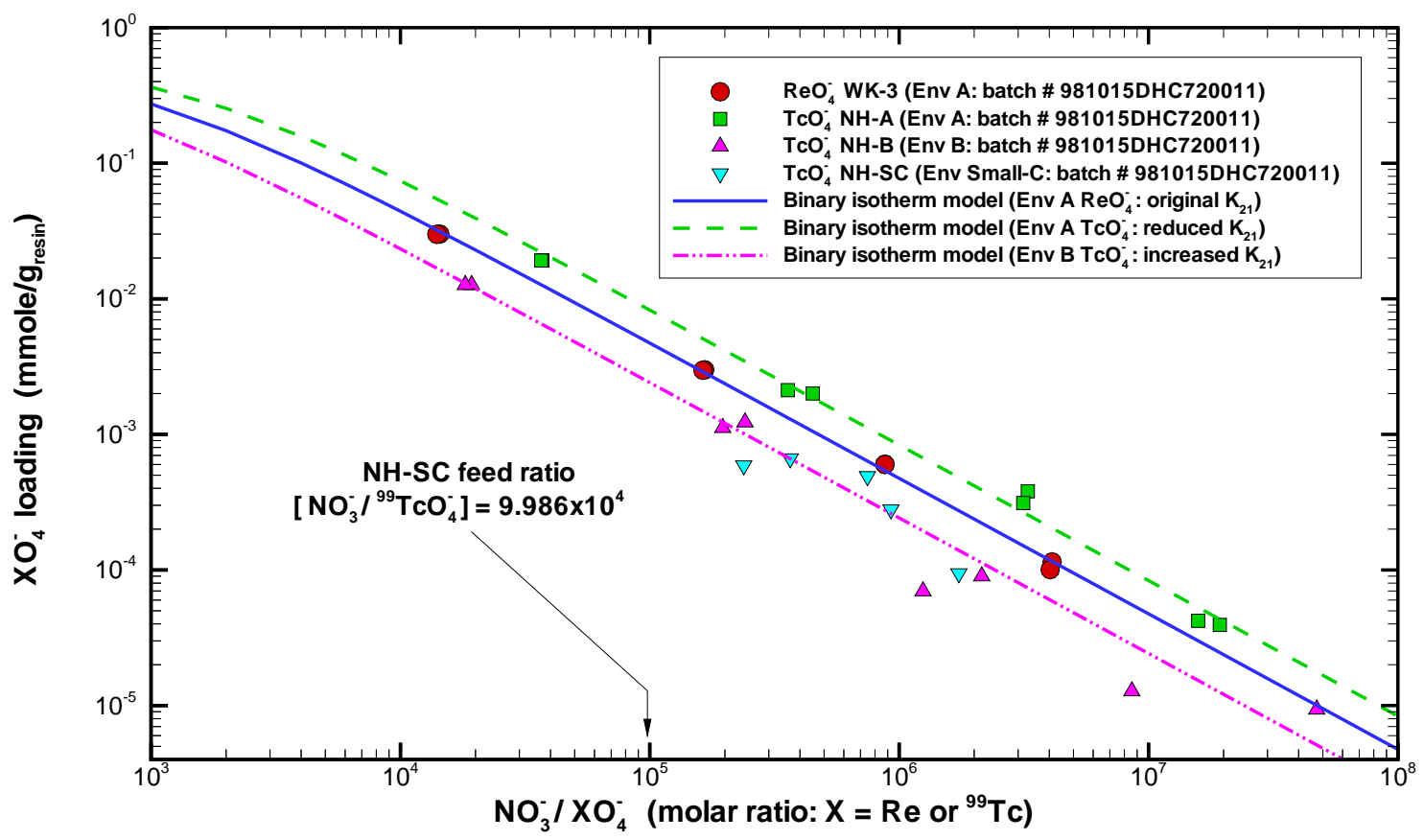

Figure 9-30. A comparison of predicted versus measured pertechnetate/perrhenate loadings on SuperLig $^{\circledR} 639$ resin for Hanford Envelope A, B, \& C wastes (King et al., 2000a; Hassan et al., 2000b). Batch specific isotherm models (batch \#981015DHC720011) are plotted. 


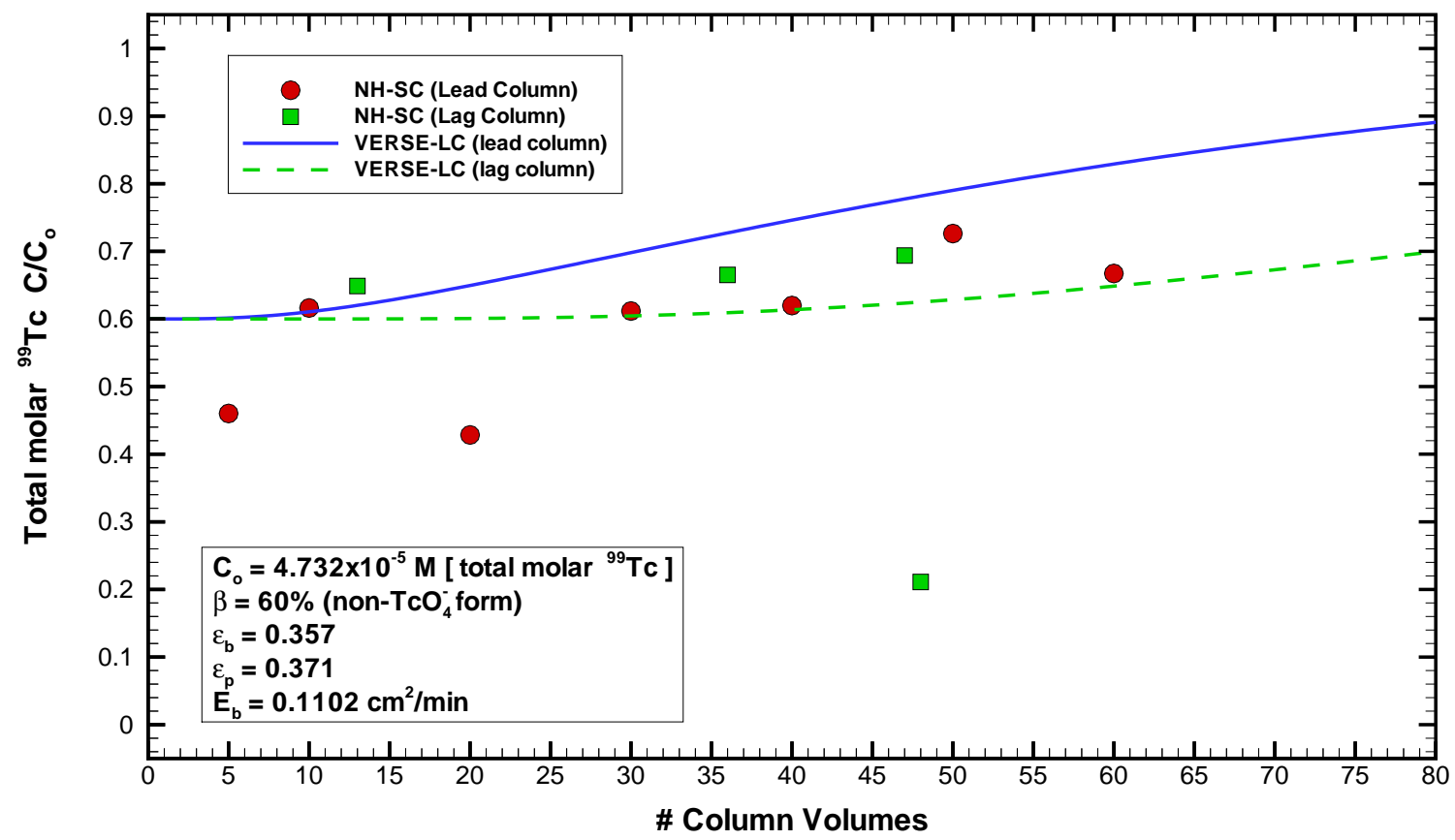

Figure 9-31. VERSE-LC total molar technetium exit breakthrough curves compared to data from Hassan et al. (2000b) based on a Hanford Envelope C (SC) waste taken from Tank 241-AN-102, $\mathrm{D}=1.1 \mathrm{~cm}, \mathrm{~L}=11.79 \mathrm{~cm}, \mathrm{U}=0.295 \mathrm{~cm} / \mathrm{min}, \mathrm{T}=25-27^{\circ} \mathrm{C}$.

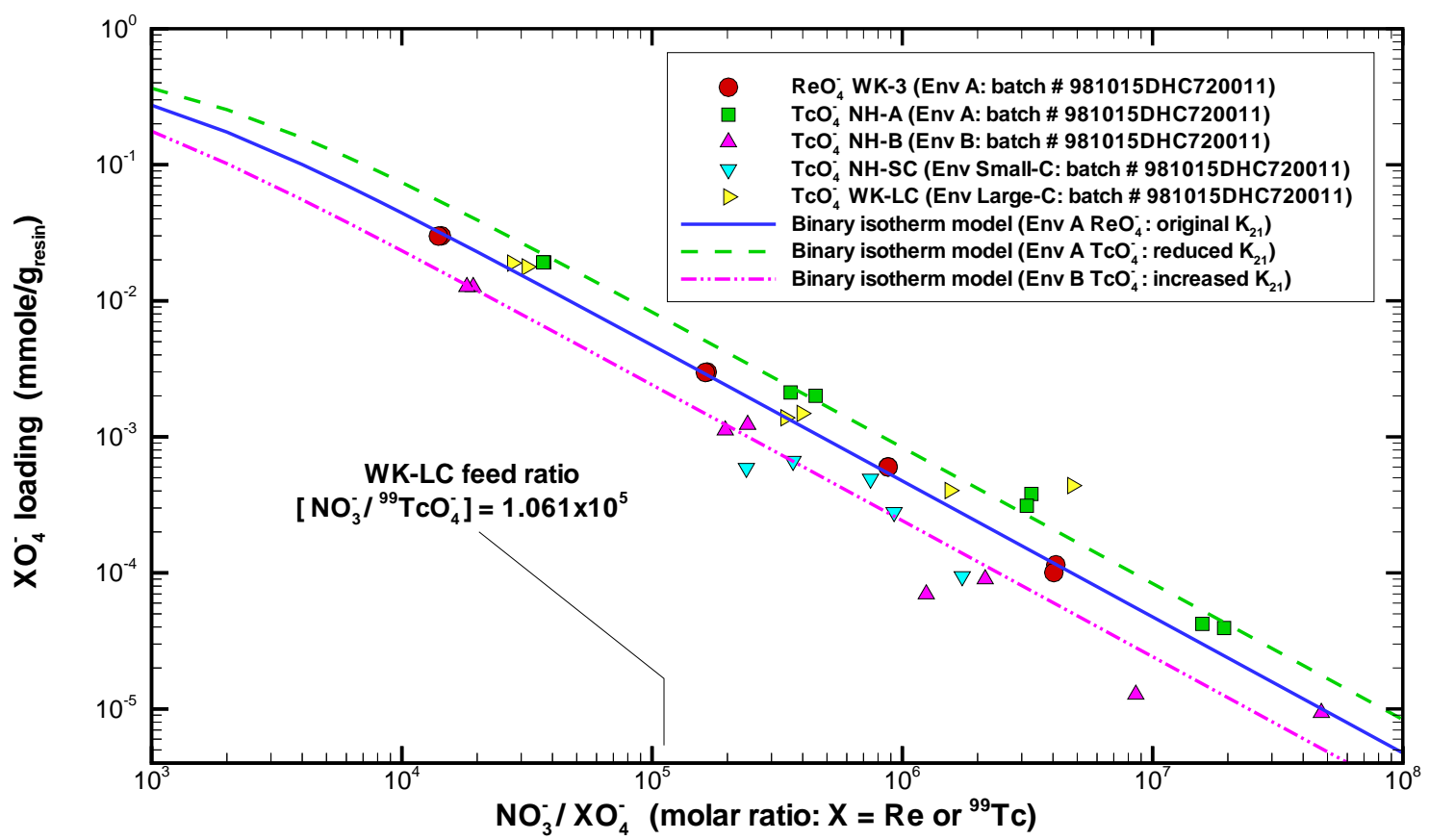

Figure 9-32. A comparison of predicted versus measured pertechnetate/perrhenate loadings on SuperLig ${ }^{\circledR} 639$ resin for Hanford Env. A B, \& C wastes (King et al., 2000a,c; Hassan et al., 2000b). Batch specific isotherm models (batch \#981015DHC720011) are plotted. 


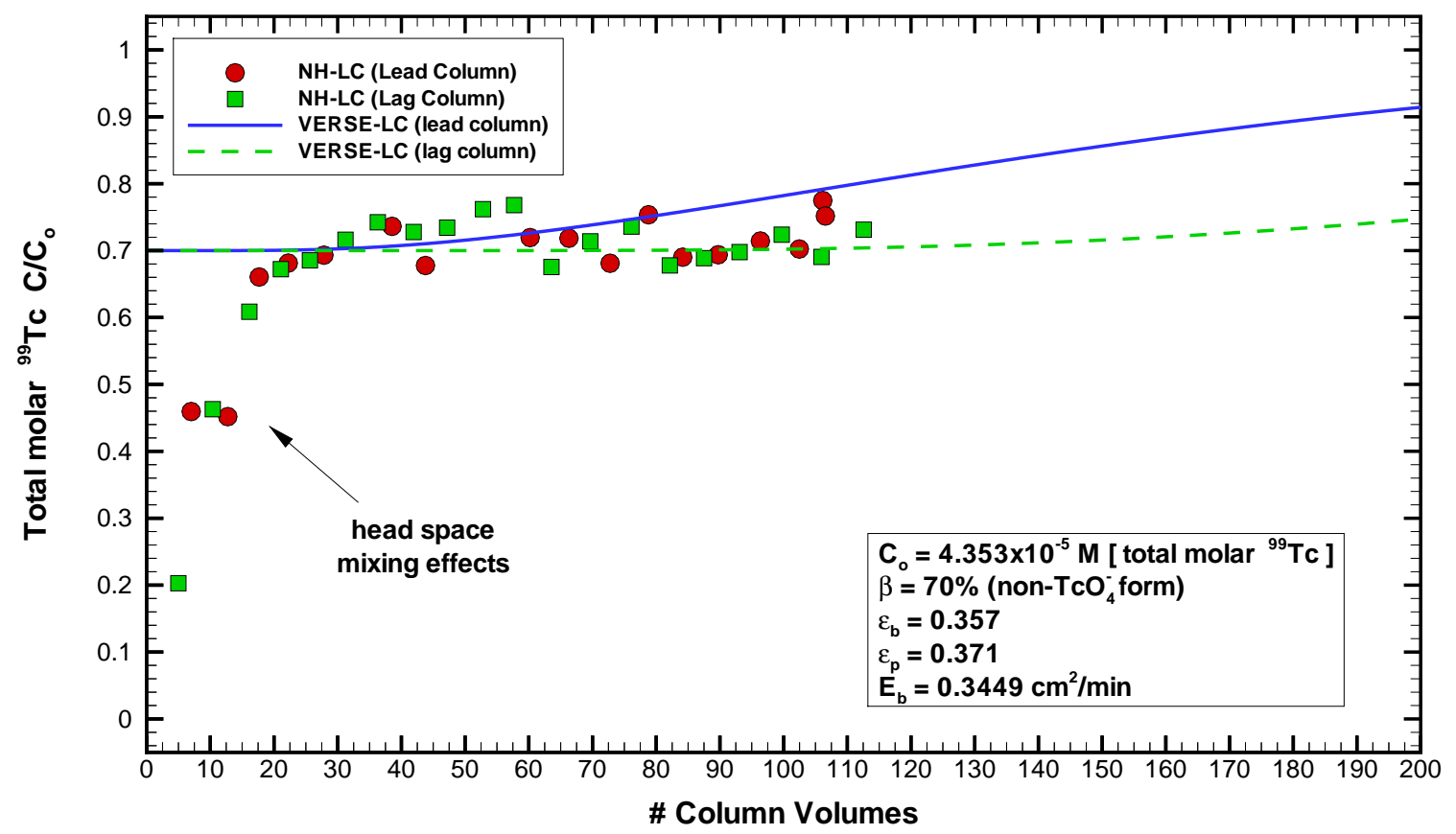

Figure 9-33. VERSE-LC total molar technetium exit breakthrough curves compared to data from King et al. (2000c) based on a Hanford Envelope C (LC) waste taken from Tank 241-AN-102, $\mathrm{D}=2.69 \mathrm{~cm}, \mathrm{~L}=51.87 \mathrm{~cm}, \mathrm{U}=0.927 \mathrm{~cm} / \mathrm{min}, \mathrm{T}=25-27{ }^{\circ} \mathrm{C}$.

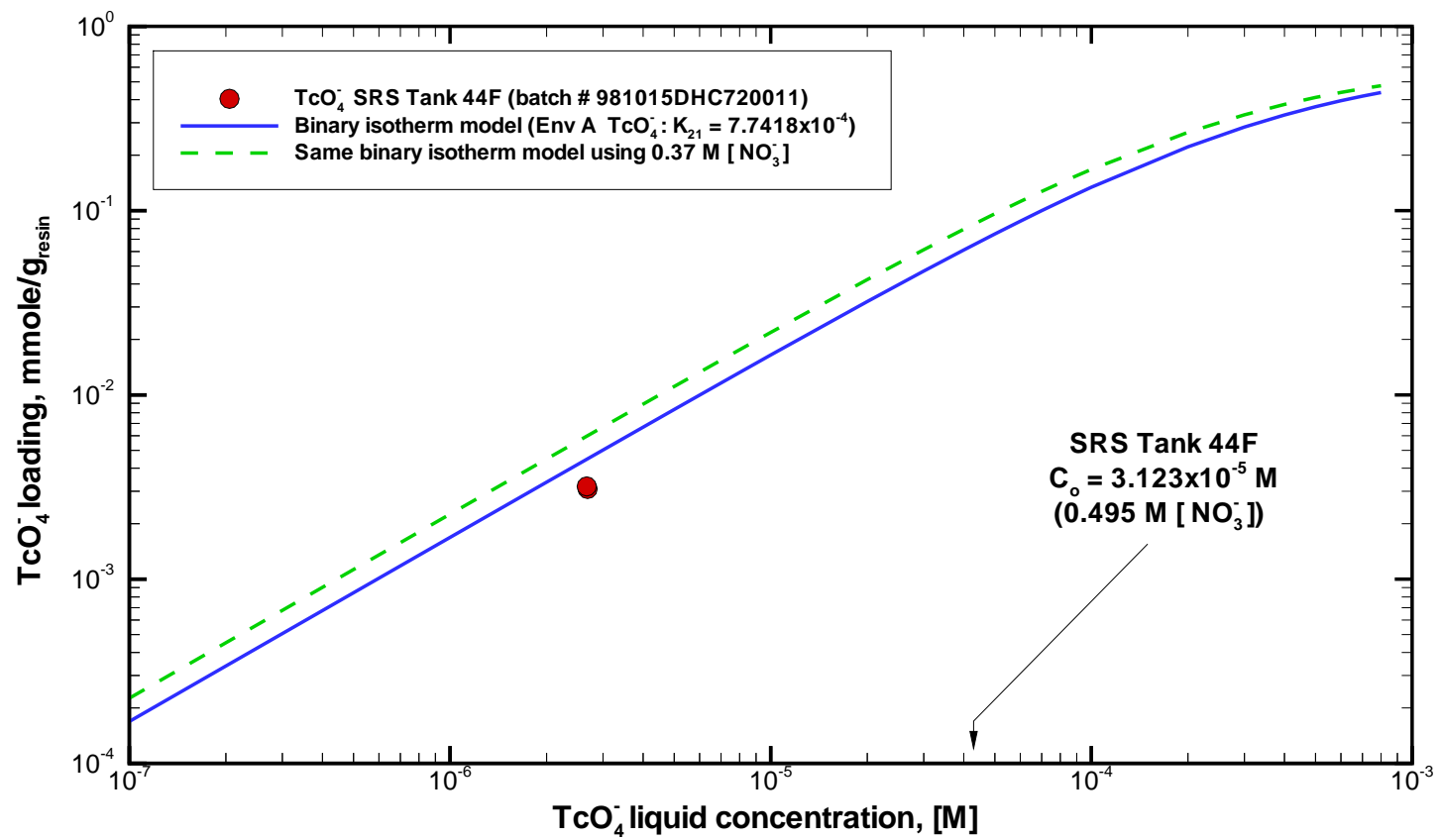

Figure 9-34. A direct comparison of predicted versus measured pertechnetate loadings on SuperLig ${ }^{\circledR} 639$ resin for SRS Tank 44F waste (King et al., 2000b). Binary isotherm models based NH-A data evaluated at expected and lower nitrate concentrations are plotted. 


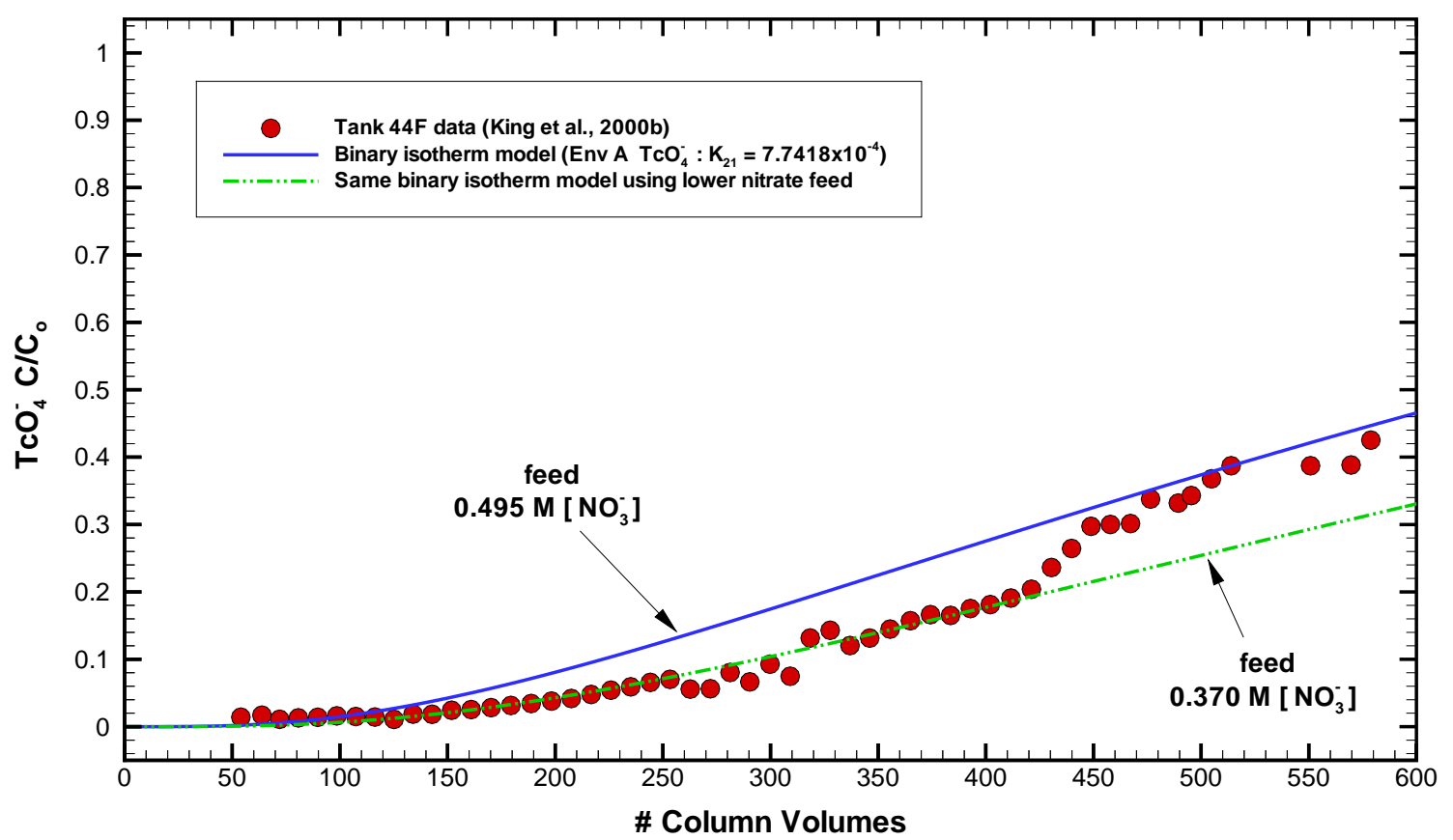

Figure 9-35. VERSE-LC total molar technetium exit breakthrough curves compared to data from King et al. (2000b) based on a SRS waste taken from Tank 44F (two nitrate estimates shown), $\mathrm{D}=2.7 \mathrm{~cm}, \mathrm{~L}=8.75 \mathrm{~cm}, \mathrm{U}=0.452 \mathrm{~cm} / \mathrm{min}, \mathrm{T}=25-26{ }^{\circ} \mathrm{C}$. 


\subsection{Full-Scale Column Predictions}

Under best estimate conditions, the predicted performance of the proposed full-scale ionexchange facility is discussed in this section. The sensitivity associated with key parameter variation is discussed also. The predictions are based on a VERSE-LC model of the lead and lag columns where the parameter settings are consistent with the values used during the assessment of the laboratory-scale and pilot-scale column experiments. The feed concentrations chosen simulate Envelope A and B Hanford wastes that are consistent with those for the "hot" smallscale pertechnetate NH-A tests (Hassan et al., 2000a) and NH-B tests (Hassan et al., 2000d), respectively. Many of the key parameters for the pilot-scale and full-scale facilities are identical (excluding column diameter and isotherm models).

\subsection{Basic Flowsheet}

The basic flowsheet for the full-scale ion-exchange columns is shown in Figure 10.1. The key parameters defining the full-scale facility are provided in Table 10-1. Two identically sized columns in series (i.e., a lead and a lag column) are used where an exit technetium concentration criterion (i.e., $<2 \%$ of the feed value) is imposed on the lag column. Each column has a void headspace that is approximately the same size as each column. Prior to loading both columns are pretreated and contain an aqueous native solution with an ionic strength of approximately $0.25 \mathrm{M}$ sodium (i.e., essentially zero technetium and nitrate are present). During the loading phase the feed solution's nitrate concentration increases from 0 to $0.998 \mathrm{M}$ for the Envelope A case study (0.232 $\mathrm{M}$ for the Envelope B case study). Inlet feed concentrations of technetium can vary from 0 to $2.580 \times 10^{-5} \mathrm{M}$ for the Envelope A case study $\left(1.324 \times 10^{-4} \mathrm{M}\right.$ for the Envelope B case study). A design flowrate of $\sim 3 \mathrm{CV} / \mathrm{hr}$ is used during the technetium loading phase. Upon reaching the lag column exit concentration criterion, the technetium loading phase is terminated and for subsequent loading cycles the lag column is placed in the lead column position with a fresh column being placed in the lag position. The loaded lead column is eluted and pretreated for future use. Fresh column implies a technetium free bed. It is assumed that the isotopic feed concentrations on a mole basis are $100 \%{ }^{99} \mathrm{Tc}$. It is assumed that technetium enters the lead column only in its pertechnetate form and no liquid-phase reactions of importance either create or consume pertechnetate during its residence time within the columns.

The technetium (in the form of pertechnetate) and nitrate concentration profiles along the column train varies with time. Due to the significant selectivity for pertechnetate by SuperLig ${ }^{\circledR} 639$ resin, the column exit breakthrough for nitrate occurs very early (i.e., within 5-10 column volumes) with pertechnetate's breakthrough significantly retarded. Key concentration points along the facility are numbered from 0 through 4 as shown in Figure 10-1. The inlet conditions correspond to point 0 while the exit product criterion is imposed at point 4 . Points 1 and 3 represent the locations where the headspace ends and the active bed begins. 


\subsection{VERSE-LC Model of Full-Scale Facility}

The VERSE-LC model representing the full-scale flowsheet is shown in Figure 10-2. To model the full-scale facility using VERSE-LC the headspaces are considered to be continuous stirred tank reactors (CSTRs). In these CSTRs perfect mixing is assumed where no chemical reactions are taking place. During a VERSE-LC simulation exit breakthrough curves at points 2 and 4 are generated along with concentration profiles over both columns at key points in time.

During the loading phase for modeling purposes a time invariant flowrate and inlet feed conditions are assumed. Both the binary homovalent system and an effective single component system have been studied. The VERSE-LC input parameters are listed for the Envelope A and Envelope B nominal case studies in Tables E-1 and E-2 of Appendix E, respectively. The VERSE-LC input and output files for typical (nominal) runs are also provided in Appendix E. The feed concentrations considered are those for the Envelope A and B Hanford wastes represented by the NH-A and NH-B samples, respectively. The simulations were run out for over a total of 1100 column volumes such that a repeating pattern occurs during subsequent cycling. Four cycles occurred as shown in the lead-column and lag-column exit breakthrough curves for technetium in Figure 10-3. The start of each cycle represents the replacement of the lead-column with the lag-column and insertion of a fully eluted (assumes complete technetium elution) and regenerated column in the lag position. For the results presented in Figure 10-3, cycle initiation occurred when the exiting technetium concentration from the lag-column reached $2 \%$ of its inlet feed concentration to the lead column (only technetium in the pertechnetate form is removed). A technetium-99 activity level of $1 \mu \mathrm{Ci} / \mathrm{ml}$ corresponds to a total technetium-99 concentration of $5.957 \times 10^{-4} \mathrm{M}$ where the radioactive half-life of $2.13 \times 10^{5}$ years for ${ }^{99} \mathrm{Tc}$ is used (see Table 10-1). For both the Envelope A and B case studies it is assumed that only technetium in its pertechnetate from is present and that no liquid-phase reactions are occurring that either create or consume pertechnetate is important within the timeframe of interest.

By the fourth cycle a repeating pattern is achieved and no additional cycles are necessary to demonstrate the long-term behavior of the facility. This is easily seen in Figure 10-3 by: (1) the repeating peak lead column exit concentrations and (2) the repeating number of column volumes required to reach the lag column exit criterion. A close-up of cycle number 4 for the Envelope A case is shown in Figure 10-4. Cycle 3 and beyond require approximately 212 column volumes to reach a technetium-99 exit concentration equal to $2 \%$ of the lead column feed concentration. As shown in Figure 10-4 once this exit criterion is reached the exit technetium concentration of the lead-column peaks at $33 \%$ of its feed value.

At the end of the second cycle (and beyond) the lead-column overall contains on average (i.e., its axial average) $\sim 69.5 \%$ of its total technetium loading capacity as shown by the technetium concentration profiles presented in Figure 10-5 (note, the fraction of column technetium loading was estimated by integrating the predicted concentration profile over the column's axial length and dividing by column length). The mixing impact associated with the void headspace (i.e., modeled as a CSTR) between the two columns is negligible as seen in Figure 10-5. The overall technetium loading (i.e., axial average) for the lag-column is $\sim 12.2 \%$ for cycle number 2 and beyond. Profile development during the course of subsequent cycles is also shown in Figure 10- 
5 for cycle numbers 1, 2, and 3 (note: cycles 3,4,5 and beyond are essentially the same as the results for cycle 2). The overall column technetium loadings are tabulated in Table 10-2.

To assess the impact resulting from using an Envelope B waste feed, the above set of calculations was redone where the nitrate feed concentration was lower while the technetium feed concentration was higher (i.e., partially compensating affects). As shown in Figures 10-6 and 107 , an $\sim 19 \%$ increase in treated column volumes results, with a technetium exit concentration from the lead-column of $\sim 36 \%$ (at the end of the later cycles). The overall column technetium loadings are also tabulated in Table 10-2.

For a linear adsorption isotherm the number of column volumes required to reach a given exit criterion will not vary beyond the second cycle. As shown in Figures 10-3 and 10-6, the number of column volumes required to reach a given exit criterion varies during the first three cycles. This characteristic variation (i.e., initially drops and then rises up and levels off) can be explained with reference to Figure 10-5 or 10-7 where the changes in concentration profile over both columns at various cycles are shown. At the end of the first cycle the highest level of concentrations within the lag-column are experienced due to its initially "technetium-free" state. Therefore, for subsequent cycles the lag-column experiences migration of technetium into its bed at the outset (due to the initial presence of technetium loading throughout in the upstream leadcolumn) reducing the number of column volumes required to reach the exit criterion. After a few cycles (note that the adsorption isotherm is slightly non-linear and no more than two cycles is required) the concentration profile throughout both columns becomes repeatable (i.e., repeatable after only three cycles for the technetium-SuperLig ${ }^{\circledR} 639$ system, while five cycles were necessary for repeatability for the cesium-SuperLig ${ }^{\circledR} 644$ system, see Hamm et al., 2000).

The exit breakthrough curves for the lag columns (dashed lines) in Figures 10-3 and 10-6 become the subsequent exit breakthrough curves for the lead columns (solid lines). A composite exit breakthrough curve for the life cycle of one specific column (i.e., originally in the lag-position during its first use and then in the lead-position for its last use) is represented in Figures 10-3 and $10-6$ by the combination of a dashed line followed by a solid line.

\subsection{Facility Decontamination Factor}

An overall average decontamination factor (D.F.) can be defined for multiple cycles as:

$$
\text { D.F. } \equiv \frac{\int_{\text {cycles }}\left(\mathrm{Qc}_{\mathrm{Cs}^{+}}^{\text {feed }}\right) \mathrm{dt}}{\int_{\text {cycles }}\left(\mathrm{Qc}_{\mathrm{Cs}^{+}}^{\text {lag-exit }}\right) \mathrm{dt}},
$$

where the integration can be performed over several loading cycles or limited to specific loading cycles. The highest D.F. occurs for the first cycle where both columns are fresh, while during later cycles the lead-column is partially loaded at the onset of a cycle, resulting in reduced D.F. values. Equation (10-1) represents the ratio of total technetium entering the facility versus the total amount exiting. For example, for a 4 cycle simulation a cumulative D.F. of 246 was 
achieved for Envelope A feed and $\sim 255$ for Envelope B feed where the lag column exit criterion was set to $2 \%$ of the inlet feed total technetium.

For both waste envelopes considered and for a lag column exit criterion of $2 \%$ of feed technetium, the D.F. for the complete range of possible operating cycles is tabulated in Table 103 (on a cumulative basis) and in Table 10-4 (on a per cycle basis). The cumulative D.F.'s listed in Table 10-3 are also plotted in Figure 10-8 where the functional dependence on the number of operating cycles processed is shown. Note that this functional dependence is nearly identical (other than a slight vertical shift) regardless of which waste envelope is considered and that the number of column volumes per cycle is less for the higher nitrate feed concentration waste (i.e., Envelope A). For estimating D.F.'s for other wastes a simple linear interpolation based on nitrate feed concentration is suggested.

The D.F.'s listed in Table 10-3 and presented in Figure 10-8 are D.F. values based on Eq. (10-1). For example, the D.F. value for the Envelope A case after three complete cycles is 253. This value was computed using Eq. (10-1) where integration was applied over the entire time period (i.e., includes cycles 1,2, and 3). D.F. values for individual cycles (such as, operation during cycle 3 alone) are listed in Table 10-4 and presented in Figure 10-9.

\subsection{Parameter Sensitivity Study}

The sensitivity of the predicted column breakthrough curve for technetium to variations in several of the model parameters was investigated to provide an indication of the reliability of the best estimate (i.e., nominal) calculated results. For this study, we chose to use the full-scale columns as the test case where the lead column exit breakthrough curves are shown. In order to show the breakthrough curves up to high loading levels, cycling the columns at a specified lag column exit criterion is turned off. These results provide an indication of the difference between nominal and worst case results that might be used to develop conservative column designs.

Table 10-6 summarizes the sensitivity parameters chosen for the study and gives a qualitative indication of model sensitivity to the parameter value. In each case, the nominal value of a single parameter was varied to a high (upper) or a low (lower) setting while the test case run was made with all other parameters held at their nominal values. The Envelope A waste feed was chosen as the nominal test case. In most cases, the range over which the parameters were varied was chosen to be indicative of the uncertainty in the parameter. Results from the sensitivity calculations are plotted in Figures 10-10 through 10-17.

\subsubsection{Axial Dispersion Sensitivity}

Figure 10-10 shows that the technetium breakthrough curve is very insensitive to the value of the axial dispersion coefficient. The nominal value of the axial dispersion coefficient is based on the Chung-Wen correlation (1968) that has an actual uncertainty on the order of $\pm 50 \%$. Column breakthrough curves at this level of uncertainty were indistinguishable from the nominal case. Therefore, runs were made at $1 / 10^{\text {th }}$ and 10 times the nominal axial dispersion coefficient so the results could be differentiated from the nominal case (only observable differences are seen during 
the front portion of the breakthrough). These results indicate that use of the Chung-Wen correlation is certainly acceptable for column design calculations.

\subsubsection{Film Diffusion/Mass Transfer Sensitivity}

Figure 10-11 shows sensitivity of the predicted breakthrough curve to a $\pm 50 \%$ variation in the mass transfer coefficient. The nominal mass transfer coefficient is based on the WilsonGeankoplis correlation (1966). Comparison to other mass transfer correlations for packed columns at low Reynolds number (Foo and Rice, 1975) indicates the $\pm 50 \%$ is a reasonable estimate of the uncertainty in this correlation. A lower mass transfer coefficient causes faster breakthrough and a slower approach to saturation. However, the effect is quite small over the sensitivity range tested and use of the nominal correlation appears to be acceptable for design calculations.

\subsubsection{Pore Diffusion Sensitivity}

Figure 10-12 shows model sensitivity to the pore diffusion coefficient for pertechnetate. As a nominal value we have used 50\% of the estimated molecular diffusion coefficient (see Section 7 for details on the basis of this estimate) to account for pore restriction and tortuosity. Since the pore diffusion coefficient can be no larger than the molecular diffusion coefficient, this value was chosen as the upper bound and the lower bound was set to $25 \%$ of this value (see predicted transient behavior for these three values in Figure 7-1). The results show a moderate-to-high sensitivity to the pore diffusion coefficient. In particular, lower pore diffusion coefficients lead to faster breakthrough and slower approach to saturation. The pore diffusion coefficient can be estimated from kinetic batch contact experiments as done in Section 7. Data on the rate of approach to adsorption equilibrium under conditions where liquid film mass transfer effects are small and pore diffusion dominates can be used to fit values to the pore diffusion coefficients. Limited data for this purpose were available for this system and it is recommended that more data be taken so that a more accurate estimate of the pore diffusion coefficients (for pertechnetate and nitrate) can be obtained.

\subsubsection{Bed and Pore Porosity Sensitivity}

Figure 10-13 shows model sensitivity to the bed porosity. As shown in Section 5, bed porosity is related to particle porosity so that varying the bed porosity necessitates changing the particle porosity as well. The nominal value of 0.357 for bed porosity is the averaged value measured by Bruening (2000a). No direct measures on particle porosity are available. Instead, an indirect method of estimating particle porosity is employed. The nominal value of 0.371 for particle porosity is computed based on available measurements of particle density and bed density for several batch ID's (Hassan et al., 1999a).

Variation of the bed porosity by \pm 0.10 represents an estimate of the reasonable extremes in bed porosity. That is, we do not expect bed porosity to be greater than $45.7 \%$ or less than $25.7 \%$. The predicted breakthrough curve, as shown in Figure 10-13, is reasonably sensitive to the chosen value. The bed and pore particle porosities are varied in such a manner that the total 
porosity of the columns remains fixed. This ensures that the same quantity of resin is used in each simulation. See Section 5 for further discussion on the functional constraints between bed and particle porosities.

The bed porosity and particle porosity (or total porosity) can be measured experimentally. Only limited experimental measurements are currently available for this system and it is recommended that additional tests be conducted. Since the results are sensitive to bed porosity, it is very useful to the modeling effort to have as many parameters as possible defined by accurate measurements. A direct measurement of bed porosity and particle porosity (or total porosity) will also help to minimize the overall uncertainty in column design calculations.

\subsubsection{Particle Radius Sensitivity}

Figure 10-14 shows model sensitivity to particle radius. The nominal value of $377 \mu \mathrm{m}$ is taken from measurements of the particle size of dry resin as discussed in Section 6. The data show a particle size distribution that appears to be truncated at higher values from instrument limitations. Based on the various particle size measurements available $377 \pm 50 \mu \mathrm{m}$ particle radius bounds were chosen.

The model can only use a single estimate of the particle radius and hence only approximates the true physical situation. In addition, the model assumes a spherical particle whereas actual particle shape may be irregular. However, for SuperLig ${ }^{\circledR} 639$ resin the spherical approximation appears to be reasonable. The model appears to be more sensitive to a smaller particle radius that sharpens the breakthrough curve. Therefore, it is more conservative to assume a larger particle radius for column design purposes. More accurate measurements of the particle size distribution would be desirable.

\subsubsection{Bed Density Sensitivity}

Figure 10-15 shows model sensitivity to the resin bed density of the columns. A variation in total ionic exchange capacity results in similar behavior as shown in Figure 10-15, since bed density and total ionic exchange capacity show up as a product in the column transport equations. Calculated results are very sensitive to the bed density since this parameter is a direct measurement of the amount of resin mass contained within the columns and thereby the total column adsorption capacity for ion exchange.

The nominal value of $0.468 \mathrm{~g} / \mathrm{ml}$ was measured for batch ID (\# 981015DHC720011) by Hassan et al. (1999a). As can be seen in Table 9-3, measured bed densities for the various columns tested (representing several batch IDs) range from 0.400 to $0.527 \mathrm{~g} / \mathrm{ml}$. This represents an approximately $\pm 13 \%$ variation about the nominal value of $0.468 \mathrm{~g} / \mathrm{ml}$. As the calculations demonstrate in Figure 10-15, a 13\% decrease in bed density significantly lowers bed capacity and gives a faster breakthrough curve. Therefore, an accurate measurement of this parameter is essential to obtaining reliable model predictions. 


\subsubsection{Flow rate Sensitivity}

Figure 10-16 shows model sensitivity to the volumetric flow rate in CV/hr. The results are for the Envelope A case, focusing on the first cycle only, where similar relative behavior exists for later cycle comparisons. All input parameter values were fixed at their nominal values, while the input volumetric flow rate was varied from 1.5 to $6.0 \mathrm{CV} / \mathrm{hr}$. However, the film diffusion coefficient varied consistent with the correlation expressed by Eq. (8-1) due to the variation in Reynolds number. For each of the five simulations shown, the exit breakthrough curve for the lead column is plotted up to the point when the technetium concentration exiting the lag column exceeds the criterion of $2 \%$ of its feed value (i.e., $5.16 \times 10^{-7} \mathrm{M}[\mathrm{Tc}]$ ). The number of column volumes required to reach $50 \%$ technetium breakthrough at the exit of the lead column and to reach the specified technetium exit criterion for the lag column are tabulated in Table 10-5.

Figure 10-16 indicates that the slower the flow rate the sharper the concentration profile remains leading to progressively higher technetium loadings on the lead column prior to reaching a fixed exit criterion for the lag column. As shown in Table 10-5 and plotted in Figure 10-17, the number of column volumes required to reach $2 \%$ breakthrough in the lag column is somewhat less sensitive to flow rate than the column volumes required to reach $50 \%$ breakthrough in the lead column. The crossover point (perhaps an optimum condition) where both criteria (i.e., lead and lag column criteria) are met simultaneously occurs near $1.5 \mathrm{CV} / \mathrm{hr}$.

\subsubsection{Sensitivity Summary}

As listed in Table 10-6 axial dispersion down the column and liquid film mass transfer across the particle boundary have a low impact on the exit breakthrough curve. Pore diffusion and average particle radius have moderate impact. Bed porosity (along with pore porosity) and bed density have high impact. Variations in average particle radius impact both the available particle surface area per unit of column volume for mass transfer and the diffusional length down each pore. Therefore, particle radius impacts both the liquid film mass transfer and pore diffusion simultaneously. Once a column volume is specified the bed density sets the total amount of resin contained within the column.

As a general rule if the predicted breakthrough curve does not cross the data near the $50 \%$ relative concentration point, then either the isotherm model or the bed density will require adjustments. As demonstrated by the sensitivity studies shown in Figures 10-10 through 10-16, only the variations in bed density shifted the predicted curves significantly throughout the relative concentration range. All the other parameter variations in essence rotated the curve about the $\sim 70 \%$ point. Without any mass transfer limitations occurring, as discussed below, the rotation point would have been about the $\sim 50 \%$ relative concentration point.

\subsection{Mass Transfer Limitations}

Resistances to mass transfer across the liquid film and diffusion down the pores contribute to local non-equilibrium with respect to the adsorption isotherm. When a significant departure exists between the actual pertechnetate concentration on the resin and the predicted value 
corresponding to the equilibrium adsorption isotherm, the ion-exchange process is said to be mass transfer limited. To estimate the degree of resistance resulting from the mass transfer processes, a comparison of the nominal Envelope A case was made to simulations where the liquid film and pore diffusion coefficients were set to very large values (i.e., large values result in negligible mass transfer resistances). Figure 10-18 shows the impact that mass transfer resistances have on the exit breakthrough curve for the lead column.

For the case where both the liquid film and pore diffusion coefficients were set to large values, the resulting breakthrough curve becomes very sharp. The slight spread (i.e., deviation from a square wave) in the breakthrough curve is a direct result of axial dispersion which appears to be a minor component (consistent with the axial dispersion sensitivity results discussed earlier). The $50 \%$ breakthrough point occurs at $\sim 381$ column volumes as compared to the nominal value of 327. As mentioned earlier, the $50 \%$ breakthrough point is predominately set by the adsorption isotherm. However, a modest level of mass transfer exists since an approximately $14 \%$ reduction in column volumes occurred.

To determine which mechanisms are limiting (if either), the results for simulations where only liquid film resistance or pore diffusion resistance is accounted for are also provided in Figure 1018. From these simulations we see that liquid film resistance is having a negligible impact on the breakthrough curve. However, mass transfer resistance due to pore diffusion has a significant impact on the shape of the breakthrough curve. These results are consistent with the earlier sensitivity results presented for film diffusion and for the pertechnetate pore diffusion coefficient.

\subsection{Impact of Feed Concentrations}

Operation of the facility is being designed to handle a range in inlet feed conditions. For an approximately fixed inlet concentration of $\sim 5 \mathrm{M}$ sodium, a range of inlet concentrations of nitrate and technetium (in the form of pertechnetate) will be experienced. The previous series of results presented above in this section assumed for the Envelope A case study a fixed inlet feed of $\sim 5 \mathrm{M}$ sodium, $0.988 \mathrm{M}$ nitrate, and $2.580 \times 10^{-5} \mathrm{M}$ technetium (all in its pertechnetate form). Below the impact on breakthrough curves and column performance is addressed for a range of nitrate and technetium inlet feed conditions believed to span the expected range of intended operations for Envelope A, B and C wastes.

\subsubsection{Impact of Nitrate Feed Concentration}

As discussed in Section 4, nitrate competes with pertechnetate (with lesser selectivity) for available adsorption sites. Using the Freundlich/Langmuir Hybrid adsorption isotherm model, Eq. (4-21), a sensitivity study was performed to estimate the impact on column performance resulting from variations in nitrate inlet feed concentration, while holding all other parameters at their nominal settings for the Envelope A case study.

The Envelope A nominal value in nitrate feed presented in earlier results was set to $0.998 \mathrm{M}$. Nitrate feed concentrations of 0.100 and $2.000 \mathrm{M}$ are also considered (where the $2.000 \mathrm{M}$ value represents an anticipated upper bound). Both lead and lag column technetium breakthrough 
curves for these three nitrate feed concentration levels are presented in Figure 10-19. The number of column volumes required to reach $50 \%$ technetium breakthrough in the lead column and to reach the lag column exit technetium criterion are listed in Table 10-7. As seen in Figure 10-19 and tabulated in Table 10-7, the inlet feed concentration of nitrate has a very significant impact on overall performance of the two columns. The results shown in Figure 10-19 and tabulated in Table 10-7 refer to a case where both columns were initially technetium free (e.g., the first cycle).

As discussed in Section 4.6, with respect to Eq. (4-21), the beta parameter for pertechnetate becomes dependent upon the nitrate feed concentration when using the effective singlecomponent approach. Variations in inlet nitrate feed concentration (or its associated selectivity coefficient) that result in the same computed beta parameter for pertechnetate result in identical technetium breakthrough curves. Therefore, using results from the above nitrate sensitivity study the impact of variations in either the selectivity coefficient or the nitrate feed concentration can be estimated.

\subsubsection{Impact of Pertechnetate Feed Concentration}

For a linear pertechnetate adsorption isotherm model, a linear transport equation is obtained where the inlet feed concentration can be factored out normalizing the transport equation. Under such conditions the normalized breakthrough curves (i.e., $\mathrm{C} / \mathrm{C}_{\mathrm{o}}$ versus column volume plots) will show no dependence on pertechnetate feed concentration. However, as can be seen by Eq. (415), the chosen adsorption isotherm model for pertechnetate is nonlinear and a dependence on inlet pertechnetate conditions is expected for sufficiently low molar ratios of nitrate to pertechnetate anions. A sensitivity study was performed to estimate the impact on column performance resulting from variations in technetium (in its pertechnetate form) inlet feed concentrations.

The nominal value in pertechnetate feed presented in earlier results was set to $2.580 \times 10^{-5} \mathrm{M}$ for the Envelope A case study. Pertechnetate feed concentrations of $1.0 \times 10^{-5} \mathrm{M}$ and $2.0 \times 10^{-4} \mathrm{M}$ are also considered (where the $2.0 \times 10^{-4} \mathrm{M}$ value represents an anticipated upper bound). Both lead and lag column technetium breakthrough curves for these three pertechnetate feed concentration levels are presented in Figure 10-20. The number of column volumes required to reach 50\% technetium breakthrough in the lead column and to reach the lag column exit technetium criterion are listed in Table 10-8.

As seen in Figure 10-20 and tabulated in Table 10-8, the inlet feed concentration of pertechnetate can have an impact on overall performance of the two columns. Considering Envelope A waste, for molar ratios of nitrate to pertechnetate greater than $\sim 2 \times 10^{4}$ the binary adsorption isotherm is relatively linear as can be seen in Figure 9-28 (i.e., green dashed line labeled as $\mathrm{TcO}_{4}{ }^{-} \mathrm{NH}-\mathrm{A}$ ). However, the upper setting of pertechnetate feed, $2.0 \times 10^{-4} \mathrm{M}$, results in a molar ratio of $4.99 \times 10^{3}$ that places part of the columns in the non-linear region of the isotherm. Therefore, as seen in Figure 10-20, the exit breakthrough curves for the lower setting and the nominal value are nearly identical while for the upper setting earlier breakthrough is observed. The results shown in 
Figure 10-20 and tabulated in Table 10-8 refer to a case where both columns were initially technetium free (e.g., the first cycle).

Table 10-1. Key column parameters for the full-scale facility.

\begin{tabular}{|c|c|c|}
\hline Parameter & Lead column & Lag column \\
\hline SuperLig $^{\circledR} 639$ batch ID, (\#) & 981015DHC720011 & 981015DHC720011 \\
\hline Bed density $^{\mathrm{a}},(\mathrm{g} / \mathrm{ml})$ & 0.4680 & 0.4680 \\
\hline $\begin{array}{c}\text { Total ionic exchange capacity, } \\
\left(\mathrm{mmole} / \mathrm{g}_{\text {resin }}\right) \\
\end{array}$ & 0.64723 & 0.64723 \\
\hline Column diameter, $(\mathrm{cm})$ & 77.0 & 77.0 \\
\hline Active bed length ${ }^{\mathrm{a}},(\mathrm{cm})$ & $\sim 225.0$ & $\sim 225.0$ \\
\hline Active column volume ${ }^{a},(L)$ & $\sim 1047.74$ & $\sim 1047.74$ \\
\hline Headspace length, (cm) & 225.0 & 225.0 \\
\hline Bed porosity, (-) & 0.357 & 0.357 \\
\hline Pore porosity, (-) & 0.371 & 0.371 \\
\hline Superficial flow velocity, $(\mathrm{cm} / \mathrm{min})$ & 11.3 & 11.3 \\
\hline Volumetric flow rate, $(\mathrm{ml} / \mathrm{min})$ & $52,619.9$ & $52,619.9$ \\
\hline Volumetric flow rate, $(\mathrm{CV} / \mathrm{hr})$ & 3.0 & 3.0 \\
\hline $\begin{array}{c}\text { Envelope A }(241-\mathrm{AN}-103) \text { feed } \\
\text { concentrations }(\mathrm{Case} 1): \\
\text { Total Technetium, }{ }^{99} \mathrm{Tc},[\mathrm{M}] \\
\text { Nitrate, } \mathrm{NO}_{3}^{-},[\mathrm{M}]\end{array}$ & $\begin{array}{l}2.580 \times 10^{-5} \\
0.998\end{array}$ & na \\
\hline $\begin{array}{c}\text { Envelope B }(241-\mathrm{AZ}-102) \text { feed } \\
\text { concentrations }(\text { Case } 2): \\
\text { Total Technetium, }{ }^{99} \mathrm{Tc},[\mathrm{M}] \\
\text { Nitrate, } \mathrm{NO}_{3}^{-},[\mathrm{M}]\end{array}$ & $\begin{array}{l}1.324 \times 10^{-4} \\
0.232\end{array}$ & na \\
\hline $\begin{array}{c}\text { Column feed non-pertechnetate } \\
\text { fraction, }(\%)\end{array}$ & $\begin{array}{l}0 \%(\text { Case } 1) \\
0 \%(\text { Case } 2)\end{array}$ & na \\
\hline $\begin{array}{c}\text { Column exit }{ }^{99} \text { Te conc. criterion } \\
(\text { Case } 1)^{\mathbf{b}}, \\
(\%,\{\mu \mathrm{Ci} / \mathrm{ml}\}, \text { and }[\mathrm{M}])\end{array}$ & na & $\begin{array}{l}<2.0 \% \text { of feed } \\
\left\{<8.662 \times 10^{-4}\right\} \\
{\left[<5.160 \times 10^{-7}\right]}\end{array}$ \\
\hline $\begin{array}{c}\text { Column exit }{ }^{99} \text { Tc conc. criterion } \\
(\text { Case } 2)^{\mathbf{b}}, \\
(\mu \mathrm{Ci} / \mathrm{ml} \text { and }[\mathrm{M}])\end{array}$ & na & $\begin{array}{l}<2.0 \% \text { of feed } \\
\left\{<4.445 \times 10^{-3}\right\} \\
{\left[<2.648 \times 10^{-6}\right]}\end{array}$ \\
\hline
\end{tabular}

${ }^{a}$ Slight swelling due to feed ionic strength variations can alter the original bed geometry and the numbers provided assume the bed's approximate size during $\left.\sim 5 \mathrm{M}^{2} \mathrm{Na}^{+}\right]$loading conditions.

${ }^{\mathrm{b}}$ An isotopic mixture on a mole basis of $100 \%{ }^{99} \mathrm{Tc}$ is assumed, where the conversion factor $1 \mu \mathrm{Ci} / \mathrm{ml}$ equals $5.95736461 \times 10^{-4} \mathrm{M}$ of ${ }^{99} \mathrm{Tc}$ is used. A radioactive half-life of $2.13 \times 10^{5}$ years for ${ }^{99} \mathrm{Tc}$ is used taken from GE Nuclear Energy (1996).

${ }^{c}$ This value of bed porosity corresponds to the value used for the intermediate-scale and small-scale column tests which is conservative when compared to the pilot-scale bed porosity value of 0.269 . 
Table 10-2. Estimated overall column technetium loadings at the end of the first and second cycles.

\begin{tabular}{|c|c|c|c|}
\hline Column & Cycle number & $\begin{array}{c}\text { Envelope A (Case 1) } \\
\mathbf{2 4 1 - A N - 1 0 3}\end{array}$ & $\begin{array}{c}\text { Envelope B (Case 2) } \\
\mathbf{2 4 1 - A Z - 1 0 2}\end{array}$ \\
\hline \hline Lead & 1 & $71.7 \%$ & $75.0 \%$ \\
\hline Lag & 1 & $13.2 \%$ & $14.5 \%$ \\
\hline \hline Lead & 2 and beyond & $69.5 \%$ & $73.0 \%$ \\
\hline Lag & 2 and beyond & $12.2 \%$ & $13.4 \%$ \\
\hline
\end{tabular}

Table 10-3. Estimated pertechnetate decontamination factors (D.F.) on a cumulative basis as a function of the number of cycles performed.

\begin{tabular}{|c|c|c|c|c|}
\hline \multirow{2}{*}{$\begin{array}{c}\text { Number of } \\
\text { cycles }\end{array}$} & \multicolumn{2}{|c|}{ Envelope A (Case 1) } & \multicolumn{2}{c|}{ Envelope B (Case 2) } \\
\cline { 2 - 5 } performed & Column volumes & D.F. & Column volumes & D.F. \\
\hline \hline 1 & 252 & 317 & 302 & 327 \\
\hline 2 & 462 & 268 & 552 & 277 \\
\hline 3 & 674 & 253 & 805 & 263 \\
\hline 4 & 886 & 246 & 1058 & 255 \\
\hline
\end{tabular}


Table 10-4. Estimated pertechnetate decontamination factors (D.F.) on a per cycle basis as a function of the number of cycles performed.

\begin{tabular}{|c|c|c|c|c|}
\hline \multirow{2}{*}{$\begin{array}{c}\text { Number of } \\
\text { cycles }\end{array}$} & \multicolumn{2}{|c|}{ Envelope A (Case 1) } & \multicolumn{2}{c|}{ Envelope B (Case 2) } \\
\cline { 2 - 5 } Performed & Column volumes & D.F. & Column volumes & D.F. \\
\hline \hline 1 & 252 & 317 & 302 & 327 \\
\hline 2 & 462 & 226 & 552 & 234 \\
\hline 3 & 674 & 227 & 805 & 235 \\
\hline 4 & 886 & 227 & 1058 & 235 \\
\hline$>4$ & $>886$ & $\sim 227$ & $>1058$ & $\sim 235$ \\
\hline
\end{tabular}

Table 10-5. Sensitivity of volumetric flowrate on the exit technetium breakthrough curve of the lead column for the Envelope A test case.

\begin{tabular}{|c|c|c|}
\hline $\begin{array}{c}\text { Volumetric Flow } \\
\text { Rate } \\
(\mathbf{C V} / \mathbf{h r})\end{array}$ & $\begin{array}{c}\text { Column Volumes Required } \\
\text { to Reach 50\% } \\
\text { Breakthrough in Lead } \\
\text { Column } \\
(\mathbf{C V})\end{array}$ & $\begin{array}{c}\text { Column Volumes Required } \\
\text { to Reach Exit Criterion in } \\
\text { Lag Column } \\
(\mathbf{C V})\end{array}$ \\
\hline 1.5 & 355 & 361 \\
\hline 2.25 & $341^{\mathrm{b}}$ & 297 \\
\hline 3.0 & $327^{\mathrm{b}}$ & 252 \\
\hline 4.5 & $299^{\mathrm{b}}$ & 193 \\
\hline 6.0 & $273^{\mathrm{b}}$ & 156 \\
\hline
\end{tabular}

${ }^{\text {a }}$ Each simulation was run up to the lag column exit ${ }^{99} \mathrm{Tc}$ concentration corresponding to $2 \%$ of its feed value.

b The 50\% breakthrough point was "not achieved" prior to reaching the lag column exit criterion. 
Table 10-6. Sensitivity variables studied and their level of impact on exit technetium breakthrough curves for the Envelope A test case.

\begin{tabular}{|c|c|c|c|}
\hline Parameter & Nominal Value & Variation & Sensitivity \\
\hline \hline Axial Dispersion & $4.0758 \mathrm{~cm}^{2} / \mathrm{min}$ & $10 \%$ and $1000 \%$ nominal & Very Low \\
\hline Mass Transfer & $0.13146 \mathrm{~cm} / \mathrm{min}$ & $\pm 50 \%$ & Low \\
\hline \hline Particle Radius & $377 \mu \mathrm{m}$ & $\pm 50 \mu \mathrm{m}$ & Moderate \\
\hline $\begin{array}{c}\text { Pore Diffusion } \\
\text { Coefficient for } \\
\text { Pertechnetate }\end{array}$ & $\begin{array}{c}1.002 \times 10^{-4} \mathrm{~cm}^{2} / \mathrm{min} \\
\left(50 \% \mathrm{D}_{\infty}\right)\end{array}$ & $25 \%$ to $100 \%$ of $\mathrm{D}_{\infty}$ & $\begin{array}{c}\text { Moderate to } \\
\text { high }\end{array}$ \\
\hline \hline Bed Porosity & 0.357 & \pm 0.10 & High \\
\hline Bed Density & $0.468 \mathrm{~g} / \mathrm{ml}$ & $\pm 13 \%$ & Very High \\
\hline Flow Rate & $3.0 \mathrm{CV} / \mathrm{hr}$ & 1.5 to $6.0 \mathrm{CV} / \mathrm{hr}$ & Very High \\
\hline
\end{tabular}

Table 10-7. Sensitivity of nitrate feed concentration on the number of column volumes required to reach $50 \%$ breakthrough in the lead column and to reach the lag column exit technetium criteria. ${ }^{\text {a }}$

\begin{tabular}{|c|c|c|}
\hline $\begin{array}{c}\text { Liquid } \mathrm{NO}_{3}{ }^{-} \text {Feed } \\
\text { Concentration } \\
{[\mathbf{M}]}\end{array}$ & $\begin{array}{c}\text { Column Volumes Required } \\
\text { to Reach 50\% Breakthrough } \\
\text { in Lead Column } \\
\text { (CV) }\end{array}$ & $\begin{array}{c}\text { Column Volumes Required } \\
\text { to Reach Lag Column Exit } \\
\text { Technetium Criterion } \\
\text { (CV) }\end{array}$ \\
\hline Envelope A (Case 1) & \multicolumn{2}{|c|}{} \\
\hline 0.100 (lower) & >> $1000^{\mathrm{b}}$ & >> $1000^{\mathrm{b}}$ \\
\hline 0.988 (nominal) & 327 & 252 \\
\hline 2.000 (upper) & 166 & 128 \\
\hline
\end{tabular}

${ }^{\text {a }}$ The column volume numbers listed refer to a case where both columns were initially technetium free (e.g., the first cycle of operation only). Each lag column exit criterion employed is based on $2 \%$ of total technetium in feed.

$\mathrm{b}$ The required column volumes greatly exceed the simulation end point. 
Table 10-8. Sensitivity of technetium feed concentration on the number of column volumes required to reach $50 \%$ breakthrough in the lead column and to reach the lag column exit technetium criteria. ${ }^{\text {a }}$

\begin{tabular}{|c|c|c|}
\hline $\begin{array}{c}\text { Liquid } \\
\text { Concentration } \\
{[\mathbf{M}]}\end{array}$ & $\begin{array}{c}\text { Column Volumes Required } \\
\text { to Reach 50\% Breakthrough } \\
\text { in Lead Column } \\
\text { (CV) }\end{array}$ & $\begin{array}{c}\text { Column Volumes Required } \\
\text { to Reach Lag Column Exit } \\
\text { Technetium Criterion } \\
\text { (CV) }\end{array}$ \\
\hline Envelope A (Case 1) & \multicolumn{2}{|c|}{} \\
\hline $1.00 \times 10^{-5}$ (lower) & 332 & 253 \\
\hline $2.58 \times 10^{-5}$ (nominal) & 327 & 252 \\
\hline $2.00 \times 10^{-4}$ (upper) & 280 & 241 \\
\hline
\end{tabular}

${ }^{a}$ The column volume numbers listed refer to a case where both columns were initially technetium free (e.g., the first cycle of operation only). Each lag column exit criterion employed is based on $2 \%$ of total technetium in feed.

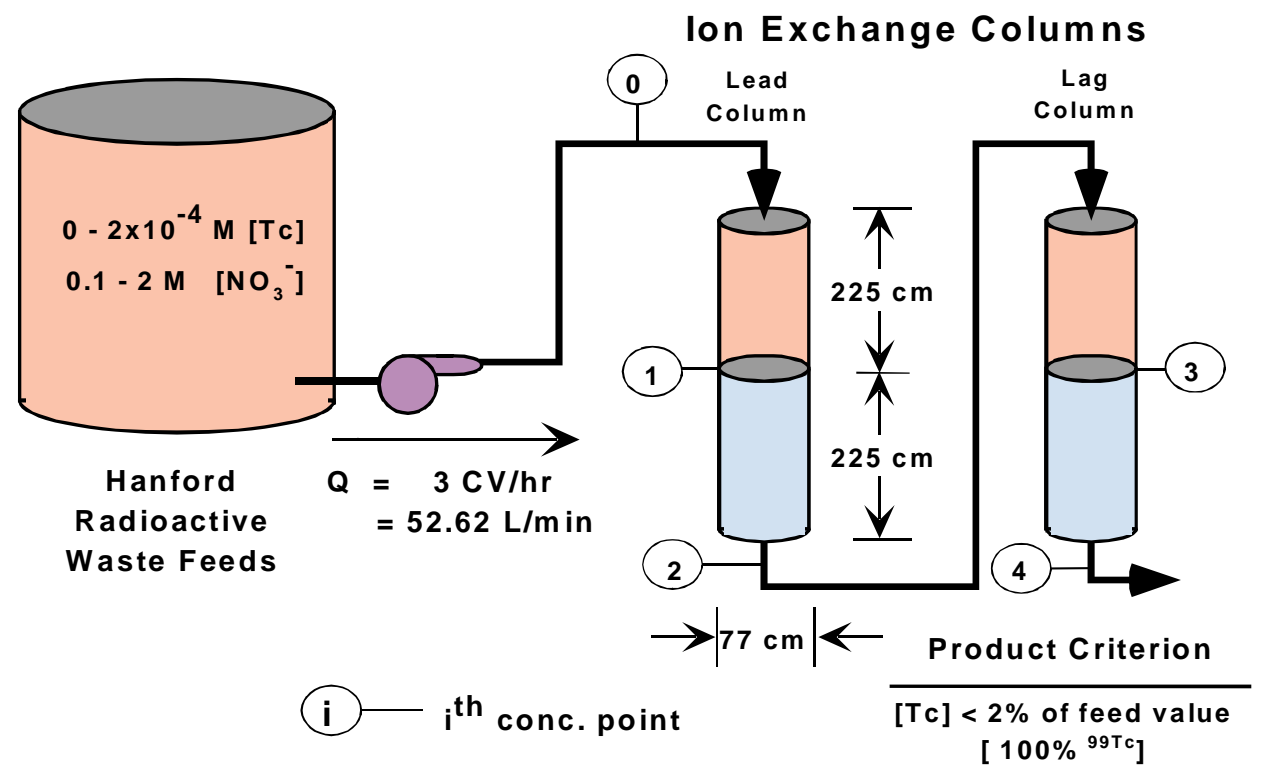

Figure 10-1. Basic flowsheet for full-scale ion exchange facility for removal of technetium (in its pertechnetate form) using the SuperLig ${ }^{\circledR} 639$ resin. 
Inlet Feed Conditions
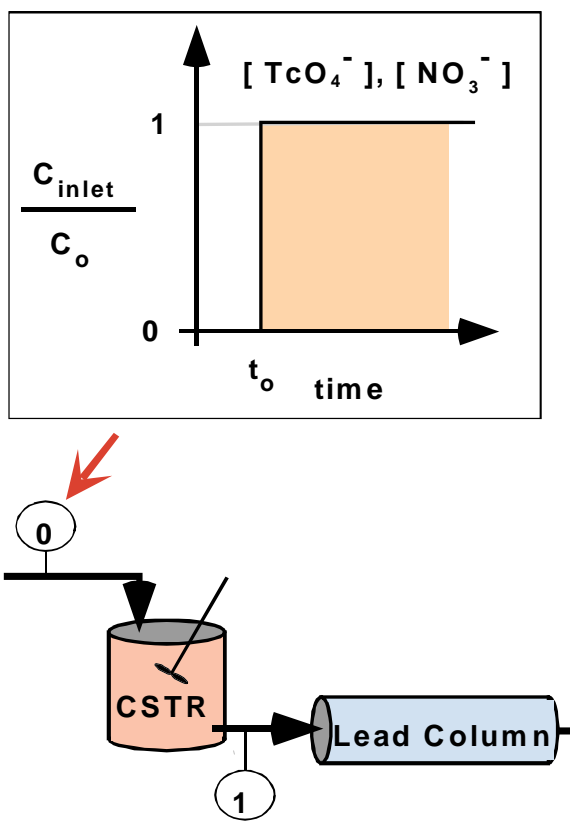

(i) $i^{\text {th }}$ conc. point
Exit Breakthrough Curves
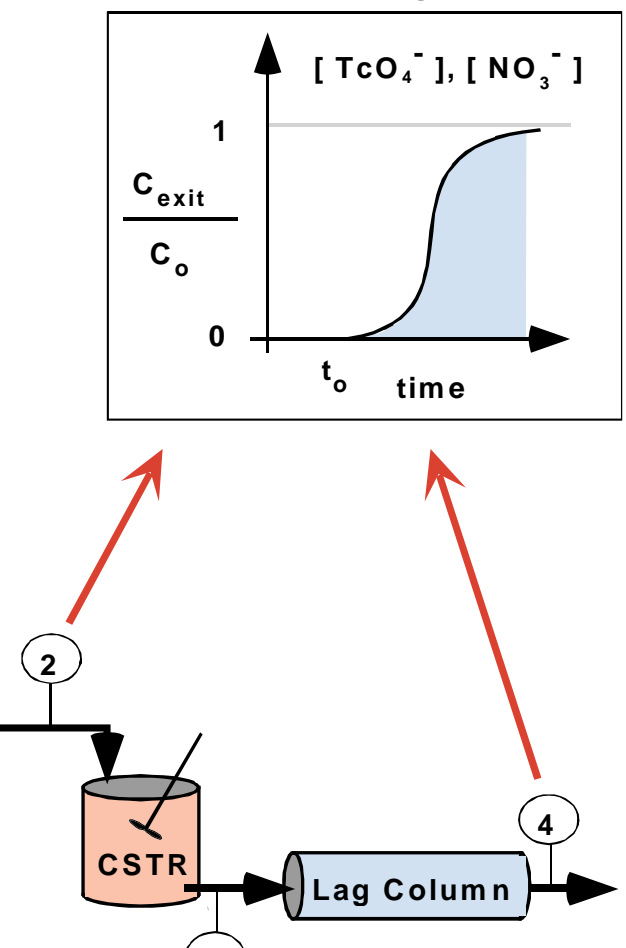

3

Figure 10-2. VERSE-LC model representing the full-scale flowsheet for removal of technetium (in its pertechnetate form) using the SuperLig ${ }^{\circledR} 639$ resin. 


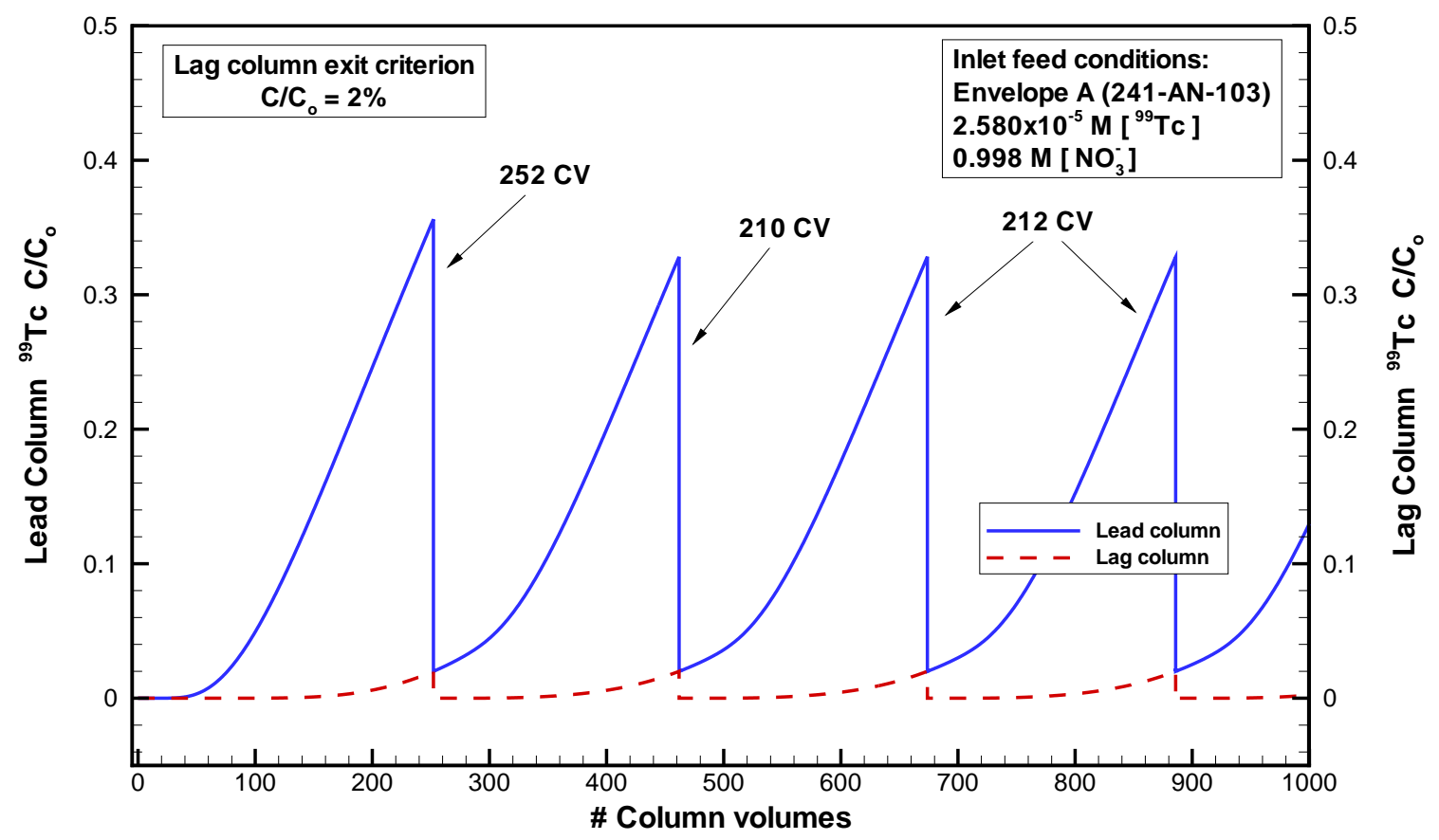

Figure 10-3. VERSE-LC model best estimate predictions for multiple cycling of the full-scale facility for the removal of technetium (in its pertechnetate form) from Envelope A waste (241-AN103) using the SuperLig ${ }^{\circledR} 639$ resin.

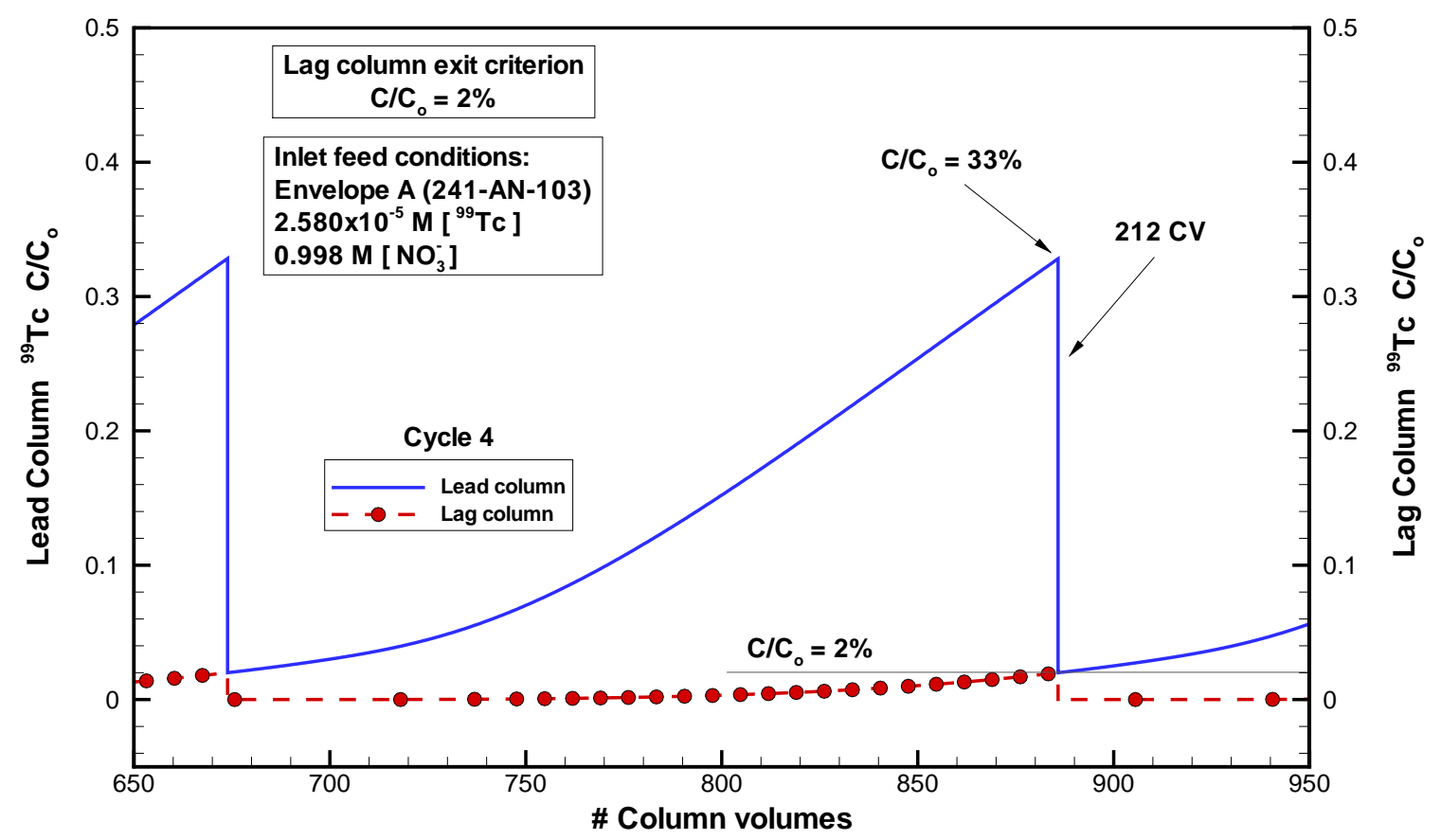

Figure 10-4. VERSE-LC model best estimate predictions for cycle number 4 of the full-scale facility for the removal of technetium (in its pertechnetate form) from Envelope A waste (241-AN103) using the SuperLig ${ }^{\circledR} 639$ resin. 


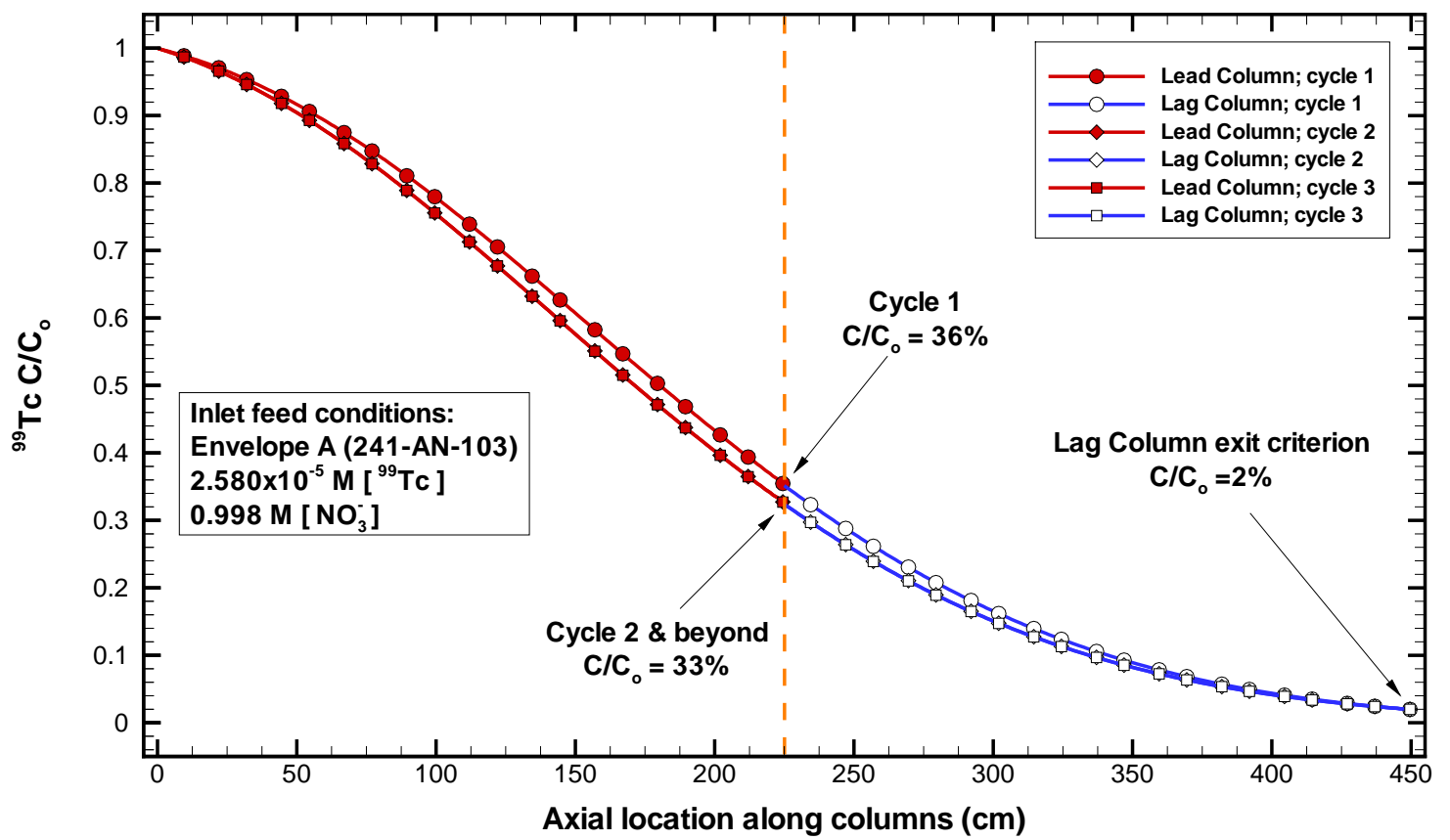

Figure 10-5. VERSE-LC model best estimate prediction of the technetium column profiles for all cycles of the full-scale facility for the removal of technetium (in its pertechnetate form) from Envelope A waste (241-AN-103) using the SuperLig ${ }^{\circledR} 639$ resin.

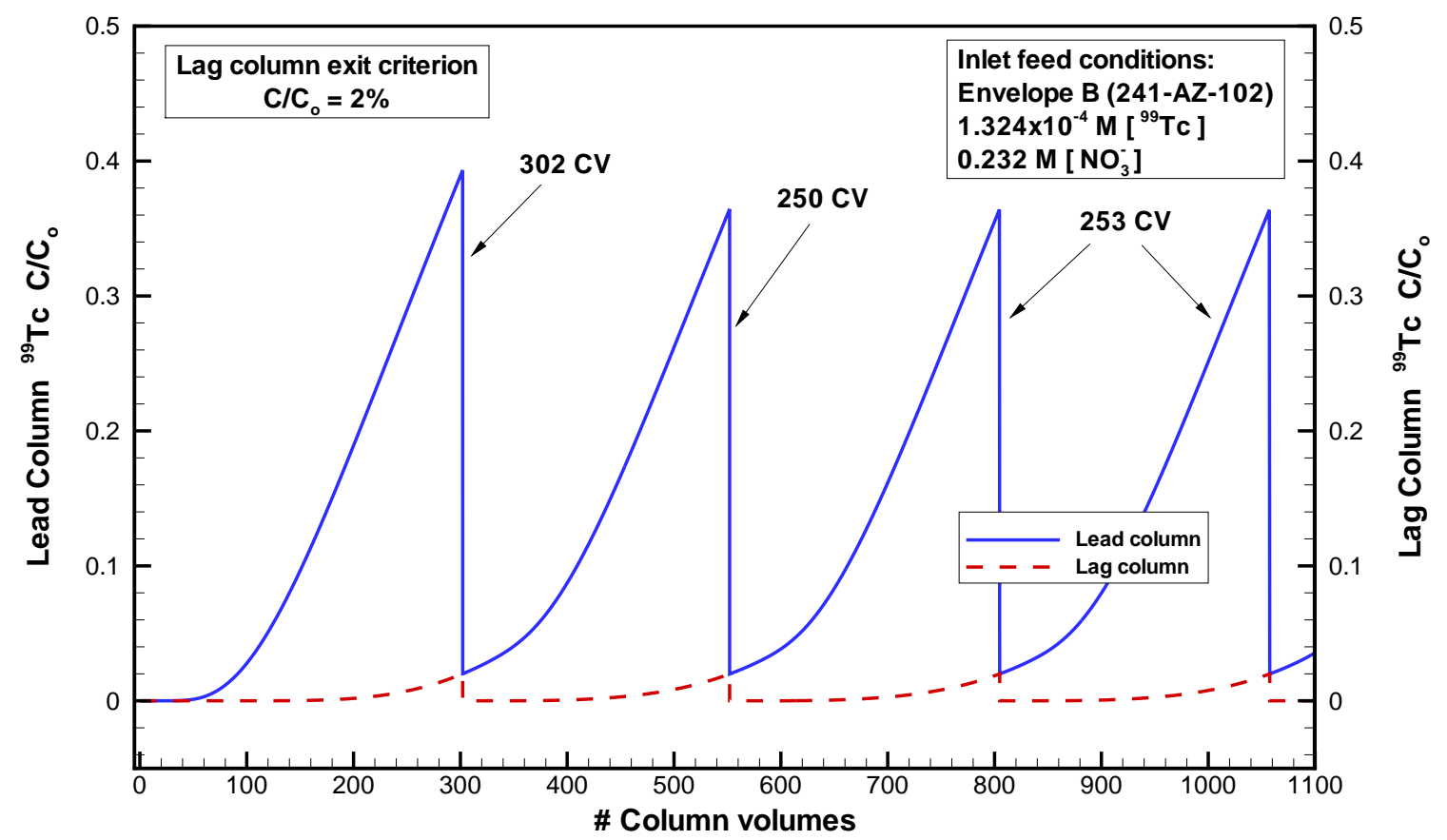

Figure 10-6. VERSE-LC model predictions for multiple cycling of the full-scale facility for the removal of technetium (in its pertechnetate form) from Envelope B waste (241-AZ-102) using the SuperLig ${ }^{\circledR} 639$ resin. 


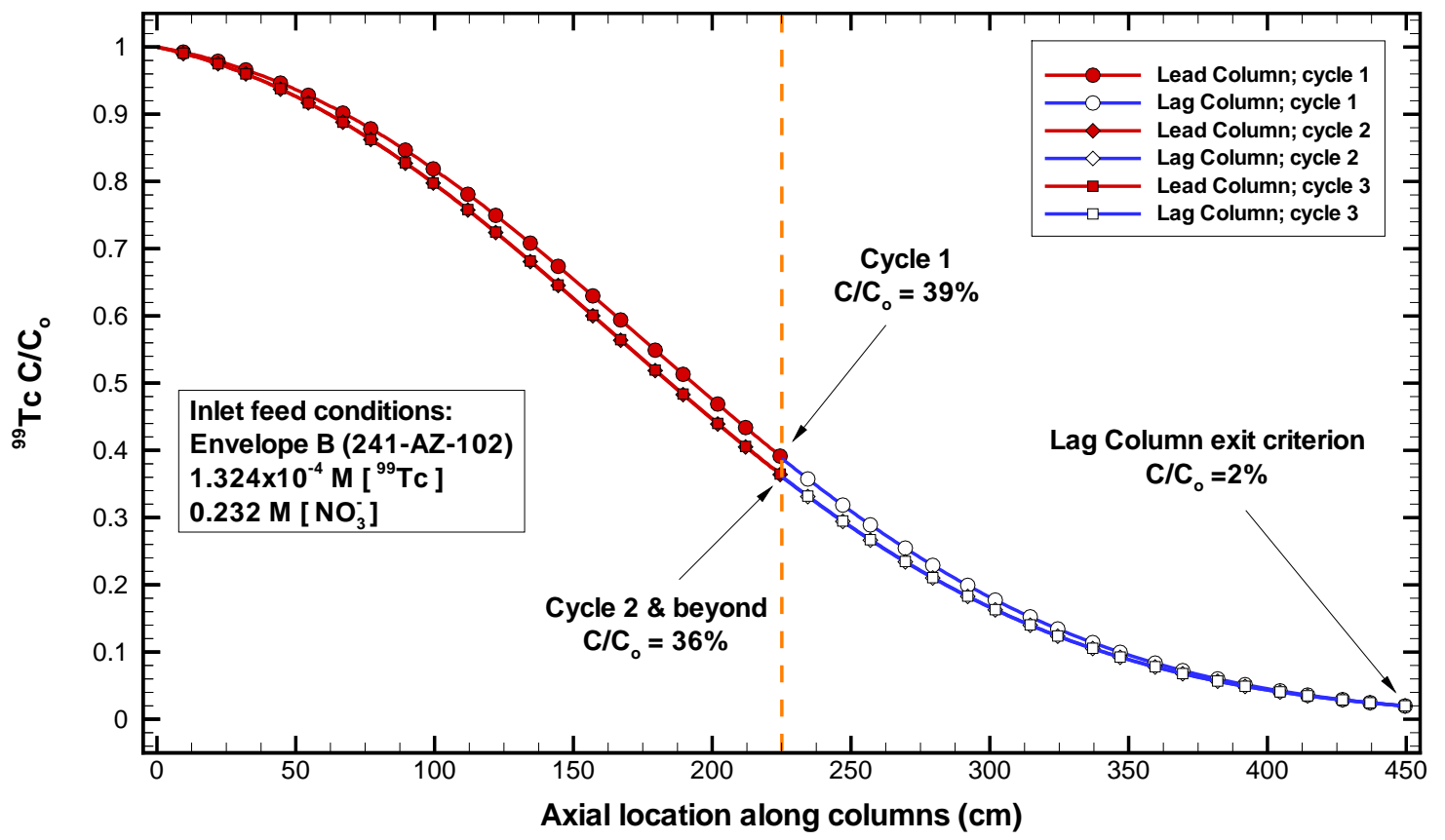

Figure 10-7. VERSE-LC model prediction of the technetium column profiles for all cycles of the fullscale facility for the removal of technetium (in its pertechnetate form) from Envelope B waste (241-AZ-102) using the SuperLig ${ }^{\circledR} 639$ resin.

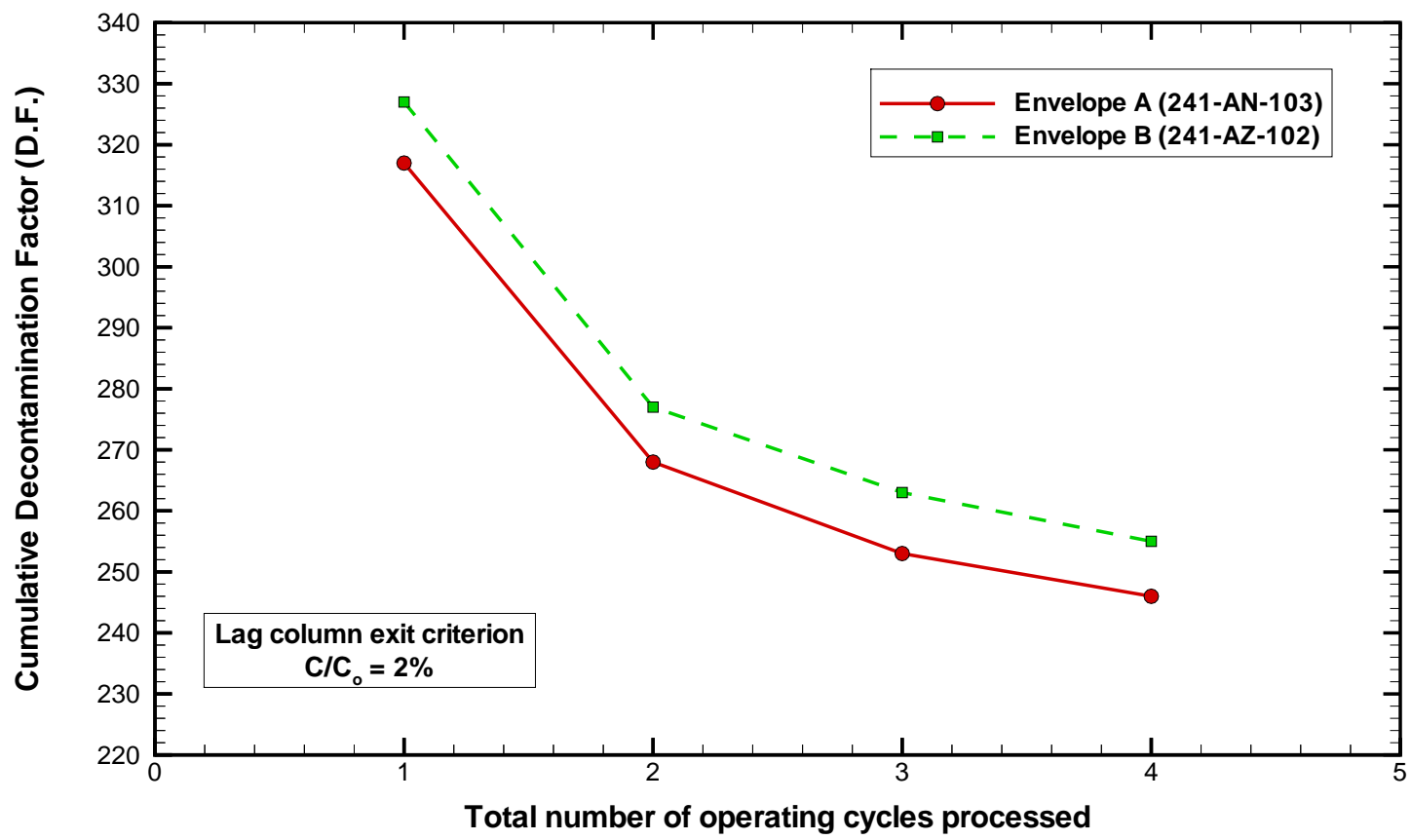

Figure 10-8. Variation of the overall pertechnetate decontamination factor on a cumulative basis with respect to the number of operating cycles assumed for each waste envelope. 
Preliminary Ion Exchange Modeling for Removal of Technetium from Revision (Date):

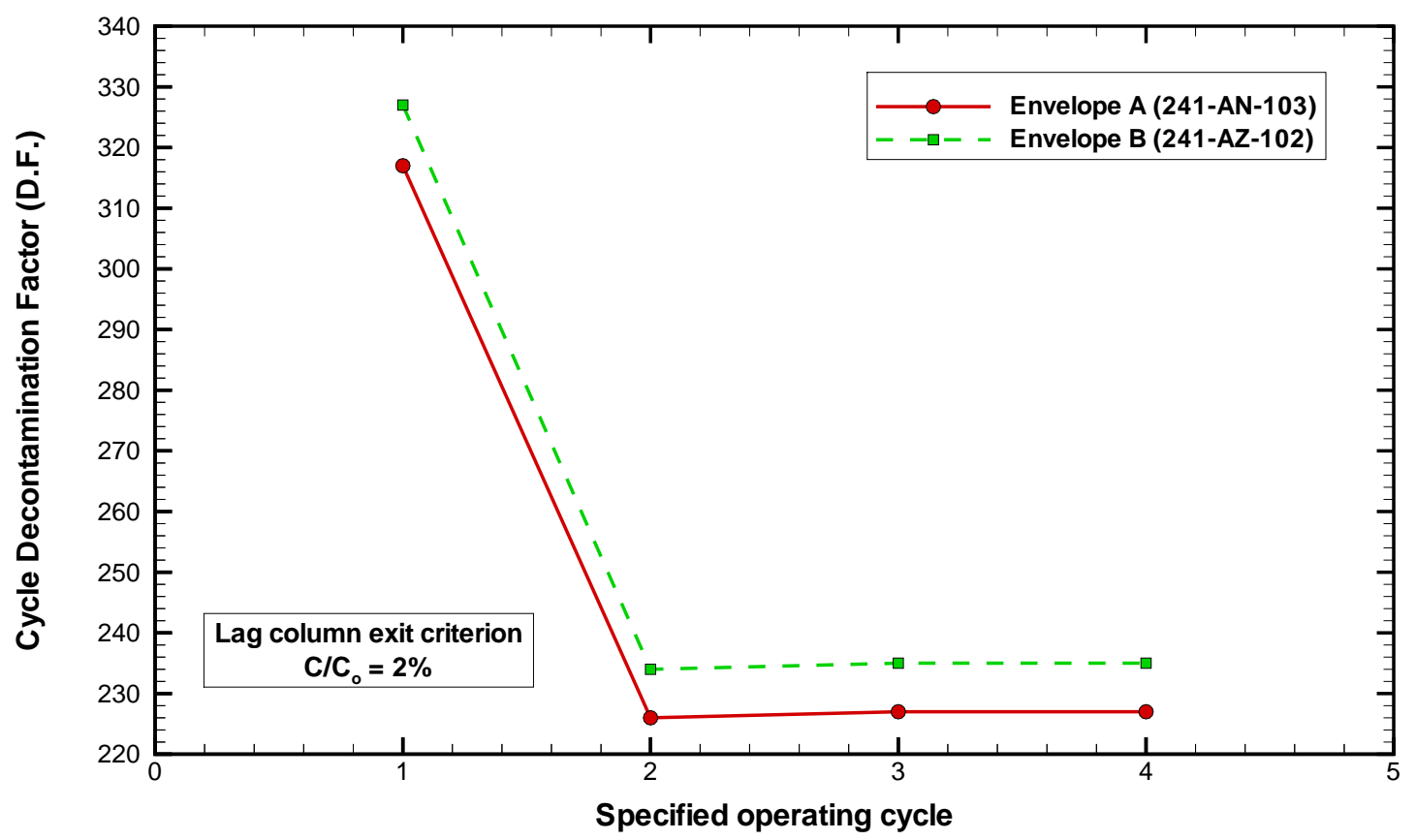

Figure 10-9. Variation of the overall pertechnetate decontamination factor on a per cycle basis for each waste envelope.

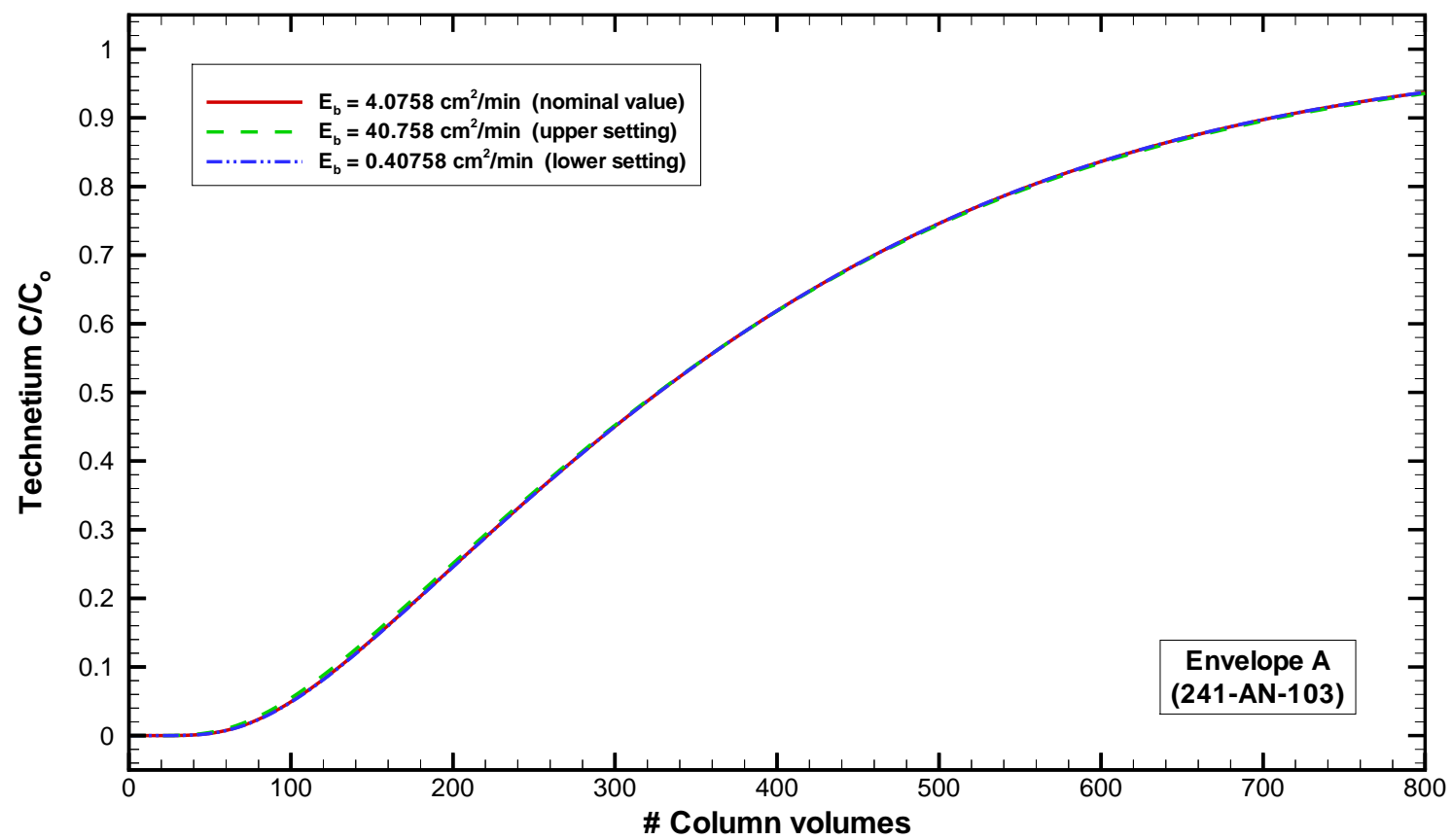

Figure 10-10. Sensitivity of full-scale column breakthrough curve to axial dispersion for the Envelope A test case. 
Preliminary Ion Exchange Modeling for Removal of Technetium from Revision (Date):

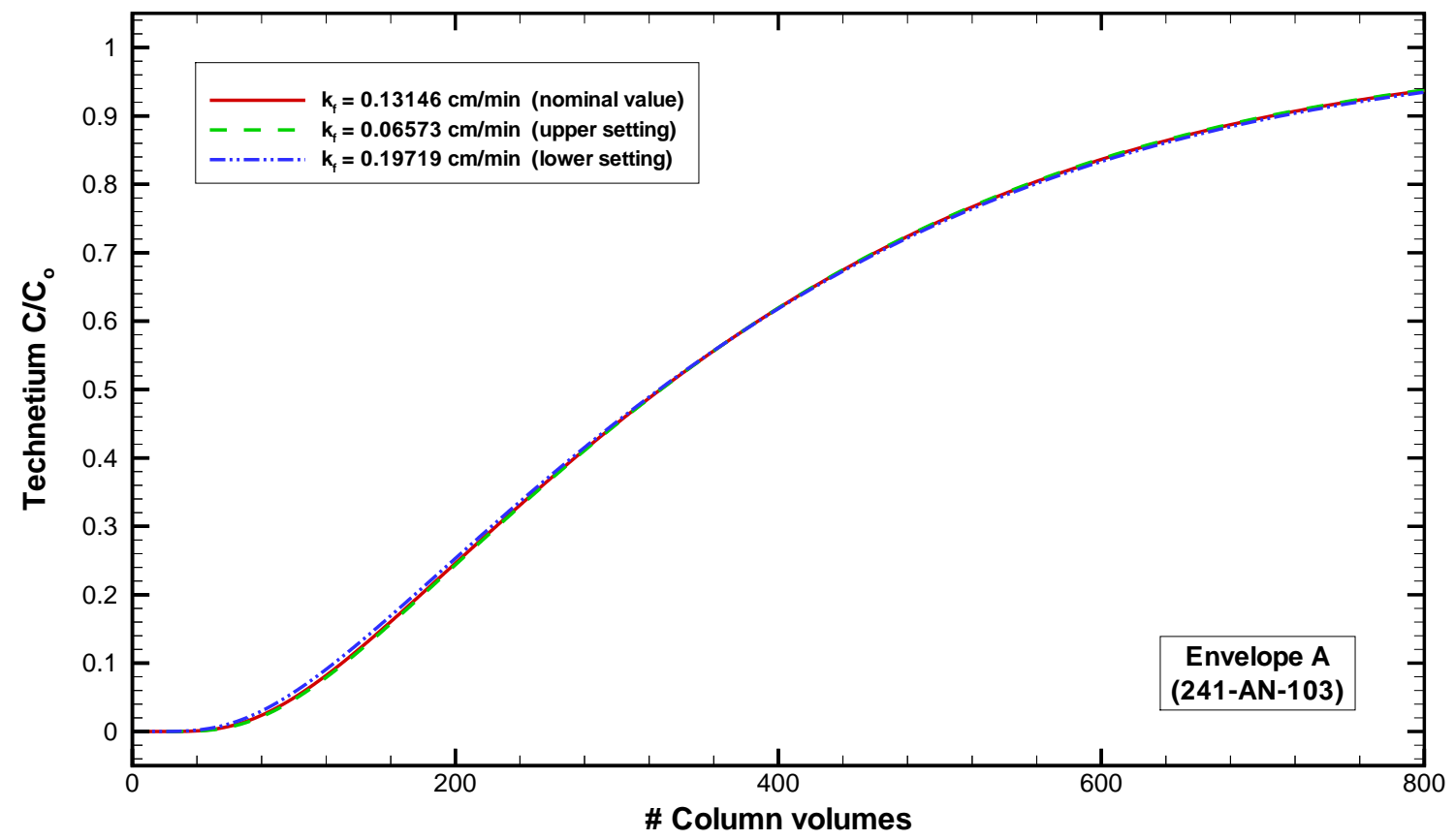

Figure 10-11. Sensitivity of full-scale column breakthrough curve to mass transfer film coefficient for the Envelope A test case.

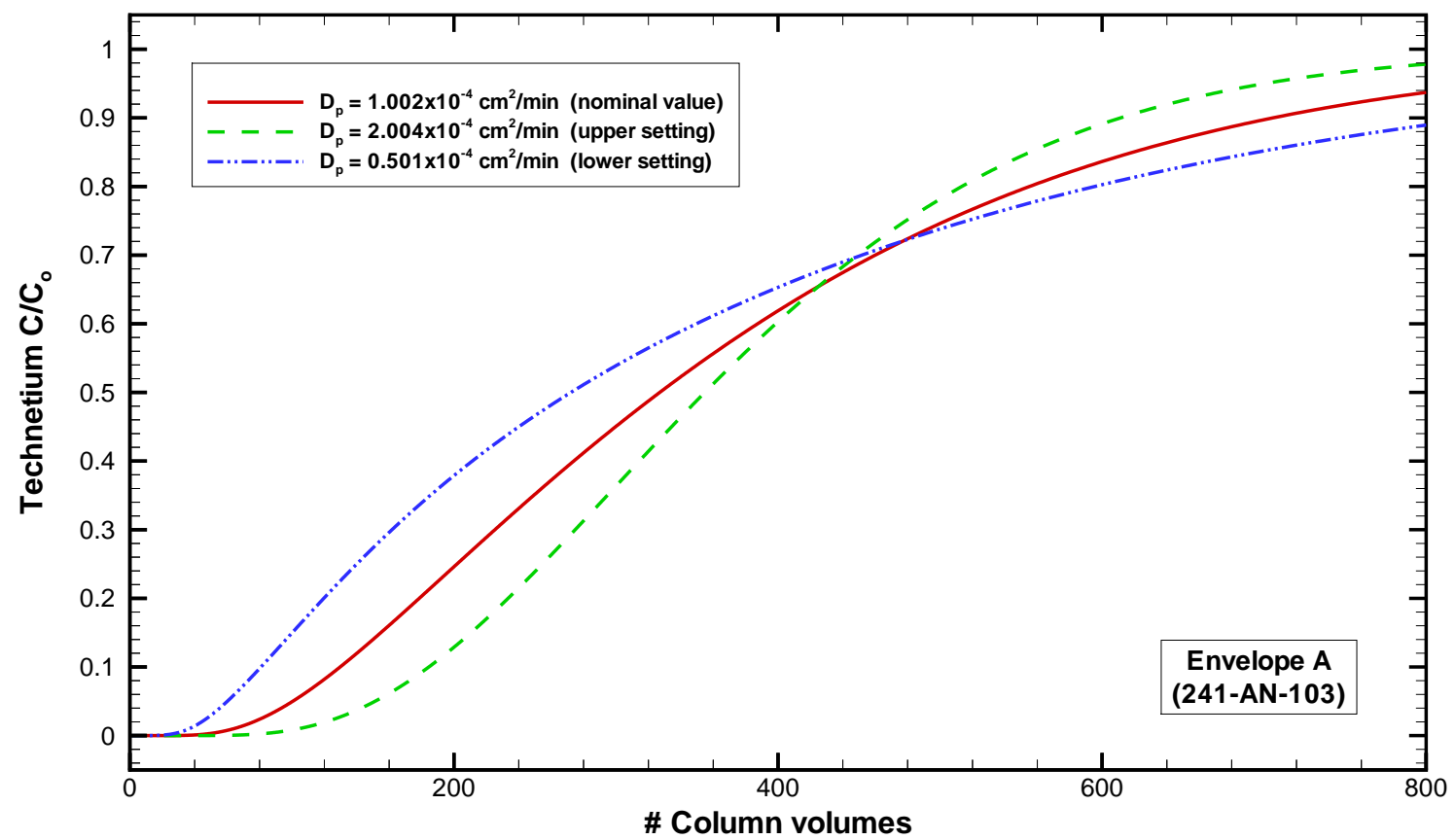

Figure 10-12. Sensitivity of full-scale column breakthrough curve to pertechnetate pore diffusivity for the Envelope A test case. 
Preliminary Ion Exchange Modeling for Removal of Technetium from Revision (Date):

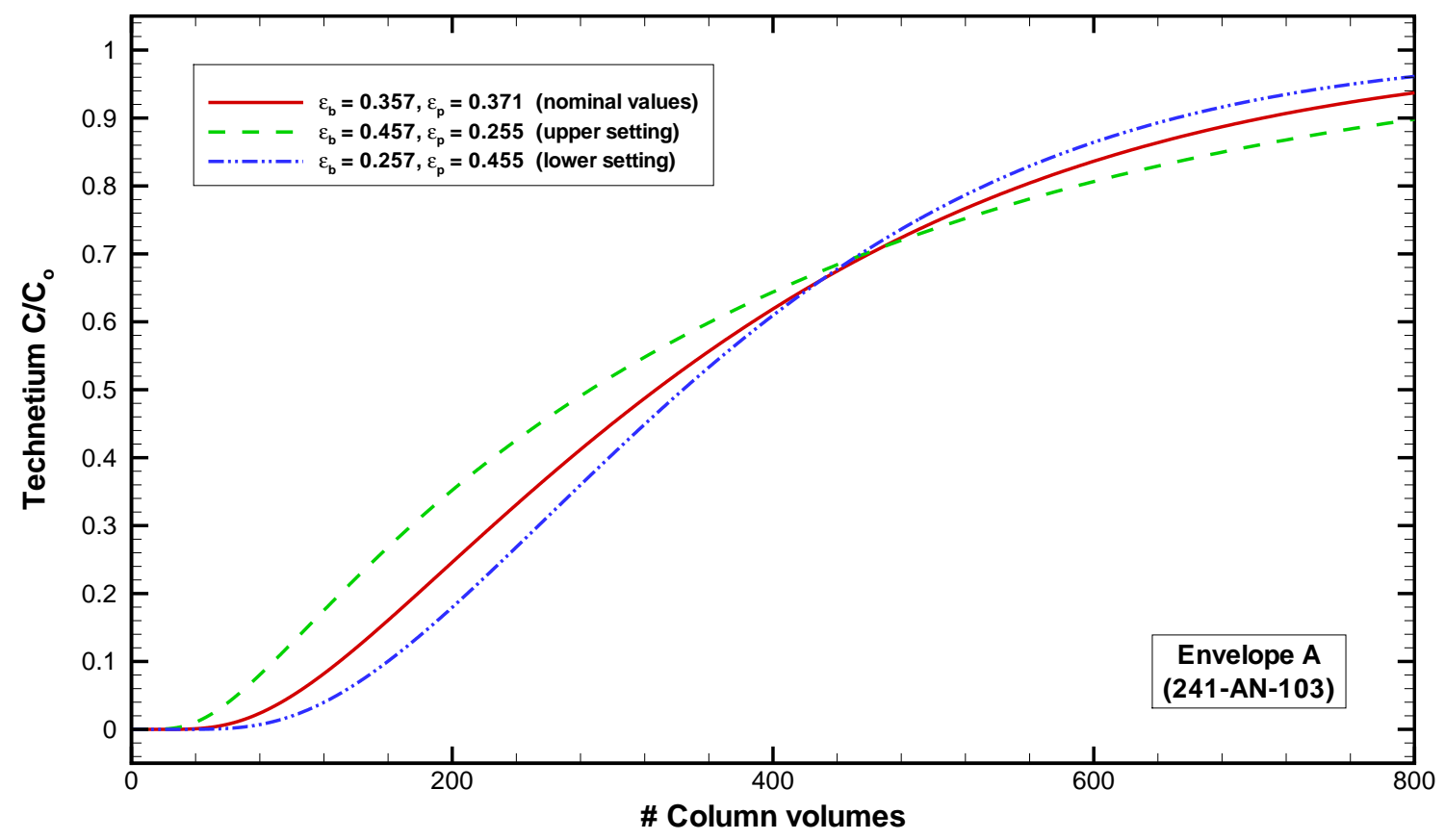

Figure 10-13. Sensitivity of full-scale column breakthrough curve to bed and particle porosities for the Envelope A test case.

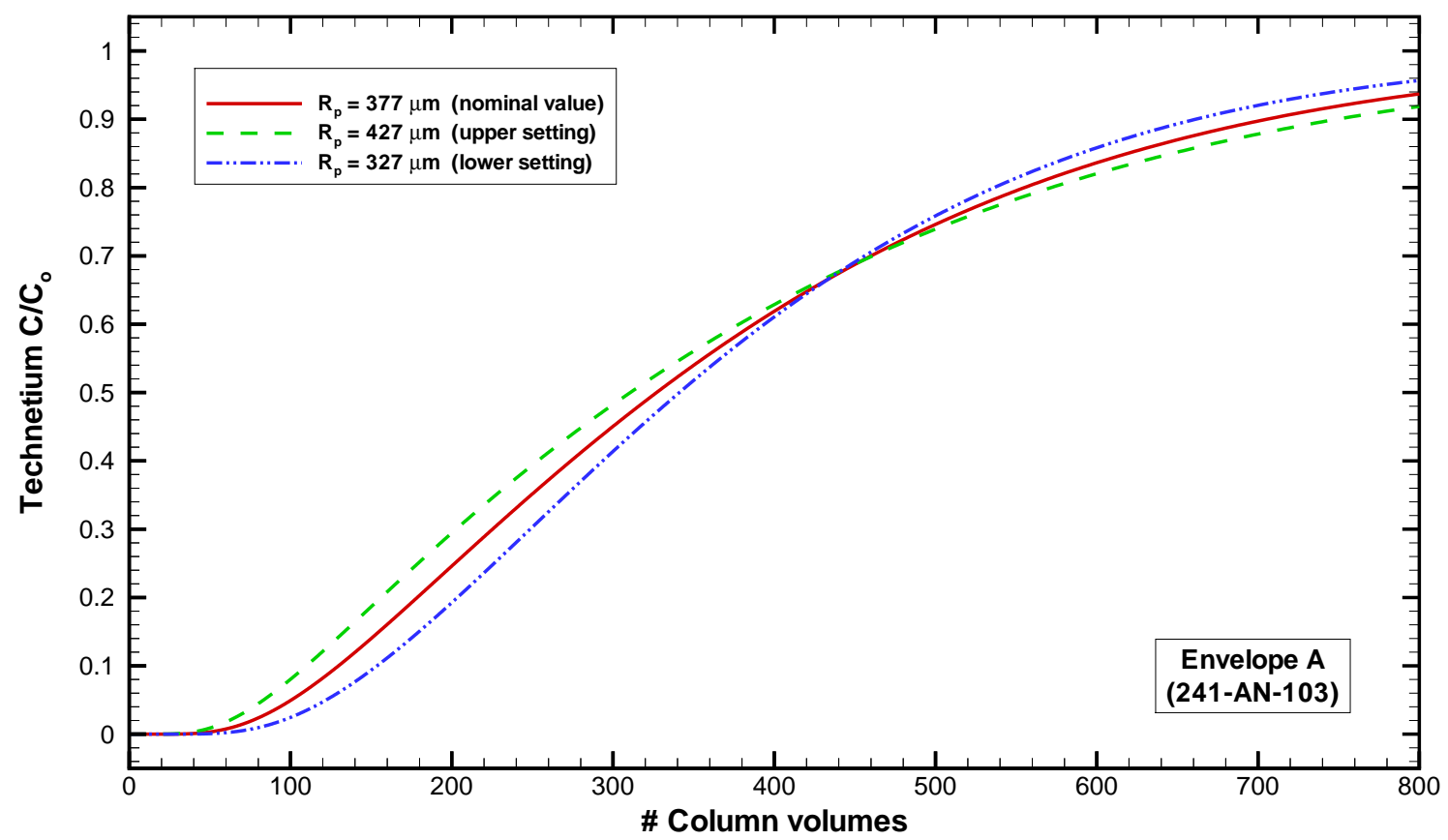

Figure 10-14. Sensitivity of full-scale column breakthrough curve to particle radius for the Envelope A test case. 


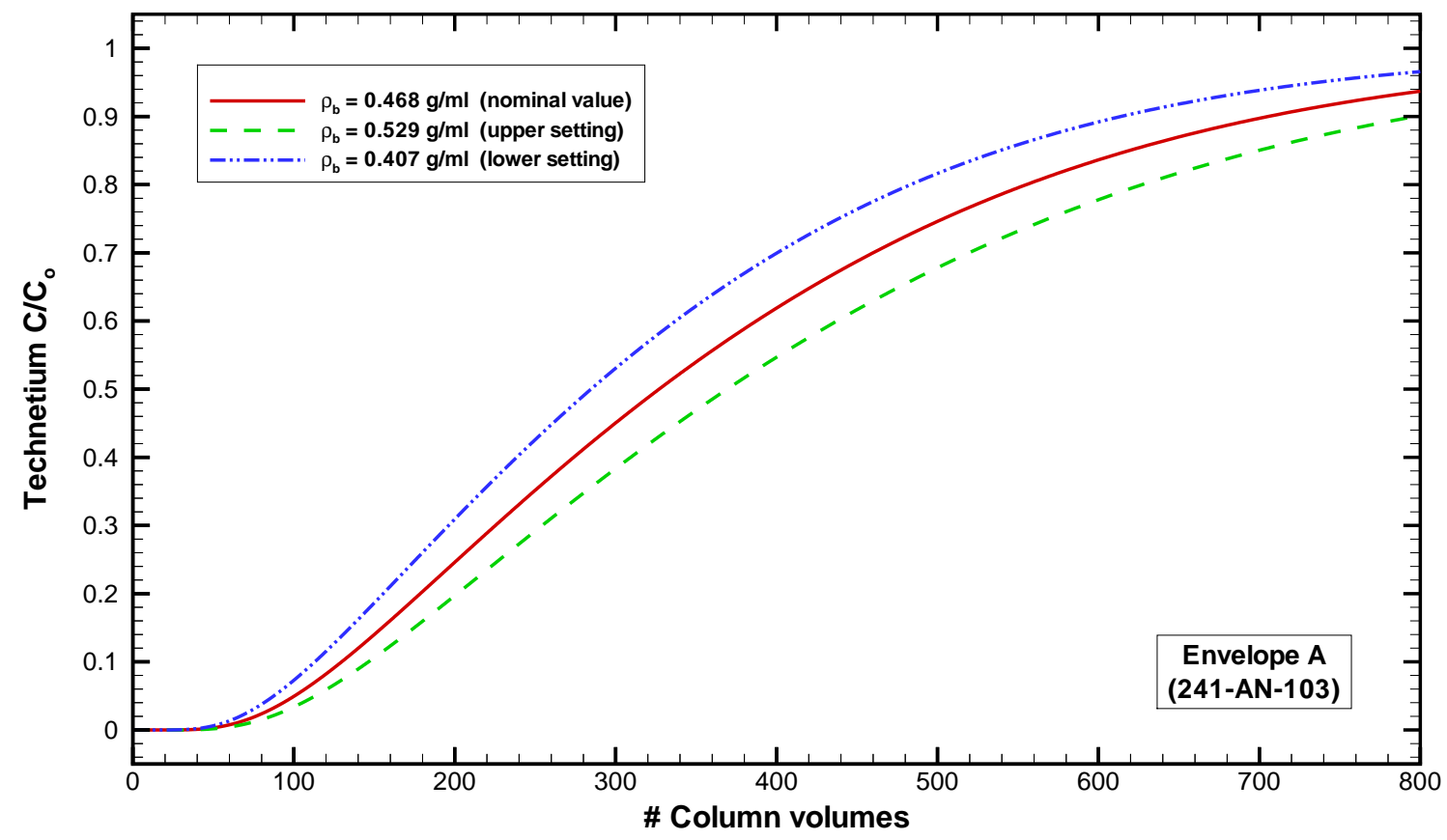

Figure 10-15. Sensitivity of full-scale column breakthrough curve to bed density for the Envelope A test case.

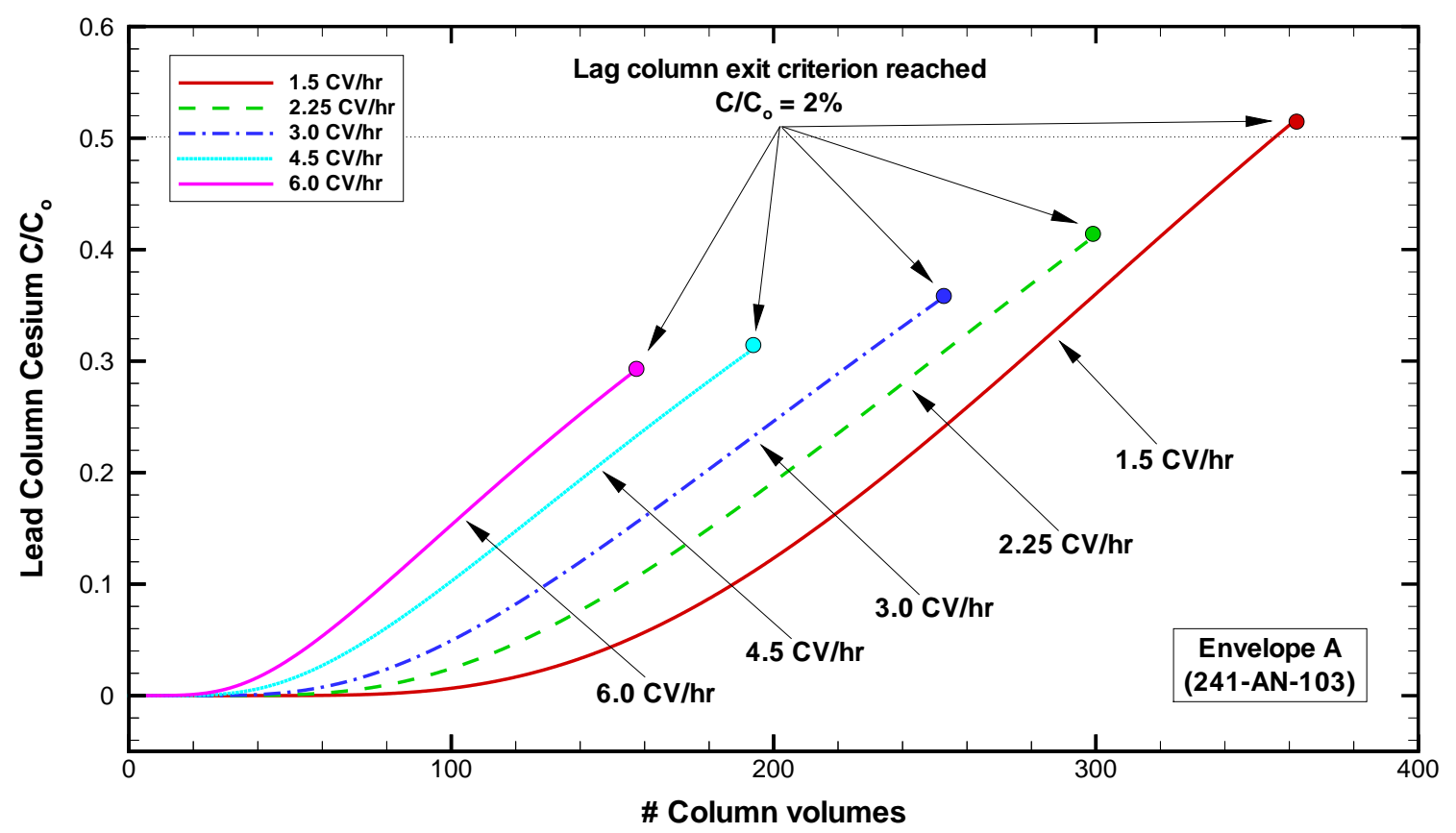

Figure 10-16. Sensitivity of volumetric flowrate on the exit technetium breakthrough curve of the lead column for the Envelope A test case. 


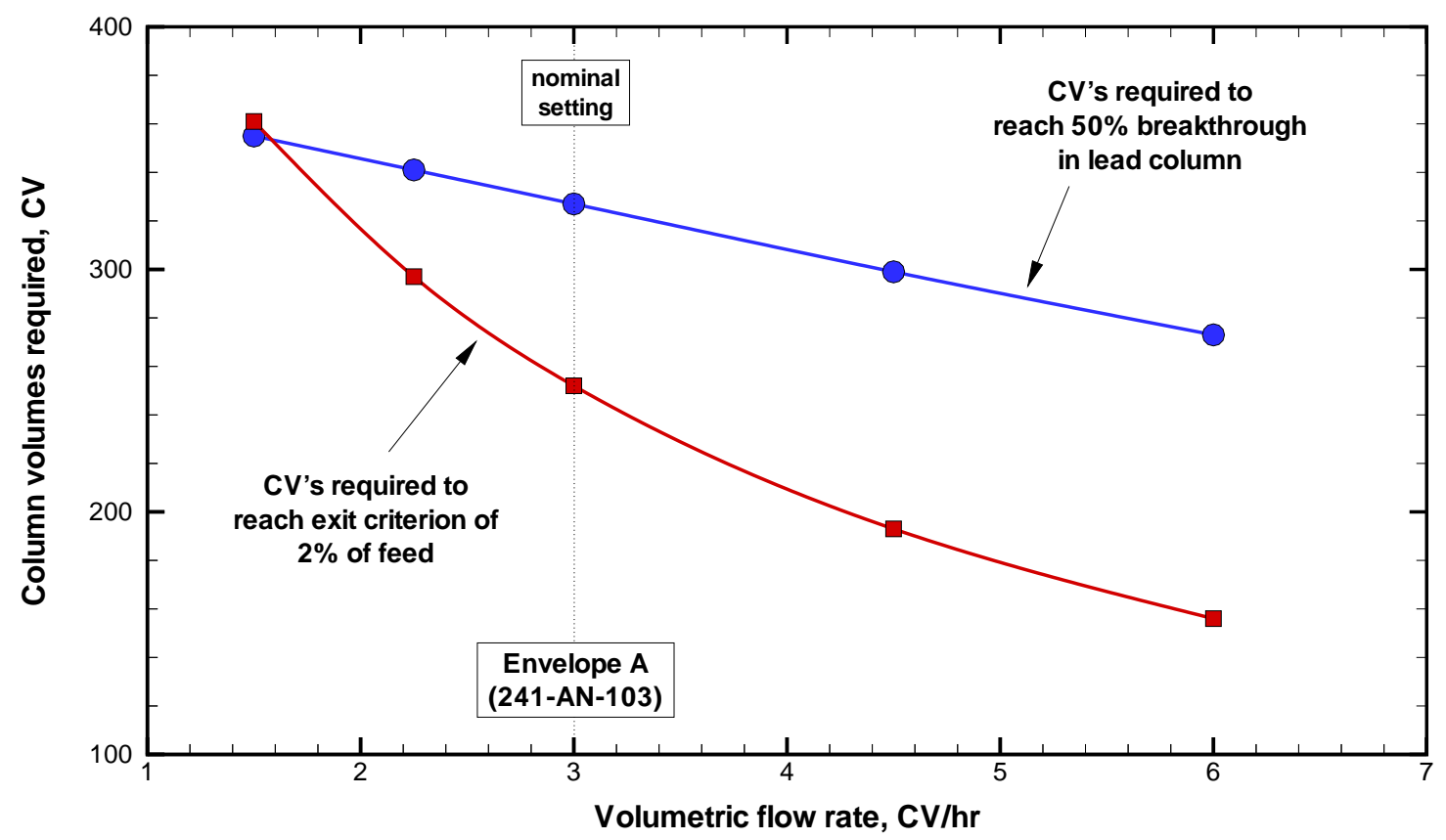

Figure 10-17. The number of column volumes required to reach $50 \%$ technetium breakthrough on the lead column and to reach $2 \%$ of the feed technetium (exit criterion) on the lag column for the Envelope A test case.

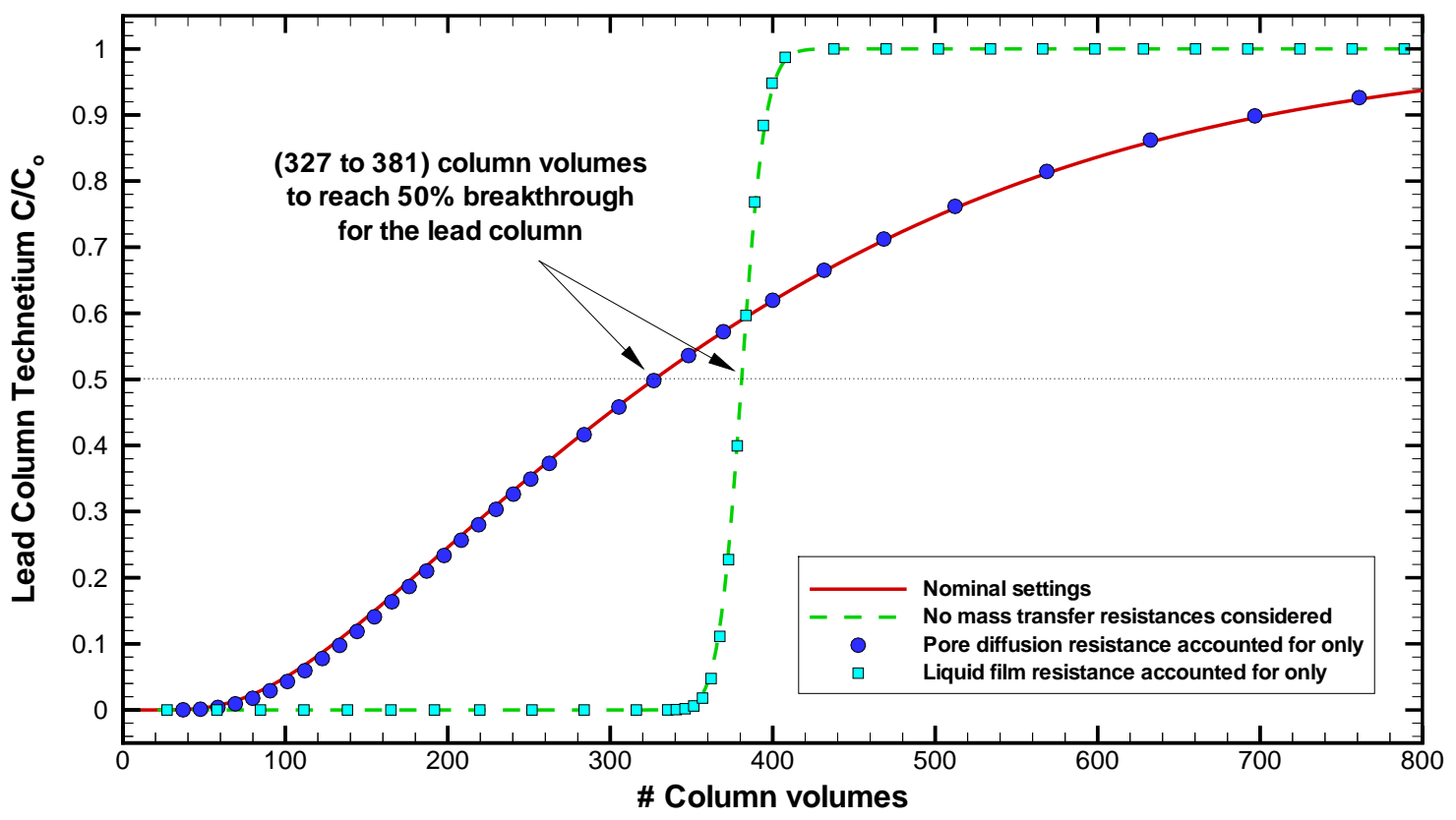

Figure 10-18. Impact of mass transfer resistance on the exit technetium breakthrough curve of the lead column for the Envelope A test case. 


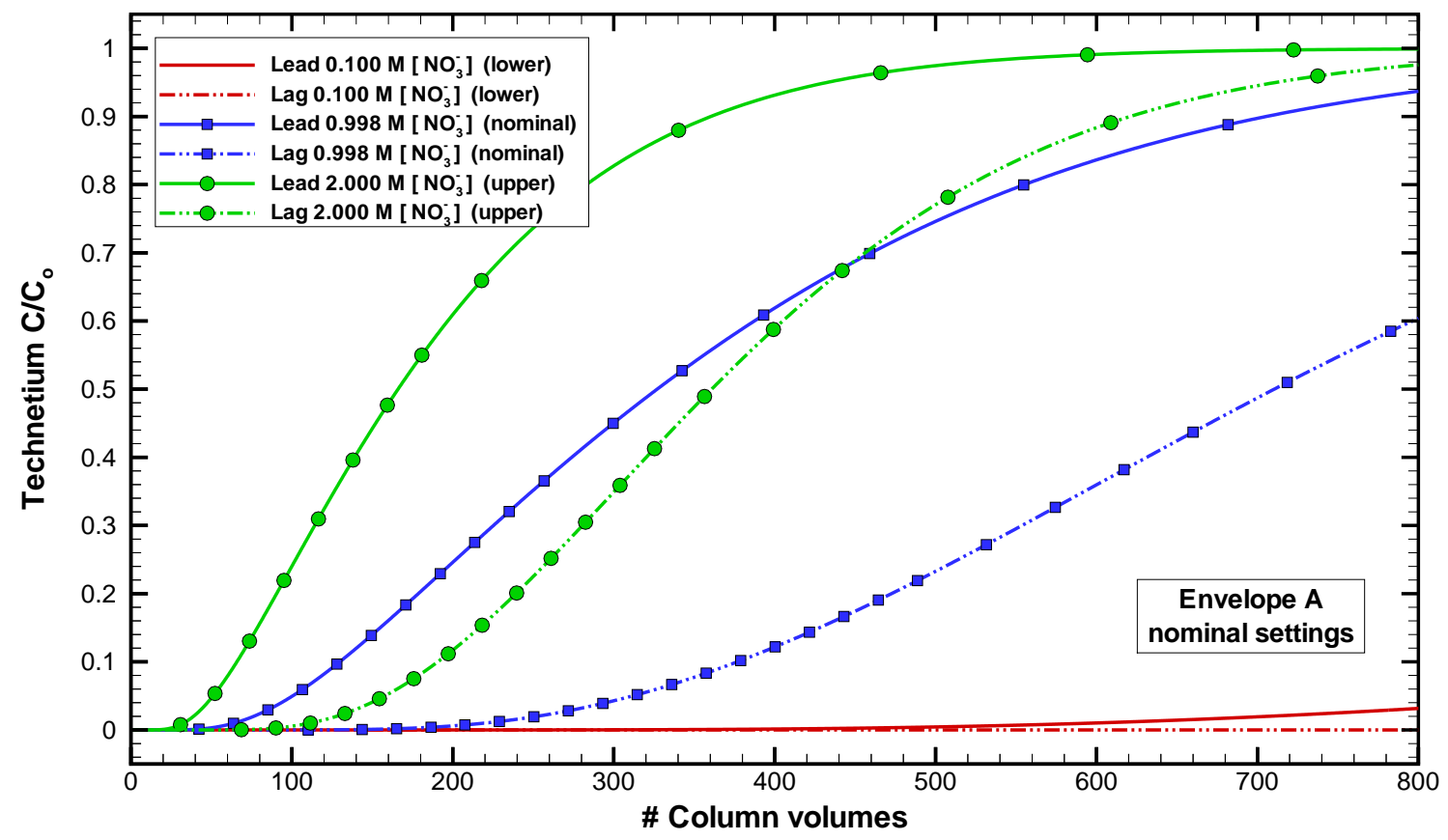

Figure 10-19. Impact of nitrate feed concentration on the exit technetium breakthrough curves for the lead and lag columns given an initially technetium free set of columns where all other parameter settings correspond to those used for the Envelope A case study.

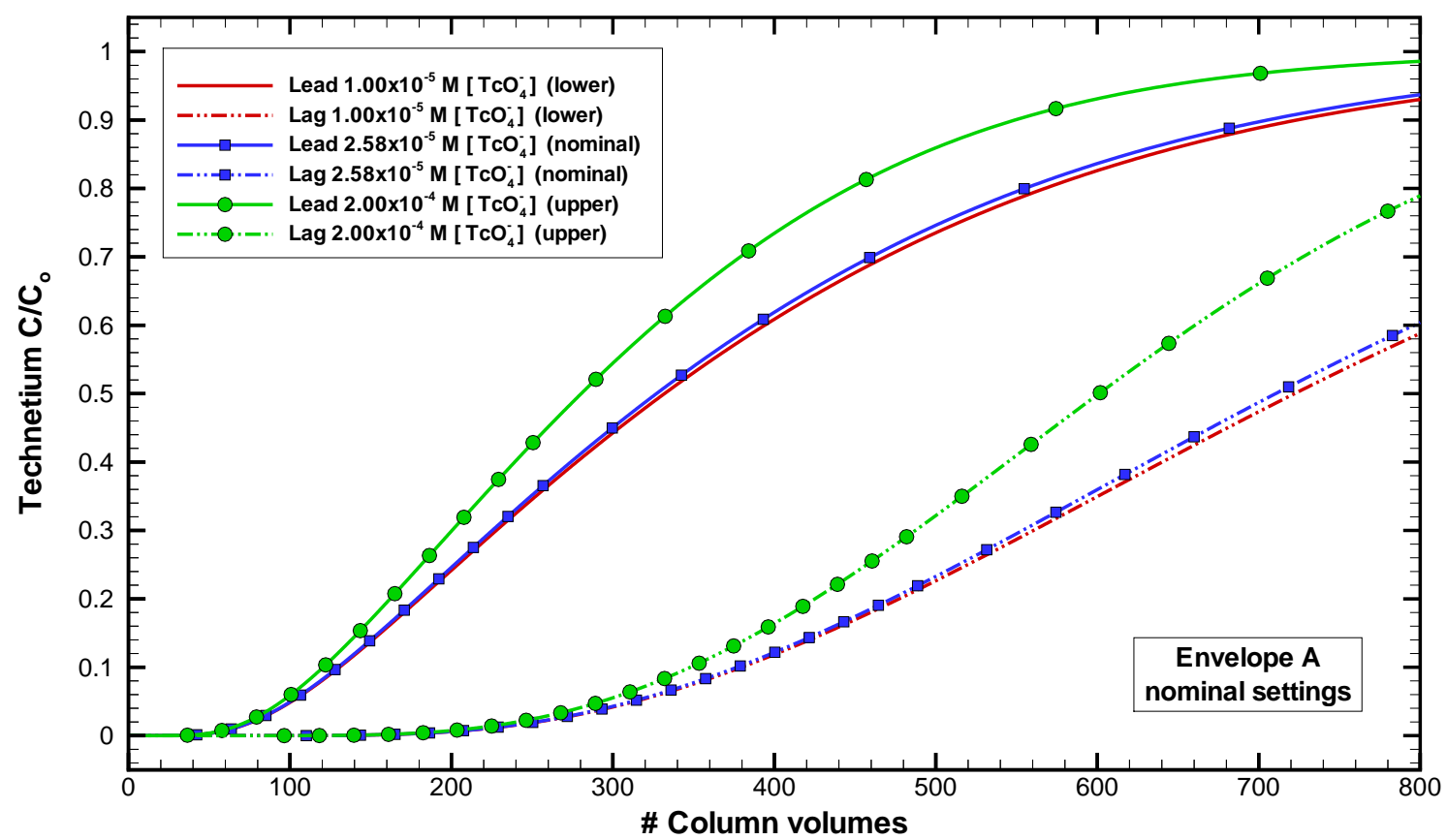

Figure 10-20. Impact of technetium feed concentration on the exit technetium breakthrough curves for the lead and lag columns given an initially technetium free set of columns where all other parameter settings correspond to those used for the Envelope A case study. 


\subsection{References}

Anderson, T. F., D. S. Abrams, and E. A. Grens, II, 1978. "Evaluation of Parameters for Nonlinear Thermodynamic Models," AIChE Journal, Vol. 24, No. 1, pp. 20-29.

Berninger, J. A., R. D. Whitley, X. Zhang, and L. N.-H. Wang, 1991. "A Versatile Model for Simulation of Reaction and Nonequilibrium Dynamics in Multicomponent Fixed-Bed Adsorption Processes," Computers Chem. Engr., Vol. 15, No. 11, pp. 749-768.

Bird, R. B., W. E. Stewart, and E. N. Lightfoot, 1960. Transport Phenomena, John Wiley and Sons, Inc., New York.

Bromley, L. A., 1973. “Thermodynamic Properties of Strong Electrolytes in Aqueous Solutions," AIChE Journal, Vol. 19, No. 2, pp. 313-320.

Bray, L. A., J. E. Amonette, G. N. Brown, T. M. Kafka, and S. F. Yates, 1995. "Efficient Separations and Processing Crosscutting Program: Develop and Test Sorbents," a FY 1995 Annual Progress Report, PNL-10750 (UC-2030), Battelle PNL, September.

Brooks, K. P., 1994. "Cesium Ion Exchange using Actual Waste: Column Size Considerations," TWRSPP-94-091, Battelle PNL, September.

Brown, G. N., S. R. Adami, L. A. Bray, S. A. Bryan, C. D. Carlson, K. J. Carson, J. R. DesChane, R. J. Elovich, S. J. Forbes, J. A. Franz, J. C. Linehan, W. J. Shaw, P. K. Tanaka, and M. R. Telander, 1995a. "Chemical and Radiation Stability of SuperLig ${ }^{\circledR}$ 644, Resorcinol-Formaldehyde, and CS-100 Cesium Ion Exchange Materials," PNL-10772 (UC2030), Battelle PNL, September.

Bruening, R. L., 2000a. "Pressure Drop through Ion Exchange Columns," Report to BNFL on Task \#TWSC99-109 Task 6 performed by IBC Advanced Technologies, Inc., January.

Bruening, R. L., 2000b. "Fluidization Velocity for Ion Exchange Materials," Report to BNFL on Task \#TWSC99-109 Task 7 performed by IBC Advanced Technologies, Inc., January.

Bruening, R. L., 2000c. "Chemical Stability of Ion Exchange Materials," Report to BNFL on Task \#TWSC99-109 Task 5 performed by IBC Advanced Technologies, Inc., February.

Byrne, E. B. and L. Lapidus, 1955. Technical Notes, "Concentration Profiles in Packed-bed Ionexchange Systems," Journal of American Chemical Soc., Vol. 77, pp. 6506.

Cairns, E. J. and J. M. Prausntiz, 1960. "Longitudinal Mixing in Packed Beds," Chemical Engr. Science, Vol. 12, pp. 20-34.

Carberry, J. J. and R. H. Bretton, 1958. "Axial Dispersion of Mass in Flow Through Fixed Beds," AIChE Journal, Vol. 4, No. 3, pp. 367-375.

Chu, J. C., J. Kalil, and W. A. Wetteroth, 1953. "Mass Transfer in a Fluidized Bed," Chemical Engr. Progress, Vol. 49, No. 3, pp. 141-149.

Chung, S. F. and C. Y. Wen, 1968. "Longitudinal Dispersion of Liquid Flowing Through Fixed and Fluidized Beds," AIChE Journal, Vol. 14, No. 6, pp. 857-866.

CRC Handbook of Chemistry and Physics, 1976. The $57^{\text {th }}$ ed.

Cussler, E. L., 1984. Diffusion: Mass Transfer in Fluid Systems, Cambridge University Press, Cambridge.

Dorweiler, V. P. and R. W. Fahien, 1959. "Mass Transfer at Low Flow Rates in a Packed Column," AIChE Journal, Vol. 5, No. 2, pp. 139-144. 
Fahien, R. W. and J. M. Smith, 1955. "Mass Transfer in Packed Beds," AIChE Journal, Vol. 1, No. 1, pp. 28-37.

Foo, S. C. and R. G. Rice, 1975. "On the Predication of Ultimate Separation in Parametric Pumps," AIChE Journal, Vol. 21, No. 6, pp.1149-1158.

Froment, G. F. and K. B. Bishoff, 1979. Chemical Reactor Analysis and Design, John Wiley and Sons, Inc., New York.

Gaffney, B. J. and T. B. Drew, 1950. "Mass Transfer from Packing to Organic Solvents in Single Phase Flow through a Column," Industrial and Engineering Chemistry, Vol. 42, No. 6, pp.1120-1126.

GE Nuclear Energy, 1996. Nuclides and Isotopes, General Electric Company, Nuclear Energy Operations, $15^{\text {th }}$ Edition, pp.31.

German, R. M., 1989. Particle Packing Characteristics, Metal Powder Industries Federation, Princeton, New Jersey.

Gunn, D. J., 1987. "Axial and Radial Dispersion in Fixed Beds," Chemical Engr. Science, Vol. 42, No. 2, pp.363-373.

Gupta, A. S. and G. Thodos, 1962. "Mass and Heat Transfer in the Flow of Fluids Through Fixed and Fluidized Beds of Spherical Particles," AIChE Journal, Vol. 8, No. 5, pp. 608-610.

Hamm, L. L., F. G. Smith, III, and A. M. Shadday, 1999. “QA Verification Package for VERSELC Version 7.80," WSRC-TR-99-00238, November.

Hamm, L. L., F. G. Smith, III, and D. J. McCabe, 2000. "Preliminary Ion Exchange Modeling for Removal of Cesium from Hanford Waste Using SuperLig ${ }^{\circledR} 644$ Resin," BNF-003-980220, June 16.

Hassan, N. M. and D. J. McCabe, 1997a. "Hanford Envelope A Tank Waste Ion Exchange Column Study (U)," SRTC-BNFL-019, Rev. 0, October 24.

Hassan, N. M. and D. J. McCabe, 1997b. "Hanford Envelope C Tank Waste Ion Exchange Column Study (U)," SRTC-BNFL-018, Rev. 0, October 24.

Hassan, N. M. and D. J. McCabe, 1997c. "Hanford Envelope A Tank Waste Ion Exchange Distribution Coefficient Study (U)," SRTC-BNFL-021, Rev. 0, November 13.

Hassan, N. M. and D. J. McCabe, 1997d. "Hanford Envelope B Tank Waste Ion Exchange Column Study (U)," SRTC-BNFL-017, Rev. 1, December 5.

Hassan, N. M. and D. J. McCabe, 1998. "Hanford Envelope C (hydroxide-adjusted) Tank Waste Batch Distribution Coefficient Study (U)," SRTC-BNFL-027, Rev. 0, January 19.

Hassan, N. M., W. D. King, and D. J. McCabe, 1999a. "SuperLig ${ }^{\circledR}$ Ion Exchange Resin Swelling and Buoyancy Study (U)," BNF-003-98-0051, March 25.

Hassan, N. M., D. J. McCabe, W. D. King, and M. L. Crowder, 2000d. "Small-Scale Ion Exchange Removal of Cesium and Technetium from Envelope B Hanford Tank 241-AZ102,” WSRC-TR-2000-00419 (SRT-RPP-2000-00036), Revision 0, October 17.

Hassan, N. M., D. J. McCabe, and W. D. King, 2000a. "Small-Scale Ion Exchange Removal of Cesium and Technetium from Hanford Tank 241-AN-103," BNF-003-98-0146, Revision 1, April 12.

Hassan, N. M., D. J. McCabe, W. D. King, and M. L. Crowder, 2000b. "Small-Scale Ion Exchange Removal of Cesium and Technetium from Hanford Tank 241-AN-102," BNF003-98-0219, Revision 0, March 29. 
Hassan, N. M., D. A. Kaplan, and D. J. McCabe, 2000c. "Mixing of Process Heels, Process Solutions, and Recycle Streams: Small-Scale Active Tests,” BNF-003-98-0246.

Helfferich, 1962. Ion Exchange, McGraw-Hill series in advanced chemistry, McGraw-Hill Book Company, Inc., New York.

Helfferich, F. G. and P. W. Carr, 1993. The review paper "Non-linear Waves in Chromatography , I. Waves, Shocks, and Shapes,” Journal of Chromatography, Vol 627, pp. 97-122.

Hritzko, B. J., D. D. Walker, and L. N.-H. Wang, 1998. "Design of a Carousel Process for Removing Cesium from SRS Waste Using Crystalline Silicotitanate Ion Exchange," October 15.

IBC Advanced Technologies, Inc., 1996. "Simulant Test Results for Cs, Sr, Tc, and TRU SuperLigands," Conducted for British Nuclear Fuels, Inc., October (report contains some IBC proprietary information).

Izatt, R. M., J. S. Bradshaw, R. L. Bruening, B. J. Tarbet, and K. E. Krakowiak, 1993. "Novel Metal Separations using SuperLig ${ }^{\circledR}$ Materials Involving Macrocyclic Chemistry," Published in The Minerals, Metals, \& Materials Society under Emerging Separation Technologies for Metals and Fuels.

Jolls, K. R. and T. J. Hanratty, 1969. "Use of Electrochemical Techniques to Study Mass Transfer Rates and Local Skin Friction to a Sphere in a Dumped Bed," AIChE Journal, Vol. 15, No. 2, pp. 199-205.

King, W. D., D. J. McCabe, and N. M. Hassan, 2000a. "Evaluation of SuperLig ${ }^{\circledR} 639$ Ion Exchange Resin for the Removal of Rhenium from Hanford Envelope A Simulant," BNF003-98-0140, Rev. 0, April 13.

King, W. D., D. J. McCabe, N. M. Hassan, and D. D. Walker, 2000b. "Intermediate-Scale Ion Exchange Removal of Technetium from Savannah River Site Tank 44F Supernate Solution," BNF-003-98-0230, Rev. 0, May 23.

King, W. D., D. J. McCabe, and N. M. Hassan, 2000c. "Intermediate-Scale Ion Exchange Removal of Cesium and Technetium from Hanford Tank 241-AN-102", WSRC-TR-200000420 (SRT-RPP-2000-00014), October 17.

Koch, D. L. and J. F. Brady, "Dispersion in Fixed Beds, 1985. ” J. Fluid Mech., Vol. 154, pp. 399-427.

Kurath, D. E., D. L. Blanchard, and J. R. Bontha, 1999. "Ion Exchange Distribution Coefficients for ${ }^{137} \mathrm{Cs}$ and ${ }^{99} \mathrm{Tc}$ removal from Hanford Tank Supernatants AW-101 (Envelope A) and AN107 (Envelope C)," PNWD/BNFL-RPT-009, Rev. 0, Project 29953, Battelle (PNNL), June.

Liles, A. W. and C. J. Geankoplis, 1960. "Axial Diffusion of Liquids in Packed Beds and End Effects," AIChE Journal, Vol. 6, No. 4, pp. 591-595.

Mackie, J. S. and P. Meares, 1955. "The Diffusion of Electrolytes in a Cation-Exchange Resin Membrane," Proc. R. Soc. Lond. Ser. A, Vol. 232, pp. 498-518.

McCabe, D. J., 1997. "Hanford Envelope B Tank Waste Ion Exchange Distribution Coefficient Study (U)," SRTC-BNFL-014, Rev. 0, August 15.

McCune, L. K. and R. H. Wilhelm, 1949. "Mass and Momentum Transfer in Solid-Liquid System - Fixed and Fluidized Beds," Industrial and Engineering Chemistry, Vol. 41, No. 6, pp. 1124-1134.

Morales, M., C. W. Spinn, and J. M. Smith, 1951. "Velocities and Effective Thermal Conductivities in Packed Beds," Industrial and Engr. Chemistry, Vol. 43, No. 1, pp. 225-232. 
Perry, J. H. (editor), 1973. Chemical Engineer's Handbook, $4^{\text {th }}$ edition, McGraw-Hill chemical engineering series, McGraw-Hill Book Company, Inc., New York, pp. 3-125 and 16-19.

Peters, D. G., J. M. Hayes, and G. M. Hieftje, 1974. Chemical Separations and Measurements Theory and Practice of Analytical Chemistry, W. B. Saunders Company, Golden Sunburst Series, Philadelphia.

Polzer, W. L., M. G. Rao, H. R. Fuentes, and R. J. Beckman, 1992. "Thermodynamically Derived Relationships between the Modified Langmuir Isotherm and Experimental Parameters," Environ. Sci. Technol., Vol. 26, No. 9, pp.1780-1786.

Reid, R. C., J. M. Prausnitz, and T. K. Sherwood, 1977. The Properties of Gases and Liquids, $3^{\text {rd }}$ edition, McGraw-Hill chemical engineering series, McGraw-Hill Book Company, Inc., New York. pp. 590-592.

Rubin, J. and R. V. James, 1973. "Dispersion-Affected Transport of Reacting Solutes in Saturated Porous Media: Galerkin Method Applied to Equilibrium-Controlled Exchange in Unidirectional Steady Water Flow," Water Resources Research, Vol. 9, No. 5, pp. 13321356.

Schroeder, N. C., S. Radzinski, J. Ball, K. Ashley, S. L. Cobb, B. Cutrell, J. M. Adams, C. Johnson, and G. D. Whitener, "Technetium Partitioning for the Hanford Tank Waste Remediation System: Anion Exchange Studies for Partitioning Technetium from Synthetic DSSF and DSS Simulants and Actual Hanford Wastes (101-SY and 103-SY) Using ReillexHPQ Resin, FY95 Final Report,” LA-UR-95-4440, Los Alamos National Laboratory.

Schwartz, C. E. and J. M. Smith, 1953. "Flow Distribution in Packed Beds," Industrial and Engr. Chemistry, Vol. 45, No. 6, pp. 1209-1218.

Smith, J. M., 1981. Chemical Engineering Kinetics, $3^{\text {rd }}$ ed., McGraw Hill, New York, pp. 331332.

Steimke, J. L., M. A. Norato, T. J. Steeper, and D. J. McCabe, 2000. "Summary of Testing of SuperLig ${ }^{\circledR} 639$ at the TFL Ion Exchange Facility," WSRC-TR-2000-00302 (SRT-RPP-200000008), Rev. 0, August 24.

Thibaud-Erkey, C., R. G. Anthony, and E. Klavetter, "Mathematical Modeling of an IonExchange Column for Nuclear Waste Remediation," Special Report RF 8761-\#2, Texas A\&M University, pg. 8.

Valocchi, A. J., R. L. Street, and P. V. Roberts, 1981. "Transport of Ion-Exchanging Solutes in Groundwater: Chromatographic Theory and Field Simulation," Water Resources Research, Vol. 17, No. 5, pp.1517-1527, October.

Walker, D. D., D. J. Adamson, T. D. Allen, R. W. Blessing, W. T. Boyce, B. H. Croy, R. A. Dewberry, D. P. Diprete, S. D. Fink, T. Hang, J. C. Hart, M. C. Hart, M. C. Lee, J. J. Olson, and M. J. Whitaker, 1999. "Cesium Removal from Savannah River Site Radioactive Waste using Crystalline Silicotitanate (IONSIV ${ }^{\circledR}$ IE-911),” WSRC-TR-99-00308, Rev. 0, September 19.

Whitley, R. D. and L. N.-H. Wang, 1996. "User's Manual VERSE (VErsatile Reaction SEparation) Simulation for Liquid Phase Adsorption and Chromatography Processes," Purdue University.

Williamson, J. E., K. E. Bazaire, and C. J. Geankoplis, 1963. "Liquid-Phase Mass Transfer at Low Reynolds Numbers," Industrial and Engineering Chemistry Fundamentals, Vol. 2, No. 2, pp. 126-129. 
Preliminary Ion Exchange Modeling for Removal of Technetium from

Wilson, E. J. and C. J. Geankoplis, 1966. "Liquid Mass Transfer at Very Low Reynolds Numbers in Packed Beds," Industrial and Engineering Chemistry Fundamentals, Vol. 5, No. 1, pp. 914.

Zheng, Z., D. Gu, and R. G. Anthony, 1995. "Estimation of Cesium Ion Exchange Distribution Coefficients for Concentrated Electrolytic Solutions When Using Crystalline Silicotitanates," Ind. Eng. Chem. Res., Vol. 34, No. 6, pp. 2142-2147. 


\section{Appendix A (Material Balances for Equilibrium Batch Tests)}

The material balance analyses discussed in this appendix support the isotherm model development presented in Section 4 of the main body of this report. The material balance analyses are used to improve the quality of the $\mathrm{K}_{\mathrm{d}}$ database obtained from the various equilibrium batch contact tests available for the pertechnetate (and perrhenate)- SuperLig ${ }^{\circledR} 639$ system. The material balance approach discussed below attempts to address the finite volume of liquidsample and resin material employed, as well as the generally unknown fraction of nonpertechnetate forms in the various envelope samples considered. Using the material balance expressions the adsorption database presented in Section 4 was created. One example is presented (i.e., data set NH-B taken by Hassan et al., 2000d) of how the original $\mathrm{K}_{\mathrm{d}}$ database was updated to create the database presented in Section 4.

To date the batch contact tests for pertechnetate have been performed using actual samples taken from various Hanford waste tanks or using simulants that mimic Envelope A waste for perrhenate studies. There are future plans to measure the adsorption characteristics of SuperLig ${ }^{\circledR}$ 639 resin in contact with simple binary ionic mixtures. Also future tests are planned to measure the total ionic capacity of the resin under varying conditions. With such data a more detailed isotherm model can be considered. However, given the current type of adsorption data available an engineering approach to developing the isotherm model for the pertechnetate (and perrhenate)- SuperLig ${ }^{\circledR} 639$ system has been employed.

\section{A.1 Equilibrium Batch Contact Test Approach}

Here batch contact tests are performed where equilibrium is assumed to occur in 24,48 , and sometimes as long as 72 hours after initial contact while continual mechanical mixing is ongoing (e.g., shaker or orbital tables). During an individual batch contact test, a small amount of SuperLig ${ }^{\circledR} 639$ resin (i.e., 0.05 to $0.18 \mathrm{~g}$ of "as received" resin) is placed into a beaker containing a known amount of a liquid-solution (i.e., 3.7 to $19.4 \mathrm{ml}$ of either an envelope sample or its simulant). The initial composition of the liquid-sample is known either through analytical means for envelope samples or based on its creation for simulant samples. For the pertechnetate (and perrhenate)- SuperLig ${ }^{\circledR} 639$ system the liquid-solution's initial nitrate and pertechnetate (or perrhenate) ion concentrations must be known (note: other competitors may in the future be determined to be important). In these contact tests generally hysteresis of the resin material's adsorption properties is assumed to be negligible. However, as discussed in Section 4, chemical stability tests indicate that some level of history dependence may be present and would account for some of the scatter observed between different data sets.

The mixture is mechanically mixed to diminish potential concentration gradients throughout the liquid-phase solution, while concentration gradients within the particle pores are diminished over time through film and diffusive mass transfer. As discussed in Section 8, the time history of the ionic concentrations of the liquid-phase solution can be used to determine ion pore diffusion coefficients and an indication as the time period of contact required to reach a specified level of 
approach to equilibrium. As discussed in Section 7, the pertechnetate and nitrate anion pore diffusion rates result in reasonable contact times to achieve near equilibrium conditions under good mechanical mixing (e.g., >97\% in $24 \mathrm{hrs,} \mathrm{>99 \%} \mathrm{in} 48 \mathrm{hrs,} \mathrm{and} 100 \%$ in $72 \mathrm{hrs}$ ). However, the degree of mechanical mixing must be controlled to limit the amount of fragmentation damage done to resin particles. At the end of the contact period (i.e., $\sim 24$ hours for the majority of $\mathbf{K}_{d}$ tests), the liquid-solution and solid-resin are separated and the final ("equilibrium") ionic concentrations are measured.

From the measured initial and final states of the liquid-solution, along with the phase ratio of the liquid-to-solid quantities tested, $\mathrm{K}_{\mathrm{d}}$ and surface loading values can be computed. Unfortunately, not all of the ionic concentrations required to compute the appropriate $K_{d}$ and surface loading values are available. A method, as discussed below, must be employed to estimate the various unknown quantities required.

\section{A.2 Material Balance Requirements}

For the available pertechnetate (and perrhenate)- SuperLig ${ }^{\circledR} 639$ system contact tests, only initial and final total technetium ${ }^{99} \mathrm{Tc}, \mathrm{MW}=98.90628$ ) or rhenium (natural abundance, $\mathrm{MW}=186.2$ ) were analytically measured (e.g., by mass-spectroscopy). Only the initial nitrate (no final) concentration levels were recorded. In order to compute pertechnetate (or perrhenate) $K_{d}$ and surface loading values, material balances (i.e., here for convenience we use molar balances) must be employed where the following two assumptions are necessary:

- No liquid-phase or surface reactions are occurring at a kinetic rate of importance where pertechnetate (or perrhenate) is being created or destroyed; and

- Only technetium (or rhenium) in the pertechnetate (or perrhenate) form is absorbed onto the SuperLig $^{\circledR} 639$ resin.

In the developments to follow only the technetium case is referred to. The rhenium case follows an identical approach. The following definitions apply to the superscripts and subscripts used in the molar balances equations:

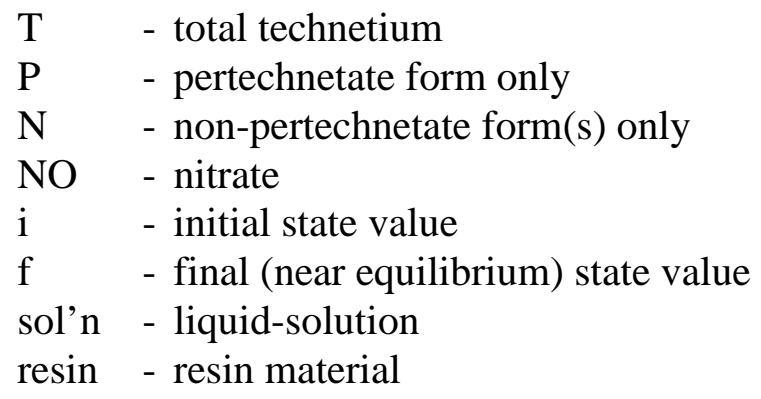

and for the concentrations and molar quantities:

c - ionic liquid-phase concentration, $[\mathrm{M}]$

$\overline{\mathrm{c}} \quad$ - ionic solid-phase (i.e., surface) concentration, $\left[\mathrm{mmole}_{\text {ion }} / \mathrm{g}_{\text {resin }}\right]$ 
$\mathrm{n} \quad$ - number of milli-moles of an ionic species, [mmole]

\section{A.2.1 Initial States}

Generally each batch contact test is performed where fresh ("naked") resin is used. Naked resin implies that the resin is new and contains no species with nitrate or pertechnetate anions at its active adsorption sites. This assumption applies to initial, as well as re-contact, batch tests. The number of active adsorption sites (in mmoles) for a specified amount of resin becomes:

$$
\mathrm{n}_{\text {sites }}=\overline{\mathrm{C}}_{\mathrm{T}} \mathrm{m}_{\text {resin }} \mathrm{F} \text {, }
$$

where

$$
\begin{array}{ll}
\mathrm{n}_{\text {sites }} & \text { - number of active adsorption sites, mmole } \\
\bar{C}_{\mathrm{T}} & \text { - total ionic capacity of resin, mmole } \\
\mathrm{m}_{\text {sites }} / \mathrm{g}_{\text {resin }} & \text { - mass of "as received" resin, } \mathrm{g} \\
\mathrm{F} & - \text { F-factor (dry-to-wet mass ratio of resin), (-) }
\end{array}
$$

Active refers to those sites assessable to species with nitrate or pertechnetate anions and play a part in the adsorption process.

As mentioned above the initial ionic concentration of nitrate is a measured quantity, while only the total technetium is being measured. An initial ionic concentration of the pertechnetate form of technetium present must be specified. In many cases an estimate (i.e., actually an upper bound) of the fraction of technetium in a non-pertechnetate form can be obtained. This can be accomplished by either:

- Performing multiple re-contact tests where the final liquid-solution of a previous contact test becomes the initial liquid-solution for a follow-on contact test; or

- Performing a column test and observing the level of early exit breakthrough that occurs in the lag column.

When column tests are available it is believed that more reliable estimates of the nonpertechnetate fractions are obtainable. The multiple re-contact tests can become increasingly more sensitive to the initial fraction of non-pertechnetate present as demonstrated in a later subsection. For the liquid-solution its initial state is specified by:

$$
\begin{gathered}
c_{i}^{N}=\eta_{i} c_{i}^{T}, \\
c_{i}^{P}=\left(1-\eta_{i}\right) c_{i}^{T},
\end{gathered}
$$

where for example, $c_{i}^{N}$, refers to the molar concentration of non-pertechnetate in the initial state of the liquid-solution. 


\section{A.2.2 Final States}

In order to establish the final state of the system, we assume that only the pertechnetate form of technetium adsorbs onto the resin, resulting in

$$
\mathrm{n}_{\text {resin }}^{\mathrm{P}} \rightarrow \mathrm{n}_{\mathrm{resin}}^{\mathrm{T}}=\left(\mathrm{c}_{\mathrm{i}}^{\mathrm{T}}-\mathrm{c}_{\mathrm{f}}^{\mathrm{T}}\right) N_{\text {sol'n }},
$$

where

$$
\begin{aligned}
& \mathrm{V}_{\text {sol'n }} \text { - volume of liquid-solution employed, } \mathrm{ml} \\
& \mathrm{n}_{\text {re sin }}^{\mathrm{P}} \text { - amount of pertechnetate adsorbed onto resin, mmoles }
\end{aligned}
$$

Using Eq. (A-3) a molar balance for the final state of pertechnetate in the liquid-solution can be written as:

$$
\mathrm{n}_{\mathrm{f}}^{\mathrm{P}}=\mathrm{n}_{\mathrm{i}}^{\mathrm{P}}-\mathrm{n}_{\mathrm{resin}}^{\mathrm{P}}=\mathrm{n}_{\mathrm{i}}^{\mathrm{P}}-\left(\mathrm{c}_{\mathrm{i}}^{\mathrm{T}}-\mathrm{c}_{\mathrm{f}}^{\mathrm{T}}\right) N_{\text {sol'n }},
$$

Equation (A-4) can be converted into the final state concentration of pertechnetate in the liquidsolution given by:

$$
c_{f}^{P} \equiv \frac{n_{f}^{P}}{V_{s o l ' n}}=c_{i}^{P}-c_{i}^{T}-c_{f}^{T}=c_{f}^{T}-\eta_{i} c_{i}^{T} .
$$

As Eq. (A-5) states, the final liquid-concentration of pertechnetate can be computed given the initial and final liquid-concentrations of total technetium and the specified initial nonpertechnetate fraction.

Due to the finite sizes (i.e., phase ratio) of liquid-solution and resin mass, and especially for recontact testing, the liquid-phase nitrate concentration level can be reduced. Molar balances can be used to determine the final state liquid-concentration for nitrate. If we assume that all active sites of the available resin is occupied by species containing either pertechnetate $(\mathrm{P})$ or nitrate (NO) then:

$$
\mathrm{n}_{\text {re sin }}^{\mathrm{NO}}=\mathrm{n}_{\text {sites }}-\mathrm{n}_{\text {re sin }}^{\mathrm{P}}
$$

The molar balance for nitrate now becomes:

$$
\mathrm{n}_{\mathrm{f}}^{\mathrm{NO}}=\mathrm{n}_{\mathrm{i}}^{\mathrm{NO}}-\mathrm{n}_{\mathrm{resin}}^{\mathrm{NO}}=\mathrm{n}_{\mathrm{i}}^{\mathrm{NO}}-\mathrm{n}_{\text {sites }}+\left(\mathrm{c}_{\mathrm{i}}^{\mathrm{T}}-\mathrm{c}_{\mathrm{f}}^{\mathrm{T}}\right) \mathrm{N}_{\text {sol'n }} \cdot
$$

Equation (A-7) can be converted into the final state concentration of nitrate in the liquid-solution given by:

$$
\mathrm{c}_{\mathrm{f}}^{\mathrm{NO}} \equiv \frac{\mathrm{n}_{\mathrm{f}}^{\mathrm{NO}}}{\mathrm{V}_{\text {sol'n }}}=\mathrm{c}_{\mathrm{i}}^{\mathrm{NO}}-\frac{\mathrm{n}_{\text {sites }}}{\mathrm{V}_{\text {sol'n }}}+\mathrm{c}_{\mathrm{i}}^{\mathrm{T}}-\mathrm{c}_{\mathrm{f}}^{\mathrm{T}} .
$$


As Eq. (A-8) states, the final liquid-concentration of nitrate can be computed given the initial and final liquid-concentrations of total technetium, the initial concentration of nitrate, and the number of active adsorption sites.

The final fraction of non-pertechnetate $(\mathrm{N})$ present in the liquid-solution can be computed from

$$
\eta_{\mathrm{f}} \equiv \frac{\mathrm{c}_{\mathrm{f}}^{\mathrm{N}}}{\mathrm{c}_{\mathrm{f}}^{\mathrm{T}}}=\eta_{\mathrm{i}} \frac{\mathrm{c}_{\mathrm{i}}^{\mathrm{T}}}{\mathrm{c}_{\mathrm{f}}^{\mathrm{T}}},
$$

where for re-contact tests Eq. (A-9) establishes the initial non-pertechnetate fraction for the next batch contact test. The final fraction always exceeds its initial fraction as expressed by Eq. (A9).

\section{A.2.3 Impact of Non-pertechnetate Fraction}

For multiple re-contact tests the initial fraction specified (or assumed) for the first contact test can be checked for reasonableness based on the ultimate final fraction of the last re-contact test. For example, too large an initial fraction can result in final fractions that exceed unity or negative final pertechnetate concentrations. To illustrate the impact to final pertechnetate concentrations resulting from uncertainty in the initial non-pertechnetate fraction, a sensitivity analyses was performed using the batch contact test data taken by Hassan et al. (2000d) and labeled NH-B in Section 4.

As indicated in Section 4, the binary isotherm model is directly impacted by the molar ratio of nitrate to pertechnetate anions in solution as expressed by Eq. (4-15). Uncertainties in this molar ratio have a direct impact on the ability of the binary isotherm model to accurately predict surface adsorption. The computed final molar ratios of nitrate to pertechnetate anions for the four contact tests (i.e., the first initial contact test followed by three re-contact tests) as a function of a specified value for the initial liquid-solution's non-pertechnetate fraction is plotted in Figure A-1.

Only a narrow range of non-pertechnetate fraction is shown (i.e., $0 \%$ to $0.4 \%$ ). As Figure A-1 indicates, progressively more sensitivity results as additional re-contact tests are performed. Based on these batch contact tests, the non-pertechnetate fraction in the Envelope B sample had to be less than $\sim 0.03 \%$. The follow-on column test performed by Hassan et al. (2000d) confirmed this fraction where no apparent early breakthrough of total technetium (in any form) was observed in the exit of the lag column.

Since the initial fraction of non-pertechnetate used in each re-contact test can be computed based on the molar balances described above, we can also estimate the remaining amount of nonpertechnetate in the liquid sample during a series of re-contact tests. For the various re-contact test series performed, the remaining amounts of non-pertechnetate in the liquid sample (i.e., in terms of percent of the initial amount of non-pertechnetate contained in the liquid sample prior to its first contact test) were computed. Figure A-2 shows the results for four re-contact series of tests. In all cases the remaining amount of non-pertechnetate in the liquid sample diminishes with each additional re-contact. A reduction in the remaining non-pertechnetate can potentially 
be the result of liquid-phase reactions converting non-pertechnetate forms into pertechnetate. However, these results depend upon the assumption that the dominant competitors for ion exchange have been identified and properly accounted for.

As shown in Figure A-12, the impact for Envelope $\mathrm{C}$ wastes is much greater than for Envelope A and B wastes. Since the non-pertechnetate fraction is much greater (i.e., $\sim 60 \%$ to $70 \%$ ) in Envelope C waste, as compared to $\sim 1 \%$ in Envelope A and B wastes, one would expect the available species that make up the non-pertechnetate to be present in larger quantities. Thereby, the re-contact tests would see a larger impact for the Envelope $\mathrm{C}$ cases.

For example, after each resin contact test the pertechnetate depleted liquid-sample would gradually be enriched in pertechnetate due to the equilibrium shift. In fact, liquid-phase reactions such as these could be beneficially used by retreatment of waste initially high in nonpertechnetate (e.g., Envelope $\mathrm{C}$ wastes) with intermediate wait times to allow equilibrium between pertechnetate and its non-pertechnetate forms to be established. Unfortunately, analytical uncertainties are large enough that the above hypothesis can not be confirmed and further $K_{d}$ tests are recommended to help determine if liquid-phase reactions are important over the time frame of interest.

\section{A.2.4 Pertechnetate Adsorption Quantities}

Given the above measured and computed initial plus final ionic concentrations, the $\mathrm{K}_{\mathrm{d}}$ and surface loading values for pertechnetate can be estimated. First, the $K_{d}$ value (in units of $\mathrm{ml} / \mathrm{g}_{\text {resin }}$ ) for pertechnetate can be computed from:

$$
\mathrm{K}_{\mathrm{d}}^{\mathrm{P}} \equiv\left[\frac{\mathrm{c}_{\mathrm{i}}^{\mathrm{P}}-\mathrm{c}_{\mathrm{f}}^{\mathrm{P}}}{\mathrm{c}_{\mathrm{f}}^{\mathrm{P}}}\right] \frac{\mathrm{V}_{\text {sol'n }}}{\mathrm{m}_{\text {resin }} \mathrm{F}},
$$

where the second quotient is typically referred to as the phase ratio (in units of $\mathrm{ml} / \mathrm{g}_{\text {resin }}$ ). The pertechnetate concentrations in Eq. (A-10) can be substituted with the expressions provided in the above subsections to arrive at:

$$
K_{d}^{P} \equiv\left[\frac{c_{i}^{T}-c_{f}^{T}}{c_{f}^{T}-\eta_{i} c_{i}^{T}}\right] \frac{V_{\text {sol'n }}}{m_{\text {resin }} F} .
$$

As indicated by Eq. (A-11), the pertechnetate $\mathrm{K}_{\mathrm{d}}$ value can be computed based on measured total technetium concentrations only when the initial fraction of non-pertechnetate is specified. Therefore, uncertainties in this initial fraction impact the computed pertechnetate $\mathrm{K}_{\mathrm{d}}$ values.

The final pertechnetate surface concentration (or loading in $\left[\mathrm{mmole}_{\mathrm{P}} / \mathrm{g}_{\mathrm{resin}}\right]$ ) can be computed using:

$$
\bar{c}_{f}^{P} \equiv K_{d}^{P} c_{f}^{P} .
$$


If the definition of the pertechnetate $\mathrm{K}_{\mathrm{d}}$ value, Eq. (A-10), is substituted into Eq. (A-12), then the pertechnetate solid-phase (i.e., surface) loading becomes:

$$
\bar{c}_{f}^{P}=\left[c_{i}^{P}-c_{f}^{P}\right] \frac{V_{\text {sol'n }}}{m_{\text {resin }} \mathrm{F}} \rightarrow\left[c_{i}^{T}-c_{f}^{T}\right] \frac{V_{\text {sol'n }}}{m_{\text {resin }} F} .
$$

As indicated by Eq. (A-13), the pertechnetate surface loading can be computed based entirely on measured total technetium concentrations and uncertainties in the initial fraction of nonpertechnetate have no impact on its computed value.

The fractional loading (i.e., dimensionless and ranges from 0 to 1 ) of pertechnetate onto the resin can be computed from the expression:

$$
\mathrm{q}^{\mathrm{P}} \equiv \frac{\overline{\mathrm{c}}_{\mathrm{f}}^{\mathrm{P}}}{\overline{\mathrm{C}}_{\mathrm{T}}},
$$

where consistent units between the surface concentration and the total ionic capacity must be used.

\section{A.3 Adsorption Isotherm Database}

Using the molar balance expressions derived in the above subsections the available data sets of batch contact tests listed in Table 4-1 have been updated to reflect these improvements. To illustrate by example how these data sets were altered, the NH-B contact data discussed above has been chosen (Hassan et al., 2000d). Table A-1 contains the original batch contact data for NH-B. Shown in Table A-1 are the test results for the Envelope B sample standard, the initial contact test, and the three re-contact tests sequentially performed. Table A-2 contains the results from the spread-sheet analysis used to implement the equations above.

In general, final nitrate liquid-concentrations were within a few percent of their initial values indicating that the phase ratios chosen were adequate for assuming relatively constant nitrate values. In certain cases inconsistencies existed between the predicted upper bound for nonpertechnetate fraction based of the re-contact tests versus values based on lag column early breakthrough. To help in determining optimum values for the initial non-pertechnetate fractions, comparisons of the isotherm data (i.e., pertechnetate loading versus molar nitrate to pertechnetate ratio) between data sets were made where sensitivity studies based on varying the nonpertechnetate fraction were evaluated. Figure A-1 illustrates the sensitivity behavior observed for the NH-B data set that is typical for all the other data sets. 
Table A-1. Adsorption isotherm " $\mathrm{K}_{\mathrm{d}}$ " data ${ }^{\mathrm{a}}$ for Pertechnetate-SuperLig ${ }^{\circledR} 639$ system measured by Hassan et al. (2000d).

\begin{tabular}{|c|c|c|c|c|c|c|c|c|c|c|}
\hline Sample ID & $\begin{array}{c}\text { Sample } \\
\text { wt. (g) }\end{array}$ & $\begin{array}{c}\text { Density } \\
(\mathrm{g} / \mathrm{ml})\end{array}$ & $\begin{array}{c}\text { Resin } \\
\text { wt. (g) }\end{array}$ & $\begin{array}{c}\text { Phase } \\
\text { ratio }\end{array}$ & $\begin{array}{c}{ }^{99} \mathrm{Tc} \\
\text { final } \\
(\mu \mathrm{g} / \mathrm{L})\end{array}$ & $\begin{array}{c}\text { Dilution } \\
\text { factor }\end{array}$ & \begin{tabular}{|c|}
${ }^{99} \mathrm{Tc}$ \\
dil. Correct \\
$(\mu \mathrm{g} / \mathrm{L})$
\end{tabular} & $\begin{array}{c}{ }^{99} \mathrm{Tc} \\
\text { removed }\end{array}$ & $\begin{array}{c}\text { Total } K_{d} \\
(\mathrm{ml} / \mathrm{g})\end{array}$ & $\begin{array}{c}\text { Percent } \\
\text { removed }\end{array}$ \\
\hline \multicolumn{11}{|l|}{ Sample standard } \\
\hline BNF-B305-AZ102-1 & 20.438 & 1.15 & - & - & 1221 & 11.44 & 13966 & & & \\
\hline BNF-B305-AZ102-1D & 20.473 & 1.15 & - & - & 1121 & 12.30 & 13788 & & & \\
\hline \multicolumn{11}{|l|}{ Initial contact } \\
\hline BNF-B305-S639-1 & 20.559 & 1.15 & 0.1808 & 98.9 & 120.2 & 11.47 & 1378 & 12499 & 908.6 & 90.1 \\
\hline BNF-B305-S639-1D & 20.624 & 1.15 & 0.1801 & 99.6 & 122.5 & 11.93 & 1461 & 12416 & 857.4 & 89.5 \\
\hline \multicolumn{11}{|l|}{$1^{\text {st }} \operatorname{Re}$-contact } \\
\hline BNF-B305-S639-1R-1 & 12.239 & 1.15 & 0.1212 & 87.8 & 12.05 & 11.30 & 136.1 & 1242 & 811.7 & 90.1 \\
\hline BNF-B305-S639-1R-1D & 12.357 & 1.15 & 0.1209 & 88.9 & 9.610 & 11.60 & 111.5 & 1349 & 1090 & 92.4 \\
\hline \multicolumn{11}{|l|}{$2^{\text {nd }}$ Re-contact } \\
\hline BNF-A325-S39-2R-1 & 8.426 & 1.15 & 0.1005 & 72.9 & 1.400 & 11.11 & 15.55 & 120.6 & 572.6 & 88.6 \\
\hline BNF-A325-S39-2R-1D & 9.018 & 1.15 & 0.1007 & 77.9 & 1.930 & 12.46 & 24.04 & 87.44 & 287.0 & 78.4 \\
\hline \multicolumn{11}{|l|}{$3^{\text {rd }}$ Re-contact } \\
\hline BNF-A325-S39-3R-1 & 4.915 & 1.15 & 0.0526 & 81.3 & 0.390 & 11.01 & 4.292 & 11.26 & 216.0 & 72.4 \\
\hline BNF-A325-S39-3R-1D & 4.212 & 1.15 & 0.0512 & 71.5 & 0.550 & 11.99 & 6.596 & 17.44 & 191.7 & 72.6 \\
\hline
\end{tabular}


Table A-2. Updated adsorption isotherm data for NH-B tests based on material balance analyses.

\begin{tabular}{|c|c|c|c|c|c|c|c|c|c|c|c|}
\hline Sample ID & $\begin{array}{l}{ }^{99} \mathrm{Tc} \\
\text { final } \\
{[\mathrm{M}]}\end{array}$ & $\begin{array}{c}\text { site conc. } \\
{[\mathrm{M}]}\end{array}$ & $\begin{array}{c}\mathrm{NO}_{3}^{-} \\
\text {initial } \\
{[\mathrm{M}]}\end{array}$ & $\begin{array}{l}\mathrm{NO}_{3}^{-} \\
\text {final } \\
{[\mathrm{M}]}\end{array}$ & $\begin{array}{c}\text { Non-TcO } \\
\text { initial } \\
\text { fraction }\end{array}$ & $\begin{array}{c}\mathrm{TcO}_{4}^{-} \\
\text {initial } \\
{[\mathrm{M}]} \\
\end{array}$ & $\begin{array}{c}\mathrm{TcO}_{4}^{-} \\
\text {final } \\
{[\mathrm{M}]}\end{array}$ & $\begin{array}{c}\mathrm{NO}_{3}^{-} / \mathrm{TcO}_{4}^{-} \\
\text {final } \\
\text { (ratio) }\end{array}$ & $\begin{array}{c}\mathrm{TcO}_{4}^{-} \\
\mathrm{K}_{\mathrm{d}} \\
(\mathrm{ml} / \mathrm{g})\end{array}$ & $\begin{array}{c}\mathrm{TcO}_{4}^{-} \\
\text {loading } \\
\text { (mmole/g) }\end{array}$ & $\begin{array}{c}\mathrm{TcO}_{4}^{-} \\
\text {loading }^{b} \\
\text { (fractional) }\end{array}$ \\
\hline \multicolumn{12}{|l|}{ Sample standard } \\
\hline BNF-B305-AZ102-1 & 1.412E-04 & & & & & & & & & & \\
\hline BNF-B305-AZ102-1D & $1.394 \mathrm{E}-04$ & & & & & & & & & & \\
\hline \multicolumn{12}{|l|}{ Initial contact } \\
\hline BNF-B305-S639-1 & $1.393 \mathrm{E}-05$ & $5.057 \mathrm{E}-03$ & 0.273 & 0.268 & $0.00027^{\mathrm{a}}$ & $1.412 \mathrm{E}-04$ & $1.390 \mathrm{E}-05$ & $1.929 \mathrm{E}+04$ & 918 & $1.266 \mathrm{E}-02$ & $2.499 \mathrm{E}-02$ \\
\hline BNF-B305-S639-1D & $1.477 \mathrm{E}-05$ & $5.021 \mathrm{E}-03$ & 0.273 & 0.268 & $0.00027^{\mathrm{a}}$ & $1.394 \mathrm{E}-04$ & $1.473 \mathrm{E}-05$ & $1.820 \mathrm{E}+04$ & 853 & $1.266 \mathrm{E}-02$ & $2.500 \mathrm{E}-02$ \\
\hline \multicolumn{12}{|l|}{$1^{\text {st }}$ Re-contact } \\
\hline BNF-B305-S639-1R-1 & $1.376 \mathrm{E}-06$ & $5.694 \mathrm{E}-03$ & 0.268 & 0.262 & 0.00274 & $1.390 \mathrm{E}-05$ & $1.338 \mathrm{E}-06$ & $1.961 \mathrm{E}+05$ & 835 & $1.117 \mathrm{E}-03$ & $2.205 \mathrm{E}-03$ \\
\hline BNF-B305-S639-1R-1D & $1.127 \mathrm{E}-06$ & $5.626 \mathrm{E}-03$ & 0.268 & 0.262 & 0.00255 & $1.473 \mathrm{E}-05$ & $1.089 \mathrm{E}-06$ & $2.409 \mathrm{E}+05$ & 1128 & $1.229 \mathrm{E}-03$ & $2.425 \mathrm{E}-03$ \\
\hline \multicolumn{12}{|l|}{$2^{\text {nd }} \operatorname{Re}$-contact } \\
\hline BNF-A325-S39-2R-1 & $1.573 \mathrm{E}-07$ & $6.858 \mathrm{E}-03$ & 0.262 & 0.256 & 0.02770 & $1.338 \mathrm{E}-06$ & $1.191 \mathrm{E}-07$ & $2.145 \mathrm{E}+06$ & 756 & $9.004 \mathrm{E}-05$ & $1.777 \mathrm{E}-04$ \\
\hline BNF-A325-S39-2R-1D & $2.431 \mathrm{E}-07$ & $6.421 \mathrm{E}-03$ & 0.262 & 0.256 & 0.03339 & $1.089 \mathrm{E}-06$ & $2.054 \mathrm{E}-07$ & $1.247 \mathrm{E}+06$ & 340 & $6.975 \mathrm{E}-05$ & $1.377 \mathrm{E}-04$ \\
\hline \multicolumn{12}{|l|}{$3^{\text {rd }}$ Re-contact } \\
\hline BNF-A325-S39-3R-1 & 4.340E-08 & $6.154 \mathrm{E}-03$ & 0.256 & 0.249 & 0.24243 & $1.191 \mathrm{E}-07$ & $5.272 \mathrm{E}-09$ & $4.730 \mathrm{E}+07$ & 1778 & $9.374 \mathrm{E}-06$ & $1.850 \mathrm{E}-05$ \\
\hline BNF-A325-S39-3R-1D & $6.669 \mathrm{E}-08$ & $6.990 \mathrm{E}-03$ & 0.256 & 0.249 & 0.15486 & $2.054 \mathrm{E}-07$ & $2.905 \mathrm{E}-08$ & $8.574 \mathrm{E}+06$ & 440 & $1.278 \mathrm{E}-05$ & $2.523 \mathrm{E}-05$ \\
\hline
\end{tabular}

a Optimum initial value based on comparison to other technetium adsorption data and the slope of their isotherms.

b SuperLig 639 resin with batch ID (\# 981015DHC720011) has an estimated total ionic capacity of $0.6472 \mathrm{mmole} / \mathrm{g}_{\text {resin }}$. 


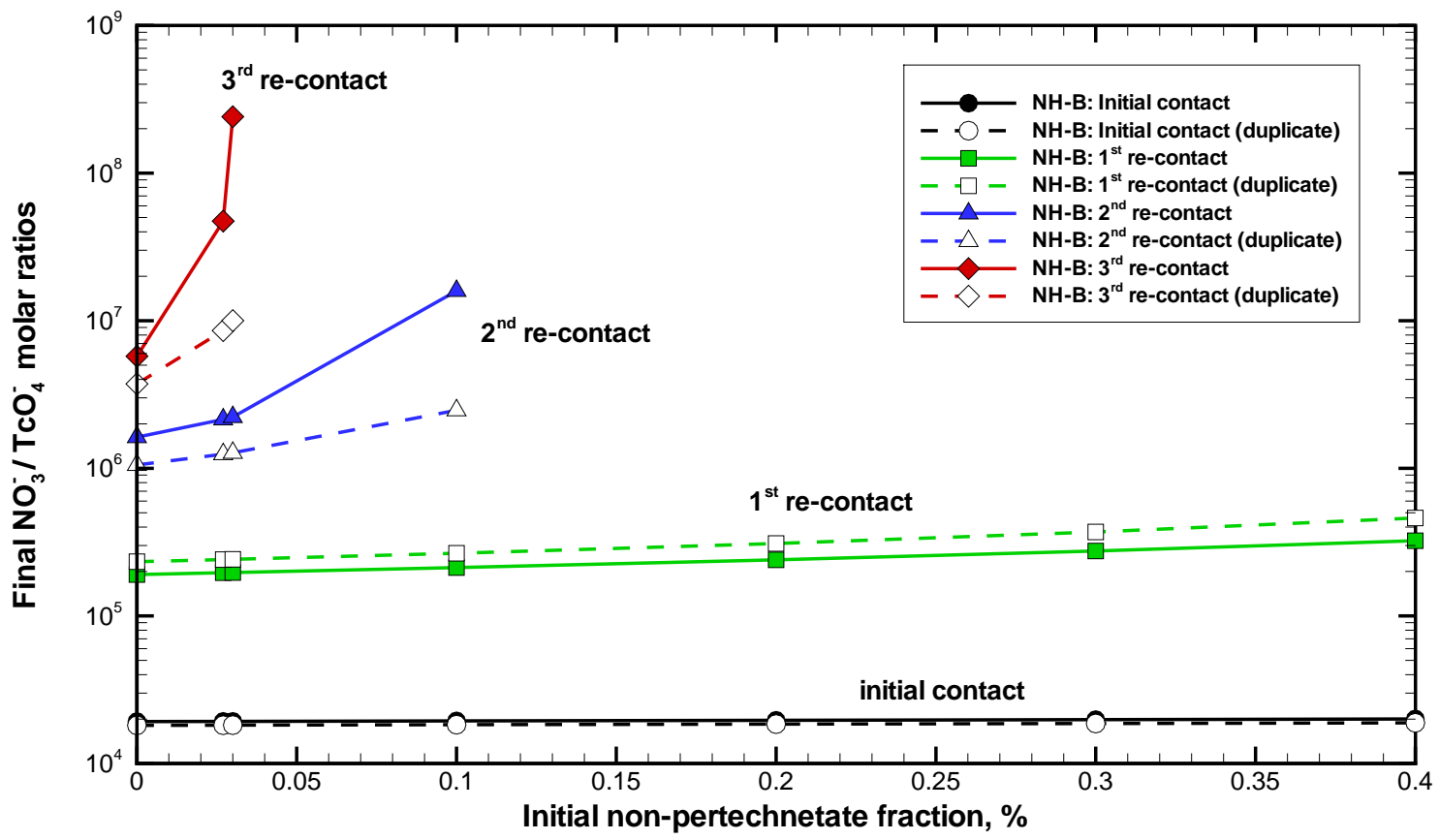

Figure A-1. Impact that initial non-pertechnetate fraction in liquid-sample has on final molar ratio of nitrate to pertechnetate during batch contact and re-contact tests on SuperLig ${ }^{\circledR} 639$ (data by Hassan et al., 2000d).

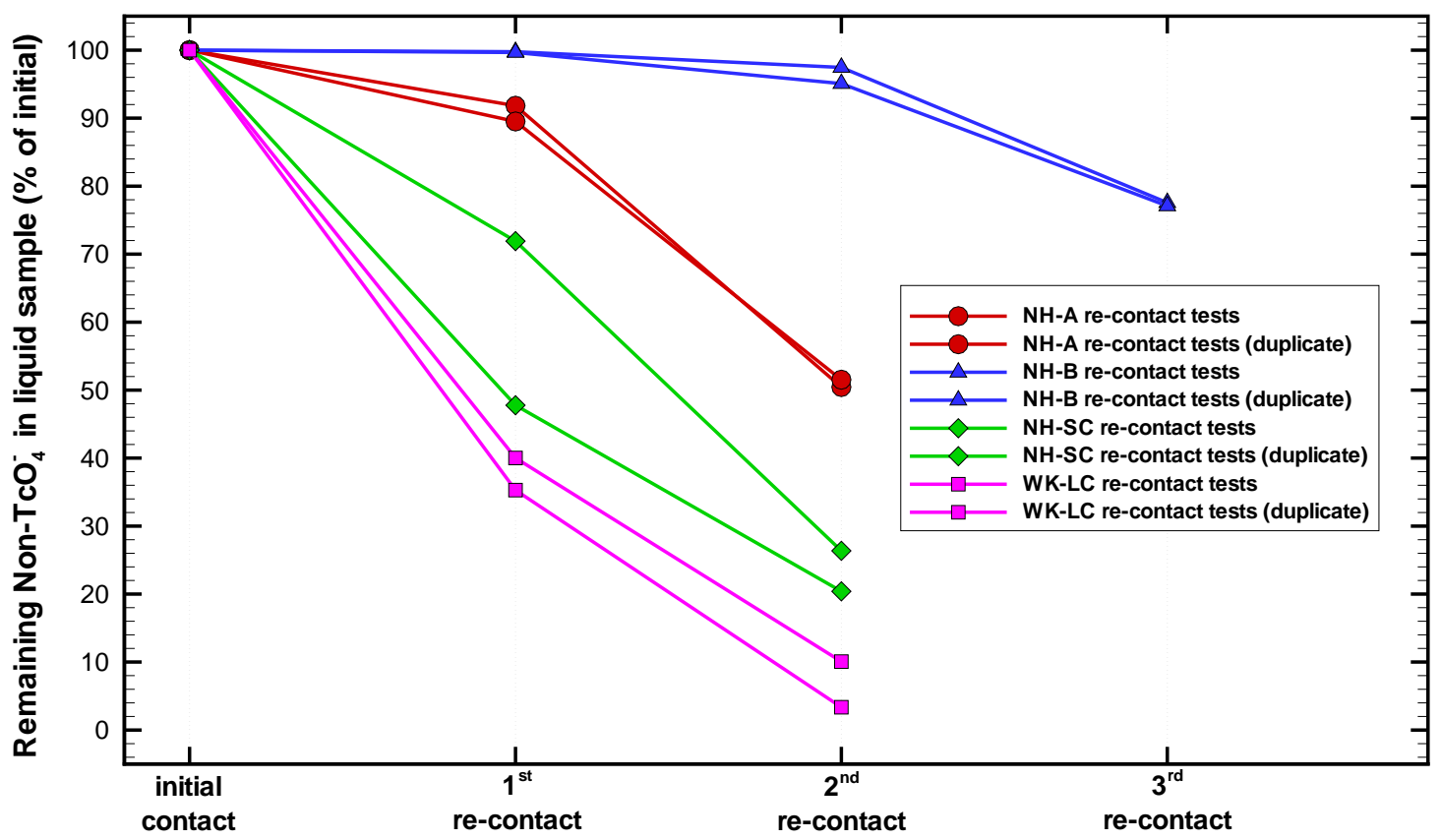

Figure A-2. The remaining amount (in terms of percent of initial amount) of non-pertechnetate contained in the liquid samples during the re-contact test series for all available re-contact tests based on pertechnetate and SuperLig ${ }^{\circledR} 639$ resin. 


\section{Appendix B (Lambda Values Based on $K_{d}$ Data)}

In previous work a loading capacity was computed and documented for many of the small-scale and intermediate-scale column tests. The technique employed was referred to as the "Lambda value" which is a column distribution coefficient that can, under certain limiting conditions, represent the computed number of column volumes required to reach $50 \%$ exit breakthrough. The Lambda values were calculated from the simple formula:

$$
\lambda=\rho_{\mathrm{b}} \mathrm{K}_{\mathrm{d}}
$$

The Lambda value estimates the adsorption affinity of a particular ion on a column volume basis, while the $\mathrm{K}_{\mathrm{d}}$ value is the adsorption affinity on a mass of resin basis. For some resin types the Lambda value is also an adequate predictor of $50 \%$ exit breakthrough, but care must be taken in its general use.

The basis behind the lambda value (and its limits of applicability) has been discussed in Appendix B of Hamm et al. (2000). The use of a lambda value in estimating the 50\% exit breakthrough point is straight-forwarded for linear isotherms where the $\mathrm{K}_{\mathrm{d}}$ value is independent of liquid-phase concentrations. The lambda value also estimates the $50 \%$ exit breakthrough point assuming that no mass transfer limiting conditions exist (i.e., negligible resistances to ion migration associated with film or pore diffusion and the presence of non-equilibrium surface adsorption). When mass transfer limitations are present the lambda value over-predicts the number of column volumes required to reach $50 \%$ breakthrough. Under these conditions the ratio of measured CVs required to reach $50 \%$ breakthrough versus the computed lambda value (by Eq. (B-1) will be less than unity. In general, the lambda value approach is unreliable and in many cases difficult to use unless an existing isotherm model is available.

As Eq. (B-1) indicates, in order to compute a lambda value a $\mathrm{K}_{\mathrm{d}}$ value must be specified. However, for non-linear isotherms (e.g., the Langmuir isotherm) the $\mathrm{K}_{\mathrm{d}}$ value varies with solute concentration and the choice in where to measure an "effective" $\mathrm{K}_{\mathrm{d}}$ value becomes important. For a favorable (convex) isotherm as shown in Figure B-1 a $\mathrm{K}_{\mathrm{d}}$ value measured at too small a solute concentration results in an over estimated Lambda value, while a $\mathrm{K}_{\mathrm{d}}$ value measured at too large a solute concentration results in an under estimated Lambda value.

An expression for the $\mathrm{K}_{\mathrm{d}}$ value of a binary isotherm model (i.e., its "chord" slope) can be computed for comparison to experimentally measured values. The binary isotherm model for $\mathrm{XO}_{4}{ }^{-}$, expressed as the molar fraction of $\mathrm{XO}_{4}{ }^{-}$residing on the resin surface sites, is given by:

$$
\mathrm{q}_{\mathrm{XO}_{4}^{-}} \equiv \frac{\overline{\mathrm{c}}_{\mathrm{XO}_{4}^{-}}}{\overline{\mathrm{C}}_{\mathrm{T}}}=\frac{\mathrm{c}_{\mathrm{pXO}_{4}^{-}}}{\mathrm{c}_{\mathrm{pXO}_{4}^{-}}+\widetilde{\mathrm{K}}_{21 \mathrm{pNO}_{3}^{-}}}
$$

The surface concentration of $\mathrm{XO}_{4}{ }^{-}$(in units of $\mathrm{mmole} / \mathrm{g}_{\text {resin }}$ ) can be expressed in terms of the $\mathrm{XO}_{4}{ }^{-} \mathrm{K}_{\mathrm{d}}$ value (in units of $\mathrm{ml} / \mathrm{g}_{\text {resin }}$ ) by: 


$$
\overline{\mathrm{c}}_{\mathrm{XO}_{4}^{-}} \equiv \mathrm{K}_{\mathrm{d} \mathrm{XO}_{4}^{-}},
$$

where the liquid-phase concentration in given in unit of molarity. Combining Eqs. (B-2) and (B3), an expression of the $\mathrm{K}_{\mathrm{d}}$ value for $\mathrm{XO}_{4}{ }^{-}$is obtained:

$$
\mathrm{K}_{\mathrm{d}}=\frac{\overline{\mathrm{C}}_{\mathrm{T}}}{\mathrm{c}_{\mathrm{XO}_{4}^{-}}+\widetilde{\mathrm{K}}_{21 \mathrm{NO}_{3}^{-}}} .
$$

Note that the $\mathrm{K}_{\mathrm{d}}$ value is a function of both the $\mathrm{NO}_{3}{ }^{-}$and $\mathrm{XO}_{4}{ }^{-}$concentration levels, not simply their molar ratio as seen in Eq. (B-2) for surface loadings. In the following subsections the lambda value approach is applied to several of the column tests assessed in Section 9 of the main body of this report.

The adsorption isotherm for the Technetium-SuperLig ${ }^{\circledR} 639$ system is a favorable isotherm that closely follows the Langmuir form. Tables B-1 and B-2 provide a listing of the measured and predicted Lambda values for several of the column tests assessed in the main body of this report. For the SuperLig ${ }^{\circledR} 639$ resin some level of mass transfer limiting conditions exists. Thus, typically the Lambda value should be expected to over predict the number of column volumes required to reach $50 \%$ breakthrough. As listed in Tables B-1 and B-2, measured Lambda values from $12 \%$ to $90 \%$ of their computed values were observed.

\section{B.1 Estimated Perrhenate Lambda Values}

The analyses for perrhenate are summarized in Table B-1. Detailed discussions for each column test presented in Table B-1 are provided in the following subsections. To briefly summarize the perrhenate column results, we conclude that:

- Over the operating range (i.e., molar ratio of nitrate to perrhenate) of each column tested, its appropriate binary isotherm is relatively linear resulting in a nearly constant $\mathrm{K}_{\mathrm{d}}$ value;

- In all cases, the computed lambda value overestimated the number of column volumes required to reach $50 \%$ exit breakthrough, implying that mass transfer limitations are important; and

- The degree of overestimate by the computed lambda value correlates well with the column tests superficial velocity confirming that mass transfer limitations are present.

\section{B.1.1 WK (Exp-1, 2, 3, and 4) Test Conditions}

As discussed by King et al. (2000a), an Envelope A waste simulant using perrhenate was considered. Three different batch materials with differing batch ID's were tested (i.e., batch ID \#980624001DC for WK-1, batch ID \#990420DHC720067 for WK-2, and batch ID \#981015DHC720011 for WK-3).

For the first batch ID series, the simulant having a nitrate concentration of $1.25 \mathrm{M}$ was used for six batch contact tests labeled WK-1 (i.e., duplicate tests were also performed for a total of 12 
data points) where one of the tests was a re-contact test. The predicted versus measured $\mathrm{K}_{\mathrm{d}}$ values for perrhenate are shown in Figure B-2. As shown in Figure B-2, over the operating range of the column experiments (i.e., WK Exp-1, Exp-2, Exp-3, and Exp-4) the perrhenate $\mathrm{K}_{\mathrm{d}}$ value is relatively constant with an average value of $\sim 200 \mathrm{ml} / \mathrm{g}_{\text {resin }}$.

For WK tests Exp-1 through Exp-3 the same column was used where the flowrate was progressively increased (i.e., superficial velocities of $0.51,5.20$, and $11.0 \mathrm{~cm} / \mathrm{min}$, respectively). Mass transfer limitations should increase as the flowrate is increased and the expected number of CVs required the reach 50\% exit breakthrough should drop. As listed in Table B-1, the experimentally measured 50\% exit breakthrough points for tests Exp-1, Exp-2, and Exp-3 were 88,22 , and $12 \mathrm{CVs}$, respectively. The computed lambda value for these three experiments is the same value of $98 \mathrm{CVs}$ as listed in Table B-1. The ratio of measure to computed values becomes $90 \%, 22 \%$, and $12 \%$ for each test, respectively. These results confirm our expectations and indicate that mass transfer limitations are perhaps starting to become important at the lowest flowrate.

For WK test Exp-4 the same resin was reused but repacked into a larger diameter column whose axial length turned out to be approximately half of the original column. A superficial velocity of $0.48 \mathrm{~cm} / \mathrm{min}$ was applied. The flowrate and inlet feed concentration of perrhenate are not identical to Exp-1 test conditions, but are similar. For Exp-4 the experimentally measured 50\% exit breakthrough point was $53 \mathrm{CVs}$. The computed lambda value for this experiment is the same as the others. The ratio of measured to computed value becomes $54 \%$ and is somewhat consistent with the other ratio values above.

\section{B.1.2 WK (Exp-5) Test Conditions}

For the second batch ID series, the simulant having a nitrate concentration of $1.25 \mathrm{M}$ was used for one batch contact test labeled WK-2 (i.e., duplicate tests were also performed for a total of 2 data points) where the test was an initial contact test. For the third batch ID series, the simulant having a nitrate concentration of $1.25 \mathrm{M}$ was used for four batch contact tests labeled WK-3 (i.e., duplicate tests were also performed for a total of 8 data points) where two of the tests were sequential re-contact tests.

The column used in test Exp-5 was packed with a 50:50 weight percent mixture of the two batch ID's used in contact tests WK-2 (\#990420DHC720067) and WK-3 (\#981015DHC720011). However, during the column modeling assessment efforts presented in Section 9, the isotherm model based only on the WK-3 adsorption data was used. The predicted versus measured $\mathrm{K}_{\mathrm{d}}$ values for perrhenate are shown in Figure B-3 for the WK-3 data (for comparison the $\mathrm{K}_{\mathrm{d}}$ data and isotherm for WK-2 is plotted as well). As shown in Figure B-3, over the operating range of the Exp-5 column experiment the perrhenate $\mathrm{K}_{\mathrm{d}}$ value is relatively constant with an average value of $\sim 377 \mathrm{ml} / \mathrm{g}_{\text {resin }}$ based purely on the WK-3 data and $\sim 450 \mathrm{ml} / \mathrm{g}_{\text {resin }}$ based on a $50: 50 \mathrm{mix}$ by mass of WK-2 and WK-3 resins.

For the WK Exp-5 column test nearly the same size column as used in the earlier Exp-1 through Exp-3 tests was used. Its superficial velocity was set to $0.43 \mathrm{~cm} / \mathrm{min}$. The flowrate and inlet 
feed concentration of perrhenate are not identical to Exp-1 test conditions, but are similar. For Exp-5 the experimentally measured 50\% exit breakthrough point was $145 \mathrm{CVs}$. The computed lambda value for this experiment is $179 \mathrm{CVs}$ based on the pure WK-3 resin and $213 \mathrm{CVs}$ for the 50:50 mixture. The ratio of measure to computed value becomes $81 \%$ for the pure WK-3 resin (and 68\% for the 50:50 mixture) and again is somewhat consistent with the other ratio values above.

\section{B.1.3 IBC (Exp-1) Test Conditions}

As discussed by IBC Advanced Technologies (1996), an Envelope A waste simulant using perrhenate was considered. One batch material was tested (i.e., batch ID not recorded). Five initial batch contact tests (i.e., IBC-1) were performed where the initial simulant perrhenate concentration was held fixed at $1.0 \times 10^{-4} \mathrm{M}$, while its nitrate concentration was varied (i.e., 1.1, $2.1,2.35,3.1$, and $4.1 \mathrm{M}$ ). A superficial velocity of $6.40 \mathrm{~cm} / \mathrm{min}$ was applied. The predicted versus measured $K_{d}$ values for perrhenate are shown in Figure B-4. As shown in Figure B-4, over the operating range of the column experiment (i.e., IBC Exp-1) the perrhenate $K_{d}$ value is relatively constant with an average value of $\sim 180 \mathrm{ml} / \mathrm{g}_{\text {resin }}$. A superficial velocity of $6.40 \mathrm{~cm} / \mathrm{min}$ was applied.

As Eq. (B-4) indicates and observed by the data in Figure B-4, the $\mathrm{K}_{\mathrm{d}}$ value depends upon both concentrations, not just the molar ratio. For the five data points shown, the molar ratio of nitrate to perrhenate varies by $41 \%$ while its $\mathrm{K}_{\mathrm{d}}$ values vary by $232 \%$. As listed in Table B-1, the experimentally measured 50\% exit breakthrough points for test Exp-1 was $41 \mathrm{CVs}$. The computed lambda value for this experiment is $72 \mathrm{CVs}$ as listed in Table B-1. The ratio of measure to computed value becomes $57 \%$.

\section{B.2 Estimated Pertechnetate Lambda Values}

The analyses for pertechnetate are summarized in Table B-2. Detailed discussions for each column test presented in Table B-2 is provided in the following subsections. To briefly summarize the pertechnetate column results, we conclude that:

- Increased data scatter is seen with regard to pertechnetate measured $\mathrm{K}_{\mathrm{d}}$ values that are believed to be the result of increased sensitivity during re-contact tests due to the assumed initial fraction of non-pertechnetate within the liquid-sample;

- Over the operating range (i.e., molar ratio of nitrate to perrhenate) of the columns tested, the appropriate binary isotherms were in some cases relatively linear resulting in a nearly constant $\mathrm{K}_{\mathrm{d}}$ value and in some cases the front portion of the column is operating in the nonlinear region;

- In all cases, the computed lambda value overestimated the number of column volumes required to reach $50 \%$ exit breakthrough, implying that mass transfer limitations are important; and

- Many of the column tests did not experimentally achieve 50\% breakthroughs and VERSE-LC simulations were used to assist in estimating the "measured" breakthrough point. 


\section{B.2.1 NH-A Test Conditions}

As discussed by Hassan et al. (2000a), two Envelope A (241-AN-103) waste samples were considered. The first sample (first filtrate) having a nitrate concentration of $1.571 \mathrm{M}$ was used for four batch contact tests (i.e., duplicate tests were also performed for a total of eight data points) where two of the tests were re-contact tests. The second sample (combined filtrate) having a nitrate concentration of $0.988 \mathrm{M}$ was used for column testing. These contact tests and column test are labeled NH-A.

The predicted versus measured $\mathrm{K}_{\mathrm{d}}$ values for pertechnetate are shown in Figure B-5. As shown in Figure B-5, over the operating range of the column experiment the pertechnetate $\mathrm{K}_{\mathrm{d}}$ value is relatively constant with an average value of $\sim 830 \mathrm{ml} / \mathrm{g}_{\text {resin. }}$. Experimentally a maximum $46.8 \%$ exit breakthrough was achieved. Using a bed density of $0.468 \mathrm{~g} / \mathrm{ml}$, the "computed" lambda value is estimated to be $\sim 388 \mathrm{CVs}$. Based on the breakthrough data an estimated $50 \%$ exit breakthrough occurs at $290 \mathrm{CVs}$. A measured to computed lambda ratio of $75 \%$ is obtained. The impact of mass transfer limitations is believed to be the predominate cause of the ratio being less than $100 \%$. The isotherm, as shown in Figure B-5, is nearly linear over the entire concentration range of interest.

\section{B.2.2 NH-B Test Conditions}

As discussed by Hassan et al. (1999a), two Envelope B (241-AZ-102) waste samples were considered. The first sample (original filtrate) having a nitrate concentration of $0.273 \mathrm{M}$ was used for four batch contact tests (i.e., duplicate tests were also performed for a total of eight data points) where three of the tests were sequential re-contact tests. The second sample (diluted filtrate) having a nitrate concentration of $0.232 \mathrm{M}$ was used for column testing. These contact tests and column test are labeled NH-B.

The estimated pertechnetate $\mathrm{K}_{\mathrm{d}}$ values from the batch re-contact data are very sensitive to the assumed initial fraction of non-pertechnetate in the liquid sample. During the three re-contact tests the liquid sample's nitrate concentration continued to drop as shown in Figure B-6. The predicted versus measured $\mathrm{K}_{\mathrm{d}}$ values for pertechnetate are shown in Figure B-6. For column test $\mathrm{NH}-\mathrm{B}$ the molar ratio of nitrate to pertechnetate is large enough to place the upper portion of the column in a region of its isotherm that exhibits non-linearity.

As shown in Figure B-6, over the operating range of the column experiment the pertechnetate $\mathrm{K}_{\mathrm{d}}$ value has an average value of $\sim 1020 \mathrm{ml} / \mathrm{g}_{\text {resin }}$, resulting in a "computed" lambda value estimated to be $\sim 388 \mathrm{CVs}$. Experimentally, only a maximum $\sim 10 \%$ exit breakthrough was achieved. Using the VERSE-LC predictions, along with the limited data, the $50 \%$ exit breakthrough is estimated to occur in 320 to $350 \mathrm{CVs}$.

\section{B.2.3 NH-SC Test Conditions}

As discussed by Hassan et al. (2000b), a "Small" Envelope C (241-AN-102) waste sample was considered. The sample having a nitrate concentration of $1.89 \mathrm{M}$ was used for three batch 
contact tests (i.e., duplicate tests were also performed for a total of six data points) where two of the tests were sequential re-contact tests. These contact tests and column test are labeled NH-SC.

Again, the estimated pertechnetate $\mathrm{K}_{\mathrm{d}}$ values from the batch re-contact data are very sensitivity to the assumed initial fraction of non-pertechnetate in the liquid sample. During the two re-contact tests the liquid sample's nitrate concentration dropped very slightly as shown in Figure B-7. The predicted versus measured $K_{d}$ values for pertechnetate are shown in Figure B-7. As shown in Figure B-7, over the operating range of the column experiment the pertechnetate $\mathrm{K}_{\mathrm{d}}$ value is relatively constant with an average value of $\sim 128 \mathrm{ml} / \mathrm{g}_{\text {resin }}$, resulting in a "computed" lambda value estimated to be $\sim 60 \mathrm{CVs}$.

Experimentally, significant data scatter exists in the measured breakthrough curves where a significant fraction of the technetium in the feed was in a non-pertechnetate form. Using the VERSE-LC predictions as shown in Figure 9-31, along with an estimated fraction of $60 \%$ nonpertechnetate feed, the $50 \%$ exit breakthrough curve for pertechnetate (i.e., $80 \%$ breakthrough for total technetium) is estimated to occur in $54 \mathrm{CVs}$. This gives a measured to computed ratio of $\sim 90 \%$.

\section{B.2.4 WK-LC Test Conditions}

As discussed by King et al. (2000c), two "Large" Envelope C (241-AN-102) waste samples were considered. The first sample having a nitrate concentration of $1.89 \mathrm{M}$ was used for four batch contact tests (i.e., duplicate tests were also performed for a total of eight data points) where two of the tests were sequential re-contact tests. The second sample (diluted filtrate) having a nitrate concentration of $1.385 \mathrm{M}$ was used for column testing. These contact tests and column test are labeled WK-LC.

Again, the estimated pertechnetate $\mathrm{K}_{\mathrm{d}}$ values from the batch re-contact data are very sensitive to the assumed initial fraction of non-pertechnetate in the liquid sample. During the two re-contact tests the liquid sample's nitrate concentration remain essentially constant. The predicted versus measured $K_{d}$ values for pertechnetate are shown in Figure B-8. As shown in Figure B-8, over the operating range of the column experiment the pertechnetate $K_{d}$ value is relatively constant with an average value of $\sim 341 \mathrm{ml} / \mathrm{g}_{\text {resin }}$, resulting in a "computed" lambda value estimated to be $\sim 161$ CVs.

Experimentally, significant data scatter exists in the measured breakthrough curves where a significant fraction of the technetium in the feed was in a non-pertechnetate form. Using the VERSE-LC predictions as shown in Figure 9-33, along with an estimated fraction of 70\% nonpertechnetate feed, the 50\% exit breakthrough curve for pertechnetate (i.e., $85 \%$ breakthrough for total technetium) is estimated to occur in $145 \mathrm{CVs}$. This gives a measured to computed ratio of $\sim 90 \%$. 


\section{B.2.5 WK-SRS Test Conditions}

As discussed by King et al. (2000b), a SRS Tank 44F waste sample was considered. The sample having a nitrate concentration of $0.495 \mathrm{M}$ was used for one batch contact test (i.e., duplicate test was performed for a total of 2 data points). These contact tests and column test are labeled WKSRS. For column test WK-SRS the molar ratio of nitrate to pertechnetate is large enough to place the upper portion of the column in a region of its isotherm that exhibits non-linearity.

The predicted versus measured $\mathrm{K}_{\mathrm{d}}$ values for pertechnetate are shown in Figure B-9. Two binary isotherm models are also shown. One is based on the WK-SRS contact data, while the other is the pertechnetate isotherm model representing Envelope A waste. VERSE-LC column modeling indicated that the second isotherm (i.e., the one representing Envelope A waste) provided better estimates of the exit breakthrough curves. As shown in Figure B-9, over the operating range of the column experiment the pertechnetate $\mathrm{K}_{\mathrm{d}}$ value has an average value of $\sim 1160 \mathrm{ml} / \mathrm{g}_{\text {resin }}$ for the SRS-based isotherm and $\sim 1670 \mathrm{ml} / \mathrm{g}_{\text {resin }}$ for the Envelope A-based isotherm. This results in "computed" lambda values of $\sim 555$ and $\sim 800 \mathrm{CVs}$, respectively.

Experimentally a maximum $42.5 \%$ exit breakthrough was achieved. Based on the breakthrough data an estimated $50 \%$ exit breakthrough occurs at $\sim 640 \mathrm{CVs}$. A measured to computed lambda ratio of $80 \%$ is obtained when the Envelope $\mathrm{A}$ isotherm is chosen. 
Table B-1. Comparison of measured versus computed Lambda values for the various perrhenate batch equilibrium tests and column experiments presented in the main body of this report.

\begin{tabular}{|c|c|c|c|c|c|c|c|c|c|}
\hline $\begin{array}{c}\text { Column } \\
\text { Test } \\
\text { ID }\end{array}$ & $\begin{array}{c}\text { Column } \\
\mathrm{ReO}_{4}^{-} \text {inlet } \\
\text { conc., } \\
\text { [M] }\end{array}$ & $\begin{array}{c}\text { Molar feed } \\
\text { ratio of } \mathrm{NO}_{3}^{-} \\
\text {to } \mathrm{ReO}_{4}^{-} \\
{[-]}\end{array}$ & $\begin{array}{l}\text { Measured or } \\
\text { Estimated }^{\text {a }} \\
50 \% \text { break- } \\
\text { through point } \\
\text { (CV) }\end{array}$ & $\begin{array}{c}\text { Bed } \\
\text { density, } \\
(\mathrm{g} / \mathrm{ml})\end{array}$ & $\begin{array}{l}\text { Average } \mathrm{K}_{\mathrm{d}} \\
\text { for } \mathrm{ReO}_{4}^{-} \\
(\mathrm{ml} / \mathrm{g})\end{array}$ & $\begin{array}{c}\text { Computed } \\
\text { ReO}_{4}^{-} \\
\text {Lambda } \\
\text { value, } \\
\text { (CV) }\end{array}$ & \begin{tabular}{|c|} 
Ratio of \\
Measured to \\
Computed \\
Lambda \\
value \\
$(\%)$
\end{tabular} & $\begin{array}{c}\text { Superficial } \\
\text { velocity } \\
(\mathrm{cm} / \mathrm{min})\end{array}$ & Reference report \\
\hline WK Exp-1 & $8.593 \times 10^{-5}$ & $1.455 \times 10^{4}$ & 88 & 0.489 & 200 & 98 & $90 \%$ & 0.51 & King et al., 2000a \\
\hline WK Exp-2 & $8.539 \times 10^{-5}$ & $1.464 \times 10^{4}$ & 22 & 0.489 & 200 & 98 & $22 \%$ & 5.20 & King et al., 2000a \\
\hline WK Exp-3 & $8.593 \times 10^{-5}$ & $1.455 \times 10^{4}$ & 12 & 0.489 & 200 & 98 & $12 \%$ & 11.0 & King et al., 2000a \\
\hline WK Exp-4 & $7.518 \times 10^{-5}$ & $1.662 \times 10^{4}$ & 53 & 0.489 & 200 & 98 & $54 \%$ & 0.48 & King et al., 2000a \\
\hline WK Exp-5 & $7.518 \times 10^{-5}$ & $1.662 \times 10^{4}$ & 145 & 0.4735 & $\begin{array}{c}377(\text { WK-3) } \\
\sim 450 \text { (mixed) }\end{array}$ & $\begin{array}{l}179(\mathrm{WK}-3) \\
213(\text { mixed })\end{array}$ & $\begin{array}{l}81 \%(\text { WK-3) } \\
68 \% \text { (mixed) }\end{array}$ & 0.43 & King et al., 2000a \\
\hline IBC Exp-1 & $1.000 \times 10^{-4}$ & $2.470 \times 10^{4}$ & 41 & 0.400 & 180 & 72 & $57 \%$ & 6.40 & $\begin{array}{c}\text { IBC Advanced } \\
\text { Technologies, } 1996\end{array}$ \\
\hline
\end{tabular}

${ }^{\mathrm{a}}$ During all of the column tests $50 \%$ perrhenate breakthrough was achieved and the column volume corresponding to $50 \%$ breakthrough was obtained by interpolation. 
Table B-2. Comparison of measured versus computed Lambda values for the various pertechnetate batch equilibrium tests and column experiments presented in the main body of this report.

\begin{tabular}{|c|c|c|c|c|c|c|c|c|c|}
\hline $\begin{array}{l}\text { Column } \\
\text { Test } \\
\text { ID }\end{array}$ & $\begin{array}{c}\text { Column } \\
\mathrm{TcO}_{4}^{-} \text {inlet } \\
\text { conc., } \\
{[\mathrm{M}]}\end{array}$ & $\begin{array}{c}\text { Molar feed } \\
\text { ratio of } \mathrm{NO}_{3}^{-} \\
\text {to } \mathrm{TcO}_{4}^{-} \\
{[-]}\end{array}$ & $\begin{array}{l}\text { Measured or } \\
\text { Estimated a } \\
50 \% \text { break- } \\
\text { through point } \\
\text { (CV) }\end{array}$ & $\begin{array}{c}\text { Bed } \\
\text { density, } \\
(\mathrm{g} / \mathrm{ml})\end{array}$ & $\begin{array}{l}\text { Average } \mathrm{K}_{\mathrm{d}}{ }^{\mathrm{b}} \\
\text { for } \mathrm{TcO}_{4}^{-} \\
(\mathrm{ml} / \mathrm{g})\end{array}$ & $\begin{array}{l}\text { Computed } \\
\text { TcO }_{4}^{-} \\
\text {Lambda } \\
\text { value, } \\
\text { (CV) }\end{array}$ & \begin{tabular}{|} 
Ratio of \\
Measured to \\
Computed \\
Lambda \\
value \\
$(\%)$
\end{tabular} & $\begin{array}{c}\text { Superficial } \\
\text { velocity } \\
(\mathrm{cm} / \mathrm{min})\end{array}$ & Reference report \\
\hline NH-A & $2.401 \times 10^{-5}$ & $4.156 \times 10^{4}$ & $\begin{array}{c}\sim 290^{\mathrm{a}} \\
(\max 46.8 \% \text { of } \\
\text { bkthru })\end{array}$ & 0.468 & 830 & 388 & $75 \%$ & 0.27 & Hassan et al., 2000a \\
\hline NH-B & $1.324 \times 10^{-4}$ & $1.751 \times 10^{3}$ & $\begin{array}{c}\sim 320 \text { to } 3500^{a} \\
\text { (max of only } \\
10 \% \text { of bkthru } \\
\text { achieved) }\end{array}$ & 0.468 & 1020 & 477 & $67 \%$ to $73 \%$ & 0.29 & Hassan et al., 2000d \\
\hline NH-SC & $1.893 \times 10^{-5}$ & $9.986 \times 10^{4}$ & $\begin{array}{l}\sim 54^{\mathrm{a}} \\
\text { (max bkthru } \\
\text { unknown) }\end{array}$ & 0.468 & 128 & 60 & $90 \%$ & 0.30 & Hassan et al., $2000 b$ \\
\hline WK-LC & $1.306 \times 10^{-5}$ & $1.061 \times 10^{5}$ & $\begin{array}{l}\sim 145^{\mathrm{a}} \\
\text { (max bkthru } \\
\text { unknown) }\end{array}$ & 0.4735 & 341 & 161 & $90 \%$ & 0.93 & King et al., 2000c \\
\hline WK-SRS & $3.123 \times 10^{-5}$ & $1.585 \times 10^{4}$ & $\begin{array}{c}\sim 640^{\mathrm{a}} \\
(\max 42.5 \% \text { of } \\
\text { bkthru })\end{array}$ & 0.4788 & $\begin{array}{c}1160 \text { (SRS data) } \\
1670 \text { (Env. A } \\
\text { data) }\end{array}$ & $\begin{array}{c}555 \text { (SRS) } \\
800 \text { (Env. A) }\end{array}$ & $80 \%$ (Env. A) & 0.45 & King et al., 2000b \\
\hline
\end{tabular}




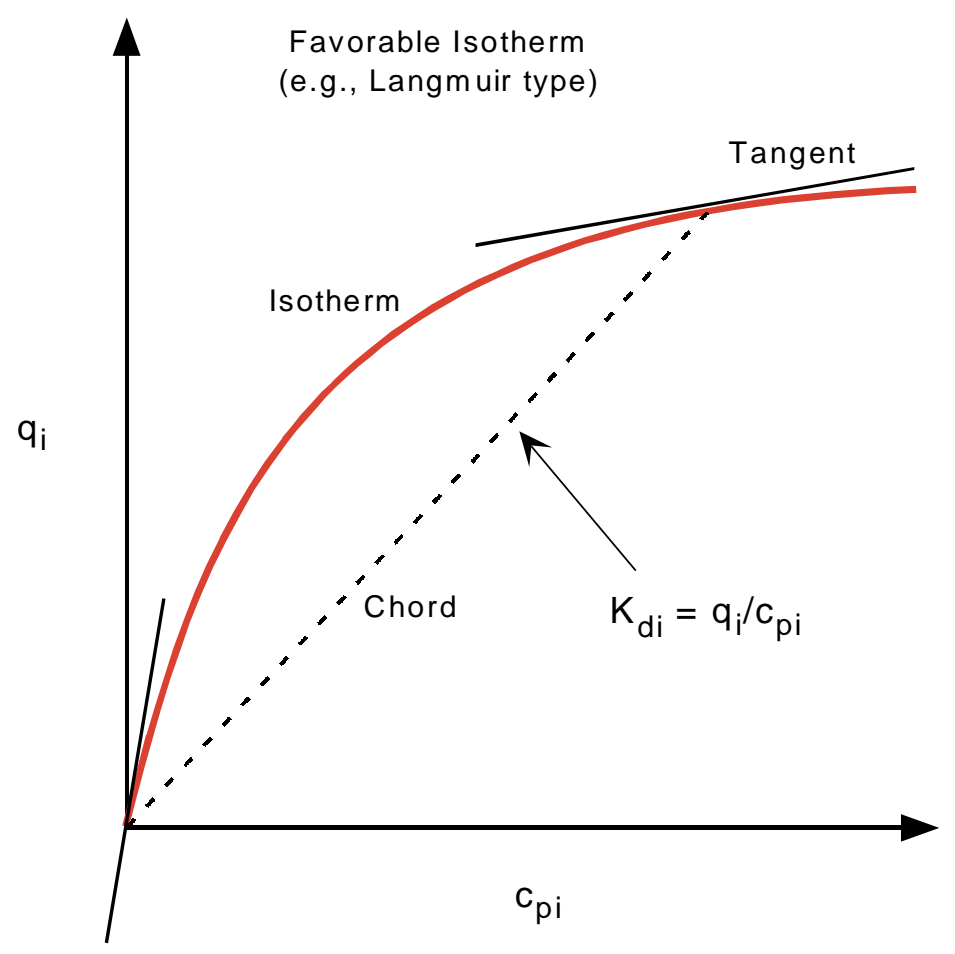

Figure B-1. A favorable isotherm with tangents $\left(\mathrm{dq}_{\mathrm{i}} / \mathrm{dc}_{\mathrm{pi}}\right)$ at $\mathrm{c}_{\mathrm{pi}}=0$ and at a point $\mathrm{c}_{\mathrm{pi}}>0$, and with a chord of that point. 


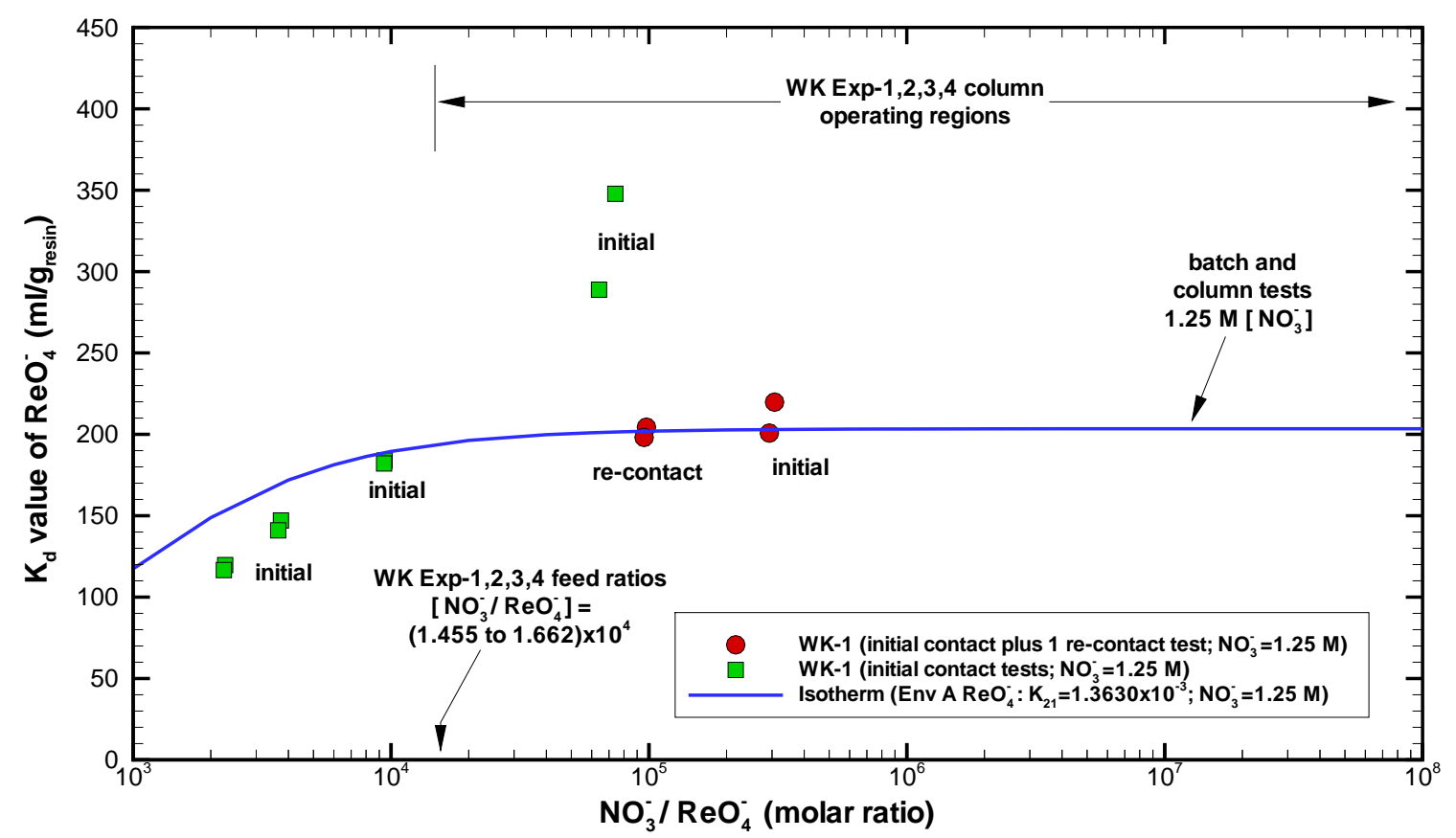

Figure B-2. Predicted versus measured perrhenate $\mathrm{K}_{\mathrm{d}}$ values for an Envelope A waste simulant where the isotherm models is shown for the nitrate level used in both batch contact test WK-1 and column tests WK Exp-1 through Exp-4 (King et al., 2000a).

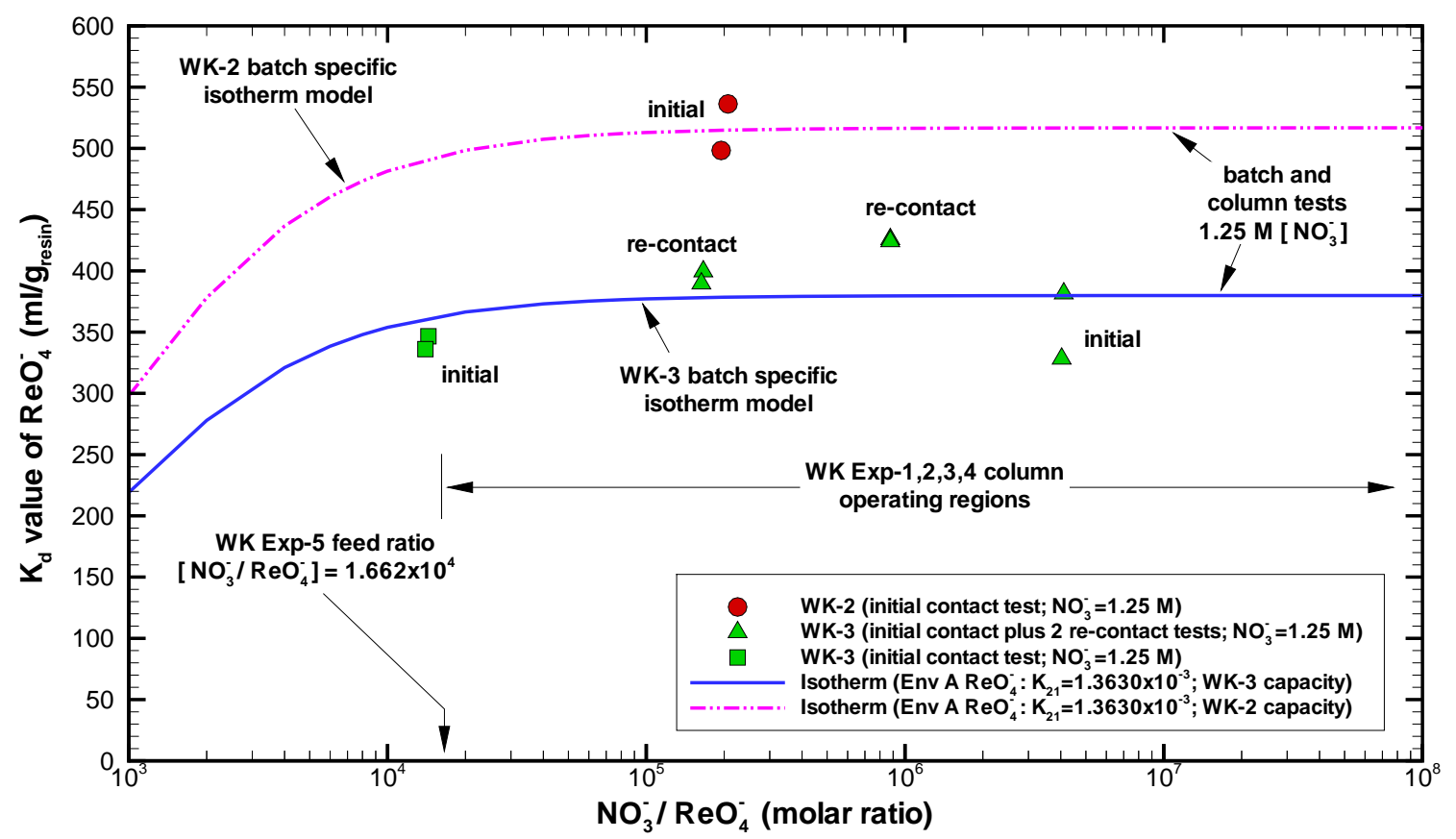

Figure B-3. Predicted versus measured perrhenate $K_{d}$ values for an Envelope A waste simulant where the isotherm models are shown for the nitrate level used in both batch contact tests WK-2 \& WK-3 and column test WK Exp-5 (King et al., 2000a). 


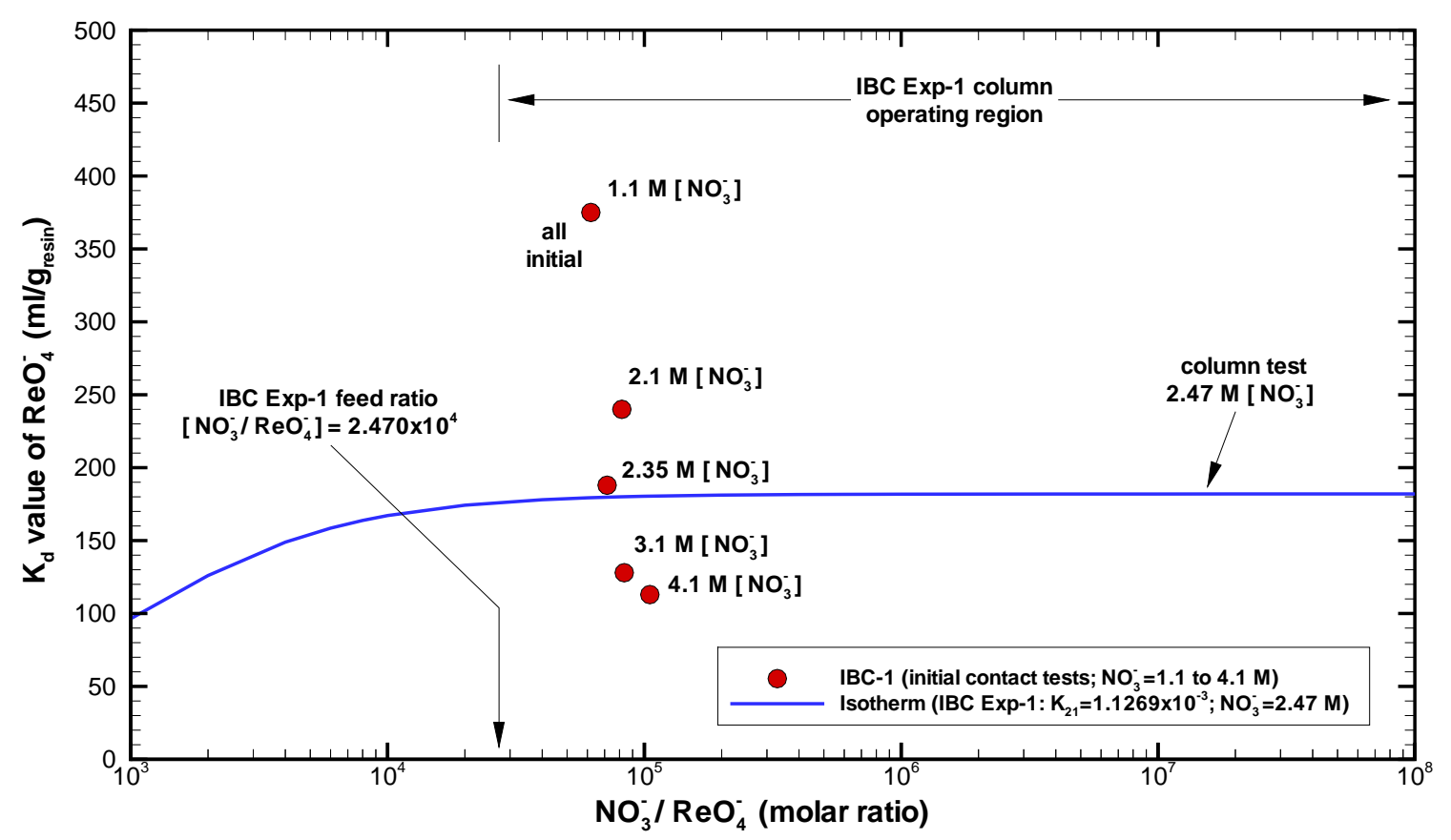

Figure B-4. Predicted versus measured perrhenate $\mathrm{K}_{\mathrm{d}}$ values for an Envelope A waste simulant where the isotherm model is shown for the nitrate level used in the column test IBC Exp-1 (IBC Advanced Technologies, 1996).

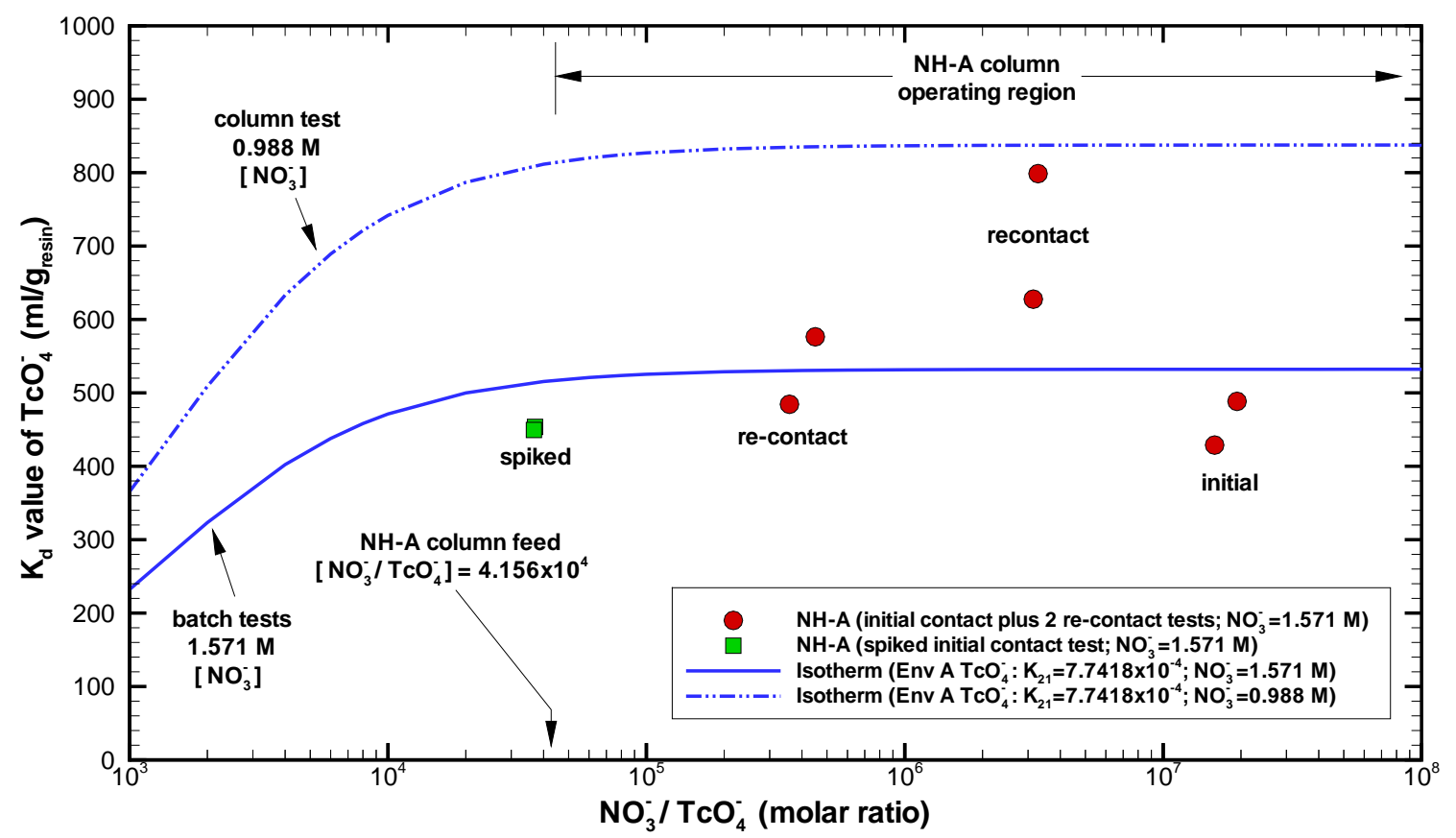

Figure B-5. Predicted versus measured pertechnetate $\mathrm{K}_{\mathrm{d}}$ values for Envelope A (241-AN-103) waste samples where the isotherm models are shown for nitrate levels used in NH-A batch contact and column testing (Hassan et al., 2000a). 


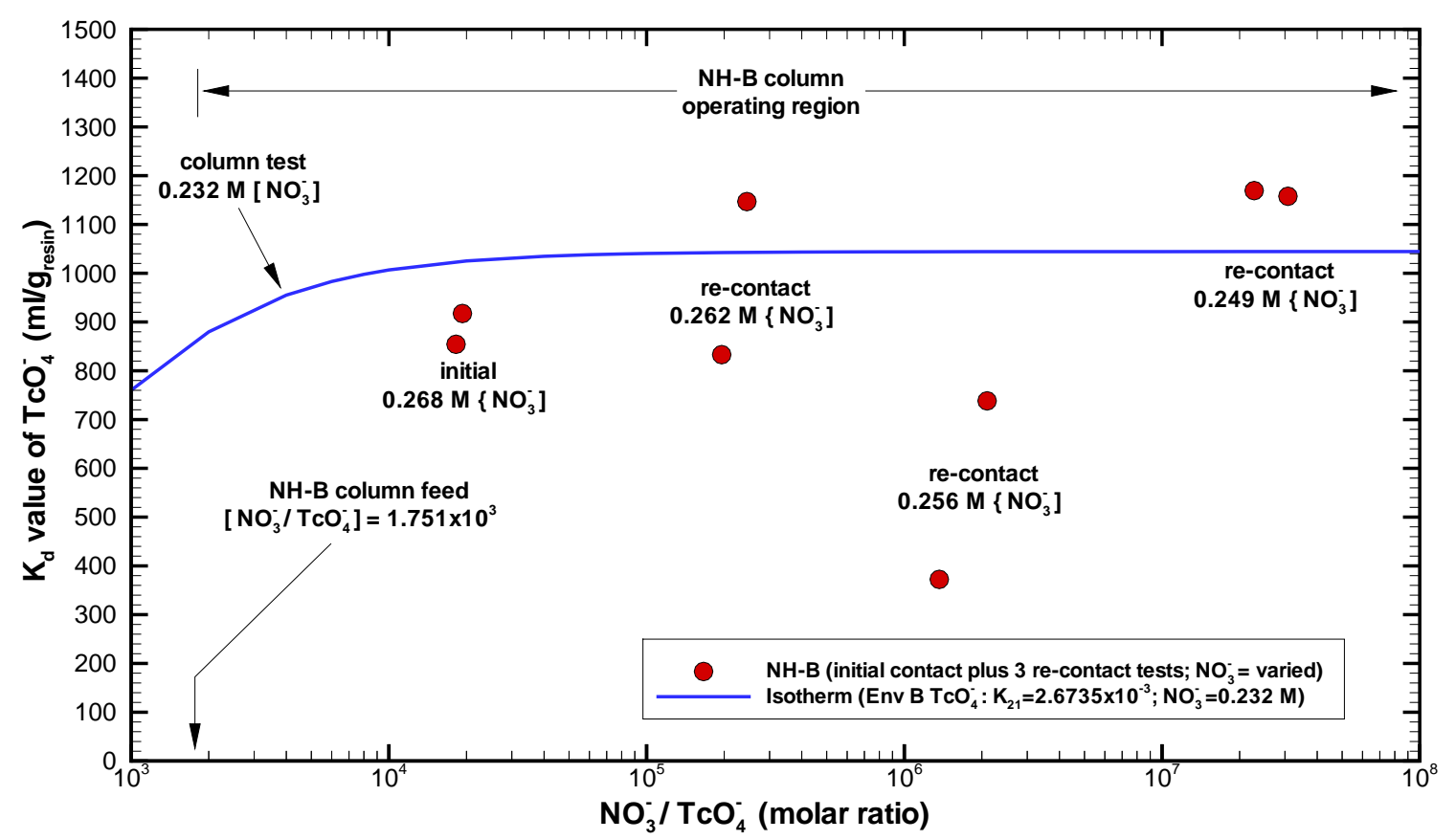

Figure B-6. Predicted versus measured pertechnetate $K_{d}$ values for Envelope B (241-AZ-102) waste samples where the isotherm model is shown for the nitrate level used in the NH-B column testing (Hassan et al., 2000d).

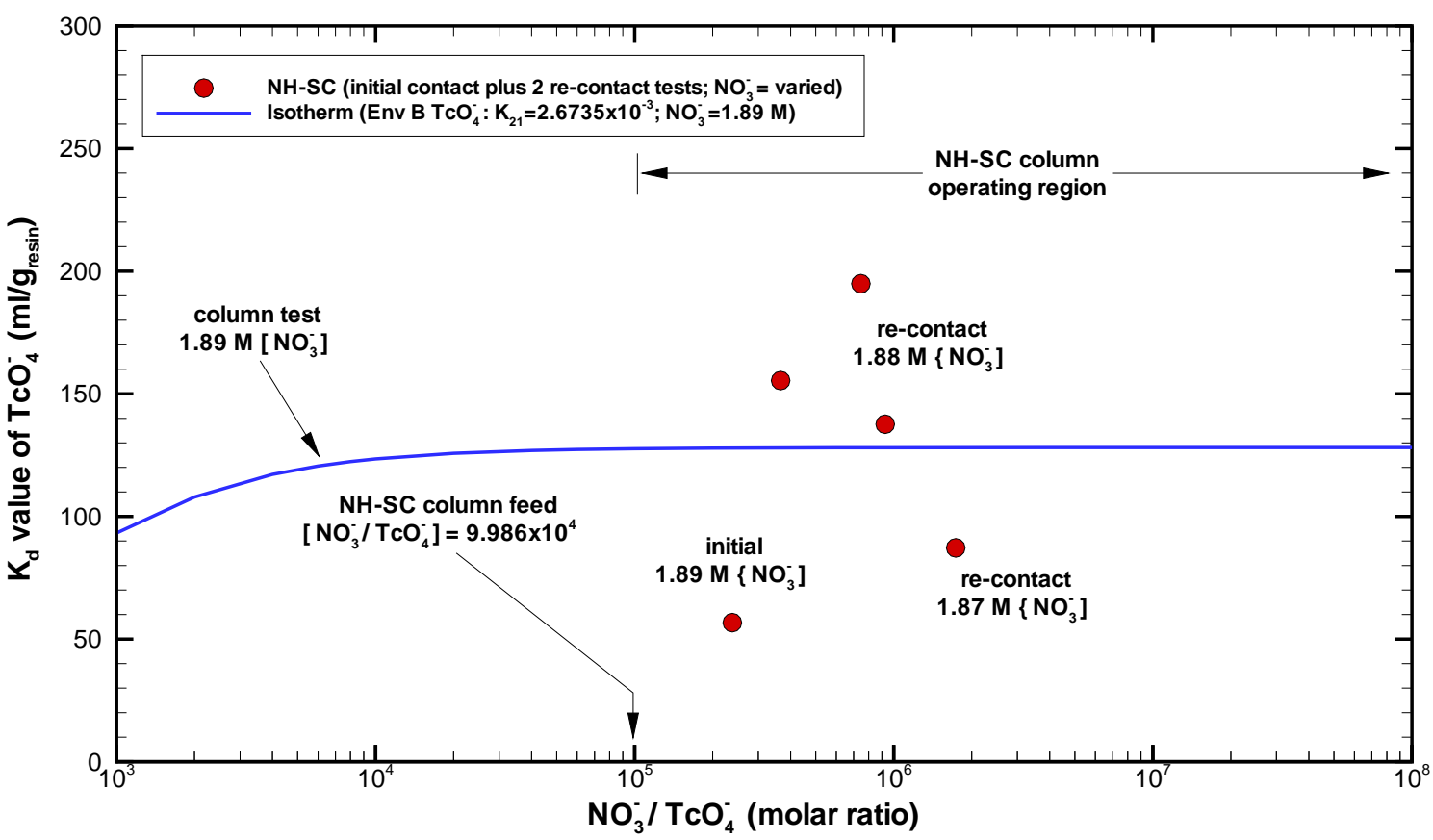

Figure B-7. Predicted versus measured pertechnetate $K_{d}$ values for Envelope "Small" C (241-AN-102) waste samples where the isotherm model is shown for the nitrate level used in the NHSC column testing (Hassan et al., 2000b). 


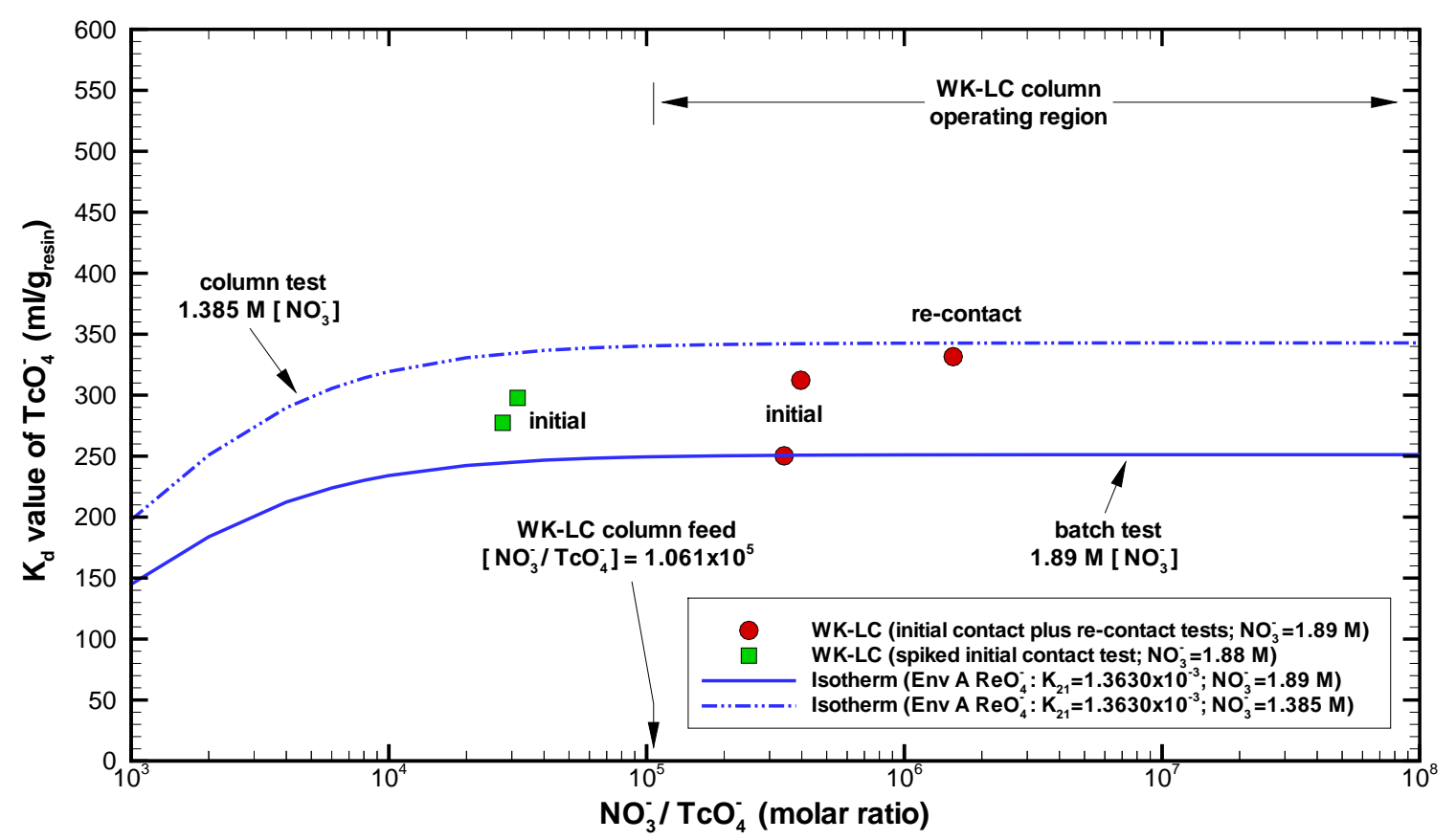

Figure B-8. Predicted versus measured pertechnetate $K_{d}$ values for Envelope "Large" C (241-AN-102) waste samples where the isotherm models are shown for the nitrate levels used in the WK-LC batch contact and column testing (King et al., 2000c).

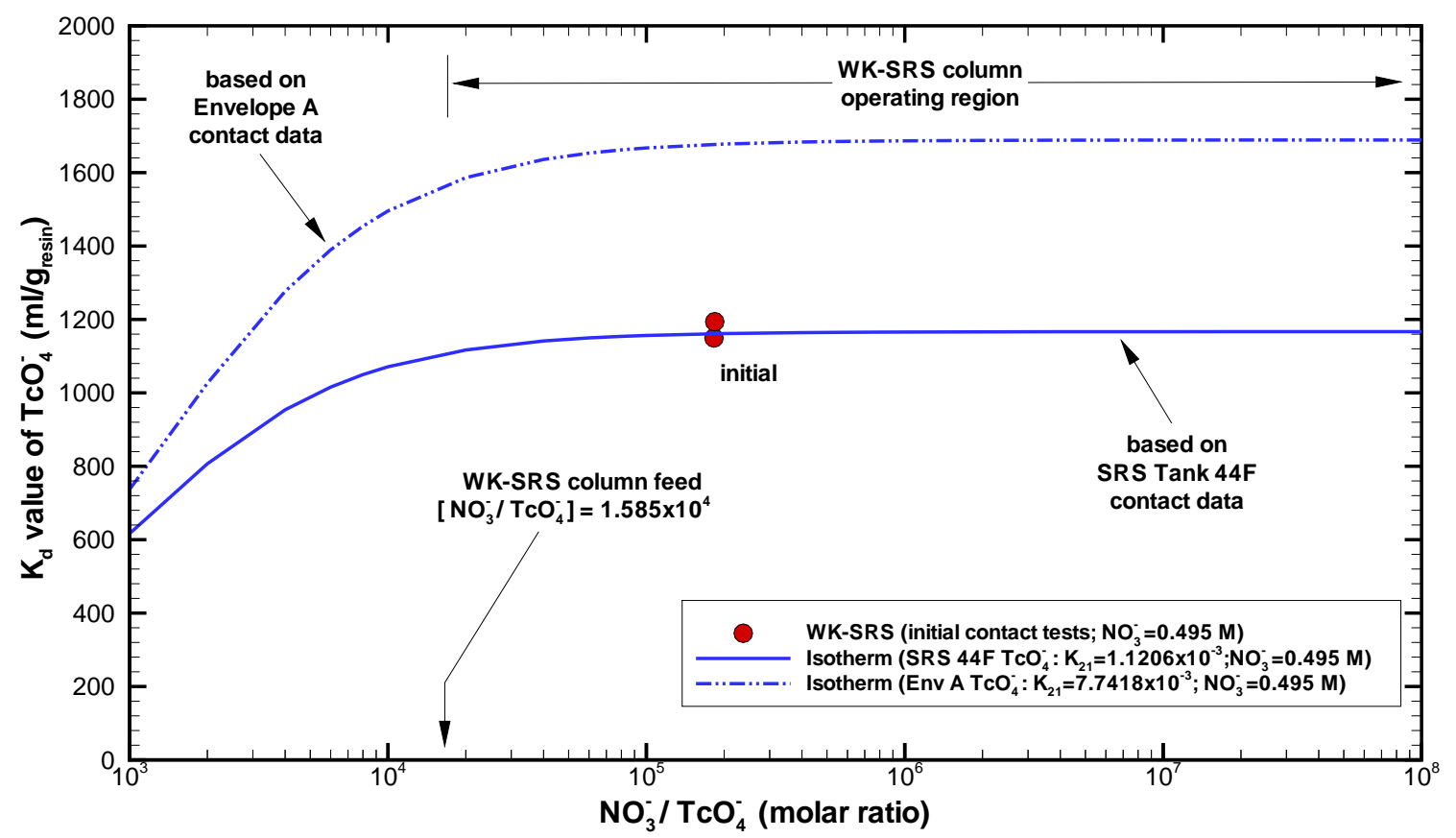

Figure B-9. Predicted versus measured pertechnetate $\mathrm{K}_{d}$ values for SRS Tank 44F waste sample where the isotherm models are shown for the nitrate level used in the WK-SRS batch contact and column testing (King et al., 2000b). 


\section{Appendix C (Batch Kinetics Test Input and Output Files)}

For reference the VERSE-LC input and output files for the batch kinetics test simulations are provided in this appendix. Several simulations were run. Tables C-1 and C-2 contain the measured transient liquid-phase technetium response corresponding to the batch kinetics tests performed and reported by Kurath et al. (1999). It is assumed that all of the technetium present exists in the pertechnetate form.

Table C-1. Key measurements made during the multiple batch kinetics tests of Kurath et al., 1999.

\begin{tabular}{|c|c|c|c|c|c|}
\hline $\begin{array}{c}\text { Batch Kinetics } \\
\text { Contact Test } \\
\text { ID }\end{array}$ & $\begin{array}{c}\text { Contact } \\
\text { time } \\
\text { (hrs) }\end{array}$ & $\begin{array}{c}\text { Initial Liquid } \\
\mathbf{N O}_{\mathbf{3}}^{-} \text {conc. } \\
{[\mathbf{M}]}\end{array}$ & $\begin{array}{c}\text { Initial Liquid } \\
\text { 99} \mathbf{T c ~ c o n c . ~} \\
{[\mathbf{M}]}\end{array}$ & $\begin{array}{c}\text { Final Liquid } \\
{ }_{\mathbf{9 9}} \mathbf{T c} \text { conc. } \\
{[\mathbf{M}]}\end{array}$ & $\begin{array}{c}\mathbf{K}_{\mathbf{d}} \mathbf{v a l u e} \\
(\mathbf{m l} / \mathbf{g})\end{array}$ \\
\hline \hline $\mathbf{W 3 9 - C}$ & 0.0 & 1.990 & $4.631 \mathrm{E}-05$ & $4.631 \mathrm{E}-05$ & 0 \\
\hline $\mathbf{W 3 9 - 0 4}$ & 4.0 & 1.990 & $4.631 \mathrm{E}-05$ & $1.254 \mathrm{E}-05$ & 277 \\
\hline $\mathbf{W 3 9 - 0 8}$ & 8.0 & 1.990 & $4.631 \mathrm{E}-05$ & $9.322 \mathrm{E}-06$ & 409 \\
\hline $\mathbf{W 3 9 - 1 6}$ & 16.0 & 1.990 & $4.631 \mathrm{E}-05$ & $7.836 \mathrm{E}-06$ & 507 \\
\hline $\mathbf{W 3 9 - 2 4}$ & 24.0 & 1.990 & $4.631 \mathrm{E}-05$ & $7.361 \mathrm{E}-06$ & 567 \\
\hline $\mathbf{W 3 9 - 4 8}$ & 48.0 & 1.990 & $4.631 \mathrm{E}-05$ & $6.481 \mathrm{E}-06$ & 640 \\
\hline $\mathbf{W 3 9 - 7 2}$ & 72.0 & 1.990 & $4.631 \mathrm{E}-05$ & $5.783 \mathrm{E}-06$ & 723 \\
\hline
\end{tabular}


Table C-2. Key parameters measured or specified during the batch kinetics tests of Kurath et al., 1999.

\begin{tabular}{|c|c|}
\hline Parameter & Parameter setting \\
\hline Temperature & $22{ }^{\circ} \mathrm{C}$ \\
\hline MW of ${ }^{99} \mathrm{Tc}$ & $98.90628 \mathrm{~g} / \mathrm{gmole}$ \\
\hline Initial non- $\mathrm{TcO}_{4}{ }^{-}$fraction & assumed $0 \%$ \\
\hline Initial liquid $\mathrm{TcO}_{4}{ }^{-}$conc. & $4.63065 \times 10^{-5} \mathrm{M}$ \\
\hline Initial liquid $\mathrm{NO}_{3}{ }^{-}$conc. & $1.990 \mathrm{M}$ \\
\hline $\begin{array}{c}\text { Final liquid } \mathrm{TcO}_{4}{ }^{-} \text {conc. } \\
\text { (actually at } 72 \text { hours) }\end{array}$ & $5.78325 \times 10^{-6} \mathrm{M}$ \\
\hline $\begin{array}{c}\text { Final liquid } \mathrm{NO}_{3}{ }^{-} \text {conc. } \\
\text { (actually at } 72 \text { hours) }\end{array}$ & $1.985 \mathrm{M}$ \\
\hline Initial liquid sample volume & $5.0 \mathrm{ml}$ \\
\hline Initial resin mass & $0.0484 \mathrm{~g}$ \\
\hline Batch $\mathrm{ID}$ & $980624001 \mathrm{DC}$ \\
\hline solid density assumed & $1.219 \mathrm{~g} / \mathrm{ml}$ \\
\hline F factor & 0.9334 \\
\hline
\end{tabular}




\section{VERSE Input for Batch Kinetic Test (Kurath et al., 1999)}

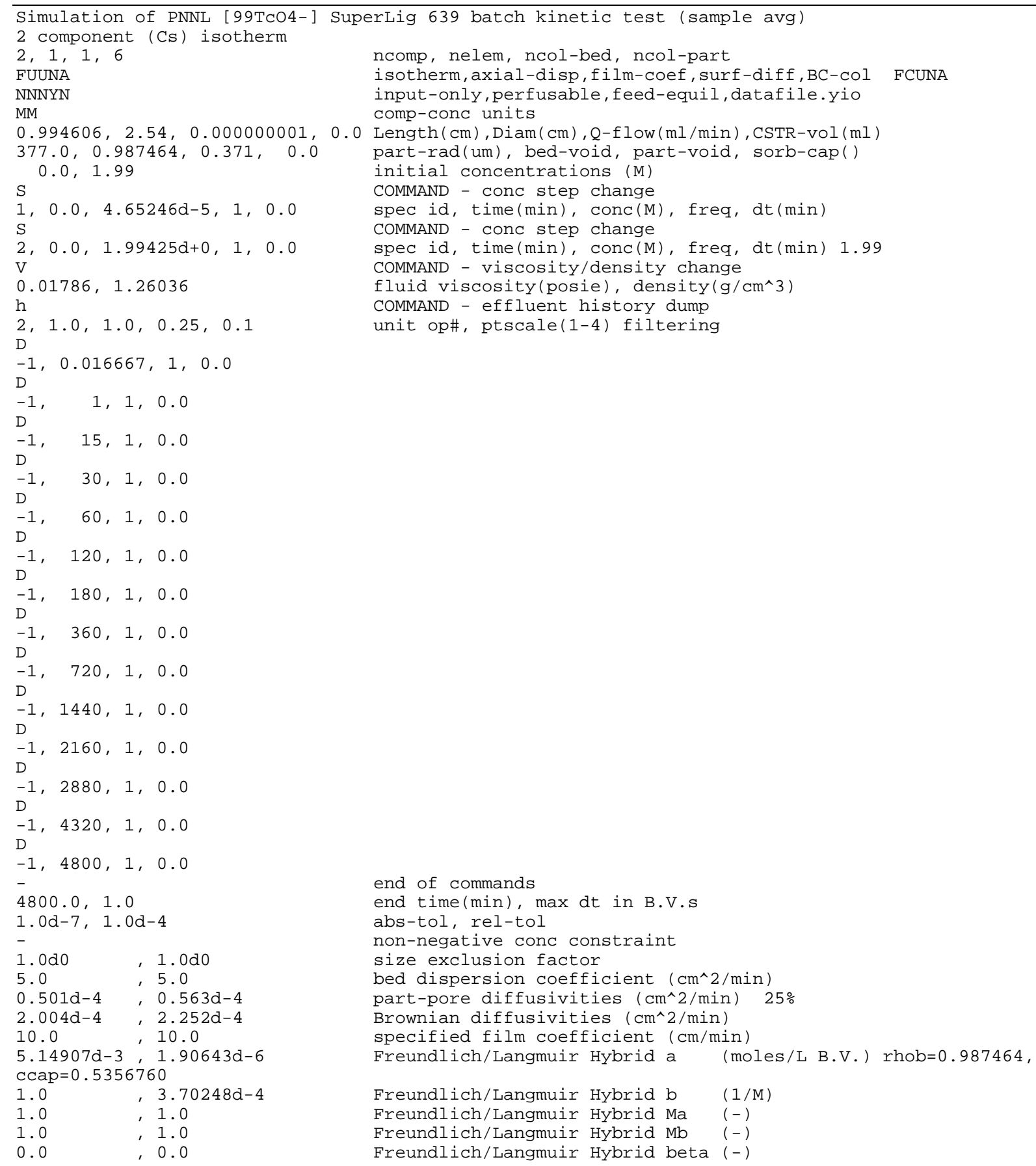




\section{VERSE Output for Batch Kinetic Test (Kurath et al., 1999)}

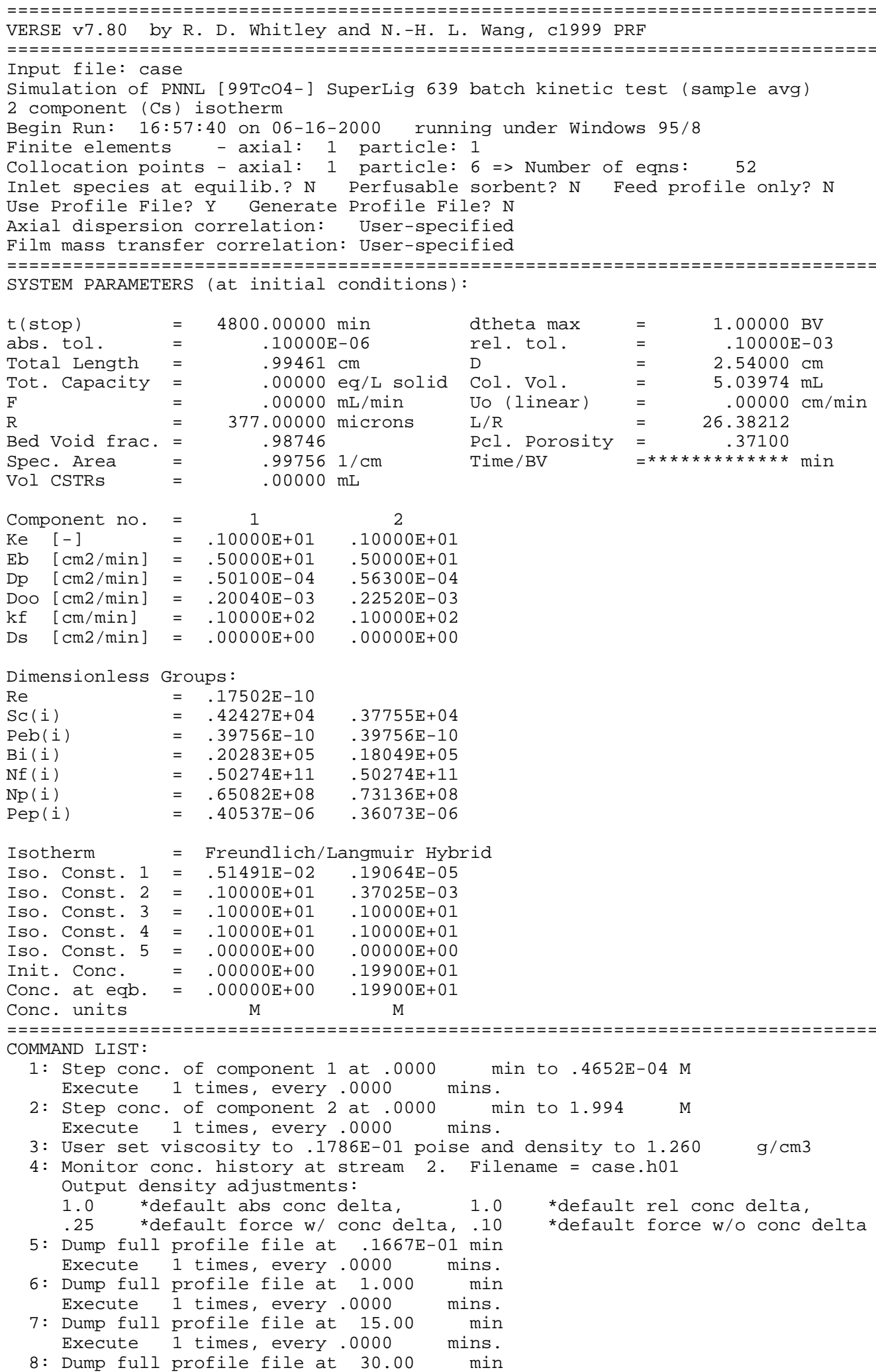

dtheta $\max =1.00000 \mathrm{BV}$ 


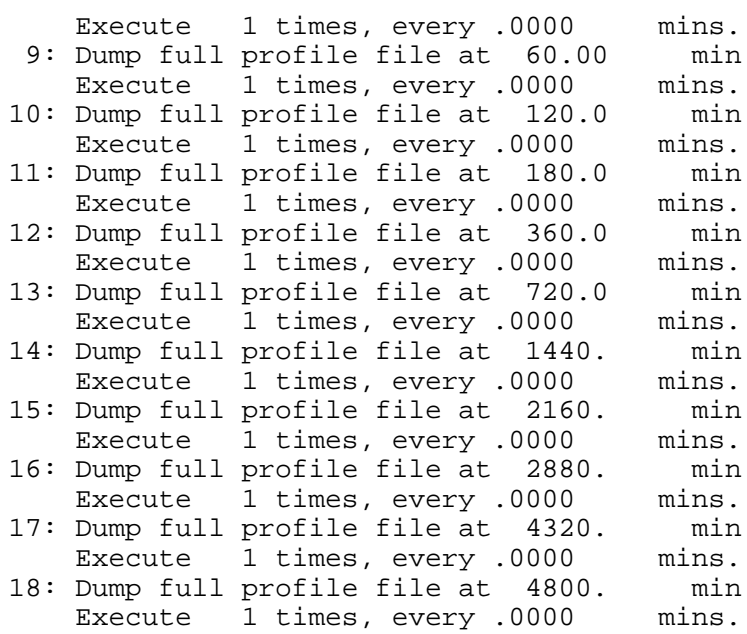




\section{Appendix D (Column Test Input and Output Files)}

For reference the VERSE-LC input and output files for the laboratory-scale (including the pilotscale) test columns are provided in this appendix. Some of the column tests were performed using perrhenate while the remainder used pertechnetate. Twenty column simulation models were run. The input and output files for each case are listed below.

\section{VERSE Input for Intermediate-Scale Perrhenate Column (WK Exp-1) Test}

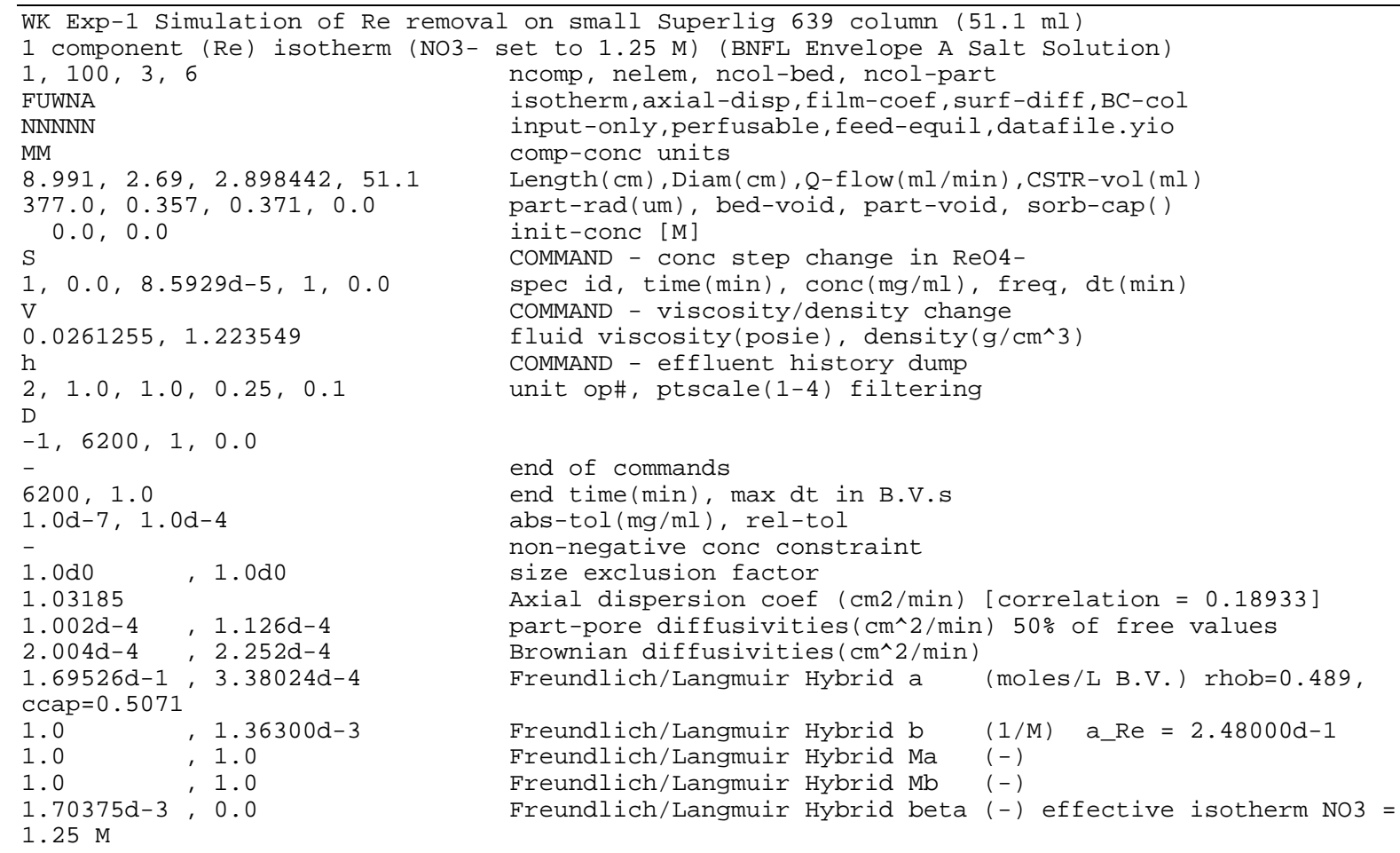

\section{VERSE Output for Intermediate-Scale Perrhenate Column (WK Exp-1) Test}

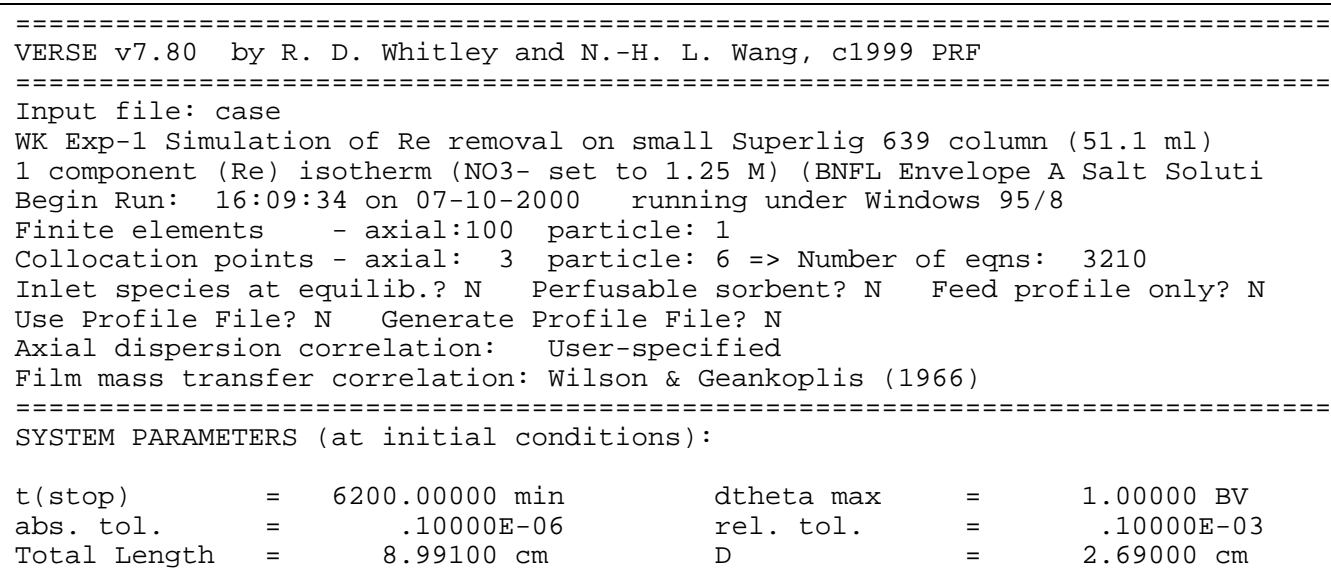




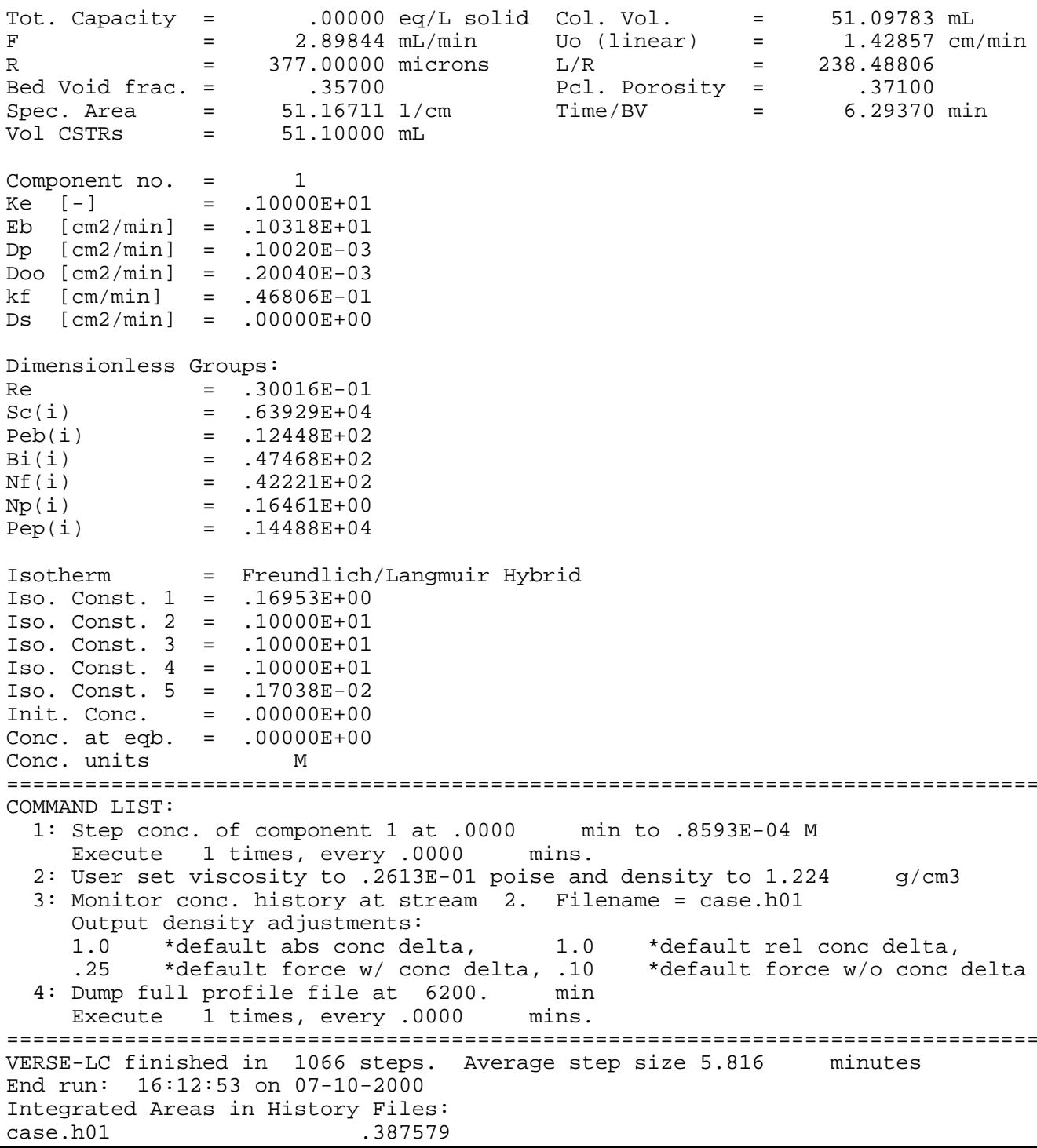

\section{VERSE Input for Intermediate-Scale Perrhenate Column (WK Exp-2) Test}

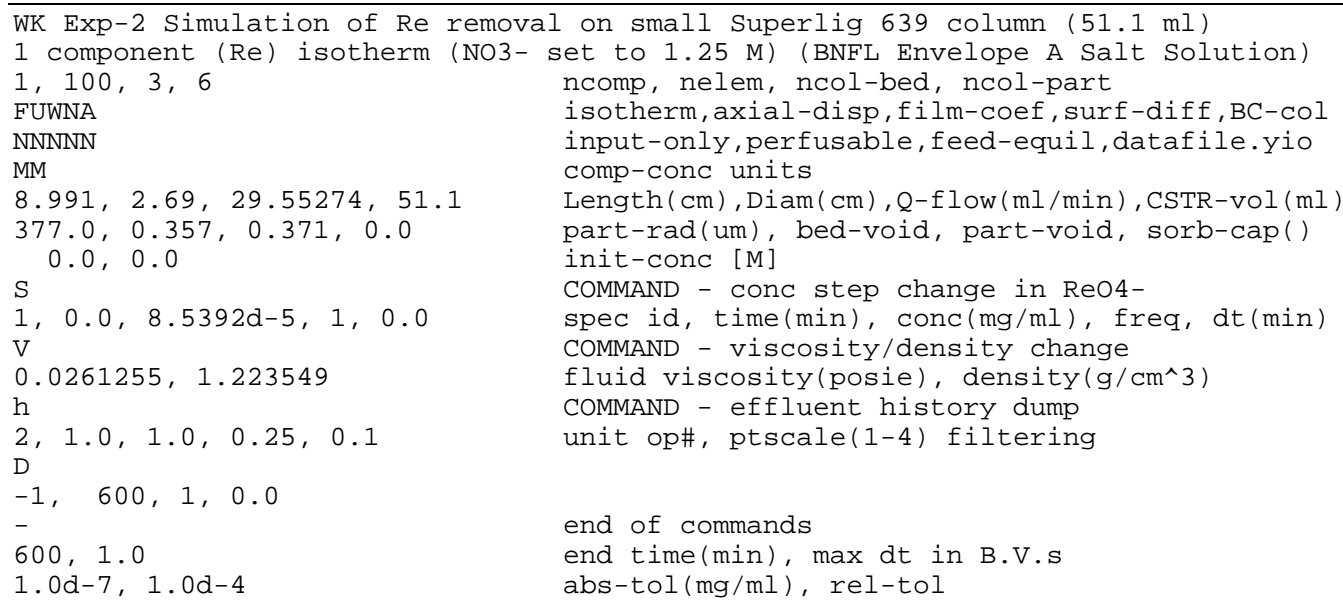


non-negative conc constraint

$1.0 \mathrm{~d} 0$, 1.0d0 size exclusion factor

$10.2013,1.126 \mathrm{~d}-4$
$1.002 \mathrm{~d}-4,4$

$2.004 d-4,2.252 d-4$

Axial dispersion coef $(\mathrm{cm} 2 / \mathrm{min})$ [correlation $=1.8718$ ]
part-pore diffusivities $\left(\mathrm{cm}^{\wedge} 2 / \mathrm{min}\right) \quad 50 \%$ of free values

$1.69526 \mathrm{~d}-1,3.38024 \mathrm{~d}-4$

Brownian diffusivities ( $\left.\mathrm{cm}^{\wedge} 2 / \mathrm{min}\right)$

$\mathrm{ccap}=0.5071$

$1.0 \quad, 1.36300 \mathrm{~d}-3$

Freundlich/Langmuir Hybrid a

(moles/L B.V.) rhob=0.489,

$1.0 \quad, 1.0$

\begin{tabular}{ll}
$1.0 \quad, 1.0$ \\
\hline $1.70375 d-3$,
\end{tabular}

Freundlich/Langmuir Hybrid b (1/M) a_Re $=2.48000 d-1$

$1.70375 d-3,0.0$

Freundlich/Langmuir Hybrid $\mathrm{Ma}$ (-) Freundlich/Langmuir Hybrid $\mathrm{Mb}$

$(-)$

$1.25 \mathrm{M}$

Freundlich/Langmuir Hybrid beta (-) effective isotherm NO3 =

\section{VERSE Output for Intermediate-Scale Perrhenate Column (WK Exp-2) Test}

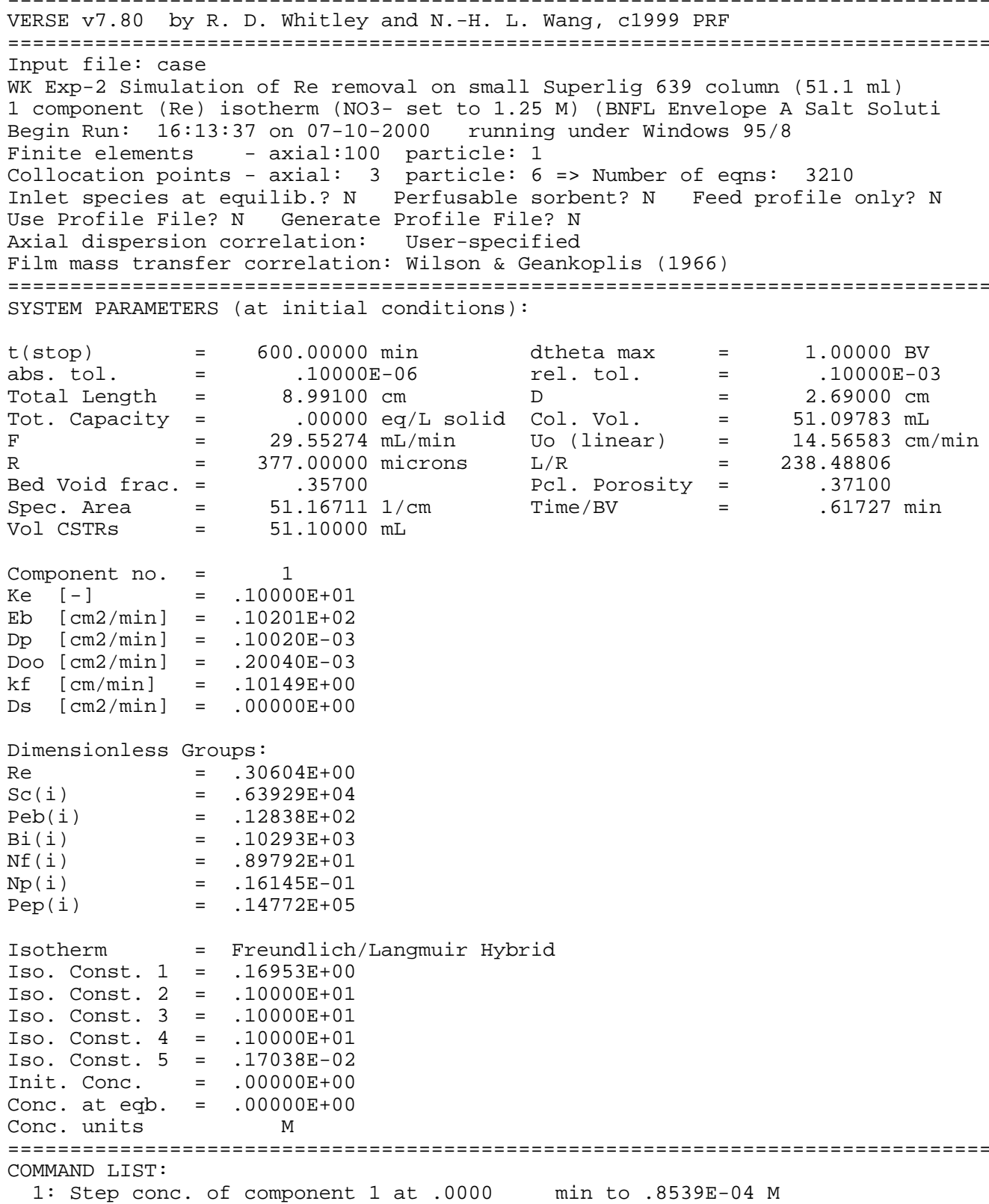




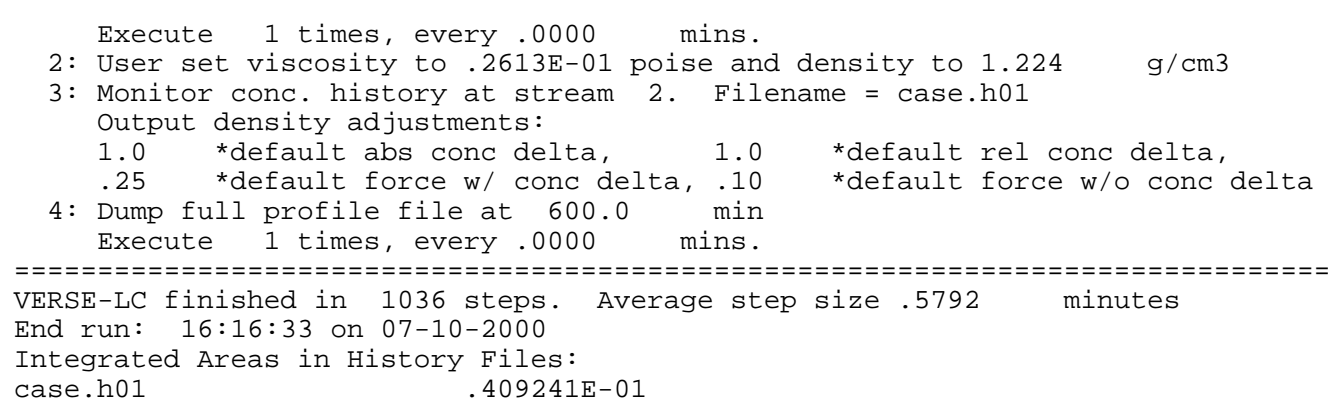

\section{VERSE Input for Intermediate-Scale Perrhenate Column (WK Exp-3) Test}

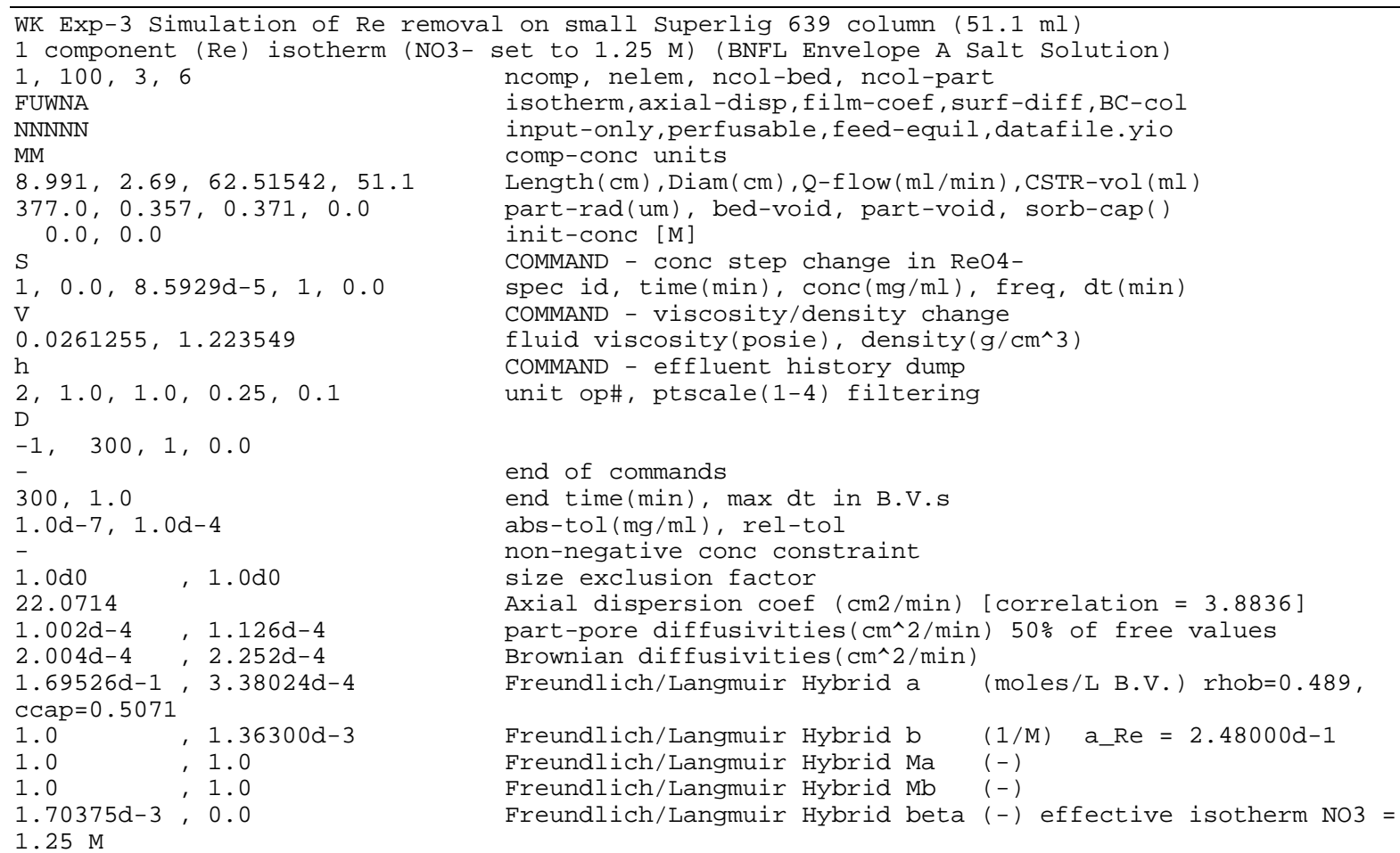

\section{VERSE Output for Intermediate-Scale Perrhenate Column (WK Exp-3) Test}

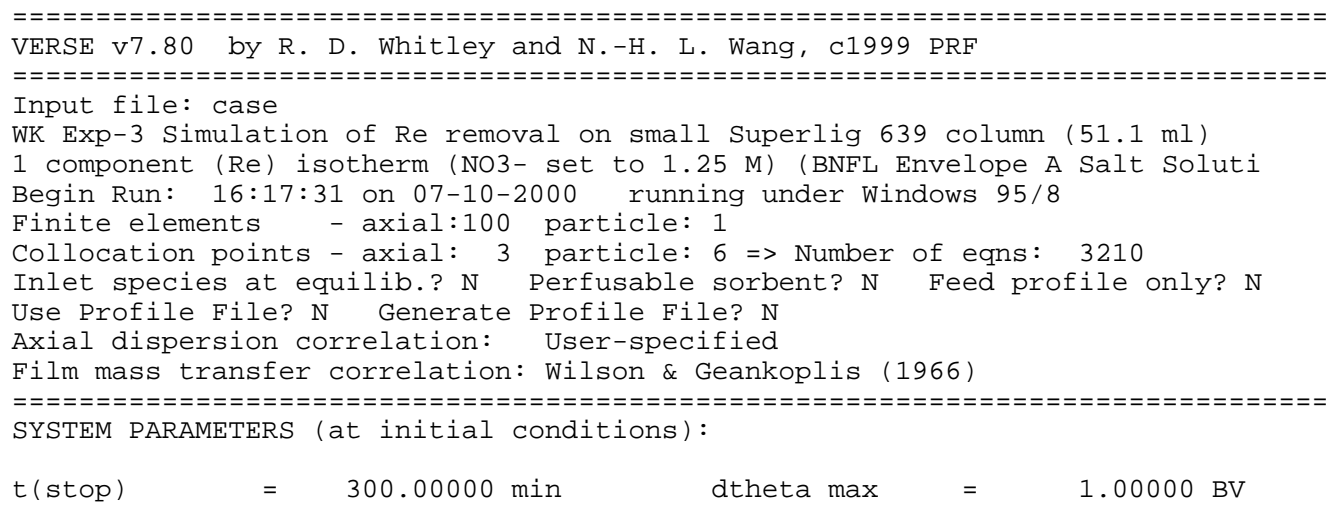




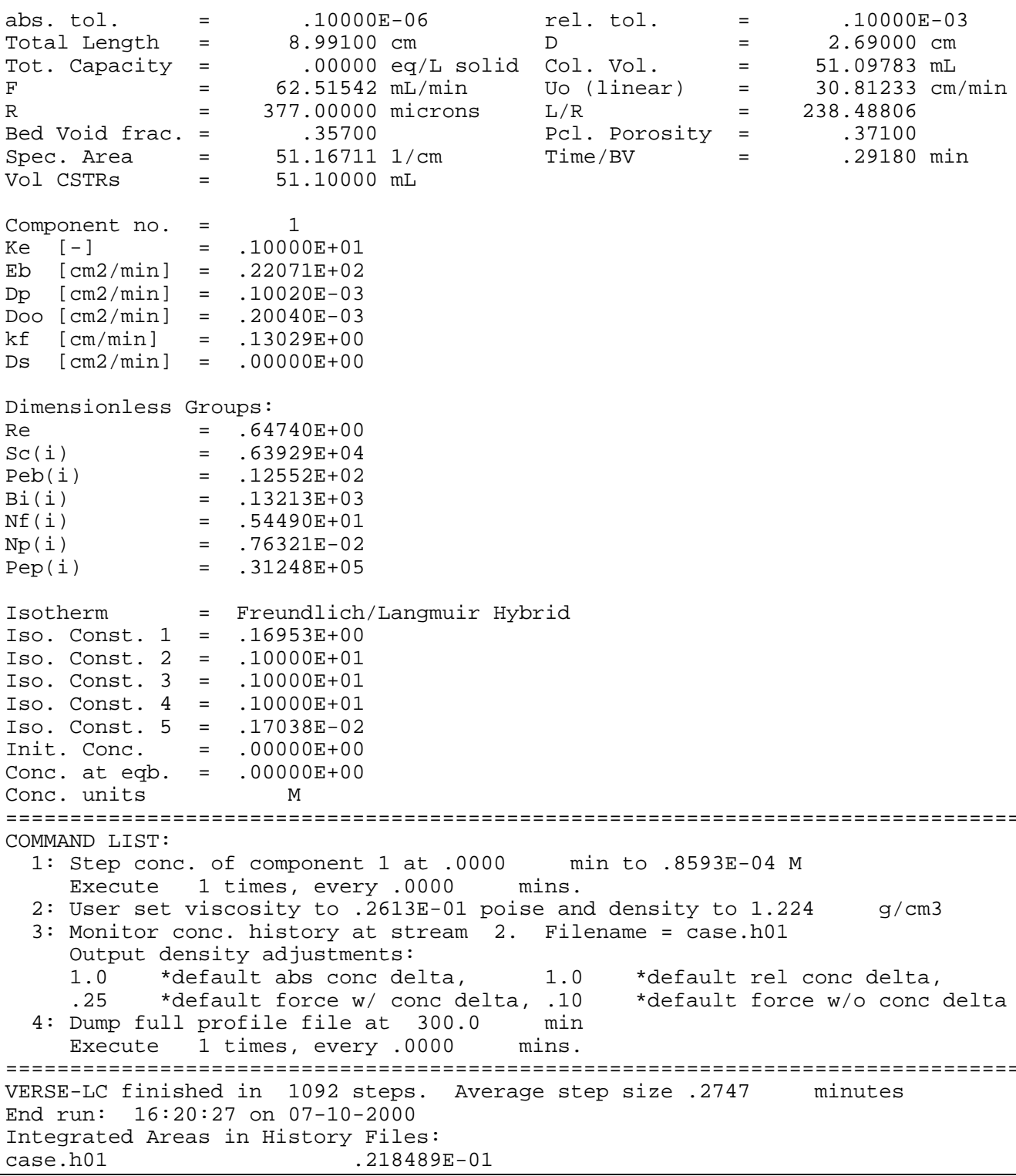

\section{VERSE Input for Intermediate-Scale Perrhenate Column (WK Exp-4) Test}

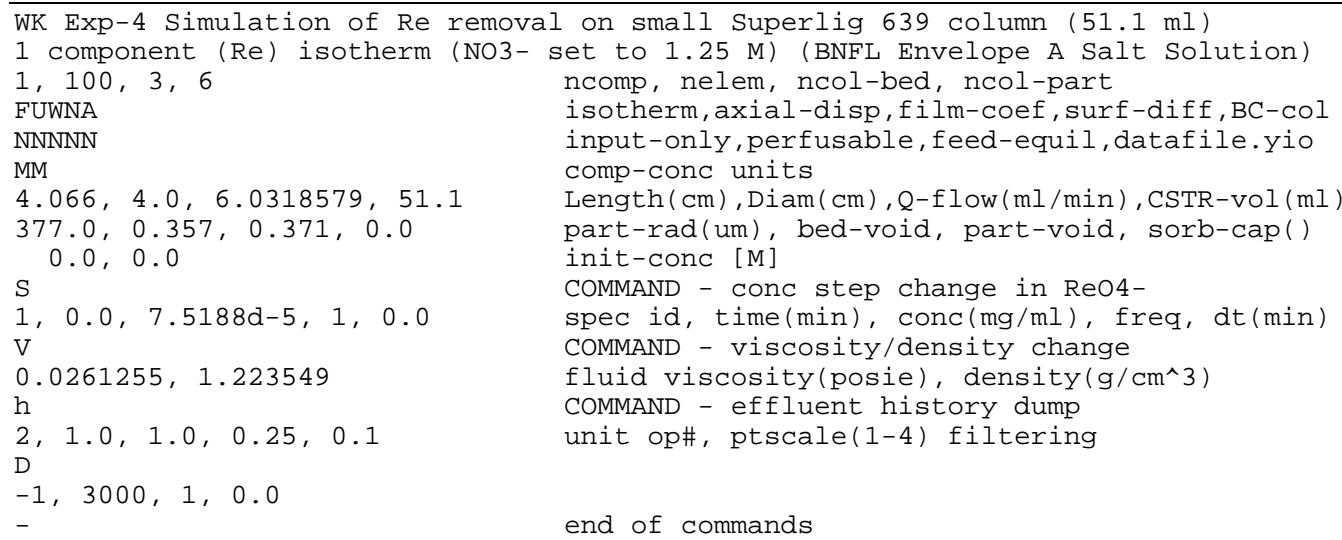




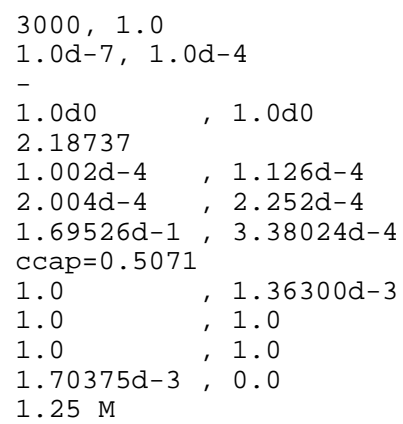

\section{VERSE Output for Intermediate-Scale Perrhenate Column (WK Exp-4) Test}

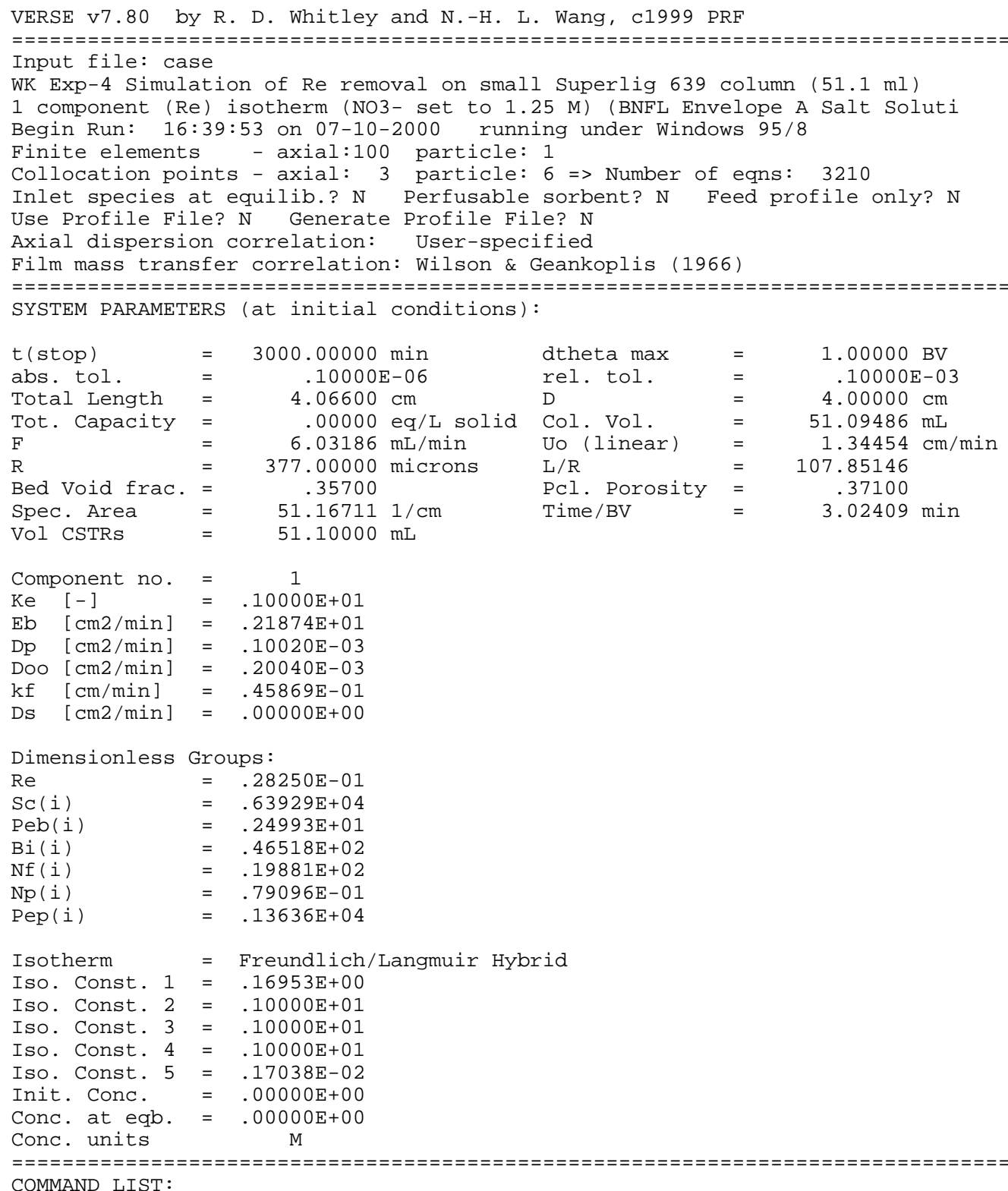


1: Step conc. of component 1 at .0000 min to.7519E-04 M Execute 1 times, every.0000 mins.

2: User set viscosity to .2613E-01 poise and density to $1.224 \mathrm{~g} / \mathrm{cm} 3$

3: Monitor conc. history at stream 2. Filename = case.h01 Output density adjustments:

1.0 *default abs conc delta, 1.0 *default rel conc delta

.25 *default force w/ conc delta, .10 *default force w/o conc delta

4: Dump full profile file at 3000 . min Execute 1 times, every .0000 mins.

\section{VERSE Input for Intermediate-Scale Perrhenate Column (WK Exp-5) Test}

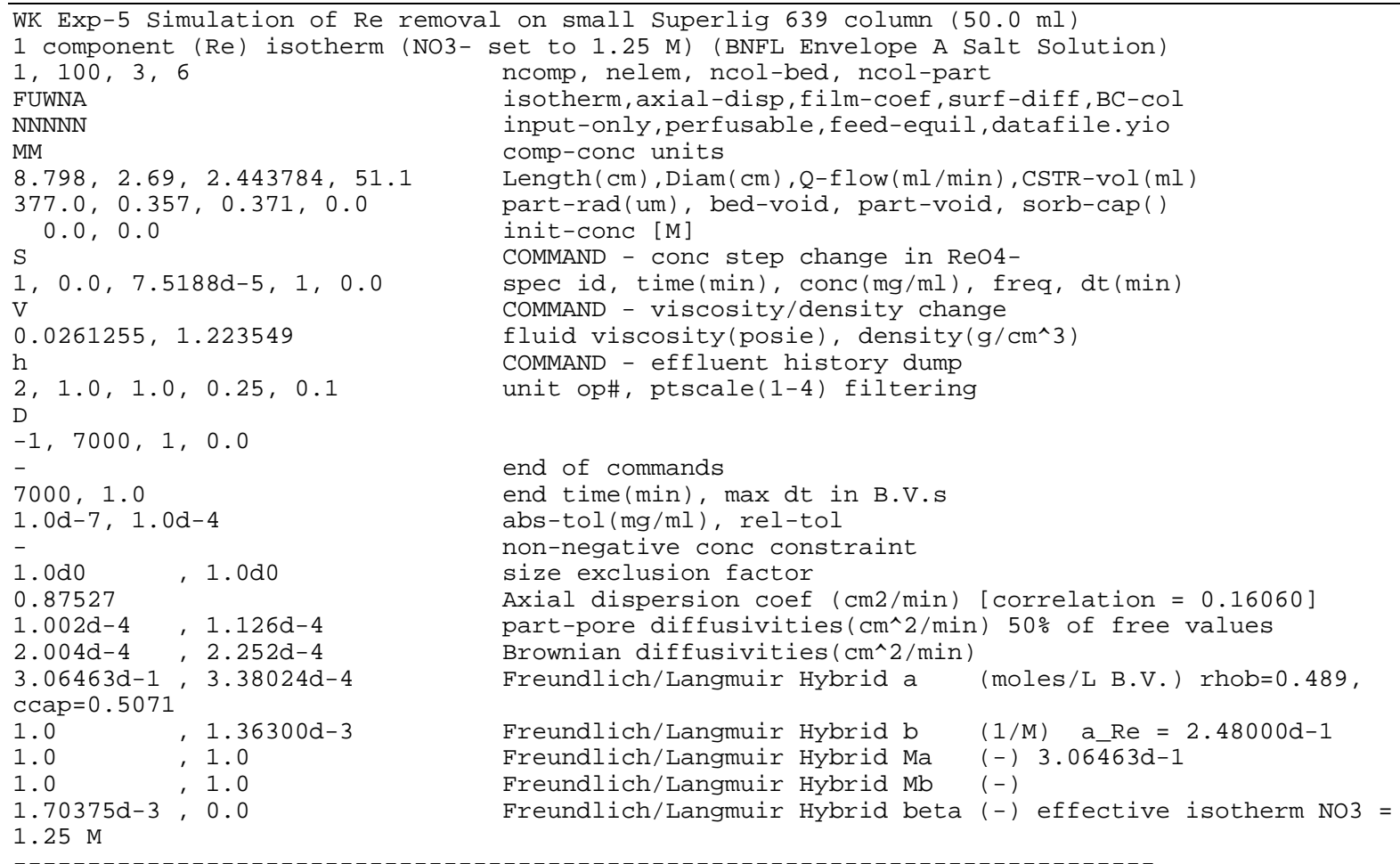

\section{VERSE Output for Intermediate-Scale Perrhenate Column (WK Exp-5) Test}

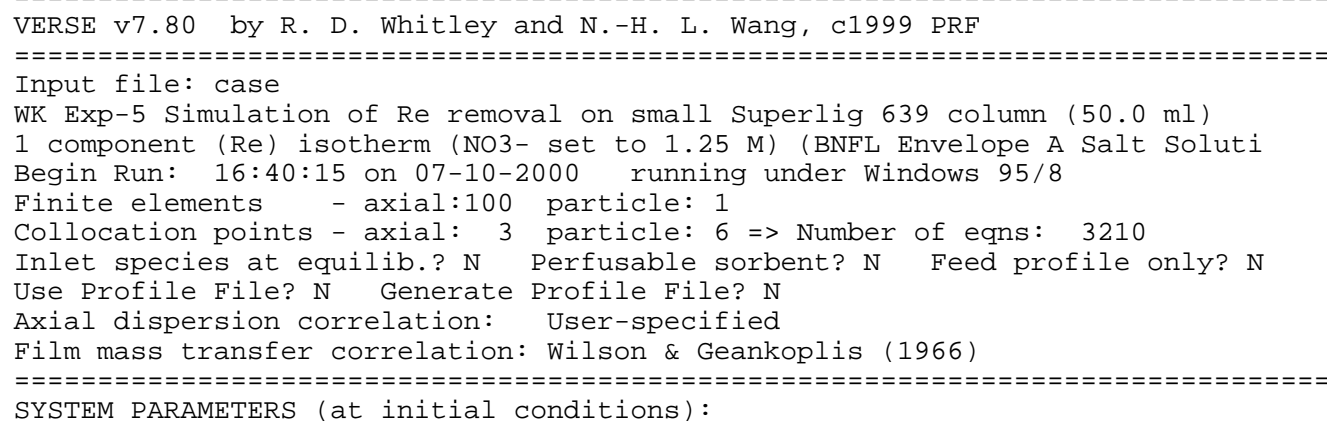




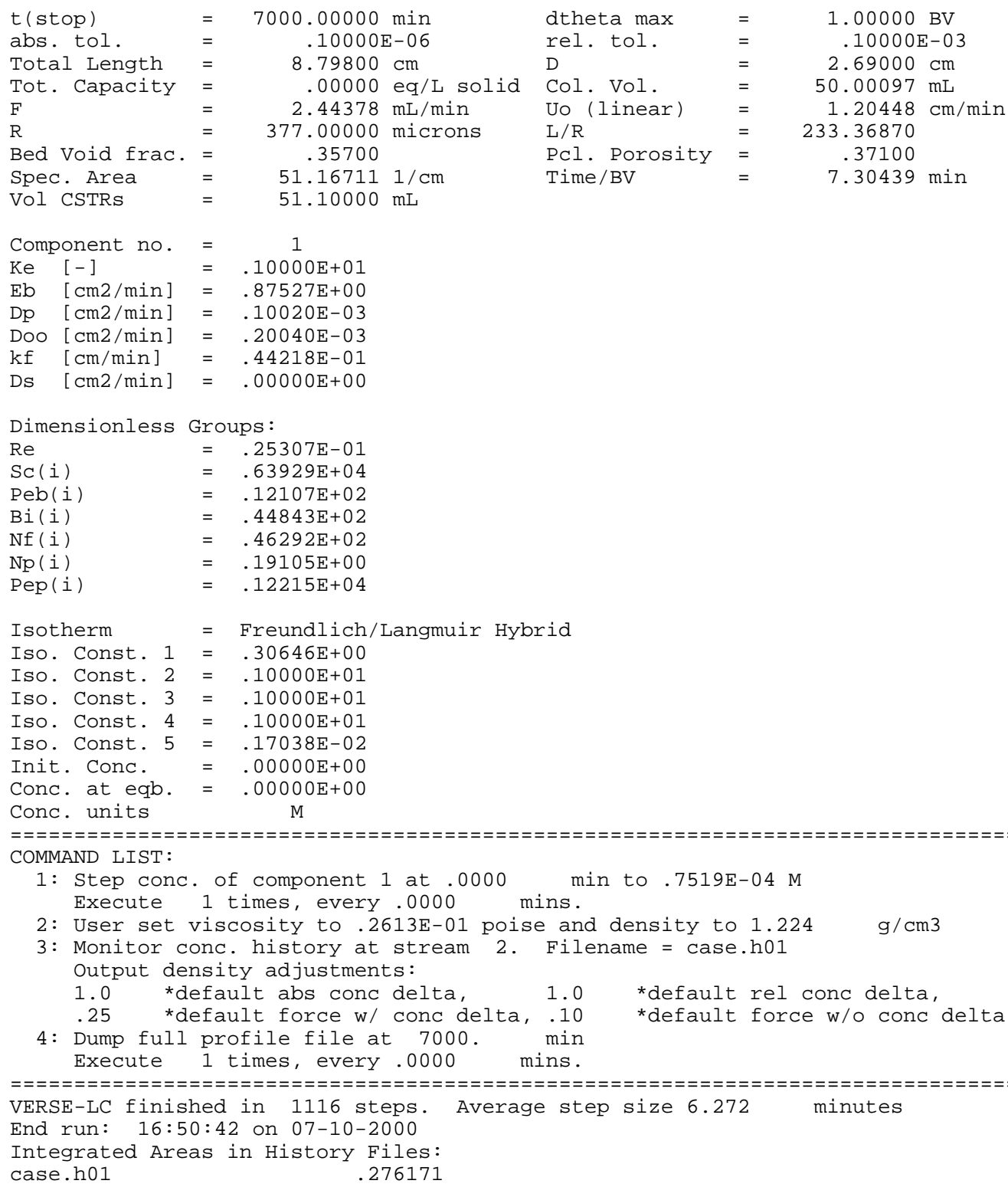

\section{VERSE Input for Intermediate-Scale Perrhenate Column (IBC Exp-1) Test}

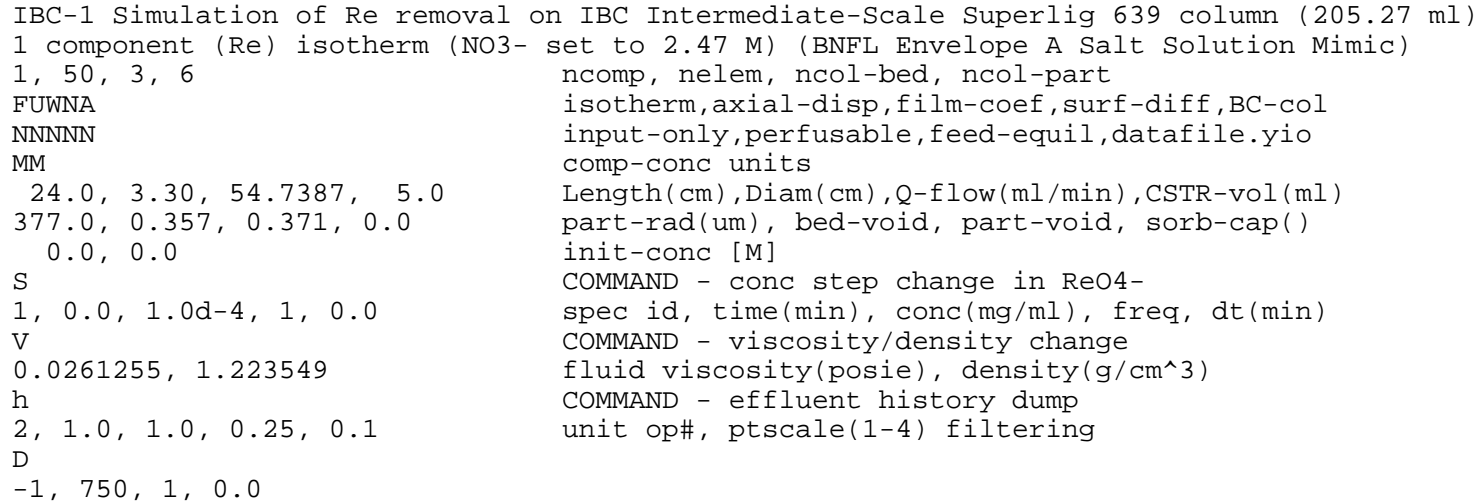


$750,1.0$

$1.0 \mathrm{~d}-7,1.0 \mathrm{~d}-4$

$-$

$1.0 \mathrm{~d} 0$

5.479

$1.002 \mathrm{~d}-4,1.126 \mathrm{~d}-4$

$2.004 \mathrm{~d}-4,2.252 \mathrm{~d}-4$

$4.03040 d-1,3.38024 d-4$

$\mathrm{ccap}=1.1742$

$1.0 \quad, 1.36300 \mathrm{~d}-3$

$1.0,1.0$

$1.0,1.0$

$3.36661 d-3,0.0$

$2.47 \mathrm{M}$ end of commands

end time (min), $\max d t$ in B.V.s

abs-tol (mg/ml), rel-tol

non-negative conc constraint

size exclusion factor

Axial dispersion coef $(\mathrm{cm} 2 / \mathrm{min})$ [correlation $=2.3325$ ]

part-pore diffusivities ( $\left.\mathrm{cm}^{\wedge} 2 / \mathrm{min}\right) 50 \%$ of free values

Brownian diffusivities $\left(\mathrm{cm}^{\wedge} 2 / \mathrm{min}\right)$

Freundlich/Langmuir Hybrid a (moles/L B.V.) rhob=0.4,

Freundlich/Langmuir Hybrid b $\quad(1 / \mathrm{M})$

Freundlich/Langmuir Hybrid $\mathrm{Ma}(-)$

Freundlich/Langmuir Hybrid Mb (-)

Freundlich/Langmuir Hybrid beta (-) effective isotherm NO3 =

\section{VERSE Output for Intermediate-Scale Perrhenate Column (IBC Exp-1) Test}

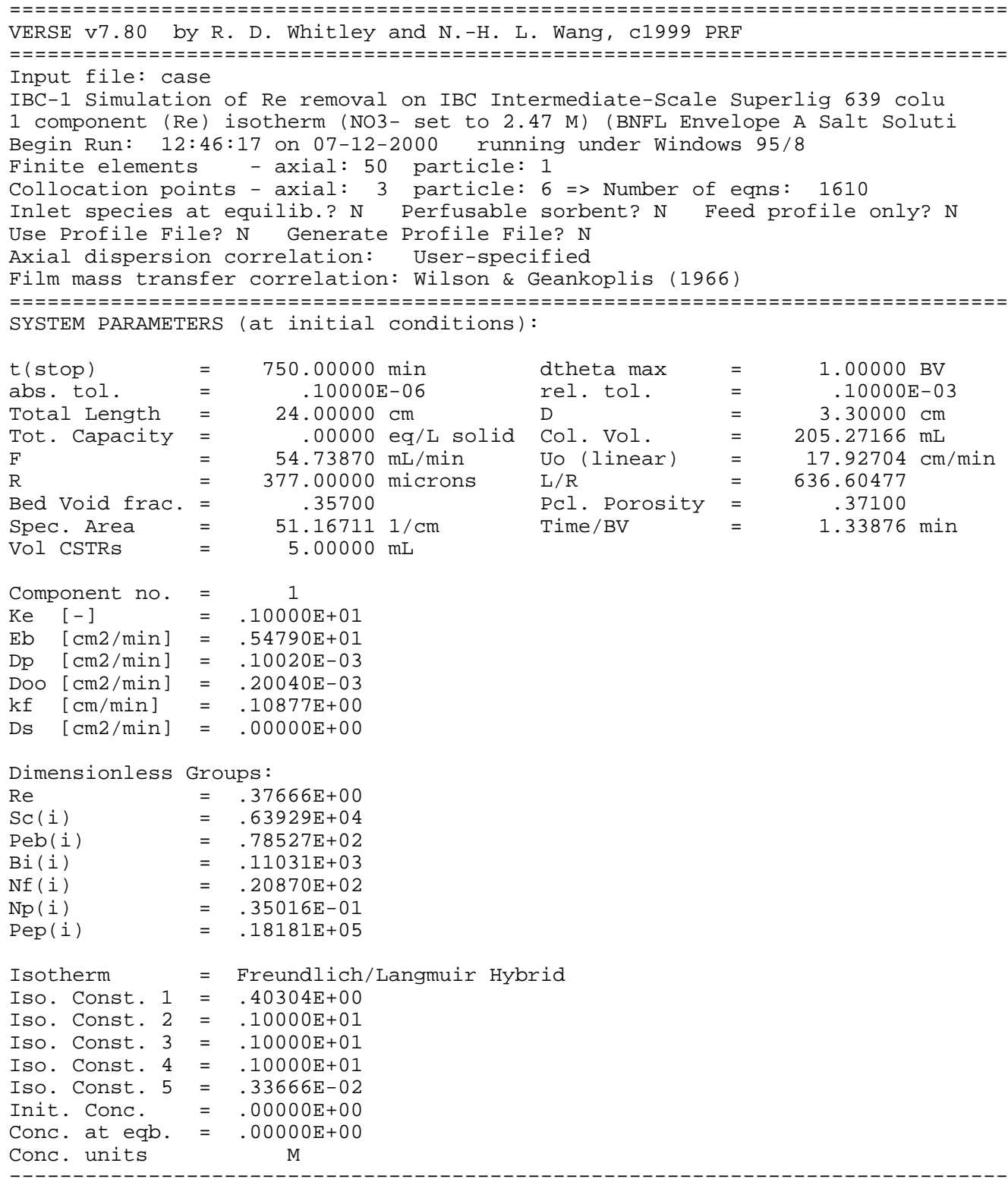




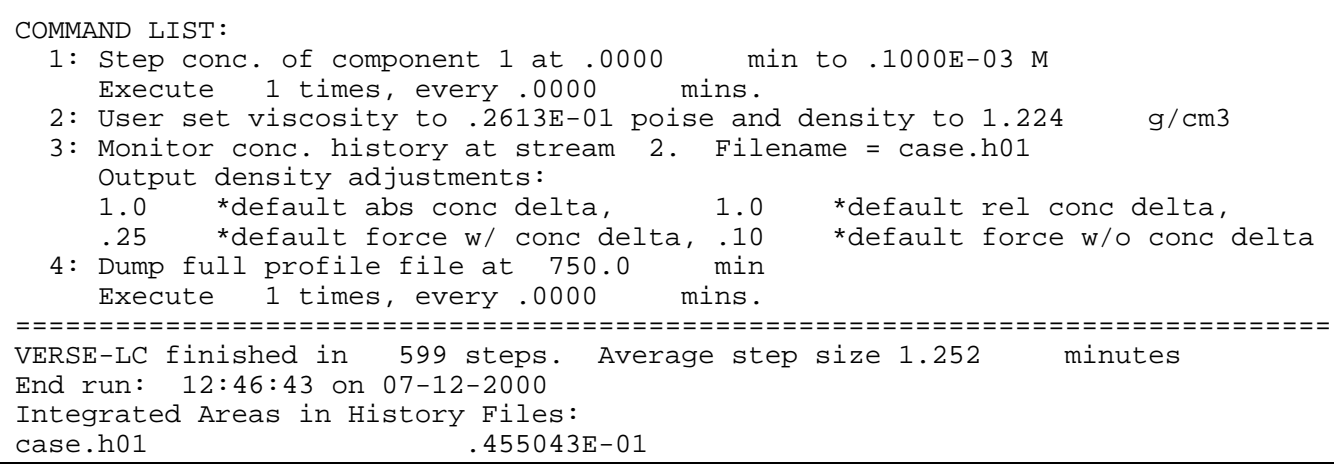

\title{
VERSE Input for Pilot-Scale Perrhenate Column (TFL Run-3) Test
}

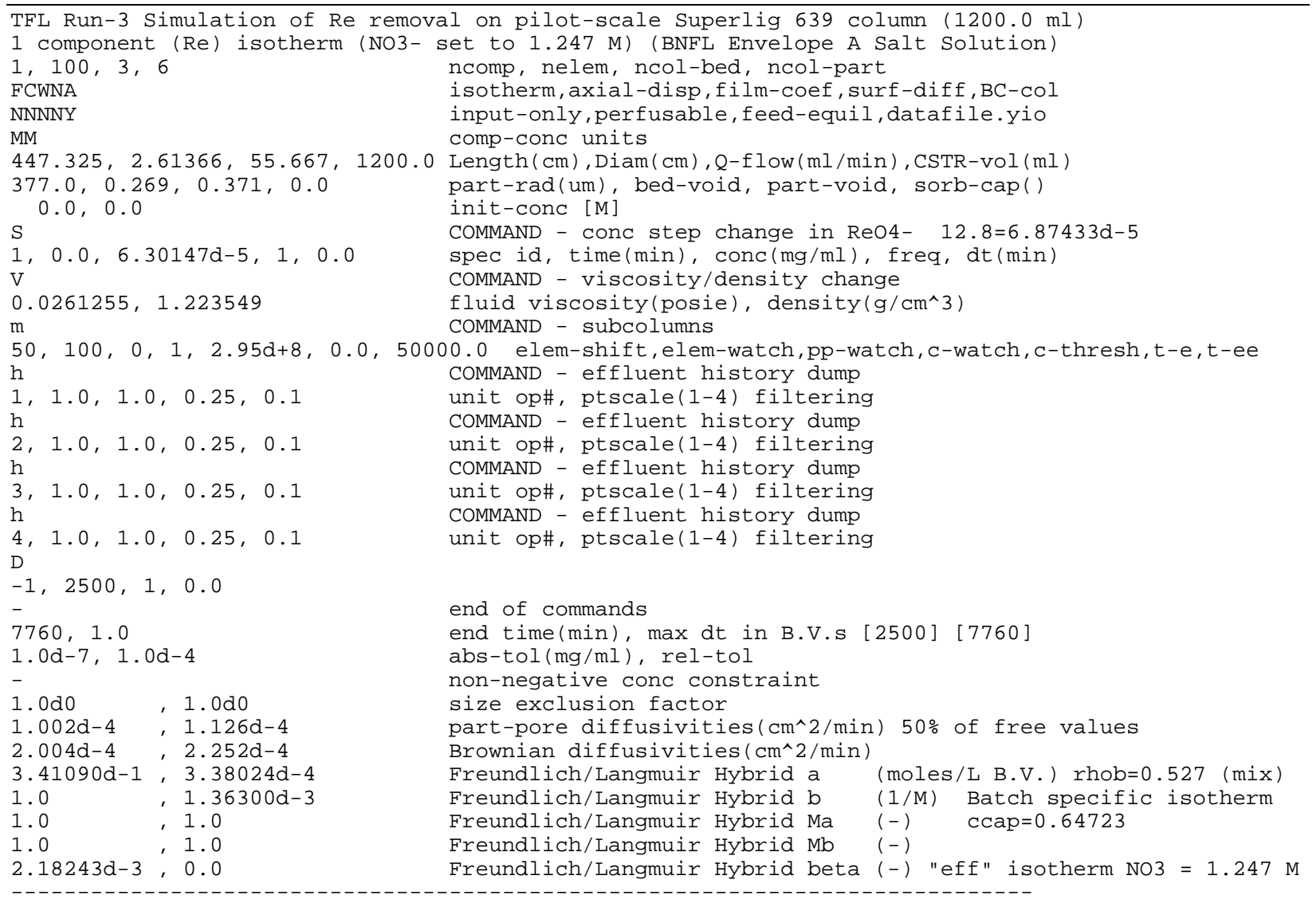

\section{VERSE Output for Pilot-Scale Perrhenate Column (TFL Run-3) Test}

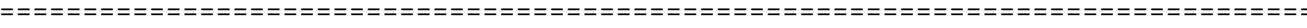 \\ VERSE V7.80 by R. D. Whitley and N.-H. L. Wang, c1999 PRF \\ Input file: case \\ TFL Run-3 Simulation of Re removal on pilot-scale Superlig 639 column (1200 \\ 1 component (Re) isotherm (NO3- set to 1.247 M) (BNFL Envelope A Salt Solut \\ Begin Run: 16:33:27 on 08-22-2000 running under Windows 95/8 \\ Finite elements - axial:100 particle: 1 \\ Collocation points - axial: 3 particle: $6=>$ Number of eqns: 3219 \\ Inlet species at equilib.? $\mathrm{N}$ Perfusable sorbent? $\mathrm{N}$ Feed profile only? $\mathrm{N}$
}


Use Profile File? N Generate Profile File? Y

Axial dispersion correlation: Chung \& Wen (1968)

Film mass transfer correlation: Wilson \& Geankoplis (1966)

Sub-Column Boundary Conditions: Axial Dispersion and CSTR

SYSTEM PARAMETERS (at initial conditions)

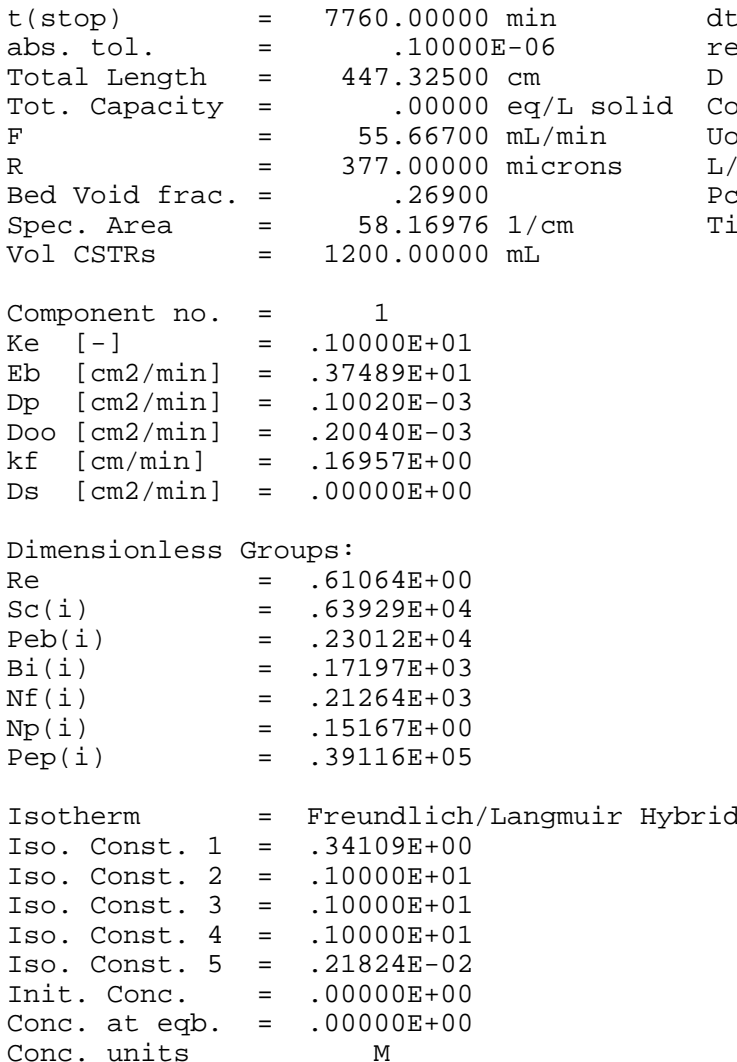

dtheta $\max =1.00000 \mathrm{BV}$

rel. tol. $=.10000 \mathrm{E}-03$ $\mathrm{D}$

Col. Vol.

Uo (linear)

$\mathrm{L} / \mathrm{R}$

Pcl. Porosity =

Time/BV =

$2.61366 \mathrm{~cm}$

$2399.99996 \mathrm{mI}$

$38.57070 \mathrm{~cm} / \mathrm{min}$

11865.38462

.37100

$5.79877 \mathrm{~min}$

$=========$
COMMAND LIST:

1: Step conc. of component 1 at .0000 min to .6301E-04 M

Execute 1 times, every .0000 mins.

2: User set viscosity to .2613E-01 poise and density to $1.224 \mathrm{~g} / \mathrm{cm} 3$

3: Carousel (conc.). Active between $t=.0000$ and .5000E+05 min. When comp. 1 reaches .2950E+09 $\mathrm{M}$ at end of node 100, shift 50 axial elements out the feed end

4: Monitor conc. history at stream 1. Filename $=$ case.h01 Output density adjustments:

1.0 *default abs conc delta, 1.0 *default rel conc delta, .25 *default force w/ conc delta, .10 *default force w/o conc delta

5: Monitor conc. history at stream 2. Filename = case.h02 Output density adjustments:

1.0 *default abs conc delta, 1.0 *default rel conc delta, .25 *default force w/ conc delta, .10 *default force w/o conc delta

6: Monitor conc. history at stream 3. Filename $=$ case.h03 Output density adjustments:

1.0 *default abs conc delta, 1.0 *default rel conc delta, .25 *default force w/ conc delta, .10 *default force w/o conc delta

7: Monitor conc. history at stream 4. Filename = case.h04 Output density adjustments:

1.0 *default abs conc delta, 1.0 *default rel conc delta, .25 *default force w/ conc delta, .10 *default force w/o conc delta

8: Dump full profile file at 2500. min Execute 1 times, every .0000 mins.

VERSE-LC finished in 1351 steps. Average step size 5.744 minutes

End run: 16:35:11 on 08-22-2000

Integrated Areas in History Files:

case.h01 .487615 
case.h02 .282844

case.h03 .281522

case.h04 $\quad .110606$

\section{VERSE Input for Pilot-Scale Perrhenate Column (TFL Run-2R) Test}

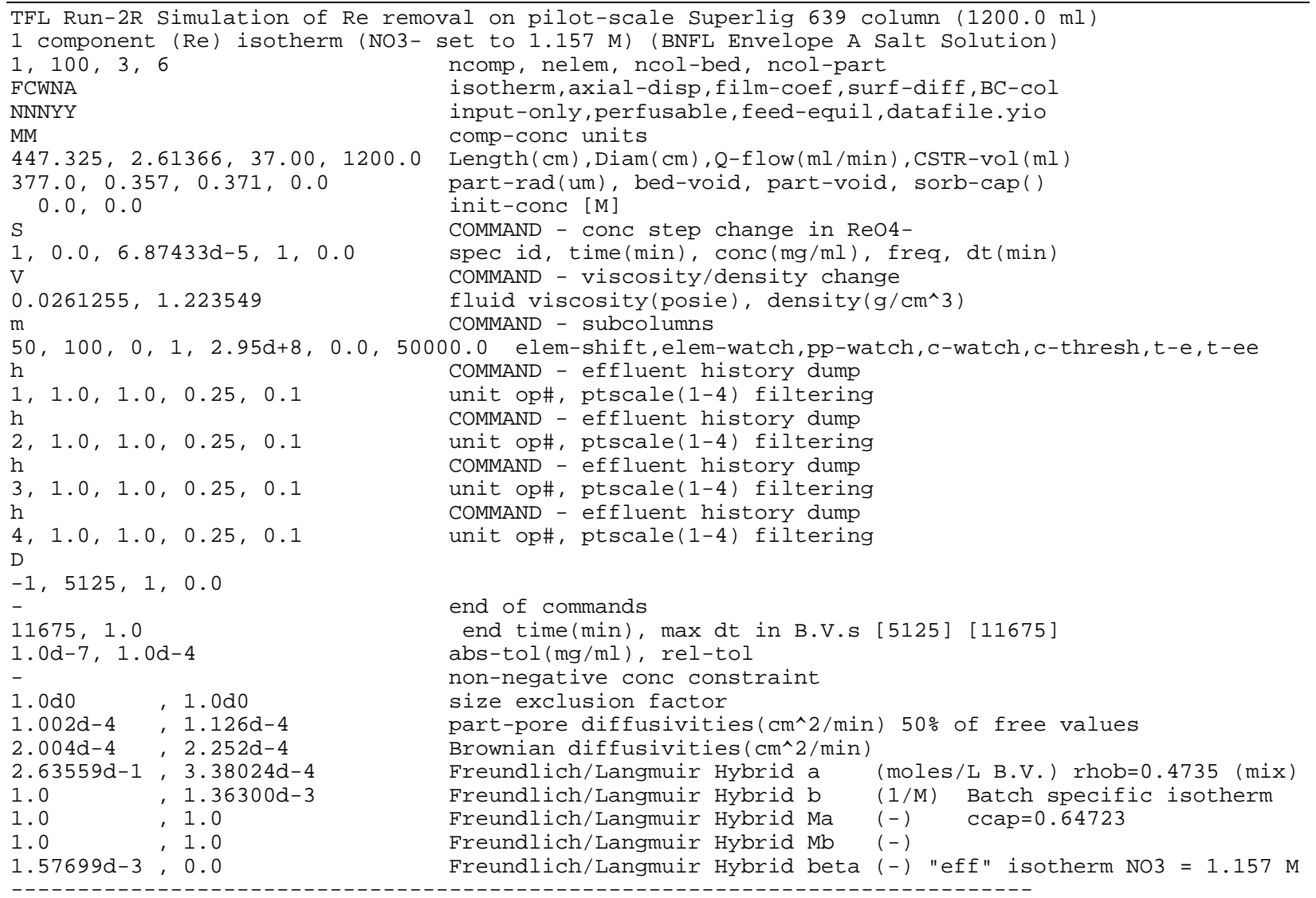

\section{VERSE Output for Pilot-Scale Perrhenate Column (TFL Run-2R) Test}

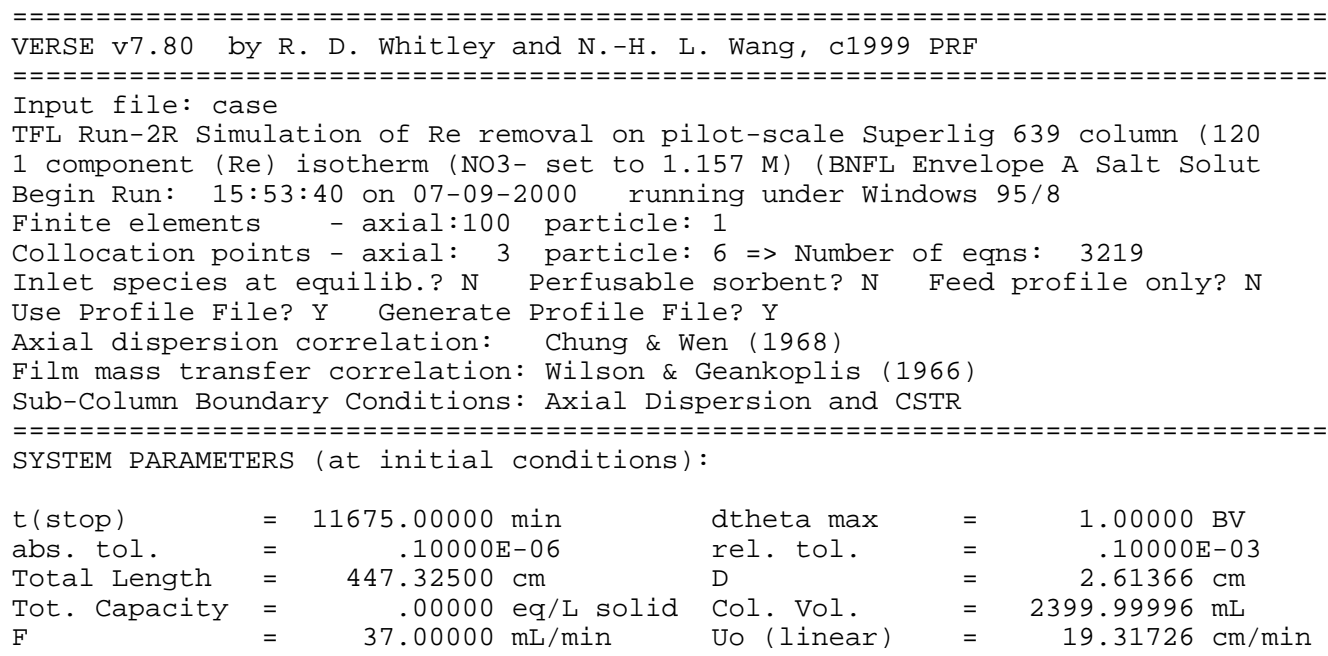




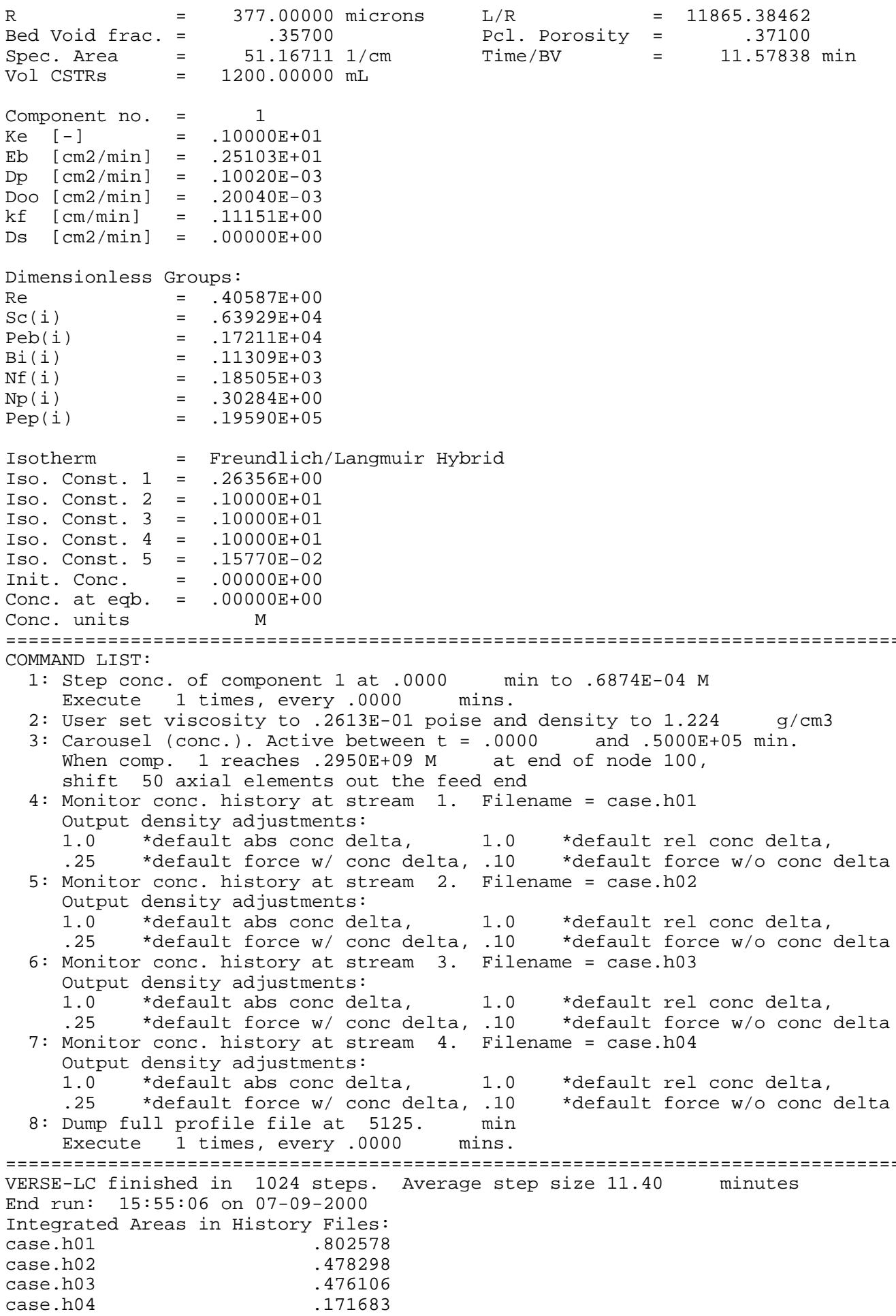

\section{VERSE Input for Pilot-Scale Perrhenate Column (TFL Run-4) Test}

TFL Run-4 Simulation of Re removal on pilot-scale Superlig 639 column (1200.0 ml)

1 component (Re) isotherm (NO3- set to $1.247 \mathrm{M}$ ) (BNFL Envelope A Salt Solution)

$1,100,3,6$ ncomp, nelem, ncol-bed, ncol-part

FCWNA isotherm, axial-disp, film-coef, surf-diff,BC-col 


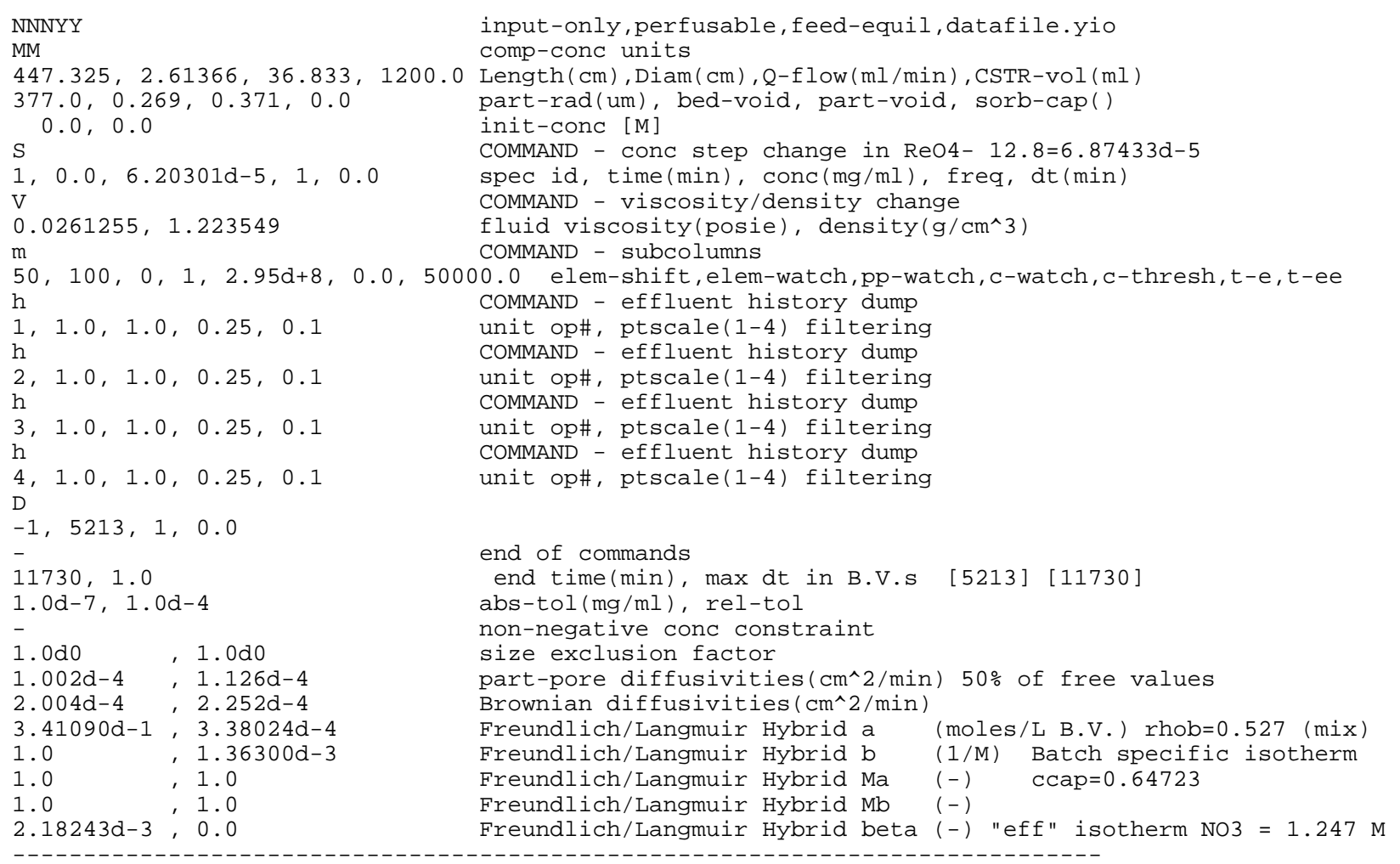

\section{VERSE Output for Pilot-Scale Perrhenate Column (TFL Run-4) Test}

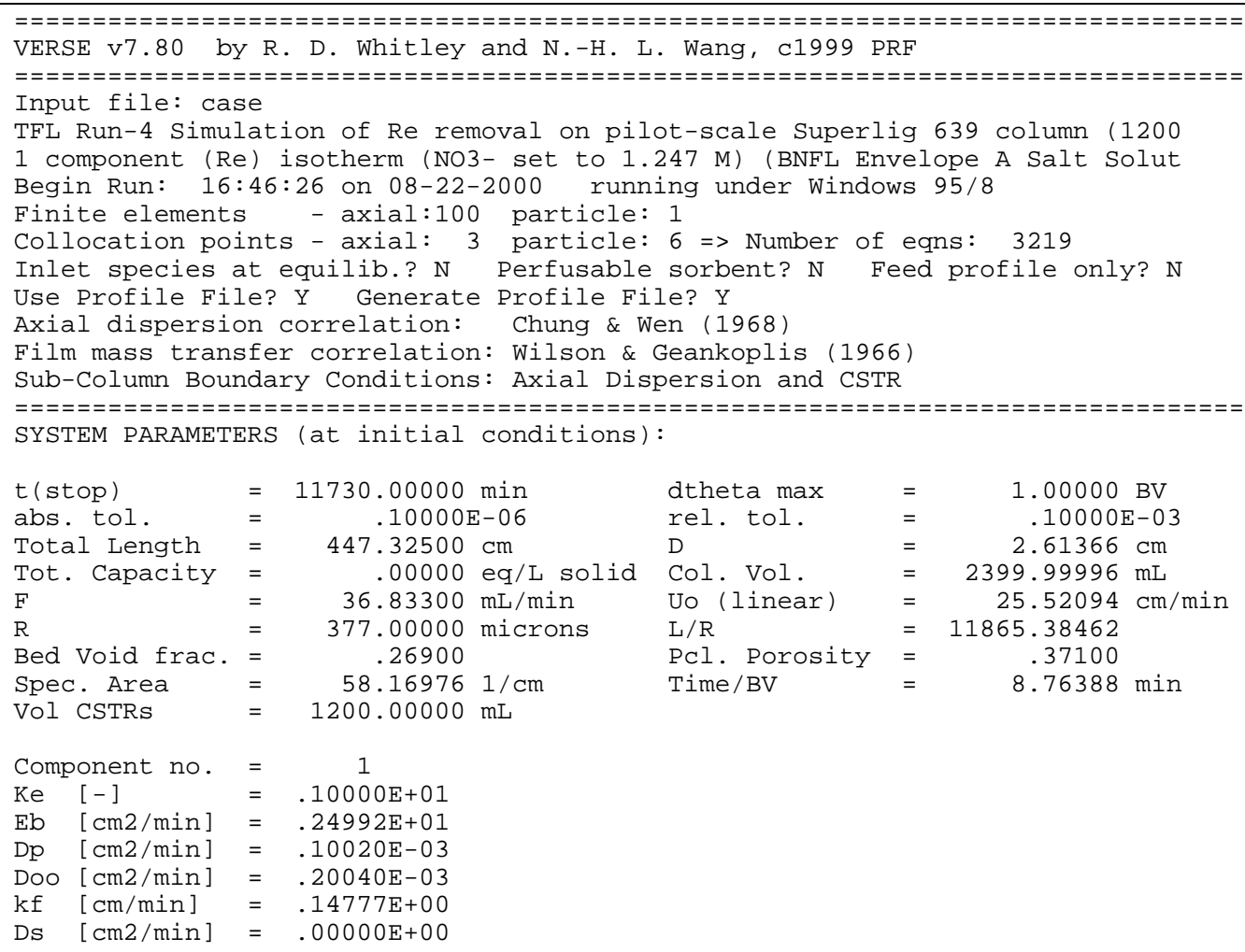




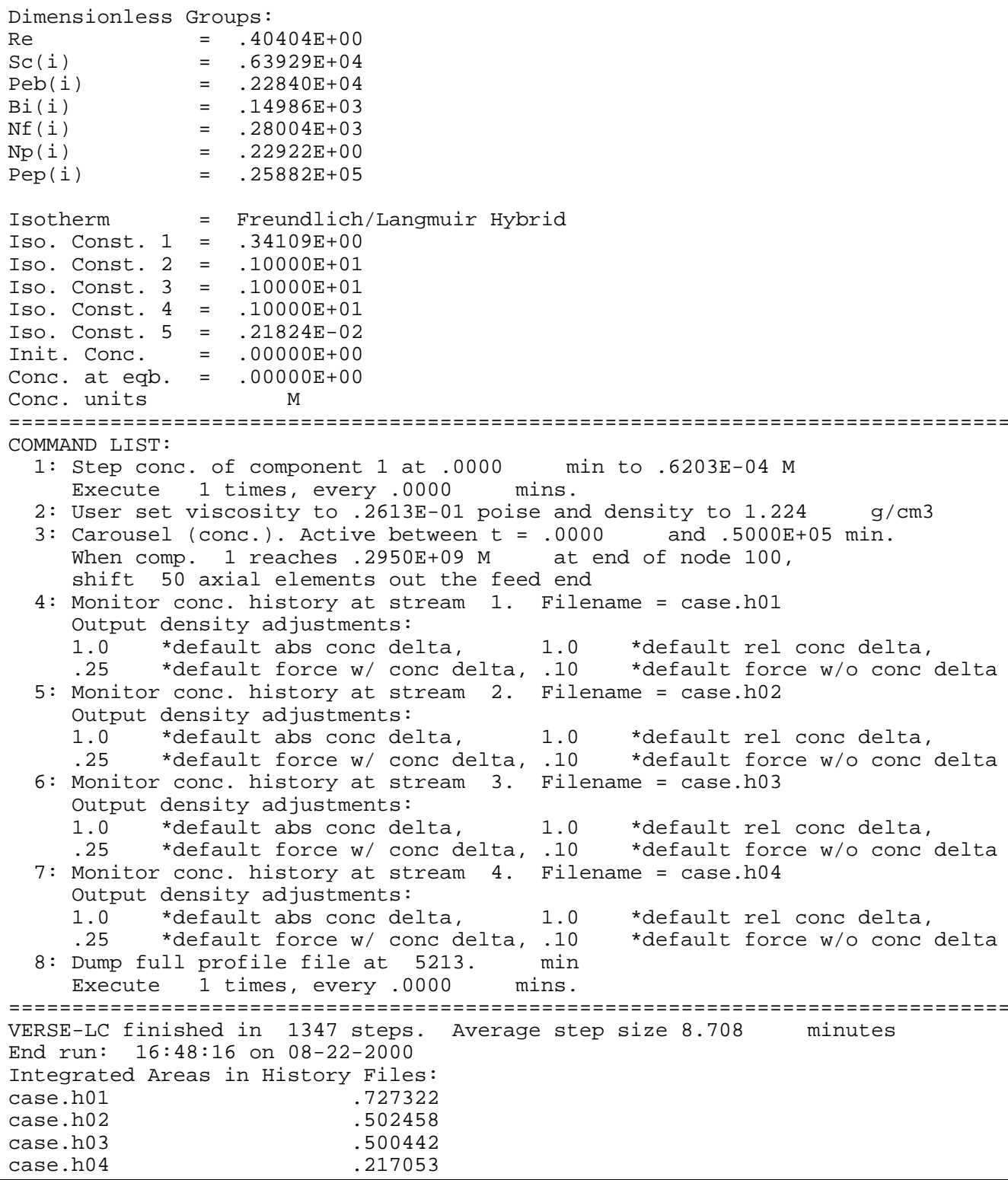

\section{VERSE Input for Pilot-Scale Perrhenate Column (TFL Run-5) Test}

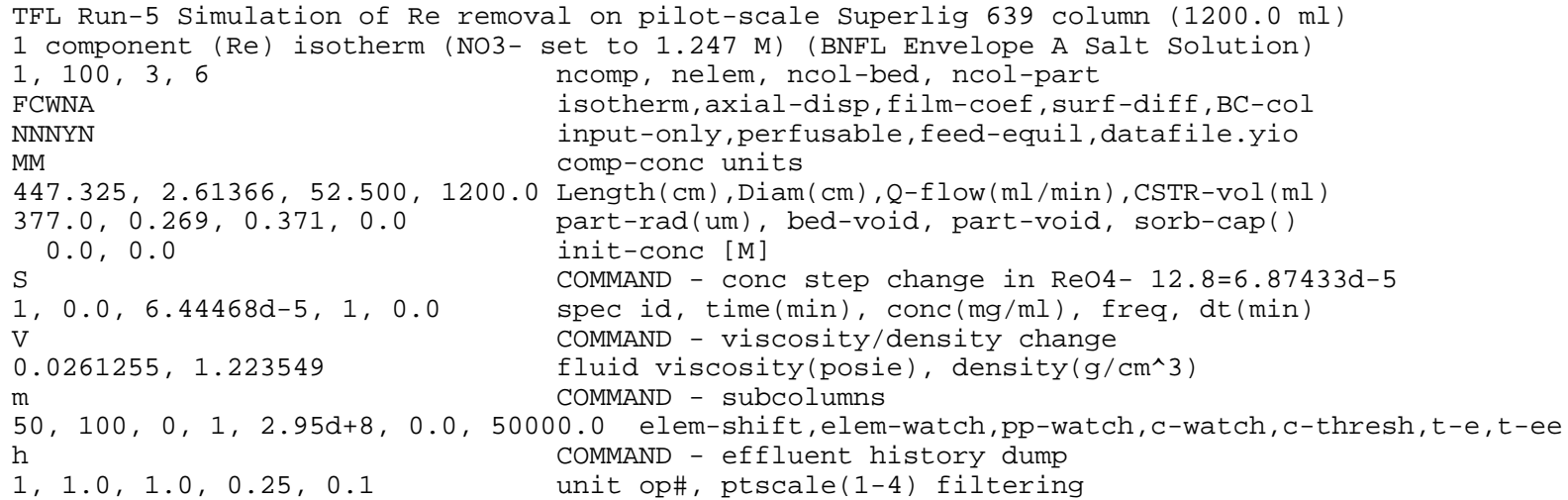


$\mathrm{h}$

$2,1.0,1.0,0.25,0.1$

$\mathrm{h}$

$3,1.0,1.0,0.25,0.1$

$4,1.0,1.0,0.25,0.1$

D

$-1,3018,1,0.0$

$8230,1.0$

$1.0 \mathrm{~d}-7,1.0 \mathrm{~d}-4$

$-$

$1.0 \mathrm{~d} 0 \quad, 1.0 \mathrm{~d} 0$

$1.002 \mathrm{~d}-4,1.126 \mathrm{~d}-4$

$2.004 d-4,2.252 d-4$

$3.41090 \mathrm{~d}-1,3.38024 \mathrm{~d}-4$

$1.0 \quad, 1.36300 \mathrm{~d}-3$

$\begin{array}{ll}1.0 & , \\ 1.0 & 1.0\end{array}$

$1.0,1.0$

$2.18243 d-3,0.0$
COMMAND - effluent history dump

unit op\#, ptscale(1-4) filtering

COMMAND - effluent history dump

unit op\#, ptscale(1-4) filtering

COMMAND - effluent history dump

unit op\#, ptscale(1-4) filtering

end of commands

end time(min), max dt in B.V.s [3018] [8230]

$\mathrm{abs}-\mathrm{tol}(\mathrm{mg} / \mathrm{ml})$, rel-tol

non-negative conc constraint

size exclusion factor

part-pore diffusivities $\left(\mathrm{cm}^{\wedge} 2 / \mathrm{min}\right) 50 \%$ of free values

Brownian diffusivities ( $\left.\mathrm{cm}^{\wedge} 2 / \mathrm{min}\right)$

Freundlich/Langmuir Hybrid a (moles/L B.V.) rhob=0.527 (mix)

Freundlich/Langmuir Hybrid b (1/M) Batch specific isotherm

Freundlich/Langmuir Hybrid Ma $\quad(-) \quad$ cCap $=0.64723$

Freundlich/Langmuir Hybrid $\mathrm{Mb} \quad(-)$

Freundlich/Langmuir Hybrid beta (-) "eff" isotherm NO3 = $1.247 \mathrm{M}$

\section{VERSE Output for Pilot-Scale Perrhenate Column (TFL Run-5) Test}

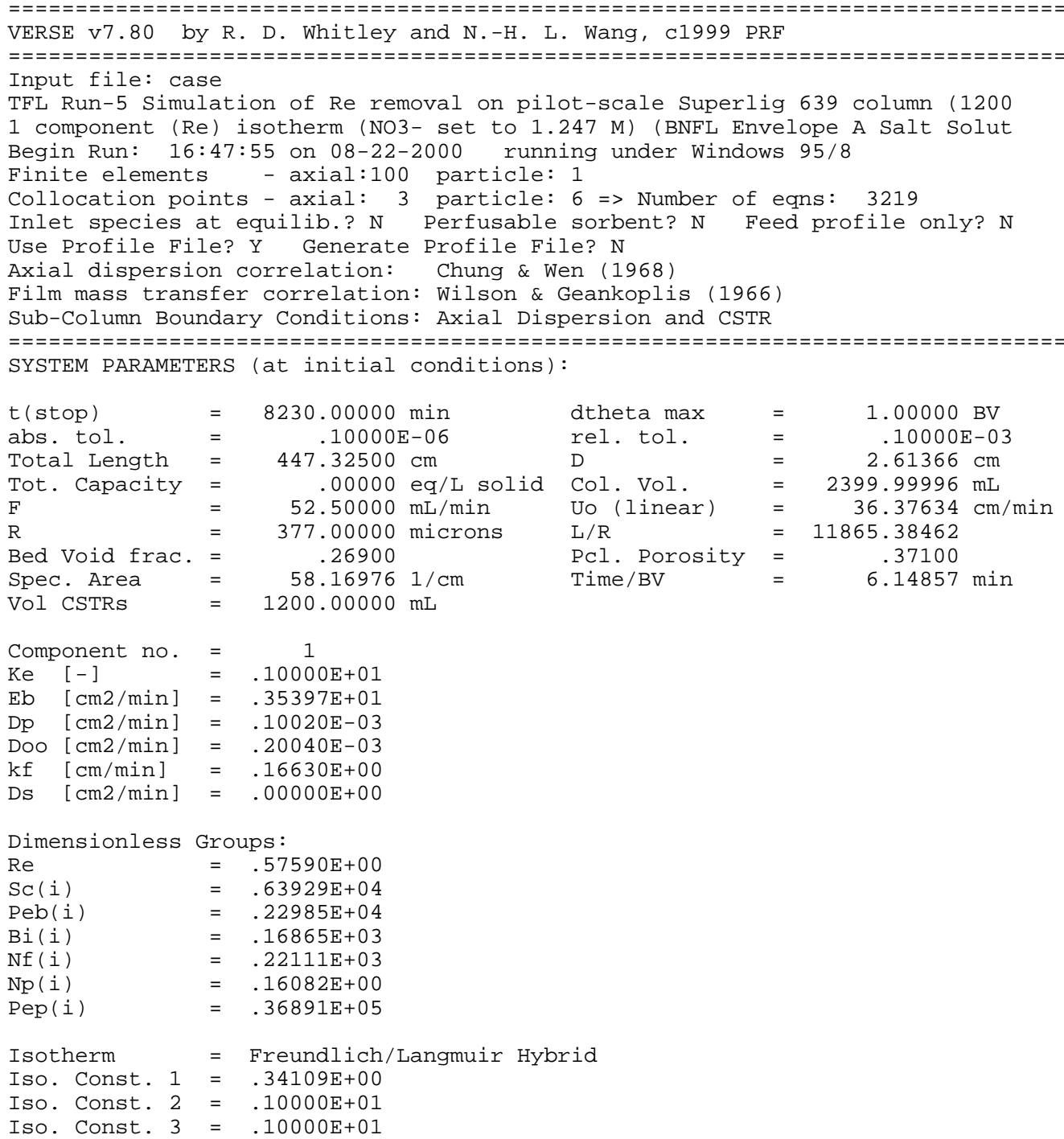




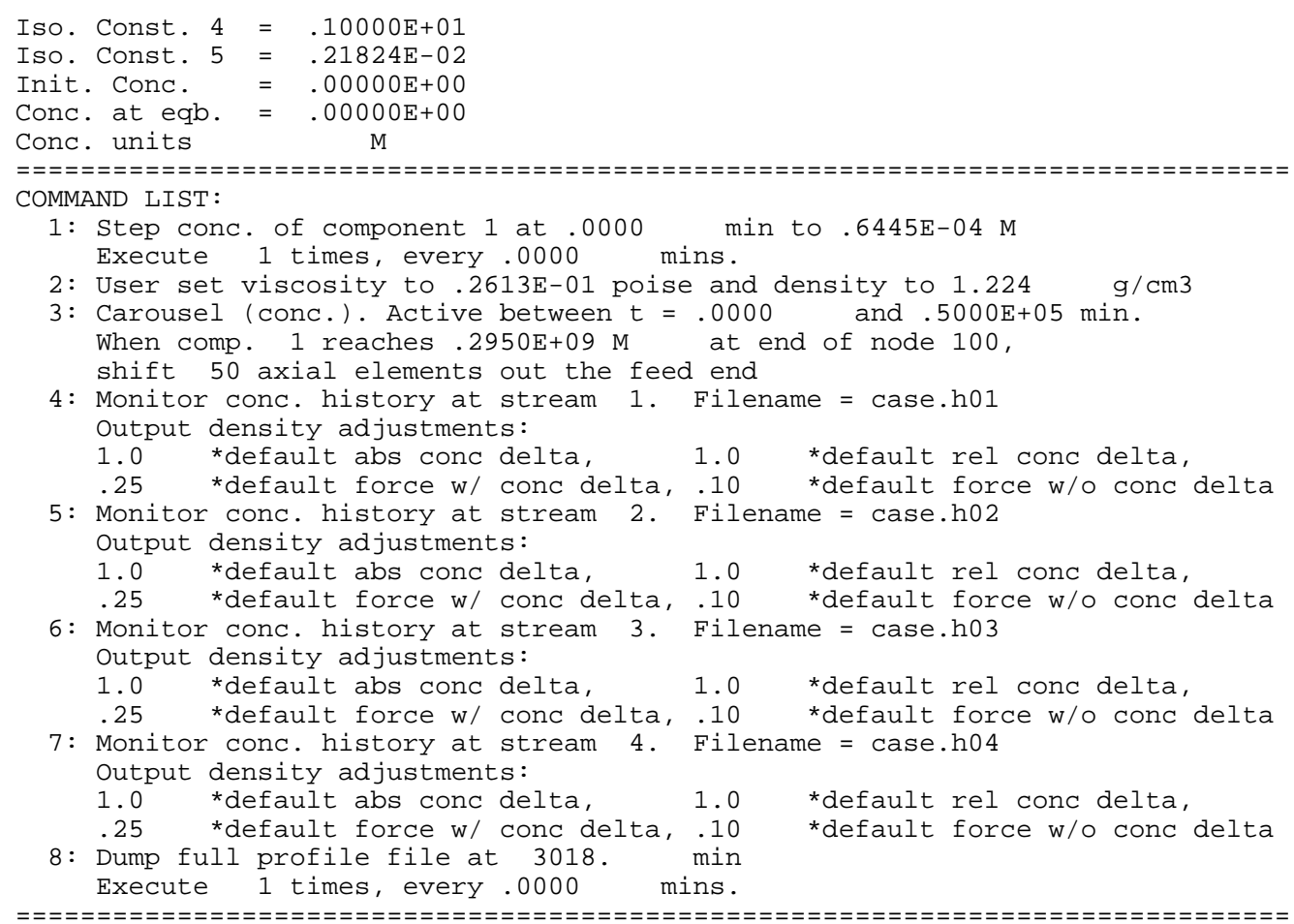

VERSE-LC finished in 1349 steps. Average step size 6.101 minutes

End run: $16: 49: 46$ on $08-22-2000$

Integrated Areas in History Files:

case.h01 .530338

case.h02 $\quad .386538$

case.h03 .385068

case.h04 .182345

\section{VERSE Input for Pilot-Scale Perrhenate Column (TFL Run-6: trans) Test}

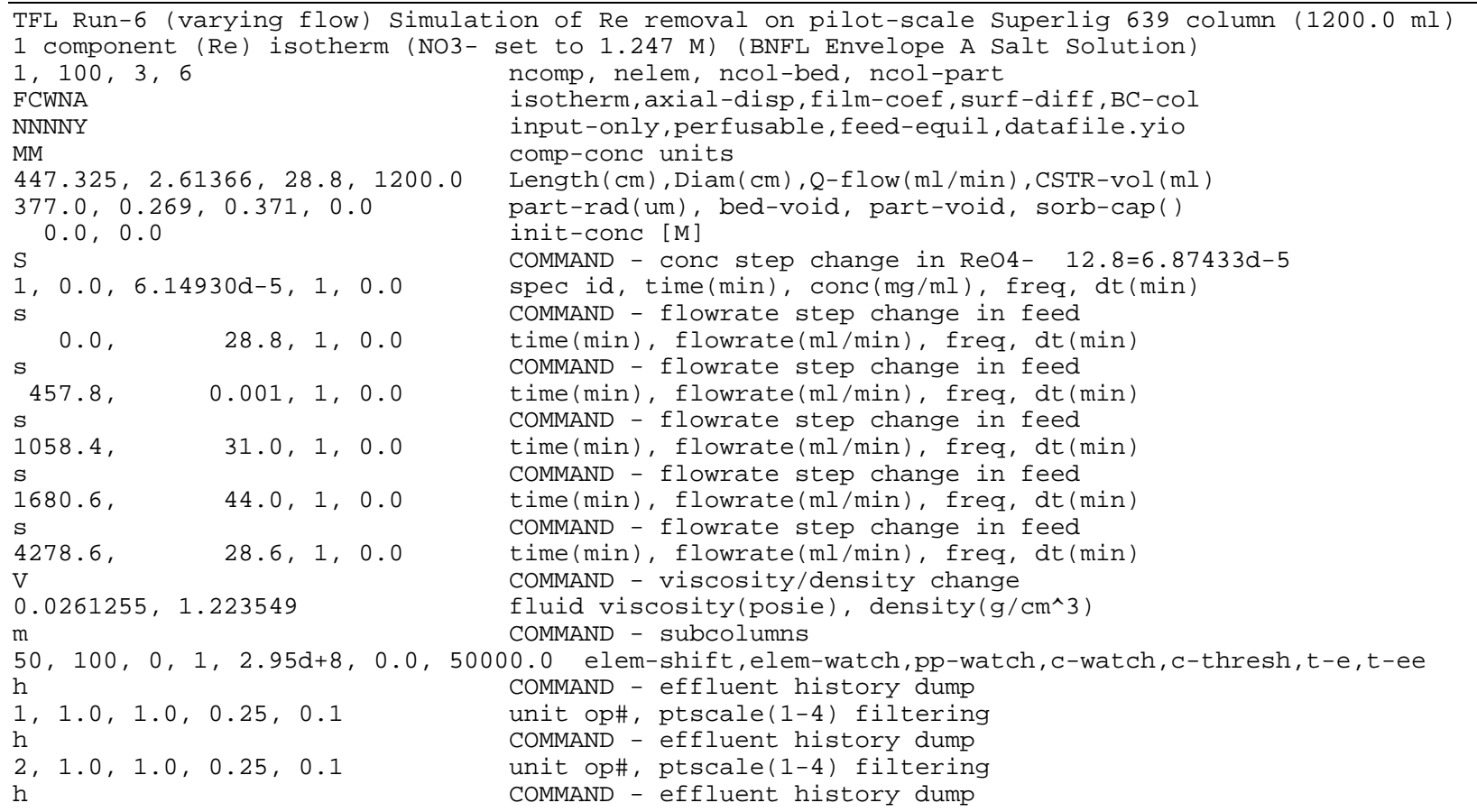




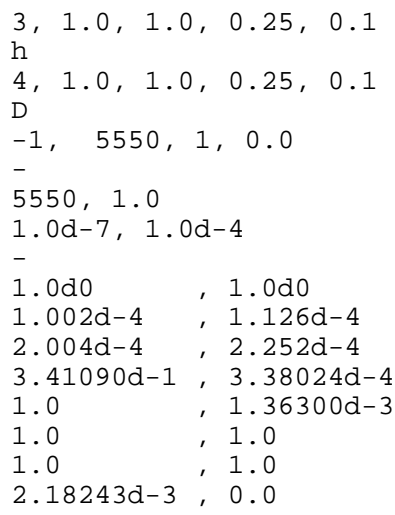

unit op\#, ptscale(1-4) filtering

COMMAND - effluent history dump

unit op\#, ptscale(1-4) filtering

end of commands

end time(min), max dt in B.V.s [5550] [15000]

abs-tol $(\mathrm{mg} / \mathrm{ml})$, rel-tol

non-negative conc constraint

size exclusion factor

part-pore diffusivities ( $\left.\mathrm{cm}^{\wedge} 2 / \mathrm{min}\right) 50 \%$ of free values

Brownian diffusivities ( $\mathrm{cm}^{\wedge} 2 / \mathrm{min}$ )

Freundlich/Langmuir Hybrid a (moles/L B.V.) rhob=0.527 (mix)

Freundlich/Langmuir Hybrid b (1/M) Batch specific isotherm

Freundlich/Langmuir Hybrid Ma $(-) \quad$ ccap $=0.64723$

Freundlich/Langmuir Hybrid Mb (-)

Freundlich/Langmuir Hybrid beta (-) "eff" isotherm NO3 $=1.247 \mathrm{M}$

\section{VERSE Output for Pilot-Scale Perrhenate Column (TFL Run-6: trans) Test}

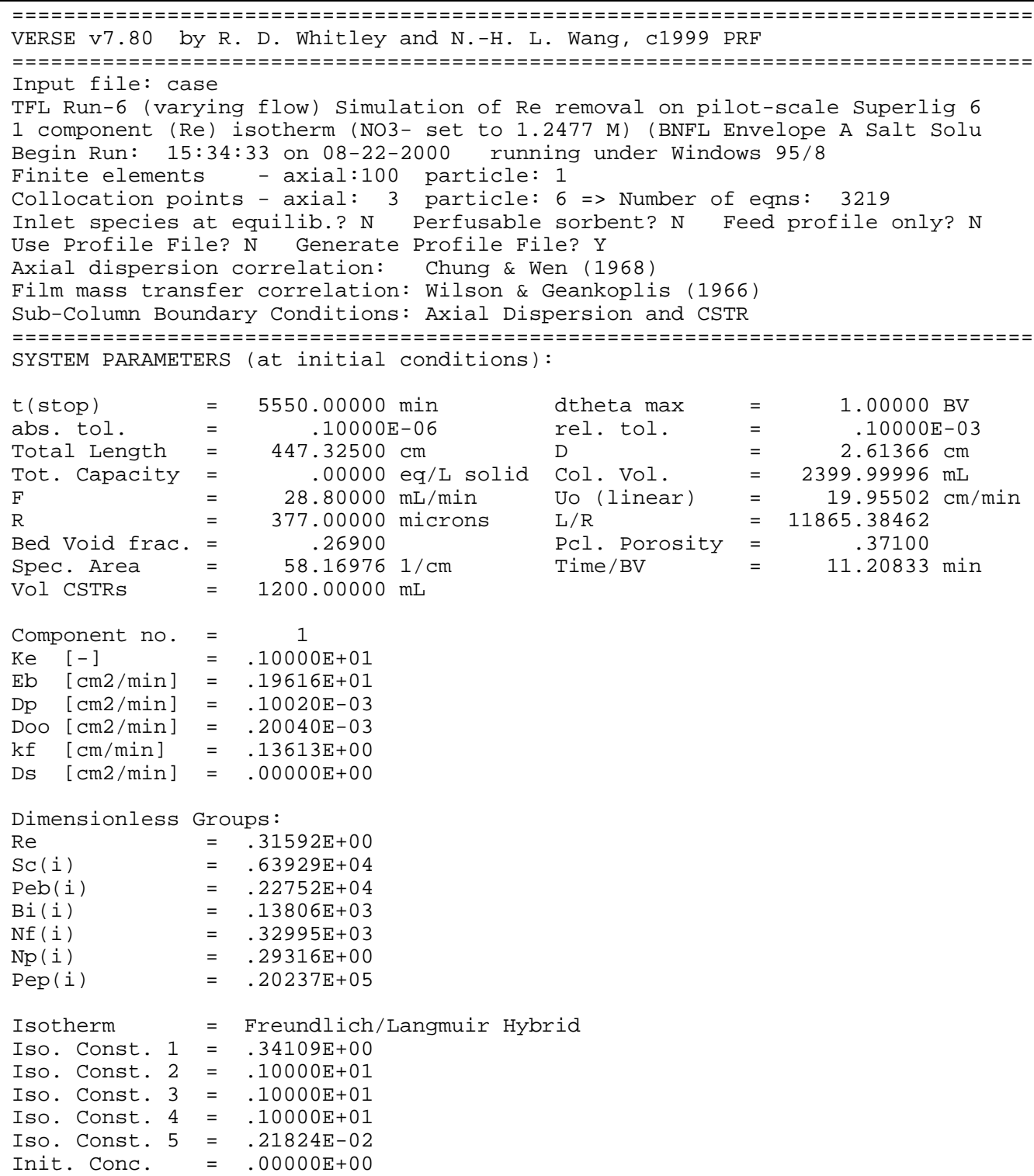




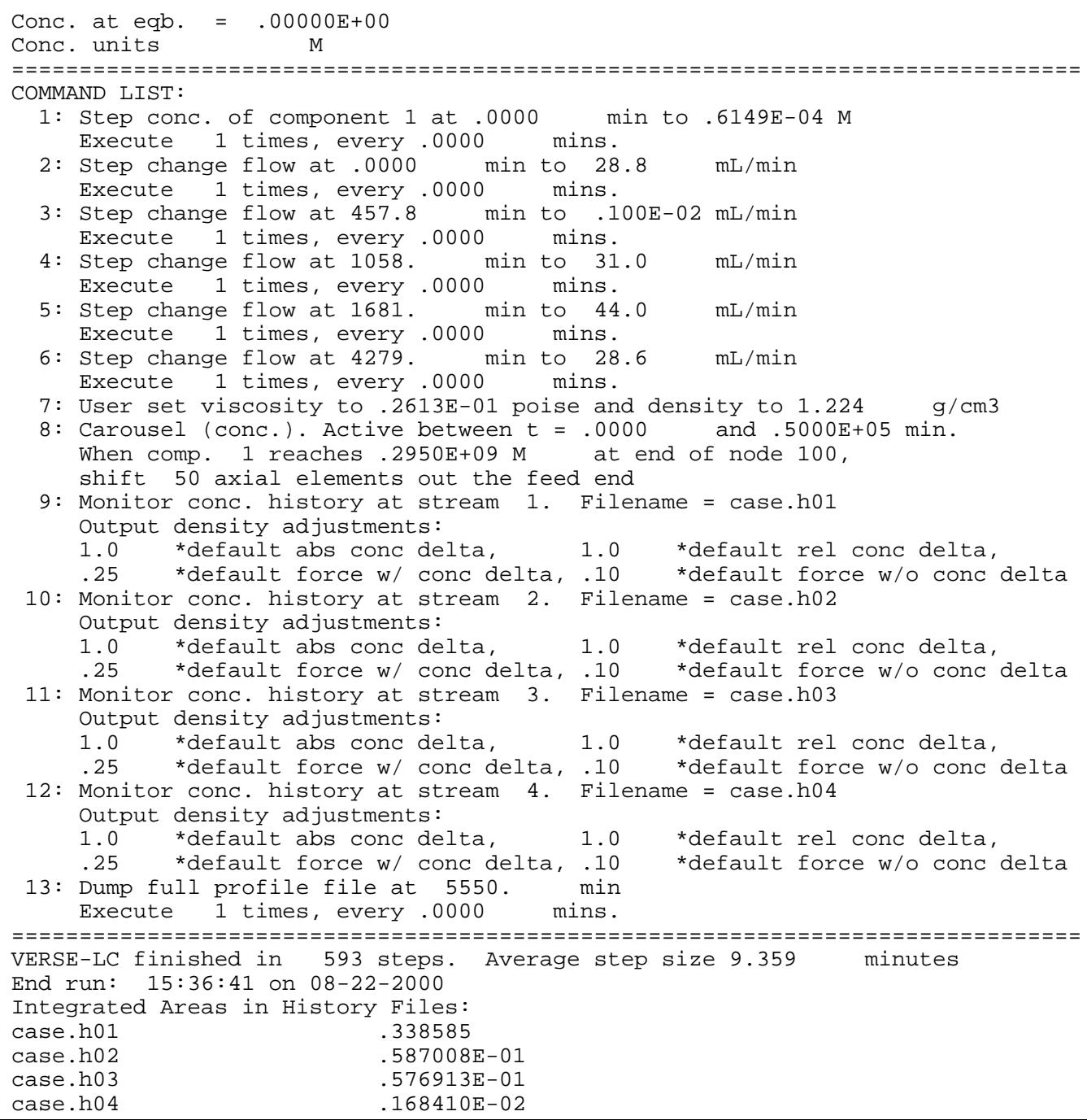

\section{VERSE Input for Pilot-Scale Perrhenate Column (TFL Run-7) Test}

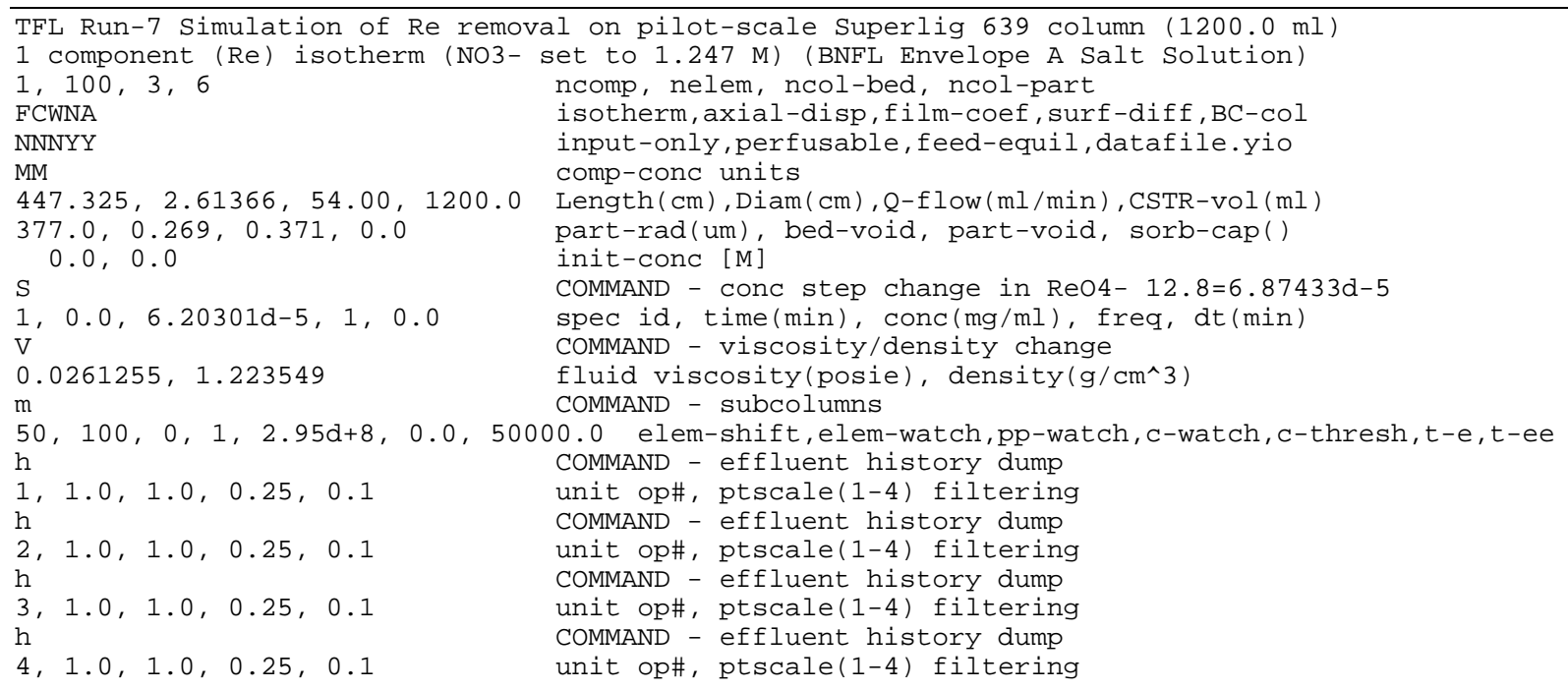


D

$-1,3000,1,0.0$

$8100,1.0$

$1.0 d-7,1.0 d-4$

end of commands

$1.0 \mathrm{~d} 0 \quad, 1.0 \mathrm{~d} 0$

end time (min), max dt in B.V.s [3000] [8100]

$1.002 \mathrm{~d}-4,1.126 \mathrm{~d}-4$

$2.004 \mathrm{~d}-4,2.252 \mathrm{~d}-4$

$3.41090 \mathrm{~d}-1,3.38024 \mathrm{~d}-4$

$1.0 \quad, 1.36300 \mathrm{~d}-3$

$1.0 \quad, 1.0$

$1.0 \quad, 1.0$

abs-tol $(\mathrm{mg} / \mathrm{ml})$, rel-tol

non-negative conc constraint

size exclusion factor

part-pore diffusivities ( $\left.\mathrm{cm}^{\wedge} 2 / \mathrm{min}\right) 50 \%$ of free values

Brownian diffusivities ( $\left.\mathrm{cm}^{\wedge} 2 / \mathrm{min}\right)$

Freundlich/Langmuir Hybrid a

Freundlich/Langmuir Hybrid b

(moles/L B.V.) rhob=0.527 (mix)

$2.18243 d-3,0.0$

Freundlich/Langmuir Hybrid Mb

$(-) \quad$ ccap $=0.64723$

Freundlich/Langmuir Hybrid beta

$(-)$

$(-)$ "eff" isotherm NO3 $=1.247 \mathrm{M}$

\section{VERSE Output for Pilot-Scale Perrhenate Column (TFL Run-7) Test}

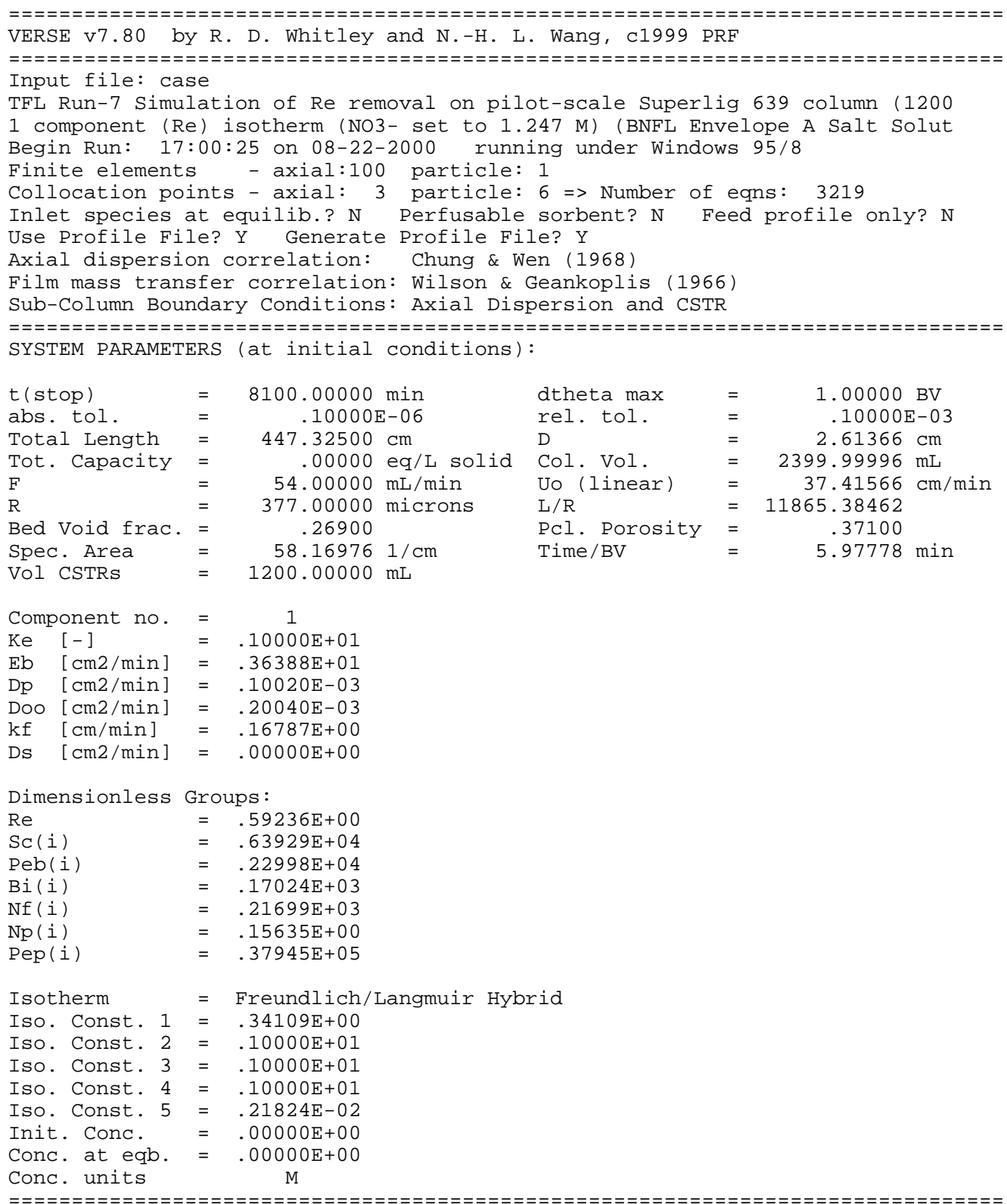




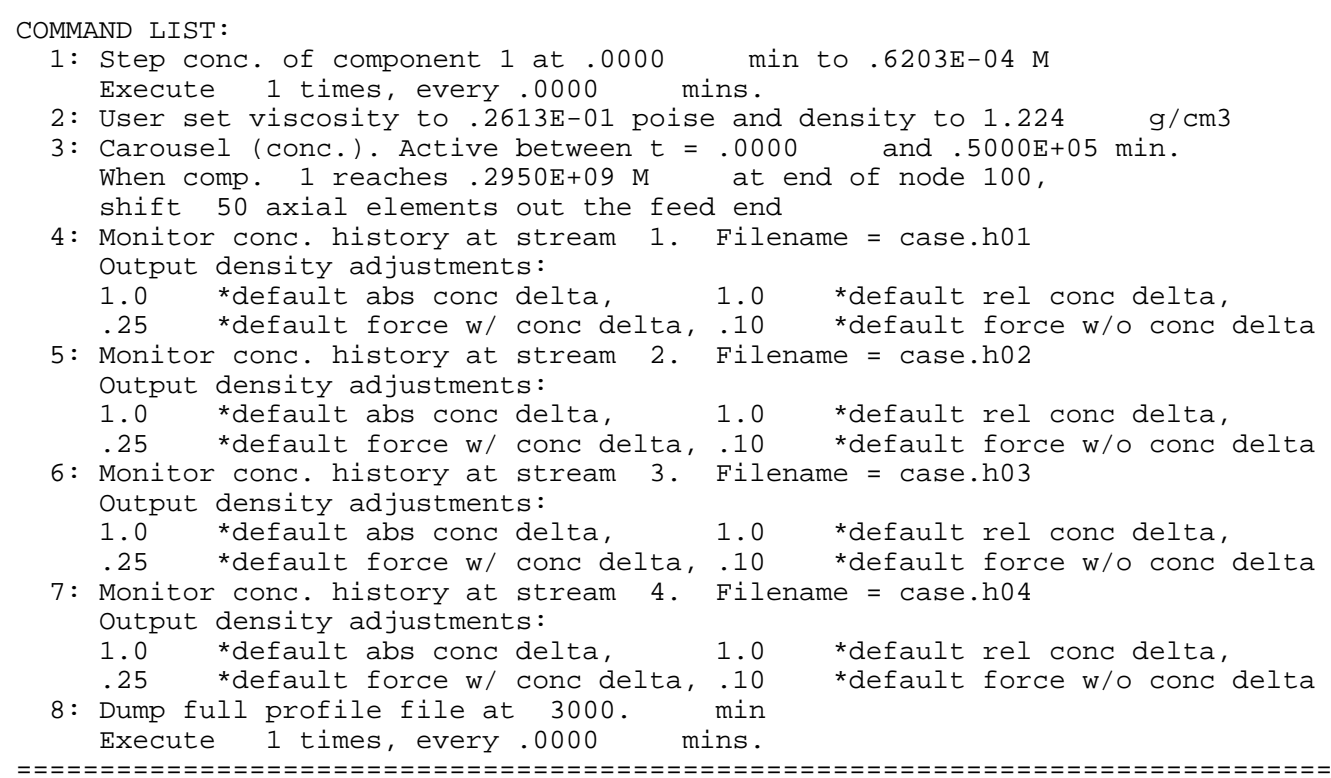

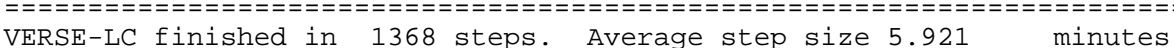

End run: 17:02:12 on 08-22-2000

Integrated Areas in History Files:

case.h01 .502432

case.h02 .329593

case.h03 .328236

case.h04 .144482

\section{VERSE Input for Pilot-Scale Perrhenate Column (TFL Run-8) Test}

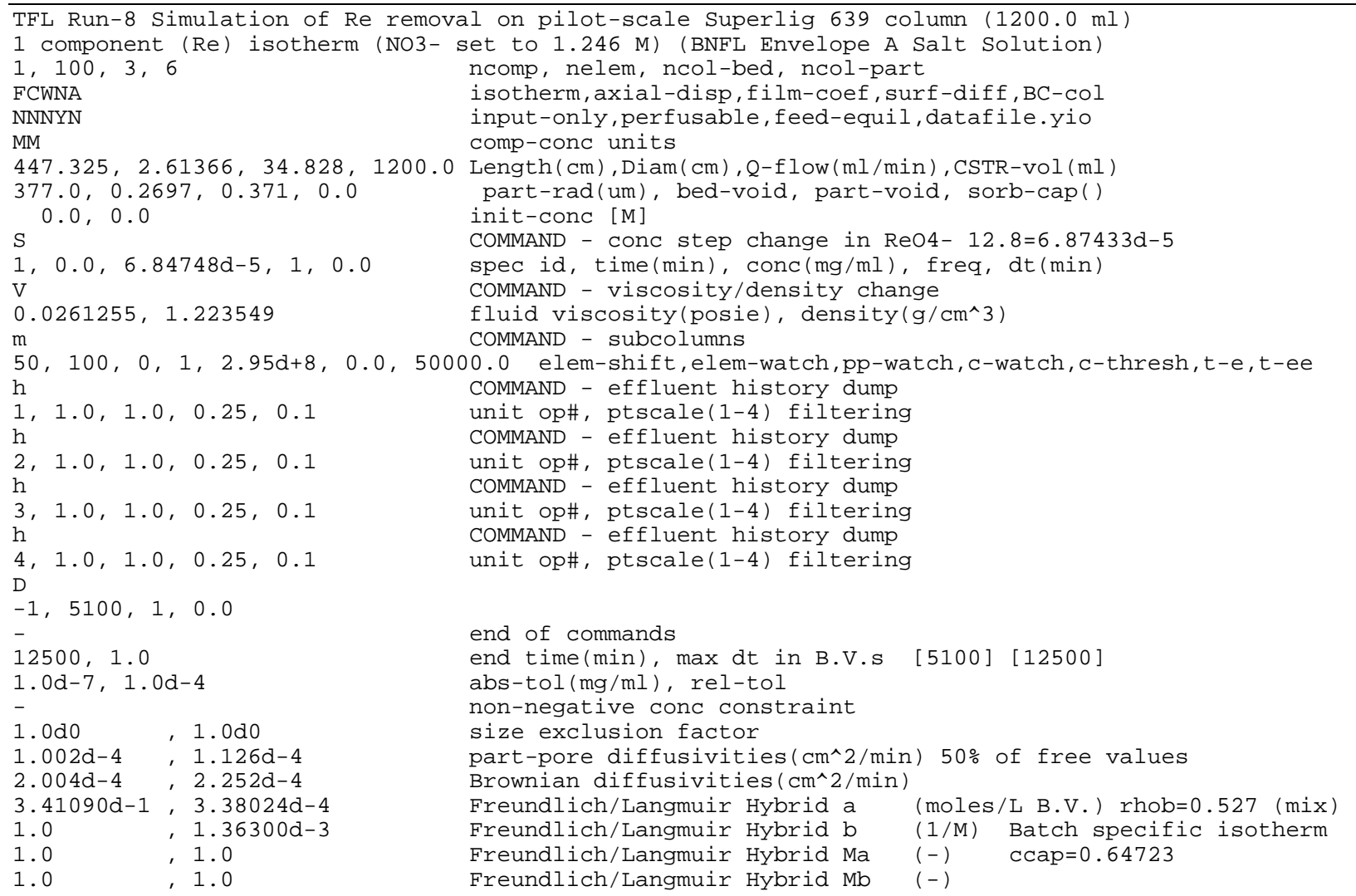




\section{VERSE Output for Pilot-Scale Perrhenate Column (TFL Run-8) Test}

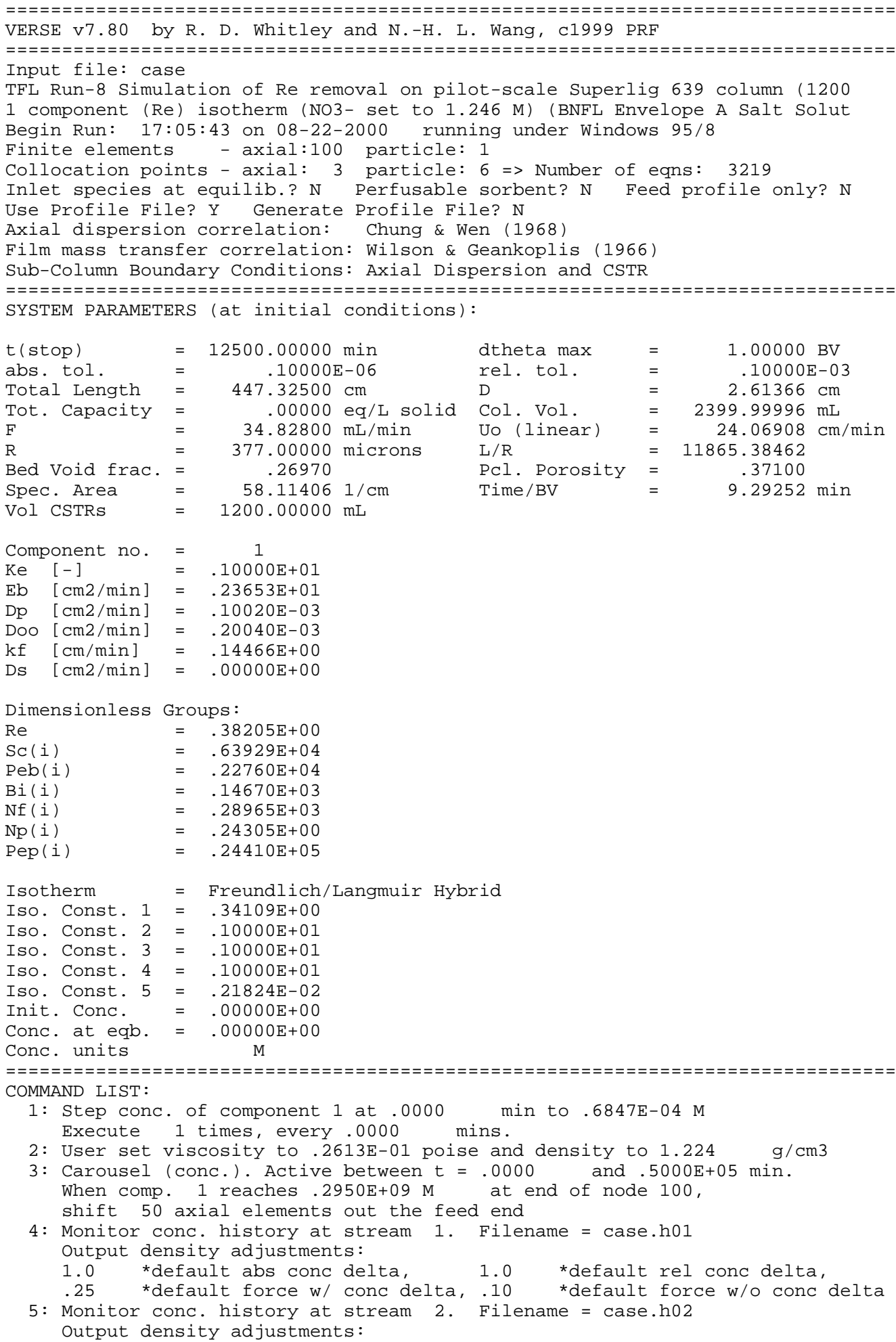




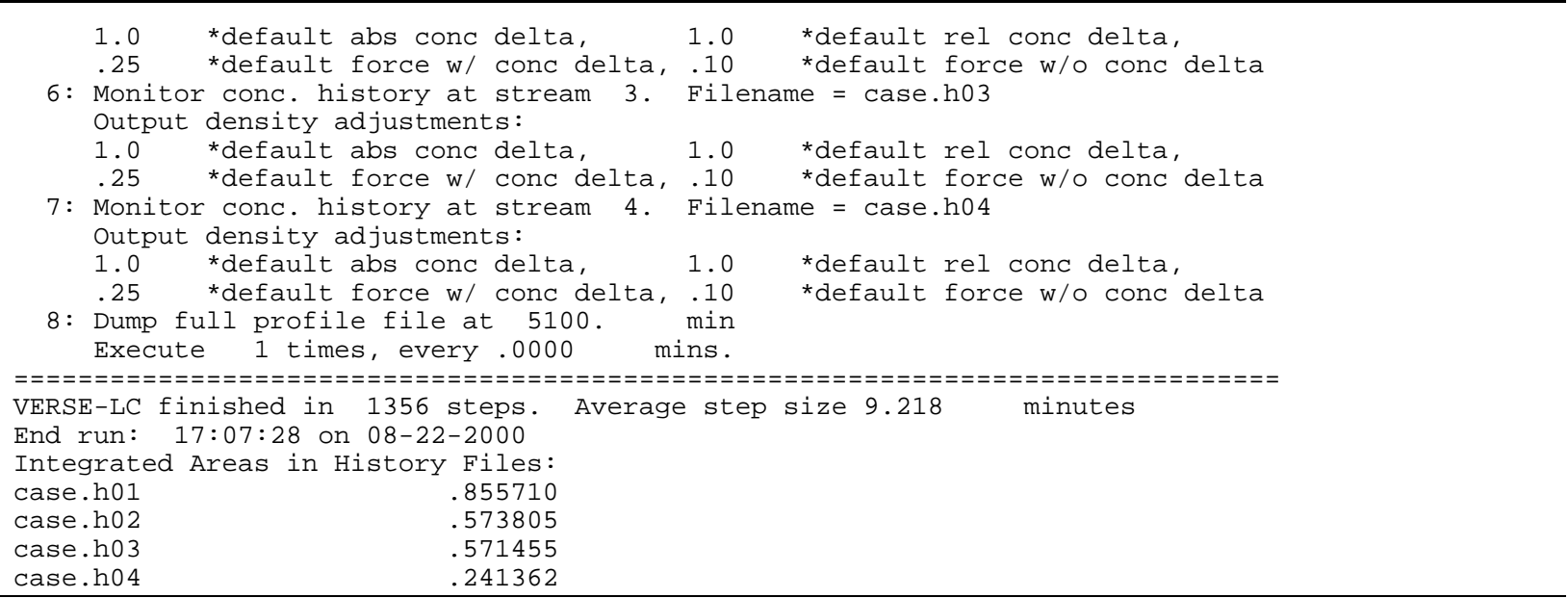

\section{VERSE Input for Pilot-Scale Perrhenate Column (TFL Run-9) Test}

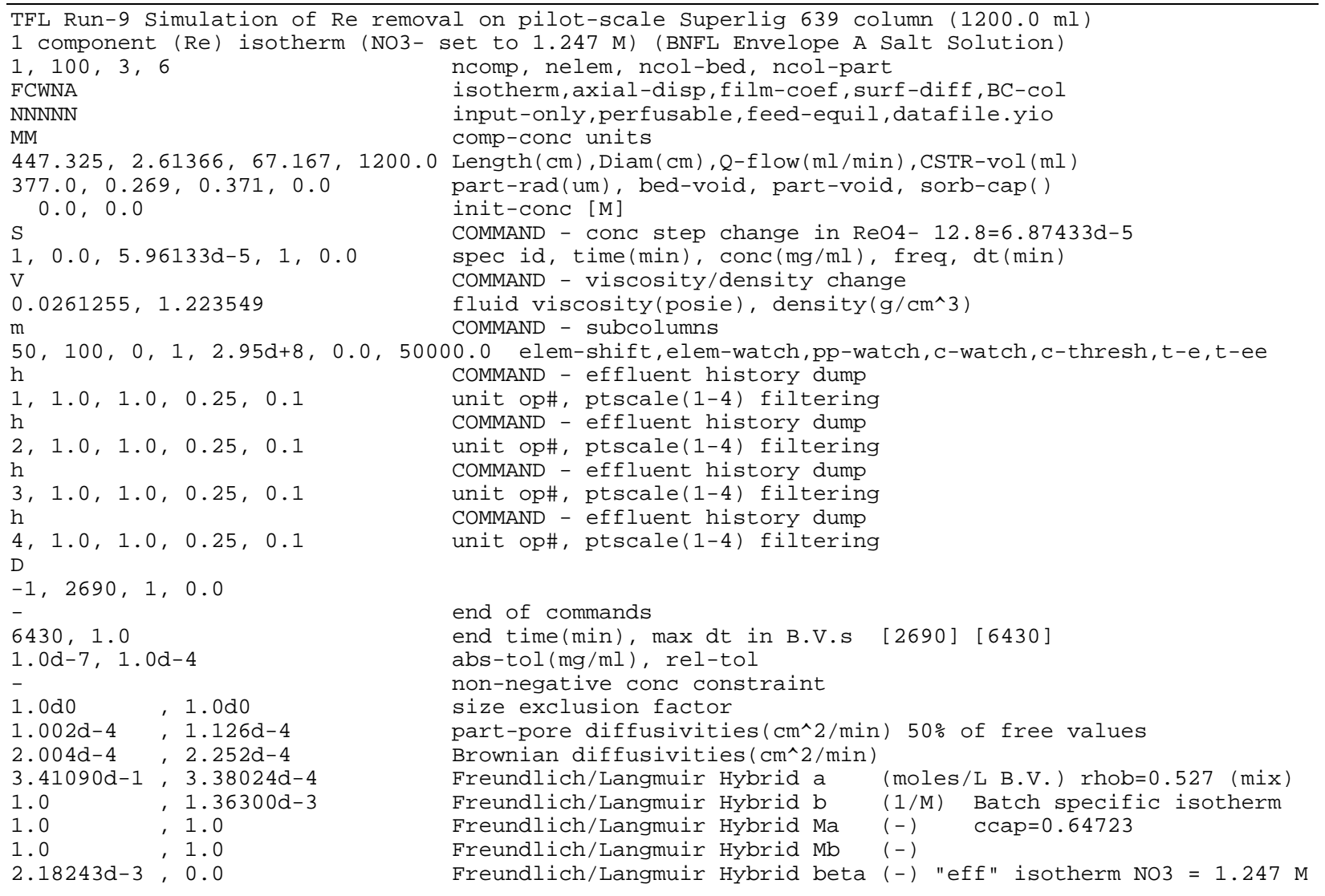

\section{VERSE Output for Pilot-Scale Perrhenate Column (TFL Run-9) Test}

VERSE V7.80 by R. D. Whitley and N.-H. L. Wang, c1999 PRF

Input file: case

TFL Run-9 Simulation of Re removal on pilot-scale Superlig 639 column (1200 
1 component (Re) isotherm (NO3- set to 1.247 M) (BNFL Envelope A Salt Solut Begin Run: 16:10:41 on 08-22-2000 running under Windows 95/8

Finite elements - axial:100 particle: 1

Collocation points - axial: 3 particle: 6 => Number of eqns: 3219

Inlet species at equilib.? $\mathrm{N}$ Perfusable sorbent? $\mathrm{N}$ Feed profile only? $\mathrm{N}$

Use Profile File? N Generate Profile File? N

Axial dispersion correlation: Chung \& Wen (1968)

Film mass transfer correlation: Wilson \& Geankoplis (1966)

Sub-Column Boundary Conditions: Axial Dispersion and CSTR

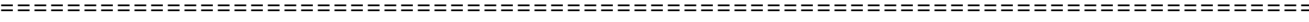

SYSTEM PARAMETERS (at initial conditions):

\begin{tabular}{|c|c|c|c|c|c|}
\hline$t($ stop) & $=$ & $6430.00000 \mathrm{~min}$ & dtheta $\max$ & 1.00000 & BV \\
\hline abs. tol. & $=$ & $.10000 \mathrm{E}-06$ & rel. tol. & .100001 & $E-03$ \\
\hline Total Length & $=$ & $447.32500 \mathrm{~cm}$ & D & 2.61366 & $\mathrm{~cm}$ \\
\hline Tot. Capacity & $=$ & $.00000 \mathrm{eq} / \mathrm{L}$ solid & Col. Vol & 2399.99996 & $\mathrm{~mL}$ \\
\hline $\mathrm{F}$ & $=$ & $67.16700 \mathrm{~mL} / \mathrm{min}$ & Uo (linear) & 46.53885 & $\mathrm{~cm} / \mathrm{min}$ \\
\hline $\mathrm{R}$ & $=$ & 377.00000 microns & $\mathrm{L} / \mathrm{R}$ & $=11865.38462$ & \\
\hline Bed Void frac. & $=$ & .26900 & Pcl. Porosity & .37100 & \\
\hline Spec. Area & $=$ & $58.169761 / \mathrm{cm}$ & Time/BV & 4.80593 & $\min$ \\
\hline Vol CSTRs & $=$ & $1200.00000 \mathrm{~mL}$ & & & \\
\hline Component no. & $=$ & 1 & & & \\
\hline $\mathrm{Ke} \quad[-]$ & $=$ & $.10000 \mathrm{E}+01$ & & & \\
\hline $\mathrm{Eb} \quad[\mathrm{cm} 2 / \mathrm{min}]$ & $=$ & $.45056 \mathrm{E}+01$ & & & \\
\hline $\mathrm{Dp} \quad[\mathrm{cm} 2 / \mathrm{min}]$ & $=$ & $.10020 \mathrm{E}-03$ & & & \\
\hline Doo $[\mathrm{cm} 2 / \mathrm{min}]$ & $=$ & $.20040 \mathrm{E}-03$ & & & \\
\hline $\operatorname{kf}[\mathrm{cm} / \mathrm{min}]$ & $=$ & $.18053 \mathrm{E}+00$ & & & \\
\hline Ds $\quad[\mathrm{cm} 2 / \mathrm{min}]$ & $=$ & $.00000 \mathrm{E}+00$ & & & \\
\hline Dimensionless & $\mathrm{Grc}$ & ups : & & & \\
\hline $\mathrm{Re}$ & $=$ & $.73679 \mathrm{E}+00$ & & & \\
\hline Sc (i) & $=$ & $.63929 \mathrm{E}+04$ & & & \\
\hline Peb (i) & $=$ & $.23102 \mathrm{E}+04$ & & & \\
\hline $\mathrm{Bi}(\mathrm{i})$ & $=$ & $.18308 \mathrm{E}+03$ & & & \\
\hline $\mathrm{Nf}(\mathrm{i})$ & $=$ & $.18762 \mathrm{E}+03$ & & & \\
\hline Np (i) & $=$ & $.12570 \mathrm{E}+00$ & & & \\
\hline Pep (i) & $=$ & $.47197 \mathrm{E}+05$ & & & \\
\hline Isotherm & $=$ & Freundlich/Langmuir Hyb & rid & & \\
\hline Iso. Const. 1 & $=$ & $.34109 \mathrm{E}+00$ & & & \\
\hline Iso. Const. 2 & $=$ & $.10000 \mathrm{E}+01$ & & & \\
\hline Iso. Const. 3 & $=$ & $.10000 \mathrm{E}+01$ & & & \\
\hline Iso. Const. 4 & $=$ & $.10000 \mathrm{E}+01$ & & & \\
\hline Iso. Const. 5 & $=$ & $.21824 \mathrm{E}-02$ & & & \\
\hline Init. Conc. & $=$ & $.00000 \mathrm{E}+00$ & & & \\
\hline $\begin{array}{l}\text { Conc. at eqb. } \\
\text { Conc. units }\end{array}$ & $=$ & $\begin{array}{c}.00000 \mathrm{E}+00 \\
\mathrm{M}\end{array}$ & & & \\
\hline
\end{tabular}

1: Step conc. of component 1 at .0000 min to .5961E-04 M

Execute 1 times, every .0000 mins.

2: User set viscosity to .2613E-01 poise and density to $1.224 \mathrm{~g} / \mathrm{cm} 3$

3: Carousel (conc.). Active between $t=.0000$ and $.5000 \mathrm{E}+05 \mathrm{~min}$.

When comp. 1 reaches .2950E+09 M at end of node 100, shift 50 axial elements out the feed end

4: Monitor conc. history at stream 1. Filename $=$ case.h01 Output density adjustments:

1.0 *default abs conc delta, 1.0 *default rel conc delta,

.25 *default force w/ conc delta, .10 *default force w/o conc delta

5: Monitor conc. history at stream 2. Filename = case.h02 Output density adjustments:

1.0 *default abs conc delta, 1.0 *default rel conc delta,

.25 *default force w/ conc delta, .10 *default force w/o conc delta

6: Monitor conc. history at stream 3. Filename = case.h03

Output density adjustments:

1.0 *default abs conc delta, 1.0 *default rel conc delta,

.25 *default force w/ conc delta, .10 *default force w/o conc delta

7: Monitor conc. history at stream 4. Filename = case.h04

Output density adjustments:

1.0 *default abs conc delta, 1.0 *default rel conc delta,

.25 *default force w/ conc delta, .10 *default force w/o conc delta

8: Dump full profile file at 2690 . min

Execute 1 times, every .0000 mins. 


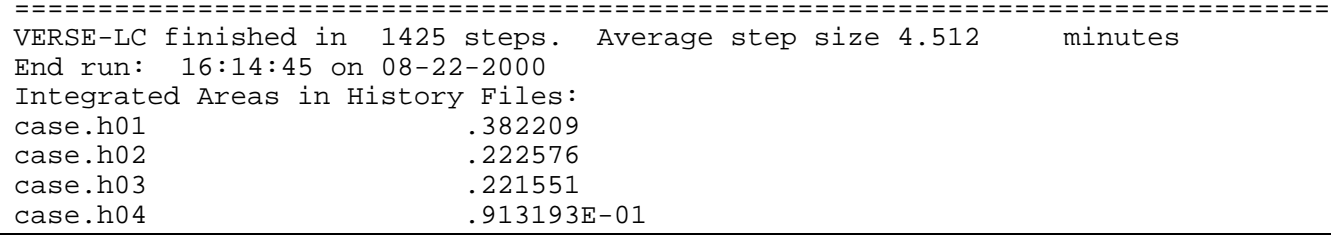

\title{
VERSE Input for Pilot-Scale Perrhenate Column (TFL Run-10) Test
}

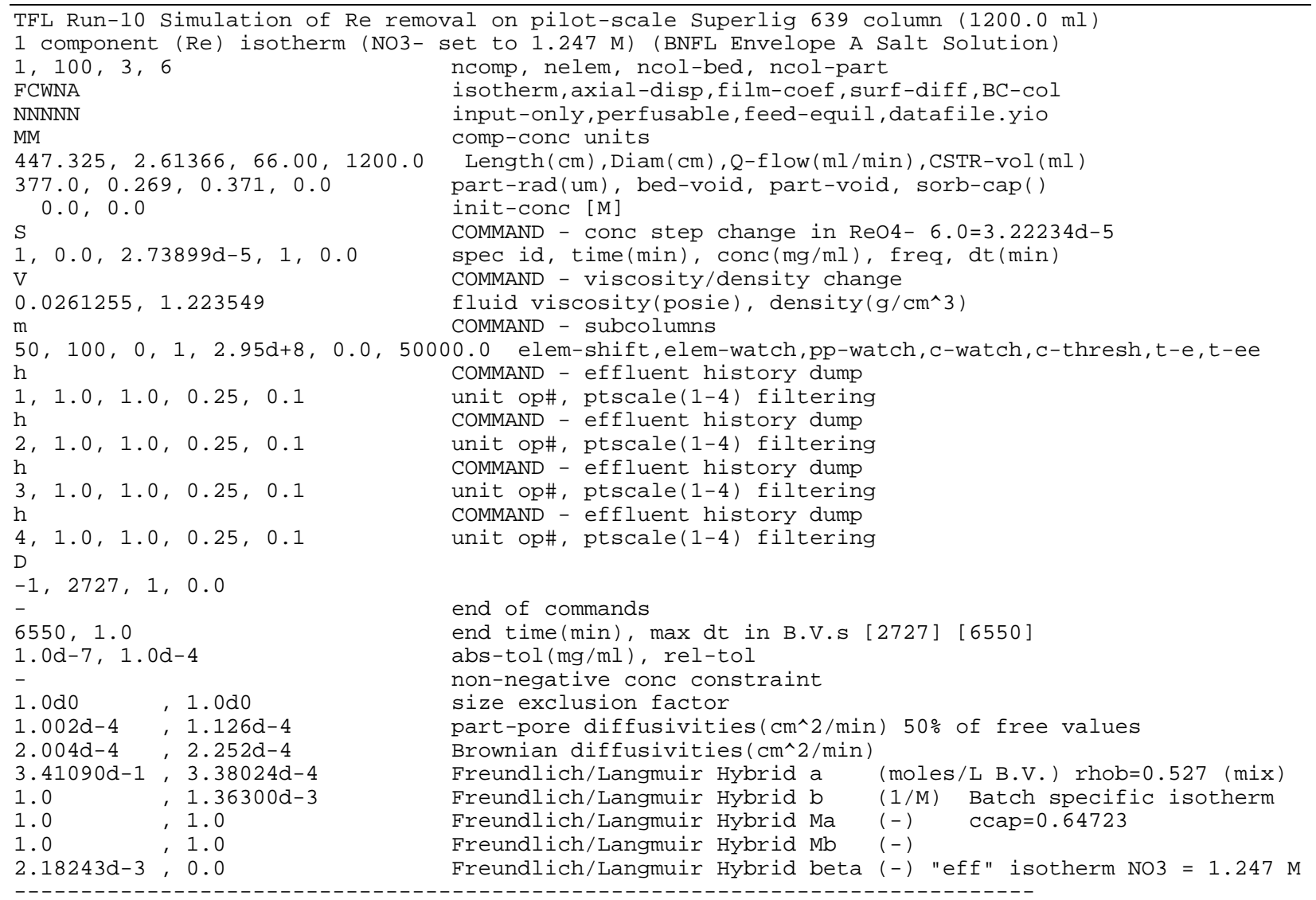

\section{VERSE Output for Pilot-Scale Perrhenate Column (TFL Run-10) Test}

\author{
VERSE V7.80 by R. D. Whitley and N.-H. L. Wang, c1999 PRF

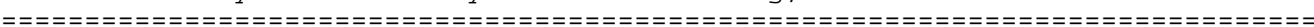 \\ Input file: case \\ TFL Run-10 Simulation of Re removal on pilot-scale Superlig 639 column (120 \\ 1 component (Re) isotherm (NO3- set to 1.247 M) (BNFL Envelope A Salt Solut \\ Begin Run: 16:20:15 on 08-22-2000 running under Windows 95/8 \\ Finite elements - axial:100 particle: 1 \\ Collocation points - axial: 3 particle: 6 => Number of eqns: 3219 \\ Inlet species at equilib.? N Perfusable sorbent? N Feed profile only? N \\ Use Profile File? N Generate Profile File? N \\ Axial dispersion correlation: Chung \& Wen (1968) \\ Film mass transfer correlation: Wilson \& Geankoplis (1966) \\ Sub-Column Boundary Conditions: Axial Dispersion and CSTR \\ SYSTEM PARAMETERS (at initial conditions):
}


WESTINGHOUSE SAVANNAH RIVER COMPANY

Report: WSRC-TR-2000-00305

Preliminary Ion Exchange Modeling for Removal of Technetium from

Revision (Date):

$0(11 / 29 / 00)$

Hanford Waste Using SuperLig ${ }^{\circledR} 639$ Resin

Page:

208 of 228

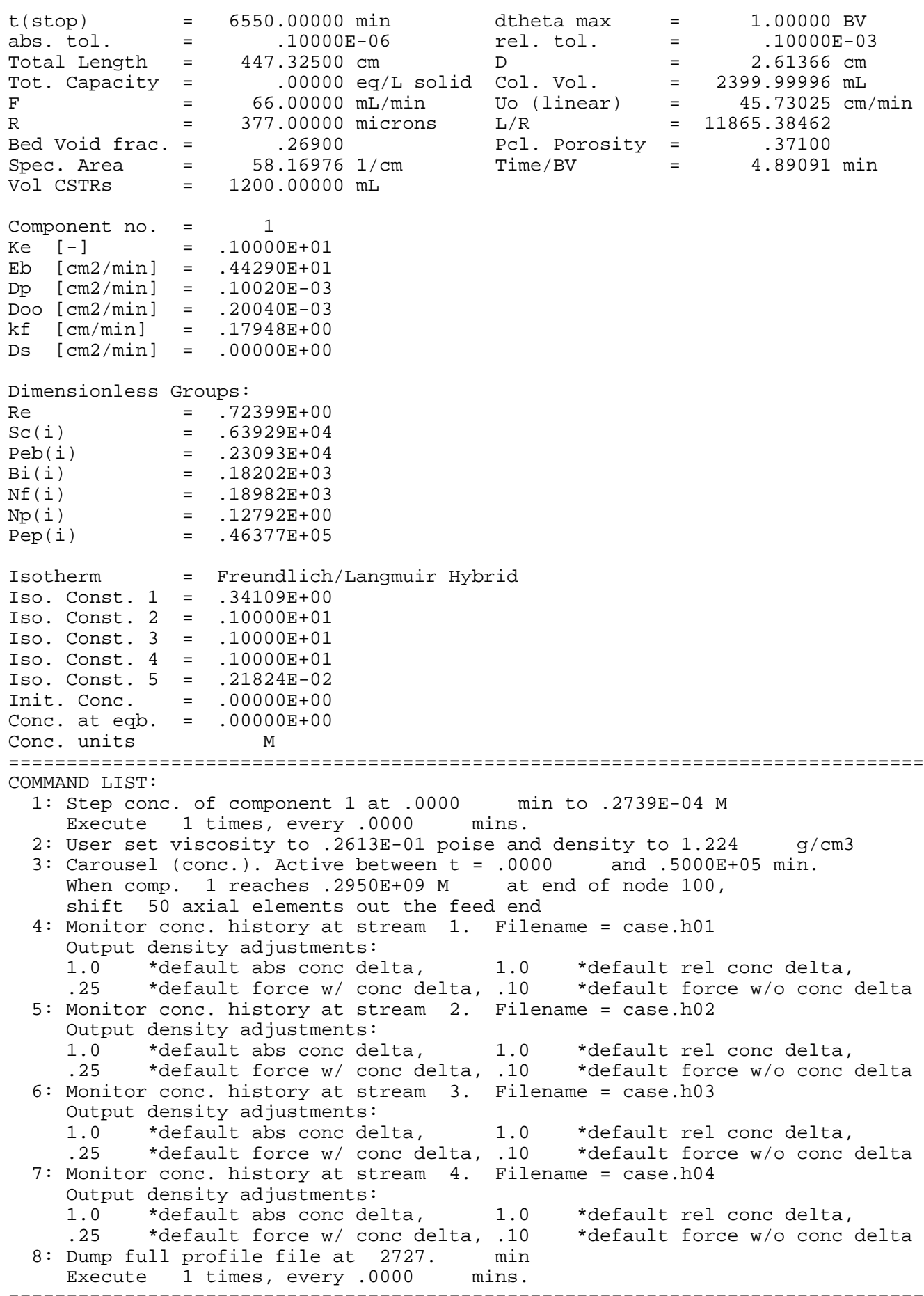

VERSE-LC finished in 1419 steps. Average step size 4.616 minutes

End run: 16:24:21 on 08-22-2000

Integrated Areas in History Files:

$\begin{array}{ll}\text { case.h01 } & .178887\end{array}$

case.h02 .103264

case.h03 $\quad .102787$

case.h04 $\quad .417504 \mathrm{E}-01$ 


\section{VERSE Input for Small-Scale Pertechnetate Column (NH-A) Test}

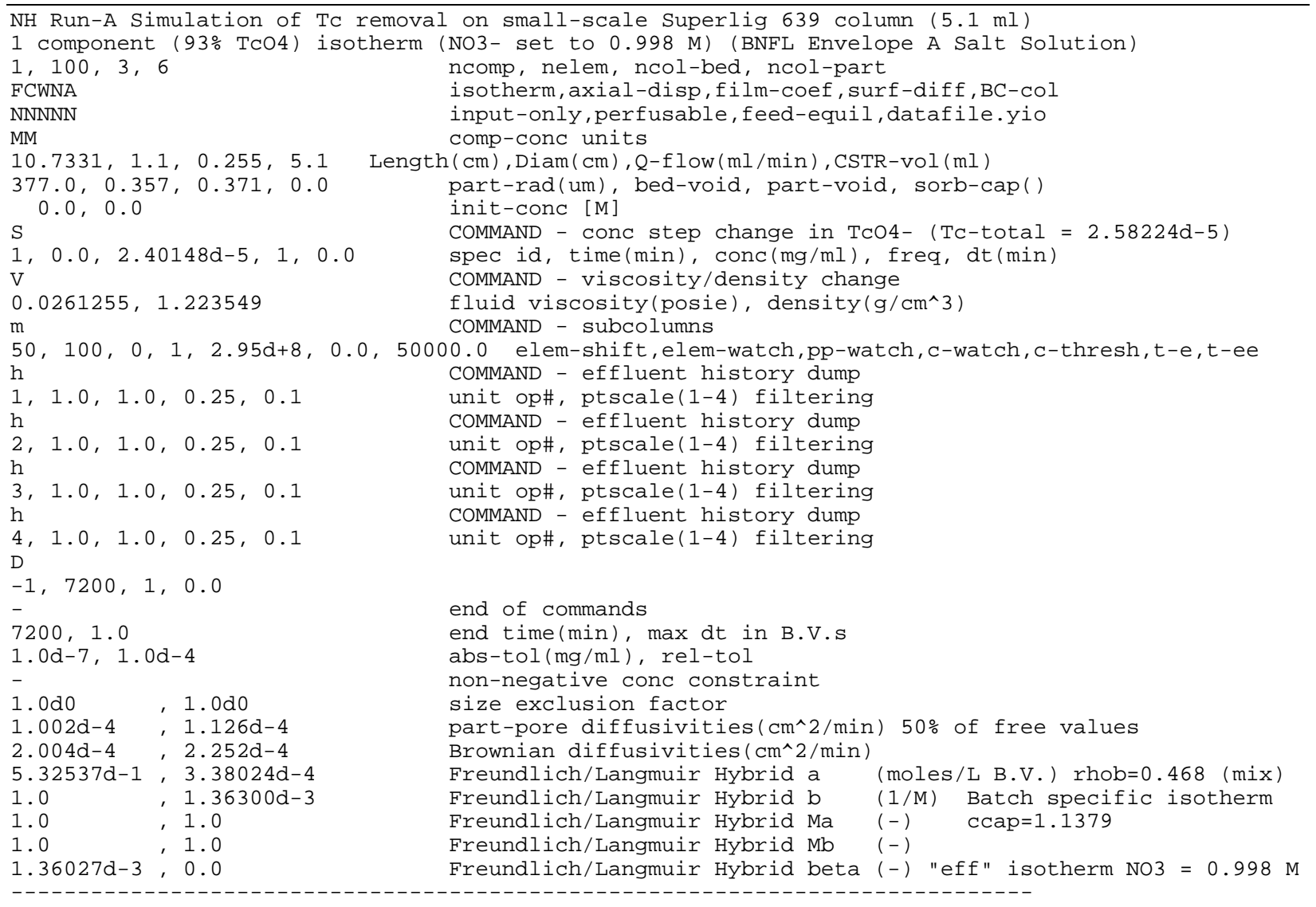

\section{VERSE Output for Small-Scale Pertechnetate Column (NH-A) Test}

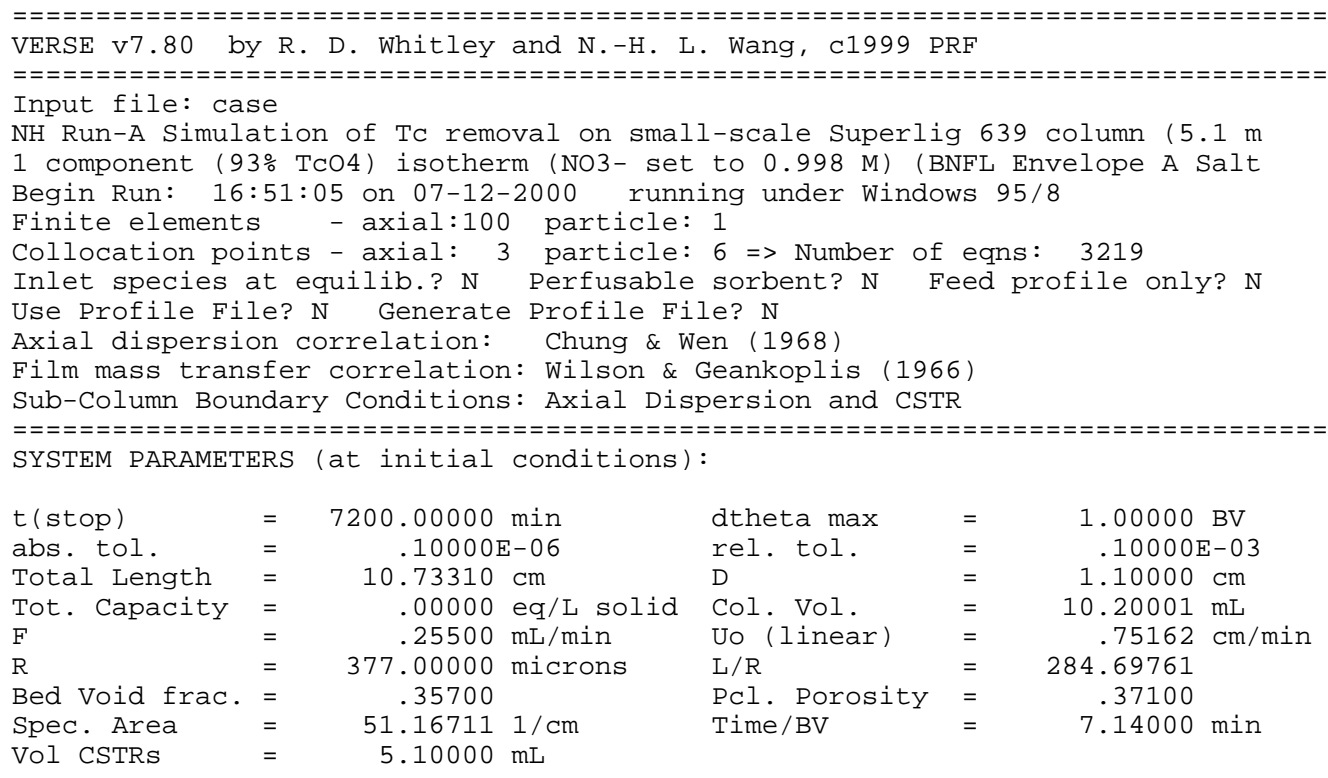




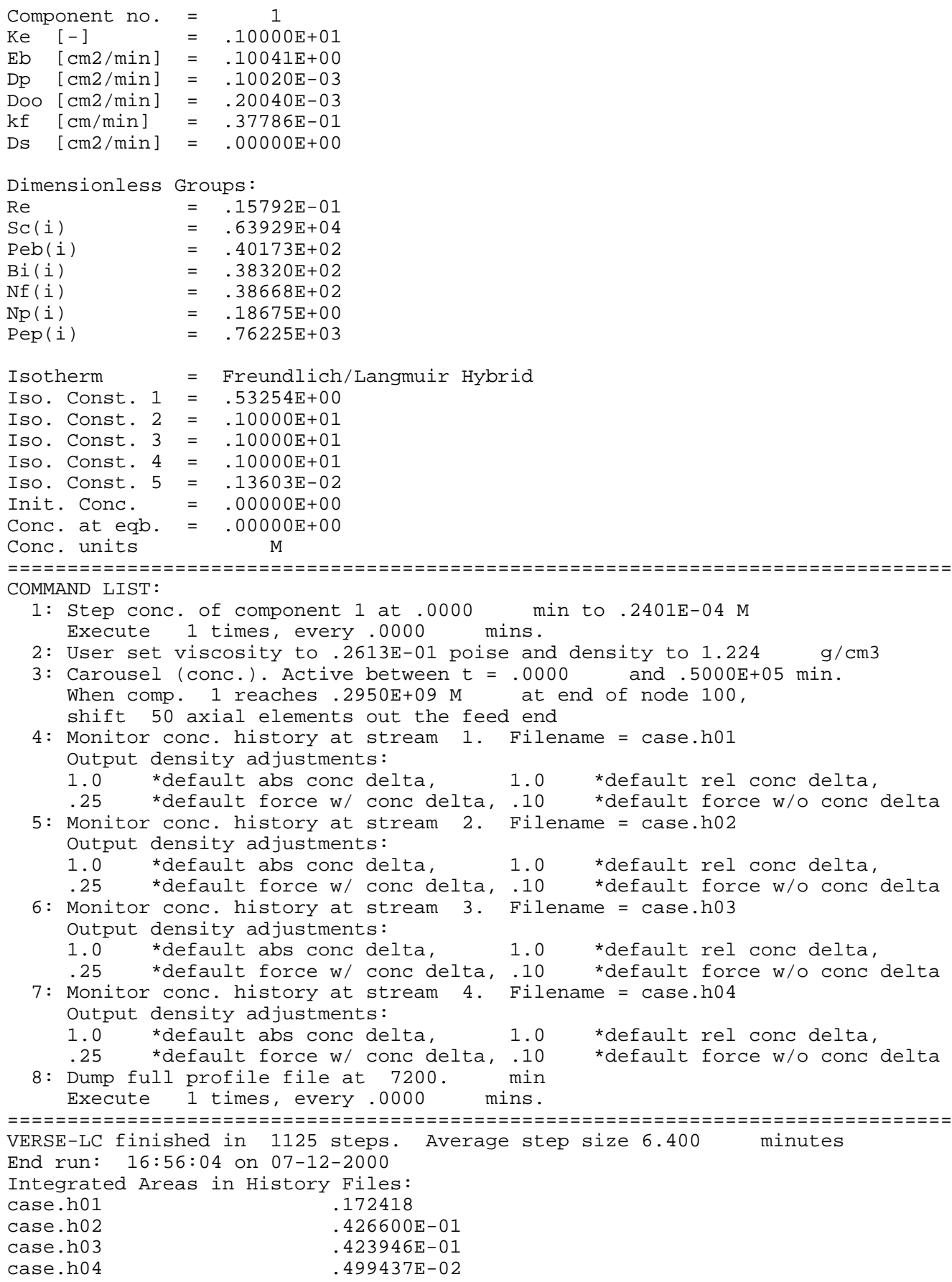

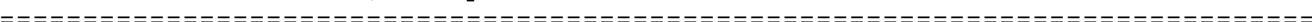

VERSE-LC finished in 1125 steps. Average step size 6.400 minutes

\section{VERSE Input for Small-Scale Pertechnetate Column (NH-B) Test}

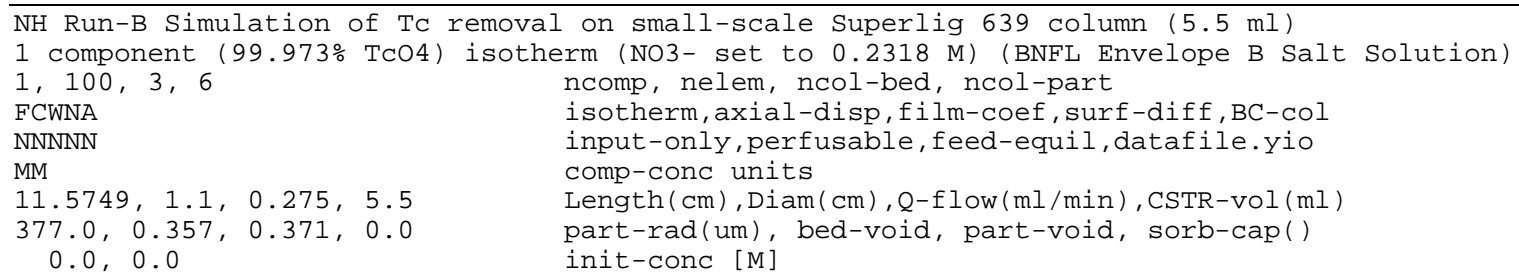




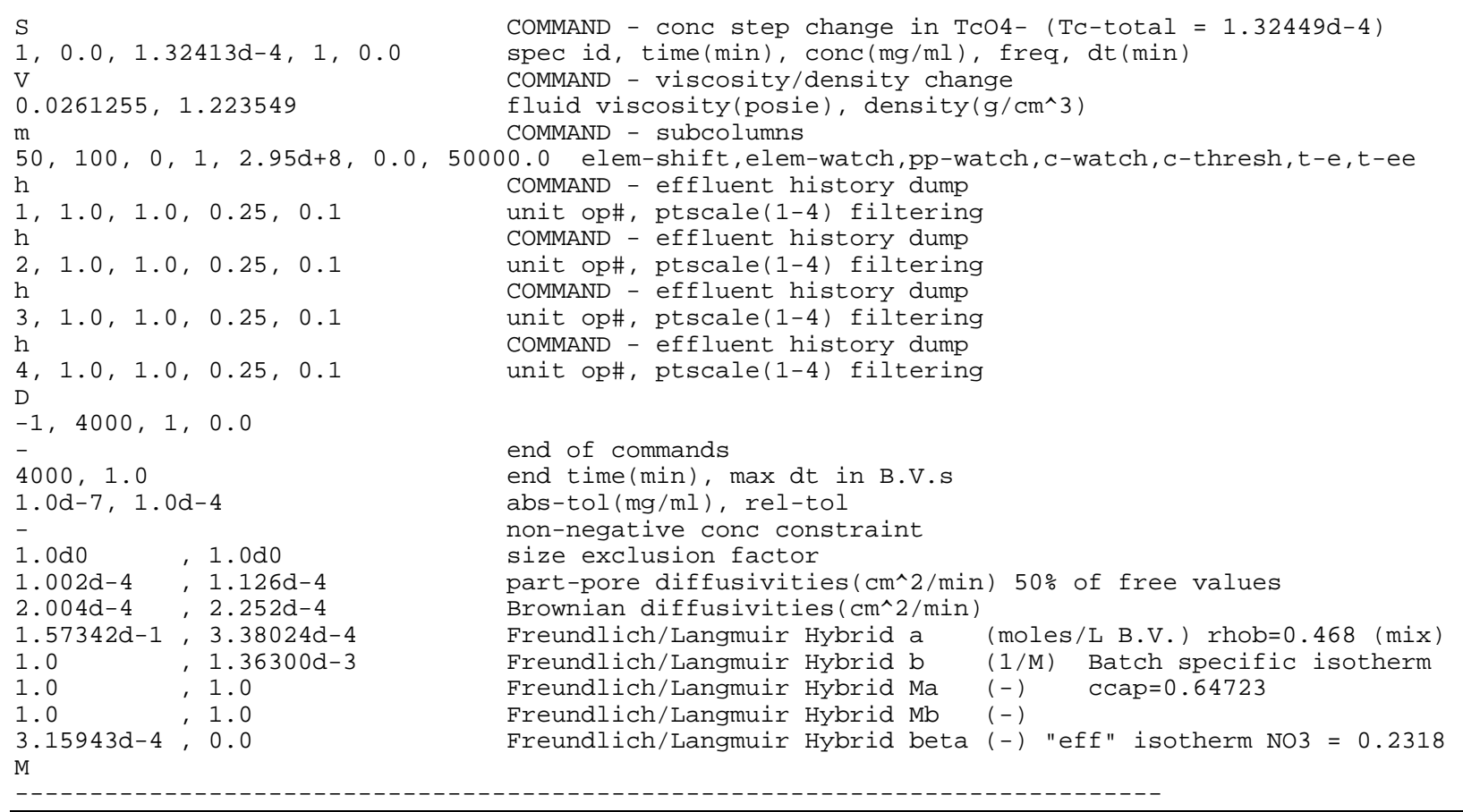

\section{VERSE Output for Small-Scale Pertechnetate Column (NH-B) Test}

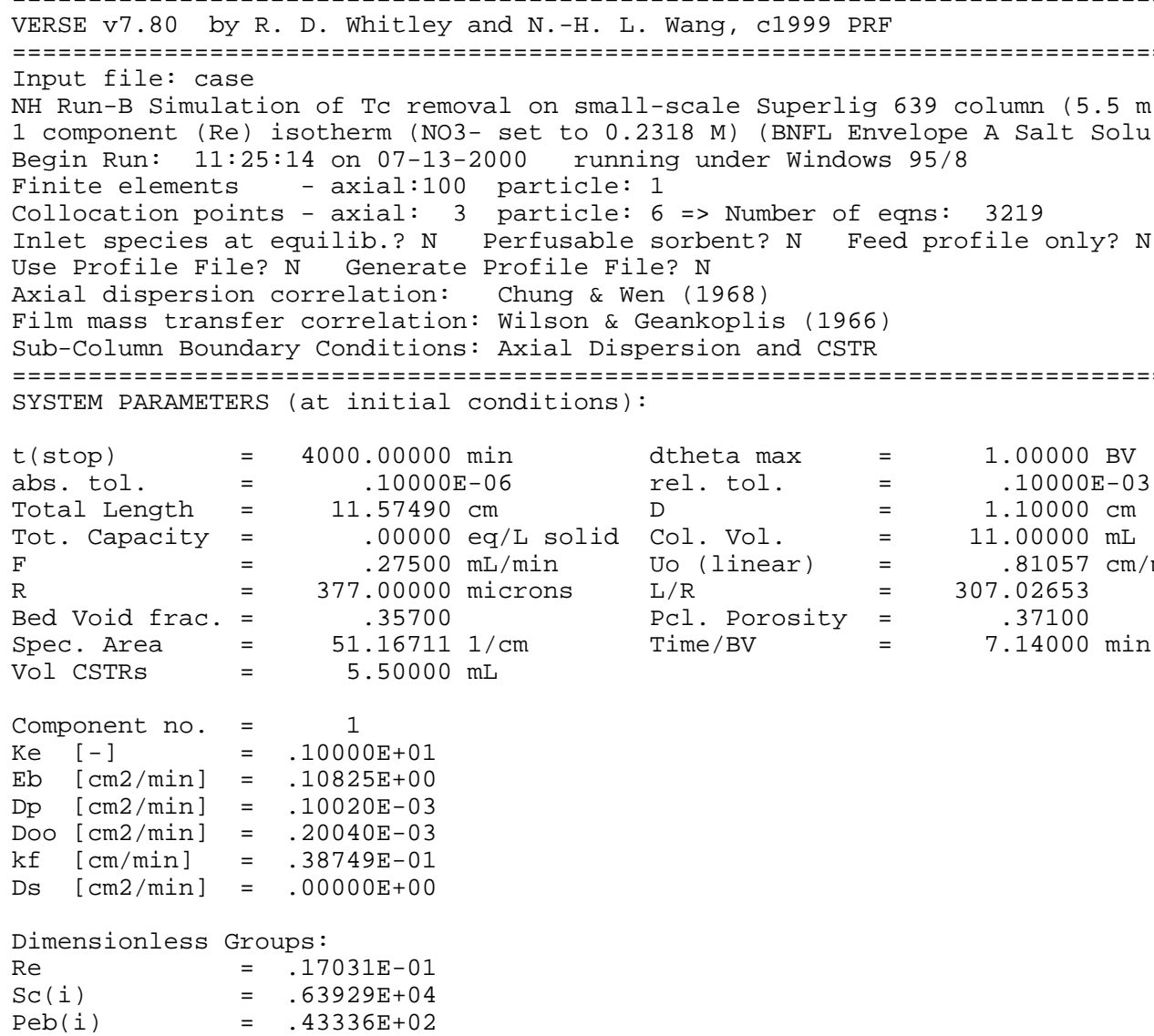




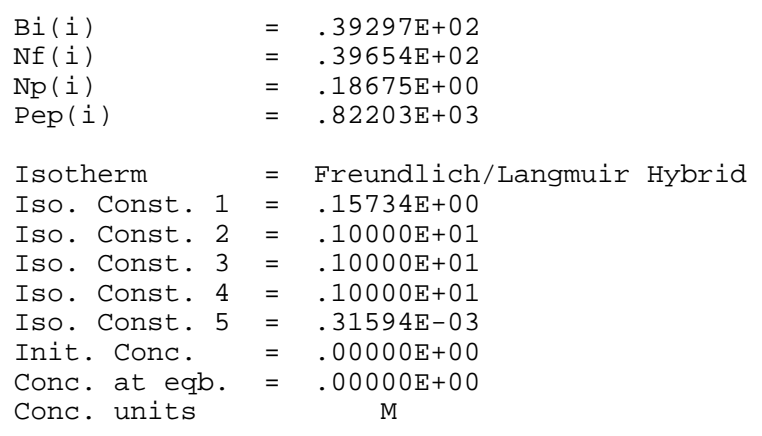

$===========+$
COMMAND LIST:

1: Step conc. of component 1 at .0000 Execute 1 times, every .0000 mins.

2: User set viscosity to $.2613 \mathrm{E}-01$ poise and density to $1.224 \mathrm{~g} / \mathrm{cm} 3$

3: Carousel (conc.). Active between $t=.0000$ and .5000E+05 min. When comp. 1 reaches .2950E+09 M at end of node 100, shift 50 axial elements out the feed end

4: Monitor conc. history at stream 1. Filename = case.h01 Output density adjustments:

1.0 *default abs conc delta, 1.0 *default rel conc delta, $.25 *$ *efault force w/ conc delta, .10 *default force w/o conc delta

5: Monitor conc. history at stream 2. Filename = case.h02 Output density adjustments: 1.0 *default abs conc delta, 1.0 *default rel conc delta, .25 *default force w/ conc delta, .10 *default force w/o conc delta

6: Monitor conc. history at stream 3. Filename = case.h03 Output density adjustments:

1.0 *default abs conc delta, 1.0 *default rel conc delta, .25 *default force w/ conc delta, .10 *default force w/o conc delta

7: Monitor conc. history at stream 4. Filename $=$ case.h04 output density adjustments:

1.0 *default abs conc delta, 1.0 *default rel conc delta, .25 *default force w/ conc delta, .10 *default force w/o conc delta

8: Dump full profile file at 4000 . min Execute 1 times, every .0000 mins.

VERSE-LC finished in 807 steps. Average step size 4.957 minutes

End run: $11: 41: 42$ on $07-13-2000$

Integrated Areas in History Files:

case.h01 .526976

case.h02 .461326E-01

case.h03 .454685E-01

case.h04 $.876431 \mathrm{E}-03$

\section{VERSE Input for Small-Scale Pertechnetate Column (NH-SC) Test}

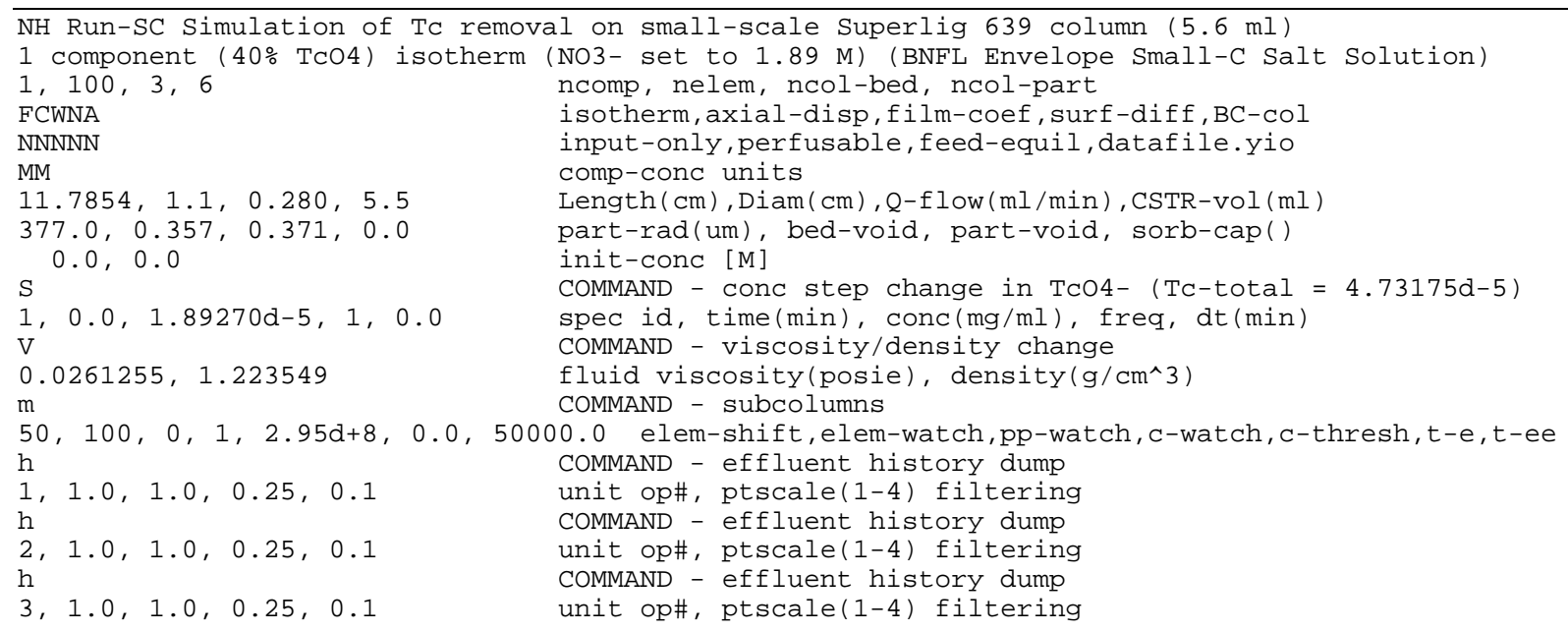


$\mathrm{h}$

$4,1.0,1.0,0.25,0.1$

$-1,1600,1,0.0$

$1600,1.0$

$1.0 d-7,1.0 d-4$

$1.0 \mathrm{~d} 0 \quad, 1.0 \mathrm{~d} 0$

$1.002 \mathrm{~d}-4,1.126 \mathrm{~d}-4$

$2.004 \mathrm{~d}-4,2.252 \mathrm{~d}-4$

$1.57342 \mathrm{~d}-1,3.38024 \mathrm{~d}-4$

$1.0 \quad, 1.36300 \mathrm{~d}-3$

$1.0,1.0$

$1.0 \quad, 1.0$

$2.57607 d-3,0.0$
COMMAND - effluent history dump

unit op\#, ptscale(1-4) filtering

end of commands

end time (min), max dt in B.V.s

abs-tol (mg/ml), rel-tol

non-negative conc constraint

size exclusion factor

part-pore diffusivities $\left(\mathrm{cm}^{\wedge} 2 / \mathrm{min}\right) 50 \%$ of free values

Brownian diffusivities $\left(\mathrm{cm}^{\wedge} 2 / \mathrm{min}\right)$

Freundlich/Langmuir Hybrid a

Freundlich/Langmuir Hybrid b

Freundlich/Langmuir Hybrid Ma

Freundlich/Langmuir Hybrid $\mathrm{Mb}$

(moles/L B.V.) rhob=0.468 (mix)

(1/M) Batch specific isotherm

(-) $\quad \mathrm{ccap}=0.3362$

$(-)$

$(-)$ "eff" isotherm NO3 $=1.89 \mathrm{M}$

\section{VERSE Output for Small-Scale Pertechnetate Column (NH-SC) Test}

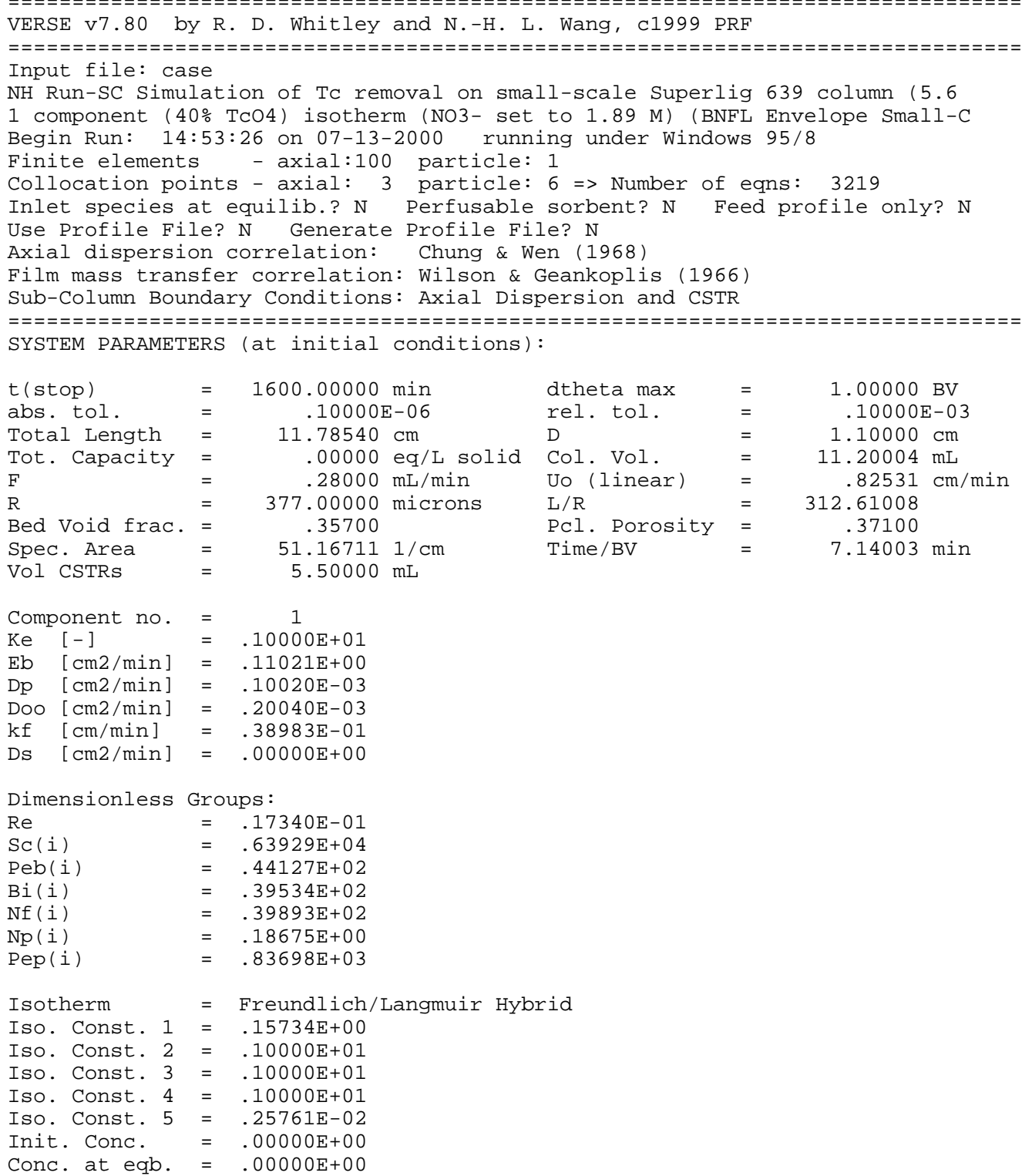




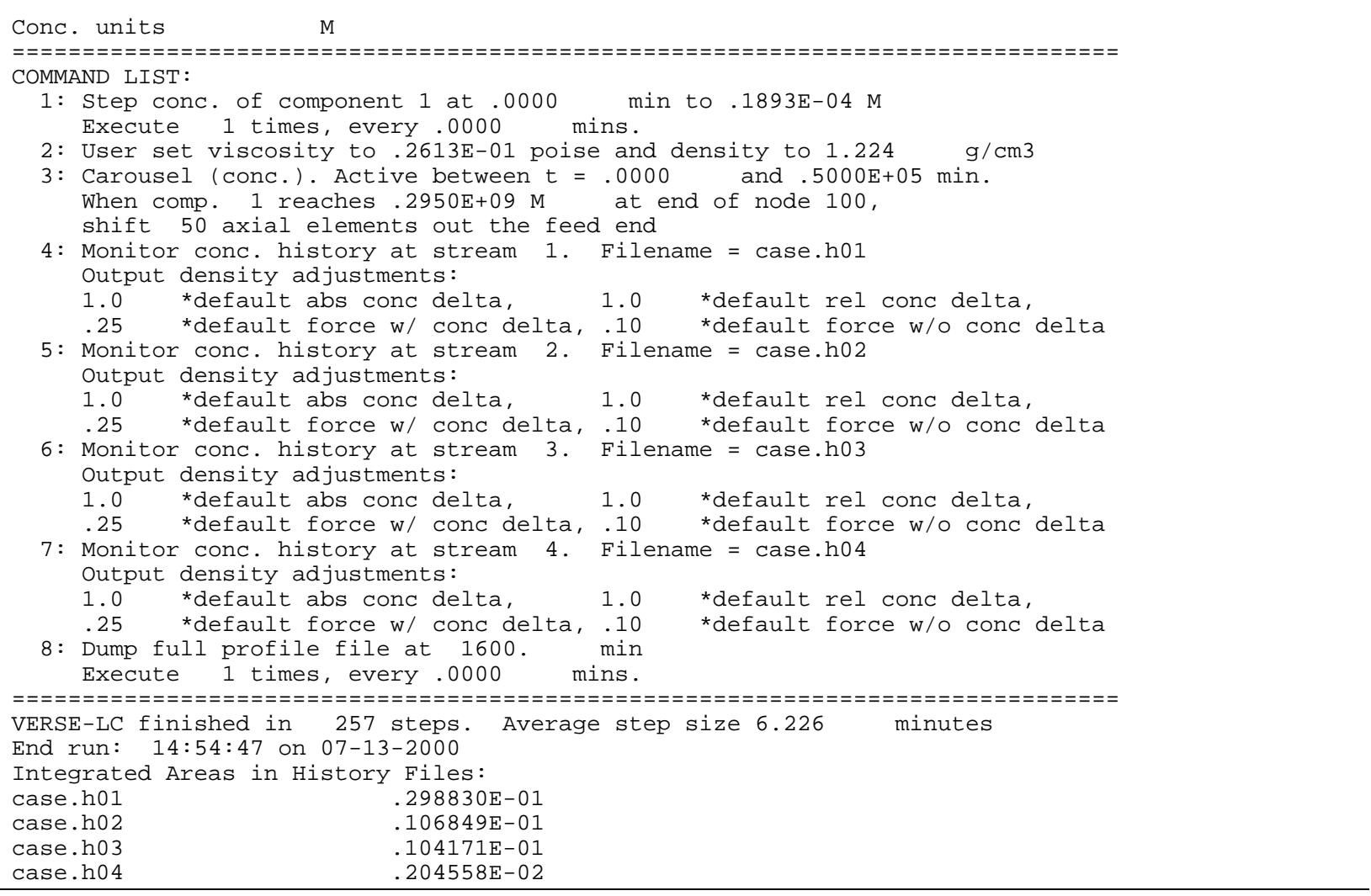

\section{VERSE Input for Intermediate-Scale Pertechnetate Column (WK-LC) Test}

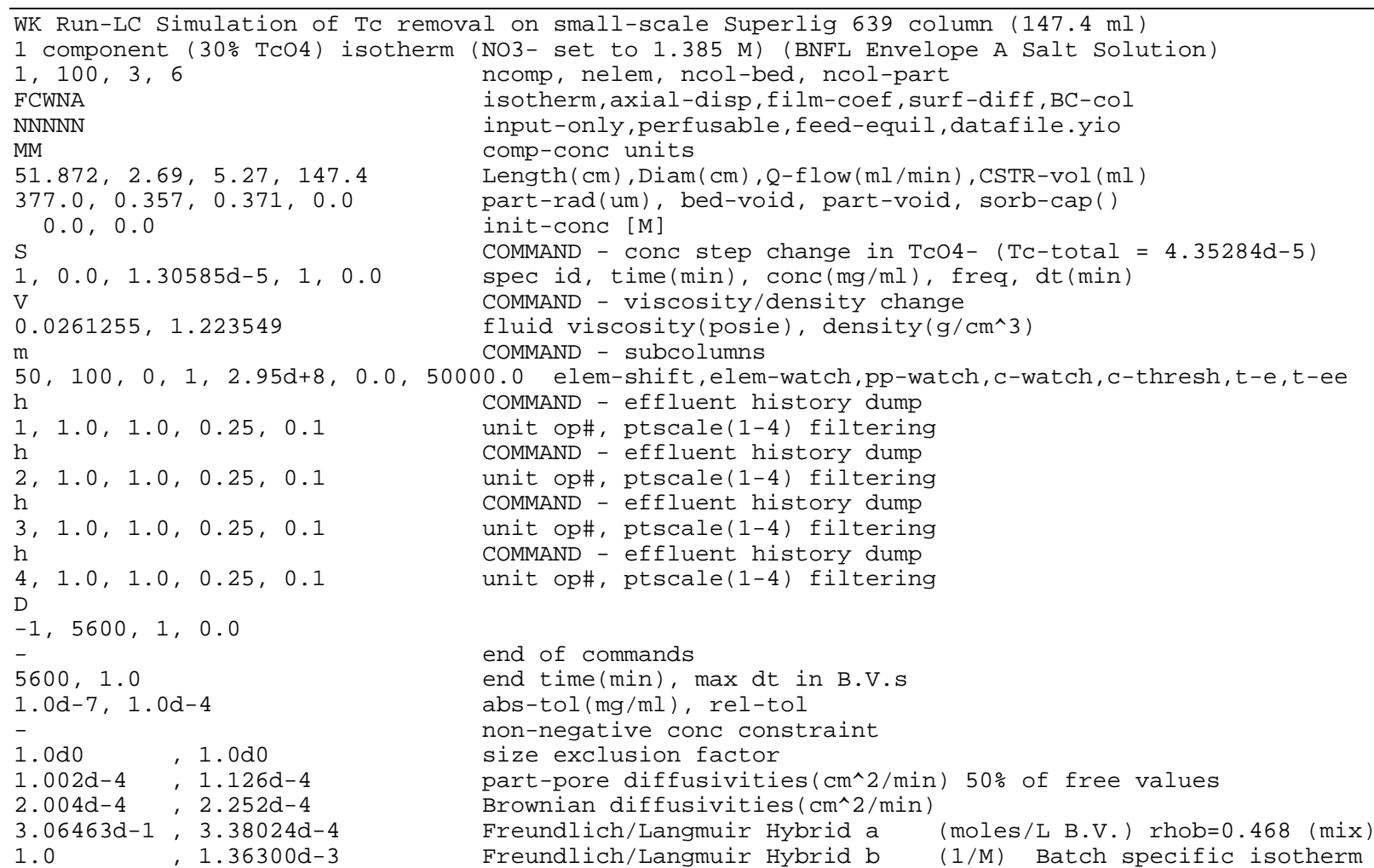




\begin{tabular}{|c|c|c|c|c|c|}
\hline 1.0 &, 1.0 & Freundlich/Langmuir & Hybrid Ma & $(-)$ & $\mathrm{ccap}=0.64723$ \\
\hline 1.0 &, 1.0 & Freundlich/Langmuir & Hybrid $\mathrm{Mb}$ & $(-)$ & \\
\hline $1.88776 \mathrm{~d}-3$ &, 0.0 & Freundlich/Langmuir & Hybrid beta & $(-)$ & "eff" isotherm NO3 $=1.385 \mathrm{M}$ \\
\hline
\end{tabular}

\section{VERSE Output for Intermediate-Scale Pertechnetate Column (WK-LC) Test}

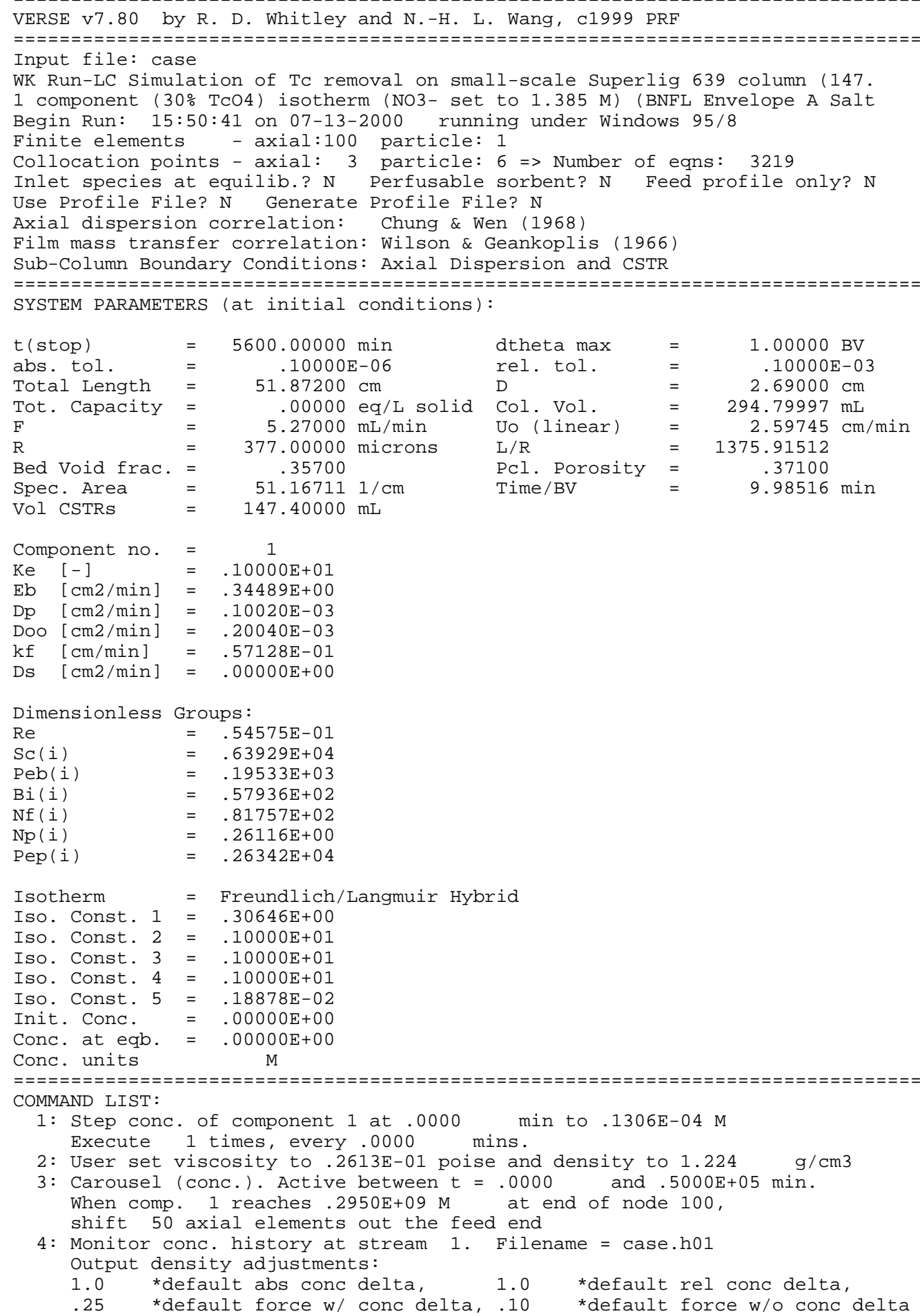


5: Monitor conc. history at stream 2. Filename = case.h02

Output density adjustments:

1.0 *default abs conc delta, 1.0 *default rel conc delta,

.25 *default force w/ conc delta, .10 *default force w/o conc delta

6: Monitor conc. history at stream 3. Filename = case.h03

Output density adjustments:

1.0 *default abs conc delta, 1.0 *default rel conc delta,

.25 *default force w/ conc delta, .10 *default force w/o conc delta

7: Monitor conc. history at stream 4. Filename = case.h04

Output density adjustments:

1.0 *default abs conc delta, 1.0 *default rel conc delta,

.25 *default force w/ conc delta, .10 *default force w/o conc delta

8: Dump full profile file at 5600. min

Execute 1 times, every .0000 mins.

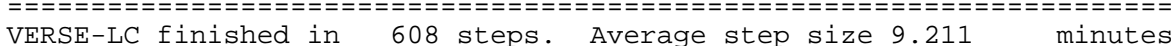

End run: 15:52:56 on 07-13-2000

Integrated Areas in History Files:

case.h01 .727445E-01

case.h02 .217841E-01

case.h03 .215241E-01

case.h04 .233502E-02

\section{VERSE Input for Intermediate-Scale Pertechnetate Column (WK-SRS) Test}

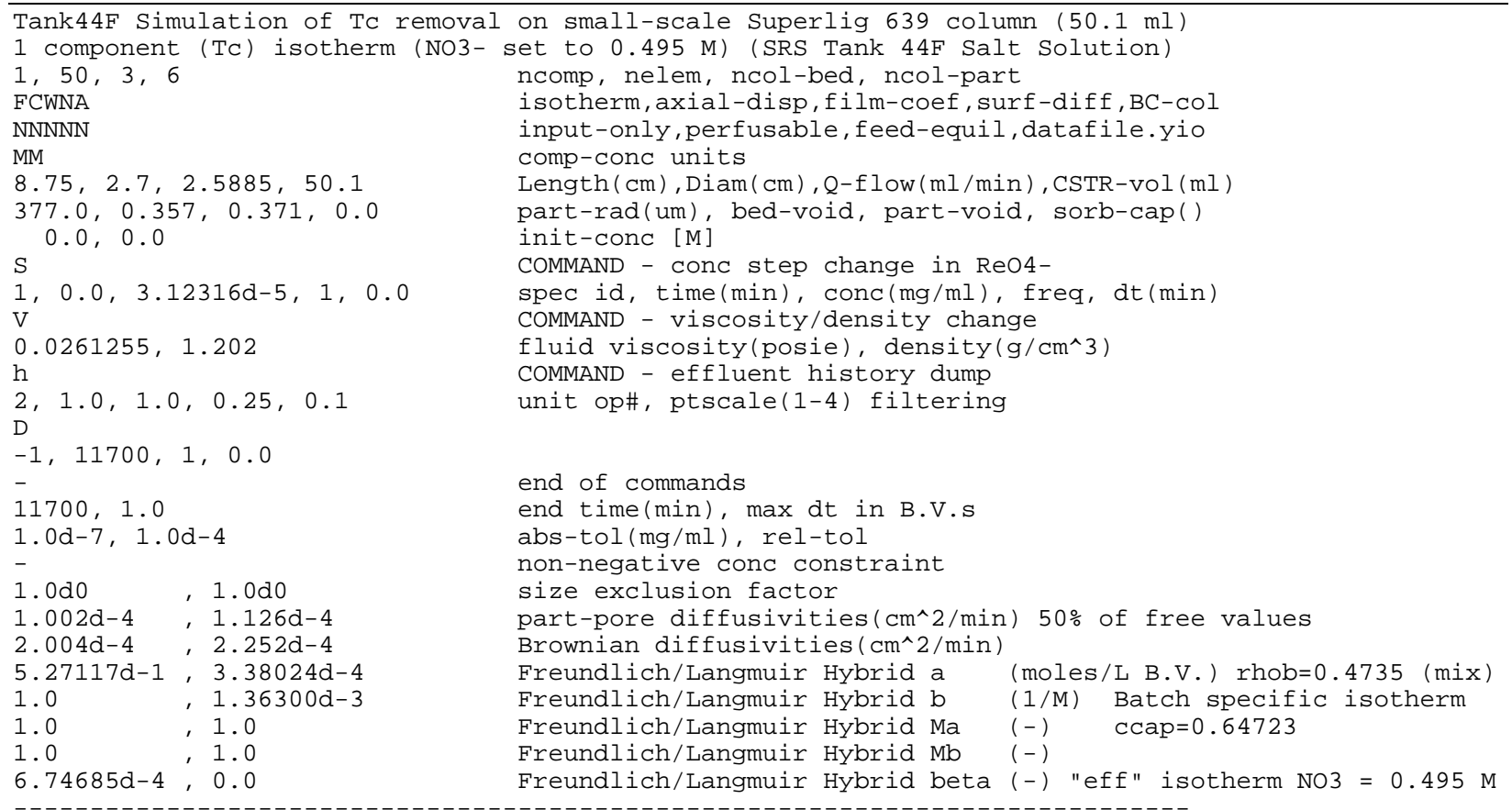

\section{VERSE Output for Intermediate-Scale Pertechnetate Column (WK-SRS) Test}

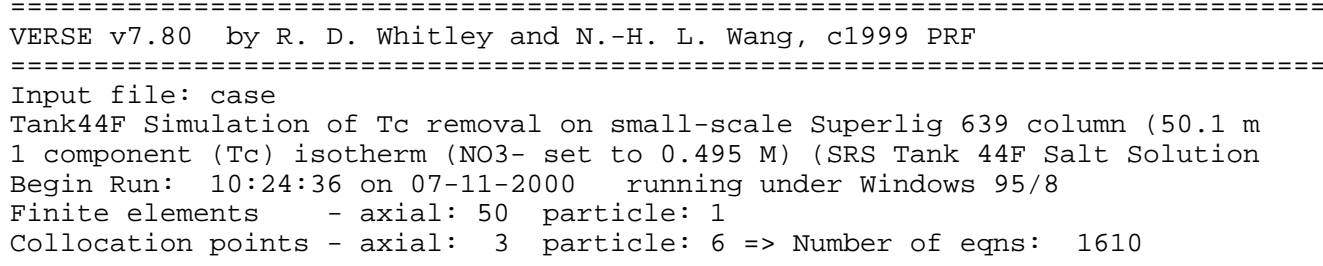


Inlet species at equilib.? $\mathrm{N}$ Perfusable sorbent? $\mathrm{N}$ Feed profile only? $\mathrm{N}$

Use Profile File? N Generate Profile File? N

Axial dispersion correlation: Chung \& Wen (1968)

Film mass transfer correlation: Wilson \& Geankoplis (1966)

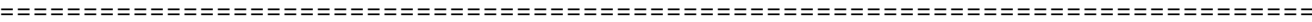

SYSTEM PARAMETERS (at initial conditions):

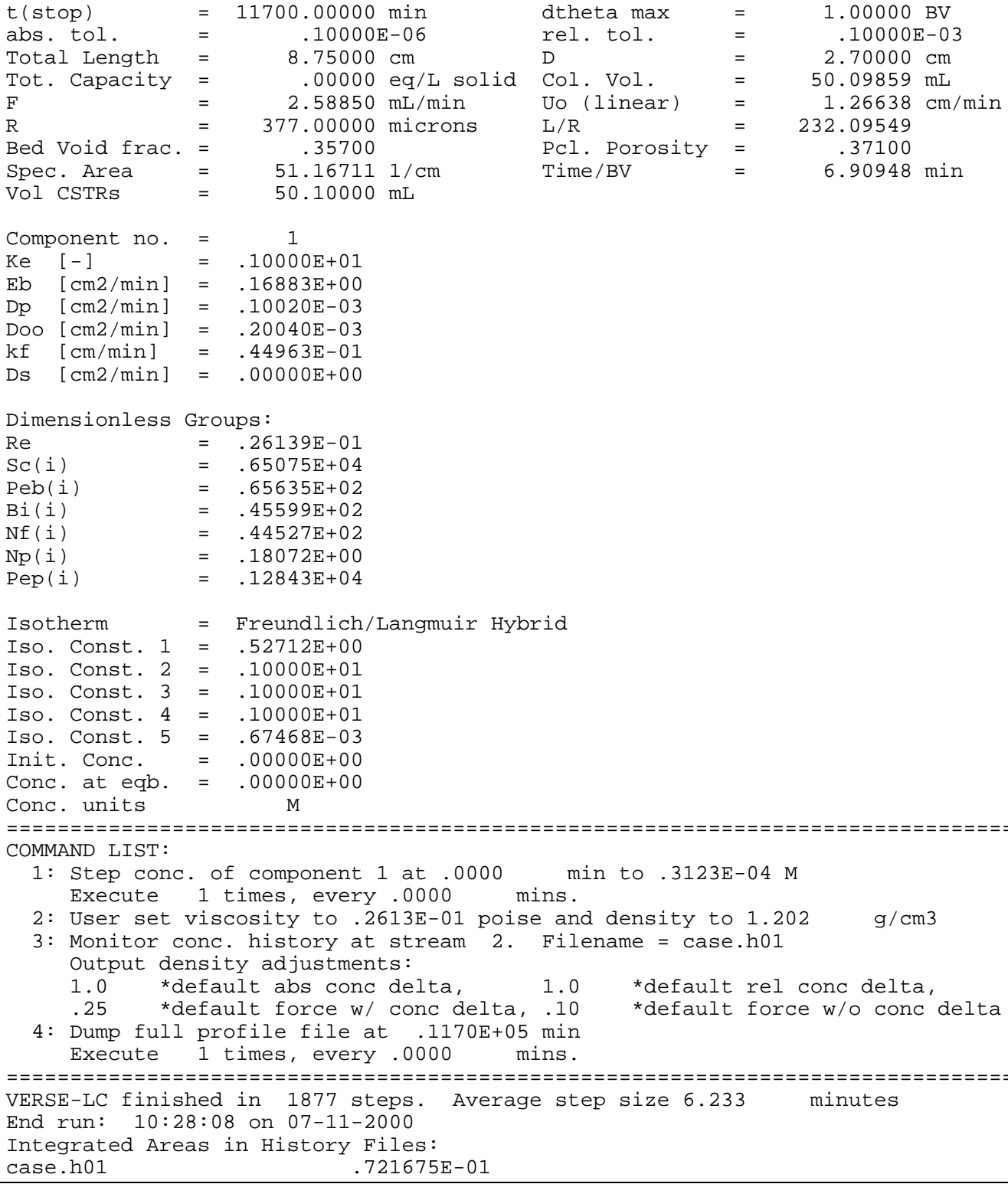

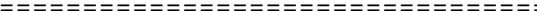




\section{Appendix E (Full-Scale Facility Input and Output Files)}

For reference the VERSE-LC input and output files for the full-scale facility are provided in this appendix. Several simulations were run. The cases presented here correspond to the "effective" single component isotherm modeling approach where the pertechnetate ion is modeled assuming the nitrate concentration to remain essentially constant throughout the columns. The key VERSE-LC input parameters for the nominal runs corresponding to the Envelope A and Envelope B case studies are provided in Table E-1 and E-2, respectively. The input/output files for the nominal runs corresponding to the Envelope A and Envelope B case studies are provided.

Note that the maximum allowable (by VERSE-LC) number of internal collocation points within the pores was chosen. Early on numerical testing to establish the minimum usable number of finite elements and collocation points (that maintains acceptable accuracy) indicated that radial concentration gradients within the particle pores were large and sharp.

Table E-1. Key parameter settings ${ }^{\text {a }}$ for VERSE-LC simulation of the "effective" single component and binary homovalent anion exchange processes for the full-scale facility when processing Envelope A feed.

\begin{tabular}{|c|c|c|}
\hline Parameter & $\begin{array}{l}\text { Parameter settings for } \\
\text { single component approach }\end{array}$ & $\begin{array}{l}\text { Parameter setting for } \\
\text { binary approach }\end{array}$ \\
\hline Number of finite elements within bed & $\begin{array}{l}50 \text { for lead } \\
50 \text { for lag }\end{array}$ & $\begin{array}{l}50 \text { for lead } \\
50 \text { for lag }\end{array}$ \\
\hline $\begin{array}{l}\text { Number of internal collocation points per } \\
\text { finite element within bed }\end{array}$ & $\begin{array}{l}3 \text { for lead } \\
3 \text { for lag }\end{array}$ & $\begin{array}{l}3 \text { for lead } \\
3 \text { for lag }\end{array}$ \\
\hline $\begin{array}{l}\text { Number of internal collocation points within } \\
\text { pores }\end{array}$ & $\begin{array}{l}6 \text { for lead } \\
6 \text { for lag }\end{array}$ & $\begin{array}{l}6 \text { for lead } \\
6 \text { for lag }\end{array}$ \\
\hline $\begin{array}{c}\text { Components explicitly modeled: } \\
1 \text { - pertechnetate } \\
2-\text { nitrate }\end{array}$ & pertechnetate & $\begin{array}{l}\text { pertechnetate } \\
\text { nitrate }\end{array}$ \\
\hline $\begin{array}{l}\text { Axial dispersion, } \mathrm{E}_{\mathrm{b}} \\
\qquad\left(\mathrm{cm}^{2} / \mathrm{min}\right)\end{array}$ & $\begin{array}{l}\text { Chung and Wen (1968) } \\
\text { correlation }\end{array}$ & $\begin{array}{l}\text { Chung and Wen (1968) } \\
\text { correlation }\end{array}$ \\
\hline $\begin{array}{l}\text { Film coefficient, } \mathrm{k}_{\mathrm{f}} \\
(\mathrm{cm} / \mathrm{min})\end{array}$ & $\begin{array}{l}\text { Wilson and Geankoplis (1966) } \\
\text { correlation }\end{array}$ & $\begin{array}{l}\text { Wilson and Geankoplis (1966) } \\
\text { correlation }\end{array}$ \\
\hline Active column lengths, $\mathrm{L}$ & $\begin{array}{l}225.0 \mathrm{~cm} \text { for lead } \\
225.0 \mathrm{~cm} \text { for lag }\end{array}$ & $\begin{array}{l}225.0 \mathrm{~cm} \text { for lead } \\
225.0 \mathrm{~cm} \text { for lag }\end{array}$ \\
\hline Column diameters, $\mathrm{D}$ & $\begin{array}{l}77.0 \mathrm{~cm} \text { for lead } \\
77.0 \mathrm{~cm} \text { for lag }\end{array}$ & $\begin{array}{l}77.0 \mathrm{~cm} \text { for lead } \\
77.0 \mathrm{~cm} \text { for lag }\end{array}$ \\
\hline Headspace volumes & $\begin{array}{l}\text { 1047.74 L for lead } \\
\text { 1047.74 L for lag }\end{array}$ & $\begin{array}{l}\text { 1047.74 L for lead } \\
\text { 1047.74 L for lag }\end{array}$ \\
\hline
\end{tabular}




\begin{tabular}{|c|c|c|}
\hline Parameter & $\begin{array}{c}\text { Parameter settings for } \\
\text { single component approach }\end{array}$ & $\begin{array}{l}\text { Parameter setting for } \\
\text { binary approach }\end{array}$ \\
\hline $\begin{array}{c}\text { Bed porosities, } \varepsilon_{\mathrm{b}} \\
(-)\end{array}$ & $\begin{array}{c}0.357 \text { for lead } \\
0.357 \text { for lag }\end{array}$ & $\begin{array}{c}0.357 \text { for lead } \\
0.357 \text { for lag }\end{array}$ \\
\hline $\begin{array}{c}\text { Particle porosities, } \varepsilon_{\mathrm{p}} \\
(-)\end{array}$ & $\begin{array}{c}0.371 \text { for lead } \\
0.371 \text { for lag }\end{array}$ & $\begin{array}{c}0.371 \text { for lead } \\
0.371 \text { for lag }\end{array}$ \\
\hline $\begin{array}{c}\text { Native (initial) concentrations } \\
\text { 1-pertechnetate } \\
\text { 2-nitrate }\end{array}$ & (1) $0.0 \mathrm{M}$ & $\begin{array}{l}\text { (1) } 0.0 \mathrm{M} \\
\text { (2) } 0.0 \mathrm{M}\end{array}$ \\
\hline $\begin{array}{c}\text { Feed (loading) concentrations } \\
\text { 1-pertechnetate } \\
\text { 2-nitrate }\end{array}$ & $\begin{array}{l}\text { (1) } 2.580 \times 10^{-5} \mathrm{M} \\
\text { (2) } 0.988 \mathrm{M}\end{array}$ & $\begin{array}{l}\text { (1) } 2.580 \times 10^{-5} \mathrm{M} \\
\text { (2) } 0.988 \mathrm{M}\end{array}$ \\
\hline Fluid dynamic viscosity, $\mu_{\mathrm{w}}$ & 0.261255 poise & 0.261255 poise \\
\hline Fluid density, $\rho_{w}$ & $1.223549 \mathrm{~g} / \mathrm{ml}$ & $1.223549 \mathrm{~g} / \mathrm{ml}$ \\
\hline $\begin{array}{l}\text { Lag column switching exit technetium } \\
\text { concentration criterion (none for lead) }\end{array}$ & $\begin{array}{l}2 \% \text { of feed for lag } \\
5.160 \times 10^{-7} \mathrm{M}\end{array}$ & $\begin{array}{c}2 \% \text { of feed for lag } \\
5.160 \times 10^{-7} \mathrm{M}\end{array}$ \\
\hline $\begin{array}{l}\text { Molecular diffusion coefficients } \\
\text { 1-pertechnetate } \\
\text { 2-nitrate }\end{array}$ & $\begin{array}{l}2.004 \times 10^{-4} \mathrm{~cm}^{2} / \mathrm{min} \\
2.252 \times 10^{-4} \mathrm{~cm}^{2} / \mathrm{min}\end{array}$ & $\begin{array}{l}2.004 \times 10^{-4} \mathrm{~cm}^{2} / \mathrm{min} \\
2.252 \times 10^{-4} \mathrm{~cm}^{2} / \mathrm{min}\end{array}$ \\
\hline $\begin{array}{l}\text { Particle pore diffusion coefficients } \\
\text { 1-pertechnetate } \\
\text { 2-nitrate }\end{array}$ & $\begin{array}{l}1.002 \times 10^{-4} \mathrm{~cm}^{2} / \mathrm{min} \\
1.126 \times 10^{-4} \mathrm{~cm}^{2} / \mathrm{min}\end{array}$ & $\begin{array}{l}1.002 \times 10^{-4} \mathrm{~cm}^{2} / \mathrm{min} \\
1.126 \times 10^{-4} \mathrm{~cm}^{2} / \mathrm{min}\end{array}$ \\
\hline $\begin{array}{l}\text { Freundlich-Langmuir Hybrid a coefficient } \\
\text { 1-pertechnetate } \\
\text { 2-nitrate }\end{array}$ & (1) $3.0290 \times 10^{-1}$ gmoles $/ \mathrm{L}_{\mathrm{BV}}$ & $\begin{array}{l}\text { (1) } 3.0290 \times 10^{-1} \text { gmoles } / L_{B V} \\
\text { (2) } 2.3450 \times 10^{-4} \text { gmoles } / L_{B V}\end{array}$ \\
\hline $\begin{array}{l}\text { Freundlich-Langmuir Hybrid b coefficient } \\
\text { 1-pertechnetate } \\
\text { 2-nitrate }\end{array}$ & (1) $1.0 \mathrm{M}^{-1}$ & $\begin{array}{l}\text { (1) } 1.0000 \times 10^{-0} \mathrm{M}^{-1} \\
\text { (2) } 7.7418 \times 10^{-4} \mathrm{M}^{-1}\end{array}$ \\
\hline $\begin{array}{c}\text { Freundlich-Langmuir Hybrid } \mathbf{M}_{\mathbf{a}} \text { coefficient } \\
\text { 1-pertechnetate } \\
\text { 2-nitrate }\end{array}$ & (1) $1.0(-)$ & $\begin{array}{l}\text { (1) } 1.0(-) \\
\text { (2) } 1.0(-)\end{array}$ \\
\hline $\begin{array}{l}\text { Freundlich-Langmuir Hybrid } \mathbf{M}_{\mathbf{b}} \text { coefficient } \\
\text { 1-pertechnetate } \\
\text { 2-nitrate }\end{array}$ & (1) $1.0(-)$ & $\begin{array}{l}\text { (1) } 1.0(-) \\
\text { (2) } 1.0(-)\end{array}$ \\
\hline $\begin{array}{c}\text { Freundlich-Langmuir Hybrid } \beta \text { coefficient } \\
\text { 1-pertechnetate } \\
\text { 2-nitrate }\end{array}$ & na & $\begin{array}{l}\text { (1) } 0.0(-) \\
\text { (2) } 0.0(-)\end{array}$ \\
\hline $\begin{array}{l}\text { Freundlich-Langmuir Hybrid } \beta \text { "effective" } \\
\text { coefficient for pertechnetate }\end{array}$ & $7.72628 \times 10^{-4}(-)$ & na \\
\hline
\end{tabular}

${ }^{\mathrm{a}}$ Isotherm model parameters are based on a bed density of $0.468 \mathrm{~g}_{\mathrm{resin}} / \mathrm{ml}$ and a total ionic exchange capacity of $0.6472 \mathrm{mmole} / \mathrm{g}_{\text {resin }}$ consistent with batch ID (\# 981015DHC720011). 
Table E-2. Key parameter settings a for VERSE-LC simulation of the "effective" single component and binary homovalent anion exchange processes for the full-scale facility when processing Envelope B feed.

\begin{tabular}{|c|c|c|}
\hline Parameter & $\begin{array}{l}\text { Parameter settings for } \\
\text { single component approach }\end{array}$ & $\begin{array}{l}\text { Parameter setting for } \\
\text { binary approach }\end{array}$ \\
\hline Number of finite elements within bed & $\begin{array}{l}50 \text { for lead } \\
50 \text { for lag }\end{array}$ & $\begin{array}{l}50 \text { for lead } \\
50 \text { for lag }\end{array}$ \\
\hline $\begin{array}{l}\text { Number of internal collocation points per } \\
\text { finite element within bed }\end{array}$ & $\begin{array}{l}3 \text { for lead } \\
3 \text { for lag }\end{array}$ & $\begin{array}{l}3 \text { for lead } \\
3 \text { for lag }\end{array}$ \\
\hline $\begin{array}{l}\text { Number of internal collocation points within } \\
\text { pores }\end{array}$ & $\begin{array}{l}6 \text { for lead } \\
6 \text { for lag }\end{array}$ & $\begin{array}{l}6 \text { for lead } \\
6 \text { for lag }\end{array}$ \\
\hline $\begin{array}{c}\text { Components explicitly modeled: } \\
1 \text { - pertechnetate } \\
2-\text { nitrate }\end{array}$ & pertechnetate & $\begin{array}{l}\text { pertechnetate } \\
\text { nitrate }\end{array}$ \\
\hline $\begin{array}{l}\text { Axial dispersion, } \mathrm{E}_{\mathrm{b}} \\
\left(\mathrm{cm}^{2} / \mathrm{min}\right)\end{array}$ & $\begin{array}{l}\text { Chung and Wen }(1968) \\
\text { correlation }\end{array}$ & $\begin{array}{l}\text { Chung and Wen }(1968) \\
\text { correlation }\end{array}$ \\
\hline $\begin{array}{l}\text { Film coefficient, } \mathrm{k}_{\mathrm{f}} \\
(\mathrm{cm} / \mathrm{min})\end{array}$ & $\begin{array}{l}\text { Wilson and Geankoplis (1966) } \\
\text { correlation }\end{array}$ & $\begin{array}{l}\text { Wilson and Geankoplis (1966) } \\
\text { correlation }\end{array}$ \\
\hline Active column lengths, $\mathrm{L}$ & $\begin{array}{l}225.0 \mathrm{~cm} \text { for lead } \\
225.0 \mathrm{~cm} \text { for lag }\end{array}$ & $\begin{array}{l}225.0 \mathrm{~cm} \text { for lead } \\
225.0 \mathrm{~cm} \text { for lag }\end{array}$ \\
\hline Column diameters, $\mathrm{D}$ & $\begin{array}{l}77.0 \mathrm{~cm} \text { for lead } \\
77.0 \mathrm{~cm} \text { for lag }\end{array}$ & $\begin{array}{l}77.0 \mathrm{~cm} \text { for lead } \\
77.0 \mathrm{~cm} \text { for lag }\end{array}$ \\
\hline Headspace volumes & $\begin{array}{l}\text { 1047.74 L for lead } \\
\text { 1047.74 L for lag }\end{array}$ & $\begin{array}{l}\text { 1047.74 L for lead } \\
\text { 1047.74 L for lag }\end{array}$ \\
\hline $\begin{array}{l}\text { Bed porosities, } \varepsilon_{\mathrm{b}} \\
(-)\end{array}$ & $\begin{array}{c}0.357 \text { for lead } \\
0.357 \text { for lag }\end{array}$ & $\begin{array}{l}0.357 \text { for lead } \\
0.357 \text { for lag }\end{array}$ \\
\hline $\begin{array}{l}\text { Particle porosities, } \varepsilon_{\mathrm{p}} \\
\qquad(-)\end{array}$ & $\begin{array}{c}0.371 \text { for lead } \\
0.371 \text { for lag }\end{array}$ & $\begin{array}{c}0.371 \text { for lead } \\
0.371 \text { for lag }\end{array}$ \\
\hline $\begin{array}{c}\text { Native (initial) concentrations } \\
\text { 1-pertechnetate } \\
\text { 2-nitrate }\end{array}$ & (1) $0.0 \mathrm{M}$ & $\begin{array}{l}\text { (1) } 0.0 \mathrm{M} \\
\text { (2) } 0.0 \mathrm{M}\end{array}$ \\
\hline $\begin{array}{c}\text { Feed (loading) concentrations } \\
\text { 1-pertechnetate } \\
\text { 2-nitrate }\end{array}$ & $\begin{array}{l}\text { (1) } 2.580 \times 10^{-5} \mathrm{M} \\
\text { (2) } 0.988 \mathrm{M} \text { for Env. A } \\
\text { (2) } 0.232 \mathrm{M} \text { for Env. B }\end{array}$ & $\begin{array}{l}\text { (1) } 2.580 \times 10^{-5} \mathrm{M} \\
\text { (2) } 0.988 \mathrm{M} \text { for Env. A } \\
\text { (2) } 0.232 \mathrm{M} \text { for Env. } \mathrm{B}\end{array}$ \\
\hline Fluid dynamic viscosity, $\mu_{\mathrm{w}}$ & 0.261255 poise & 0.261255 poise \\
\hline Fluid density, $\rho_{\mathrm{w}}$ & $1.223549 \mathrm{~g} / \mathrm{ml}$ & $1.223549 \mathrm{~g} / \mathrm{ml}$ \\
\hline
\end{tabular}




\begin{tabular}{|c|c|c|}
\hline Parameter & $\begin{array}{c}\text { Parameter settings for } \\
\text { single component approach }\end{array}$ & $\begin{array}{l}\text { Parameter setting for } \\
\text { binary approach }\end{array}$ \\
\hline $\begin{array}{l}\text { Lag column switching exit technetium } \\
\text { concentration criterion } \\
\text { (none for lead) }\end{array}$ & $\begin{array}{c}2 \% \text { of feed for lag } \\
5.160 \times 10^{-7} \mathrm{M} \text { for Env. A } \\
2.648 \times 10^{-6} \mathrm{M} \text { for Env. B }\end{array}$ & $\begin{array}{c}2 \% \text { of feed for lag } \\
5.160 \times 10^{-7} \mathrm{M} \text { for Env. A } \\
2.648 \times 10^{-6} \mathrm{M} \text { for Env. B }\end{array}$ \\
\hline $\begin{array}{l}\text { Molecular diffusion coefficients } \\
\text { 1-pertechnetate } \\
\text { 2-nitrate }\end{array}$ & $\begin{array}{l}2.004 \times 10^{-4} \mathrm{~cm}^{2} / \mathrm{min} \\
2.252 \times 10^{-4} \mathrm{~cm}^{2} / \mathrm{min}\end{array}$ & $\begin{array}{l}2.004 \times 10^{-4} \mathrm{~cm}^{2} / \mathrm{min} \\
2.252 \times 10^{-4} \mathrm{~cm}^{2} / \mathrm{min}\end{array}$ \\
\hline $\begin{array}{c}\text { Particle pore diffusion coefficients } \\
\text { 1-pertechnetate } \\
\text { 2-nitrate }\end{array}$ & $\begin{array}{l}1.002 \times 10^{-4} \mathrm{~cm}^{2} / \mathrm{min} \\
1.126 \times 10^{-4} \mathrm{~cm}^{2} / \mathrm{min}\end{array}$ & $\begin{array}{l}1.002 \times 10^{-4} \mathrm{~cm}^{2} / \mathrm{min} \\
1.126 \times 10^{-4} \mathrm{~cm}^{2} / \mathrm{min}\end{array}$ \\
\hline $\begin{array}{l}\text { Freundlich-Langmuir Hybrid a coefficient } \\
\text { 1-pertechnetate } \\
\text { 2-nitrate }\end{array}$ & (1) $3.0290 \times 10^{-1}$ gmoles $/ \mathrm{L}_{\mathrm{BV}}$ & $\begin{array}{l}\text { (1) } 3.0290 \times 10^{-1} \text { gmoles } / L_{B V} \\
\text { (2) } 8.0982 \times 10^{-4} \text { gmoles } / L_{B V}\end{array}$ \\
\hline $\begin{array}{l}\text { Freundlich-Langmuir Hybrid b coefficient } \\
\text { 1-pertechnetate } \\
\text { 2-nitrate }\end{array}$ & (1) $1.0 \mathrm{M}^{-1}$ & $\begin{array}{l}\text { (1) } 1.0000 \times 10^{-0} \mathrm{M}^{-1} \\
\text { (2) } 2.6735 \times 10^{-3} \mathrm{M}^{-1}\end{array}$ \\
\hline $\begin{array}{c}\text { Freundlich-Langmuir Hybrid } \mathbf{M}_{\mathbf{a}} \text { coefficient } \\
\text { 1-pertechnetate } \\
\text { 2-nitrate }\end{array}$ & (1) $1.0(-)$ & $\begin{array}{l}\text { (1) } 1.0(-) \\
\text { (2) } 1.0(-)\end{array}$ \\
\hline $\begin{array}{c}\text { Freundlich-Langmuir Hybrid } \mathbf{M}_{\mathbf{b}} \text { coefficient } \\
\text { 1-pertechnetate } \\
\text { 2-nitrate }\end{array}$ & (1) $1.0(-)$ & $\begin{array}{l}\text { (1) } 1.0(-) \\
\text { (2) } 1.0(-)\end{array}$ \\
\hline $\begin{array}{l}\text { Freundlich-Langmuir Hybrid } \beta \text { coefficient } \\
\text { 1-pertechnetate } \\
\text { 2-nitrate }\end{array}$ & na & $\begin{array}{l}\text { (1) } 0.0(-) \\
\text { (2) } 0.0(-)\end{array}$ \\
\hline $\begin{array}{l}\text { Freundlich-Langmuir Hybrid } \beta \text { "effective" } \\
\text { coefficient for pertechnetate }\end{array}$ & $6.19724 \times 10^{-4}(-)$ & na \\
\hline
\end{tabular}

${ }^{\mathrm{a}}$ Isotherm model parameters are based on a bed density of $0.468 \mathrm{~g}_{\mathrm{resin}} / \mathrm{ml}$ and a total ionic exchange capacity of $0.6472 \mathrm{mmole} / \mathrm{g}_{\text {resin }}$ consistent with batch ID (\# 981015DHC720011). 


\title{
VERSE Input for Full-Scale Facility (Env. A: Single Component Model)
}

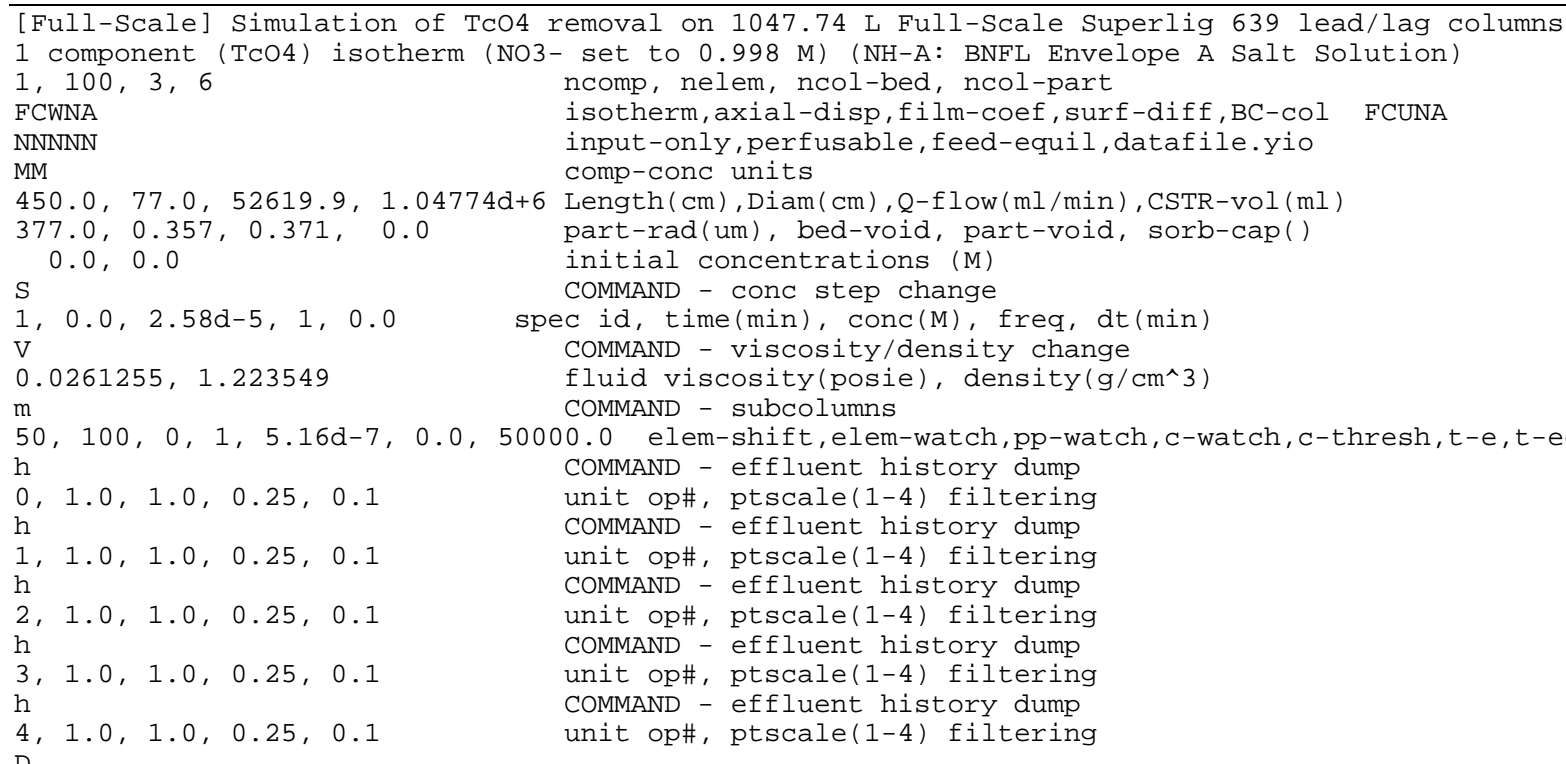

$-1, \quad 5000.0,1,0.0$

$\mathrm{D}$

$-1,9180.0,1,0.0$

$-1,13400.0,1,0.0$

$-1,17640.0,1,0.0$

$20000.0,1.0$

$1.0 d-7,1.0 d-4$

$1.0 \mathrm{~d} 0,1.0 \mathrm{~d} 0$

$1.002 \mathrm{~d}-4,1.126 \mathrm{~d}-4$

$2.004 \mathrm{~d}-4,2.252 \mathrm{~d}-4$

$3.02904 \mathrm{~d}-1,2.3450 \mathrm{~d}-4$

$1.0 \quad, 7.7418 d-4$

$1.0 \quad, 1.0$

$1.0 \quad 1.0$

$7.72628 d-4,0.0$

end of commands

end time(min), $\max d t$ in B.V.s

abs-tol, rel-tol

non-negative conc constraint

size exclusion factor

part-pore diffusivities $\left(\mathrm{cm}^{\wedge} 2 / \mathrm{min}\right) 50 \%$ of free values

Brownian diffusivities ( $\mathrm{cm}^{\wedge} 2 / \mathrm{min}$ )

Freundlich/Langmuir Hybrid a (moles/L B.V.) rhob=0.468 (mix)

Freundlich/Langmuir Hybrid b (1/M) Batch specific isotherm

Freundlich/Langmuir Hybrid Ma $\quad(-) \quad$ ccap $=0.6472$

Freundlich/Langmuir Hybrid $\mathrm{Mb} \quad(-)$

Freundlich/Langmuir Hybrid beta (-) "eff" isotherm NO3 = $0.998 \mathrm{M}$

\section{VERSE Output for Full-Scale Facility (Env. A: Single Component Model)}

\author{
VERSE V7.80 by R. D. Whitley and N.-H. L. Wang, c1999 PRF

$=========$ \\ Input file: case \\ [Full-Scale] Simulation of TcO4 removal on 1047.74 L Full-Scale Superlig 63 \\ 1 component (TcO4) isotherm (NO3- set to $0.998 \mathrm{M}$ ) (NH-A: BNFL Envelope A Sa \\ Begin Run: 12:38:59 on 08-04-2000 running under Windows 95/8 \\ Finite elements - axial:100 particle: 1 \\ Collocation points - axial: 3 particle: 6 => Number of eqns: 3219 \\ Inlet species at equilib.? $\mathrm{N}$ Perfusable sorbent? $\mathrm{N}$ Feed profile only? $\mathrm{N}$ \\ Use Profile File? N Generate Profile File? N \\ Axial dispersion correlation: Chung \& Wen (1968) \\ Film mass transfer correlation: Wilson \& Geankoplis (1966) \\ Sub-Column Boundary Conditions: Axial Dispersion and CSTR

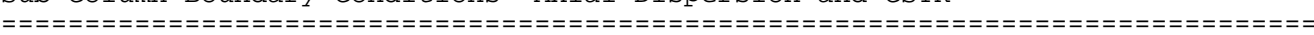 \\ SYSTEM PARAMETERS (at initial conditions):
}


WESTINGHOUSE SAVANNAH RIVER COMPANY

Report:

WSRC-TR-2000-00305

Preliminary Ion Exchange Modeling for Removal of Technetium from

Revision (Date):

$0(11 / 29 / 00)$

Hanford Waste Using SuperLig ${ }^{\circledR} 639$ Resin

Page:

224 of 228

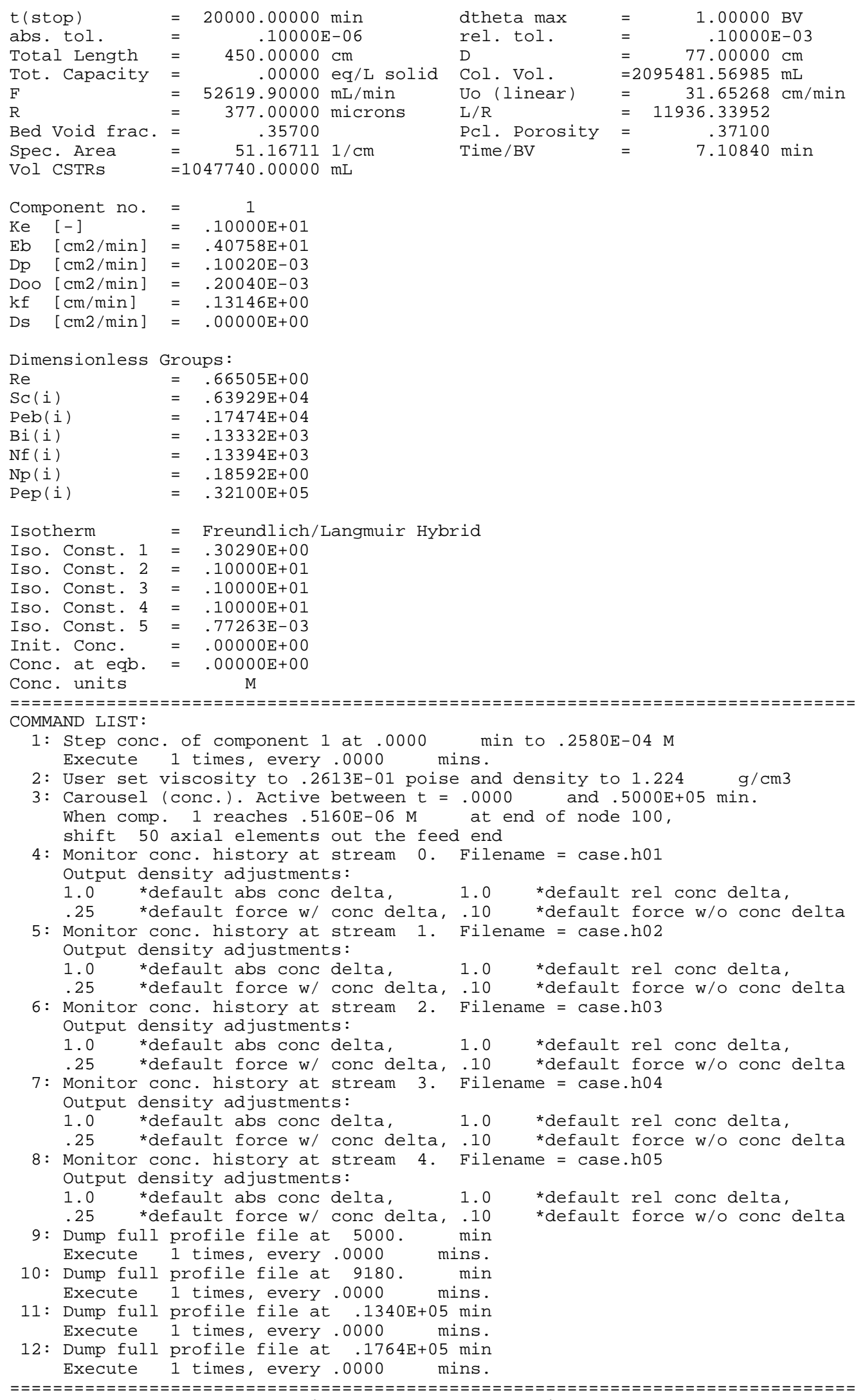


Conc. Carousel caused bed shift at $t=9198 . \quad \mathrm{min}$

Conc. Carousel caused bed shift at $t=.1342 \mathrm{E}+05 \mathrm{~min}$

Conc. Carousel caused bed shift at $t=.1764 \mathrm{E}+05 \mathrm{~min}$

VERSE-LC finished in 3330 steps. Average step size 6.006 minutes

End run: 13:12:59 on 08-04-2000

Integrated Areas in History Files:

case.h01 .516000

case.h02 . .514085

case.h03 .643094E-01

case.h04 .635953E-01

case.h05 .188060E-02

\section{VERSE Input for Full-Scale Facility (Env. B: Single Component Model)}

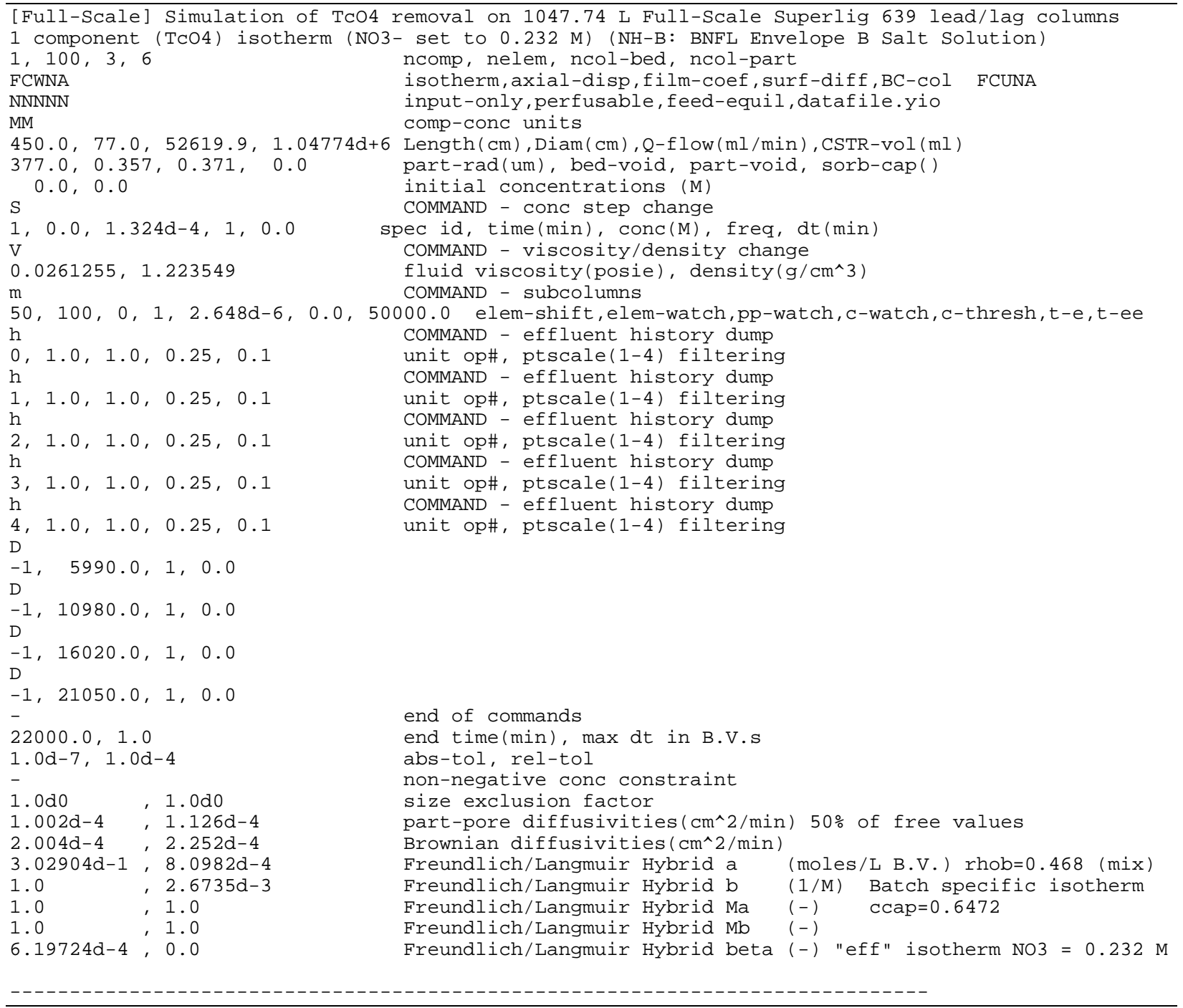

\section{VERSE Output for Full-Scale Facility (Env. B: Single Component Model)}




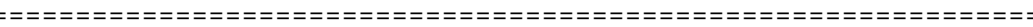

Input file: case

[Full-Scale] Simulation of TcO4 removal on 1047.74 L Full-Scale Superlig 63

1 component ( $\mathrm{TCO} 4$ ) isotherm (NO3- set to $0.232 \mathrm{M}$ ) (NH-B: BNFL Envelope $\mathrm{B}$ Sa

Begin Run: 14:33:49 on 08-04-2000 running under Windows 95/8

Finite elements - axial:100 particle: 1

Collocation points - axial: 3 particle: 6 => Number of eqns: 3219

Inlet species at equilib.? N Perfusable sorbent? $\mathrm{N}$ Feed profile only? $\mathrm{N}$

Use Profile File? N Generate Profile File? N

Axial dispersion correlation: Chung \& Wen (1968)

Film mass transfer correlation: Wilson \& Geankoplis (1966)

Sub-Column Boundary Conditions: Axial Dispersion and CSTR

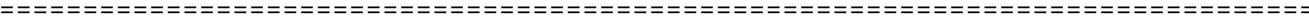

SYSTEM PARAMETERS (at initial conditions):

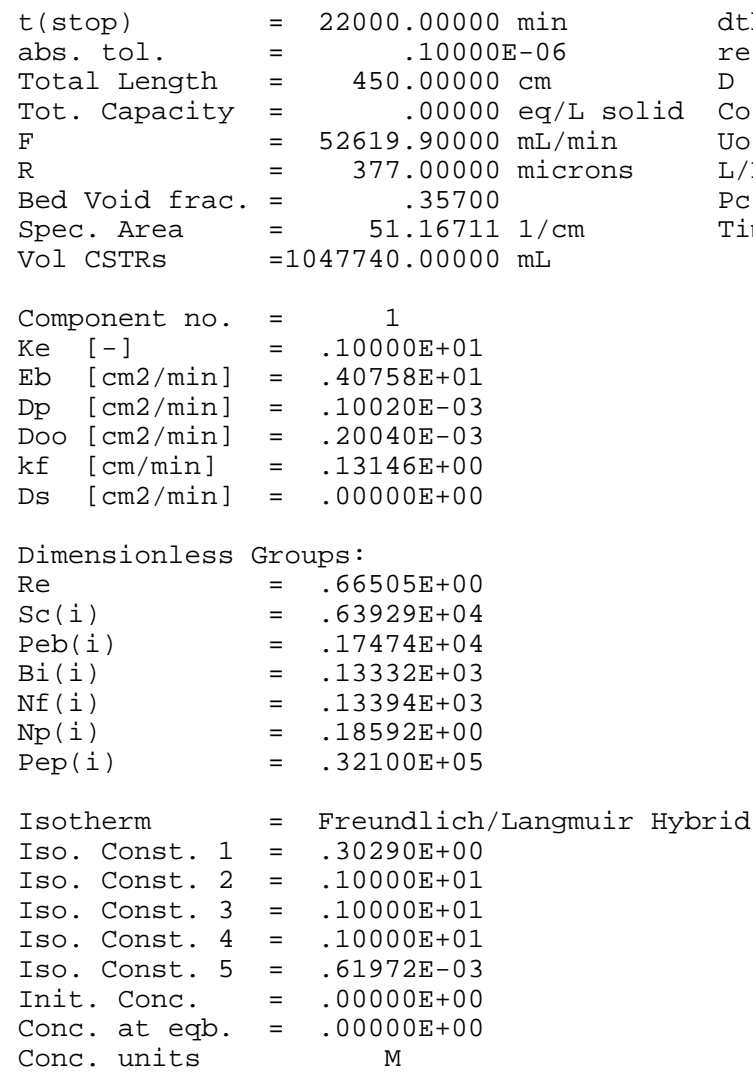


